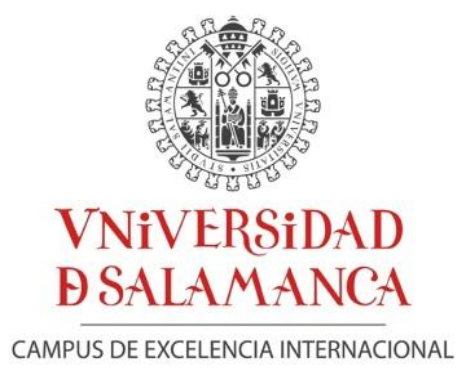

FACULTAD DE CIENCIAS SOCIALES

DEPARTAMENTO DE SOCIOLOGIA Y COMUNICACIÓN

\title{
CUIDADORES INFORMALES DE PERSONAS DEPENDIENTES EN CHILE. ASPECTOS PSICOSOCIALES Y CULTURALES
}

Tesis para optar al título de doctor

presentada por

Deiza Yanet Troncoso Miranda

Director, doctor Jesús Rivera Navarro

Codirectora, doctora Paulina Osorio Parraguez

Salamanca, 2013 

A mi madre y mi hermano Miguel Ángel, ellos motivaron todo el proceso de esta investigación e inspiraron fortaleza en los momentos difíciles 

YO NO TENGO SOLEDAD

Es la noche desamparo

de las sierras hasta el mar.

Pero yo, la que te mece,

¡Yo no tengo soledad!

Es el cielo desamparo

si la luna cae al mar.

Pero yo, la que te estrecha,

¡Yo no tengo soledad!

Es el mundo desamparo

y la carne triste va

Pero yo, la que te oprime,

¡Yo no tengo soledad!

Ternura, Gabriela Mistral

Siento que la etapa que estoy cerrando no solo corresponde al término de un período en mi vida, va más allá de mi existencia, abarca varias generaciones de mi familia, creo que lo que culmino y logro es fruto del esfuerzo de todas las mujeres que me antecedieron; desde mis abuelas, que con inexistente acceso a la educación me criaron sabiamente; a mi madre, mi Elsita, que con corazón generoso y una mente clara supo inculcar en mi valores y conciencia social.

Muchos de los momentos vividos en estos años en tierras españolas servirían para hacer una novela, quizás ha sido el tiempo más difícil que he vivido, a pesar de ello no he tenido soledad... por eso quiero agradecer a todos los que me han acompañado en este recorrido.

Primeramente, quiero agradecer a Jesús Rivera, director de esta tesis doctoral, quien desde un comienzo me animó a la realización del doctorado, trabajó a la par de mis tiempos con dedicación y compromiso, dispuso todos los medios a su alcance para que 
pudiera finalizar esta investigación. Asimismo le reconozco por su respetuosa relación profesional, consideración de mi experiencia profesional y personal, y por la amistad que en estos años se ha forjado.

Igualmente, quiero agradecer las conversaciones, jornadas de trabajo, colaboraciones generosas de mi codirectora Paulina Osorio, y de amigas, amigos y colegas que ayudaron en la elaboración de esta tesis, gracias a Irma, María Eugenia, Nelcy, Rosita, Marco y Consuelo.

También a quienes colaboraron desinteresadamente con mi trabajo de campo en Chile. De forma principal a las cuidadoras y cuidadores que me permitieron conocer sus experiencias, abriendo sus casas y sus vidas. Así también a quienes me ayudaron a llegar a los cuidadores, Claudia Silva, Tanya Olvera, Macarena Torres, Myriam Allende, Claudina Marín, Cristian Galdames y Berónica Miranda.

En lo más íntimo, mi reconocimiento principal a mis padres, hermanos, tíos, primos y amigos en Chile; y a mi familia en España, Mariela, sus hijos y su esposo, todos ellos de múltiples formas siempre estuvieron conmigo.

Y mis amigos en España que fueron mi segunda familia, con cariño estuvieron ahí en la dicha y en la adversidad. También a mis amigas terapeutas Ruth y Silvia que, superando las distancias gracias a la tecnología, desde Oregón y Valparaíso apoyaron mi alma.

A los amigos y amigas de la sala de investigación de la biblioteca Francisco de Vitoria, que entre cafés y conversaciones fueron un incentivo en el trabajo diario, en la labor de hormiga que representa el día a día de la elaboración de una investigación.

Finalmente, no quiero dejar de reconocer y recomendar la energía y motivación que la música -en sus múltiples estilos, armónica a los momentos de esta investigación-, la natación y las caminatas por Salamanca representaron en mi trayecto como doctoranda.

Sólo me queda decir como Violeta Parra "gracias a la vida que me ha dado tanto..." 


\section{ÍNDICE DE CONTENIDOS}

RESUMEN DE LA INVESTIGACIÓN ........................................................................ 1

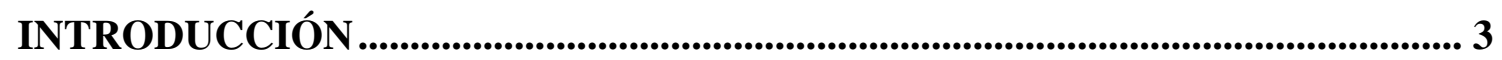

PARTE I: APROXIMACIÓN TEÓRICA ........................................................... 9

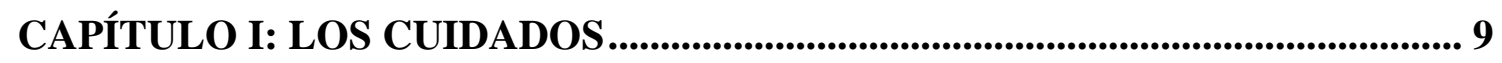

1.1. Conceptos fundamentales: discapacidad y dependencia.................................... 9

1.1.1. Conceptualización y evaluación de la dependencia ................................. 12

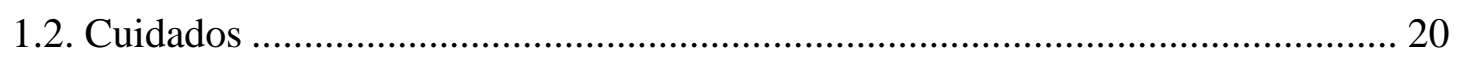

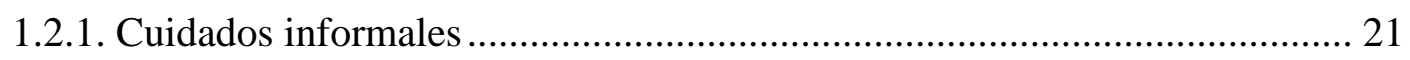

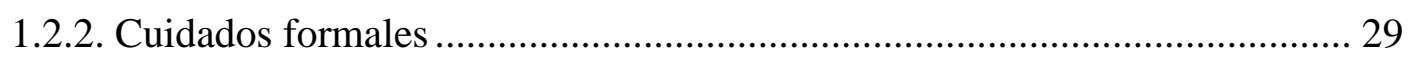

CAPÍTULO II: SISTEMAS DE PROTECIÓN A PERSONAS EN SITUACIÓN

DE DEPENDENCIA ........................................................................................ 39

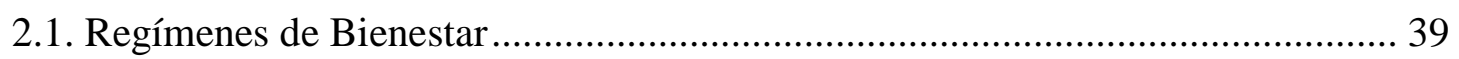

2.1.1. Régimen Socialdemócrata o Universal................................................ 41

2.1.2. Régimen Corporativista o Conservador ................................................. 42

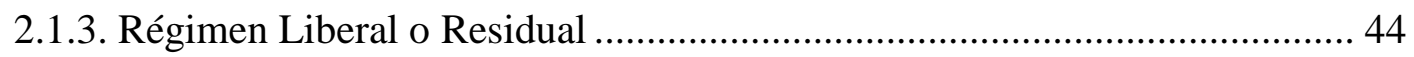

2.1.4. El Régimen de Bienestar Latino Rudimentario ........................................ 48

2.1.5. Los Regímenes de Bienestar en América Latina......................................... 51

2.2. Sistemas de Atención a la Dependencia ............................................................ 54

2.2.1. La atención a las personas en situación de dependencia en los países nórdicos 54

2.2.2. La atención a las personas en situación de dependencia en países que desarrollan el régimen corporativista .......................................................... 57

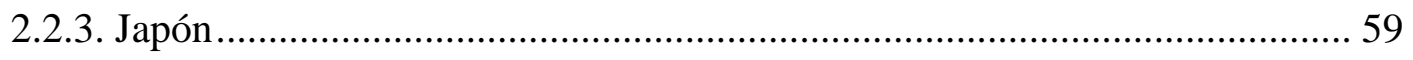

2.2.4. La atención a las personas en situación de dependencia en países que desarrollan el régimen liberal o residual. 61 
2.2.5. La atención a las personas en situación de dependencia en países que

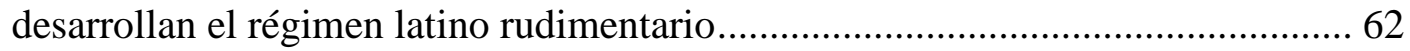

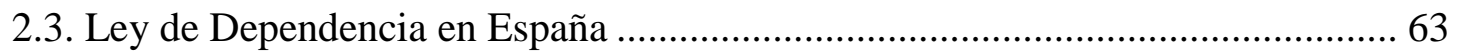

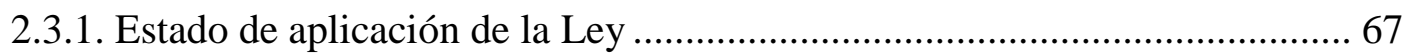

CAPÍTULO III: PARTICULARIDADES DE LOS CUIDADORES Y DEL

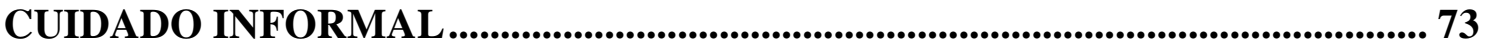

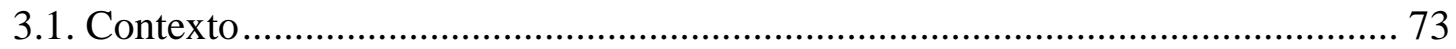

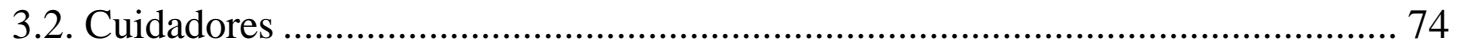

3.2.1. Tipología de cuidadores informales ....................................................... 74

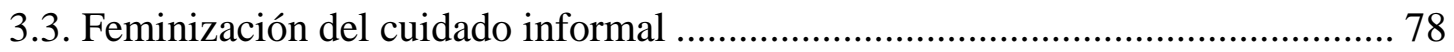

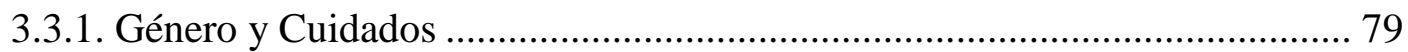

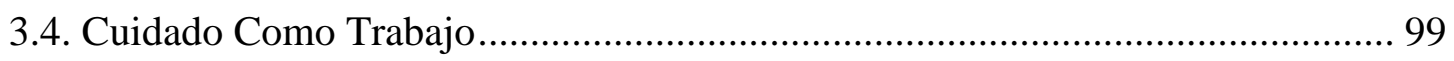

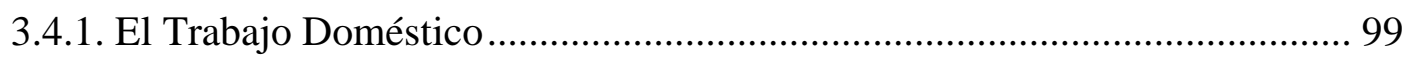

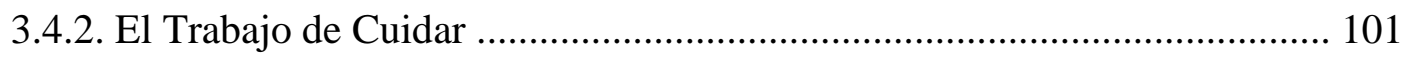

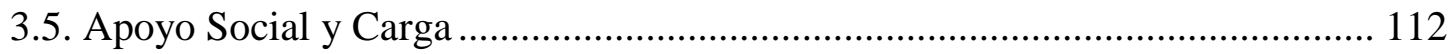

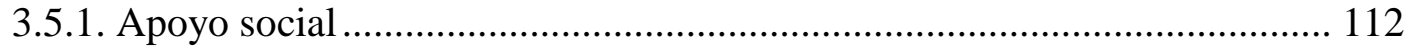

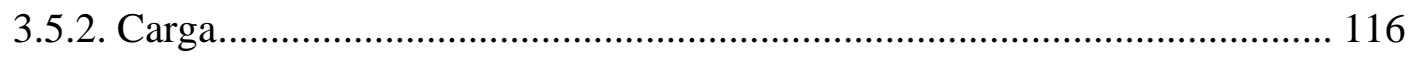

3.6. Maltrato en el entorno del cuidado ................................................................. 124

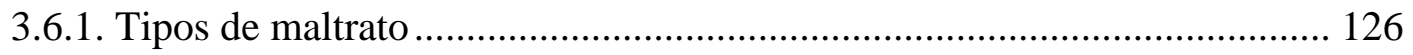

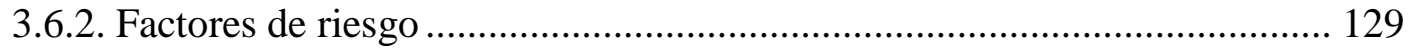

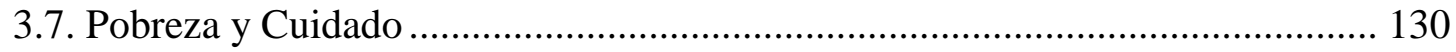

\section{CAPÍTULO IV: LA DEPENDENCIA Y LOS CUIDADOS A PERSONAS EN} SITUACIÓN DE DEPENDENCIA EN CHILE .................................................... 133

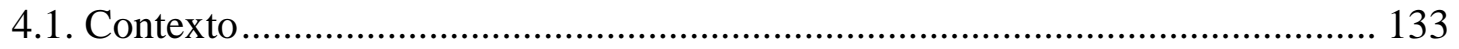

4.2. Aspectos de la Política Social Chilena …........................................................ 136

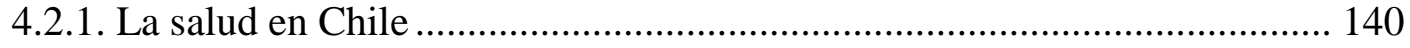

4.2.2. Sistema de Pensiones............................................................................ 152 
4.3. Características de la discapacidad en Chile ..................................................... 159

4.3.1. Personas discapacitadas ¿Quiénes son?................................................ 160

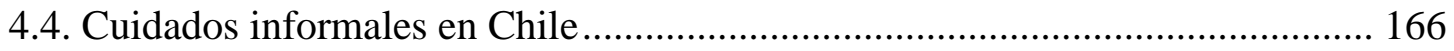

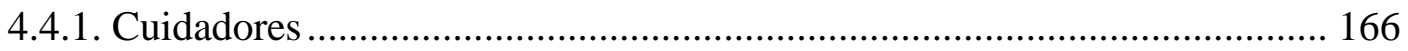

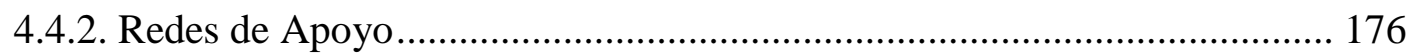

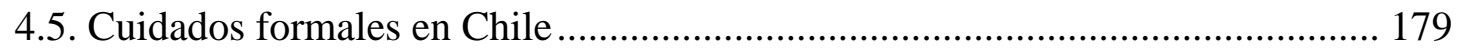

4.5.1. El Estado y los centros residenciales .................................................. 179

4.5.2. La acción de ONGs y Movimientos Asociativos .................................... 181

PARTE II: TRABAJO EMPÍRICO Y ANÁLISIS ..................................................... 187

CAPÍTULO V: MARCO METODOLÓGICO......................................................... 187

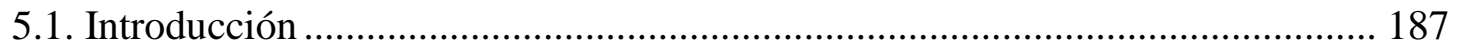

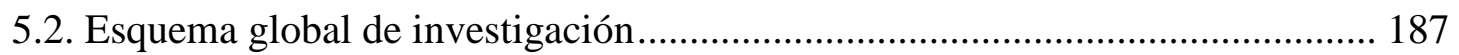

5.2.1. Problema y preguntas de investigación ................................................ 187

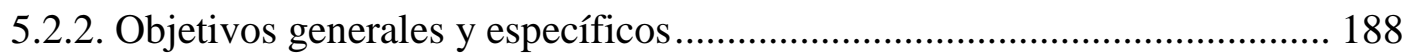

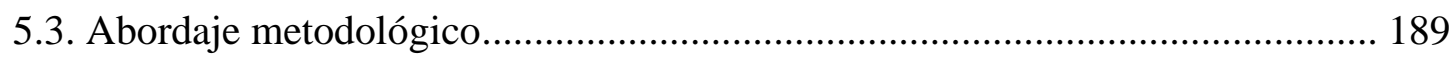

5.3.1. Teoría Fundamentada como diseño de investigación............................... 190

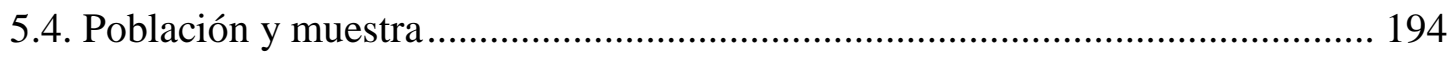

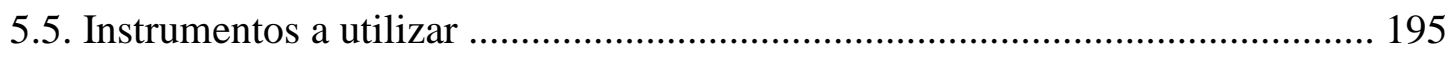

5.5.1. Herramientas de recolección de datos ........................................................ 195

5.5.2. Instrumentos de recolección de datos ........................................................ 196

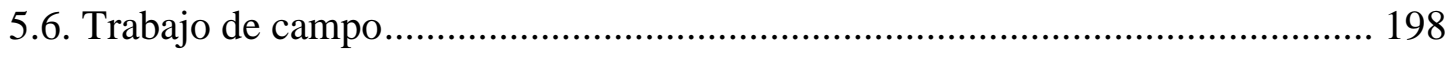

5.6.1. Gestiones para contactar con posibles entrevistados/as .......................... 198

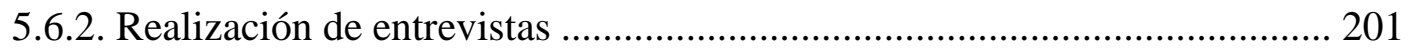

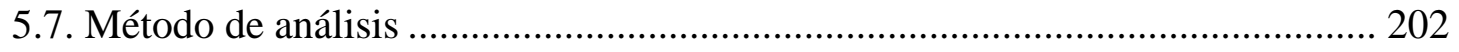

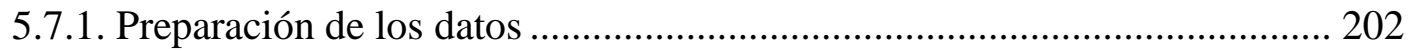

Página | IX 
5.7.3. Organización y presentación de los datos............................................... 203

5.7.4. Mapa conceptual de estructura categorial desarrollada ............................. 205

CAPITULO VI: ANÁLISIS .................................................................................... 207

I. TEMA. ACTITUDES Y MOTIVACIONES DEL CUIDADOR FRENTE AL

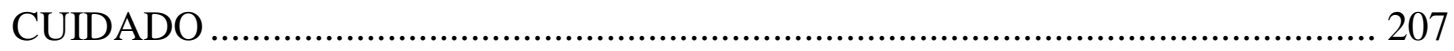

1.1. CATEGORÍA “ACTITUDES FRENTE AL CUIDADO”. ........................... 207

Propiedad “Actitud positiva/optimista/estoica".................................................. 208

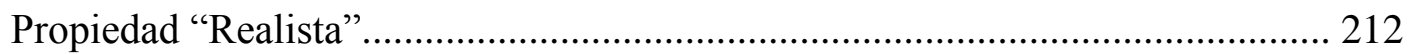

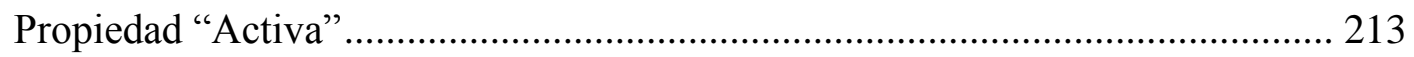

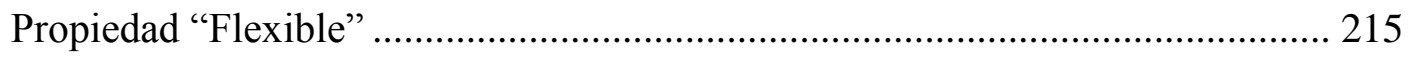

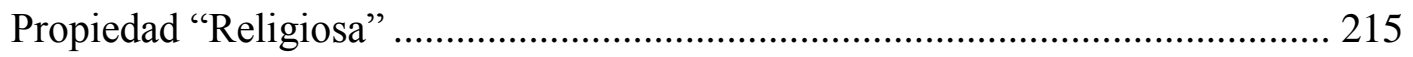

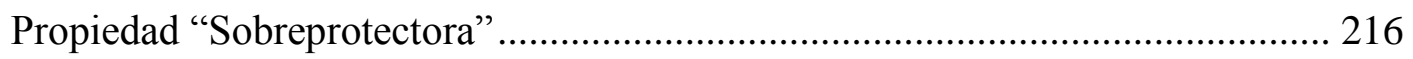

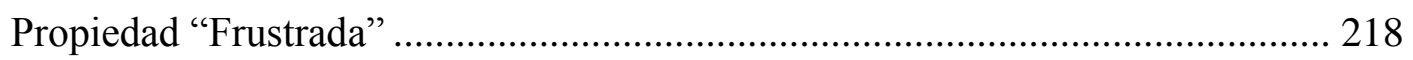

Propiedad "Temor al futuro" ....................................................................... 219

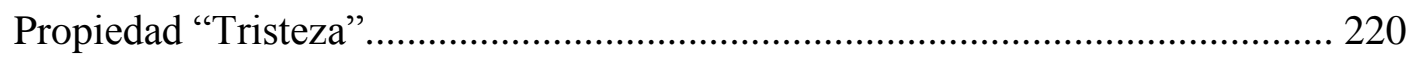

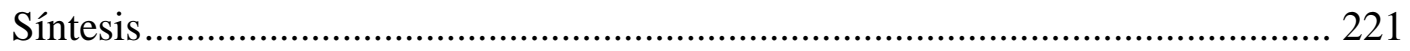

1.2. CATEGORÍA “MOTIVACIONES PARA EL CUIDADO”........................ 221

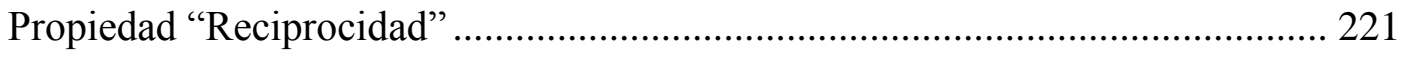

Propiedad "Sentimiento del deber" .............................................................. 225

II. TEMA DE ANÁLISIS. TAREA DEL CUIDADO Y SUS CONSECUENCIAS 229

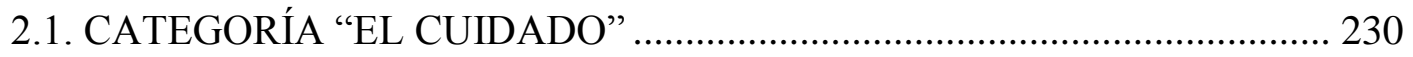

Propiedad "Vestimenta y aseo personal del dependiente" .................................. 230

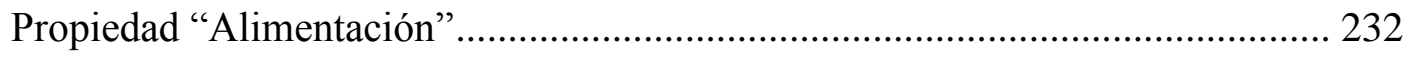

Propiedad "Movilización del dependiente" .................................................... 235

Propiedad "Tratamientos, procedimientos de rehabilitación”............................ 237 
Propiedad "Cuidados especiales para los dependientes con déficits cognitivos y/o demencias"..... 238

Propiedad "Actuación ante emergencias" ......................................................... 239

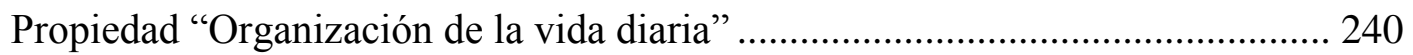

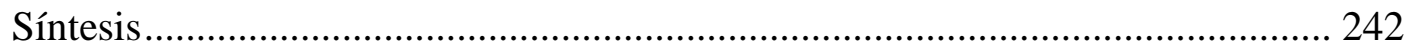

2.2. CATEGORÍA “EL CUIDADOR”......................................................... 243

Propiedad "Perfil "sociodemográfico" de los cuidadores"................................ 243

Propiedad "Personalidad del cuidador" ...................................................... 250

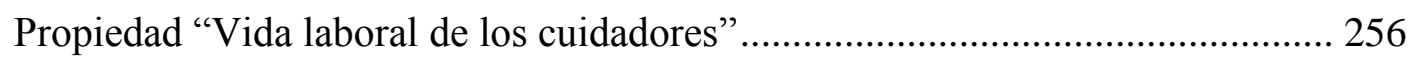

Propiedad "Sentido que otorgaban al trabajo" ................................................. 260

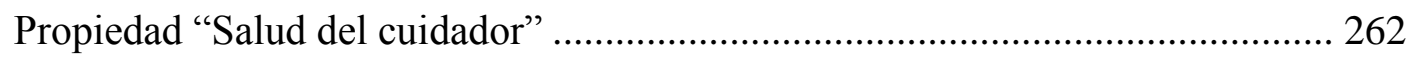

Propiedad "Factores que influyen en la salud del cuidador" .............................. 266

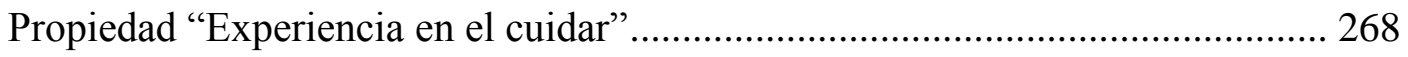

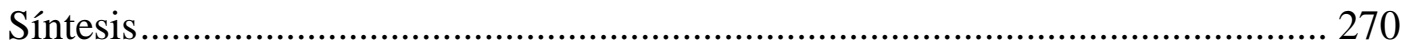

2.3. CATEGORÍA “LA PERSONA DEPENDIENTE”...................................... 272

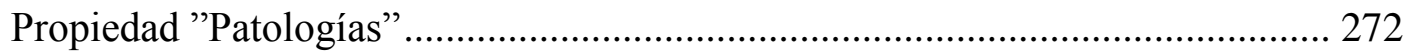

Propiedad "Vida antes y después de la enfermedad" ......................................... 281

Propiedad "Influencia de los tratamientos en el estado de ánimo del dependiente". 285

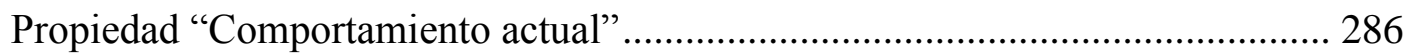

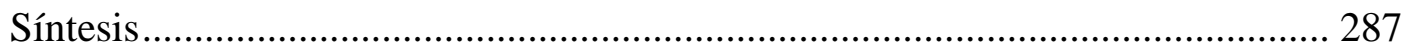

2.4. CATEGORÍA "CONSECUENCIAS DEL CUIDADO EN LA VIDA DEL

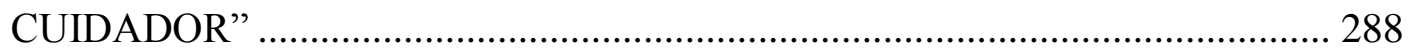

SUBCATEGORÍA “Consecuencias generales para el cuidador por el apoyo a su familiar" 289

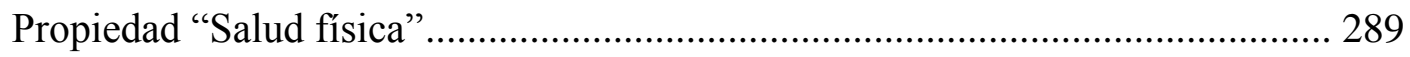

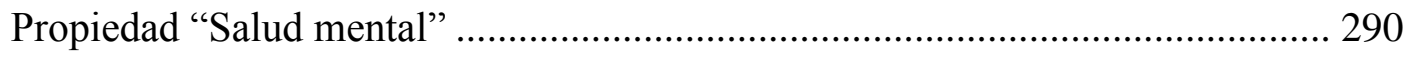


Propiedad "Salud social"

SUBCATEGORÍA "Consecuencias del cuidado en la familia"

Propiedad "Economía familiar". 294

Propiedad "Dinámicas familiares" 295

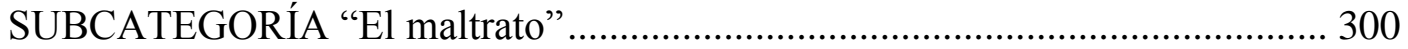

Propiedad "El cuidador como maltratador"........................................................ 300

Propiedad "La persona dependiente como maltratador" .................................. 303

Propiedad "Violencia en la familia del cuidador" ............................................... 304

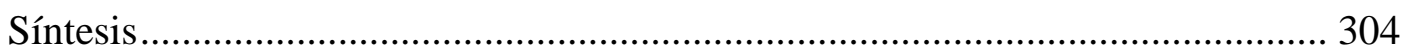

III. TEMA. FACTORES DE PROTECCIÓN Y RIESGO DE SOBRECARGA DEL

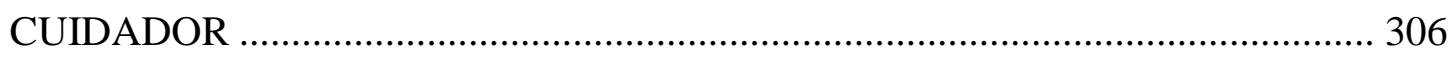

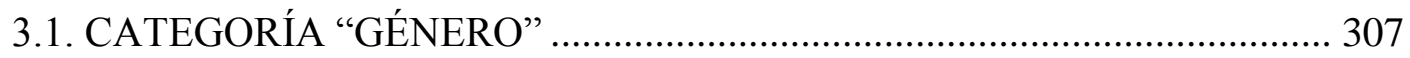

Propiedad "Identidades de género reflejados en el cuidado" .............................. 307

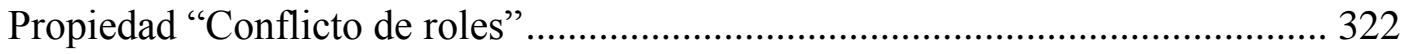

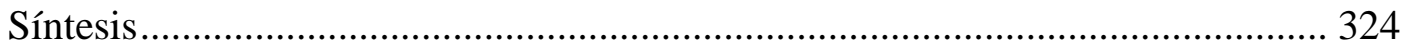

3.2. CATEGORÍA "SITUACIÓN SOCIOECONÓMICA DE LOS CUIDADORES

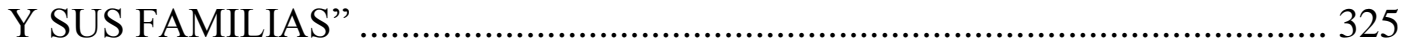

Propiedad "Situación socioeconómica del cuidador y su familia" ..................... 325

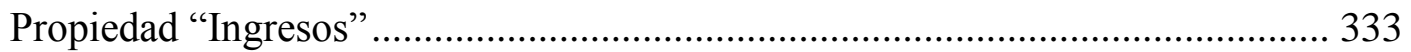

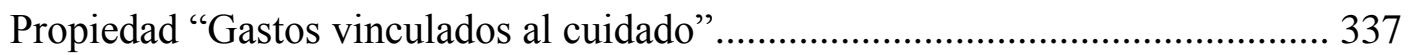

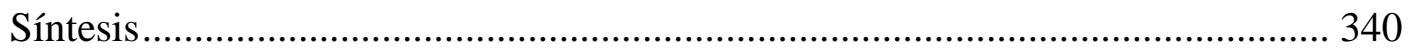

3.3. CATEGORÍA "FACTORES QUE INFLUYEN EN LA CALIDAD DE LA RELACIÓN CUIDADOR - DEPENDIENTE" ................................................ 342

Propiedad "Relación previa a la situación de dependencia entre cuidador y

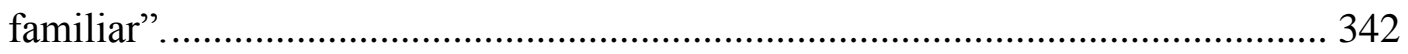

Propiedad "Tipo de relación de parentesco" ......................................................... 343

Propiedad "Madurez emocional del cuidador" ................................................... 343

Página $\mid$ XII 
Propiedad "Existencia de reciprocidad del cuidador con el dependiente"

Propiedad "Tipo de patología padecida por el dependiente" 345

Propiedad "Posibilidad de reemplazo en el cuidado"..... 346

3.4. CATEGORÍA "REDES DE APOYO INFORMAL" 347

Propiedad “Apoyo de familia (microsocial)" ....................................................... 348

Propiedad “Ayuda de vecinos y amigos (mesosocial)" "........................................ 351

Propiedades “Apoyo de organizaciones (macrosocial)" ................................... 353

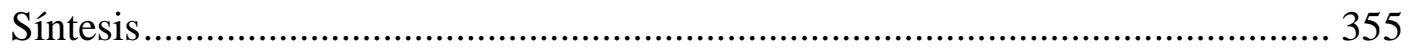

3.5. CATEGORÍA “CUIDADOS FORMALES”............................................... 356

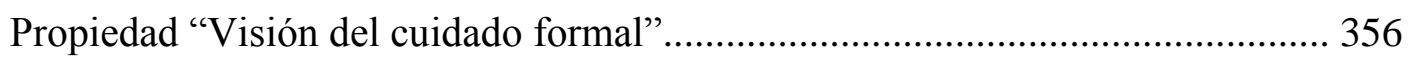

Propiedad "Existencia de cuidado formal" ..................................................... 359

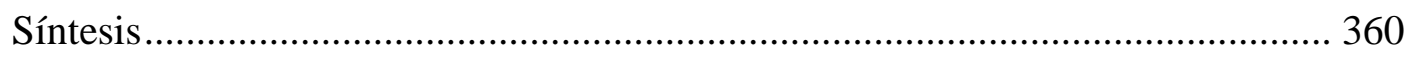

3.6. CATEGORÍA “AUTOPERCEPCIÓN DEL FUTURO POR PARTE DEL

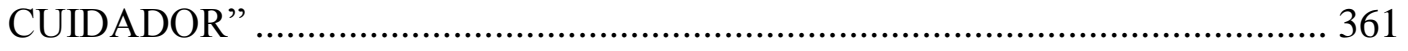

Propiedad "Enfrentamiento temeroso del futuro" ............................................... 361

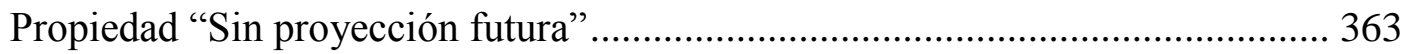

Propiedad "Optimismo, con planes futuros" ...................................................... 364

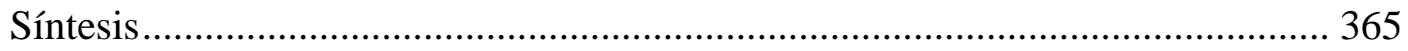

3.7. CATEGORÍA “MANIFESTACIONES DE SOBRECARGA” .................... 366

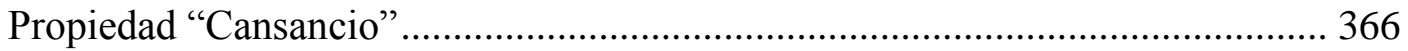

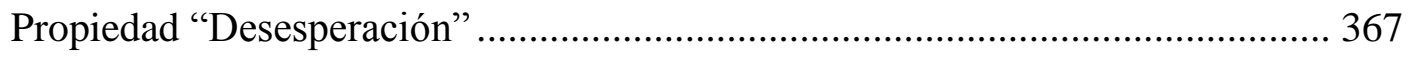

IV. TEMA DE ANÁLISIS. “INFLUENCIA DEL MEDIO URBANO Y RURAL EN

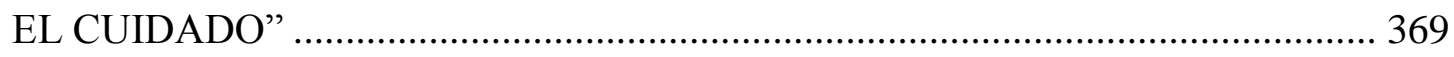

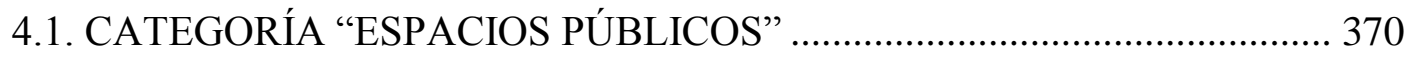

Propiedad "Transporte en los medios urbano y rural" ..................................... 370

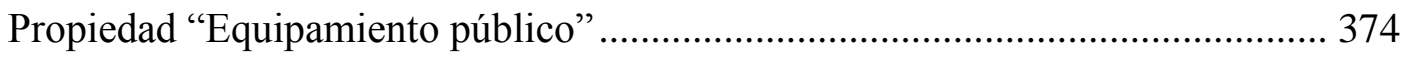


Propiedad “Accesibilidad espacial pública".

4.2. CATEGORÍA "VIVIENDA DEL DEPENDIENTE"

Propiedad "Vivienda del dependiente" 379

Propiedad "Adaptaciones y/o estrategias adoptadas". 381

4.3. CATEGORÍA "VENTAJAS Y DESVENTAJAS DE LOS MEDIOS URBANOS Y RURALES PARA EL CUIDADOR”

Propiedad "Ventajas y desventajas de vivir en el medio urbano para el cuidador" 383

Propiedad "Ventajas y desventajas de vivir en el medio rural para el cuidador". 384

Síntesis del tema 386

V. TEMA "PERCEPCIÓN DE LOS CUIDADORES DEL ESTADO” 388

5.1. CATEGORÍA "SALUD PÚBLICA" 389

Propiedad "Atención primaria" 389

Propiedad "Planes o programas de salud" 395

Propiedad "Atención secundaria y terciaria en salud" 396

Propiedad "Salud Laboral". 398

Propiedad "Problemas de la salud pública". 399

Síntesis 402

5.2. CATEGORÍA "SALUD PRIVADA" 403

Propiedad "Motivos por la atención en la salud privada" 403

Propiedad "Tipos de atenciones e instituciones en salud privada" 404

Síntesis 407

\subsection{CATEGORÍA "PENSIONES"} 407

Propiedad "Comportamiento previsional" 408

Propiedad "Tipos de pensiones" 409

Síntesis 413 
Propiedad "Acceso a la educación".

Propiedad "Calidad de la educación especial"

Síntesis

5.5. CATEGORÍA “DEMANDAS DE LOS CUIDADORES AL ESTADO” .... 420

Propiedad "Apoyo económico"

Propiedad "Apoyo en atenciones en salud"

Propiedad "Formación y reconocimiento"

Síntesis

CAPÍTULO VII. DISCUSIÓN Y CONCLUSIONES

Situación psicosocial y cultural de los cuidadores informales de personas dependientes

Posibles diferencias en la situación de cuidadores informales rurales y urbanos 436 Aspectos de la situación psicosocial y cultural de los cuidadores que son susceptibles de mejorar desde la política social

ANEXOS

Anexo 1. Consentimiento informado para los participantes de entrevistas

Anexo 2. Guión o pauta de entrevista.

Anexo 3. Ficha del cuidador . 485

Anexo 4. Tareas del cuidador 486

Anexo 5. Escala de sobrecarga del cuidador de Zarit (Caregiver Burden Interview), adaptación española 489

Anexo 6. Mapas Chile y Sudamérica. 492 


\section{ÍNDICE DE CUADROS}

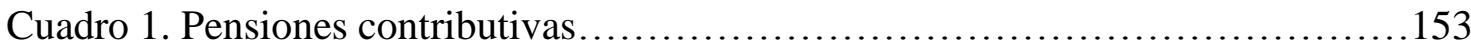

Cuadro 2. Sistema Solidario de pensiones chileno....................................156

Cuadro 3. Cuidadores de acuerdo a medio en el que habitan, sexo y municipio .243

Cuadro 4. Edad de los cuidadores y parentesco con el familiar que cuidan .244

Cuadro 5. Estado civil de los entrevistados .245

Cuadro 6. Nivel educacional alcanzado por los cuidadores. 246

Cuadro 7. Número de personas que viven con el cuidador y que podrían prestarle ayuda con el(los) dependiente(s).

Cuadro 8. Tiempo que llevan cuidando. 247

Cuadro 9. Ocupación de los cuidadores al momento de la entrevista. .256

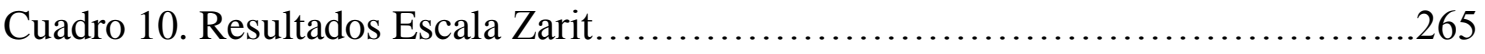

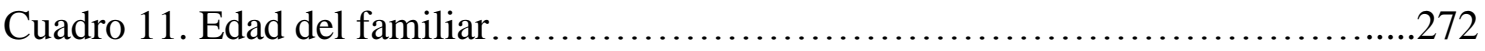

Cuadro 12. Enfermedad que sufre el dependiente...................................273

Cuadro 13. Ficha del cuidador (información básica del cuidador).....................485

\section{ÍNDICE MAPAS Y MAPAS CONCEPTUALES}

Mapa 1. Región Metropolitana de Santiago de Chile.................................200

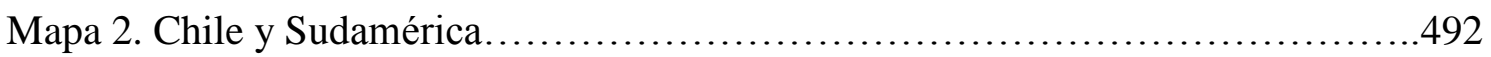

Mapa conceptual. Estructura general de análisis....................................205

Mapa conceptual tema 1. Actitudes y motivaciones del cuidador frente al

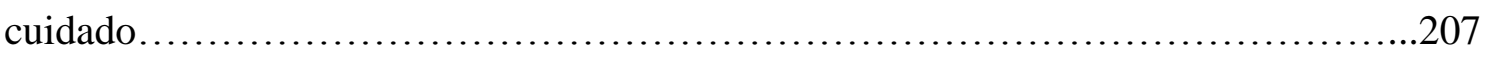

Mapa conceptual tema 2. Tarea del cuidado y sus consecuencias......................229

Mapa conceptual tema 3. Factores de protección y de riesgo de sobrecarga...........306

Mapa conceptual tema 4. Influencia del medio urbano y rural en el cuidado............369

Mapa conceptual tema 5. Percepción de los cuidadores del Estado......................388 


\section{RESUMEN DE LA INVESTIGACIÓN}

La investigación que a continuación se presenta trata sobre los cuidados informales a personas dependientes en Chile. El estudio empírico fue realizado en la Región Metropolitana de Santiago de Chile, con cuidadores informales de personas con dependencias de diversas edades, y de estratos socioeconómicos bajos y medios-bajos. La información recopilada fue tratada con metodología cualitativa, específicamente la Teoría Fundamentada. Los principales resultados hallados indican que los cuidados en Chile, tanto en zonas urbanas como rurales, eran responsabilidad exclusiva de las mujeres. El Estado chileno se encontraba cumpliendo un rol subsidiario en esta problemática, aún en los sectores más deprimidos de la sociedad. Estos rasgos junto a la variable socioeconómica, la dinámica poblacional y la creciente incorporación de la mujer al mercado laboral hacían que la situación de los cuidados en Chile estuviera en situación de crisis y apremiante intervención. 
Página | 2 


\section{INTRODUCCIÓN}

\section{Presentación de la investigación}

La forma en que tradicionalmente se desarrollaba el cuidado hacia las personas con dependencias en occidente, en la cual las mujeres de las familias se hacían cargo de quienes necesitaran atención, se ha visto modificada por cambios culturales y sociales. Estas transformaciones en la prestación de cuidados informales a la dependencia dicen relación con: cambios en la oferta del cuidado y la demanda de éste; cambios en la posición social de las personas que necesitan de cuidados; modificaciones en las políticas de bienestar; y mayor diversidad en el tipo de situaciones que requieren de cuidado y sus cuidadores (Cameron y Moss 2007).

Los cambios anteriormente mencionados también han ocurrido en la sociedad chilena, con distintos matices. La oferta de cuidados en Chile, asociada al desempeño no remunerado de esta actividad por la mujer, fue afectada en cuanto a disposición y tiempo por varios motivos: la incorporación creciente de la mujer al mercado laboral; el mayor nivel de instrucción alcanzado por las chilenas, que incide en el anterior factor; y los cambios demográficos que han repercutido en el tamaño de las familias, haciéndolas cada vez más pequeñas y por tanto con menos miembros en posibilidad de cuidar del que lo necesite.

Del mismo modo, la demanda de cuidados en el país se ha visto acrecentada por cambios demográficos. Chile se encuentra en una transición demográfica avanzada hacia el envejecimiento poblacional, donde la esperanza de vida ha evolucionado desde 54,8 años en 1950 a 78 años -75,5 para hombres y 81,5 en mujeres- en 2005 (Instituto Nacional de Estadísticas y Comisión Económica para América Latina y el Caribe 2005). 


\section{Introducción}

Se pronostica ${ }^{1}$ que para el año 2025 la población mayor de 65 años representará un $14,07 \%$ de la población chilena. Este panorama vaticina el aumento progresivo de personas con necesidad de cuidados en el país. Ya en 2009, el Estudio nacional de la dependencia en las personas mayores (Servicio Nacional del Adulto Mayor, INTA, Microdatos 2009) indicaba que un 24,1\% de la población mayor de 60 años tenía algún tipo de dependencia.

Pero la dependencia no es solo un fenómeno de personas mayores, a pesar de que ellos son los que más discapacidades presentan, el Primer estudio nacional de discapacidad, efectuado en $2004^{2}$ (Fondo Nacional de la Discapacidad, Instituto Nacional de Estadísticas 2005) indicaba que un 12,9\% de la población chilena tenía una o más discapacidades, de este porcentaje el 17,9\% era menor de 30 años.

Otro de los cambios es la situación social de las personas que necesitan de cuidados, ésta ha variado en los últimos 20 años en Chile debido a que, con la recuperación de la democracia, se generó la reivindicación de derechos ciudadanos y reconocimiento de la diversidad. Este fenómeno repercutió en la creación de una institucionalidad estatal que abordó la discapacidad y que desarrolló una importante labor en la consideración de las personas con discapacidad como sujetos activos y ciudadanos con derechos.

Es importante mencionar que la política social pública chilena no tenía un rol protagonista en el tema de los cuidados. La responsabilidad primera en esta problemática era de la familia, y el Estado participaba en caso de desamparo del dependiente, principalmente a través de instituciones privadas sin fines de lucro que le prestaban servicios. Lentamente, el Estado chileno está generando cambios en su política de bienestar, pero en el ámbito de los cuidados a la dependencia su papel aún es secundario.

Si revisamos los estudios sociales efectuados en el área de la dependencia en Chile, encontramos numerosos trabajos sobre este grupo, diversos en tipos de dependencias y metodologías de abordaje. Pero el ámbito de los cuidados, tanto formales como

\footnotetext{
${ }^{1}$ Se utilizan proyecciones para el 2010 porque aún no están disponibles los datos del Censo 2012, desagregados por edades.

${ }^{2}$ ENDISC-2004, Encuesta a hogares aplicada a una muestra probabilística, trietápica a 13769 viviendas.
}

Página 4 


\section{Introducción}

informales, se encuentra pobremente documentado. Generalmente, ha sido abordado de forma tangencial por los estudios sobre dependencia, realizando descripciones estadísticas en relación al dependiente. La realidad sociocultural de los cuidadores de personas con dependencias es un ámbito de estudio que está por explorar.

Los argumentos anteriormente expuestos son los que motivan esta investigación, conocer la situación de los cuidados informales a la dependencia en Chile a través de la voz de los cuidadores. Dentro de las variables que fueron consideradas está el medio en el que habitan cuidadores y sus dependientes, nos pareció importante observar si existían diferencias en las formas en que se desarrollaba la actividad debido a que la experiencia latinoamericana sí reportaba resultados distintos para el cuidado efectuado en zonas urbanas y el desempeñado en zonas rurales.

Específicamente, nuestra intención es realizar esta investigación en sectores socioeconómicos bajos y medios-bajos, porque estos grupos son quienes mayormente deben desempeñarse como cuidadores de sus familiares al no contar con medios económicos que les permitan delegar esta actividad en un cuidador formal o institución. Esta decisión se ve reforzada si consideramos el dato que nos entrega el Primer estudio nacional de discapacidad en 2004 (Fondo Nacional de la Discapacidad e Instituto Nacional de Estadísticas 2005) que indica que en la población en condiciones socioeconómicas bajas la prevalencia de discapacidad pasa de 12,93\% global al $20 \%$.

Este estudio pretende, en un primer lugar, ser un aporte teórico y empírico en el ámbito de los estudios sobre los cuidados informales a la dependencia. Así también, busca contribuir al entendimiento de las múltiples variables que inciden en el desarrollo de la actividad estudiada. Por último, aspira a contribuir a la discusión sobre aspectos que deberían ser incluidos en el desarrollo de iniciativas -política pública, planes y programas- dirigidas a los cuidadores y sus dependientes.

La investigación que se desarrolla es de tipo cualitativa, transversal, exploratoria y descriptiva. Específicamente el trabajo de campo y el análisis fue guiado por la metodología planteada por la Teoría Fundamentada. El acceso a la información empírica fue posible gracias a las entrevistas semiestructuradas realizadas a cuidadores de personas dependientes de diversas edades -aunque con porcentaje importante de 


\section{Introducción}

personas mayores-, habitantes de comunas urbanas y rurales de la Región Metropolitana de Santiago de Chile. En esta instancia también se aplicaron otros instrumentos a las personas entrevistadas. El análisis de las entrevistas fue apoyado en el programa informático ATLAS.ti.

Esta tesis doctoral se divide en dos partes. En la primera de ellas realizamos una aproximación teórica sobre los principales aspectos socioculturales y de políticas sociales relacionados con los cuidados a la dependencia, contextualizando la problemática en Chile. Podemos distinguir en esta parte de la investigación cuatro capítulos:

En el primer capítulo realizamos una revisión general de la temática de los cuidados, definiendo conceptos fundamentales para esta investigación, tales como: discapacidad, dependencia, cuidados, cuidados informales y cuidados formales. Si bien el concepto del cuidado y los cuidados informales serán tratados en profundidad en capítulos posteriores, en este apartado buscamos explicar las bases de los conceptos con los que trabajaremos.

En el segundo capítulo, nos referimos a los sistemas de atención a las personas en situación de dependencia. La primera parte de este capítulo trata sobre los regímenes de bienestar, con la finalidad de tener un marco de referencia general que posteriormente nos permitirá analizar los principales sistemas de atención a la dependencia. Finalizamos este capítulo con una consideración a la Ley de dependencia en España y su estado de aplicación.

El capítulo tercero pretendió abarcar las particularidades asociadas a la figura del cuidador y del cuidado informal. Los temas abordados en este apartado fueron: tipos de cuidadores informales; la feminización del cuidado; el desempeño del cuidado como trabajo; el apoyo social y la carga; el maltrato en el entorno del cuidado; y la relación entre pobreza y cuidados informales.

Finalizamos esta parte con un cuarto capítulo en donde trabajamos el tema de la dependencia y los cuidados a personas en situación de dependencia en Chile. En esta sección procuramos entregar una visión sobre los aspectos más relevantes de la política 


\section{Introducción}

social chilena, en directa relación con esta investigación, es decir, la salud, el sistema de pensiones y la educación. Luego describimos la situación de la discapacidad en Chile; para proseguir con los cuidados informales, cuidadores y redes de apoyo. El capítulo finaliza reseñando la realidad de los cuidados formales en el país, tanto en los entregados por instituciones públicas como privadas.

La segunda parte de este estudio está referida al trabajo empírico desarrollado para el estudio de la problemática planteada. Esta parte consta de 3 capítulos. El capítulo quinto está dedicado a explicar la metodología que fue utilizada en esta investigación: explicación y descripción de la Teoría Fundamentada, de los instrumentos utilizados, del trabajo de campo y el método de análisis.

En el capítulo sexto de este documento se desarrolla el análisis de la información recogida en el trabajo de campo y sus resultados. De acuerdo al diseño de investigación expuesto en el capítulo cinco, el análisis se desarrolla en relación a cinco temas: actitudes y motivaciones del cuidador frente al cuidado; la tarea del cuidado y sus consecuencias; los factores de protección y de riesgo de sobrecarga del cuidador; la influencia del medio urbano y rural en el cuidado; y la percepción que los cuidadores tienen del Estado. Cada uno de estos temas se examina en categorías, propiedades y dimensiones.

La discusión y conclusiones de esta tesis doctoral son tratadas en el capítulo séptimo. La discusión está orientada a confrontar los resultados obtenidos con experiencias similares y la teoría en las temáticas tratadas, bajo la estructura de los objetivos de esta investigación. Posteriormente, se exponen los principales hallazgos encontrados, la importancia del estudio, los resultados inesperados, las limitaciones de la investigación, y se realizan recomendaciones para futuros estudios. En el apartado Anexos se encuentran los instrumentos utilizados para la recolección de datos. 
Página $\mid 8$ 


\section{PARTE I: APROXIMACIÓN TEÓRICA}

\section{CAPÍTULO I: LOS CUIDADOS}

\subsection{Conceptos fundamentales: discapacidad y dependencia}

Con la intención de comprender la dependencia y los cuidados que a ella se asocian consideramos necesario revisar el recorrido histórico del concepto de discapacidad. En 1975, la "Declaración de Derechos de los Impedidos" de las Naciones Unidas utilizó el término impedido para referirse a "toda persona incapacitada de subvenir por sí misma, en su totalidad o parte, a las necesidades de una vida individual o social normal a consecuencia de una deficiencia, congénita o no, de sus facultades físicas o mentales" (Alto Comisionado de las Naciones Unidas para los Derechos Humanos 1975). Años más tarde, la Organización Mundial de la Salud, distinguió, en su Clasificación Internacional de Deficiencias, Discapacidades y Minusvalías $(\mathrm{CIDDM})^{3}$ entre deficiencia, discapacidad y minusvalía. Deficiencia fue definida como "la pérdida o anormalidad permanente o transitoria -psicológica, fisiológica o anatómica- de estructura o de función". Por discapacidad, "cualquier restricción o impedimento del funcionamiento de una actividad, ocasionados por una deficiencia, en la forma o dentro del ámbito considerado normal para el ser humano". Finalmente, se reservó el término minusvalía para referirse a la "incapacidad que constituye una desventaja para una persona dada, en cuanto limita o impide el cumplimiento de una función que es normal para esa persona según la edad, el sexo y los factores sociales y culturales”. Esta definición de minusvalía supone una síntesis del denominado "modelo médico", en el que la discapacidad se ve como un problema o defecto inherente a la persona, causado por una enfermedad o problema de salud, y el "modelo social" de discapacidad, para el que la discapacidad no deriva sólo de una condición de la persona, sino de la interacción de esta condición con el ambiente social (de Lorenzo 2003).

\footnotetext{
${ }^{3}$ Propuesta con carácter experimental por la OMS en 1980.
}

Página 9 
En los últimos tiempos se imponen los términos discapacidad y persona con discapacidad, utilizándolos como sinónimos de minusvalía, persona con minusvalía y minusválido, éstas últimas vienen siendo objeto de un progresivo desuso por poseer ciertas connotaciones negativas. Siguiendo esta tendencia, la Organización Mundial de la Salud ha adoptado en su nueva Clasificación Internacional del Funcionamiento, la Discapacidad y la Salud (CIF) (Organización Mundial de la Salud 2001), el término discapacidad como concepto genérico para las tres perspectivas: corporal, individual y social. La expresión discapacidad persiste en la CIF como concepto genérico que incluye déficits, limitaciones en la actividad -la "discapacidad" de la CIDDM- y restricciones en la participación -lo que, en la CIDDM, se denominaba "minusvalía"-. La discapacidad indica los aspectos negativos de la interacción entre un individuo (con una condición de salud) y sus factores contextuales (factores ambientales y personales) (Vázquez-Barquero et al. 2001).

Así también, el Consejo de Europa ${ }^{4}$ constituyó a mediados de la década de los noventa un grupo de expertos que trabajó en la elaboración de un texto de consenso que pudiese ser asumido desde la mayoría de los países miembros de este organismo internacional. El resultado de ese trabajo fue la aprobación, en septiembre de 1998, por el Comité de Ministros del Consejo de Europa, de una recomendación relativa a la dependencia. En dicha recomendación el Consejo de Europa define la dependencia como "un estado en el que se encuentran las personas que por razones ligadas a la falta o la pérdida de autonomía física, psíquica o intelectual tienen necesidad de asistencia y/o ayudas importantes a fin de realizar los actos corrientes de la vida diaria y, de modo particular, los referentes al cuidado personal" (Consejo de Europa 1998:11).

Esta definición es coherente con la definición realizada por la OMS en la CIF, ya que se entiende a la dependencia como el resultado de un proceso que se inicia con la aparición de un déficit en el funcionamiento corporal, psíquico o intelectual como consecuencia de una enfermedad o accidente. Este déficit conlleva una limitación en la actividad. Cuando esta limitación no puede compensarse mediante la adaptación del entorno, provoca una restricción en la participación que se concreta en la dependencia de la

\footnotetext{
${ }^{4}$ Organismo europeo que ha promovido diversas iniciativas y recomendaciones con el objeto de mejorar la situación de las personas dependientes y la de sus cuidadores.
} 
ayuda de otras personas para realizar las actividades de la vida cotidiana. Ésta definición de dependencia será la que asumimos en este trabajo.

La evidencia empírica disponible muestra que existe una estrecha relación entre dependencia y edad, ya que el porcentaje de individuos con limitaciones en su capacidad funcional aumenta conforme consideramos grupos de población de mayor edad. Ese aumento en las tasas de prevalencia por grupos de edad no se produce a un ritmo constante, sino que existe una edad (alrededor de los 80 años) en que dicho aumento se acelera notablemente (Rodríguez Cabrero 2004). No es extraño por ello que la dependencia se vea como un problema estrechamente vinculado al envejecimiento demográfico y que algunas veces, en una visión reduccionista, se tienda a considerar la dependencia como un fenómeno que afecta sólo a los mayores.

En realidad, la dependencia recorre toda la estructura de edades de la población. No se puede circunscribir por ello el fenómeno de la dependencia al colectivo de las personas mayores, aun cuando sean éstas las que con más intensidad se ven afectadas. La dependencia puede aparecer en cualquier momento de la vida. Puede estar presente desde el nacimiento, desencadenarse a consecuencia de un accidente o de una enfermedad aguda en la infancia, la juventud o la vida adulta o, más frecuentemente, ir apareciendo a medida que las personas envejecen, como consecuencia de enfermedades crónicas o como reflejo de una pérdida general en las funciones fisiológicas, atribuible al proceso global de senescencia (Instituto de Mayores y Servicios Sociales 2004).

Las malformaciones congénitas, los accidentes (laborales, de tráfico, domésticos) y las nuevas enfermedades invalidantes (como el SIDA -Síndrome de inmunodeficiencia adquirida-) son factores que contribuyen a hacer de la dependencia un problema social de primera magnitud. Sin embargo, el proceso acelerado de envejecimiento de la población está dando una dimensión nueva al problema, tanto cuantitativa como cualitativamente, al coincidir con cambios profundos en la estructura social de la familia y de la población cuidadora. Obviamente, la necesidad de asistencia y/o cuidados derivada de las situaciones de dependencia ha existido siempre; lo que ha cambiado es su dimensión, su importancia social tha dejado de verse como un problema exclusivamente individual o familiar para pasar a percibirse como un problema que afecta a la sociedad en su conjunto- y su naturaleza -en tanto que supone una 
redefinición de los objetivos y funciones del Estado e implica nuevos compromisos de protección y financiación- (Instituto de Mayores y Servicios Sociales 2004).

La situación actual de la dependencia ha cambiado sustancialmente respecto a la que existía hace 40 años atrás, ya que ésta estaba cubierta por un manto que la hacía invisible socialmente. Generalmente, la curación o la muerte rápida a causa de la enfermedad aguda originaban una dependencia de corta duración, esta brevedad temporal ofrecía pocas posibilidades sociales de una percepción colectiva del estatus de dependiente entre los ancianos más allá de la proveniente del propio envejecimiento. Para la mayoría de la población la esperanza de vida era menor a los 50 años y quienes cumplían más de 60 años eran una minoría, por lo tanto se perdían en los espacios sociales al ser tan pocos. Además, estaba la reclusión de sujetos con dependencias prolongadas en instituciones destinadas para los excluidos, principalmente aquellos discapacitados mentales y psíquicos; esta reclusión generalmente se efectuaba durante la juventud o la adultez, prolongándose hasta la vejez, los individuos nunca salían de estas instituciones, por lo tanto esta dependencia de larga duración nunca se veía (Robles 2006b).

\subsubsection{Conceptualización y evaluación de la dependencia}

La universalidad e importancia que tienen las situaciones de dependencia, en muy diversos aspectos de la vida personal, familiar, social, médica, económica, asistencial, etc., ha hecho que sean múltiples disciplinas y profesionales los que se encarguen de su estudio. Esta pluridisciplinaridad aporta una importante e inagotable fuente de datos, definiciones y baremos, que profundizan y enriquecen su estudio. Pero también ha sido frecuentemente fuente de confusión, desarrollándose paralelamente múltiples terminologías, definiciones, escalas de valoración y métodos de clasificación. Ejemplo de ello es que desde la rehabilitación se incide fundamentalmente en los aspectos motórico-funcionales derivados de problemas neuromusculoesqueléticos; desde la geriatría, se hace hincapié en aspectos fisiológico-cognitivos y asistenciales derivados de senectud y la demencia; desde la medicina de familia y cuidados paliativos, el objetivo es el control de los síntomas y de la calidad de vida; desde la valoración de la discapacidad y la medicina evaluadora, la atención se centra en aspectos tendentes a la graduación, para la consecución de indemnizaciones, prestaciones y acceso a servicios; 
desde la psicología, los esfuerzos se canalizan en aspectos del desarrollo y socialización de los apoyos requeridos; en el trabajo social, los ejes son los aspectos domésticos, del entorno y apoyo a los cuidadores; los prestadores de servicios ponen el acento en las cargas de trabajo; los propios afectados y/o de sus familias focalizan sus esfuerzos en aspectos reivindicativos de los derechos humanos y de la autonomía sobre las decisiones que afecten a su propia vida. Finalmente, desde el ámbito de las políticas sociales, la línea central de trabajo es la necesidad de controlar recursos y subvenciones, y el rediseño de las políticas sociales y socio-sanitarias.

La situación antes descrita hacía necesaria una mayor precisión conceptual de las herramientas de clasificación y de valoración de las personas susceptibles de atención y de las problemáticas que les rodean. La Organización Mundial de la Salud (OMS), consciente de este problema, aprobó la Clasificación Internacional del Funcionamiento, de la Discapacidad y de la Salud (CIF), herramienta que trata de aproximar, simplificar y unificar tanto terminologías como sistemas de graduación de todos los problemas relacionados con la discapacidad (Organización Mundial de la Salud 2001).

Recordemos que, de acuerdo a la definición que la OMS realiza en la CIF, la discapacidad es un concepto que engloba todos los problemas que interactúan multidireccionalmente entre la persona y el contexto socio-ambiental en el que se desenvuelve, y las interacciones con los factores tanto personales como ambientales, que pueden actuar como barreras y ayudas.

Habitualmente, se tiende a considerar la dependencia como un hecho estático, lineal o progresivo y propio de personas mayores enfermas. En este sentido, uno de los problemas más graves es el de no identificar claramente la relación de la dependencia con la discapacidad, tendiendo a clasificarlas y valorarlas por separado, como si fueran cosas distintas, olvidando que la dependencia siempre es consecuencia de un grado severo de discapacidad.

En el estudio de criterios y técnicas de valoración de la dependencia, consideraremos que dentro del contexto de las condiciones de salud de la persona la discapacidad es un atributo inseparable de la dependencia. La persona, por tanto, como consecuencia de 
una gran discapacidad, requerirá de ayuda o apoyos de alguien (o de algo) para poder realizar (o mejorar el rendimiento funcional) ciertas actividades.

Es importante recalcar que frecuentemente se confunden las deficiencias o las limitaciones para realizar una actividad concreta con la necesidad de ayuda para realizarla, ya que la discapacidad puede existir en diversos grados sin que por ello exista dependencia.

Con el motivo de sistematizar y comprender de forma cabal los componentes de la discapacidad, que suelen ser valorados por las distintas escalas de dependencia, creemos necesario explicitar su tipificación en categorías, de esta forma, podemos distinguir tres bloques interrelacionados entre sí y coherentes con la propuesta de la CIF:

\footnotetext{
$1^{\circ}$ Estructuras y funciones del cuerpo (deficiencias)

$2^{\circ}$ Actividades que realiza la persona (limitaciones y restricciones)

$3^{\circ}$ Contexto con el que interactúa (ayudas personales o técnicas y barreras)
}

La medición de la dependencia dependerá fundamentalmente del estudio de ciertas actividades, en las cuales se va a necesitar la ayuda de otra persona (y va a ser muy importante la intensidad de la misma), pero sin dejar de tener en cuenta su interacción con el contexto ambiental y personal ni con las deficiencias. En la medida que se aspire obtener mayor sensibilidad y/o especificidad en la valoración de la dependencia, se debe ir diferenciando y midiendo los tres componentes, deficiencia, actividades y ayuda, sin prescindir de ninguno de ellos.

Con respecto a las escalas de medición de la dependencia, en la actualidad se está lejos de conseguir un método o instrumento unificado y consensuado internacionalmente para la valoración de las situaciones de dependencia, por la universalización del problema y su pluridisciplinaridad, afectando a problemas no sólo de tipo sociosanitario, sino también cultural, económico o contextual de difícil estudio, sistematización e implementación hasta la fecha. Esta falta de unificación conlleva, como lógica consecuencia, múltiples criterios para definir y clasificar la dependencia, así como cientos de baremos y escalas para graduarla. 
La primera dificultad es simplemente el identificar las tablas, índices o baremos que se utilizan para valorar la dependencia, ya que casi ninguno hace referencia explícita a ello. Así, nos encontraremos con índices, tablas o baremos a los cuales se les denominará: de las Actividades de la vida diaria (AVD), de Clasificación Funcional, de Medida de Independencia Funcional (MIF), de Funcionamiento físico y problemas estructurales (RAI), de Necesidad de Ayuda de Tercera Persona (ATP), de Cuidados de larga duración, de Incapacidad Física, de Incapacidad Funcional, de Autovalimiento, de Autonomía, de Adaptación a las dificultades para realizar de forma independiente o autónoma las actividades de autocuidado, con el calificativo de "funcionales" (de incapacidad funcional, de independencia funcional) desde que Barthel clasificara una serie de actividades que denominó "básicas" como "clasificación funcional”. Esta forma de clasificación de la dependencia creó una confusión con la tipología de las funciones corporales (respiratoria, cardiovascular, mentales, metabólicas) y que la CIF clasifican en un grupo aparte, desdibujando de este modo la diferencia que quiere marcar la CIF entre la limitación para realizar actividades del individuo en su contexto y las deficiencias de las estructuras y de las funciones del cuerpo. Otros identifican el término funcional como la expresión de la capacidad del individuo de vivir independientemente en su medio. También podría entenderse -y ser motivo de confusión- por incapacidad funcional la incapacidad para el buen "funcionamiento" del individuo en realizar cualquier actividad según el concepto de funcionamiento de la CIF, pero para esto la CIF aconseja el uso del término global Discapacidad.

Otro término a destacar, nuevamente confuso, es el término autonomía usada a modo de antónimo de la palabra dependencia, confundiéndose con el de autodeterminación (como capacidad de decisión sobre su propia vida), el cual se usa actualmente cada vez con más frecuencia. Por último, la valoración de la dependencia suele estar en muchos casos solapada en una serie de valoraciones denominadas multidimensionales, globales o integrales, cuyos objetivos van normalmente mucho más allá del estudio de los problemas de funcionamiento/discapacidad y dependencia de la persona, como son el del seguimiento de los tratamientos, planificación y adecuación de servicios, coordinación de profesionales y cuidadores, etc. 
A falta de un instrumento estandarizado para valorar las situaciones de dependencia y vistos en la situación de elegir uno dentro de los existentes, resulta fundamental reflexionar sobre ciertas cuestiones, tales como: qué es lo que realmente se quiere valorar (el grado de limitación de la persona, la intensidad de la ayuda, el gasto sanitario, etc.), en qué contexto (domicilio, residencia, hospital de media-larga estancia, etc.), cuál es la población a la que se va a valorar (cualquier colectivo o colectivos específicos: enfermos terminales, demencias seniles, retrasos mentales, etc.) y para qué (aumentar la calidad de vida, prestación asistencial, prestación económica, gestión y control de gasto, etc.). Algunas de estas cuestiones son de trascendental importancia, debido a lo inapropiado de algunos de estos baremos para su aplicación generalizada, y por estar, en muchas ocasiones, fuera del colectivo o el contexto para el que se idearon.

En lo referente a la definición, clasificación y graduación de los problemas de salud, funcionamiento y discapacidad relacionados con la dependencia, se cuenta con herramientas reconocidas internacionalmente por el CIE y el CIF, que certeramente pueden ayudar a articular consensos en esta área.

De acuerdo a lo anterior y reflexionando sobre los métodos más importantes de valoración de la dependencia, en la elaboración de una herramienta de uso pluridisciplinar se deberían contemplar las siguientes enfermedades o problemas (Instituto de Mayores y Servicios Sociales 2004):

1. Las enfermedades y problemas de las condiciones de salud, que se reconocen en la Clasificación de enfermedades y problemas de salud relacionados (CIE-10) de la OMS.

2. Los problemas referentes a las deficiencias corporales registrados en la clasificación de estructuras y funciones corporales de la Clasificación de Funcionamiento y Discapacidad (CIF) de la OMS.

3. Los problemas referentes a las limitaciones para realizar actividades (o en su caso a las actividades en que se da la situación de necesidad de ayuda o dependencia para realizarlas) agrupados en la clasificación de actividades de la Clasificación de Funcionamiento y Discapacidad (CIF) de la OMS. 
4. Los problemas referentes a los factores ambientales y/o personales que están interactuando con la persona, y en su caso de las ayudas técnicas o personales que pueda precisar, ateniéndonos a la clasificación de Factores Contextuales de la Clasificación de Funcionamiento y Discapacidad (CIF) de la OMS.

La graduación de todos los problemas anteriormente mencionados (condiciones de salud, deficiencias corporales, limitaciones para realizar actividades, ayudas técnicas necesarias para la autonomía) se realizan mediante la escala en cinco niveles de gravedad de los problemas propuesta por la Clasificación de Funcionamiento y Discapacidad (CIF) de la OMS:

$$
\begin{aligned}
& \text { No hay problema (0-4\%) } \\
& \text { Problema Ligero (5-24\%) } \\
& \text { Problema Moderado (25-49\%) } \\
& \text { Problema Grave (50-96\%) } \\
& \text { Problema Completo (96-100\%) }
\end{aligned}
$$

Los dos primeros grupos presentan bajos niveles de dependencia, y se identifican con personas válidas o no dependientes. Se considera que los individuos que se ubican a partir del 25\% de afectación de su problemática en la vida diaria ya son dependientes, siendo éste el umbral de dependencia.

Las actividades de la vida diaria se agrupan en los nueve grupos de actividades de la vida recogidos en la clasificación de primer nivel Clasificación de Funcionamiento y Discapacidad (CIF) de la OMS (cada uno de estos grupos utiliza una terminología concreta y un significado exacto en cada una de sus definiciones):

1. Aprendizaje y aplicación del conocimiento.

2. Tareas y demandas generales.

3. Comunicación.

4. Movilidad.

5. Autocuidado.

6. Vida doméstica.

7. Interacciones y relaciones personales. 


\section{8. Áreas principales de la vida (Educación/Trabajo/Economía). \\ 9. Vida comunitaria, social y cívica.}

Así también, el Imserso (Instituto de Mayores y Servicios Sociales 2004: 99) recomienda que la escala que se utilice recoja las siguientes características o cualidades:

1. Información de los objetivos y finalidades del estudio o baremo, así como la población a la que va dirigida y el consentimiento de la persona a la que se evalúa, o de su tutor, en el caso de que aquella no sea capaz de contestar por sí misma un cuestionario.

2. Aplicación universal. Debe permitir su aplicación a cualquier persona, con diferentes estados de salud, etiología y severidad de sus problemas, edad, cultura, etc.

3. Debe permitir la elección de las actividades que sea procedente valorar, acotando claramente el área de dependencia que se pretende estudiar (actividades de autocuidado, de movilidad dentro o fuera del domicilio, actividades domésticas, de relación interpersonal, laborales, actividades de ocio y tiempo libre, etc.), sin realizar inferencias injustificadas entre éstas y otras actividades no valoradas.

4. Debe tener, tanto en el título como en sus apartados, claridad y concreción de las definiciones, con lenguaje sencillo, evitando ambigüedades o repeticiones, aceptado internacionalmente, libre de tecnicismos y que admita su aplicación y comprensión pluridisciplinar.

5. Debe diferenciar la necesidad de ayudas materiales o técnicas de la de apoyos humanos.

6. Debe identificar claramente el contexto en el que se desarrollan las actividades a valorar, siendo sensible a su descripción y a la información sobre sus posibles modificaciones, en concreto:

- Contexto real (institucional o domiciliario).

- Contexto neutral sin barreras o estandarizado. 
- Contexto subjetivo (anterior, futuro posible con adaptaciones, pronosticable, etc.).

7. Debe ofrecer la posibilidad de análisis desde distintos niveles de complejidad, tanto cuantitativo (intensidad, frecuencia), cualitativo (isogrupos ${ }^{5}$, perfiles de usuarios, representación visual etc.) como temporal (temporalidad de la ayuda para cada actividad, variabilidad a lo largo del tiempo por mejoría o empeoramiento).

8. Debe graduar la severidad del problema cumpliendo criterios de sensibilidad (con niveles de graduación que puedan reflejar la severidad del problema, tanto a nivel global como parcial), fiabilidad (con resultados similares entre evaluadores pluridisciplinares) y validez (debe medir el problema esperado y su resultado ser compatible con el de otros baremos que midan el mismo problema).

9. Una vez definida la dependencia y sus criterios de valoración y partiendo de la premisa de tratarse de conceptos distintos pero estrechamente relacionados, debe de ser también sensible a la discriminación de la pérdida autonomía intelectual y las cargas de trabajo generadas.

10. Debe recoger fundamentalmente aspectos sobre el funcionamiento y el contexto del individuo, pero también sobre aspectos básicos de las condiciones de salud alteradas, de enfermedades y de las deficiencias físicas y/o psíquicas que originan la situación de dependencia, pudiendo compatibilizarse los datos obtenidos con los de otras herramientas de valoración pluridisciplinar y pudiéndose también comparar, a nivel estadístico, los distintos usuarios, administraciones y disciplinas, mediante el uso de codificación unificada y aceptada internacionalmente, en concreto la CIE y la CIF.

11. Posibilidad de servir como herramienta a la hora de programar intervenciones en el tiempo, tanto desde el punto de vista particular como desde el de las políticas sociales, tendentes a disminuir o paliar de la forma más eficaz la situación de dependencia, teniendo siempre como guía el respeto a la autonomía de la persona dependiente y potenciando su implicación en el proceso de toma de decisiones.

\footnotetext{
${ }^{5}$ Hace referencia a agrupar a los individuos por clase de dependencia, por cargas de trabajo o por gravedad.
} 


\subsection{Cuidados}

La dependencia es una situación referencial en la que una persona precisa de otras. Hay al menos dos sujetos implicados en la relación; el que necesita y el que es necesitado. Así como la proporción de niños disminuye constantemente -en los países desarrollados y en muchos en vías del desarrollo- en comparación con el conjunto de la población, la proporción de personas dependientes por razones de edad, enfermedad física o mental y por otros tipos de marginalidad física y social crece de modo imparable. Lo que este cambio estructural pone en cuestión es la base en que se asientan las relaciones entre las personas dependientes y su entorno familiar y social (Durán 2006).

La aparición del cuidado se debe a la condición de vulnerabilidad de los dependientes y su incapacidad de cuidar de sí mismos, haciendo inevitable que otros se hagan cargo de resolver sus necesidades (Smith; Kittay en Robles 2006b). El cuidado responde a las necesidades de los dependientes y garantiza su sobrevivencia biológica y social, empleando los recursos sociales, materiales, simbólicos y afectivos más adecuados para satisfacer cualquier tipo de necesidad del sujeto dependiente. El cuidado sólo existe en la medida de la existencia de necesidades en un dependiente, en este sentido, cuidado y dependencia son interdependientes.

El cuidado es un recurso social que alivia la dependencia, siendo indiscutible la obligatoriedad de dicho alivio, la pregunta que cabe realizar es quién debe otorgar el cuidado, ¿es una responsabilidad pública o privada? La disputa de si ciertos asuntos sociales son eventos privados o de interés público emerge en las discusiones y negociaciones de múltiples fenómenos sociales al momento de legislar y diseñar políticas para enfrentarlas, y el cuidado a largo plazo es uno de ellos. Dentro de esta disputa hay dos posiciones: una alude a una responsabilidad exclusiva de la familia; la otra, reconoce la participación de la familia pero considera también la obligación de la sociedad de responder a las demandas de la dependencia.

De acuerdo a la primera posición, el cuidado a largo plazo debe ser resuelto con los recursos materiales, sociales y simbólicos disponibles en los espacios privados de los hogares y sus familias y dejar al Estado atender otros asuntos de interés público más prioritarios. La única posibilidad de una participación del Estado es en casos de 
abandono o carencia de una familia. Uno de los argumentos de esta posición es el temor a que las familias abandonen el cuidado si se crean y ponen en marcha políticas sociales en torno al cuidado a largo plazo (Kane y Penrod en Robles 2006).

La segunda posición defiende que el cuidado a largo plazo es también una responsabilidad de la sociedad, es un asunto de interés público y deben diseñarse políticas sociales para garantizar un cuidado a largo plazo para todos los miembros de la sociedad. Si bien, la familia y el individuo dependiente hacen su parte, el Estado debe jugar un papel más activo a través de apoyar a los cuidadores de la familia, especialmente a las mujeres cuidadoras. Estos servicios deben estar disponibles para todo el que lo necesite independientemente de su estatus financiero y posición en la sociedad. Ello significa pasar la carga de la familia hacia la sociedad, y con ello aliviar a las familias de tener que soportarla a solas. Bajo esta perspectiva el cuidado debe ser objeto de políticas sociales. En este sentido, las políticas sociales deben responder tanto a las necesidades del dependiente como de la familia, otorgando servicios permanentemente de cuidado de largo plazo con el fin de garantizar la sobrevivencia del individuo dependiente (Robles 2006b).

Estas dos posiciones frente a la responsabilidad y acción de los cuidados se plasman en la tipología más básica de los cuidados, los cuidados informales y formales (De los Reyes 2001; García-Calvente, Mateo-Rodríguez y Eguiguren 2004).

\subsubsection{Cuidados informales}

Con objeto de realizar una revisión del concepto cuidados informales -apoyo informal-, en primer lugar es preciso diferenciar lo que es actividad social, lo que son redes sociales y lo que es apoyo social, dentro del cual también cabe la diversificación por tipos de apoyo.

La actividad social hace referencia a la frecuencia de contactos sociales. Las redes sociales indican las características estructurales de las relaciones mantenidas por una persona (tamaño o densidad de las mismas, número de relaciones, frecuencia de contactos, proximidad física, etc.) (Lozares 1996). Finalmente, el apoyo social constituye la forma de ayuda o transferencias que una persona puede recibir proveniente 
de sus redes sociales (Guzmán, Huenchuan y Montes de Oca 2003). Existe relativa independencia entre el mantenimiento de relaciones sociales y la provisión de apoyo, sin que tampoco exista evidencia empírica que explique adecuadamente las relaciones entre las características estructurales de las redes sociales (tamaño, grado de cohesión) y las funcionales (prestación de apoyo) (Instituto de Mayores y Servicios Sociales 2004). Esto quiere decir que el hecho de tener una amplia red social (familia, amistades, etc.) no garantiza por sí mismo que se va a contar con apoyo suficiente cuando sobreviene una necesidad de ayuda de carácter prolongado o permanente. Este tema será desarrollado en mayor profundidad en el capítulo III sobre las particularidades de los cuidadores y del cuidado informal.

El cuidado informal es prestado por parientes, amigos o vecinos. Este conjunto difuso de redes suele caracterizarse por su reducido tamaño, por existir afectividad en la relación y por realizar el cuidado no de manera ocasional, sino mediante un compromiso de cierta permanencia o duración. Sin embargo, por extensión, el término se aplica también a otros agentes de intervención, como pueden ser las asociaciones de ayuda mutua y el voluntariado. Con respecto a ellos, algunos autores (Springer y Brubaker; Litwak en Instituto de Mayores y Servicios Sociales 2004) introdujeron matices dirigidos a distinguir y excluir de la noción de apoyo informal a aquellas personas cuidadoras que pertenecen a una estructura burocratizada, cuya organización refleje una ideología de racionalidad y eficiencia.

Para el contexto de esta investigación se entenderá que:

Los cuidados informales son prestados básicamente por la red social de las personas a los que se procura estos cuidados (Béland, Zunzunegui; Robinson, Steele; Rodríguez en Rivera 2001) y aquella constituida por la familia del sujeto que necesita dichos cuidados, aunque pueden estar incluidos también amigos y vecinos (Requena en Rivera 2001).

Según esta concepción, quedan excluidos del esquema apoyo informal todos los cuidados y atenciones que son dispensados por profesionales dependientes de los servicios sociales o sanitarios organizados, del mercado o de organizaciones de ayuda mutua o voluntariado. 
La familia es la responsable por excelencia del cuidado de sus miembros dependientes en casi todo el mundo. Los discursos lo asumen como un hecho, las normas culturales así lo definen y cualquiera lo ha experimentado en la vida diaria. Debido al mayor número de enfermos crónicos viviendo en el hogar, en el término de cuidado se incluye a la familia como un elemento más de la atención a la enfermedad (Ellis-Hill y Payne en Robles 2004). El rol de cuidador ${ }^{6}$ recae principalmente en la mujer, debido a que en los países occidentales ella todavía cumple un papel fundamental en la provisión de cuidados a los miembros de la familia y en las labores del hogar (Robles 2006b). Además, en el caso de los ancianos dependientes, la obligación filial es la norma cultural que define no sólo que la familia es la responsable de su cuidado, sino también quién de la familia tendría la obligación de asumir esta responsabilidad. Los hijos -las hijas principalmente- son quienes deben cuidar de sus padres cuando llegan a viejos.

El hogar de los cuidadores debe sufrir transformaciones con el fin de crear un ambiente propicio para la organización moral y táctica de las diversas acciones de cuidado, pero que permitan al mismo tiempo mantener en "marcha la casa", es decir, conservar un cierto orden doméstico en aras de conservar su función dentro de la reproducción social de sus ocupantes sanos pero, admitiendo, al mismo tiempo, un cierto desorden que posibilite la existencia material y espacial al cuidado (Robles 2003a). Por lo general las acciones que se realizan vienen dadas con anterioridad al cuidado, ya que forman parte del funcionamiento de un hogar, pero una vez que el cuidado aparece se transforman en un sentido simbólico más que pragmático. Es decir, continúa igual el cómo hacer las actividades, lo que cambia es el sentido atribuido, ahora están orientadas a satisfacer las necesidades de un dependiente enfermo y no sólo las de los miembros sanos del hogar.

Las cuatro áreas de esta línea de cuidado son:

a) Apoyo económico, que cubre total o parcialmente los gastos generados por el padecimiento y su atención, la manutención de la persona dependiente y los derivados de las modificaciones que sufra el hogar. Este aporte es paralelo a las aportaciones económicas que realizan los trabajadores para la reproducción social de la unidad

\footnotetext{
${ }^{6}$ El tema de de los tipos de cuidadores y la feminización del cuidado será tratado con mayor profundidad en el capítulo III.
} 
doméstica, es decir, se destina un aporte específico a los gastos del dependiente y su atención.

b) Área del trabajo doméstico, proporciona los recursos y servicios apropiados en cuanto a aseo y orden en el ambiente de la vivienda, los enseres personales de la persona dependiente y su alimentación.

c) Área de cuidados personales, cubre acciones que substituyen las funciones y desempeños corporales del dependiente, las cuales dependen del grado de dependencia. Según las condiciones de la persona se le puede ayudar a alimentarse, vestirse o asearse o suplirlo por completo en la realización de estas actividades.

d) Organización de un ambiente de cuidado, convierte el hogar en un "cuarto de enfermo" con la finalidad de facilitar las acciones de las otras dos líneas de cuidado y, al mismo tiempo, satisfacer las necesidades del propio dependiente.

Estas acciones son poco visibles porque sirven de basamento a las otras áreas y líneas de cuidado. Básicamente funcionan como un elemento integrador entre el hogar y el cuidado; sin este puente, el orden doméstico y el cuidado son prácticamente irrealizables.

Es importante destacar que el cuidado informal se ve determinado por los siguientes factores (Colectivo IOE 1995):

- La estructura familiar (composición de cada hogar).

- La existencia de uno o más cuidadores principales y los elementos asociados al trabajo desempeñado por éstos (carga emocional y física).

- La elaboración de diversas estrategias dentro del seno familiar para cuidar al dependiente (rotación ${ }^{7}$, contratación de personal, colaboración de otros miembros de la familia).

- Nivel socioeconómico de la familia de la persona con dependencia.

\footnotetext{
7 Cambios alternativos de la persona dependiente - se le denomina también golondrina- en varios domicilios familiares (Delicado 2006).
} 
Leticia Robles, investigadora mexicana, indica en su artículo: "El cuidado en el hogar a los enfermos crónicos: un sistema de autoatención" (2004) que el cuidado posee seis características:

- El fin de una acción cambia de acuerdo a las circunstancias, el "no comentarle algo" a la persona con dependencia varía el fin y de acuerdo a sus condiciones: si está en una fase estable, obviarle problemas familiares tiene un sentido preventivo, en cambio, si está en una fase de deterioro, no decirle la gravedad de su estado es para protegerle.

- Una acción no es exclusiva de una línea de cuidado, ya que puede pertenecer simultáneamente a varias áreas y líneas de cuidado. Preparar una infusión al dependiente es una acción de la línea del hogar del área de trabajo doméstico por su preparación, al mismo tiempo se ubica en la línea de la atención a la discapacidad como una medida para aliviar molestias -del área de manejo de las molestias- y como parte de la búsqueda de opciones de atención terapéutica.

- El cuidado es un continuum, conforme la persona pierde autonomía, las acciones lo substituyen cada vez más: en el aseo personal, primero, se le coloca una silla para que se bañe sentado, después, se le ayuda a enjabonarse, más adelante, se le baña en la cama.

- Hay acciones centrales y periféricas, estas últimas crean las condiciones propicias o ponen al alcance los recursos necesarios para las acciones centrales: transportarlo a los centros de urgencias es una acción previa y necesaria para lograr que reciba atención médica, en cambio, las acciones centrales resuelven directamente las necesidades del dependiente, por ejemplo dar consuelo.

- Acciones procedentes de varias líneas y áreas forman una "unidad de cuidado" porque tienen un arreglo en tiempo y espacio secuencial y no son independientes. Una "unidad de cuidado" durante una crisis consistiría en identificarla, decidirse por una atención médica de urgencias y trasladarlo al hospital. En esta unidad las acciones pertenecen a tres áreas: establecimiento de un diagnóstico, atención terapéutica a la discapacidad y cuidados personales. 
- La "invisibilidad" de ciertas acciones como cuidado, la no visibilidad es porque originalmente pertenecen a otras esferas de la vida cotidiana y el cuidado se las apropia, el trabajo doméstico es un ejemplo claro de esta situación: la preparación de los alimentos para la familia es una actividad previa a la enfermedad, cuando la preparación se ajusta a las indicaciones de un régimen dietético se convierte en una acción de cuidado.

El Colectivo IOE (1995) en su investigación cualitativa sobre el cuidado informal en España distingue cuatro discursos ideológicos que están tras los discursos de los cuidadores informales entrevistados, he aquí las características de cada uno de ellos:

1. La solidaridad "comunitaria" presente en las cuidadoras con bajo nivel educacional y con valores enraizados en la España rural. Su referente es la estructura familiar tradicional en donde los mayores son los depositarios de la tradición y constituyen el centro de la vida familiar. En esta visión los cuidadores definen un "nosotros" etnocéntrico por el que sacrifican su independencia personal y se deben en general al grupo y en particular a sus padres.

2. La solidaridad "orgánica" que plantea que al Estado le corresponde asumir, al menos en parte, la responsabilidad del bienestar de los ancianos y que las administraciones se deben plegar a las necesidades de las familias. Este es un discurso más presente en las clases medias-bajas en proceso de precarización, conscientes de sus derechos como trabajadores y ciudadanos, pero en posición de dependencia (clientelismo). Se reclama sistemas de protección por parte del Estado, que apoyen a los cuidadores y creación de instituciones para el caso en el que la familia no pueda asumir el cuidado.

3. La solidaridad "liberal" responsabiliza a los individuos como sujetos de su propio bienestar durante su vida, así también en la vejez. No deberían esperar que otros le cuiden, ni siquiera la propia familia, es el sujeto quien debe prever tal situación futura y asegurar su bienestar en la vejez. En este discurso se valora la "competitividad" como clave del éxito social.

4. La solidaridad "socialista" requiere la reunión de las personas que tienen un problema común para promover fórmulas de cooperación que beneficien a todos. Este punto de 
vista es defendido por los cuidadores que forman parte de organizaciones de familiares de enfermos o que colaboran en ellas.

Estas cuatro posiciones apuntan a lógicas discursivas distintas que muestran la polivalencia entre un polo más tradicional a uno moderno. Éste último está tensionado por elementos de cada uno de los distintos tipos de solidaridad, por eso no permiten afirmar que sea liberal o tradicional de forma pura.

La presencia simultánea de estos cuatro discursos en la población cuidadora se ve condicionada por un proceso de transformación profundo, debido a tres cambios coincidentes: a) declive del potencial de cuidadores familiares a causa de la reducción del número de mujeres cuidadoras y el aumento del número de ancianos que precisan cuidados de larga duración; b) cambios en el modelo tradicional de familia debido al aumento de la tasa de divorcios, familias monoparentales y permanencia de los hijos en el hogar hasta edades próximas a los 30 años, sumado a una enorme diversidad en el tipo de familias; c) finalmente, cambios en la posición social de la mujer asociados a su incorporación creciente al mercado laboral que reducen la población cuidadora y, sobre todo, la intensidad de los horarios (Rodríguez Cabrero 2004).

Además, se presentan problemáticas comunes en las familias que cuentan con una persona con dependencia, algunas de estas son:

- Supeditación a la persona que se cuida (en mayor o menor grado de acuerdo al grado de dependencia).

- Alteración de la vida personal del cuidador.

- Desequilibrio en las relaciones sociales y familiares.

- Impacto sobre la salud del cuidador.

- Cambio, mayor o menor, en la vida del cuidador (Livingston, Manel, Katona; Montgomery; Zarit, Todd, Zarit en Rivera 2001).

\section{Cuidado Informal a Personas Mayores}

La definición del cuidado, en el caso de un dependiente a causa del envejecimiento cuenta con ciertas particularidades. Su rasgo más distintivo es que es un cuidado de largo plazo, porque la dependencia es prolongada y no se constituye en una práctica 
social esporádica. Otro rasgo es su curso ascendente, es decir, al inicio es un cuidado de baja intensidad pero conforme los niveles de dependencia aumentan, se incrementa el cuidado, representando un consumo intensivo y extensivo de recursos de toda índole, y a medida que se va incrementando la dependencia es necesario un mayor uso de recursos para el cuidado.

El tipo de dependiente define el contenido pragmático del cuidado (Robles 2006b), es decir, saber cuáles son las acciones particulares del cuidado a un mayor sólo es posible a partir de conocer sus necesidades en su calidad de dependiente, en este sentido se debe pensar al cuidado en una variedad de direcciones: las estrategias dirigidas a resolver las necesidades emanadas del hecho de envejecer y del necesario enfrentamiento a esta nueva condición social tanto en términos individuales como sociales; las acciones para apoyar el trance de convertirse de un adulto a una persona envejecida; los mecanismos de negociación del entorno social y espacial al interior del hogar para satisfacer las necesidades del viejo y las de sus otros habitantes en su calidad de sujetos nodependientes.

El rol social de cuidador corresponde a un nuevo actor en el escenario de la vejez y sus rasgos lo distinguen y diferencian de otros roles sociales, como son los de parentesco. El cuidador tiene la responsabilidad principal de la ejecución de las acciones de cuidado y de garantizar su permanencia, de esta forma se espera y se norma que un cuidador "se haga cargo de" todo aquello que el dependiente -el mayor- es incapaz de hacer.

El cuidado es construido socialmente como una responsabilidad femenina, no por atributos de la mujer sino por el sitio que ocupa en la división social del trabajo. Además, el rol es permanente, una vez que una hija o esposa asume el rol de cuidadora no hay posibilidades de abandonarlo o que alguien la substituya, aunque haya otra mujer con disponibilidad para ejercer esta función, ya que este rol se designa, generalmente, sin posibilidades de negociación.

Finalmente, está el tipo de relación interpersonal entre cuidador y anciano, caracterizada por una especial relación intersubjetiva entre ambos. Así, es de esperar no solamente una especial cercanía emocional entre ambos, sino igualmente, la presencia de relaciones de poder o de interdependencia o de reciprocidad entre ellos (Robles 2006b). 


\subsubsection{Cuidados formales}

En la atención a las personas dependientes intervienen tres agentes: la familia cuidadora, el sector público con su oferta de servicios y prestaciones económicas y la oferta privada, tanto mercantil como no lucrativa. Dentro del cuidado informal ya hemos revisado el rol de la familia, a continuación revisaremos el papel desempeñado por el Estado, las organizaciones lucrativas y no lucrativas.

La población en situación de dependencia está constituida por individuos de todas las edades, aunque el incremento de este grupo se acelera a partir de los 50 años. Entre el colectivo de menores de 65 años destacan, entre otros, los grupos de niños con trastornos graves de desarrollo, jóvenes y adultos con secuelas graves de accidentes, personas con deficiencias intelectuales severas y profundas, sujetos afectados de graves y generalizadas lesiones neurológicas, enfermos mentales con graves deterioros y, en general, pacientes con enfermedades crónicas degenerativas.

A pesar de la heterogeneidad del colectivo de las personas con discapacidad, con distintas deficiencias y con grados diferentes de severidad en sus limitaciones, todos tienen en común la demanda a la sociedad, de manera puntual o de forma intensiva a lo largo de su vida, de apoyos extraordinarios para vivir dignamente o para participar en igualdad de condiciones en la vida económica, social y cultural de su comunidad.

En lo que resta de este apartado realizaremos la descripción de los distintos tipos de recursos ideados para atender a la dependencia, tomando como referencia los recursos ofrecidos en España (Instituto de Mayores y Servicios Sociales 2004). La forma en que los Estados responden a estas demandas será tratada en el capítulo II.

\section{El Estado}

Actualmente el Estado -a través de los sistemas de servicios sociales, de salud y/o de seguridad social-, las empresas y organizaciones no lucrativas ofrecen un amplio abanico de recursos técnicos que intentan dar respuesta social y/o sanitaria al colectivo de personas con discapacidad en situación de dependencia. Con independencia de quien sea que entregue estos recursos, éstos pueden agruparse en dos grandes categorías: la de servicios y centros y la de prestaciones. 
A. Servicios y Centros, que pueden ser agrupados en:

- Servicios de atención primaria.

- Servicios de atención domiciliaria.

- Servicios y/o centros de atención diurna.

- Centros residenciales.

- Centros de especialidades y de referencia.

- Políticas de ayuda al cuidador

- Servicios de atención primaria:

Centros de Salud y Consultorios. Son centros donde se desarrolla la atención primaria de salud prestando, fundamentalmente, servicios de medicina general, pediatría y enfermería.

Centros de Servicios Sociales. Son equipamientos de carácter comunitario que dan soporte a las prestaciones básicas, cuya función es la atención a la problemática social tanto en un nivel individual y familiar como de desarrollo comunitario. Entre los servicios básicos que prestan se destacan los de información y orientación, los de apoyo a la unidad de convivencia y ayuda a domicilio, los de prevención e inserción social o los de fomento de la solidaridad y la cooperación social.

Centros de Atención a personas con discapacidad. Son centros de carácter ambulatorio en los que se prestan servicios de información, valoración, evaluación, diagnóstico, orientación, tratamientos de rehabilitación y recuperación profesional a las personas afectadas por cualquier tipo de discapacidad.

- Servicios de atención domiciliaria.

Asistencia sanitaria en el domicilio. Es un servicio prestado desde los centros sanitarios de atención primaria, que otorga cuidados de salud integrales y en su domicilio a las personas con necesidades sanitarias y a sus familias, con el propósito de promover, mantener y restaurar la salud o, en su caso, minimizar el efecto de la enfermedad o la discapacidad. 
Hospitalización a domicilio. Es un recurso que presta atención en el domicilio, desde el hospital de referencia, a determinados usuarios que requieren un cuidado sanitario que, de no existir, precisarían de una estancia hospitalaria, durante un tiempo limitado y siempre bajo la supervisión y el apoyo de profesionales sanitarios; esta modalidad de atención produce una menor distorsión en la vida del paciente y en la de su familia o cuidadores que si la persona incapacitada tuviera que ser atendida regularmente en un hospital, ya que, entre otras ventajas, se proporciona una atención más cercana.

Apoyo a la unidad de convivencia y ayuda a domicilio. Se presta una serie de atenciones o cuidados de carácter personal, psicosocial, educativo, doméstico y técnico a familias y personas con dificultades para procurarse su bienestar físico, social y psicológico, proporcionándoles la posibilidad de continuar en su entorno natural.

Teleasistencia. Es un servicio para la atención telefónica ininterrumpida, con un equipamiento de comunicaciones e informática específicos, que permite a las personas con discapacidad, que viven solas y/o con graves problemas de movilidad, mantener una comunicación inmediata con un centro de atención que presta la respuesta adecuada. De esta manera este servicio ofrece seguridad y tranquilidad ante situaciones de riesgo, propicia además la permanencia en el domicilio, evitando la innecesaria institucionalización.

- Servicios y/o centros de atención diurna

Están constituidos por centros generales y/o específicos que ofrecen una atención integral durante el día a aquellas personas que, por sus discapacidades y con la finalidad de permanecer en su entorno habitual, precisan mejorar o mantener su nivel de autonomía; estos centros proporcionan al mismo tiempo un apoyo al cuidador principal y se caracterizan además por ser una estructura funcional compensatoria del hogar y una alternativa al ingreso de la persona con discapacidad en un centro residencial. Los centros de atención diurna más significativos son:

Hospital de Día. Centro exclusivamente sanitario con la funcionalidad de dar un tratamiento puntual, limitado en el tiempo, a un paciente que necesita de unos cuidados y/o supervisión con frecuencia menor a la que se presta en una unidad de internamiento 
hospitalario, evitando de esta manera una estancia hospitalaria de 24 horas; también suelen ser empleados como recursos de evaluación y diagnóstico.

Centro de Día. Se define este recurso como un servicio sociosanitario y de apoyo familiar que ofrece durante el día atención a las necesidades personales básicas, terapéuticas y socioculturales de las personas con diferentes grados de discapacidad, promoviendo la permanencia en su entorno habitual. Su objetivo general es favorecer unas condiciones de vida dignas entre las personas usuarias del centro y sus familiares, facilitando la continuidad en sus modos de vida y el logro de un mayor nivel de autonomía.

Centro ocupacional. Este tipo de centro tiene como finalidad asegurar los servicios de terapia ocupacional y de ajuste personal y social a las personas con discapacidad y enfermos mentales cuya acusada discapacidad temporal o permanente les impida su integración en una empresa o en un centro especial de empleo. La importancia de este tipo de centros estriba en el destacado papel que juegan en la normalización de determinadas personas con discapacidad física o intelectual así como en enfermos mentales.

Centros y servicios de rehabilitación. Constituyen un conjunto muy variado de recursos, tanto dentro de los sistemas de salud (rehabilitación hospitalaria, centros de salud mental, etc.), como en el ámbito de los servicios sociales, de empresas (rehabilitación profesional en el sector de las mutuas patronales) y en el sector de las entidades sin fin de lucro (por ejemplo: atención precoz, rehabilitación logopédica, etc.).

Centros y servicios de respiro familiar. Destinados a prestar servicios de atención integral por un período limitado de tiempo a miembros de una unidad familiar, con el fin de permitir a sus cuidadores espacios de tiempo libre y descanso.

\section{- Centros Residenciales}

Podemos distinguir diferentes tipos, según su naturaleza y finalidad, de esta forma distinguimos las siguientes entidades o centros: 
Unidad de media estancia. También denominada unidad de convalecencia y/o de rehabilitación, forma parte de un modelo asistencial destinado a la mejora funcional, a la prevención del deterioro o de la discapacidad y a la recuperación de los procesos derivados de una enfermedad reciente. Estas unidades pueden estar ubicadas en hospitales de agudos o fuera de ellos y pueden dar respuesta a gran parte de las demandas que se generan en los hospitales de agudos para la provisión de cuidados continuados

Unidad de larga estancia hospitalaria. Son unidades específicas de internamiento con cuidados sanitarios en donde las previsiones de alta se alargan en el tiempo, aunque limitado.

Centros residenciales. Son centros en los que viven de forma definitiva o temporal personas con distinto nivel de dependencia y en los que se presta una atención integral con el objetivo de mantener o mejorar la autonomía personal, atender sus necesidades básicas de salud y facilitar su integración y participación social en el medio. Entre los centros residenciales para personas con discapacidad gravemente afectadas cabría significar en particular los centros de atención a minusválidos físicos y los centros de atención a minusválidos psíquicos, así como los centros psiquiátricos. Los centros residenciales ofrecen con frecuencia programas de estancia temporal, que consisten en la permanencia de la persona en el centro durante un período de tiempo limitado en atención a circunstancias excepcionales del cuidador principal o del propio usuario.

Otros alojamientos alternativos. La prestación de alojamiento alternativo puede definirse como el conjunto de actuaciones que se realizan desde el ámbito de los servicios sociales para conseguir que una persona en situación de necesidad cuente con un marco estable para el desarrollo de la convivencia. Este tipo de alojamientos son presentados bajo la denominación de minirresidencias, viviendas tuteladas, viviendas protegidas o casas-hogar, cumplen con la finalidad de contribuir a mantener las capacidades funcionales del usuario, proporcionando un apoyo social básico; los servicios fundamentales que ofrecen son los de alojamiento, relación y convivencia. 
Centros de recuperación profesional. Son establecimientos que disponen de un conjunto idóneo de instalaciones y de profesionales para facilitar la integración sociolaboral de las personas con discapacidad.

- Centros de especialidades y de referencia

Son centros que cumplen una doble misión, por un lado son centros de atención directa a personas con un tipo específico de problemática; por otro son centros de referencia estatal para la promoción y apoyo técnico a otros recursos del sector. En tanto que centros de referencia estatal dedicados a promocionar recursos (servicios, equipamientos, métodos y técnicas de información, etc.), suelen desarrollar servicios de información y documentación, de investigación, de formación de especialistas, de consultoría y asistencia técnica.

- Políticas de ayuda al cuidador

Aparte de las medidas que anteriormente se han mencionado y que afectan al cuidador, este tipo de ayudas favorecen principalmente al cuidador que realiza un trabajo fuera de su hogar. Las políticas pueden enmarcarse dentro de la conciliación de la vida familiar y laboral, pudiendo consistir en la concesión de excedencias para el cuidado de un familiar por razón de dependencia o reducción de las jornadas de trabajo (Rodríguez Cabrero 2004).

B. Prestaciones, que pueden ser dividirse en:

- Prestaciones económicas. El Estado puede poner a disposición de la población con discapacidad y sus familias un conjunto de prestaciones económicas, pensiones contributivas y no contributivas, desgravaciones fiscales y otras prestaciones económicas. Así también puede hacer entrega de subvenciones destinadas al mantenimiento de ONGs y entidades que participan en la atención de esta población y sus familias. 
- Prestaciones técnicas. Se incluyen en este apartado recursos destinados a la accesibilidad y nuevas tecnologías.

- Prestaciones ortoprotésicas y ayudas técnicas. Se hace referencia a cualquier producto, instrumento, equipo o tecnología adaptada o diseñada específicamente para apoyar la rehabilitación de una persona enferma o con discapacidad. Tienen especial importancia para las personas con discapacidad gravemente afectadas las ayudas técnicas para el cuidado personal, la comunicación, la movilidad, y las tareas domésticas; de igual manera, también destacamos en estas prestaciones las ayudas para la rehabilitación como la órtesis y la prótesis.

- Ayudas para adaptaciones del hogar. Se trata de un conjunto de actuaciones dirigidas a adecuar los entornos a las necesidades específicas de personas enfermas o con discapacidad, y suelen consistir en actuaciones arquitectónicas, equipamientos y tecnologías especiales.

- Ayudas para la realización de proyectos de $\mathrm{I}+\mathrm{D}+\mathrm{i}$. Se refiere a los programas que tienen por objeto poner en práctica una serie de actuaciones que persigan la búsqueda de soluciones que favorezcan la normalización de la vida de las personas con discapacidad, y que se concretan en actuaciones dirigidas a la promoción de la accesibilidad arquitectónica, urbanística y a los medios de transporte; también últimamente se han puesto esfuerzos en el incremento de la comunicación y la investigación de nuevas tecnologías.

\section{La acción de ONGs y Movimientos Asociativos}

Mención especial requiere el accionar de ONGs, asociaciones, federaciones y confederaciones del movimiento asociativo de personas con discapacidad, que prestan una serie de servicios, programas y acciones tendentes a mejorar las condiciones y la calidad de vida en las que se encuentran sus asociados o el colectivo al que atienden. La cartera de servicios prestada y gestionada por estas organizaciones supone en algunas realidades la complementación de la atención prestada por el Estado, o la primera y más importante alternativa de atención y ayuda para los discapacitados. Para comprender mejor su acción, podemos distinguir entre las acciones que se llevan a cabo en centros o servicios con vocación permanente y las que tienen lugar a través de programas. Entre los centros y servicios cabe destacar los siguientes: 
Capítulo I. Los cuidados

- Información y asesoramiento.

- Atención temprana.

- Rehabilitación.

- Educación.

- Atención domiciliaria.

- Atención diurna.

- Centros ocupacionales.

- Atención residencial.

- Empleo (centros especiales de empleo, servicios de integración u orientación laboral).

- Ocio y tiempo libre.

La tipología de programas que estas organizaciones ofrecen igualmente puede ser variada, entre ellos:

- Familias.

- Autogestores.

- Vacaciones.

- Desventaja social.

- Campañas de sensibilización.

- Formación de profesionales y del voluntariado.

En España cumplen un importante rol instituciones dirigidas a las personas dependientes o que tiene programas o iniciativas para ellos y sus familias. Entre las más importantes podemos mencionara a Cruz Roja Española, ONCE, Asociación de Familiares de Enfermos de Alzheimer, ASPACE.

En Chile algunas de las instituciones que se dedican a la atención de las personas con dependencia son Fundación Las Rosas, Fundación COANIL, Fundación TELETÓN, Asociación Chilena de Padres y Amigos de los Autistas (ASPAUT) y Corporación Alzheimer Chile. 
El enfoque sociosanitario de la atención a las personas con discapacidad en situación de dependencia

Desde hace ya algún tiempo existe en Europa una verdadera preocupación y polémica por diseñar e impulsar fórmulas que permitan abordar de una manera integral el bienestar de un número importante de personas que, por sus graves problemas de salud y riesgos de exclusión social, precisan de asistencia sanitaria y de asistencia social de forma continuada y simultánea:

- Niños con trastornos graves y generalizados de desarrollo.

- Personas con enfermedades crónicas evolutivas.

- Personas con discapacidad física o intelectual.

- Personas con enfermedad mental crónica.

- Personas con deterioro de sus capacidades funcionales o psíquicas a causa de su avanzada edad.

Por ello dentro del estudio que realizamos sobre las personas con discapacidad en situación de dependencia, no podemos dejar de considerar la necesidad palpable de potenciar unos servicios sociosanitarios que permitan abordar de manera integral la atención a este colectivo.

Se entenderá por atención sociosanitaria el conjunto coordinado de prestaciones sociales y sanitarias de larga duración y de cuidados no profesionales, destinados a cuantas personas presentan deficiencias o enfermedades crónicas y/o graves problemas de marginación, que les están impidiendo o dificultando gravemente su autonomía personal, su bienestar y/o su integración social (Instituto de Mayores y Servicios Sociales 2004).

La finalidad última de la atención sociosanitaria es contribuir, junto con otros sistemas, al logro de la máxima calidad de vida de los usuarios y al mayor grado posible de autonomía personal y de participación social, respetando sus estilos de vida y sus preferencias. 
Como principios fundamentales de la atención sociosanitaria, cabe destacar los siguientes:

- El mantenimiento de la persona en su entorno habitual.

- La intervención conjunta de los servicios sociales y los sanitarios.

- Los cuidados a domicilio, como eje vertebrador del modelo.

- La participación de la persona como usuario y, en su caso, de su familia o del cuidador principal en el proceso de toma de decisiones y en la atención.

- La promoción y articulación de los mecanismos necesarios para proporcionar apoyo a los cuidadores.

- La valoración integral y continuada del usuario y de su entorno a lo largo de todo el proceso de atención.

- La disponibilidad de instrumentos compartidos de valoración del usuario y de su entorno, que faciliten la planificación de los cuidados y la provisión de los servicios. 


\section{CAPÍTULO II: SISTEMAS DE PROTECIÓN A PERSONAS EN SITUACIÓN DE DEPENDENCIA}

Previo al análisis de los distintos modelos de protección a la dependencia es necesario revisar con detenimiento cuáles son los sistemas que dan origen a dispares modelos, por ello la primera parte de este capítulo trata sobre los Regímenes de bienestar.

\subsection{Regímenes de Bienestar}

La dependencia de los individuos de los ingresos laborales constituye el principal factor de riesgo en las sociedades capitalistas actuales, debido a que la ausencia de esos ingresos afecta la supervivencia física del individuo. La Política social, y los diversos Estados de bienestar en que ésta deriva, vienen a representar la gestión pública de los riesgos sociales, una administración de los riesgos intrínsecos a las relaciones sociales, en las que básicamente el trabajo está mercantilizado (Navarro Ruvalcaba 2006).

En la administración pública de los riesgos sociales intervienen tres instituciones: el Estado, la familia y el mercado, que dependiendo del momento histórico y las características culturales han dado origen a particulares modelos de gestionar las inseguridades que pueden afectar a los ciudadanos. El sociólogo danés Gøsta EspingAndersen ha desarrollado su trabajo en el ámbito del Estado de bienestar, generando un análisis extenso que entrega un modelo teórico para su análisis. Una de sus aportaciones ha sido la postulación de la idea de que el análisis debe dirigirse, primero, a identificar diversos modelos de Estado de bienestar; y segundo, a identificar regímenes de bienestar. Así, cada modelo y régimen de bienestar incluye no sólo determinadas políticas sociales con sus derechos y prestaciones correspondientes, sino también ciertas oportunidades laborales y cierto grado de igualdad social.

"El Estado de Bienestar es definido de forma amplia como el conjunto de organizaciones públicas que proveen servicios sociales con el fin de mejorar las condiciones de vida y promocionar la igualdad de oportunidades de sus ciudadanos" (Navarro Ruvalcaba 2006: 110). 
La combinación institucional del Estado, el mercado y la familia da como resultado dos procesos de independencia o autonomía del bienestar de las familias y las personas. El primer proceso, relacionado con el mercado de trabajo y afín a los derechos sociales de la ciudadanía, es el de la "desmercantilización" (de-commodification) que constituye la forma en que los ciudadanos gozan de unos derechos que les permiten liberarse de su dependencia del mercado, ello en el marco de las sociedades contemporáneas en donde los mercados son globales y hegemónicos, y en donde la suerte de los ciudadanos ha pasado a depender de forma creciente de la relación monetaria. El segundo proceso es el de la "desfamiliarización" (de-familialization), puesto en relación con los sistemas familiares de cuidados y protección, que considera el grado de reducción de la dependencia del individuo respecto de la familia o, a la inversa, el aumento de la capacidad de control del individuo de recursos económicos, independientemente de las reciprocidades familiares o conyugales (Esping-Andersen 2000).

El autor delimita tres regímenes de bienestar de acuerdo a las diversas formas que asumen Estado, familia y mercado en la gestión de los riesgos, lo que a su vez implican diferentes modelos de solidaridad social. A grosso modo, estos regímenes se definen a partir de la manera en que se asignan las coberturas sociales -derechos- y de cómo se financian las mismas -obligaciones-, pero también considerando los distintos grados de desigualdad social que generan. Tomando en cuenta estas premisas se identifican tres regímenes de bienestar en el mundo occidental: el socialdemócrata o universal, el conservador o corporativista y el liberal o residual (Esping-Andersen 1993). Los regímenes de bienestar cuentan con "etiquetas" más bien propias del sistema político, no sólo por su origen histórico, sino porque, lejos de constituir paquetes de políticas aisladas, forman verdaderos sistemas en la medida en que contribuyen de manera decisiva a la institucionalización de las preferencias de clase y del comportamiento político, de modo que sus vicisitudes afectan con carácter decisivo a las tendencias electorales a largo plazo (Espina 2002).

Resulta importante aclarar que estos regímenes constituyen un instrumento útil para el análisis, pero no representan la realidad de un país ni su Estado de bienestar, ya que ello significaría relevar aspectos tan importantes como la historia particular, la situación económica y la dinámica social peculiar. 


\subsubsection{Régimen Socialdemócrata o Universal}

El régimen socialdemócrata, presente en los países nórdicos y, con algunas particularidades, en Holanda, es el que ha ido más lejos en la extensión de los principios de desmercantilización, desfamiliarización y universalismo. En vez de tolerar un dualismo entre el Estado y el mercado, promueve una igualación desde arriba y no desde abajo. Uno de los requisitos característicos de este modelo es el pleno empleo, sin el cual no podría funcionar debido a que la financiación del gasto social estatal proviene básicamente de una fiscalidad progresiva. Todos contribuyen al sistema, todos se benefician de él, pero al mismo tiempo todos dependen de él. Este régimen se basa en la socialización máxima de los costes del trabajo de reproducción de las familias con la finalidad de que no se agoten los recursos de sus miembros. Además, la fiscalidad progresiva duplica los efectos redistributivos de los programas del Estado, pues obliga a las personas de ingresos más elevados a pagar una proporción más grande de impuestos.

Para Korpi (1989), el valor fundamental que subyace en el modelo de bienestar socialdemócrata es el de la igualdad social. Su objetivo es transformar la igualdad legal en igualdad económica e igualdad social. Pero ambas igualdades, por importantes que parezcan, son sólo primordiales en tanto que medios para alcanzar el fin mayor: una sociedad sin clases o distinciones de casta. Una precondición mínima para eso es la eliminación de la pobreza.

La Universalidad en este régimen está directamente relacionada con el concepto de desmercantilización, pues propone socializar de manera colectiva el riesgo social otorgando coberturas generales en los derechos sociales. Los roles del mercado de la familia se ven minimizados, ya que los derechos y deberes recaen en el conjunto de la sociedad y no en el individuo, así el Estado se consolida como la principal institución que gestiona el riesgo.

Es así como la desmercantilización se ve expresada en la asignación universal de servicios para el cuidado de la salud, la educación, la vivienda y la seguridad en el ingreso en la comunidad, en lugar de ser beneficios y servicios del Estado. Dichas prestaciones no son compradas y ni vendidas, su distribución no se rige por la distribución del ingreso y la riqueza dentro de la comunidad. 
El concepto de desfamiliarización se expresa en que el Estado asume la responsabilidad de prestar cuidados a la gente mayor, a los incapacitados y a los menores, siendo éste el sistema que más estimula la inserción de las mujeres en el mercado de trabajo, inherente al principio del pleno empleo para todos los ciudadanos (Flaquer 2000).

\subsubsection{Régimen Corporativista o Conservador}

Este modelo está basado en el régimen de seguridad social de raíz "Bismarckiana"; se encuentra desarrollado en Alemania, Austria, Francia, Bélgica e Italia, es conocido como el sistema más conservador de todos; primero, porque es el resultado de la transformación del antiguo sistema de seguridad social alemán que en su momento cumplió una función legitimadora de un régimen político escasamente democrático, que intentaba mantener las diferencias de estatus entre los distintos trabajadores, así el disfrute de los derechos sociales estaba asociado con la clase social y con el estatus laboral y ocupacional; por otra parte, se ve notablemente influenciado por la iglesia, especialmente la iglesia católica, que presiona por mantener un reparto tradicional de los roles en los hogares en función del género.

La visión corporativista de la familia es la de una familia patriarcal, con jefe de hogar masculino, sostén de la familia, y que conecta al hogar con la sociedad a través de su pertenencia a la fuerza de trabajo, y la mujer ama de casa, relacionada con la sociedad principalmente a través del trabajo de su marido (Esping-Andersen en Navarro Ruvalcaba 2006); en términos de Esping-Andersen esta lógica genera un bajo nivel de desfamiliarización. Este modelo estimula la maternidad y desincentiva la participación de la mujer en el mercado de trabajo, especialmente cuando los niños son pequeños, lo que genera la dependencia de sus maridos que, como cotizantes en el sistema de seguridad social, son los "auténticos" titulares de los derechos sociales.

La seguridad social en el régimen corporativista protege individualmente a los trabajadores, asegurándoles la ocupación mediante estrictas normas de contratación y despido, estructurándose a partir de sistemas de seguro social vinculados al empleo y asumiendo la lógica familiar antes descrita. En el régimen conservador los planes de seguro privado son escasos (Esping-Andersen 2000). 
El modelo corporativista basa su actuación en dos aspectos relacionados entre sí: 1) que las personas se integren apropiadamente en grupos, y 2) que esos grupos, a su vez, tomen a su cargo su propio bienestar o cuidado. Así como los corporativistas confían en la ayuda mutua entre los grupos para promover el crecimiento en la gran economía, también lo hacen en la "ayuda mutua" dentro de los grupos mismos para cuidar de aquellos que caen en situaciones extremas o adversas. Ello dibuja una particular forma de asignar la responsabilidad de ayuda de los individuos carentes, bajo está lógica subsidiaria el primer responsable de ello es la familia. Si la familia falla, la responsabilidad ha recaído, históricamente, en la parroquia de la iglesia local o en las asociaciones voluntarias, y luego en las asociaciones profesionales o ocupacionales, y sólo después, en la municipalidad (o el Estado como tal). La idea central que subyace a este modelo es que el Estado sólo interviene cuando la familia agota sus posibilidades de prestar servicios a sus miembros, servicios que principalmente son desempeñados por la mujer (Flaquer 2000).

Si tomamos en consideración su teoría económica subyacente, el corporativismo opera sobre premisas sociales sociales-comunitaristas, que tienen mucho en común con las encíclicas papales sobre la "dignidad" del trabajador, percibido como merecedor de respeto. La riqueza es generada a través de la cooperación social y la colaboración. En la vertiente clásica del corporativismo, la economía capitalista pone énfasis en las ventajas económicas de una "división del trabajo" y de una especialización dentro de las esferas. El corporativismo recomienda la cooperación entre todos los grupos principales de la sociedad -capital y trabajador, y todos los demás- para el mayor bienestar común. Esa es la fuerza del término "social” en la visión estándar de la economía corporativista, es decir, como una "economía social de mercado".

Las metas básicas de la política de bienestar corporativista son la seguridad y la estabilidad. Todos tendrán acceso al cuidado y a la seguridad social, y aspiran a que ningún grupo social se imponga sobre el otro. Su meta principal es la de conservar el orden social existente y su modelo de distribución, en contraste con el Estado de bienestar socialdemócrata y su franca intención de alterar el modelo por medio de la redistribución (Instituto de Mayores y Servicios Sociales 2004). 
En síntesis, este régimen se caracteriza por el rol central de la familia, el carácter marginal del mercado y la acción subsidiaria del Estado en la provisión social. Presenta un alto grado de desmercantilización para el hombre proveedor y es explícitamente "familista" (Esping-Andersen 2000).

\subsubsection{Régimen Liberal o Residual}

El régimen de bienestar liberal agrupa a los países anglosajones -como EEUU, Nueva Zelandia, Australia y Canadá - y sintéticamente se caracteriza por contar con un Estado residual en la asistencia social, en donde predomina la individualización de los riesgos y donde la promoción de soluciones se deja en manos del mercado. Históricamente, este modelo se erigió durante la época de la "Gran Transformación" asociada con la Revolución Industrial y encontró su florecimiento en Inglaterra con la Nueva Ley de Pobres de 1812 (Blaug en Navarro Ruvalcaba 2006). Este modelo es impulsado por las propuestas del Banco Mundial y otros organismos internacionales.

En síntesis este modelo se configura como un sistema público, financiado mediante impuestos, de cobertura limitada, destinado a satisfacer las necesidades básicas de los ciudadanos en situación de dependencia con insuficiencia de recursos económicos y, por tanto, de alcance y extensión también limitada.

Este régimen es denominado como "residual" en el sentido que tiene una definición estrecha de quien tiene derecho a los beneficios sociales, limitando su accionar a aquellos casos en que la familia y/o el mercado no pueden dar solución. Tiene un claro enfoque asistencial basado en necesidades y un sesgo hacia la focalización. Para ello desarrolla medios e instrumentos que permitan determinar y/o demostrar las necesidades de las personas/hogares. También es "residual" porque su política social adhiere a una concepción estrecha de los riesgos que debieran ser considerados como sociales. El enfoque más residual y focalizado que aplican los países anglosajones en el ámbito de la protección social se basa en la hipótesis de que los problemas relacionados con las fallas de mercado suelen limitarse a casos especiales, como las madres solteras, que tienen dificultades objetivas para satisfacer sus necesidades en mercados normales (EspingAndersen en Sunkel 2006). En este modelo tanto las transferencias universales como los planes de seguridad social son modestos. 
El régimen de bienestar liberal promueve el mercado como el pilar central de la tríada Estado, familia, mercado. Los estados de bienestar liberales tienen en común la adopción de un componente de tributación negativa, que ofrece un piso mínimo de ingreso a los pobres y a los trabajadores de bajos sueldos, junto con el incremento de los incentivos a los sectores de mayores ingresos para que contraten servicios pagado (Esping-Andersen 2000).

De esta forma y conforme a la individualización de los riesgos, en la evolución histórica de este tipo de régimen, destaca que la protección social del sector privado se ha ido desplazando desde la cobertura colectiva de riesgos -los planes de seguro social por empresa- a la suscripción individual de planes de pensión y salud y a la prestación de servicios por el mercado (Esping-Andersen 2000).

Este régimen está asociado con un grado de desmercantilización muy bajo, que fomenta una estructura social dual: de una parte, los beneficiarios de las prestaciones -los pobres y marginados-, y por otra, la clase media mayoritaria (Flaquer 2000). La primera tarea del régimen de bienestar liberal es separar a aquellos que son genuinamente incapaces de hacer cualquier contribución productiva de aquellos que por voluntad propia no quieren hacerlo. Se infiere que aquellos, que optan "voluntariamente" por no hacer ningún contribución, piensan que así están mejor, es decir, su pobreza es producto de una opción individual. De forma distinta, el Estado sí interviene en aquellos casos en los que se comprueba que son genuinamente incapaces de hacer cualquier contribución productiva, eso sí, con un carácter más caritativo que reconociendo los derechos de sus ciudadanos. Por lo general, organiza una política de bienestar social para aliviar la situación extrema de aquellos individuos realmente incapaces de beneficiarse del funcionamiento ordinario de la economía de mercado (Waldron, en Navarro Ruvalcaba 2006). Por lo tanto, la política social liberal se caracteriza porque sus beneficios son cerrados y focalizados, por ello están dirigidos a las personas con auténticas necesidades, sólo se entregan ayudas sociales a los individuos cuya necesidad de servicio sea demostrable (el cuidado médico sólo al enfermo, vivienda nada más a los desamparados, y así sucesivamente). Estos beneficios están focalizados en aquellos individuos que no cuentan con los recursos suficientes (tomando en cuenta sus ingresos $\mathrm{y}$ recursos $\mathrm{y}$, en algunos casos, de los familiares y amigos) para satisfacer esas 
necesidades por sí mismos. Los beneficios se dirigen a individuos carentes por razones legítimas; para determinar esa condición, se utilizan "pruebas" para evaluar a los demandantes de la ayuda.

El primer objetivo dentro de las políticas liberales de alivio de la pobreza es proteger al individuo contra la amenaza de la "dependencia sobre el bienestar". El temor es que las personas vean la ayuda pública como un primer recurso, en lugar de que sea el último, de que dependan de las ayudas públicas, en lugar de depender de sus propios esfuerzos para tener una vida segura.

Se debe señalar que dentro de este régimen existe un fuerte peso de las organizaciones no lucrativas (entre ellas las religiosas), y que la carga de los cuidados recae en la familia (Instituto de Mayores y Servicios Sociales 2004).

Además, el régimen liberal deja en una desprotección casi total a las clases medias, puesto que, por una parte, los requisitos de acceso sobre renta disponible les impide acceder a los servicios de provisión pública y, por otra, sus ingresos son insuficientes para costearse, en el ámbito privado, esos mismos servicios, especialmente los de mayor coste como son las plazas residenciales.

Una creciente demanda social caracteriza a los países que se ajustan a este modelo, en los que la gestión privada de los servicios prima sobre la pública. Al mismo tiempo, la descentralización de los servicios sociales está dando lugar a un incremento de los desequilibrios territoriales en la extensión y calidad de los mismos.

En síntesis, este régimen se caracteriza por el rol central del mercado y el rol marginal del Estado. Presenta grados mínimos de "desmercantilización" y un familismo implícito.

\section{Críticas a la Propuesta Analítica de Esping-Andersen}

La propuesta de Esping-Andersen sobre los tres regímenes de bienestar asigna en cada uno de ellos unas determinadas funciones al Estado y al Mercado, y además esboza un 
papel determinado para la Familia. Sin embargo, este último aspecto representó uno de los aspectos más débiles de su propuesta.

De hecho, él dio por sentado que en todas las sociedades de bienestar las unidades familiares eran las encargadas de proveer servicios y cuidados gratuitos a sus miembros, sin ahondar en que ello ocurría porque era el resultado de la peculiar posición ocupada por las mujeres en el sistema de reproducción social. Todos los Estados de bienestar contienen una importante dimensión de género que había permanecido teóricamente invisible hasta que fue puesta de relieve por la crítica feminista. Según este punto de vista, el criterio de desmercantilización sería insuficiente para dar cuenta de la medida en que los ciudadanos gozan de derechos sociales, ya que las mujeres que no están integradas en el mercado laboral no pueden recibir los beneficios de la desmercantilización si previamente no han entrado en él.

Una de las primeras reacciones críticas a la obra de Esping-Andersen fue la de Jane Lewis. Esta investigadora planteó la necesidad de incorporar al concepto de régimen de bienestar la relación entre el trabajo remunerado y no remunerado y la contribución de éste último al bienestar de las familias. Lewis propone analizar la medida en que los Estados de bienestar se basan en el modelo de familia llamado del "varón sustentador" (male breadwinner family model), que tiende a superponerse a los distintos tipos propuestos. Así, por ejemplo, en Irlanda y Gran Bretaña aparece un modelo familiar del varón sustentador "fuerte", con una participación marginal de las mujeres en el mercado de trabajo, escasos servicios de guardería infantil y exiguos derechos de maternidad. En cambio, en Francia encontramos un modelo familiar del varón sustentador "modificado", con una integración de las mujeres en el mercado laboral mucho más intensa y un mayor reconocimiento de sus derechos como trabajadoras y madres al mismo tiempo. Por último, Suecia constituye un buen ejemplo de modelo familiar del varón sustentador "débil”, ya que durante los años sesenta y setenta diversos gobiernos socialdemócratas impulsaron la inserción laboral de las mujeres, avanzando hacia una familia de doble empleo mediante la introducción de servicios de guardería, excedencias parentales y un impuesto sobre la renta individualizado (Flaquer 2000).

Una segunda línea de críticas dirigidas al libro de Esping-Andersen se centró en su omisión de los países del sur de Europa. El único país meridional estudiado por Esping- 
Andersen fue Italia, al que clasificó junto a los integrantes de la tradición corporativa continental. Ni Portugal, ni España, ni Grecia aparecían mencionados en su estudio de 1990.

En su libro Fundamentos Sociales de las Economías Postindustriales, Esping-Andersen recoge y admite muchas de las críticas formuladas por las autoras feministas, pero en cambio se niega a aceptar la existencia de un régimen de bienestar mediterráneo. Para él, los Estados europeos disponen todavía de un margen considerable para tomar decisiones en materia de política social y ello hace que hoy en día existan grandes diferencias en la estructura social de cada país. Si bien introduce la dimensión familiar con firmeza en su obra, continúa defendiendo la idea de que todos los casos empíricos de Estados de bienestar europeos encajan en su tipología tripartita. Según él, los países mediterráneos como España, Italia y Grecia no serían sino casos extremos del régimen corporativo continental (Esping-Andersen 2000), uno de cuyos rasgos más sobresalientes sería el familismo (Flaquer 2000).

\subsubsection{El Régimen de Bienestar Latino Rudimentario}

La tipología de los regímenes del bienestar no se agota en el modelo que propone Esping-Andersen, de esta forma Leibfried (en Flaquer 2000) plantea crear un cuarto tipo de régimen que englobe al conjunto de naciones meridionales, en el cual los países del "arco latino" (España, Portugal, Grecia, y hasta cierto punto Italia y Francia) podrían constituir un tipo de Estado de bienestar propio. Frente a los tres regímenes descritos por Esping-Andersen, Leibfried llama a este cuarto tipo "rudimentario" en la medida en que en estos países se da una contradicción entre el derecho al trabajo y al bienestar proclamado en los textos constitucionales y su puesta en práctica tan sólo de manera parcial. Leibfried afirma que lo que parece faltar en los países del "arco latino" es la implementación jurídica, institucional y social de las promesas constitucionales. La caracterización de Leibfried de los países mediterráneos pone el acento en su relativo "subdesarrollo", puesto que su rasgo más distintivo es no alcanzar los criterios imperantes en la Europa central o septentrional.

Rasgos comunes de los Estados de bienestar mediterráneos son los siguientes: 1) un sistema de mantenimiento de rentas muy fragmentado y "corporativo", con una marcada 
polarización interna (extremos de generosidad como sucede con las pensiones -sobre todo en Italia- acompañados de enormes vacíos en otras áreas de protección social); 2) alejamiento de las tradiciones corporativas en el campo de la sanidad y establecimiento (al menos parcial) de servicios nacionales de salud basados en principios universalistas; 3) un bajo grado de penetración del Estado en la esfera del bienestar y una mezcla entre actores e instituciones públicos y privados que garantice unos mínimos de bienestar social a los ciudadanos; y 4) la persistencia del clientelismo y la formación -en algunos casos- de "máquinas de patronazgo" muy elaboradas para el reparto selectivo de los subsidios monetarios (Ferrera en Flaquer 2000).

La mezcla de sistemas universalistas de atención sanitaria con planes de pensiones basados en la ocupación es corriente en todos los países del sur de Europa (Guillén, 1997). Para algunos analistas, el tipo latino rudimentario puede considerarse como un modelo en la medida que presenta una combinación original de "ocupacionalismo" (sistemas de mantenimiento de rentas) y "universalismo" (sistema sanitario) que no se encuentra en otras partes de Europa (Ferrera 1996).

Otra de las características de los Estados de bienestar de la Europa meridional es que no se da un plan nacional de rentas mínimas garantizadas legalmente para los individuos y las familias. Salvo en Portugal, no existe una red nacional de seguridad que sirva como último recurso, aunque en España e Italia, en que la asistencia social se halla bajo la responsabilidad exclusiva de las Comunidades Autónomas o de las autoridades regionales, respectivamente, se han desarrollado algunos planes locales con niveles de provisión muy dispares e irregulares (Flaquer 2004).

Una de las principales diferencias entre los países del sur de Europa y otras naciones del tipo de régimen conservador, calificados como "familistas" en su conjunto por EspingAndersen (2000), es la medida en que tienen políticas familiares explícitas. En la Europa meridional se da por sentado que los hogares son los principales responsables del bienestar de sus miembros y, por tanto, la política familiar queda en segundo término. Ésta es la razón por la cual los ciudadanos de esos países conceden a la familia una gran prioridad en su escala de valores. Sus niveles de bienestar dependen más de sus disposiciones y relaciones familiares que de las medidas desplegadas por las instituciones del Estado de bienestar. Esto es lo que causa al mismo tiempo la fuerza y 
la cohesión de la familia y la reproducción de un sistema basado en una cantidad muy reducida de medidas públicas amigables para la familia. El déficit de los sistemas de bienestar meridionales no es tanto resultado de un bajo nivel de desmercantilización como de desfamiliarización. Ello está en consonancia con la lógica del sistema, porque colocar el peso de la responsabilidad del bienestar sobre los hogares sólo es posible si un sector de la población, a saber, las mujeres casadas, no tiene directamente acceso a las transferencias monetarias. Ello da lugar a una situación de dependencia mutua de hombres y mujeres, en la cual los primeros se encargan de aportar los ingresos y las segundas de los servicios de cuidados. Esta relación simbiótica explica por qué los lazos familiares son tan fuertes en los países del sur de Europa (Flaquer 2004).

A diferencia de la atención sanitaria, de las pensiones de jubilación y de la educación, que fueron definidas como prioridad nacional y en que hubo una fuerte voluntad política para conseguir una cobertura casi universal (Flaquer 2004), la política familiar acaba de arrancar en los países mediterráneos.

En el caso de España, su Estado del bienestar se caracteriza por su escaso desarrollo, siendo uno de los más retrasados de la Unión Europea (UE). Vicenç Navarro (2006) analiza que si consideramos el gasto público en protección social como porcentaje del PIB, observamos que en el año 2002 el gasto público en protección social en España fue sólo el 19,7\% del PIB comparado con el 26,9\% del promedio de la UE-15, convirtiéndose ese año en el país de la UE con menor gasto público en protección social. El déficit social ${ }^{8}$ está en constante crecimiento y genera lo que Navarro llama la desconvergencia social con respecto los países de la UE, lo que ha afectado negativamente a la calidad de los servicios públicos y al tamaño de las prestaciones a la ciudadanía, y muy especialmente a las clases populares. Frente a esta visión crítica se debe señalar que en estos últimos años España ha desarrollado dos grandes iniciativas: la Ley Orgánica de Igualdad entre Mujeres y Hombres, y la Ley de Promoción de Autonomía Personal y Atención a Personas en Situación de Dependencia (Salido y Moreno 2007), ésta última será abordada más adelante en este capítulo.

\footnotetext{
${ }^{8}$ Definido como la distancia en dinero gastado en protección social entre España y el promedio de la UE (Navarro 2006:42).
} 


\subsubsection{Los Regímenes de Bienestar en América Latina}

De acuerdo a la intención de este trabajo resulta importante situar dentro del análisis de los regímenes de bienestar a los países latinoamericanos, que a pesar de su diversidad cuentan con un recorrido histórico similar. En América Latina la política social tradicional se ha enfocado, en su mayoría, hacia el sector salarial, y en el tema de las transferencias monetarias y de servicios sociales se ha basado en el modelo de seguridad social. Los esquemas de seguridad social fueron desarrollados de manera muy fragmentada, y en los primeros años de la década de 1980 los antiguos modelos fueron acosados por problemas financieros (Mesa-Lago 1999). Estos problemas se agravaron severamente a causa de la crisis económica posterior, que abrió el camino para la aplicación de profundas reformas. El Fondo Monetario Internacional (FMI) exigió a los gobiernos latinoamericanos realizar "ajustes estructurales", es decir recortar gastos en los sectores sociales, entre ellos el sector salud (Homedes y Ugalde 2005).

A tono con los lineamientos económicos de corte neoliberal, el enfoque dominante sobre la reforma de las políticas sociales en América Latina fue la privatización, la focalización y la descentralización (Navarro Ruvalcaba 2006). La focalización ${ }^{9}$ se constituyó en uno de los principales mecanismos de política social promovidos por las agencias internacionales, principalmente el Banco Mundial que aprovechó la situación inestable y fortaleció su sistema de préstamos, convirtiéndose en la agencia internacional qué más fondos prestaba a países en vías desarrollo (Homedes y Ugalde 2005).

Aquellos países que se adscribieron totalmente a un sistema económico neoliberal se alejaron de las políticas sociales de corte universalista y se inclinaron por el enfoque residual o liberal, en el cual desempeñan un papel creciente la seguridad privada, la provisión privada de servicios sociales y una restricción en la actuación del Estado, que se hace cargo sólo de los más pobres de entre los pobres, un claro ejemplo es el enfoque

\footnotetext{
${ }^{9}$ Focalizar es identificar con la mayor precisión posible a los beneficiarios potenciales y diseñar el programa con el objetivo de asegurar un impacto per cápita elevado sobre el grupo seleccionado, mediante transferencias monetarias o entrega de bienes o servicios. La focalización aspira a mejorar el diseño de los programas, ya que cuanto más precisa sea la identificación del problema (carencias a satisfacer) y de quienes lo padecen (población objetivo) más fácil resultará diseñar medidas diferenciadas y específicas para su solución; la focalización aumenta, además, la eficiencia en el uso de los recursos escasos y eleva el impacto al concentrar los recursos en la población de mayor riesgo (Franco 1996).
}

Página $\mid 51$ 
adoptado en las políticas sociales en Chile en la década de los 80', asunto que será ahondado en el capítulo IV.

En todos los países existen sistemas privados de previsión además de los sistemas públicos de servicios sociales. Argentina, Costa Rica, Cuba, Uruguay, Brasil, Jamaica, las Bahamas y Barbados tienen los sistemas de seguridad social más extensamente desarrollados. En casi todos esos países se estableció, aunque de manera relativa, un sistema de seguridad social basado en el modelo de Bismarck, el cual se fue extendiendo progresivamente a sectores cada vez más amplios de la colectividad. Al menos formalmente la población de ese grupo de países está altamente amparada por ese sistema. En el extremo opuesto se encuentran países como Honduras, Guatemala, El Salvador, República Dominicana y Bolivia, en donde el porcentaje de la población que está protegida por sistemas públicos de seguridad social es bajo (Navarro 2006).

Las reformas impulsadas en muchos países de América Latina integran no sólo esfuerzos para privatizar partes de los sistemas de salud y de pensiones, y dirigir la provisión de servicios públicos hacia los grupos pobres, sino también para descentralizar parte de la responsabilidad en el otorgamiento de servicios sociales hacia los niveles locales de gobierno (Navarro 2006). Pero el proceso descentralizador no consiguió los objetivos que anunciaban sus promotores, tales como mejorar la calidad, la eficiencia, la equidad y la participación comunitaria. Por el contrario, en los países latinoamericanos, las reformas contribuyeron a aumentar la desigualdad y a usar los recursos menos eficientemente. Por otro lado, la privatización perpetuó la inequidad en el acceso a los servicios sociales -de salud especialmente-, y no hay pruebas de que haya contribuido a mejorar la calidad ni la eficiencia de los sistemas (Homedes y Ugalde 2005).

Esta contextualización general nos ayuda a entender los esfuerzos que se han realizado por clasificar o definir a los Estados de bienestar y a las políticas sociales aplicadas en los países de América Latina. Por ejemplo, Carmelo Mesa-Lago (1999) clasifica los sistemas de bienestar en los distintos países por sus inicios históricos y grados de maduración en pioneros, intermedios y tardíos en el desarrollo de sus sistemas de protección social. Los primeros se caracterizan por su cobertura universal o casi universal en servicios de protección social básicos y por una gran estratificación en la 
calidad y condiciones de acceso a dichos servicios. Los países tardíos presentan una baja cobertura poblacional, una limitada gama de servicios, y una desigualdad en la calidad y número de beneficios para los sectores protegidos. Dentro de los países intermedios se distinguen dos tipos diferentes: los que han avanzado hacia un modelo estratificado maduro desde la lógica excluyente de los modelos tardíos, y los que han avanzado en niveles de cobertura, oferta y calidad de servicios sin incurrir en los errores de estratificación de los sistemas pioneros (Costa Rica, por ejemplo). Como puede confirmarse, la clasificación de Mesa Lago gira en torno al desarrollo o evolución de las políticas sociales en los países de América Latina.

En este mismo sentido, existen otros autores que abordan en forma general y global los Estados de bienestar en América Latina por medio del análisis en los cambios y la evolución de los derechos sociales en el contexto de la realidad latinoamericana. Desde este enfoque se esgrime que en el continente latinoamericano el deterioro de las políticas y programas sociales se ha dado, por un lado, por medio de la desestructuración de las políticas públicas consolidadas históricamente y, por el otro, del desmantelamiento de programas que existían de manera precaria. Además, se puede señalar una brecha entre las conquistas constitucionales, por ejemplo, en los casos brasileño y colombiano, y las políticas sociales efectivamente implementadas. En términos muy generales se puede describir la trayectoria de las políticas sociales en Latinoamérica como un camino que va de "un universalismo estratificado hacia programas de tipo focalizados" (Raczynski 1999).

A modo de síntesis, Lautier (en Navarro Ruvalcaba 2006) menciona tres rasgos característicos de los Estados de bienestar en América Latina: 1) la aparición inicialmente de un sistema de seguro social (para accidentes de trabajo, enfermedad y jubilación) destinado a sectores específicos de la población asalariada; 2) la inclusión de los sindicatos en un contexto de falta de libertad sindical, y 3) la conversión de los mecanismos asistencialistas en bases para el clientelismo político. 


\subsection{Sistemas de Atención a la Dependencia}

La revisión que acabamos de realizar nos ayudará a comprender la diversidad de los sistemas de atención a la dependencia. Éstos pueden ser clasificados sintéticamente en modelos de naturaleza universal y en modelos de carácter asistencial (Jacobzone, Cambois y Robine 2000). La tendencia general dominante en los países de la Unión Europea, respecto de la protección social de la dependencia, se orienta hacia modelos de naturaleza universal, si bien son modelos con topes, que prestan servicios o conceden prestaciones monetarias que cubren una parte del coste de los cuidados de larga duración y donde, por tanto, el copago es una característica común de todos los países en mayor o menor medida. El asistencialismo en este campo está en cierto retroceso a favor de la universalización del derecho social a la protección de las situaciones diversas de dependencia, lo que supone que la accesibilidad no depende únicamente de los recursos del beneficiario, sino de la necesidad sociosanitaria evaluada. Hoy en día, la necesidad de cuidados es un criterio que cuenta con creciente acuerdo, lo que no impide que la financiación del coste de servicios sea compartida por la protección social pública, que proporciona cobertura a una parte sustantiva del coste, y una participación del usuario.

Podemos diferenciar cuatro modelos de protección social de la dependencia que se corresponden, en cierto modo, con cuatro modelos de Estado de Bienestar: Nórdico, Corporativista, Liberal y Latino.

\subsubsection{La atención a las personas en situación de dependencia en los países nórdicos}

Los países nórdicos son los más típicos representantes del régimen de bienestar Socialdemócrata o Universal, que se caracteriza por un amplio compromiso público con la protección social, dentro de un sistema universal y financiado principalmente por medio de impuestos. El acceso a los servicios médicos y sociales es universal, para todos los residentes, de forma gratuita o con una tarifa moderada, y están integrados dentro del mismo sistema general. Son principalmente públicos, aunque en los últimos años hay en algunos aspectos una mezcla de público y privado. Además, cuentan con un elevado nivel de des-familiarización, donde el potencial de cuidados de la familia se ha 
reducido, a través de cambios normativos paralelos que han contribuido a que la demanda de atención deje de dirigirse a la familia y vaya hacia el sistema de atención formalmente organizado, en detrimento del apoyo informal.

Financieramente, el gasto total para políticas sociales y de protección social en estos países es el más alto de Europa (alrededor del 31\% del Producto Nacional Bruto). Este sistema da mayor prioridad a los servicios que a las ayudas económicas, y de aquí que los servicios públicos sean generosos y de alto nivel en comparación con la mayoría de los restantes estados europeos. Es también notable la integración de los servicios sanitarios y sociales bajo el mismo sistema de financiación, lo cual implica que los servicios sociales (incluyendo los cuidados de larga duración) son especialmente generosos respecto a los países que tienen concentrados sus recursos en los servicios estrictamente médicos.

Los sistemas nórdicos no disponen de seguros públicos de protección a la dependencia, más propios de regímenes de bienestar corporativistas, sino que la protección de la dependencia se ha ido constituyendo como una extensión lógica del universalismo protector de estos modelos a medida que se ha evidenciado la necesidad de proteger a las personas con necesidad de cuidados de larga duración (Rodríguez Cabrero 2004). Revisemos cuáles son los rasgos comunes en los sistemas de atención a personas en situación de dependencia (Instituto de Mayores y Servicios Sociales 2004):

En primer lugar, la protección a la dependencia se ha producido progresivamente como consecuencia del envejecimiento de la población a partir de las últimas décadas del siglo XX. Es una extensión de las prestaciones y servicios sociales y sanitarios ya existentes para las personas con dependencia.

En segundo lugar, la cobertura es universal, no asistencial, de modo que la prueba de recursos no existe, excepto para gestionar el copago a definir en cada caso concreto en función del nivel de renta.

En tercer lugar, es un sistema fundamentalmente de prestación de servicios, ya que la tradición familiar de cuidados informales es menos intensa que en los sistemas del sur de Europa y de régimen corporativo. Se trata de un sistema de servicios que, hasta muy 
recientemente, ha sido predominantemente público pero que lentamente ha ido introduciendo la prestación de servicios de tipo privado. La privatización de la gestión de los servicios se está abriendo paso por razones de eficiencia y control del gasto público.

En cuarto lugar, en cuanto a financiación, hay que señalar que es, de manera dominante, de tipo público -vía impuestos- y compartida por el Estado y las Administraciones Territoriales. A ello hay que añadir el copago que, como antes decíamos, varía según la renta y el tipo de servicio.

En quinto lugar, se trata de un modelo que, durante los últimos años, ha tendido a la municipalización, la producción mercantil de los servicios (por ejemplo, en Suecia la mitad de la producción de los servicios sociales es desarrollada por cuatro grandes empresas privadas) y la privatización de la atención según el nivel de renta y educación (los ciudadanos con mayor nivel educativo que recibían servicios privados eran el $4 \%$ al principio de la década de los noventa, diez años más tarde ese porcentaje era del $26 \%$; igualmente, el recurso a la ayuda informal en los ciudadanos con menor nivel educativo ha pasado del 50 al $61 \%$ en ese mismo período).

En último lugar, se trata de países con los mayores niveles de gasto público sobre el PIB en cuidados de larga duración en la Unión Europea, con la excepción de Finlandia (1,6\% del PIB). En 2000, los porcentajes de gasto de Dinamarca y Suecia fueron respectivamente el 3\% y 2,8\% del PIB. Sólo los Países Bajos tenían un porcentaje similar (2,6\%). Sin embargo, el crecimiento de esta partida de gastos ha abierto el debate sobre la viabilidad financiera de los cuidados de larga duración, lo que puede generar reformas similares a las adoptadas en los sistemas continentales: importancia de las prestaciones monetarias frente a los servicios, ampliación del espacio mercantil de la gestión y una mayor participación del usuario en el coste de los servicios.

Se debe considerar además que la organización territorial de los países nórdicos se estructura en tres niveles de gobierno: Estado, Condado y Municipio. Los Municipios disfrutan de una considerable independencia dentro del marco de las leyes y de la regulación financiera del Estado, de esta forma, mientras que las pensiones de jubilación son responsabilidad del Estado (gobierno nacional), los servicios dependen del 
Municipio (gobierno local). Los hospitales y algunos otros servicios médicos especializados están basados en el nivel del Condado (gobierno regional), mientras que, como apuntábamos anteriormente, todos los demás servicios para mayores y para personas con discapacidad son responsabilidad del gobierno municipal, bajo la legislación y la regulación financiera establecida por el gobierno central.

Finalmente, resulta importante mencionar que la tendencia de la proporción de atención en instituciones, tanto en el caso de personas mayores, como en el de personas con discapacidad, ha bajado sustancialmente mientras se han expandido las viviendas protegidas (sheltered housing) y los servicios comunitarios. La proporción de institucionalización entre los mayores de 80 años descendió desde el 23\% en 1975 hasta el $13 \%$ en 1995, mientras la proporción de residencia vigilada se incrementaba desde el 1 al $8 \%$ y la de los usuarios de ayuda a domicilio crecía aproximadamente del 30 al $45 \%$ (para las personas de más de 80 años) en el mismo período. Similares proporciones se observan en el caso de las personas con discapacidad.

La tasa de institucionalización de los mayores dependientes se consideró durante mucho tiempo un indicador nacional de nivel de desarrollo y de bienestar social, porque ello significaba que el Estado, a través de las diversas instituciones administrativas, sociales y sanitarias, contaba con recursos e infraestructura que permitiera brindar este servicio a la población (Hunter, McKeganey y McPherson en Rivera 2001). Pero a partir de la década de los setenta, y de forma progresiva, la postura se ha orientado hacia políticas de mantenimiento en el domicilio, intentando que los mayores con cierto grado de dependencia vivan el mayor tiempo posible en su hogar, con los apoyos necesarios, retrasando a la vez la institucionalización (Comisión de las Comunidades Europeas; European Comission en Rivera 2001).

\subsubsection{La atención a las personas en situación de dependencia en países que desarrollan el régimen corporativista}

En este sistema la protección social a la dependencia se sitúa, al igual que las pensiones, el seguro de desempleo y la protección a la familia, en el ámbito de la Seguridad Social y es, por lo tanto, financiado y gestionado en este marco. 
Todos los países que han optado por este modelo -Alemania, Austria, Luxemburgo y Francia- reconocen la naturaleza de derecho subjetivo de la protección de la dependencia, independientemente de la situación económica, superando la tradición asistencialista y de responsabilidad de la familia en este campo. Esta forma de aseguramiento de la dependencia pretende cubrir las necesidades de servicios de la persona que en su momento puedan presentarse. La prestación puede servir para apoyar a la familia cuidadora o para sustituirla (Rodríguez Cabrero 2004).

La situación de dependencia se evalúa en grados o niveles de gravedad, de los que se derivan prestaciones monetarias de diferente cuantía o servicios de distinta intensidad o duración. En general, en estos sistemas se da un amplio margen de elección a la persona dependiente o su familia, que puede optar entre prestaciones monetarias y servicios. Esta libertad de elección, basada en el respeto a las tradiciones y preferencias familiares y culturales, no obsta para que se tienda a favorecer la prestación de servicios, bien sea duplicando la cuantía de éstos, cuando se recurre a entidades prestadoras respecto de la familia (Alemania), bien sea reduciendo la libertad de elección de la persona en situación de dependencia a medida que aumenta la gravedad de la dependencia, lo que pone de manifiesto la importancia que se da a que la atención más especializada sea cubierta por profesionales (Luxemburgo).

Estos sistemas se financian fundamentalmente con cotizaciones a la Seguridad Social de los trabajadores en activo y en algunos países también con las de empresarios y de los propios pensionistas. También suele haber financiación vía impuestos, para cubrir las prestaciones no contributivas y/o equilibrar financieramente el sistema.

La gestión de las prestaciones económicas suele ser centralizada, mientras que la de los servicios está descentralizada en las administraciones territoriales. Las prestaciones tienen un tope, cubren una parte importante del coste, aunque no la totalidad, lo que obliga al beneficiario a participar en la financiación de los servicios. Ello tiene como finalidad no sólo contribuir a la financiación, sino también introducir un freno o contención del gasto.

Se contemplan también ayudas al cuidador, tanto en excedencias del trabajo para los cuidadores informales, como en la cobertura de las cotizaciones a la Seguridad Social, 
así como el desarrollo de servicios de respiro y de apoyo para períodos de vacaciones o necesidades especiales (Instituto de Mayores y Servicios Sociales 2004).

Finalmente, desde el punto de vista de la evaluación de este modelo, después de varios años de existencia (once en el caso de Austria, nueve en el caso alemán), se constata que la incorporación de los beneficiarios al sistema se ha producido de una forma más lenta de lo previsto, y que el coste es menor que el de los sistemas universales, financiados vía impuestos, pues en los países que lo han implantado el gasto alcanza valores de entre el 1,2\% al 1,5\% del PIB. Se debe agregar que existe una elevada opción de los usuarios del sistema por las prestaciones monetarias, en detrimento de los servicios profesionalizados. Esto último no revela sino dos hechos: que la oferta de servicios es crónicamente baja -Austria- y que la tradición de cuidados familiares es aún muy sólida (Rodríguez Cabrero 2004).

\subsubsection{Japón}

Dentro de esta sección nos parece adecuado revisar la situación de la atención a la dependencia en este país asiático. Japón aplica desde el año 2000 un nuevo modelo de cuidados de larga duración de doble naturaleza: contributiva y asistencial. La atención se sitúa en la senda de los sistemas de tipo corporativo -cobertura universal y modelo general de Seguridad Social- cubriendo los costes de los cuidados personales mientras que la asistencia sanitaria tiene otra vía de financiación y gestión, aunque en la aplicación de los servicios no siempre es posible realizar dicha diferenciación.

Japón se enfrenta a un serio desafío, ya que un $19.9 \%$ de su población tiene 65 años o más, con elevadas esperanzas de vida (86,2 años para las mujeres y 79 años para los varones) y baja tasa de fecundidad -1,27 hijos por mujer en edad de procrear en 2005(Population Division of the Department of Economic and Social Affairs of the United Nations Secretariat 2008). El crecimiento de las necesidades sociales de cuidados de larga duración y los cambios en la estructura de cuidados informales han cristalizado en un modelo de solidaridad colectiva mediante la implantación de un sistema de cobertura universal en su doble dimensión contributiva y no contributiva, financiado con cotizaciones e impuestos, además de una contribución fija del $10 \%$ del coste de los 
servicios (lo que reduce el consumo residencial y favorece el de tipo domiciliario) (Instituto de Mayores y Servicios Sociales 2004).

El modelo japonés es un modelo de regulación, financiación y supervisión pública, gestión municipal y provisión privada mercantil de servicios. Toda persona en situación de dependencia debe certificar dicha situación por un equipo multidisciplinar; dicha certificación es efectiva durante 6 meses y se debe renovarse cada año para acceder a las prestaciones que recibe o para cambiar del grado de dependencia. El plan de cuidados lo define un administrador de casos del municipio correspondiente.

La población susceptible de acceder al sistema es la población mayor de 40 años diferenciándose dos grupos: de 40 a 64 años y 65 y más años. Los grados de dependencia son la base de las prestaciones que se dividen en dos grupos: prestaciones de ayuda (servicio domiciliario) y prestaciones de cuidados (en este caso pueden elegir o combinar servicios a domicilio o residenciales), ésta última, a su vez, tiene cinco niveles prestacionales.

El sistema de financiación del sistema es mediante cotizaciones (nivel contributivo para activos y pasivos) e impuestos (nivel asistencial). En todo caso, en la financiación participan los ciudadanos y los diferentes niveles de gobierno, de forma que en el año 2004 la distribución de la financiación se presentaba de la siguiente forma: la población de 65 y más contribuye con el $17 \%$ de los ingresos totales, la población de 40 a 64 con el $33 \%$, el Estado con el 25\%, las provincias con el 12,5\% y los municipios con el restante 12,5\% (Instituto de Mayores y Servicios Sociales 2004: 711).

En suma, el sistema japonés es un modelo singular de cobertura universal basado en la participación de todos los agentes institucionales y los ciudadanos en el sostenimiento del sistema. 


\subsubsection{La atención a las personas en situación de dependencia en países que desarrollan el régimen liberal o residual}

Para referirnos a este tipo de atención a la dependencia nos referiremos en específico al caso estadounidense, ya que representa un típico exponente del modelo liberal, caracterizado por el carácter asistencial del conjunto de sus servicios sociales y específicamente de los cuidados de larga duración.

El principio básico de la política social de los Estados Unidos ha sido el individualismo propio de la economía neoliberal. Las viejas leyes de pobres, combinadas con la caridad privada, fueron el modo dominante de ayuda para el anciano y el indigente (incluso para las viudas y los huérfanos) a lo largo del primer tercio del siglo XX, después de dos o tres generaciones en que la mayoría de los otros países industrializados habían promulgado las pensiones públicas de vejez. En este modelo, la ayuda pública se considera como un programa "residual", que con base en pruebas de medios se ofrece a los que son incapaces de cuidarse por sí mismos y a sus familias por medio de los mecanismos ordinarios del mercado y su correspondiente seguro social.

La entrega de ayuda por "prueba de medios" ha tomado varias formas en Estados Unidos: desde la asistencia social hasta los programas federales como el Medicaid y el seguro de complementación del ingreso. Además, de manera relevante si se compara con los demás países industrializados, Estados Unidos ha carecido de cualquier "subsidio familiar universal" o "beneficio a la niñez"; en lugar de las ayudas mencionadas, el Estado ofrece sólo ayuda a familias con niños dependientes y con base en estrictas pruebas de medios (Navarro Ruvalcaba 2006).

En el sistema estadounidense existen dos posibilidades de protección social a la dependencia:

La primera es de tipo estrictamente privado, se trata de pólizas de long-term care insurance que cubren una cantidad máxima de dinero en función de la cuantía de la póliza. Este producto puede ser comprado en el mercado de seguros o facilitado por un empresario privado o público (los empleados del gobierno federal, el US Postal Service y miembros de las fuerzas armadas, también algunos Estados a sus funcionarios). 
Algunas compañías permiten utilizar los seguros de vida para pagar enfermedades terminales o de larga duración.

La segunda modalidad es de tipo público y tiene dos vías de acceso, por una parte, mediante el Medicare la población de 65 años y más tiene derecho a asistencia de corta duración en centros de asistidos o en residencias; el coste de dicha atención es cubierto parcialmente, teniendo que completar el paciente la diferencia mediante sus propios recursos o seguros privados. En cuanto a la población sin recursos, con necesidades de cuidados de larga duración, pueden recibir ayuda en la parte no cubierta por el Medicare mediante el recurso al sistema del Medicaid. Este sistema es de tipo federal, si bien en su aplicación hay variación entre Estados. Las residencias privadas tienen que admitir a los beneficiarios del Medicaid, vía concierto, si disponen de plazas.

La provisión de servicios es, en conjunto, privada y su cobertura es baja en ayuda a domicilio (2,7\% de la población de 65 y más años) y con un cierto peso de las residencias asistidas (4,2\% de cobertura de la mencionada población mayor) (Instituto de Mayores y Servicios Sociales 2004).

\subsubsection{La atención a las personas en situación de dependencia en países que desarrollan el régimen latino rudimentario}

De acuerdo a Rodríguez Cabrero (2004) los países del "arco latino ${ }^{10 "}$ se caracterizan de forma general porque cuentan con deficientes iniciativas de atención a la dependencia, haciendo recaer sobre la familia el mayor peso de los cuidados, particularmente sobre la mujer. El sistema público de cuidados de larga duración es de naturaleza asistencial (para pobres prácticamente), insuficiente en recursos, orientado a las prestaciones económicas más que a los servicios (el déficit de los servicios, comunitarios sobre todo, es una realidad ampliamente reconocida) y con notables desequilibrios territoriales.

Algunos de estos países, como Italia y España, están en un proceso de modernización y extensión de la red de servicios sociales, si bien su retraso es aún muy importante en

\footnotetext{
${ }^{10}$ En referencia a países del mediterráneo europeo: España, Portugal, Grecia, y hasta cierto punto Italia y Francia.
} 
comparación con la mayoría de los países del centro y norte de la UE. La descentralización, la gestión privada de los servicios y una creciente demanda social caracterizan a estos países. Pero la descentralización de los servicios sociales está suponiendo un incremento de los desequilibrios sociales en cuanto a la extensión y calidad de los mismos.

Los cambios sociodemográficos, en especial el envejecimiento creciente de sus poblaciones, presionan en favor de generar modelos protectores de tipo universal. Sin embargo, las políticas de contención del gasto social y la derivación de la responsabilidad desde el Estado a las regiones y municipios en materia de servicios sociales están inhibiendo el desarrollo de políticas de Estado para la protección de las personas dependientes. En el caso de España, previo a la vigencia de la Ley de Dependencia, las Comunidades Autónomas desarrollaron planes propios relacionados directa o indirectamente con la dependencia, en parte, como consecuencia de la inacción del Estado central.

\subsection{Ley de Dependencia en España}

El Estado de bienestar español, previo a la promulgación de la Ley de Promoción de la Autonomía Personal y Atención a Personas en Situación de Dependencia (en adelante Ley de Dependencia), contaba con un modelo asistencial de atención a la dependencia, cuya protección resultaba fragmentaria, parcial e insuficiente, y dejaba fuera de la protección del Estado a las amplias clases medias de España. La implantación del nuevo sistema de atención a la dependencia busca modificar la situación existente, ya que hasta ese entonces sólo se accedía a la oferta pública cuando se demostraba la escasez de rentas y la falta de apoyo familiar (Valcarce 2008).

Se debe señalar que las distintas administraciones autonómicas desarrollaban de forma dispar programas que buscaban dar atención a los usuarios dependientes, pero no existía uniformidad en los criterios ni en las prestaciones entregadas. En este contexto el papel de los cuidados informales resultaba importantísimo para enfrentar el aumento creciente de demanda por cuidados, provocada en gran parte por el envejecimiento de la población española. 
La Ley de Dependencia (Ley 39/2006, de 14 de diciembre) fue aprobada con el apoyo mayoritario de las principales fuerzas políticas del país y su objetivo principal era regular las condiciones básicas para garantizar la igualdad de los ciudadanos en el derecho de la promoción de la autonomía personal y atención a dependientes (Boletín Oficial del Estado 2006). La Ley reconoce un nuevo derecho universal y subjetivo de ciudadanía, que garantiza atención y cuidados a las personas dependientes, dando así cobertura a las necesidades de los familiares de aquellas (Salido y Moreno 2007).

Los principios que inspiran la Ley son:

- El carácter universal de las prestaciones.

- El acceso a las prestaciones en condiciones de igualdad.

- La participación de todas las administraciones en el ejercicio de sus competencias.

La Ley de Dependencia garantiza la igualdad básica en el acceso a las prestaciones de las personas, independiente de su lugar de residencia, sin embargo, las administraciones autonómicas y locales pueden realizar una ampliación de dichas prestaciones (con cargo a sus presupuestos).

Con esta legislación se busca consolidar el 'cuarto pilar' de servicios sociales del Estado del bienestar en España, mediante la constitución de un Sistema de Autonomía y Atención a la Dependencia (SAAD), que garantice las condiciones básicas y la previsión de los niveles de protección referidos por la Ley. También crea el Consejo territorial del SAAD que se encarga de acordar el marco de cooperación entre las instituciones públicas, la intensidad de los servicios del catálogo, condiciones y cuantía de las prestaciones económicas, criterios de participación de los beneficiarios y el baremo para el reconocimiento de la situación de dependencia.

La financiación del sistema se determina anualmente dentro de los presupuestos generales del Estado. La Administración General del Estado aporta una cantidad que debe ser, al menos, igualada por la Comunidad Autónoma. Los usuarios participan también en la financiación según el tipo y coste del servicio y su capacidad económica personal, ésta última se tendrá en cuenta para determinar la cuantía de las prestaciones 
económicas. Se debe aclarar que ningún ciudadano queda fuera de la cobertura del sistema por no disponer de recursos económicos.

El grado y nivel de dependencia se determina mediante la aplicación del baremo (acordado por el Consejo Territorial del SAAD) que tiene su referente en la Clasificación Internacional del Funcionamiento, la Discapacidad y la Salud (CIF). Este baremo establece los criterios objetivos de valoración del grado de autonomía de la persona, de su capacidad para realizar las distintas actividades de la vida diaria, los intervalos de puntuación para cada uno de los grados y niveles de dependencia, y el protocolo con los procedimientos y técnicas a seguir para la valoración de las aptitudes observadas. Los grados de dependencia definidos son los siguientes:

Grado I - Dependencia Moderada La persona necesita ayuda para realizar varias actividades básicas de la vida diaria (ABVD), al menos una vez al día o tiene necesidades de apoyo intermitente o limitado para su autonomía personal.

Grado II - Dependencia Severa La persona necesita ayuda para realizar varias ABVD dos o tres veces al día, pero no requiere el apoyo permanente de un cuidador o tiene necesidades de apoyo extenso para su autonomía personal.

Grado III - Gran Dependencia La persona necesita ayuda para realizar varias ABVD varias veces al día y, por su pérdida total de autonomía física, mental, intelectual o sensorial, necesita el apoyo indispensable y continuo de otra persona o tiene necesidades de apoyo generalizado para su autonomía personal.

Cada uno de los grados se clasifica en dos niveles, en función de la autonomía de la persona y de la intensidad del cuidado que requiere.

Las prestaciones del sistema pueden tener la naturaleza de servicios o de prestaciones económicas, y están destinados a promover la autonomía personal y atender a aquellos con dificultad para realizar las actividades de la vida diaria (AVD). Los servicios del catálogo son de carácter prioritario y se prestan a través de la oferta pública de la red de servicios sociales de cada administración autónoma, mediante centros y servicios públicos o privados debidamente acreditados; si no es posible la atención en alguno de estos servicios, se entrega, de forma excepcional, la prestación económica vinculada, 
que está destinada a cubrir los gastos del servicio previsto en el Programa Individual de Atención de cada usuario.

El catálogo de servicios está formado por:

1. Servicio de la prevención de las situaciones de dependencia y promoción de la autonomía personal.

2. Servicio de teleasistencia.

3. Servicio de ayuda a domicilio.

4. Servicio de centro de día y de noche.

5. Servicio de atención residencial.

En cuanto a las prestaciones económicas, éstas pueden ser de tres tipos:

1. Vinculadas al servicio.

2. Para cuidados en el entorno familiar y apoyo a los cuidadores no profesionales.

3. Asistencia personal.

Para el reconocimiento del derecho la persona dependiente, o quien ostente su representación, debe realizar la solicitud frente a su administración autonómica correspondiente. Los servicios de valoración, prescripción de servicios y prestaciones y la gestión de las prestaciones económicas se efectúan por la directamente por las administraciones públicas. Los servicios sociales presentan al usuario un Programa Individual de Atención en el que se determinan las modalidades de intervención más adecuadas de acuerdo sus necesidades, con posibilidad de elección entre las alternativas propuestas.

Algunos aspectos a destacar de la protección universal garantizada por la Ley:

- Establece los derechos y obligaciones de las personas dependientes.

- Establece limitaciones en el acceso, al tener que superar el baremo de entrada al sistema (en función del grado y nivel de dependencia).

- No se exige a los usuarios requisitos específicos de afiliación o cotización.

- Asegura la calidad de la red de servicios prestados por los agentes públicos y privados. 
La prioridad en el acceso a las prestaciones se determina por el grado y nivel de dependencia. La Ley de Dependencia previó el siguiente calendario de aplicación:

Año 2007: Todos los grandes dependientes (grado III), en sus 2 niveles.

Año 2008: Dependientes Severos (grado II), nivel 2.

Año 2009: Dependientes Severos, nivel 1.

Año 2011: Dependientes Moderados (grado I), nivel 2.

Año 2013: Dependientes Moderados, nivel 1.

Año 2015: Fin período de aplicación de la Ley.

\subsubsection{Estado de aplicación de la Ley}

La Ley de dependencia comenzó su aplicación en el año 2007 y ella no ha estado exenta de dificultades. A continuación se detallan los aspectos más relevantes:

Sobre la dimensión sociosanitaria: la Ley de Dependencia establece que corresponde a las administraciones autonómicas establecer los procedimientos de coordinación sociosanitaria en el marco del SAAD, creando, en su caso, los órganos de coordinación que proceda. Sin embargo, aparte de esta previsión y de la inclusión como principio inspirador de la colaboración de los servicios sociales y sanitarios en la prestación de los servicios a los usuarios del SAAD, lo cierto es que la Ley no ha especificado lo suficiente este tema, y ello a pesar de que los posicionamientos de los diferentes actores sociales, antes de que se promulgase la Ley, insistieron en la necesidad de aprovechar la ocasión para establecer un auténtico esquema de coordinación sociosanitaria (Jiménez 2007).

La falta de definición del ámbito de lo sociosanitario ha sido también criticada porque deja en manos de las Comunidades Autónomas la posibilidad de mercantilizar y "medicalizar" la atención sociosanitaria, lo que, además de no responder a las necesidades de las personas con dependencia, tendría un importante impacto sobre el gasto sanitario (Jiménez 2007). 
A nivel de autonomías encontramos realidades diversas, mencionamos aquellas en las que sí se ha intentado coordinar esta dimensión, por ejemplo, en Andalucía se ha puesto en marcha el sistema DIRAYA, un sistema de información que sustenta la integración de los servicios sanitarios (atención primaria, especializada y visitas a urgencias) y prescripciones de medicamentos, donde cada ciudadano tiene un registro único de salud electrónico. Galicia ha propuesto un sistema integrado de atención a las personas con dependencias. Navarra ha creado la Agencia Navarra para la Dependencia que depende de servicios sociales, pero está separada de la atención sanitaria. En Cataluña hay varias experiencias de integración que necesitan un apoyo político y financiero para su continuidad (Zunzunegui y Lázaro 2008).

Una mejora en la atención a la dependencia debería pasar por una mayor integración entre la prestación de los servicios sanitarios y los sociales. Además de más coordinación, esta medida bien aplicada podría redundar en la posible reducción de recursos necesarios, en la racionalización de los tratamientos rehabilitadores, en una disminución de las estancias hospitalarias y una mayor sensación de seguridad para las personas dependientes y sus familias. Se debe hacer mención que en España, algunos equipos de atención primaria disponen de programas domiciliarios que hacen seguimientos proactivos de pacientes con patología múltiple, mediante la figura de la enfermera de enlace (que sirve de puente entre los servicios de atención primaria y el hospital), además de integrar en los equipos sanitarios personal de los servicios sociales (Gispert 2009). En este contexto la valoración de las necesidades de las personas se podría realizar de manera más fiable por profesionales sanitarios, que conocen por sí mismos las limitaciones de las personas, junto con los profesionales que están al tanto de su entorno social.

Sobre la atención geriátrica. La atención geriátrica, dentro del Sistema Nacional de Salud, ha sido otra de las demandas formuladas reiteradamente por los actores sociales en relación con la dependencia. Entre los pronunciamientos más claros en este sentido está el de la Confederación Española de Organizaciones de Mayores, para la cual es impensable desplegar con éxito la Ley de Dependencia sin desarrollar paralelamente la atención geriátrica. En el mismo sentido se pronunciaba la Sociedad Española de Geriatría y Gerontología, que plantea que la Ley debería exigir al Servicio Nacional de 
Salud el desarrollo de la atención geriátrica, tanto en aspectos preventivos como de atención sanitaria de la dependencia, incluyéndola dentro del catálogo de prestaciones que la Ley establece (Jiménez 2007).

Sobre los modelos de intervención. Los pronunciamientos de los actores sociales también han insistido en la necesidad de introducir cambios en los modelos de intervención que faciliten la continuidad de los cuidados, como la metodología de gestión de casos, que se ha demostrado eficaz para la atención a las personas en su entorno comunitario (lo que requiere esfuerzos adicionales de coordinación de servicios en comparación con la atención residencial) y es especialmente apropiada para la atención de personas con múltiples problemas y necesidades, que necesitan definir, localizar y obtener servicios de diferentes sistemas de atención y agentes proveedores. La introducción de la figura del gestor de casos ha sido defendida por las organizaciones corporativas de la enfermería y del trabajo social, en tanto que implica la existencia de una figura profesional que acompaña a la persona y a su familia, desde el momento mismo de la valoración de su situación y de la elaboración del plan individual de cuidados, a lo largo de todo su proceso de dependencia, buscando y gestionando los servicios y programas que sean más adecuados en cada momento, evaluando permanentemente los resultados obtenidos (Jiménez 2007).

Sobre las desigualdades territoriales. Los datos actualizados relativos a la aplicación de la Ley de Dependencia ponen de manifiesto una enorme variabilidad entre Comunidades Autónomas, tanto en lo que se refiere a las solicitudes como a los dictámenes y beneficiarios con derecho a prestación; por ejemplo, los datos acumulados a 1 de abril de 2009 (Sistema de Autonomía y Atención a la Dependencia e Instituto de Mayores y Servicios Sociales 2009) muestran que el 30\% de las solicitudes proceden de Andalucía, comunidad que representa algo menos del 18\% de la población española, mientras que sólo el 4,5\% procede de la comunidad de Madrid en la que vive el 13,6\% de los habitantes del país. Dicho en otros términos el $23,1 \%$ y el $4,5 \%$ de las personas mayores de 65 años de esas comunidades, respectivamente, solicitaron la prestación. También llama la atención que las proporciones de solicitudes resultantes con derecho a prestación sean tan distintas, sobre todo en aquellas comunidades con una gran mayoría de las valoraciones realizadas. Así, el 100\% de las solicitudes de la región de Murcia se 
resolvieron con derecho a prestación, en cambio en Cantabria solo lo fueron en el $75,1 \%$, aunque el porcentaje de solicitudes (357) por habitante mayor de 65 años es parecida en ambas comunidades (12,2\% y 14\% respectivamente). Estas grandes diferencias sugieren que, como mínimo, la difusión de la información sobre las prestaciones y los trámites para su gestión distan de ser homogéneos y que probablemente tampoco lo sean los criterios de valoración, a pesar de la existencia de un único baremo (Gispert 2009).

La diferenciación en la aplicación de la Ley en las distintas autonomías puede estar conduciendo a enormes e irreversibles desigualdades territoriales, paradójicamente en contra de lo inicialmente buscado por la Ley de Dependencia que busca garantizar las prestaciones reconociendo el derecho subjetivo de todo ciudadano, independientemente del lugar de residencia (Asociación Estatal de Directores y Gerentes en Servicios Sociales de España 2008).

Sobre el abuso de la prestación económica. Mención aparte merece una de las medidas que propone la Ley con carácter "excepcional” la posibilidad de recibir una prestación económica para ser atendido por cuidadores no profesionales, como pueden ser los familiares de la persona dependiente, que resulta ser el medio más utilizado en la aplicación de la Ley. Destacando que al año 2008, la mayor parte de las autonomías no había prescrito servicios domiciliarios y/o teleasistencia (Asociación Estatal de Directores y Gerentes en Servicios Sociales de España 2008).

Sobre el sistema de copago. Las fuentes de financiación del SAAD son tres: las aportaciones del gobierno central, las aportaciones de las administraciones autonómicas y las aportaciones de los usuarios. A fines del 2008, a través de un acuerdo alcanzado en el Consejo Territorial del SAAD, se definieron algunos requisitos genéricos sobre el sistema de copagos, que no habían sido lo suficientemente aclarados en la Ley. Sin embargo, puesto que son las administraciones autonómicas quienes tienen potestad para definir concretamente dichos sistemas, los retos que plantea definir un buen sistema de copago siguen estando en cuestión (Casado 2009).

La Ley de Dependencia y el SAAD constituyen el cuarto pilar del Estado de bienestar español y por ende una de las iniciativas de política social más importante de los 
últimos tiempos. Sin embargo, producto de las reformas económicas que el gobierno de Partido Popular emprendió debido a la crisis económica que afecta a España, el SAAD se ha visto seriamente afectado. Los recursos económicos para financiar la ley fueron mermados y ello repercutió en la disminución de la cuantía de las prestaciones a los cuidadores; en el sistema del copago incrementando las aportaciones a las prestaciones a percibir; en la supresión de la cotización de los cuidadores en la Seguridad Social por parte del Estado $^{11}$; y en el aplazamiento hasta el año 2015 del ingreso al SAAD de los dependientes menos graves (Prats 2013).

Ejemplo de lo anterior, es que a noviembre de 2012 la afiliación a la Seguridad Social española descendió en 145.000 cuidadores de personas dependientes, un 85\% de las que constaban como tal en sus registros (Gómez y Morán 2012). Para los cuatro primeros meses del año 2013, el número de beneficiarios de ayudas cayó en 3.316 personas y, si se comparan con agosto del año pasado, bajó al menos en 18.883. Asimismo, a pesar de que la lista de espera descendió por distintas razones, esta ascendía a 218.345; es decir, que casi una de cada cuatro personas con derecho a recibir prestaciones o servicios no las recibía (Prats 2013).

\footnotetext{
${ }^{11}$ Desde que en 2007 entró en vigor la Ley de Dependencia, el Ministerio de Sanidad y Servicios Sociales se hizo cargo de la cotización de las cuidadoras familiares, un 92\% mujeres (Gómez y Morán 2012).
}

Página $\mid 71$ 
Página | 72 


\section{CAPÍTULO III: PARTICULARIDADES DE LOS CUIDADORES Y DEL CUIDADO INFORMAL}

\subsection{Contexto}

La situación actual del cuidado en occidente ha sufrido transformaciones importantes debido a numerosos cambios en la cultura y sociedad actual (Cameron y Moss 2007), contextualizar previamente estas modificaciones puede ayudar a entender de mejor forma los contenidos que serán tratados en éste capítulo. Las transformaciones que afectan directamente al contexto del cuidado son:

1. Cambios en la demanda y oferta de cuidados:

- Cambios en la potencialidad de empleo de tiempo y de atención, a las personas que lo precisen, en los cuidadores informales, debido al aumento del empleo femenino, el descenso de la población de mujeres de bajo nivel educativo y los cambios demográficos que generan "familias escuálidas" (es decir, menos miembros en cada generación al disminuir el tamaño de la familia) (Cameron y Moss 2007).

- Mayor demanda de servicios de cuidados a causa de los cambios demográficos, económicos y sociales (como el envejecimiento de la población o el aumento del empleo de ambos cónyuges).

2. Cambios en la posición social de los usuarios de servicios de cuidados:

- El cambio en la percepción social de los usuarios de servicios, con mayor énfasis en su consideración como sujetos activos, ciudadanos con derechos y consumidores y en la formación, integración, autonomía, elección y desarrollo.

\section{Cambios en la política de bienestar:}

- Mayor énfasis en la descentralización y en los enfoques integradores y globales que entrañan colaboración y trabajo en red, combinación de prestaciones, elección y flexibilidad.

- Límites cada vez más imprecisos entre los ámbitos, hasta ahora distintos, de las políticas y de la prestación. 
- Mayor hincapié en la privatización de servicios, prestación externa, selección de las prestaciones y capacitación a los usuarios de servicios para que adquieran estos directamente las habilidades necesarias para el cuidado (mediante la formación y en muchos casos mediante el pago directo).

\section{Mayor diversidad:}

- La variedad de los usuarios de servicios y su familia, en cuanto a características, condiciones y requisitos, aumenta en paralelo a la diversidad étnica, la diversidad de los hogares y la flexibilidad y el carácter "atípico" que adquieren las condiciones de empleo de las sociedades contemporáneas.

\subsection{Cuidadores}

\subsubsection{Tipología de cuidadores informales}

Recordemos que el cuidado informal es brindado principalmente por familiares, pudiendo participar en él amigos y vecinos. Los cuidadores informales generalmente no disponen de formación (los cambios acaecidos en España en los últimos años, y comentados anteriormente, no nos permiten todavía afirmar que la mayoría de los cuidadores tienen la formación idónea para cuidar a su familiar), no son remunerados por su tarea (a excepción hecha de los cuidadores que en España se han amparado en el artículo 4 del capítulo II de la ley de la dependencia ${ }^{12}$, aunque tenemos que tener en cuenta que la ley de la dependencia se encuentra en estos momentos "bloqueada" debido a la situación económica y a la decisión del actual gobierno de España, con lo cual los "salarios" destinados a los cuidadores informales han descendido drásticamente) y tienen un elevado grado de compromiso hacia su trabajo, caracterizada por el afecto y una atención que no tiene límites de horarios.

En el estudio de los cuidadores informales a personas dependientes, las principales tipologías existentes están realizadas en base al cuidado de personas mayores con cierto grado de incapacidad; dichas tipologías son las que pasaremos a revisar a continuación.

\footnotetext{
${ }^{12}$ La Ley de la Dependencia fue publicada el viernes 15 de diciembre de 2006 en el Boletín Oficial del Estado (BOE) n n 299, con título Ley 39/2006.
} 
M ${ }^{a}$ Cristina de los Reyes (2001) nos remite al carácter principal o secundario que cumple el cuidador en su labor. El cuidador principal o primario generalmente está dentro del entorno familiar y asume la total responsabilidad que implica en cuidado de la persona con dependencia, por lo general este rol es desempeñado por el cónyuge o familiar femenino más próximo. A diferencia de éste el cuidador secundario no tiene la responsabilidad principal del cuidado y su labor es más bien complementaria (De los Reyes 2001; Pérez, Abanto y Labarta 1996). La cooperación entre los diferentes tipos de cuidadores puede ser fundamental para la superación de la vulnerabilidad de las personas dependientes y cuidadores informales en el contexto del hogar.

Rodríguez (1994) basa su clasificación en un análisis histórico de la relación del cuidador y la persona con dependencia, según si la convivencia del anciano con la familia que le presta cuidados existía de forma previa a la necesidad de cuidados o se vio provocada por éstos. En base a este criterio el autor establece dos tipos de cuidadores principales:

a. El cuidador tradicional. Este tipo de cuidador ha vivido siempre o hace muchos años con el/los anciano/s, por tanto no se convierte en cuidador en un momento determinado, lo hace progresivamente a medida que el/los anciano/s de su hogar envejecen y se deterioran. El tránsito gradual a la dependencia es apenas percibido por el cuidador, más aún si el mayor no presenta una dependencia funcional excesiva. Las acciones de cuidado suponen una actividad adicional al conjunto de actividades domésticas que han ido incorporándose poco a poco y generalmente no suponen conflicto. Este rol es generalmente desempeñado por hijas -solteras, viudas o separadas-, esposas o nueras. La forma progresiva en que la persona se transforma en cuidador se da dentro de las pautas tradicionales, en donde el cuidado a los mayores es una obligación moral mezclada con la afectividad que se ha creado con la convivencia, una historia de intercambios de cuidados recíprocos.

b. El cuidador moderno-urbano. Este tipo de cuidador es más común en sociedades occidentales, modernas y en familias nucleares. Este cuidador asume este papel cuando el mayor comienza a experimentar problemas de dependencia. La aparición de situaciones de enfermedad fuerza a los familiares a tomar decisiones y crear una nueva relación cuidador-cuidado como parte de una obligación familiar. El asumir el papel de 
cuidador genera conflictos y tensiones. Los conflictos surgen por la adopción de nuevos roles sociales y el cambio en las relaciones familiares. Las mujeres cuidadoras, que se ajustan a este tipo, suelen tener vida laboral, teniendo que responder a su papel social, laboral y a su nuevo papel de cuidadora, lo que suele generar tensiones por la contradicción entre los diversos roles que debe desempeñar (Robles 2003), conflicto que no se observa en los cuidadores tradicionales.

Pérez et al. (1996) reconocen diversos tipos de cuidadores: el cuidador formal, el cuidador principal, etc., pero ellos ponen el acento en la relación de parentesco que tiene el cuidador con el mayor dependiente: el cuidador cónyuge, el/los cuidador/es hijo/s (especialmente las hijas), el cuidador "otro familiar", el cuidador vecino o amigo, etc.

Tanto Pérez et al. (1996) como Cantor (Cantor en Rivera 2001) y Robles (2006) coinciden en la tipología de cuidadores de acuerdo al parentesco con el mayor dependiente, pero los dos últimos investigadores agregan que existe una selección de cuidadores ordenada jerárquicamente. La cercanía del parentesco y las expectativas culturales son factores que determinan la predictibilidad del miembro de la familia que primero se involucra en las tareas de cuidado. La esposa tiene preferencia, le siguen las hijas, los hijos, otros parientes, amigos y vecinos. Este modelo se conoce como modelo jerárquico compensatorio o jerarquía de sustitución, que define el orden del parentesco que primero otorga apoyo social al mayor dependiente y quién lo sustituye cuando está ausente, o si existe y no está disponible (Robles 2006).

Los diferentes tipos de cuidadores revisados se articulan en torno a dos aspectos: la existencia de convivencia previa o no a la dependencia del mayor, y la relación de parentesco del cuidador con el mayor dependiente. Creemos que el segundo aspecto se adapta mejor a la realidad actual de los cuidadores, ya que el primer aspecto representado en la tipología cuidador tradicional / cuidador moderno-urbano- se ve lentamente diluido, observándose que progresivamente se mezclan sus dos categorías con predominio del cuidador moderno-urbano (Rivera 2001). 
Con la finalidad de identificar de mejor forma las características que presentan los cuidadores recogemos el perfil social que $\mathbf{M}^{\mathrm{a}}$ Ángeles Durán (2006) identifica en los cuidadores españoles:

\section{Es mujer.}

2. Tiene una edad intermedia entre 50 y 60 años como promedio, resultante éste de la amalgama de la generación de cónyuges y de hijos; sin embargo, el porcentaje de cuidadores de edad avanzada es bastante elevado ${ }^{13}$.

3. No tiene empleo, y si antes lo tuvo ha tenido que abandonarlo.

4. Dedica más de 40 horas semanales al cuidado del dependiente. No es raro que esta cifra se duplique o triplique.

5. Tiene dificultades económicas.

6. Asume casi en exclusiva el cuidado del dependiente, y tiene dificultad para mantener sus relaciones sociales.

7. La atención a la persona dependiente la presta durante largos años, y su expectativa es que seguirá haciéndolo.

8. Padece patologías múltiples, especialmente cansancio, carencia y trastornos del sueño, dolores de espalda y, frecuentemente, depresión.

9. No tiene tiempo ni oportunidad de cuidarse a sí misma/o.

10. Siente miedo respecto a su futuro.

Estas características sitúan a estas personas ante un mayor riesgo de ocurrencia de consecuencias negativas para su bienestar mental y físico. De hecho, una gran cantidad de personas cuidadoras se encuentran actualmente en situaciones claramente dramáticas, en las que su rol de cuidadoras exclusivas de sus familiares dependientes les lleva a rozar o incluso traspasar los límites de su capacidad física y psicológica (Losada et al. 2007).

\footnotetext{
${ }^{13}$ Entre 65 y 74 años son aproximadamente el $20 \%$ del total de la población cuidadora y los cuidadores con más de 75 años de edad superan el 10\% del total de dicha población cuidadora." (Instituto de Mayores y Servicios Sociales 2004).
} 


\subsection{Feminización del cuidado informal}

La feminización de los cuidados es una situación común a distintas culturas de occidente. De hecho la población cuidadora europea es mayormente femenina, y a pesar del crecimiento de los sistemas formales de cuidados personales, sociales y sanitarios en los Estados de bienestar de la Unión Europea (independiente de las amplias diferencias existentes entre ellos), el papel central de los cuidados informales realizados por mujeres sigue prevaleciendo (Instituto de Mayores y Servicios Sociales 2004). La situación en Latinoamérica es similar, el cuidado recae mayoritariamente en las mujeres, pero se encuentran en mayor desventaja con respecto a sus pares europeas debido al pobre desarrollo de los sistemas formales de cuidados personales, sociales y sanitarios.

Los estudios muestran como, en el cuidado en el hogar a enfermos crónicos adultos y ancianos, son mujeres quienes asumen la atención a la persona dependiente a partir del parentesco de esposa e hija. Este hecho ha sido reiteradamente reportado en la literatura anglosajona, aunque también es documentado, desde algo más de una década en España (Durán 1999, Benería 1999, Izquierdo 2003, Carrasco 2006, Pérez Orozco 2005) y algo más recientemente en América Latina (Robles 2004). La presencia de la esposa e hija como cuidadoras de enfermos adultos y ancianos se comprende a partir del ciclo de vida familiar, es decir, los parentescos disponibles son la esposa o las hijas, que pertenecen a la misma generación de la persona cuidada o a la descendiente. La esposa es un recurso, siempre y cuando no requiera ella misma de cuidados por estar enferma. La otra opción son las hijas, que como adultas pueden asumir esta responsabilidad plenamente. Es frecuente el caso de una persona mayor mujer, potencial cuidadora, pero al requerir ser atendida se convierte en persona dependiente que es asistida por sus hijas.

Está tan afianzada aún la certeza de que el cuidado de las personas mayores es cosa de mujeres que ilustres demógrafos y gerontólogos realizan sus análisis prospectivos, utilizando como parámetro fundamental lo que se conoce como "potencial de cuidados familiares" (Instituto de Mayores y Servicios Sociales 2004). Este potencial se halla poniendo en relación el número de personas mayores de 70 años con el número de mujeres que se encuentran entre los 45 y los 69 años de edad. El cálculo se hace con 
análisis prospectivos y se concluye que de aquí al futuro muchas menos mujeres tendrán que cuidar a muchas más personas mayores, lo que pone en peligro los niveles de apoyo informal hoy existentes.

La socióloga María Ángeles Durán (1999, 2006), pionera en el estudio de los cuidados en España, señala que la estimación de la oferta potencial de cuidados presenta disparidades, porque ésta no es solo debería ser considerada como una categoría demográfica, sino que deben considerarse sus aspectos sociales y políticos. La oferta potencial de cuidados no debe estar en razón de la estructura por edad y sexo de la población, sino de la respuesta colectiva que se ofrezca al aumento de la demanda de cuidados.

Antes de analizar en profundidad la relación entre el cuidado y el género creemos necesario destacar las palabras de Badgett y Folbre (1999) quienes realizan una observación sobre los matices de significado que adquiere la palabra cuidado en la lengua inglesa, ya que no es exactamente lo mismo to care for (cuidar, atender) que to care about (tener afecto, querer); y lo mismo ocurre con to care, to take care y to take care of, que expresan diversos matices de compromiso humano del sujeto. El American Heritage Dictionary da dos definiciones bastante negativas de care como sustantivo: 1) inquietud del ánimo, como cuando se tienen grandes responsabilidades; preocupación. 2) desasosiego, sufrimiento psíquico, pena. Como verbo, sus dos primeras definiciones son, sin embargo, positivas: 1) preocuparse o interesarse por alguien o algo; 2) prestar a una persona el cuidado que necesita, estar pendiente de ella. Da la impresión, pues, de que preocuparse o interesarse por alguien es asumir una inquietud o sentir una pena. Estos significados, recientemente expuestos, señalan el carácter negativo que puede llegar a tener la acción de cuidar; por esta razón estas definiciones no parecen muy acertadas. En los textos feministas se ha empezado a utilizar el término care con un sentido más concreto: no es sólo un sentimiento, sino una responsabilidad.

\subsubsection{Género y Cuidados}

De acuerdo a la teoría de género, el comportamiento de un hombre o de una mujer está basado en las diferencias socioeconómicas y culturales entre los sexos. Estas pautas de comportamiento están íntimamente relacionadas con los conceptos acuñados en el seno 
de la sociedad respecto del altruismo para con la familia y el egoísmo individual (Badgett y Folbre 1999: 347).

Se nos cataloga como mujeres y hombres cuando nos someternos a las reglamentaciones de género. Por ello el género siempre es un hacer, aunque no un hacer por parte de un sujeto que se pueda considerar preexistente a la acción (Izquierdo 2001: 56). La interpretación de esas reglamentaciones, obedecerlas sólo parcialmente o desobedecerlas, deshace el género, lo vuelve problemático, pone en evidencia su carácter contingente. La "mujer" y el "hombre" no tienen existencia anterior a las relaciones sociales (Izquierdo 2003b: 76).

Así mismo, lo que denominamos "mujer" y "hombre" no son sujetos sometidos a relaciones desiguales, sino efectos del poder que la desigualdad social hace posibles. De entre las múltiples relaciones de poder, las económicas son fundamentales, ya que el impacto de lo económico sobre otros ámbitos y dimensiones de la vida hace que la división sexual del trabajo tenga un efecto constituyente de subjetividades.

Los sujetos se configuran en el reparto de responsabilidades, y las subjetividades que se construyen en sociedades como la nuestra remiten a un hombre provisor-protector, guerrero y a una mujer cuidadora. El reconocimiento que recibe del hombre es dependiente de su función económica política o bélica, y el de la mujer queda difuminado en la familia, o la maternidad. Esa configuración de los géneros se corresponde con la división sexual del trabajo. El espacio que se tiene está asociado al lugar que se ocupa en la división sexual del trabajo (Izquierdo 2003b).

La división sexual del trabajo construye la subjetividad femenina orientada al cuidado, a la conexión con los demás, a la disposición a satisfacer las necesidades ajenas. Esa disposición comporta que el otro, además de ser objeto de preocupación, sea instrumento de realización y de confirmación de la valía de la mujer. La organización sexista del trabajo construye también la subjetividad masculina que complementa la femenina, hace al hombre y lo hace dispuesto a realizar sus objetivos, a eliminar obstáculos para conseguirlo, a movilizarse en la defensa de los más débiles (Durán 1999; Izquierdo 2003a: 3). 
María Jesús Izquierdo (2003b) afirma que la división del trabajo crea una solidaridad forzada, un sistema de mutuas dependencias organizado jerárquicamente: dependencia y subordinación de los niños, viejos y enfermos respecto de la mujer, de la mujer respecto del hombre, del hombre ganador de pan respecto del empresario. La investigadora señala que se trata de una solidaridad forzada, porque no se dispone de vías alternativas para la cooperación, ya que los costes en los que se incurre cuando se toman vías alternativas son tan altos que se acaba volviendo al modo de vida dominante. La solidaridad, en este caso, tiene un fundamento económico, el móvil de tener en cuenta a los demás no es tanto la aceptación recíproca como el interés.

¿Cómo emerge la subjetividad en este contexto? Siguiendo a Axel Honneth (Honneth en Izquierdo 2003b), relacionamos las actitudes morales con el reconocimiento, entendiendo que cada tipo de cualidad moral se corresponde con un tipo de reconocimiento, así lo moral y lo social se dan la mano, si social es el sentimiento de aceptación recíproca, moral es garantizar conjuntamente las condiciones de nuestra integridad personal. Si contemplamos la división sexual del trabajo desde la perspectiva de "lo social", cuyo motor es el amor, y no de "lo económico", cuyo motor es el interés, podemos tomar como expresiones de amor al otro el modo en que la división sexual del trabajo orienta las interacciones sociales. Si tomamos en consideración la dimensión social de la división sexual del trabajo, suponemos que ésta genera formas especializadas de expresar ese amor, de expresar el sentimiento social. Precisamente encontraremos dos expresiones del amor, no sólo del interés, en la actividad económica: la femenina y la masculina. Y hallaremos un común denominador para ambas: el cuidado tal como es definido por Fisher y Tronto: "el tipo de actividades que abarca todo lo que hacemos para mantener, continuar, y reparar nuestro "mundo" de modo que podamos vivir en él lo mejor posible.” (Bubeck en Izquierdo 2003b).

En este contexto es subjetivada como mujer al individuo que desarrolla la tendencia a la conexión con el otro, que está abierta a sus necesidades y opiniones, atenta a sus señales, vínculo que se expresa moralmente en el cuidado de los otros. La dimensión psíquica de la feminidad suele ir acompañada de un imperativo moral por el que la mujer prioriza las necesidades de los demás frente a las propias. Realiza un compromiso con el cuidado que la pone en situación de vulnerabilidad que pueden exponerla a 
relaciones de dominación e incluso explotación (Durán 1999). La subjetivación experimentada por la mujer, al orientar su accionar con respecto a otros, la sustrae de capacidad de defender su espacio, de concebir un espacio propio, situación que puede alcanzar los extremos de despersonalizar su existencia y/o anular la diferencia entre su subjetividad y la de aquellos a los que cuida.

En relación a la subjetivación del individuo como hombre, se señala que su máxima moral es la de proveer para que la vida de otros sea posible, pero ésta es una provisión excluyente ya que si consideramos que la subjetividad del hombre se construye en términos de acción, de la capacidad de tomar, de emprender, de hacer, de poseer, de conseguir lo que se desea, este razonamiento nos lleva a la percepción del otro como rival, como obstáculo a la hora de conseguir las metas propuestas. De este modo la figura del hombre protector, proveedor de su familia se construye en la relación de competencia con otros. Y desde su posición de productor, la posición masculina entraña desapego respecto del hipotético beneficiario de su actividad. En lo psíquico, se configura una subjetividad asertiva, orientada a la consecución de objetivos, no tan dependiente de las valoraciones que los demás puedan realizar de su persona, como de hacer lo que se propone (Izquierdo 2003a).

Desde este razonamiento la división sexual del trabajo está acompañada por un proceso de disociación entre la mujer y el hombre que favorece extraños pensamientos omnipotentes. La mujer puede fantasear que la vida de los demás depende por entero de ella, y que por ende puede anticipar y satisfacer cualquier necesidad, en desmedro de las propias necesidades por estar pendiente de captar la de los otros. La base emocional de esa fantasía es una actitud que tiene aspectos amorosos, resentidos y despreciativos ante las carencias de los demás, pero no de ella. De igual modo, el hombre al creer que los otros no pueden cubrir sus necesidades ni son capaces de defender sus vidas alimenta igualmente un sentimiento de omnipotencia que, así como en el caso de la mujer puede traducirse en una mezcla de amor, resentimiento y desprecio por el otro, en su caso puede llevar a que se comporte de forma agresiva con aquellas personas que dependen de él, y en la mujer a adoptar actitudes manipuladoras y de chantaje emocional con sus “otros" (Izquierdo 2003b). 
Si nos referimos al proceso de socialización del cuidado, tanto la división sexual del trabajo como la organización de las actividades mercantiles, son antidemocráticas al disponer las actividades productivas de un modo autoritario. No favorecen el debate sobre algo tan básico como el modo en que nos organizamos para producir nuestra existencia ya que la participación social es asignada en función del sexo, y la participación en la dirección de la producción es independiente de la aportación laboral que se realiza.

Ma Ángeles Durán (1999) afirma que la socialización del cuidado, desde la condición de ciudadanía, es subvencionada por las mujeres en la medida que ellas se ocupan de los dependientes. El trabajo que realizan las mujeres representa un ahorro de recursos para los hombres, les libera de responsabilidades vitales y les permite disponer de tiempo libre para actividades de participación social. Las empresas se ahorran los costes de producción de la vida humana en aquella parte que corresponde a la población que no se halla en una situación económicamente remunerada. En cuanto al Estado, éste asume parcial y limitadamente las tareas de cuidado, aplica un "servicio social obligatorio" a las mujeres pero lo presenta como si fuese una actividad privada o propia del ámbito íntimo. Al establecerse una relación de incompatibilidad entre el trabajo doméstico y el remunerado, al dar preferencia a los hombres en el mercado de empleo, al no considerar como desempleada a toda mujer que hallándose en condiciones de trabajar no tiene trabajo remunerado, se coloca a las mujeres en posición de aportar un trabajo imprescindible para la comunidad como si fuera cuestión de voluntad individual y por tanto una actividad privada respecto de la que el Estado, supuestamente respetuoso de la autonomía de los ciudadanos, no debiera intervenir (Izquierdo 2003a: 19).

\subsubsection{Recorrido teórico del cuidado desde la mirada del género, la ética del cuidado}

El recorrido teórico que se desarrolla en relación a las actividades de cuidado visto desde la perspectiva de género ha generado múltiples interpretaciones, a continuación se exponen las líneas más destacadas.

En 1982, Carol Gilligan en su libro In a Different Voice, cuestiona el razonamiento de autores como Piaget, Kohlberg o Freud quienes sostienen, desde distintas lógicas, que el desarrollo moral de las mujeres es deficiente. Ella critica la paradoja que considera 
como cualidades innatas de la mujer el cuidado y la sensibilidad hacia las necesidades de los otros, y por otro lado que esas virtudes sean vistas como deficiencias respecto del desarrollo moral. La postura de Gilligan es que los "acuerdos" que conforman el juicio moral son distintos entre la mujer y el hombre, y no responde a que la mujer presente déficits en su desarrollo moral. La forma en que la mujer plantea los juicios morales es en términos de cuidado y responsabilidad, por ello el desarrollo de su pensamiento moral está sujeto a la comprensión de la responsabilidad en las relaciones concretas, en donde la interacción cara a cara y el contexto de la misma cobran especial relevancia. Además, destaca Gilligan, que los planteamientos de Piaget y de Kohlberg son androcentristas, ya que se refieren al desarrollo moral como un proceso único, universal, cuando el proceso que describen sólo es aplicable a los hombres (Gilligan en Izquierdo 2003b).

Joan Tronto (2002) plantea una explicación alternativa a Gilligan, desde el terreno de la ciencia política se cuestiona la pertinencia de una ética del cuidado. Primero plantea que en el razonamiento de Gilligan se encuentran mezcladas dos líneas de reflexión: sobre la diferencia y sobre el cuidado, resultando un producto que correlaciona el cuidado con la feminidad, tema que no preocupa de forma particular a Tronto, sino las consecuencias de ello, es decir su intención es salvaguardar la ética del cuidado y hacer de ésta una ética universal y no sólo la ética particular de las mujeres, que es lo que realiza Gilligan.

Al conferir Tronto a la ética del cuidado un alcance universal, proveer y recibir cuidados pasan a ser componentes universales de las relaciones humanas y no sólo exclusivas de las mujeres. Además, cree que las diferencias entre hombres y mujeres a la hora de asumir responsabilidades de cuidado no son exclusivamente atribuibles al género, como piensa Gilligan, sino que están más relacionadas con las desigualdades sociales existentes. La investigadora defiende la construcción de una teoría del cuidado en términos de teoría moral y política. La ética del cuidado es una alternativa a las teorías de la justicia vigentes ya que no se sitúa en los márgenes de la moral y la política, ni siquiera para complementarla, sino que se convierte en su fundamento mismo.

Es destacable en el razonamiento de Tronto cómo pone en evidencia el poder que subyace a las relaciones de cuidado, pero no se centra exclusivamente en las Página 84 
consecuencias que tiene para la relación el hecho de que quien cuida tenga poder sobre quien es cuidado, sino en el hecho que contar con poder permite descargar las responsabilidades de cuidado en otros. Visiones distintas del mismo fenómeno que evidencian el juego de poder implícito en las relaciones de cuidado (Izquierdo 2003b: 75).

Diemunt Elisabet Bubeck, en su libro Care, Gender and Justice (1995), presenta un enfoque que tiene la virtud de superar la contraposición entre justicia y cuidado, rescatando la importancia de los cuidados públicos. Justicia y cuidado, que se presentaron como alternativas contrapuestas, están necesariamente conectados en su argumentación. Por una parte, los principios de justicia juegan un papel importante en que sea o no aceptable una ética del cuidado, por la otra, al advertir de que el cuidado no tiene lugar únicamente en la familia sino también en la esfera pública, subraya la importancia de generalizar. La práctica del cuidado no se puede limitar al conocimiento individualizado de las necesidades, sino que requiere de principios generales, como los que provee el conocimiento científico, de hecho, suponer que los cuidados se limitan a relaciones interpersonales entre personas próximas, y tienen lugar en el ámbito privado, implica que dichos cuidados quedan al margen del desarrollo científico-técnico y por tanto su práctica no se beneficia de estos desarrollos.

La conceptualización del cuidado realizada por esta investigadora es la siguiente: "el cuidado (caring for) es la satisfacción de las necesidades de una persona por otra persona donde la interacción cara-a-cara entre cuidador y cuidado es un elemento crucial del conjunto de la actividad y donde la necesidad es de tal naturaleza que no puede ser satisfecha por la propia persona necesitada" (Bubeck 1995: 129). Esta definición transforma al cuidado en una actividad social por excelencia, reservando el concepto de cuidado para ciertos casos, donde existe precariedad y vulnerabilidad en el hecho de no ser autosuficientes. Bubeck utiliza el término servicios para diferenciar del anterior y referirse a los casos en que la persona objeto de atención podría, si quisiera, hacerse cargo de satisfacer sus necesidades. Al derivar los cuidados del principio de justicia se reconoce públicamente la carga del cuidador, haciendo patente su desigual distribución y así también la de los cuidados. La consideración privada de la actividad de cuidado implica desigualdades de origen, ya que no todos pueden acceder a ella, 
además dicha consideración la dejaría fuera del alcance de las teorías de justicia; de ahí que Bubeck plantee que esta actividad debe ser socializada y formar parte de las obligaciones de la ciudadanía. De acuerdo a los planteamientos de esta investigadora se delimitan las actividades de las mujeres como trabajo de cuidado y las de los hombres como trabajo de provisión y de lucha. Es así como las mujeres, al verse influidas por una ética del cuidado, trasladan su interés personal en los demás, lo que les expone a ser explotadas ya que pierden de vista sus intereses y necesidades. La desatención a sí mismas lleva a las mujeres a realizar actividades de servicios más que de cuidados, debido a que a quien dirige sus cuidados son individuos potencialmente autosuficientes. Esto se refleja claramente en la labor que la mujer realiza a la hora de dar respuesta a las necesidades de su marido y de sus hijos, dando cobertura incluso la parte que corresponde al padre con respecto a los hijos.

Por otro lado, el cuidado genera un fuerte sentimiento de poder y realización en la mujer. Ese doble componente del cuidado explica que las mujeres adopten una actitud contradictoria frente al cuidado, por una parte se sienten invadidas y desgastadas y al mismo tiempo no pueden tolerar que aquellos a quienes cuidan puedan prescindir de sus atenciones.

Bubeck va más allá de la subordinación de las mujeres, llegando a establecer una conexión entre el cuidado y la explotación de las mujeres como consecuencia de la ética del cuidado. La orientación ética mueve a las mujeres a cubrir las necesidades ajenas hasta el punto de quedar en situación de empobrecimiento y privación, condiciones que facilitan su sometimiento.

A modo de crítica, se le reprocha que sus argumentos tienen un sesgo ginecocéntrico, ya que utiliza distinta lógica cuando habla de las mujeres que cuando habla de los hombres. Siguiendo la lógica de la investigadora, si lo que mueve a las mujeres es la ética del cuidado ¿qué es lo que mueve a los hombres?, si consideramos que ellos construyen su subjetividad desde el rol de proveedores y luchadores, podríamos suponer que lo que les mueve es una ética de la provisión y de la defensa, y por ende también podemos afirmar que ellos se dejan someter al mecanismo de la explotación debido a la ética que les mueve, llegando a proveer y defender a quien no lo necesita, de modo similar a como la mujer confunde servicios con cuidados (Izquierdo 2003b). 
En 2002, la investigadora Joan Tronto consolida su postura frente al cuidado, respondiendo a la propuesta que Jody Heymann realiza. Heymann (2002), feminista que aboga por dar mayor valor a los cuidados, plantea que si el tiempo fuera organizado alrededor del cuidado de forma más racional, entonces más niños tendrían mejores posibilidades de éxito en la escuela, los parientes más ancianos recibirían atención adecuada, el trabajo y la productividad mejoraría, y la sociedad sería mejor. Tronto observa una falla fundamental en su argumento: el cuidar continuará siendo una actividad subordinada y subvalorada en el marco de una economía competitiva. En esta sociedad en donde se privilegia al productor, cuidar bien dentro de la familia más que algo positivo se convierte en un enemigo de la igualdad de oportunidades.

No cabe duda de que lo que Heymann ha demostrado es que, entre otros problemas y cargas que se enfrentan, los menos favorecidos de nuestra sociedad también tienen menos recursos a su disposición para satisfacer sus necesidades de cuidado. A la larga, la única forma de remediar esta situación es reconocer la necesidad universal de cuidados y no limitarla a la preocupación por los más jóvenes, ancianos, y enfermos. Todo el mundo necesita y utiliza el cuidado al igual que todo el mundo presta atención. Tronto hace hincapié en que el cambio sólo puede ocurrir en una estructura social diferente a la predominante, que ya no requiera que las personas compitan entre sí para hacer frente a sus necesidades básicas de manera adecuada, una estructura social que conciba la atención no como un bien privado, sino como un valor público y amplio (Tronto 2002). Además, la investigadora afirma que, paradojalmente, los cuidados cuentan con un alto valor social, ya que el poder social de un grupo está determinado en ver si es capaz de forzar a otros para llevar a cabo su labor de cuidado, la distribución del trabajo del cuidado refleja este poder. La privatización del cuidado reproductivo, que ha acompañado cada vez más a la naturaleza pública del trabajo productivo, también refleja el poder social de los diferentes grupos. La gente poderosa puede evadir el trabajo del cuidado en otras personas: de hombres a mujeres, de clases altas a la clase baja. El trabajo del cuidado es a menudo exigente, inflexible e improductivo. Las personas que hacen este trabajo reconocen su valor intrínseco, pero no encaja bien en una sociedad que valora la innovación y la acumulación de la riqueza (Tronto 2002). 


\subsubsection{Visión político-económica del cuidado y el género}

Tradicionalmente, la economía ha definido su objeto de estudio dentro de unas fronteras estrechas y excluyentes: sólo se considera "económico" lo que tiene una dimensión mercantil. En consecuencia, todos los procesos que tienen lugar al margen del mercado, por definición, quedarán excluidos del campo de estudio de la disciplina económica. Particularmente grave es la exclusión de los distintos trabajos que no se realizan bajo relaciones capitalistas mercantiles, pero que son absolutamente necesarios para que la vida continúe e incluso son indispensables para que el mercado pueda funcionar. Nos referimos aquí especialmente a los trabajos no remunerados que desarrollan principalmente las mujeres en el hogar (en específico los cuidados). La economía se define falsamente como "autónoma" sin aceptar ni reconocer que descansa y se apoya en otros sectores o actividades que caen fuera de la órbita mercantil (Elson, Budlender y Sharp; Carrasco y Mayordomo; Pichio en Carrasco 2006a).

La resolución histórica de los cuidados está determinada por la división sexual que se realiza del trabajo. Como anteriormente se mencionó, se construyen dos espacios socioeconómicos escindidos, en donde uno predomina por sobre el otro, haciéndolo invisible. El espacio de la reproducción social -el espacio privado- resuelve las tensiones estructurales y readecúa las distorsiones que se pueden generar en los procesos de satisfacción de las necesidades humanas, como consecuencia de poner en el centro las necesidades de acumulación generadas por el espacio de la producción -el espacio público-. Los mercados -y los agentes (masculinos) que lo protagonizanprecisan crear el imaginario social de que son autosuficientes, porque de dicho imaginario derivan en gran medida su legitimidad para situarse en el epicentro. Para construir esta imagen han de ocultar el trabajo de cuidados del que se nutren (Pérez Orozco 2005: 209). Asimismo, al analizar la realidad de las mujeres como colectivo, podemos afirmar que éstas no se encuentran totalmente ausentes de la esfera pública, ellas han participado del mercado laboral y muchas fueron independientes del salario masculino. Por ello, la investigadora Amaia Pérez Orozco (2005) señala que su presencia es ausente ya que el modelo social imperante, que escinde los espacios públicos y privados, hace invisible la situación de esas mujeres que atravesaban las fronteras y realizaban trabajos asalariados. 
Nuevas miradas en el género han ahondado en la temática de las actividades desarrolladas en el hogar, destacando que éstas no son comparables con las de mercado, distinguiendo las cualificaciones y capacidades específicas de las mujeres ejercidas en el interior del hogar (no reconocidas oficialmente) y formas de organizar y estructurar la vida y el trabajo que otorgan a las mujeres una identidad distinta a la masculina (Borderías y Carrasco en Carrasco 2006a). En definitiva, se trata de un trabajo diferente, cuyo objetivo es el cuidado de la vida y el bienestar de las personas del hogar y no el logro de beneficios, como es en su gran mayoría el trabajo de mercado. Desde esta nueva perspectiva, las mujeres no son personas secundarias y dependientes sino personas activas, actoras de su propia historia, creadoras de culturas y valores del trabajo distintos a los del modelo masculino. Las ideas anteriores tomaron cuerpo en el llamado "esquema producción-reproducción", que simboliza la existencia de dos trabajos, con características propias aunque interrelacionados, que participan con un grado equiparable de importancia en la reproducción del sistema global. Desde esta perspectiva se planteará, en lo fundamental, conceder a la organización social de la reproducción humana la misma importancia conceptual que a la organización de la producción asalariada. Como conceptos teóricos, ambas esferas coexisten en el mismo nivel de abstracción: la existencia de una requiere de la existencia de la otra. De esta manera, se está rechazando la idea de que la esfera de la reproducción es subsidiaria de la de producción y se entiende el sistema como una estructura en la cual ambas esferas aparecen articuladas entre sí, sin que exista necesariamente dependencia de una respecto de la otra (Humphries y Rubery, Carrasco, Picchio en Carrasco 2006a). Con ello se está produciendo una ruptura importante: la identificación del trabajo doméstico se está alejando del modelo masculino mercantil dominante y se está reconociendo por sus características propias.

La revisión del recorrido conceptual nos permite visualizar el llamado marco de análisis producción-reproducción para señalar la existencia de dos tipos de trabajos; dicho marco fue útil y clarificador en su momento y permitió hacer visible el trabajo familiar doméstico, pero no permite escapar de la dimensión mercantil patriarcal. De hecho, la actividad con definición y valoración propia continuaba siendo la producción mercantil y la otra, la reproducción, sólo podía existir en la medida que se reflejaba en la anterior. La necesidad de romper con dicho esquema exige trascender la dicotomía producción- 
reproducción y entender los procesos de producción y trabajo como un único proceso más complejo cuyo objetivo es la satisfacción de las necesidades humanas y los niveles de vida. Se plantea que, de manera distinta, los distintos trabajos participan en los procesos de mantenimiento de la vida humana (Carrasco 2006a: 41).

Desde la economía feminista -o de una parte de ella- se insiste en la urgente necesidad de incorporar en los modelos macroeconómicos -así como en el diseño e implementación de políticas públicas- el trabajo familiar doméstico y el trabajo de cuidados, ya que sin él, no sólo las personas, sino ni siquiera el mercado podrían subsistir. Si creemos que el objetivo social, económico y político central son las personas, su calidad de vida y bienestar, entonces el "cuidado" es una parte constitutiva fundamental. También desde la óptica económica, es importante destacar que la asignación de responsabilidades de cuidado del dependiente, marcada fuertemente por el género, no supone necesariamente asignación de tiempo o ingresos para desarrollarse. Una vez que la responsabilidad del cuidado es asumida, no disminuyen por falta de recursos para satisfacerlas, en la práctica, hace que la gente pobre que asume dicho compromiso restrinja sus posibilidades de conseguir mejoras en su situación económica vía mercado laboral; esto lleva a que Susan Himmelweit afirme que cuanto más desigual son los ingresos, y teniendo en cuenta la asignación de género de la responsabilidad de cuidado, mayor es la desigualdad entre hombres y mujeres (Himmelweit 2008: 3).

El vigente interés político en el tema de los cuidados, al menos en economías desarrolladas, se plantea como respuesta tardía a la creciente participación de la mujer en la fuerza laboral, situación que rompe con el modelo macho "ganador del pan" (breadwinner)/ mujer cuidadora. No obstante, la idea original de esta dicotomía tiene un fuerte arraigo en el discurso público y efectos importantes en la política. El desarrollo de una política social para los cuidados, en función de su contenido específico como de su aplicación, puede exacerbar o aminorar las desigualdades sociales y de género.

Himmelweit señala que una estrategia política-económica para el cuidado podría contrarrestar el creciente énfasis mundial en el aumento el crecimiento y el empleo, ya que aquellos que asumen las responsabilidades de cuidado, a pesar de las presiones que reciban desde el mercado, pagarán un precio mayor por realizar esta labor y pueden 
tener menos influencia en el ámbito de las decisiones políticas que quienes sí responden a las normas sociales y económicas vigentes (Himmelweit 2008: 12).

Desde las arenas políticas surge el interés en desarrollar presupuestos con sensibilidad de género, planteándose como una poderosa herramienta política que tendría amplias repercusiones, no sólo en términos de equidad social y económica sino también en la consecución de determinados estándares de vida. Desde ésta última perspectiva es posible hacer visibles los trabajos de cuidados como elemento central del desarrollo humano, yendo mucho más allá de la idea de igualdad de oportunidades, ya que permite plantear las responsabilidades reproductivas como tema social y político de primer orden, y no como un aspecto privado (de responsabilidad femenina); este asunto requiere de la negociación política explícita entre instituciones públicas y privadas. La forma en que finalmente se diseñen e implementen dichas políticas públicas, y cómo se otorguen las transferencias monetarias, estará configurando una organización específica de distribución del tiempo y del trabajo entre lo mercantil y lo doméstico. La importancia de este enfoque es poner a la administración pública en relación directa con los estándares de vida de la población, destacando el valor del trabajo de cuidados. La tensión histórica entre el beneficio privado y el bienestar de la población exige la participación del sector público para la organización y redistribución de los recursos, en función de los estándares de calidad de vida generalizados (Carrasco 2006b: 22).

El cuidado también implica afectos, relaciones, soporte emocional, etc., aspectos necesarios para el desarrollo humano y que, sin embargo, han ido quedando ocultos en la medida que el trabajo doméstico ha comenzado a visibilizarse. Entonces, también se trata de insistir en la necesidad de hacer emerger estas dimensiones intangibles que fácilmente escapan a los análisis y estadísticas tradicionales (Carrasco 2006a: 41).

\subsubsection{Ciudadanía, Familia y Desfamiliarización}

La división público-privado tiene su correlato microsocial en la familia nuclear tradicional, la familia fordista. Un modelo familiar ${ }^{14}$ que no implica sólo la distribución

\footnotetext{
${ }^{14}$ Se le denomina modelo a este tipo de familia, porque de forma pura no se ha manifestado más que en ciertos grupos sociales privilegiados (familias blancas, burguesas y heterosexuales), pero sí ha funcionado
}

Página $\mid 91$ 
de tareas por géneros, sino que además la construcción diferenciada de subjetividades. Es así como a las mujeres se les socializa en cuidar al resto y a los hombres en el ser cuidados. Así también la heterosexualidad en el matrimonio que conforma esa familia nuclear, es un elemento central del sistema público-privado que naturaliza la división social del trabajo; y así como arriba indicáramos, se construye una subjetividad femenina que mantiene un sistema económico basado en el constante drenaje de recursos desde las mujeres a los hombres; este drenaje se da entre otras vías, a través de la realización gratuita del trabajo de cuidados.

La responsabilidad para con los miembros de la familia es un acto de obediencia que se fundamenta en el sentimiento de solidaridad, entendida ésta como participar de una suerte común. Se requiere todo un aparato de ingeniería social para construir la moderna familia así como la concepción actual de la obligación familiar. También se requiere para construir la noción de individuo y de libertad individual. Se concibe la sociedad como un agregado de individuos libres e iguales, y a la vez se atribuye a la familia una consistencia orgánica, donde las funciones no son cuestión de opción libre, sino responsabilidad moral, y por si acaso también obligación legal. La tensión entre la independencia y la dependencia de sus miembros se soporta concibiendo una ciudadanía hecha a base de exclusiones, todas ellas relacionadas con distintas dimensiones del cuidado. Sus implícitos constitucionales son: un hombre provisor y protector, y una mujer cuidadora y nutriz, objeto de protección. Izquierdo afirma que como norma social ha estado públicamente apoyada y promovida: "las condiciones económicas y jurídicas favorecían la construcción del hombre como cabeza de familia" (Izquierdo 1998: 25). El cuidado se fundamenta en la división sexual del trabajo, y su existencia es la condición que sustenta al ciudadano concebido como individuo (Izquierdo 2003a: 6). Este modelo de ciudadanía es impensable si no lleva el añadido de este tipo de familia. El individuo autónomo, productivo, requiere de una infraestructura doméstica que facilita la ficción. Izquierdo señala que el pacto constitucional, mito con el que se legitiman las democracias modernas, supone un punto cero en que los ciudadanos se dotan de un marco para establecer sus relaciones, repartir responsabilidades, enunciar derechos y libertades. El ciudadano-individuo lo es a expensas de disponer de una infraestructura

como norma social a la que se debe tender y con respecto a la cual se establece la desviación del resto (Pérez Orozco 2005: 212). 
logística y de cuidado, responsabilidad que se asigna al complemento del ciudadano, la mujer, a la que corresponde dotar de infraestructura al hombre para que éste pueda ejercer sus funciones de ciudadano. Si la mujer no se ajusta a ese papel, si pretende ser ciudadana-individuo se rompen las bases del pacto constitucional, es decir, la relación de complementariedad por la que el hombre se funda como ciudadano activo, provisor y defensor y la mujer como cuidadora y nutriz (Izquierdo 2003a: 6).

Se evidencia que esta concepción actual de ciudadanía que responsabiliza a las familias, específicamente a las mujeres, de los costes de producción de la vida humana, genera una tensión que se radica entre la obligación de hacerse cargo de los dependientes por tener con ellos vínculos de parentesco y la libertad actual de conformar una familia, lo que se traduce en un reparto de cargas desigual y en un estímulo a que la familia desaparezca.

La extrapolación de estas reflexiones al ámbito de la ordenación del Estado, nos permite observar que el modelo fordista de familia y la división sexual del trabajo son base común para la estructuración de los distintos Estados de bienestar. Esto se concreta en, al menos, cuatro aspectos: la ideología familista subyacente; la identificación de la familia nuclear como sujeto de derechos (que conlleva la distinción entre derechos directos y derivados); el reconocimiento único del empleo como fuente de derechos (tanto de sistemas contributivos como categoriales); y el alcance de las prestaciones, que, por un lado, cubren los riesgos que típicamente sufren los hombres, sobretodo la falta de empleo, y, por otro, supone la dependencia no reconocida en la provisión de servicios de bienestar por parte de las mujeres de forma no remunerada o mal remunerada. La Investigadora Amaia Pérez Orozco cita a Lewis (1992) y Lewis y Ostner (1994), quienes establecen tres niveles de fortaleza de dicho modelo de reparto de roles y creación de subjetividades por géneros: los países con un fuerte modelo "hombre ganador del pan" (por ejemplo Gran Bretaña, Alemania, Holanda, España), los que adoptan un modelo moderado (por ejemplo Francia) y aquellos con un modelo débil (Suecia y Dinamarca) (Pérez Orozco 2005). 
Precisamente, una de las críticas realizadas desde el feminismo a la tipología sobre los Estados de bienestar ${ }^{15}$, realizada por Esping-Andersen (1993), es que en su clasificación, en un primer momento, se ignora el rol que cumplen los hogares y las redes sociales en la provisión de recursos. Es ahí donde cobra especial relevancia el concepto de desfamiliarización, que alude al grado en que una persona puede renunciar a cuidar -puede ejercer su derecho a no cuidar-, porque sabe que esa atención será proporcionada por otros; concepto que legitima el derecho a "no cuidar" y que esto no implique poner en riesgo a los necesitados de cuidados.

El derecho social de ser cuidados por estar en situación de dependencia es hoy en día una realidad de pocas sociedades. El Estado mantiene una posición subsidiaria ante el rol que debe cumplir la familia, se limita a sustituir al tejido familiar cuando éste no está presente. En el caso de que sí esté, no lo complementa ni apoya de forma suficiente, llegando incluso a imponer su responsabilidad en el cuidado. La inexistencia de un derecho a no ser cuidada/o implica la simultánea negación del derecho a no cuidar a quiénes están socialmente responsabilizadas/os de dicha atención, es decir, las unidades domésticas y dentro de ellas, las mujeres. Por tanto, el bajo grado de desfamiliarización accesible implica el poco o nulo desarrollo del derecho a no cuidar. Además el derecho a cuidar, como anteriormente señaláramos, está determinado porque las necesidades de cuidado y la capacidad de prestarlos se distribuye de forma desigual en la sociedad, haciendo hincapié en la capacidad económica para comprar servicios de cuidados lo que determinaría ejercer de forma individual el derecho a no cuidar (Himmelweit 2008).

\subsubsection{Crisis de los cuidados}

Múltiples factores están desestabilizando este modelo previo de organización socioeconómica, que estamos visualizando en torno a la cobertura de la necesidad de cuidados:

- Los cambios en las propias necesidades de cuidado.

- Los cambios en las unidades de decisión económica y de gestión de la vida cotidiana.

- Los cambios en los roles de las mujeres (Pérez Orozco 2005: 216).

\footnotetext{
${ }^{15} \mathrm{El}$ tema de los distintos Estados de bienestar es tratado en el capítulo II.
} 
El reconocimiento de la crisis actual de cuidados nos permite observar una estrategia redistributiva del trabajo de cuidados en el seno del colectivo femenino. La satisfacción de las necesidades de cuidados se organiza en torno a redes de mujeres, entre las cuales se producen trasvases de cuidados que se apoyan sobre distintos ejes de categorización. Dichos trasvases se organizan en torno a tres ejes: por una parte, las estrategias individuales de conciliación, que a su vez suelen apoyarse en al menos una de las otras vías de traslación de responsabilidad, la redistribución intergeneracional, y la redistribución por eje de clases y etnia ligada a la transferencia de ciertos cuidados a los mercados (Pérez Orozco 2005:234).

En la redistribución generacional la responsabilidad de cuidar se reorganiza entre la familia extensa, siguiendo una lógica de consanguineidad y género (Tobío 2002: 22). Este mecanismo resalta la continuidad de los roles de género, haciendo que sean mayoritariamente las mujeres quienes adquieran la responsabilidad, sobre todo las mujeres con un vínculo de sangre con otras mujeres. En esta organización del trabajo destaca la inexistencia de límites al trabajo no remunerado, tanto en el sentido de descansos, vacaciones, etc., como en lo relativo al ciclo vital, no existe jubilación posible del trabajo de cuidados no remunerado (Pérez Orozco 2005: 237). Además, puede suceder a la vez, dentro del colectivo femenino, el fenómeno de la redistribución en base a ejes de estratificación social como la clase y la etnia. Ello está directamente vinculado a la compra de servicios en el mercado, tanto a través de empresas (y del tercer sector) como mediante la contratación directa de servicios domésticos. Esta redistribución supone que el reparto desigual del trabajo de cuidados está pasando, en parte, de ser intra-familiar a ser inter-familiar, manteniéndose la relevancia del género, aunque estructurado por otros ejes.

\subsubsection{Jerarquía de Sustitución}

Asumimos que el rol de cuidador está bien definido, aunque éste es, generalmente, invisible porque se subsume en los roles de parentesco, es decir, la mujer en su calidad de madre, hija o esposa adquiere el rol de cuidadora pero se continúan valorando las acciones de cuidado como parte de las responsabilidades de su rol de parentesco. No se reconoce la adjudicación de un nuevo y diferente rol, sino se construye como una ampliación del de parentesco. Además este rol es permanente, una vez que una hija o 
esposa asume el rol de cuidadora no hay posibilidades de abandonarlo o que alguien la substituya, aunque sea otra mujer, y es que este rol se designa sin posibilidades de negociación (Robles 2006b). A las mujeres casi siempre les resulta inevitable asumir la responsabilidad del cuidado del familiar mayor dependiente, que en primer lugar es para las esposas de los hombres que tienen una situación de dependencia; en segundo lugar, suele ser inevitable para una hija soltera; después vendrá la hija divorciada; luego la hija más cercana al domicilio o la más generosa. Si no se da el caso de la existencia de estas mujeres "favoritas" para el puesto, o si, por alguna circunstancia extraña, no se hacen cargo de las tareas de cuidados, vendría el puesto de las nueras, las hermanas, las vecinas, las amigas, etc.

Victor Cicirelli (1990) propone analizar los parentescos que se involucran en el cuidado a través de un modelo ideal: la Jerarquía de la Sustitución (JS). Esta graduación define el orden del parentesco que primero otorga apoyo social al anciano y quién lo sustituye en caso de ausencia, no existencia o no disponibilidad. El orden es $1^{\circ}$ cónyuge, $2^{\circ}$ hijos, $3^{\circ}$ otros parientes, $4^{\circ}$ amigos o vecinos. Es necesario destacar que esta clasificación no contempla la dimensión de género y que la cercanía del parentesco y las expectativas culturales son factores que determinan la predictibilidad del parentesco (Cicirelli 1990).

La antropóloga Leticia Robles retoma el concepto de la JS y, en base a sus investigaciones realizadas en México, confirma que la JS del cuidado está marcada por el género, tanto por el número de mujeres que se dedican a ella, como porque culturalmente se le considera una tarea femenina (Robles 2006a: 250).

Robles evidencia que la literatura de corte feminista da explicaciones macrosociales a esta situación, pero no consideran las interpretaciones que los propios actores dan a este fenómeno. Para ello, investiga, desde la perspectiva del mayor dependiente, quiénes son los actores que deben cumplir con la obligación familiar, así como el razonamiento que sustenta la preferencia por uno de sus miembros. En definitiva, trata de dar cuenta de cómo se construye el proceso de feminización de la obligación familiar desde la perspectiva microsocial.

Uno de los resultados más relevantes de la investigación de Leticia Robles es que las diferencias más relevantes en la jerarquía de sustitución se dan en los espacios urbanos 
y los rurales. La JS, tanto rural como urbana, muestra cómo, desde la perspectiva de los ancianos, la familia continúa siendo la responsable del cuidado y la atención a los más viejos. La injerencia de otras fuentes de la red social, más allá de la familia, son colocados en un segundo término e incluso los recursos formales de cuidado son excluidos como parte de sus expectativas. Este es un punto que reiteradamente se ha señalado en la literatura para poblaciones hispanas y que aquí se confirma de nuevo.

El primer familiar en esta jerarquía, los cónyuges como cuidadores, se justifican en áreas rurales por dos motivos: la convivencia y la obligación conyugal. Generalmente las expectativas se centran más en la esposa que en el esposo, ya que la mujer es más longeva y el cuidado se relaciona con su feminidad (Robles 2006a: 260), pero el papel protagonista de los hijos desplaza a los cónyuges en el campo de las expectativas de los ancianos al colocar a estos como el principal actor social de quien se espera el cuidado durante la vejez.

La preferencia de los mayores por algún hijo que les cuide tiene una marcada connotación de género, el hijo/a es de acuerdo al sexo del anciano, y esto ocurre tanto en entornos rurales como urbanos. La justificación de ello es que existe un rechazo a que un hijo/a de sexo contrario realice la labor de cuidado por el tema del control social del cuerpo. Ante la imposibilidad de contar con un cuidador del mismo sexo, los ancianos resignifican la participación del cuidador (con frases como: "es un buen hijo"), mostrando una visión asexuada del cuidado y aludiendo al principio de reciprocidad principalmente en zonas rurales-.

La visión de género tiene un papel central en las construcciones sobre los actores sociales del cuidado. Sin lugar a dudas, la mujer es de quien se espera recibir cuidado durante la vejez, especialmente de las hijas. Esto ocurre tanto en zonas urbanas como rurales, y la imagen de la hija como cuidadora ideal es debido a que ella cuenta con las siguientes características:

- Posee virtudes femeninas, paciencia, empatía, disponibilidad, amor al otro. En contraposición con las características que se le atributen al hombre como menos pacientes, menos empáticos, menos disponibles, menos amorosos. Los rasgos distintivos de su masculinidad son otros y no apropiados para el cuidado.

Página $\mid 97$ 
- Ubicación en la división social del trabajo; la hija en su rol de ama de casa, localizada en el espacio del hogar, está más capacitada para ser cuidadora. El hijo no está en casa todo el tiempo, sus conocimientos fundamentales lo habilitan para trabajar fuera del hogar, y el varón no desea hacer quehaceres femeninos. El cuidado no es parte del comportamiento esperado en un hombre.

- Calidad de su cuidado; la hija desarrolla un cuidado mejor y más completo, el varón es inútil en esas labores.

Los mayores, entrevistados por Robles, conceptualizan el cuidado como una tarea femenina, ya que se considera que este es un trabajo propio y específico de las mujeres. Pero además, las mujeres son los actores sociales idóneos para el cuidado por su ubicación en la división sexual del trabajo, ya que las mujeres poseen de forma natural los rasgos esenciales para el cuidado, de ahí su aptitud para desempeñarlo.

Asimismo, estos ancianos coinciden en tres elementos a la hora de definir sus expectativas de cuidado:

- Otorgan un papel central al cuidado

- Priorizan la obligación filial por sobre la obligación conyugal.

- Dan al cuidador ideal rostro femenino (Robles 2006a: 277).

Esta investigadora analiza los procesos por los cuales se da la feminización de la obligación filial y concluye que la obligación filial no es un asunto de todos los hijos, sino de las hijas, y que es necesario considerar esta dimensión en los análisis microsociales de este fenómeno.

La imagen de la hija, como cuidador ideal dentro del imaginario de estos mayores, puede llegar a convertirse en una fuente seria de tensiones sociales en el futuro inmediato, principalmente por la creciente incorporación de la mujer al mercado laboral y porque las generaciones más jóvenes organizan sus vidas de forma distinta (familias más pequeñas, viviendas más pequeñas, etc.). Además, el conflicto podría generarse 
también a nivel de políticas sociales, ya que rigen en su diseño concepciones conservadoras del rol de la mujer para sus familias.

El solo hecho que las mujeres se incorporen al mercado laboral, salgan del hogar, hace que las hijas pierdan casi todos los rasgos que los mayores atribuyen a una hija cuidadora (Robles 2006a: 281). La incorporación de la mujer como trabajadora remunerada genera resistencias en diferentes actores:

- Desde la perspectiva de los mayores y sus pares, la hija no cumple totalmente con su obligación filial porque no es una cuidadora de tiempo completo como marca el imaginario colectivo de éstos.

- Los encargados de aplicar las políticas sociales y programas para mayores verán esta conducta como una negligencia filial, pudiendo llegar a calificarle de abandono. Esta visión puede generar exclusiones de los posibles beneficios de protección social que pudieran generarse para la atención de la vejez.

\subsection{Cuidado Como Trabajo}

\subsubsection{EI Trabajo Doméstico}

Dentro de la investigación desarrollada por la economía feminista ha cobrado un rol importante el tema del trabajo de las mujeres. Tradicionalmente, la economía se ha definido como un sistema cerrado con respecto a su objeto de estudio, el mundo público mercantil, y con fronteras muy estrechas de análisis, donde se ha identificado con el empleo. Sin embargo, desde la economía feminista se plantea que el sistema socioeconómico necesita para su funcionamiento y continuidad de diversas actividades que, en general se denominan trabajos, pero que algunos de ellos caen fuera de los límites señalados por la economía. De estos trabajos excluidos los más relevantes por su contenido y por el tiempo que implican su realización son el trabajo doméstico y de cuidados. Visibilizar estas actividades y destacar su relevancia social ha permitido realizar un análisis amplio, realista y acucioso de los sistemas socioeconómicos que sustentan nuestras sociedades y brindan la oportunidad de valorar los trabajos y la producción doméstica (Durán 1999; Carrasco 2006b: 16). 
Se comienzan a destacar las características propias de las actividades realizadas en el hogar, no comparables con las de mercado, reconociendo cualificaciones y capacidades específicas de las mujeres desarrolladas en el interior del hogar (no reconocidas oficialmente) y formas de organizar y estructurar la vida y el trabajo que conforman en las mujeres una identidad distinta a la masculina. En suma, se trata de un trabajo diferente, cuyo objetivo es el cuidado de la vida y el bienestar de las personas del hogar y no el logro de beneficios, como es en su gran mayoría el trabajo de mercado. Desde esta nueva perspectiva, las mujeres no son consideradas personas secundarias y dependientes sino personas activas, actoras de su propia historia, creadoras de culturas y valores del trabajo distintos a los del modelo masculino.

En este contexto, el análisis cada vez más profundo del contenido de las actividades desarrolladas en el hogar desembocó en plantear los aspectos subjetivos de las necesidades humanas y el importante papel que jugaba el "trabajo de cuidados" (Durán 1999: 260). De esta manera, el "cuidado" (traducción imprecisa del inglés “care") comenzó a emerger como un aspecto central del trabajo doméstico, como la dimensión fundamental que lo aleja del trabajo asalariado. El "trabajo doméstico" -que incluye las actividades de cuidados- se presenta en esta nueva perspectiva no como un conjunto de tareas que se pueden catalogar, sino más bien como un conjunto de necesidades que hay que satisfacer (Carrasco 2006a: 46).

La identificación de los aspectos subjetivos del trabajo doméstico -que tienen que ver directamente con los cuidados, la calidad de vida y el bienestar- implica la necesidad de valorar esta actividad por sí misma, de reconocerla como el trabajo fundamental para que la vida continúe. En consecuencia, el trabajo doméstico debiera servir de referente y no el trabajo realizado en el mercado. Esto representó un cambio de paradigma: el eje central de la sociedad y, por tanto, del análisis debería ser la actividad compleja realizada en el hogar, que permite a las personas crecer, desarrollarse y mantenerse como tales.

El cuidado requiere de tareas concretas como lavar, limpiar, comprar, atender personas, etc., pero la relación no necesariamente se realiza al ejecutar una tarea. La relación es un plus que, cuando existe, queda incorporado en la realización de la actividad. Se pueden ejecutar las tareas de infinitas formas, estableciendo distintos tipos de relación, que 
influirá directamente en el resultado de la acción, en la calidad o característica del cuidado (Bosch en Carrasco 2006a: 46).

Leticia Robles afirma que el cuidado de una persona dependiente o un mayor es un trabajo, por tratarse de una acción social cuyo fin consiste en proporcionar los medios de subsistencia al dependiente y que, a semejanza de cualquier otro trabajo, transforma recursos materiales y simbólicos que implican gasto de tiempo y energía (Robles 2003a). Incluso va más lejos y asevera que el cuidado a los dependientes no debería ser contado como un elemento más del trabajo doméstico, sino como un trabajo diferente e independiente de éste. Ella considera que si el trabajo doméstico incluye una multiplicidad de acciones de variada índole que dan paso a un trabajo en sí mismo, igual acontece con el cuidado de los dependientes, de hecho, el cuidado responde específicamente a las necesidades de los dependientes, a diferencia del trabajo doméstico que resuelve las necesidades de todos los integrantes autónomos e independientes del hogar, de ahí que afirme que constituye un trabajo diferente al doméstico.

\subsubsection{El Trabajo de Cuidar}

El trabajo de cuidar es entendido como un tipo de actividad que exige una atención personal, de unos servicios que normalmente se prestan cara a cara, en una relación de confianza mutua, y cuyos destinatarios a menudo no pueden expresar con claridad sus necesidades, como los niños pequeños, los enfermos o los ancianos. De acuerdo a la revisión que hemos realizado este trabajo, el cuidar está fuertemente determinado por las normas de género que fijan la división sexual del trabajo.

\subsubsection{Diferencias sociales entre los sexos y normas del trabajo de cuidados}

Tradicionalmente, los teóricos neoclásicos a la hora de analizar el trabajo de cuidar han establecido una línea divisoria rigurosa entre la esfera del altruismo (la familia) y la del interés personal (el mercado), en cambio, el análisis feminista sostiene que este tipo de trabajo en la familia es a veces impuesto y no altruista. Con independencia de la amplitud de las diferencias innatas que pueda haber entre hombres y mujeres, las normas sociales ejercen una fuerte presión para que se asuman funciones diferentes según el sexo, concretamente, asignan a las mujeres más responsabilidad en lo tocante 
al cuidado de las personas dependientes, un cometido que casi literalmente exige altruismo.

Joan Tronto, autora feminista, señala que privar a las personas de oportunidades reales de defender su propio interés puede incitarlas a vivir a través de otros, utilizando la actividad de cuidar como sustituto de una gratificación más personal (Tronto en Badgett y Folbre 1999: 354). Además, existen pactos culturales que determinan que quienes se dedican a cuidar de los demás son muchas veces rehenes de su propia actividad. La mayoría de las formas de negociación se basan en la amenaza de negar algo valioso y por este motivo, las personas que se ocupan de los demás actúan casi por definición por unos motivos intrínsecos que les impiden denegar la atención que prestan. Ante este escenario, se presenta como solución el que las mujeres deben tener exactamente los mismos derechos individuales que los hombres, pero ello deja sin resolver el problema de cómo definir esos derechos y de cómo equilibrarlos con las responsabilidades sociales. Las mujeres han sido siempre especialmente sensibles a las tensiones entre solidaridad e individualismo. Un pacto cultural que se limite a que las mujeres puedan actuar más como los hombres, que redefina la feminidad en términos más masculinos y egoístas, es menos atractivo que un pacto que redefina la masculinidad en términos más femeninos y solidarios, ahora bien, un pacto de esas características resulta muy difícil de negociar. Incluso, se están poniendo en tela de juicio las normas sociales tradicionales de la masculinidad proponiendo que el trabajo de cuidar debe ser tan masculino como femenino, debido a que influyentes análisis sobre la discriminación profesional basada en el sexo llegan a la conclusión de que es necesario repudiar los estereotipos (Anker en Badgett y Folbre 1999), pero esto es un proceso mucho más complicado de lo que parece a primera vista. Los estereotipos son especialmente resistentes al cambio cuando benefician a quienes tienen el poder económico y cultural para defenderlos.

Muchos sociólogos ven con optimismo los intentos de estimular la participación masculina en el trabajo de cuidar como un medio de reducir la desigualdad entre los sexos (Mahoney en Badgett y Folbre 1999: 357), pero este tipo de trabajo es costoso y los hombres son reacios a asumir responsabilidades que reduzcan sus ingresos 
profesionales, igual que lo son a trabajar en ocupaciones que están peor pagadas que la mayoría de las típicamente masculinas.

M.V. Lee Badgett y Nancy Folbre plantean que la única forma de apoyar y proteger el trabajo de cuidados es a través de la realización conjunta de las siguientes acciones: reducir las presiones que ejerce el trabajo remunerado sobre la vida familiar; imponer criterios estrictos de calidad a los servicios asistenciales de carácter comercial; e impulsar la preparación profesional y la entrega de quienes se ganan la vida atendiendo a los demás (Badgett y Folbre 1999: 362).

En cuanto a los aspectos psicológicos del cuidado y la mujer, esta actividad está inmersa en la lógica del sacrificio, un sacrificio que puede entrañar -sin pretenderlo- un grado de reconocimiento social. Sin embargo, hay aspectos agazapados bajo el sacrificio, no concebido como un don, sino en su opuesto, es decir, como una obligación que deriva en un potente instrumento de control. Pensemos que el cuidado tiene su anverso, puesto que si el rol femenino ha estado asociado al desprendimiento de sí, a la renuncia, reproducir el papel de "mujer abnegada" hasta la extenuación, bien podría implicar asumir espléndidamente las obligaciones adscritas al género femenino (Murillo 2003: 7).

El cuidado puede volverse incompatible con el ejercicio de la individualidad, no hay lugar para acceder al tiempo propio, ni como derecho, ni como trato de favor. La excelencia del sacrificio, de la entrega, la renuncia son virtudes femeninas; cuando las circunstancias son críticas se activan las relaciones de cuidado, pautado como un don, como una entrega incondicional en el discurso social, obligando al que lo recibe, en justa correspondencia, el agradecimiento, el cual conlleva también contraer deudas que no son explícitas del todo (Murillo 2003: 8).

\subsubsection{Medición y uso del tiempo}

La decisión del trabajo al interior del hogar sigue generalmente un eje de género, que hace a las mujeres "dependientes" respecto de los ingresos aportados por los varones, y a los varones les hace igualmente "dependientes" respecto a los servicios no remunerados que producen las mujeres para el hogar (Durán 2006). 
El trabajo desempeñado en el hogar no es una unidad homogénea como el trabajo remunerado, ya que incluye una amplia gama de actividades en lo tocante al trabajo doméstico propiamente dicho y al cuidado de los niños. Esta noción del trabajo en el hogar es válida sólo durante una determinada etapa de la vida de la mujer e incluso de la familia; el cuidado de los niños se presenta durante las etapas de expansión y de dispersión temprana de las familias, cuando las mujeres son adultas jóvenes y todavía hay hijos menores de 18 años. Una vez que los hijos crecen, sólo permanece el trabajo doméstico, lo que supuestamente debería simplificarlo. Pero como ya hemos mencionado esto no siempre es así, pues algunas deben desempeñar otro tipo de cuidados: a los mayores y familiares con dependencia cuya atención se prolonga más allá de la etapa de crianza de los hijos. En este sentido, la doble jornada de trabajo continúa en las etapas tardías de la vida de las mujeres, pero no es la misma que cuando eran jóvenes (Robles 2003a: 76). El cuidado de los niños es reemplazado por el cuidado de adultos dependientes: enfermos crónicos y ancianos.

La definición y utilización del concepto "dependencia" es relativamente nuevo en los estudios sociales. Sorprende precisamente que sea una terminología reciente, ya que el tema es antiguo, desde siempre las personas hemos necesitado cuidados y en diversas etapas de nuestra vida somos dependientes. Más aún, precisamente por ser personas sociales, todos y todas somos continuamente interdependientes, al menos en términos relacionales. Ahora bien, la "dependencia" como proceso humano y social se ha mantenido invisible mientras las mujeres han asumido el cuidado de todas las personas en el interior del hogar, pero cuando el proceso de reincorporación de las mujeres al trabajo de mercado se solapa con el aumento de la esperanza de vida, un tipo específico de dependencia -el cuidado de las personas mayores- comienza a entenderse -al menos en alguna dimensión- como un problema social. Y de aquí que en la literatura económica y social, el término de dependencia aparezca casi exclusivamente ligado al envejecimiento demográfico (Carrasco 2006a: 54).

Los estudios sobre el uso del tiempo han colaborado en poner de manifiesto la doble jornada y la doble presencia de las mujeres y han permitido realizar análisis aplicados para estudiar la interrelación entre ambos trabajos y sus efectos en la vida de las mujeres. La medición en tiempo del trabajo realizado en los hogares también ha 
permitido desarrollar un campo de estudio sobre la valoración del trabajo doméstico. Pero han sido los enfoques de género interdisciplinares los que en las últimas décadas han desarrollado otras formas de aproximación al estudio del tiempo. Desde esta nueva visión, se plantea que no todo el tiempo es dinero, no todas las relaciones humanas están mediatizadas por el tiempo mercantilizado, no todos los tiempos son homogéneos ni todo el tiempo de trabajo es remunerado. Se comienzan a estudiar los llamados "tiempos generadores de la reproducción" que consideran los tiempos que caen fuera de la hegemonía de los tiempos mercantilizados y que incluyen tiempos necesarios para la vida: cuidados, afectos, mantenimiento, gestión y administración doméstica, relaciones, ocio, etc. El problema es, entonces, que el tiempo medido, centrado en el tiempo de trabajo mercantil, transformado en nuestras sociedades industrializadas en tiempo dinero, preside el resto de los tiempos bajo una organización productivista y masculina. Bajo esta lógica, se difuminan las dimensiones más cualitativas del tiempo, aquellas más propias de la experiencia femenina ligadas al ciclo de vida y el correspondiente cuidado de las personas (Carrasco 2006a: 49).

En definitiva, a pesar de que los estudios de uso del tiempo marcan un punto de inflexión en el intento de hacer visible el trabajo realizado por las mujeres en el hogar y contribuyen de forma importante a poner de relieve las desigualdades de sexo/género en relación al trabajo, presentan, sin embargo, algunas limitaciones que les impiden recoger la complejidad de las distintas dimensiones que presenta la organización, el desarrollo y los cuidados de la práctica femenina del trabajo no remunerado realizado en los hogares. Ahora que los estudios de uso del tiempo comienzan a implementarse en un número importante de países, es oportuno y necesario revisar su metodología para o bien mejorarla o bien complementarla con otro tipo de instrumentos que permitan obtener información imposible de recoger con un diario de uso del tiempo (Carrasco 2006a: 51). Si consideramos que el bienestar social no viene determinado por el "éxito de mercado" sino por la calidad de las relaciones humana, a este objeto, es necesario a nivel teórico seguir indagando en las dimensiones del tiempo y del cuidado y, a nivel más aplicado, rechazar como única medida del tiempo la medida cuantitativa, porque oculta las dimensiones cualitativas ligadas directamente con las actividades de cuidados, e investigar metodologías que combinen aspectos cualitativos y cuantitativos y que 
permitan posteriormente incorporar en el análisis económico los aspectos subjetivos del cuidado.

\subsubsection{Doble o triple jornada de trabajo femenino}

La doble jornada de trabajo femenina implica simultanear el trabajo remunerado y el del hogar, este último incluye el trabajo doméstico y el cuidado de los niños. Sin embargo, el envejecimiento y la enfermedad crónica pueden transformar la doble jornada en una triple, porque el cuidado del enfermo es un trabajo diferente al doméstico (Robles 2003a: 76). Las cuidadoras integran el cuidado del enfermo como una jornada más de trabajo en su vida. La mujer no abandona, suspende o delega las actividades relacionadas con sus otros roles sociales a causa del cuidado, sino que crea tiempos propios para el cuidado a partir de la reorganización de los espacios y los tiempos de las otras actividades. En este sentido, organizar el tiempo de cuidado implica coordinarlo con los tiempos de sus otros roles sociales bajo un esquema de orden temporal de simultaneidad y sucesión entre el tiempo del cuidado y los tiempos de los otros roles sociales, ya sea creando un tiempo exclusivo para el cuidado o uno compartido con otras actividades cotidianas. Esta integración del cuidado a la vida cotidiana constituye la base para comprender cómo se organiza en el contexto de una vida que demanda la realización de varios trabajos a la vez, es decir, hay que lidiar con la presencia temporal de roles ineludibles. La integración descansa en la jerarquización de las acciones de los distintos trabajos a partir de su estatus laboral y biográfico.

Un primer aspecto de esta doble jornada es el grado con el que el cuidado desplaza otras actividades cotidianas: el cuidado ocupa el primer o el segundo lugar de prioridad, dependiendo de si la cuidadora participa o no en el mercado laboral. Cuando la cuidadora es parte de la fuerza de trabajo, el cuidado se organiza como elemento subordinado al trabajo remunerado. Esto se refleja en una jornada dividida en dos partes, el tiempo del trabajo y el tiempo del cuidado. En estos casos, siempre se respeta el tiempo del trabajo como una unidad temporal independiente y de mayor jerarquía, por lo que el cuidado ocupa el tiempo libre. En la investigación realizada por Robles (2003a), siempre el trabajo remunerado ocupaba la posición más elevada en la jerarquía y el cuidado estaba en igual posición o por debajo, pero nunca por encima del trabajo remunerado (Robles 2003a: 92). 
La situación de las cuidadoras que no trabajaban y eran exclusivamente amas de casa refuerza el patrón de organización anterior. En estas circunstancias, el cuidado ocupa la posición más alta en la jerarquía porque no compite con el trabajo remunerado por la posición más elevada. El trabajo doméstico se organiza subordinado al cuidado bajo un esquema de seudo-continuidades para las otras esferas de la vida cotidiana y de continuidad total para el cuidado.

Las cuidadoras no son únicamente trabajadoras, amas de casa y cuidadoras, sino también esposas, abuelas, hijas, cuidadoras de hijos y nietos. Cada uno de estos roles demanda tiempo y energía para realizar las actividades propias de cada uno, aunque con ritmos diferentes, ya que algunos roles no son permanentes, sino esporádicos en tiempo y espacio. Este contexto de copresencia de roles sociales significa que la vida de las cuidadoras está saturada de actividades, es decir, de trabajos. Este argumento permite a Robles sustentar la hipótesis de que la doble jornada de trabajo femenino se incrementa a una triple jornada cuando se considera que al trabajo del hogar y al que la mujer realiza fuera del hogar se le suma el trabajo inherente al cuidado. La excesiva carga de trabajo obviamente constituye una de las principales problemáticas de las cuidadoras

Robles considera que la construcción conceptual de la doble jornada ha coadyuvado a mantener ocultos los varios trabajos que implica el llamado trabajo del hogar. Manejarlo conceptualmente como si fuera un solo trabajo con múltiples actividades o cuando más dividido en dos ámbitos -el trabajo doméstico y el cuidado de los niños-, equivale a ocultar dos jornadas de trabajo que deberían ser analizados por separado. Una, el trabajo doméstico, la otra, el trabajo del cuidado de los dependientes. En estas circunstancias, el cuidado de los niños y el cuidado de los enfermos adultos y ancianos deben ser entendidos como trabajo de cuidado a un dependiente, es decir, el trabajo del cuidado, reconocerlo como trabajo significa redimensionar la doble jornada. De entrada, el trabajo del cuidado no es parte o una extensión del trabajo doméstico, y en segundo lugar, la doble jornada de las mujeres trabajadoras no es tal, ser trabajadora remunerada, ama de casa y cuidadora de un enfermo crónico implica reconocer la existencia de una triple jornada de trabajo, no de dos como comúnmente se afirma (Robles 2003a: 96). Si bien la investigación acerca de la vivencia de ser mujer trabajadora y ama de casa permitía sustentar el concepto de doble jornada, al introducir el concepto de trabajo del 
cuidado obliga a discutir y reelaborar dicho concepto, ya que la situación del número de jornadas y las cargas de trabajo cambian. Ser mujer trabajadora y ama de casa implica una doble jornada, no así cuando se es cuidadora de un enfermo crónico adulto o anciano porque se pasa a una triple jornada, y si consideramos el cuidado a los niños hijos o nietos- tendremos que pensar en una cuádruple jornada de trabajo (Robles 2003).

\subsubsection{La carrera de cuidadora}

Los cuidados a la dependencia generan la posibilidad de que las mujeres cuiden a varios sujetos dependientes en su vida, posibilidad que puede darse en dos sentidos, una, que cuiden simultáneamente a varios dependientes, por ejemplo mujeres adultas que cuidan a sus hijos pequeños y a alguno de sus padres ancianos, fenómeno conocido como "competencia de roles"; la otra es cuando una misma mujer es cuidadora toda su vida, aquí habría dos variantes: 1) la mujer que atiende durante gran parte de su vida a un mismo dependiente, este es el caso de las madres con hijos enfermos crónicos desde su nacimiento o niñez, a quienes cuidan a lo largo de su niñez, juventud y adultez -y debido a que ellas mueren antes que sus hijos enfermos crónicos, son madres que nunca abandonan el cuidado una vez que lo inician-; 2) una mujer que cuida a diferentes dependientes a lo largo de la vida; esto es posible si consideramos el ciclo de vida de la familia, cualquier familia puede enfrentar el cuidado de varios dependientes a lo largo de su vida ya sea niños, adultos o viejos.

Las situaciones anteriores evidencian las condiciones de las mujeres que desarrollan una "carrera" como cuidadoras. Respecto de esta afirmación es importante realizar una serie de reflexiones: primero, no es posible visibilizar este fenómeno sin un análisis diacrónico, es decir, sólo es posible verlo cuando se considera el curso de vida de las mujeres cuidadoras, ya que al analizar las trayectorias de vida de éstas encontramos que algunas de ellas ya habían sido cuidadoras en el pasado; segundo, la repetición en el rol de cuidadora se prolonga hasta la ancianidad; estudios en diferentes cohortes generacionales muestran que la posibilidad de convertirse en hija-cuidadora aparece en la cuarta o quinta década de la vida (Moen, Robinson y Fields en Robles 2003c), pero la situación no es la misma para las esposas, ellas realizan el trabajo del cuidado en plena etapa de la vejez, aún cuando pudieron iniciarse en la adultez; ser una anciana-cuidadora puede implicar que sea la primera vez que lo sea, pero también que sea la última de una 
larga "carrera" como tal; si es así, significa que el desgaste sufrido en las experiencias previas se acumula con la actual en una situación de mayor desventaja; ser anciana y estar cuidando después de una historia de cuidados anteriores es enfrentar al cuidado con la energía y los recursos mermados, a diferencia de cuando se es hija y se cuenta con mayores recursos y energía; el asunto es relevante porque se sabe que el cuidado genera pesadas cargas ${ }^{16}$ de trabajo y con consecuencias en varios ámbitos de la vida personal, familiar y social (Robles 2003c).

\subsubsection{La doble presencia/ausencia}

Las mujeres que deben combinar sus trabajos con los trabajos de cuidados no remunerados buscan estrategias múltiples para gestionar el conflicto de lógicas en el que se ven insertas ${ }^{17}$. Dependen también de las normas morales sobre las conductas de género, marcadas por grupos sociales (clase, etnicidad, sexualidad, ideología, etc.). Entre las estrategias que podemos identificar, se encuentran las variaciones en la organización de los cuidados en el ámbito doméstico: el cambio en el contenido del trabajo de cuidados (reducción de ciertas tareas, renuncia a las prescindibles) o en la intensidad (simultaneidad de tareas, recorte del tiempo dedicado a cada una); sustitución de tiempo de ocio por tiempo de trabajo; las negociaciones cotidianas para redistribuir tareas (con un limitado impacto y no suele ir acompañada de la delegación de la gestión) (Pérez Orozco 2005: 236).

Es imposible obviar que quienes deben adaptar sus variados tipos de trabajo -las mujeres- son quienes tienen mayor probabilidad de sufrir múltiples discriminaciones en el mercado laboral. "Hemos progresado de la forma original de domesticidad, la versión de ganador del pan/ama de casa, a la forma actual de domesticidad, el sistema trabajador ideal/cuidadora marginalizada" (David 201 en Izquierdo 1998). Esta marginalización pretende ser recogida con el concepto de doble presencia/ausencia. Este término simboliza "ese estar y no estar en ninguno de los dos lugares y el sufrimiento y limitaciones que tal situación comporta" (Izquierdo 1998: 356). Las tensiones surgidas

\footnotetext{
${ }^{16}$ Tema tratado en el siguiente epígrafe de este capítulo.

${ }^{17}$ Estas estrategias múltiples difieren en cada contexto y son resultado de una multiplicidad de factores. En España, la vía fundamental es la búsqueda de ayuda informal o remunerada, mientras que en Alemania, se opta más por modalidades de inserción laboral que permita una mayor compatibilización de ambas responsabilidades, sobre todo, el empleo a tiempo parcial (Caixeta 2004 en Pérez Orozco 2005).
}

Página | 109 
de estas rigideces simultáneas las experimentan en sus propios cuerpos quienes son responsables de la reproducción cotidiana -condensada en el trabajo de cuidados- al mismo tiempo que tienen que actuar en el mercado laboral, las mujeres. Otra dimensión adicional de la doble presencia/ ausencia es la ambigüedad, reflejando la voluntad de las mujeres de no separar las distintas facetas de sus vidas. Este concepto capta el protagonismo dual de las mujeres, la contraposición de objetivos sociales, la imposibilidad de conciliar ambos, encarnada en los propios cuerpos femeninos, y la negativa de las mujeres a elegir y aceptar que la estructura socioeconómica es una realidad escindida.

El fenómeno de doble presencia/ausencia es una expansión tendencial, aunque con modificaciones, de las tensiones vividas históricamente por las mujeres de clase obrera. Por eso Pérez Orozco cree que presentar la crisis de los cuidados como un fenómeno relativamente novedoso es un concepto inherentemente clasista $\mathrm{y}$, probablemente, etnocéntrico. La autora cree que la situación debe ser entendida como una expansión de un fenómeno ya vivido por las mujeres de las clases con menor poder y no tanto como algo novedoso (Pérez Orozco 2005: 241).

En suma, para las mujeres, la realidad vivencial es mucho más compleja, la división de espacios les ha representado una ruptura impuesta que no responde a su propia realidad. Asumir el trabajo de cuidados y participar en otros ámbitos sociales les ha significado estar moviéndose en un continuo, en un ir y venir entre los distintos espacios de relaciones (doble presencia/ausencia), entre el trabajo remunerado, el no remunerado, los servicios públicos, las relaciones familiares, etc. Ello ha requerido establecer una amplia diversidad de redes de mujeres (madres- hijas-abuelas; nueras-suegras; amigas; vecinas; cuñadas; madres de escuela, etc.) que han posibilitado su participación en los distintos espacios a la vez que se realizaban las actividades de cuidados necesarias para que la vida cotidiana continuara.

Pero todas las redes de relaciones y de cuidados sostenidas por las mujeres, que interaccionan en los distintos espacios, han permanecido invisibles y se ha mantenido la idea de una sociedad dividida en ámbitos independientes. Hacer visible la falacia de la dicotomía es también visibilizar y dar valor -particularmente en el simbólico- a la actividad de cuidados y de relaciones desarrollada por las mujeres. Una sociedad, que 
tenga como objetivo la calidad de vida de la población, requiere entonces establecer nuevos pactos sociales que otorguen valor a la relación y al cuidado basándose en la experiencia de las redes invisibles de las mujeres. La falsa separación de los espacios también tiene consecuencias en la forma en que se conciben los servicios públicos. En España, por ejemplo, los servicios más básicos ofrecidos por el sector público -como son sanidad y educación- están diseñados y organizados considerando la acción del trabajo no remunerado. La actividad que en ellos se realiza, ya sea de cuidados, relación, aprendizaje o socialización, es un continuo entre la institución y el hogar (Carrasco 2006a: 47).

\subsubsection{Vulnerabilidad del trabajo de cuidar}

Dentro de la revisión realizada en este capítulo resulta necesario referirnos a las condiciones de cuidado y al derecho a ello. Las condiciones en que se realiza el trabajo de cuidado no remunerado muchas veces distan de ser dignas, ya que se trata de una actividad sin remuneración, sin contraprestaciones, sin control del tiempo de trabajo, ni de los recursos imprescindibles para su realización, sin legislación que regule dicha actividad y evite situaciones de indefensión y abusos. Éste queda sujeto a múltiples variables -recursos monetarios disponibles, negociación intrafamiliar, tipos de redes de apoyo- al no existir una garantía pública de condiciones dignas.

En conjunto, los hombres disfrutan de un derecho a no cuidar; por el contrario, las mujeres no disfrutan del derecho a no cuidar y las condiciones para ello no están garantizadas. El actual papel subsidiario del Estado en el tema de los cuidados, junto a los roles de género, hacen que la desfamiliarización accesible a las mujeres sea muy baja. Por otro lado, en la medida en que la respuesta creciente a la situación de crisis de los cuidados pase por la mercantilización de éstos, los mercados adquieren una centralidad aún mayor. Nuestras sociedades estarían caracterizándose por la distinta forma de acceder a la satisfacción de necesidades, en general y en específico de cuidado: grupos con poder adquisitivo suficiente que satisfarían una proporción mayor de sus necesidades a través de los mercados, y segmentos sin ese poder adquisitivo que dependerían cada vez más de los trabajos no remunerados y de formas de aprovisionamiento no monetizados. 
La asunción de las mujeres de su rol de cuidadoras en lo doméstico, en un contexto en que los mercados, los hombres como colectivo, y el Estado siguen sin asumir responsabilidades en la gestión cotidiana de la sostenibilidad de la vida, implica que los cuidados tengan que seguir resolviéndose de forma invisible. Pero las dimensiones de invisibilidad sí se transforman, dejando de estar tan firmemente asociadas al espacio doméstico y a lo no monetizado. La escisión público/privado se difumina, hay cuidados que están en lo público y en lo privado a la vez. Los trabajos de cuidados, en parte, comienzan a ser más habitualmente remunerados, pero en condiciones laborales de precariedad, vulnerabilidad, informalidad, etc. relacionados con el proceso de feminización del trabajo. Pérez Orozco afirma que las dimensiones de la invisibilidad del trabajo de cuidados mutan, pero es la condición de invisibilidad la que se perpetúa (Pérez Orozco 2005: 245). Si el ámbito de los cuidados es un lugar privilegiado para evidenciar las desigualdades de género, es inevitable no mencionar que este espacio está condicionado por la estructura del sistema económico en que vivimos y que se relaciona con desigualdades sociales básicas como la pobreza y la precarización, y con la regulación íntima de nuestros modelos de vida.

\subsection{Apoyo Social y Carga}

De forma previa hemos tratado extensamente en este capítulo el tema de los cuidadores, la feminización del cuidado y el del trabajo de cuidar. Siguiendo el desarrollo de nuestro análisis nos interesa desarrollar factores que creemos fundamentales para entender la actividad del cuidado: el apoyo social y la carga que implica el cuidar.

\subsubsection{Apoyo social}

Delimitar el concepto que nos ocupa no es tarea fácil, ya que existe una gran cantidad de definiciones y variadas actividades que se han incluido bajo este término, el apoyo social es un concepto multidimensional y dinámico. Barrón (1996), en un intento de aproximación al concepto, refiere una idea guía: el apoyo social es un concepto claramente interactivo, que se refiere en cualquier caso a transacciones entre personas (Felton y Shinn 1992 en Barrón). 
En la búsqueda de conceptualización adecuada al contexto de esta investigación, Gallardo (2013) nos refiere que las definiciones que se han dado al apoyo social varían de acuerdo a la perspectiva de análisis, bien sea ésta funcional, estructural o integradora.

Para los alcances de este estudio, consideraremos la formulación realizada, desde una perspectiva estructural, por Khan y Antonucci (1980 en Guzmán, Huenchuan y Montes de Oca 2003). Estos investigadores entienden el apoyo social "como las transacciones interpersonales que implican ayuda, afecto y afirmación" de las redes sociales de pertenencia, dirigidas a potenciar, mantener o restituir el bienestar del receptor. A este conjunto de transacciones también se le da el término genérico de "transferencias", y se presentan como un flujo de intercambio y circulación de recursos, acciones e información.

Bajo el constructo de apoyo social debemos distinguir los siguientes aspectos:

- Diferentes niveles de análisis: comunitario, redes sociales y relaciones íntimas.

- Identificación del tipo de apoyo o vínculo.

- Disponibilidad y sostenimiento de las redes de apoyo.

En lo que respecta a los niveles de análisis, Lin, Dean y Ensel (1986 en Gallardo) diferencian tres ámbitos en los que el apoyo social se genera o podría generarse: nivel íntimo o microsocial; un nivel de redes sociales o mesosocial; y el nivel de la comunidad o macrosocial. La separación analítica que se realiza entre los niveles no implica que estos no estén interconectados y sean dependientes.

En el nivel de las relaciones íntimas o microsocial, encontramos las transacciones que corresponden al círculo de confianza del individuo, y que suponen el nivel más significativo para éste. Las relaciones que aquí ocurren son las que se asocian directamente con el bienestar y la salud, esperándose intercambios recíprocos y mutuos en este nivel, compartiendo un sentimiento de responsabilidad con el otro.

El nivel de las redes sociales, o mesosocial, aportan al individuo un sentido de unión con los demás por la posibilidad de acceder directa o indirectamente a un número amplio de personas, aunque sea de forma indirecta. Barón (1996: 12) afirma que en este 
nivel se suelen incluir todos los contactos sociales que mantienen las personas, así como las propiedades de las redes sociales: densidad, tamaño u homogeneidad, entre otras.

En el nivel comunitario o macrosocial, el apoyo social proporciona una sensación de pertenencia e integración social. La integración social es evaluada normalmente en función de estar implicado en determinados roles y contextos sociales, considerándose como medida de integración social el estado civil, la pertenencia a asociaciones comunitarias, clubes, iglesias, etcétera.

Considerando el apoyo desde la perspectiva de su funcionalidad, distinguimos tres tipos de apoyo o transferencia (Guzmán et. al.2003, Barrón 1996):

- Apoyo social emocional. Hace referencia a sentimientos de bienestar afectivo, como las expresiones de cariño, muestras de confianza, empatía, respeto, sentimientos asociados a la familia y preocupación por el otro.

- Apoyo social instrumental o material. Es definido como acciones o materiales proporcionados por otros, que facilitan la realización de tareas cotidianas y/o resolución de problemas prácticos. Aquí se consideran las ayudas en forma de cuidado, acompañamiento, realización de labores del hogar, apoyos monetarios (dinero en efectivo, regalos y otros) y no monetarios (apoyo material en forma de comida, ropa, pago de facturas, etc.).

- Apoyo social informacional. Referido al proceso de entrega de información, consejo o guía que ayude al cuidador en la comprensión de la realidad que experimenta y/o le ayude a adaptarse a los cambios que en ella se dan. Resulta complicado diferenciar entre esta función y la de apoyo emocional, porque dar consejo puede ser percibido por el receptor como una expresión de cariño y preocupación por él.

Desde la perspectiva de la disponibilidad y el sostenimiento de los apoyos sociales y las redes, corresponde tener en consideración el factor demográfico, que considere el nivel de fecundidad, migración, patrones de formación y disolución de uniones, y factores no demográficos, tales como la estabilidad en el empleo o el nivel de bienestar de otros miembros de la familia. 
Pero la amplia disponibilidad de personas no necesariamente es signo de un mayor apoyo, ya que debemos considerar aquellas personas con las que el sujeto potencialmente cuenta como fuente de ayuda disponible o en condiciones de brindarla al momento de necesitarla. Guzmán, Huenchuan y Montes de Oca nos remiten, como ejemplo, que en contextos pobres se observa que la ayuda familiar está limitada por la necesidad de ayuda de otros miembros del grupo o por la búsqueda de ascensión social. Esta situación demuestra que la no disponibilidad de redes de apoyo puede ser una de las facetas de la pobreza (2003: 52).

Otro aspecto a considerar en el estudio del apoyo social es la distinción que existe entre el apoyo social recibido y el apoyo social percibido. El primero alude al intercambio real de apoyos; en tanto que el segundo alude a la percepción subjetiva de que se produce el apoyo, es decir a transacciones subjetivas. Caplan (1974 en Gallardo) hacía referencia a las transacciones objetivas y subjetivas, indicando que el apoyo social podía consistir en un intercambio real o en una percepción subjetiva de que ese intercambio pudiese generarse en un contexto determinado. Así, la distinción entre lo objetivo y lo subjetivo no es solo conceptual, sino que también se refiere a lo operativo o efectivo, ya que pueden no coincidir.

El apoyo social también puede ser examinado desde la fuente que genera dicha transacción, desde ese punto de vista, podríamos distinguir los apoyos sociales de fuentes formales y los apoyos sociales de fuentes informales. El sistema formal de apoyo posee una organización burocrática, contempla objetivos específicos en ciertas áreas determinadas y utiliza a profesionales o voluntarios para garantizar el logro de sus metas (Sánchez 1994). El sistema informal está constituido por las redes personales y las redes comunitarias no estructuradas como programas de apoyo. Es en este ámbito donde se inscribe el apoyo de la familia, las redes de vecinos o amigos y las redes comunitarias.

Para finalizar haremos referencia a hallazgos específicos del apoyo social en el ámbito de los cuidados.

En el artículo denominado "El rol de cuidador de personas dependientes y sus repercusiones sobre su calidad de vida y su salud" (López, Orueta, Gómez-Caro, 
Sánchez, Carmona y Alonso 2009), los investigadores concluían que entre los factores que generaban mayor deterioro de la esfera psíquica del cuidador estaban el tiempo que llevaban desempeñando este rol, el nivel de dependencia de la persona atendida, la sensación de sobrecarga y la falta de apoyo social. Midieron el apoyo social funcional percibido a través del cuestionario Duke-UNC, en él la mayoría de los cuidadores señalaba como suficiente el apoyo social recibido. Pero los autores consideraban que esta percepción no se ajustaba a la realidad, creen que puede estar relacionada con que un alto porcentaje de cuidadores entrevistados eran mujeres que no trabajaba fuera del hogar, lo que facilitaba el desempeño de su rol. Ellos planteaban que los cambios que la sociedad experimenta en sus modelos familiares, podría dificultar la asunción de las funciones de cuidado dedicada a los miembros dependientes.

Con respecto a la misma problemática, García-Calvente y otros (García-Calvente, Mateo-Rodríguez y Eguiguren 2004: 139) proponían instancias de apoyo social a cuidadores de personas dependientes articuladas desde el Estado, específicamente hacían referencia a las características de género que determinan el cuidado y a la desigual distribución de responsabilidades y cargas que implican el cuidado de los dependientes, tanto en ámbitos privados como públicos. Por ello, señalaban que las políticas dirigidas a apoyar a los cuidadores deberían ser, ante todo, políticas de reducción de las desigualdades y de fomento de la equidad.

En el ámbito latinoamericano, Gallardo (2013), en su investigación sobre personas mayores del norte de Chile, señalaba que era relevante conectar al grupo familiar de la persona mayor con las instituciones y redes comunitarias de apoyo a las personas mayores, dotando así a los cuidadores de herramientas que le permitiesen desempeñar mejor su labor.

\subsubsection{Carga}

Una concepción muy arraigada y generalizada en nuestras sociedades es la certidumbre de que cuidar de las personas mayores es una obligación moral. Ahora bien, al analizar con detenimiento este sentimiento general de obligación observamos una diversidad de aspectos: unos son de carácter positivo (del deber moral cumplido que ennoblece a quien lo practica), pero otros presentan ribetes negativos (imposición social y de la 
propia conciencia, que se debate con otras preferencias y sentimientos vitales). Esta ambigüedad determina que el sentido de obligación moral contribuya a generar un cruce de sensaciones contradictorias y encontradas, que está bastante generalizado entre quienes han asumido la tarea de cuidar a una persona en situación de dependencia, y que es uno de sus rasgos más definitorios.

¿Por qué se produce esta ambivalencia? Seguramente porque el cumplimiento de la obligación moral de cuidar a quienes lo precisan en ocasiones es incompatible con la natural aspiración, que también se tiene, a desarrollar una vida personal y profesional propia. Cuando el grado de dependencia es importante, la deseable compatibilización de ambas funciones se torna impracticable, lo que favorece la generación o incremento de estrés, el cual origina, a su vez, efectos negativos para la persona que lo experimenta. Éstos han sido denominados por los especialistas como "carga" del cuidador, concepto que en sus inicios fue elaborado como un estado subjetivo asociado al conjunto de actitudes y reacciones emocionales que la persona que cuida experimenta sobre la función que realiza; en dicho concepto posteriormente se introdujo también una parte objetiva, referida al grado de cambios y perturbaciones en diversos aspectos del ámbito doméstico de la vida de los cuidadores, por ejemplo restricciones en el tiempo libre, etc. (Montorio et al. 1998). Actualmente, la definición del constructo de carga se ha multidimensionalizado, y se define como: "conjunto de problemas tanto físicos, como psicológicos o emocionales, sociales y financieros que pueden experimentar los miembros de la familia que cuidan de adultos dependientes" (George y Gwyther en Molina, Iáñez y Iáñez 2005).

La definición, anteriormente descrita, es corroborada por Yanguas, Leturia y Leturia (2001), quienes afirman que la responsabilidad de proveer cuidados a personas dependientes, por parte de sus familias, tiene efectos en diversos aspectos de la vida del individuo; los autores asumen que el concepto de carga no contiene sólo elementos subjetivos. El trabajo de Montorio et al. (1998) también confirma la multidimensionalidad del concepto señalando tres dimensiones observables en él:

Impacto del cuidado o valoración por parte del cuidador o cuidadora acerca de los efectos que tiene en él o ella la prestación de cuidados a su familia mayor 
(disminución del tiempo libre, falta de intimidad, deterioro en la vida social, sensación de pérdida de control sobre su vida, deterioro de la salud).

Carga interpersonal, referida a la percepción que el cuidador o cuidadora tiene acerca de su relación con la persona a la que cuida, sentimientos de vergüenza, enfado o tensión hacia su familiar, deseos de delegar el cuidado o sentimientos de indecisión acerca de cómo cuidar.

Expectativas de autoeficacia, se trata de una dimensión que refleja la creencia del cuidador en torno a su capacidad para cuidar y sus expectativas acerca de sus posibilidades para mantener en el tiempo la situación de cuidado.

La carga sufrida por el cuidador es un concepto complejo que describe los efectos estresantes por el cumplimiento de dicha función. Ante la gran diversidad de factores intervinientes -la situación que lleva al cuidador a ocuparse de una persona dependiente, las habilidades para el cuidado, tipo de sentimientos que les lleva a realizar el rol (desde la obligación al acto voluntario), recursos disponibles, tipo de cuidado de las personas dependientes en función del tipo de dependencia que presentan, la personalidad de la persona a cuidar, la historia en común con los cuidadores, la posibilidad de que acepten el cuidado de una u otra manera, etc.-; diferentes autores han formulado diversos modelos explicativos sobre las diversas variables influyentes en el cuidado. Lazarus y Flokman afirman que la reacción al estrés que produce al cuidado es mitigada por la capacidad de evaluar esa amenaza percibida, así como por el tipo de afrontamiento; desde el modelo de Pearlin y colaboradores se enfatiza que los conflictos con otros miembros de la familia y la disminución de la autoestima, por ejemplo, pueden tener efectos en la capacidad de afrontamiento de los cuidadores en su red de apoyo social. Así, también, Vitaliano y colaboradores desarrollaron un modelo donde el "distrés" es conceptualizado como resultado de las relaciones entre estresores objetivos y recursos psicológicos, sociales y emocionales del cuidador (en Yanguas et al. 2001).

Dentro de los modelos conceptuales elaborados para explicar la carga del cuidador nos detendremos en el desarrollado por Pearlin, Lieberman, Menaghan y Mullan (en Yanguas et al. 2001), que lo interpretan en base a la relación de tres componentes principales: estresores, consecuencias o resultados del cuidado y variables moduladoras. 
Los estresores a su vez se dividen en estresores primarios y secundarios, los primarios son las demandas y tareas que se demandan al cuidador, tanto por parte de la persona cuidada, como las que la propia situación de cuidado crea (ayuda en actividades de la vida diaria, hacer frente a los problemas de conducta y/o emocionales de la persona cuidada). Los estresores secundarios están relacionados con los cambios que se producen en la vida de los cuidadores, como resultado de los esfuerzos que el cuidado de una persona dependiente trae consigo. Algunos estudios han comprobado que el requerimiento, por parte de la persona dependiente, al cuidador de ayuda en actividades de la vida diaria provoca menos consecuencias negativas al proveedor de cuidados, que cuando la persona dependiente tiene problemas de conducta o emocionales (Yanguas et al. 2001).

El segundo componente, los resultados o consecuencias de los cuidados, se refiere a los cambios disruptivos que la experiencia del cuidado hace surgir en la vida del cuidador, aquí se pueden destacar:

- Los conflictos familiares, en el que se observan tres dimensiones, la primera está relacionada con la enfermedad que provoca la dependencia y la manera de proveer cuidado; la segunda está asociada a cómo y cuántos miembros de la familia deben cuidar a la persona dependiente; y la tercera está vinculada a la ayuda que recibe o necesita el cuidador principal. Se constata que los conflictos son más frecuentes entre hijos/as cuidadores que entre esposos cuidadores. Generalmente los conflictos familiares se relacionan con consecuencias negativas del cuidado, especialmente con sentimientos de depresivos y de ira.

- Problemas laborales, se identifican cuatro predictores de conflicto entre cuidado y trabajo, el primer predictor es la salud psicoafectiva de los miembros de la familia cuidadora; el segundo, el número de tareas que el cuidador debe realizar; el tercero es la presencia de hijos pequeños en la residencia del cuidador; el último predictor hacer referencia a la relación ambigua y solapada entre las responsabilidades laborales y las responsabilidades respecto al cuidado. Además de estos predictores, existen otras condiciones que se relacionan con el aumento del absentismo laboral y el estrés de los cuidadores, como el género del trabajador, el estado civil, el nivel de cualificación laboral, los ingresos 
familiares, la flexibilidad laboral y nivel de severidad de la dependencia (relativa a la intensidad necesaria del cuidado).

- Disminución del tiempo libre y de las actividades sociales; esta consecuencia se encuentra vinculada al apoyo social, ya que, en general, los cuidadores que perciben su situación de cuidado como muy demandante, pueden limitar sus actividades sociales y perder así posibilidades de encontrar apoyo social.

- Trastornos en salud física y psíquica; los cuidadores suelen presentar autoevaluaciones negativas de salud y presencia de síntomas psicosomáticos; además las situaciones de cuidado estresantes están relacionadas con problemas cardiovasculares e inmunológicos. En cuanto a la salud psíquica, trastornos afectivos como la depresión son bastante frecuentes entre los cuidadores, pudiendo presentar también altos niveles de ira y hostilidad.

Finalmente, las variables moduladoras son aquellas que regulan los efectos de los estresores que aparecen a la hora de desarrollar el cuidado, las más importantes son el apoyo social y el afrontamiento. La existencia de estas variables equivale a asegurar que el cuidador tiene recursos para hacer frente a situaciones de estrés, es decir es capaz de controlar, modificar y entender los eventos a los que se debe confrontar.

El apoyo social. Debemos considerar otra conceptualización distinta a la ya explicada de este término. El apoyo social también puede constituirse en la variable moduladora más importante para la familia cuidadora, al representar una importante fuente de ayuda a la hora de hacer frente a las situaciones del cuidado. Las categorías de apoyo más importantes para el ámbito del cuidado son: el apoyo instrumental y el apoyo emocional. Los beneficios del apoyo social en el aminoramiento del estrés se observan a nivel de la salud física y mental, por ejemplo, en cuidadores de personas con demencia destaca la relación entre apoyo social percibido y la menor carga subjetiva en estos cuidadores. En esposas cuidadoras de enfermos de Alzheimer, el apoyo social tiene un efecto amortiguador respecto al estrés crónico en el sistema inmunitario de ellas. Los cuidadores que tienen mayor capacidad adquisitiva, o mayor nivel de apoyo social, tiene mayores posibilidades que los que carecen del mismo para evitar las consecuencias más severas del cuidado como pueden ser los trastornos depresivos (Yanguas et al. 2001). 
Afrontamiento Representa las respuestas a los estresores a fin de disminuir sus consecuencias negativas. Yanguas et al. (2001) mencionan tres tipos de afrontamientos:

- Afrontamiento de problemas, que incluye estrategia de afrontamiento ante los estresores o de situaciones específicas de cuidado, por ejemplo discernir el comportamiento que debe de tomar un cuidador cuando se siente agredido por la persona cuidada.

- Afrontamiento de tipo cognitivo, representado por los esfuerzos de manejo de las diferentes maneras de entender las situaciones de estrés, y que es reelaborado a través de la experiencia del cuidador, por ejemplo la consideración de que el culpable de la situación de cuidado es la enfermedad y no la persona que es dependiente.

- Afrontamiento de tipo emocional en el que se incluyen el manejo de los síntomas del estrés, por ejemplo el control de sentimientos depresivos o psicosomáticos.

Diversas investigaciones han demostrado que el afrontamiento de tipo cognitivo y la resolución de problemas están relacionados con un menor "distrés"; y que el afrontamiento de tipo emocional está relacionado con mayores niveles de "distrés" (Haley, Levine, Brown y Bartyolucci; Vitaliano et al. en Yanguas et al. 2001). La eficacia de las estrategias de afrontamiento depende de la naturaleza de los estresores, así como del nivel de estrés del cuidador. Cuando los estresores no son fácilmente modificables, el poder redefinir el cuidado y las consecuencias del mismo (afrontamiento de tipo cognitivo) puede ser más eficaz para el cuidador.

El afrontamiento y los estresores mantienen una relación recíproca, debido a que los estresores ponen en marcha el afrontamiento ante una situación determinada, a la vez que los esfuerzos efectivos de manejos de situaciones estresantes puede hacer que disminuya la frecuencia con que estas situaciones no deseadas aparezcan, en cambio un afrontamiento no efectivo puede aumentar los problemas conductuales u emocionales en la persona cuidada.

Se debe destacar que en todo episodio de estrés cada uno de los componentes descritos estresores, consecuencias del cuidado y variables moduladoras- se ven influenciados por 
un contexto que está condicionado por las relaciones de parentesco y género, así como por el nivel sociocultural del cuidador y la persona dependiente.

En general, se acepta que las relaciones de parentesco entre el cuidador y la persona cuidada es una variable influyente a la hora de matizar el tipo de sentimientos y obligaciones del cuidador respecto a la persona cuidada, así como en la posible dificultad del cuidado y el nivel de "distrés". Los sentimientos de compromiso y obligación de los cuidadores tienen, por ejemplo, influencia sobre la duración del cuidado y, en este sentido, esposas e hijas suelen proveer la mayor parte del cuidado de larga duración. También se ha comprobado la importancia de la historia pasada, así como la trascendencia de la calidad de las relaciones antes de empezar la tarea de cuidado; cuentan con un menor nivel de distrés los cuidadores que tiene una buena calidad de relaciones previas al cuidado o los que opinan que su labor es por una cuestión de reciprocidad (Yanguas et al. 2001).

La pertenencia a una cultura determinada y el estatus socioeconómico (así como el nivel cultural) afecta principalmente a como los cuidadores desarrollan las labores de cuidado. Diferentes grupos étnicos difieren en creencias sobre la importancia del cuidado de las personas mayores, así como de las personas con discapacidad, para algunos grupos, el cuidado en el domicilio es una de las prioridades más importantes, mientras que otros grupos consideran más importante el cuidado profesional (Lawton, Rajagopal, Brody y Kleban en Yanguas et al. 2001). El estatus socioeconómico, la clase social, y el nivel cultural tienen una compleja relación con el proceso de cuidado; los cuidadores y personas con dependencia, que tienen bajo nivel socioeconómico, cuentan con un menor número de recursos disponibles, una mayor carga sus cuidadores, menor acceso a información y a recursos públicos.

Para finalizar, quisiéramos referirnos a los instrumentos con los que se ha intentado medir el concepto de carga. Dichos instrumentos están directamente relacionados con los modelos conceptuales con los que operativamente se ha intentado explicar este concepto (Martín et. al. 1996).

El primero de ellos está basado en relacionar la carga del cuidador con el tipo específico de deterioro y las necesidades del paciente, de acuerdo a las dificultades que se 
presenten al cuidador en resolver dichas necesidades. En este modelo a mayor deterioro del paciente mayor carga en el cuidador. Los instrumentos desarrollados para valorar la carga desde este modelo constan de un listado de problemas que pueden presentar los dependientes y que sean significativos para los cuidadores. Como ejemplo de este tipo de instrumento está la Escala Comportamental de Gilleard (Behaviour Chek List).

Una segunda forma de medir la carga consiste en emplear instrumentos no específicos, que miden dimensiones como calidad de vida y/o presencia de síndromes psicopatológicos (ansiedad o depresión). De este modo existen trabajos que para medir la carga del cuidador han utilizado el Inventario de Depresión de Beck o la Escala de Autoevaluación para la depresión de Zung, el Cuestionario de Salud General de Goldberg o con el Life Satisfaction Index que mide la calidad de vida.

Un último modelo se deriva de la teoría general del estrés, entendiendo que el cuidador debe enfrentarse a determinados factores estresantes, y su respuesta está mediada por procesos psicológicos (el impacto emocional ante los factores estresantes, principalmente), la posibilidad de utilización de soporte sociofamiliar y estrategias de manejo. El cuidador, como resultado de la interacción entre acontecimientos estresantes y mediadores de respuesta, puede experimentar una vivencia subjetiva de sobrecarga (burden), como otras consecuencias negativas en su salud. En este enfoque se diseñaron instrumentos como la Cargiver Burden Scale de Zarit o Escala de Sobrecarga del Cuidador de Zarit (Zarit 1980 en Martín 1996).

Este último instrumento es el que será utilizado para obtener información al respecto de la carga que experimenten los cuidadores a entrevistar en esta investigación. La Escala de Sobrecarga del Cuidador de Zarit es un instrumento autoadministrado del cual existen varias versiones, la más utilizada es la que está conformada por 22 ítems, mayores detalles de cómo funciona esta escala aparecen en el apartado metodológico y la versión a aplicar está en el anexo 5. 


\subsection{Maltrato en el entorno del cuidado}

El cuidado está íntimamente relacionado con el maltrato y de hecho las relaciones de cuidado tienen un carácter fuertemente ambivalente. Del lado del cuidador/a, por el hecho de tender a la conexión con el otro, por suponer que debe y es capaz de anticipar lo que desea y que debe anteponer las necesidades de quien requiere cuidados a las propias, se enfrenta a un conflicto. Se mueve entre la afirmación de su identidad, forzando a que el objeto de sus cuidados tenga para con él/ella actos reconocimiento por la atención y cuidados recibidos, y la negación de la propia subjetividad por anteponer el otro y sus necesidades a lo que el cuidador desea o necesita, que siempre queda en segundo término. El otro y su bienestar es un fin para quien le atiende, pero al mismo tiempo es un instrumento, el medio del que se dota para confirmar su propia potencia e invulnerabilidad. La posición de cuidadora o cuidador requiere encontrar el equilibrio entre dos estados emocionales (Izquierdo 2003). En el ámbito de los cuidados a la dependencia, el tema del maltrato ha sido investigado principalmente en el grupo de las personas mayores, por ello gran parte de éste epígrafe se centra en este grupo.

El maltrato al anciano emerge como problema social hace pocos años y no porque antes no existiera, sino porque siempre ha sido un problema "oculto". A veces los ancianos no quieren reconocerse como víctimas de malos tratos por temor a represalias, o al confinamiento en instituciones, o simplemente porque prefieren negar una realidad que les resulta insoportable; por otra parte, los familiares o los cuidadores, no van a dar facilidades en la detección por razones obvias, y la respuesta de los profesionales sanitarios al problema generalmente se ve truncada por la escases de recursos sociales para dar una solución al problema.

Existe un gran acuerdo entre los investigadores en que no ha habido una definición universalmente aceptada de lo que son los malos tratos hacia las personas mayores. Esta falta de acuerdo se ve reflejada, por ejemplo, en la gran variedad de términos que se han utilizado para referirse a ellos. Daly y Jogerst (en Touza, Segura y Prado 2009) destacan el uso de términos como el "síndrome de mayor vapuleado" (battered elder syndome), "maltrato hacia los mayores, "abuso de los abuelos" (granny abuse), "abuelas vapuleadas" (granny battering), "padres vapuleados" (parent battering) o "maltrato en la vejez (old age abuse). 
En los últimos años, se ha venido realizando un especial esfuerzo desde distintos países y organismos por llegar a una definición aceptada internacionalmente, con este objetivo, desde la Red Internacional de Prevención del Abuso y Maltrato a la Vejez (INPEA) y la Organización Mundial de la Salud, se han promovido diversos encuentros internacionales; sus resultados han sido recogidos en la "Declaración de Toronto" para la prevención global del maltrato de las personas mayores, en la que se define maltrato como:

La acción única o repetida, o la falta de respuesta apropiada, que ocurre dentro de cualquier relación donde existe una expectativa de confianza y la cual produzca daño o angustia a una persona anciana. Puede ser de varios tipos: físico, psicológico/emocional, sexual, financiero o simplemente reflejado en un acto de negligencia intencional o por omisión (Organización Mundial de la Salud 2002:2).

En España, en 1996, se celebró la I Conferencia Nacional de Consenso sobre el Anciano Maltratado, de la que surgió la Declaración de Almería, según la cual:

Maltrato a mayores sería todo acto u omisión sufrido por personas de 65 años o más, que vulnera la integridad física, psíquica, sexual y económica, el principio de autonomía o un derecho fundamental del individuo; que es percibido por éste o constatado objetivamente, con independencia de la intencionalidad y del medio donde ocurra (familiar, comunidad e instituciones). (Kessler et al 1996:369).

Otra definición utilizada en la literatura científica es la aportada por el Consejo de Europa que define al maltrato como: "todo acto u omisión cometido contra una persona mayor, en el cuadro de la vida familiar o institucional, y que atente contra su vida, seguridad económica, integridad física-psíquica, su libertad o comprometa gravemente el desarrollo de su personalidad" (Conseil de l'Europe en Muñoz 2004:20).

Comparando estas definiciones podemos observar que:

1. Todas coinciden en señalar que los malos tratos hacia las personas mayores pueden consistir tanto en acciones cono en la omisión de acciones.

2. La intencionalidad de la conducta de la persona que maltrata es citada en las definiciones para indicar que no es un requisito necesario para que se considere la existencia de una situación de malos tratos. 
3. Los malos tratos hacia las personas mayores se pueden dar en el ámbito de la comunidad, en una institución o dentro de la familia.

4. Los malos tratos se definen teniendo en cuenta tanto el daño real como el potencial. Los daños pueden ser físicos, psicológicos, económicos, restricciones a la libertad de la persona o cualquier otro derecho fundamental que se vea vulnerado (Touza et al.2009).

Previo al abordaje de la tipología de maltratos, Isabel Iborra (2005) en su texto "concepto y tipos de maltrato de mayores" realiza dos importantes precisiones a tener en cuenta:

i) En primer lugar, es necesario distinguir entre contextos en los que se desarrolla el maltrato y tipos de maltrato. La familia y las instituciones son los dos principales contextos en los que pueden desarrollarse los distintos tipos de maltrato. El maltrato familiar e institucional no son, pues, tipos de maltrato propiamente dicho sino diferentes ámbitos en los que el mismo puede aparecer en sus diversas manifestaciones.

ii) En segundo lugar, a la hora de determinar el tipo de maltrato que está sufriendo una persona no debemos confundir las acciones abusivas con las consecuencias de estos abusos. Esto es, aunque la mayoría de conductas negligentes tendrán como resultado efectos físicos (úlceras de decúbitos, por ejemplo), no deben calificarse de maltrato físico. Del mismo modo, un abuso sexual o, incluso, un abuso económico pueden tener efectos psicológicos devastadores en la víctima, pero no por ello diremos que han sufrido un maltrato emocional o psicológico. No se debe calificar los tipos de maltrato que sufren las personas mayores por los tipos de efectos que éstos tengan en las víctimas (Iborra 2005).

\subsubsection{Tipos de maltrato}

En la literatura especializada no existe consenso en el establecimiento de una tipología común. El Centro Reina Sofía establece cinco categorías dentro del maltrato de personas mayores: maltrato físico, maltrato emocional, negligencia, abuso económico y abuso sexual. Se trata de la misma tipología que tradicionalmente se ha empleado en el maltrato infantil pero añadiendo, por razones obvias, el abuso económico (Iborra 2005). Esta clasificación coincide con la de diversos autores (Bazo 2004; Brown, Kingston y Wilson 1999) y con la de INPEA y Action on Elder Abuse, dos de las organizaciones 
que más en profundidad se han dedicado en los últimos años al estudio del maltrato de personas mayores. Así, el Consejo de Europa establece seis categorías, entre las que se pueden encontrar la violación de derechos y la violencia medicamentosa. El National Center on Elder Abuse considera dos tipos (además de las 5 categorías definidas por el Centro Reina Sofía): el abandono y la auto-negligencia (Iborra 2005).

La tipología que presentamos a continuación es la desarrollada por Muñoz Tortosa (2004), que propone cuatro categorías de maltrato de tipo primario, más una en donde aglutina las que pueden resultar difíciles de clasificar dentro de las condiciones previas.

\section{Malos tratos físicos}

Una persona maltratada físicamente es, conceptualmente, la que sufre agresiones físicas por parte de alguna/s persona/s de su entorno (familiar, cónyuge, hijo, cuidador, vecino, etcétera) y cuya conducta puede poner en peligro su desarrollo físico, social o emocional.

Cualquier conducta de abuso o de abandono que provoque lesiones /enfermedad /trastornos independientemente de su gravedad y de su cronicidad (aunque sólo tenga lugar alguna vez), se debe considerar maltrato. Sin embargo, el maltrato físico tan sólo representa una pequeña parte de todo lo que supone el problema en sí.

\section{Malos tratos psicológicos o emocionales}

Las investigaciones concuerdan en determinar que esta forma de abuso es la más frecuente, se produce cuando el cuidador inflige agresión verbal crónica, angustia o aflicción mental que hiere la identidad y dignidad de la persona dependiente. El abuso psicológico supone la deshumanización de la víctima a través del miedo, las amenazas, el abuso verbal, etc.

Algunos autores han identificado subtipos de maltrato psicológico, de esta forma, se señalan el rechazo/degradación (negarse a ayudar, no hacer caso a las peticiones de ayuda e insultar, despreciar o humillar), el terror (se produce con amenazas, lesiones o abandono de la persona) y el aislamiento.

\section{Negligencia}

Se produce cuando se actúa intencionadamente para no atender las necesidades de la persona, y puede manifestarse en un sentido activo o pasivo. 
La negligencia activa sucede cuando los cuidadores, aun siendo conscientes de sus obligaciones, rehúsan prestarle la atención necesaria. Los actos más comunes de negligencia se centran en malnutrición, higiene personal inadecuada, denegación liberada de asistencia médica o de medicamentos y abandono.

La negligencia pasiva u olvido es otro de los malos tratos más comunes sufridos por las personas mayores, y sucede cuando al anciano no se le tiene en cuenta para nada, se le confina en el último rincón del hábitat familiar o institucional y se olvida llamarle para comer, asearse, hablar, relacionarse, etc.

Algunas clasificaciones de maltrato incluyen en esta tipología el self-neglect o autonegligencia, que se caracteriza como la amenaza hacia la propia salud o seguridad. En los ancianos, la autonegligencia se manifiesta como una negativa o falta de servicio a sí mismo de comida adecuada, agua, vestimenta, abrigo, higiene personal, medicación (como es prescrita) y medidas de seguridad.

\section{Violencia económica}

Es difícil definir la violencia económica porque no se considera sólo como el acaparamiento de los bienes materiales de la persona cuidada, sino que se considera también la actitud del perpetrador al realizar estas acciones. Con frecuencia la violencia económica desemboca en violencia física o psicológica y aparece tanto en el medio familiar como en el ámbito institucional. Las personas mayores están particularmente expuestas a sufrir la violencia económica debido a su fragilidad física y a su escasa capacidad para defenderse.

\section{Otros tipos de maltrato}

- Violación de derechos; incluye la violación de la Declaración Universal de los

Derechos Humanos, que establece derechos básicos en las esferas civil, política, social económica y cultural.

- Abuso sexual; es todo contacto sexual sin consentimiento, incluido la violación, el atentado al pudor y el acoso sexual por parte del encargado de cuidar a una persona dependiente. Se debe dejar constancia que algunos autores lo incluyen dentro del maltrato físico (Iborra 2005). 
- Violencia medicamentosa; se la considera como administración inadecuada de medicamentos al dependiente por parte del cuidador. Incluye las acciones deliberadas o accidentales.

\subsubsection{Factores de riesgo}

Es importante tener en cuenta que el maltrato a mayores no es la consecuencia de un único factor, sino el resultado de la combinación de factores personales, familiares, sociales y culturales. Los factores de riesgo de maltrato pueden agruparse en función de si están presentes en la persona mayor, en el responsable del maltrato o en el contexto de la situación de cuidado. Algunos factores de riesgo están presentes tanto en el ámbito comunitario como en el institucional. Aquí se expondrán únicamente los asociados al ámbito familiar, contexto en el que se produce el maltrato hacia las personas mayores con mayor frecuencia (Pérez Rojo 2008).

En primer lugar, entre los factores de riesgo presentes en la persona mayor cabe destacar el género, ser mujer es un factor de riesgo. Otros factores de riesgo serían la edad, de manera que a mayor edad, mayor riesgo; el estado civil, siendo las personas casadas las que presentarían más riesgo; determinados rasgos de personalidad, como que la persona se culpe de la situación, que muestre lealtad excesiva hacia el responsable del maltrato, o resignación; la presencia de comportamientos provocadores y/o agresivos, presentes especialmente en personas con demencia; el deterioro cognitivo -demencia, enfermedad de Alzhéimer-; y la dependencia (física, económica, etc.) aunque en este aspecto no hay resultados concluyentes, y no puede asumirse una relación directa entre la dependencia y el maltrato- (Pérez Rojo 2008).

En segundo lugar, entre los factores de riesgo presentes en el responsable del maltrato, cabe señalar el género, siendo las mujeres las que, al asumir con mayor frecuencia el cuidado de la persona mayor, presentan mayor riesgo de infligir malos tratos. Otras investigaciones señalan que el género está relacionado con el tipo de maltrato (Pillemer y Wolf: Penhale en Pérez Rojo 2008), los hombres serían más frecuentemente responsables del maltrato físico, mientras que las mujeres lo serían de negligencia. También son factores, que han sido relacionados con la probabilidad de maltrato hacia las personas mayores, la inexperiencia -falta de conocimientos y entrenamiento 
adecuados- en el cuidado de una persona mayor, la presencia de trastornos psicológicos -depresión, ansiedad, demencia-, determinados factores de personalidad - que culpe a la persona mayor de la situación, no tenga paciencia, o que no comprenda sus necesidades, el abuso de sustancias como el alcohol u otras drogas, la presencia de sentimientos negativos, como la ira y la hostilidad, el estrés, la sobrecarga y la dependencia económica del cuidador de la persona mayor.

En último lugar, entre los factores de riesgo presentes en la situación de cuidado, se encuentran la cantidad de ayuda (formal e informal) recibida, siendo los cuidadores que menos ayuda reciben los que presentan mayor riesgo de maltrato; la falta de contactos informales y/o formales, es decir, el aislamiento social, tanto en el cuidador como en la persona mayor; el desgaste de los vínculos intergeneracionales; la convivencia conjunta del cuidador y la persona mayor; la calidad de la relación entre el cuidador y la persona mayor -anterior y actual-, siendo más probable el riesgo cuanto peor es la calidad de la relación en ambos momentos; y el número de personas que ocupan la vivienda, ya que si el domicilio es compartido por demasiados individuos se puede producir falta de espacio e intimidad.

\subsection{Pobreza y Cuidado}

Finalmente, nos parece importante referirnos a un aspecto substancial del cuidado informal en países en donde los Estados no han desarrollado iniciativas a favor de la protección de la dependencia o éstas son insuficientes -el caso de los países latinoamericanos-: el empobrecimiento de las familias y por ende de los cuidadores. En dichas naciones el cuidado informal a los ancianos, enfermos crónicos, discapacitados o cualquier tipo de dependiente se caracteriza por ser un trabajo no-pagado, femenino y devaluado.

Desde la perspectiva de la feminidad del cuidado, análisis y discusiones llevaron a mostrar que existía un empobrecimiento a causa de éste (Robles 2003b). Desde una visión macrosocial se han identificado tres mecanismos o vías de ello: a) el cuidado es un no-trabajo; b) el cuidado es incompatible con el trabajo remunerado y; c) no hay prestaciones sociales para las cuidadoras. 
a) El cuidado es un no-trabajo porque pertenece a la esfera privada o del ámbito del hogar. El trabajo se da exclusivamente en el mundo laboral externo al hogar, "en la casa no existe". Las acciones del hogar son acciones de la reproducción social y éstas no generan bienes ni servicios sino exclusivamente prácticas simbólicas que no son valorizadas como trabajo. Además, las prácticas del mundo laboral son trabajo pagado y las del hogar no; debido a que son concebidas como no-trabajo, son prácticas que no reciben remuneración económica.

b) El trabajador "ideal" en las sociedades modernas es quien cumple una jornada laboral de 40 horas semanales durante todo el año y está disponible para trabajar horas extras porque no tiene compromisos familiares que se lo impidan, como el cuidado de los niños y/o los dependientes. Esto conlleva a que el trabajo siempre es prioritario sobre el resto de las esferas de la vida cotidiana, como sería la familia, la diversión, el descanso, la actividad social. Y como el mercado laboral está estructurado prioritariamente bajo este esquema, las cuidadoras frecuentemente no pueden desempeñarse como trabajadores "ideales" ya que las demandas del cuidado se lo impiden. El que el trabajo compita con el cuidado hace que la mujer trabajadora y cuidadora al mismo tiempo abandone o reajuste sus jornadas laborales. Las mujeres dejan el empleo porque son una fuerza de trabajo sacrificable, ya que su ingreso es complementario y menor al percibido por el proveedor económico de dicho hogar.

c) La salida del mercado laboral de las mujeres cuidadoras implica la disminución de sus ingresos o pérdida de un ingreso propio, así como de las prestaciones sociales de un trabajo remunerado y, a largo plazo, supone ingresar a la vejez en peores condiciones económicas que sus pares que permanecieron en el ámbito del trabajo remunerado.

Esta visión evidencia la concepción de que el cuidado es una responsabilidad de la familia y no del Estado. Se argumenta que ahí, al interior del hogar, se encuentran los mejores espacios y las relaciones interpersonales óptimas para que cualquier tipo de dependiente reciba un cuidado de calidad. De intervenir el Estado, se cree, se desalentaría el cuidado familiar y se abandonaría a los dependientes a los servicios estatales. Esta negativa para asumir la responsabilidad estatal a través de servicios directos a los dependientes, se extiende también a sus cuidadores. 
Estos tres mecanismos, -el cuidado no es trabajo, es incompatible con el trabajo remunerado y la ausencia de políticas sociales dirigidas a las cuidadoras- originan que la mujer cuidadora experimente una reducción significativa de su capital económico a lo largo de su vida, es decir, empobrece. Estas circunstancias las colocan en una situación de vulnerabilidad y dependencia económica con respecto a terceros durante el cuidado y posterior a él.

El capital humano adquirido por el cuidado no puede transferirse al mercado laboral, en éste el sujeto se habilita para desempeñarse como trabajador que le permite colocarse en puestos ocupacionales. Estos rasgos están ausentes en el capital acumulado con el cuidado porque es una acción de la reproducción social, los cuidadores terminan como individuos no competitivos a nivel laboral. En la década de 1990, la perspectiva de la discusión cambió de enfoque: las diferencias y las particularidades de los contextos comenzaron a tomarse en cuenta para explicar esta compleja relación entre cuidado y empobrecimiento. La premisa es que no todas las cuidadoras empobrecen de la misma manera, ni enfrentan contextos sociales y políticos similares para desempeñar su rol en las mismas condiciones, por lo que algunas lo hacen en situaciones de pobreza, pero otras no (Robles 2003b). 


\section{CAPÍTULO IV: LA DEPENDENCIA Y LOS CUIDADOS A PERSONAS EN SITUACIÓN DE DEPENDENCIA EN CHILE}

\subsection{Contexto}

En las últimas cuatro décadas, Chile ha experimentado notables cambios en su política social, que radican principalmente en acontecimientos históricos que afectaron al país. En 1973 se produce el golpe de Estado al gobierno socialista, elegido democráticamente, y se instaura una dictadura que se mantuvo por 17 años.

El primer gobierno de la Concertación de partidos por la democracia se encontró, en 1990, con un país que, en el plano económico, tenía sus cuentas fiscales equilibradas y crecía a un ritmo sostenido. Este cuadro económico favorable se contraponía con un significativo déficit en el plano social. La inestabilidad de la economía en la década de 1970 y 1980, sumada a una fe ciega en el mercado y a intentos significativos y perseverantes por "desmontar" el Estado social, que se había construido en el país a lo largo del siglo $\mathrm{XX}$, traspasaron al mercado y al sector privado el máximo de las decisiones y responsabilidades, reformando las instituciones y la gestión de la política social. Estas reformas implicaron el traspaso de la gestión de los servicios y la ejecución de programas a entes subnacionales y/o del sector privado (descentralización, en particular traspasando responsabilidades en el área social a las municipalidades, y privatización que se expresó en la incorporación de agentes privados en la entrega de servicios) y la incorporación de mecanismos de mercado e incentivos económicos en el funcionamiento de los servicios (subsidios a la demanda, facturación por atención prestada en salud). Como consecuencia de estas reformas se dispararon las tasas de desempleo, que en los peores momentos alcanzaron cifras superiores al 30\% de la población potencialmente activa (Ffrench-Davis en Raczynski y Serrano 2005). Se produjo, a la vez, una caída en el valor real de los salarios y en la cobertura de la previsión social, deterioro en la infraestructura, manutención y equipamiento de los sectores sociales, así como en la situación laboral de sus funcionarios y profesionales. Además, se produjo un importante incremento en el déficit habitacional, que afectó con 
particular intensidad a los estratos de escasos recursos y una reducción de los espacios públicos, los cuales eran tradicionalmente ocupados por los diversos estratos sociales.

Dicha situación obligó al gobierno militar a crear una red social dirigida a los sectores en pobreza crónica y a los que se vieron afectados negativamente por la operatoria del mercado o no lograron acceder a él. Para estos sectores se definieron ayudas como el Subsidio Único Familiar (SUF), la pensión asistencial, centros abiertos, etc. El conjunto de las acciones en el ámbito social se focalizó en los sectores más pobres, desarrollando instrumentos para lograr esta meta. Surge la ficha de caracterización socioeconómica (ficha CAS) y más adelante la Encuesta de Caracterización Socioeconómica (CASEN).

Así también, la estructura de la educación regular acentúo su segmentación social, algo similar ocurrió con la atención médica y de salud. En las grandes ciudades, en particular Santiago, producto de políticas vinculadas al mercado de uso del suelo y de erradicación de población, desde comunas con mejores niveles de vida y más centrales a comunas periféricas, se hizo cada vez menos frecuente la interacción entre estratos sociales. De acuerdo a el economista Ricardo Ffrench-Davis, en el momento más agudo, el 25\% de los hogares fueron calificados como indigentes y el $20 \%$ de pobre no indigente ${ }^{18}$. Al recuperarse la economía, a partir de 1985-86, estas cifras mejoraron, no obstante su nivel en 1989-90 reflejó una situación deteriorada respecto a la que imperaba veinte años antes. La concentración del ingreso familiar aumentó fuertemente y el nivel de gasto de los hogares del Gran Santiago ${ }^{19}$ mostraba un deterioro continuo en el $60 \%$ de los hogares con menor gasto, deterioro que fue más acentuado mientras más pobre era el sector de la población. El 40\% más pobre de los hogares perdió participación, desde un $19,4 \%$ en 1969 a un $14,5 \%$ en 1978 y a un $12,6 \%$ en 1988 , situación que contrasta con el quintil más alto que aumentó su participación de un $44,5 \%$ a un $51,0 \%$ y un $54,9 \%$ en los años antedichos (Ffrench-Davis en Raczynski y Serrano 2005).

\footnotetext{
${ }^{18}$ La definición de pobreza, utilizada en Chile, está referida a la línea de pobreza, la cual se calcula en base al ingreso per cápita total del hogar. Si ese ingreso no alcanza el valor de una canasta básica de alimentos (que contiene los requerimientos calóricos mínimos para asegurar la subsistencia del individuo, definida por la CEPAL), las personas que componen ese hogar son indigentes. Por otra parte si ese ingreso se encuentra entre una y dos canastas, las personas de ese hogar son pobres no indigentes (Ministerio de Planificación s.f.).

${ }^{19}$ Con Gran Santiago se hace referencia a todas las comunas urbanas de la Región Metropolitana, y no solo a la comuna llamada Santiago-centro.
} 
El primer gobierno "concertacionista" recibió un país con un presupuesto social disminuido, déficits importantes en infraestructura y equipamiento, educación y salud, además los funcionarios que trabajaban en estos sectores se sentían molestos con las reformas descentralizadoras y privatizadoras de esos años; también destacamos la existencia de municipalidades que no habían asumido liderazgo alguno en materias de desarrollo social y combate a la pobreza y limitaban su rol social a la administración de los servicios de educación y salud y la red social compensatoria que les fue impuesta contra su voluntad. La política social se concebía como un despliegue de medidas paliativas de asistencia a los más pobres; no había programas de desarrollo orientados a grupos vulnerables y los conceptos de derechos y ciudadanía estaban del todo ausentes.

Con el regreso del país a la democracia, en el año 1990, se produjo una reafirmación del papel que debe jugar el Estado en el ámbito social y una redefinición de la relación entre crecimiento económico y desarrollo social, enfatizando la complementariedad de ambos procesos.

Rasgos característicos del período de los gobiernos de la Concertación fueron:

- Una política social más activa en lo sectorial y en el diseño de nuevas instituciones y programas sociales.

- Una política social orientada preferentemente a los sectores pobres, pero que intenta no dejar de lado el apoyo a los sectores medios que viven precariamente y que aborda temas transversales como la calidad de la educación, la problemática de género, el acceso a la justicia, etc.

- Una formulación más compleja de los objetivos, contenidos y prioridades de la política social orientada específicamente a los sectores pobres, intentando transformaciones desde una acción asistencial a una promocional.

- El refuerzo y ampliación de modalidades descentralizadas de ejecución de programas sociales y a través de terceros (ONGs, organizaciones sociales, sector privado lucrativo).

El proceso, obviamente, no fue homogéneo ni lineal, pero puede afirmarse que el primer paso fue dar un fuerte impulso a la política social sectorial; el segundo implementar programas para vulnerabilidades específicas y, simultáneamente, activar a los municipios como agentes del desarrollo local. Lentamente, la preocupación comenzó a 
trasladarse desde el problema de la cobertura -la llamada deuda social-, a problemas de calidad en los servicios entregados, pertinencia, eficiencia y respeto ciudadano en los procesos de gestión y entrega de los servicios. Más adelante comenzarían a levantarse preocupaciones sobre un ámbito más político: los temas de participación ciudadana, derechos, cuenta pública y ciudadanía social. A la vez, se comenzó a discutir cómo pasar desde la atención individual y de ventanilla a una red de apoyo o asistencia a las personas, familias y organizaciones (Serrano y Raczynski 2003).

El desarrollo del Estado social en Chile, desde 1990 hasta la fecha, ha introducido importantes modificaciones en materia de sus principios y conceptos originales, en sus objetivos, diseños y metodologías, y en sus formas de organización y gestión. Todas estas transformaciones apuntaron a una incorporación creciente y sistemática de elementos referidos a la equidad, la coparticipación de los actores de la protección y el bienestar social y la introducción de la temática de los derechos de ciudadanía, que en su conjunto modificaron sustancialmente el modus operandi de la política social de los años 80, al tiempo que permaneció y profundizó la descentralización de las tareas sociales, la provisión de servicios y ejecución de programas por parte de agentes no gubernamentales, con y sin fines de lucro, y la incorporación de criterios de mercado, de competencia y el aporte privado al financiamiento de los servicios y la asignación de recursos.

\subsection{Aspectos de la Política Social Chilena}

La política social de los gobiernos de la Concertación ${ }^{20}$, se encuadró dentro de dos principios, Crecimiento y Equidad, que tuvieron distintos énfasis a lo largo de los diferentes gobiernos “concertacionistas". La expansión de la política social se manifestó en los siguientes cambios:

a) Reforma tributaria e incremento del gasto social; la reforma tributaria, aprobada a pocos meses de la formación del primer gobierno de la Concertación, permitió incrementar significativamente el gasto social (aumento de $17 \%$ respecto al presupuesto heredado del gobierno militar, con aumentos adicionales en años siguientes). Las

\footnotetext{
${ }^{20}$ Entre 1990 y 2010, fueron cuatro los gobiernos de la concertación de partidos por la democracia. 1990 - 1994 Patricio Aylwin Azócar; 1994 - 2000 Eduardo Frei Ruiz-Tagle; 2000 - 2006 Ricardo Lagos Escobar; y 2006 -2010 Michelle Bachelet Jeria.
} 
primeras medidas fueron reajustar el valor del subsidio único familiar, la pensión mínima y las pensiones de bajo monto, aumentar los recursos para inversión, equipamiento, compra de insumos y salarios en educación y salud y para programas de vivienda y equipamiento comunitario, y poner en marcha algunas nuevas instituciones y programas.

Adicionalmente, aumentó el gasto con fines sociales, recurriendo a mecanismos de copago de la familia en educación y el desarrollo de modalidades de concesión privada para el financiamiento de grandes obras de infraestructura, "liberando" recursos públicos para destinarlos a fines sociales. El tercer gobierno de la Concertación logró subir en un punto el impuesto al valor agregado (quedando en 19\%), para financiar el Sistema de Protección Social Chile Solidario ${ }^{21}$ y el Plan AUGE en Salud ${ }^{22}$.

b) Rediseño de la institucionalidad social; se crearon numerosas agencias especializadas y programas de desarrollo que operaron al interior de dichas agencias. Ello dio cuenta de un cambio sustantivo en la lógica de acción de la política social, antes centrada casi exclusivamente en el desarrollo de temas sectoriales y subsidios sociales focalizados, y, con los gobiernos de concertación, articulados a través de una agenda social más compleja para abordar las necesidades específicas de la población. Esta nueva agenda social aplicó programas promocionales que entregaron herramientas, expandieron capacidades, fortalecieron la información y la voz de sus destinatarios. Es así como surgieron instituciones y programas dirigidos específicamente a población pobre urbana y rural, mujeres, campesinos, indígenas, jóvenes y discapacitados.

Estas instituciones cruzaron y combinaron dos órdenes de preocupaciones. Por un lado, la preocupación por la pobreza, y por otro, la preocupación por la vulnerabilidad social propia de cada uno de los segmentos poblacionales con su temática específica. Entre las instituciones creadas, y que están relacionadas con el objeto de este trabajo, corresponde

\footnotetext{
${ }^{21}$ Chile Solidario es el componente del Sistema de Protección Social que se dedica a la atención de familias, personas y territorios que se encuentran en situación de vulnerabilidad. Se creó en el año 2002, como una estrategia gubernamental orientada a la superación de la pobreza extrema. Posteriormente, la consolidación de una red institucional de apoyo a la integración social, la generación de mecanismos para la ampliación de las oportunidades puestas a disposición de las personas en los territorios y la instauración de la Ficha de Protección Social, permitieron que Chile Solidario ampliara su cobertura hacia otros grupos, generando iniciativas para atender diversas situaciones de vulnerabilidad que afectan a la población (Chile Solidario s.f.).

${ }^{22}$ El plan AUGE será tratado más adelante.
} 
mencionar al Ministerio de Planificación y Cooperación (MIDEPLAN, hoy Ministerio de Desarrollo Social) que diseñaba y aplicaba políticas, planes y programas de desarrollo social a nivel nacional y regional, proponía metas de inversión pública y evaluaba los proyectos de inversión financiados por el Estado, coordinaba las diferentes iniciativas del sector público encaminadas a erradicar la pobreza, orientaba la cooperación internacional que el país recibía, e implementaba y ejecutaba las políticas y programas orientados hacia grupos prioritarios -infancia, juventud, adulto mayor, discapacitados, mujeres e indígenas- a través de sus servicios relacionados. También destacamos al Fondo Nacional de la Discapacidad (FONADIS, hoy Servicio Nacional de Discapacidad SENADIS), entidad autónoma relacionada con el ejecutivo a través del Ministerio de Planificación y Cooperación, buscaba contribuir a la integración social y a la equiparación de oportunidades de las personas con discapacidad; entre sus principales servicios estaban la entrega de ayudas técnicas y ortoprotésicas, el Programa de becas de apoyo técnico para alumnos con discapacidad, las oficinas de intermediación laboral, orientadas a la colocación laboral de personas con discapacidad y fondos concursables ${ }^{23}$ de proyectos orientados a apoyar esta población. Por último, no podemos dejar de mencionar al Servicio Nacional del Adulto Mayor (SENAMA), sometido a la supervigilancia del Ministerio Secretaría General de la Presidencia, hoy dependiente del Ministerio de Desarrollo Social. Esta institución fue creada en 2002, siendo su principal función proponer políticas y coordinar acciones, especialmente del sector público, que faciliten la integración del adulto mayor en todos los ámbitos sociales, ya sea en la familia, en la educación, en el trabajo o en la recreación; también administra el Fondo Nacional del Adulto Mayor y coordina los beneficios de salud, educación, vivienda, turismo, deportes, justicia, discapacidad, transporte, destinados a este colectivo (Raczynski y Serrano 2005).

En marzo de 2010, asume la presidencia de Chile Sebastián Piñera, representante de la derecha política. Aunque su gobierno aún está en curso quisiéramos apuntar algunos aspectos relevantes de la política social desplegada hasta la fecha en que se escribe este trabajo (primavera de 2013).

\footnotetext{
${ }^{23}$ Los fondos concursables eran mecanismos de asignación de recursos, que le otorgaban a los propios ciudadanos la responsabilidad de definir e implementar lo que ellos consideraran necesario para mejorar su calidad de vida. Para las organizaciones sociales, el acceso a financiamiento constituía una importante herramienta ya que los hacía participe en los procesos de desarrollo que vivía el país.
} 
En su primer discurso, el presidente apunta que el eje principal de su política social estaría centrado en el esfuerzo para que el país se convierta en un país desarrollado, en donde se elimine la pobreza y exista igualdad de oportunidades (Piñera 2010). En esta tarea, afirmaba que el rol del Estado era fundamental para garantizar que la población tuviese la oportunidad de acceder a niveles mínimos de bienestar, que le aseguraran una vida digna y confortable. Dentro de los principales hitos de la política social desarrollada por este gobierno destacan (Ministerio Secretaria General de la Presidencia 2011):

- La creación del Ministerio de Desarrollo Social, institución responsable de la coordinación de las políticas sociales y de la correcta focalización de éstas.

- La implementación del Ingreso Ético Familiar, beneficio dirigido a las familias más vulnerables con la finalidad de que superen dicha situación.

- La disminución de un 95\% de las listas de espera AUGE, y la implementación del Bono automático AUGE que permite a los pacientes, en lista de espera, recibir atención oportuna (efectivo con prestadores públicos y privados).

No podemos dejar de apuntar que a este gobierno le correspondió asumir la reconstrucción del país tras el terremoto del 27 de febrero de 2010, acontecimiento que generó importantes daños en la infraestructura pública y privada de la zona más densamente poblada del territorio.

Las críticas que se realizan a la política social de este gobierno apuntan a la forma de resolver las problemáticas que se han planteado en áreas como salud o educación, en donde la profunda desconfianza frente a la gestión pública (ya presente en los últimos gobiernos de la Concertación), reflejada en la baja inversión en estas áreas, incentiva de forma creciente la compra de servicios al sector privado. Es por esto que las acciones de política social emprendidas son vistas como una continuidad de las políticas sociales de los gobiernos anteriores, aún cuando es probable que se acentúen los esfuerzos por ampliar la participación privada de servicios (Rivera s.f.).

Antes de comenzar el análisis por áreas de la política social referente a las problemáticas que tocan más directamente nuestro tema de estudio, quisiéramos advertir 
un elemento que aparece de forma reiterada en nuestra revisión. En la actualidad, la Ficha de Protección Social (ex Ficha CAS) es el instrumento de estratificación social que utiliza el Estado para seleccionar a los beneficiarios de los programas sociales que tienen como objetivo atender a la población en situación de vulnerabilidad en Chile. Este instrumento pretende identificar a las familias vulnerables, asignándoles un puntaje que expresa la medición de la capacidad generadora de ingresos de los miembros del hogar, ajustado al nivel de necesidades económicas y cuantificadas en relación al número de personas residentes en el hogar (considerando las necesidades especiales de miembros que presenten algún tipo de discapacidad física o mental).

El Ministerio de Desarrollo Social era el responsable del diseño y administración de la información proporcionada por esta herramienta, y los municipios se encargaron de recolectar la información. Su aplicación comenzó a mediados del 2006 y las estadísticas indican que a fines de 2009 ya se habían encuestado a cerca de 11 millones de personas (equivalentes a dos tercios de la población nacional). Los principales problemas de este instrumento radican en la utilización de algunas variables que no están sujetas a un proceso de verificación, y las diferencias importantes en los criterios que utilizan los equipos comunales que realizan las entrevistas para reportar la discapacidad (Herrera, Larrañaga y Telias 2010).

\subsubsection{La salud en Chile}

Consideramos necesario comenzar nuestro análisis con la descripción del sistema de salud, debido a que creemos que ésta es una de las áreas en donde el contacto de lo privado - la labor del cuidado del dependiente- con lo público -relación con el sistema de salud- es más frecuente y cotidiano. Además, el sistema de salud chileno tiene particularidades que resultan importantes de exponer para poder comprender el contexto en el que nuestro grupo de estudio se desempeñaba. Comenzaremos nuestro examen contextualizando las condiciones generales de salud de los chilenos.

\subsubsection{Condiciones de salud}

Chile, junto a Cuba y Costa Rica, presenta los mejores niveles de salud de América Latina. De acuerdo a los indicadores proporcionados por la Organización Panamericana de salud para el año 2012 (Organización Panamericana de Salud 2012), el país 
presentaba una de las tasas de mortalidad infantil más bajas de América Latina -6,9 menores de un año por 1.000 nacidos vivos-, solo superada por Cuba, y que contrasta con la media de la región, 15,5. La mortalidad materna también presenta una baja razón, 18,3 (por 100.000 nacidos vivos) muy por debajo de la razón media para América Latina $(69,1)$. Por último, la esperanza de vida aumentó de 63,5 años en 1970 a 79,3 años (82,4 años para las mujeres y 76,2 años en hombres), siendo solo superada por los 79,5 años de esperanza de vida de Costa Rica. Estas cifras representan los enormes avances en el mejoramiento de la salud y hace que los chilenos tengan en la actualidad una probabilidad de vivir al nacer cuatro veces mayor que la que presentaban en el siglo pasado.

La transición epidemiológica que ha acompañado a estos cambios está caracterizada por un brusco descenso en las enfermedades transmisibles y un gradual incremento de enfermedades no transmisibles. De acuerdo a los datos aportados por la Encuesta Nacional de Salud 2009-2010 (Ministerio de Salud s.f.), entre las enfermedades con mayor prevalencia en la población chilena están el sobrepeso (39,3\%), el colesterol elevado $(38,7 \%)$, la hipertensión $(26,6 \%)$ y la obesidad $(25,1 \%)$, patologías que tienen directa relación con los estilos de vida de la población. Entre las principales causas de muerte en Chile para el año 2010 estaban las enfermedades del sistema circulatorio, los tumores malignos y muy por detrás las enfermedades del sistema respiratorio (INE 2012).

Además, la Encuesta Nacional de Salud 2009-2010 destaca que la mayor parte de los problemas de salud crónicos de los chilenos, muestran una tendencia educacional evidente, ya que hay mayor prevalencia de ellos en la población con menos de ocho años de estudios. Este grupo de población está conformado por personas de mayor edad, sin embargo, en dicho estudio se observan gradientes estadísticamente significativas para muchos problemas de salud aún controlando por el efecto de la composición por sexo y edad, denotando la conjunción de otros factores que determinan que los estratos socialmente más empobrecidos presenten mayor carga de morbilidad y factores de riesgo. 


\subsubsection{Sistema de salud en Chile}

El sistema de salud que operaba en Chile al momento de la realización de esta investigación es fruto de las severas reformas emprendidas en los años 80’ y de los ajustes al sistema que los gobiernos de la Concertación realizaron en las dos décadas que gobernaron. La ley establece que los trabajadores activos debían cotizar un 7\% de sus ingresos mensuales para su seguro de salud. Los cotizantes podían optar entre dos sistemas, un sistema público que opera con la lógica solidaria de la seguridad social y un sistema privado, a modo de seguros de salud, con una clara orientación individual. Los afiliados al sistema público obtenían preferentemente acceso a la atención en salud a través de los centros de atención primaria administrados por los municipios, y a la red de hospitales públicos ${ }^{24}$. Por otro lado, los adscritos al sistema privado, a las instituciones de salud previsional más conocidas como Isapres, accedían a prestadores privados a través de una modalidad de libre elección, la cual utiliza como método de pago un sistema de reembolso por prestaciones otorgadas.

De acuerdo a las estadísticas que maneja el Fondo Nacional de Salud (Fondo Nacional de Salud s.f.) para el año 2011, un 76,2\% de la población nacional era beneficiario del sistema público, un 16,9\% del sistema Isapres, y un 6,9\% eran particulares y miembros de las Fuerzas Armadas ${ }^{25}$ que no se encontraban en ninguno de los dos sistemas anteriores.

El sistema público era presidido por el Ministerio de Salud, organismo que se encargaba del diseño de políticas y programas y la coordinación de las entidades del área. La institución encargada de recaudar, administrar y distribuir los recursos financieros del sistema público era el Fondo Nacional de Salud (Fonasa). Es este servicio el que gestionaba el seguro social de salud de los usuarios del sector público.

\footnotetext{
${ }^{24}$ En el sistema público de salud también existe la libre elección de prestadores privados, aunque está limitada a los cotizantes de mayores ingresos. La modalidad libre elección del sistema público es entregado por profesionales y establecimientos de salud privados que hayan suscrito convenio con FONASA. Los hospitales públicos atienden bajo esta modalidad en el caso que el usuario elija su médico tratante y/o se hospitaliza en una sala de pensionado o medio pensionado.

${ }^{25}$ Los miembros de las Fuerzas Armadas (Ejército, marina, aviación y policía) y sus familias son beneficiarios de un seguro de salud ajeno a Fonasa y las Isapres que les presta atención en instalaciones y con proveedores propios. Este seguro de salud se financia con los impuestos generales (BecerrilMontekio, Reyes y Annick 2011).
} 
La atención pública de salud primaria estaba a cargo de los Centros de Atención Primaria $^{26}$ que proporcionaban servicios curativos de baja complejidad técnica a través de una modalidad de atención abierta a la vez que se realizaban actividades de fomento y prevención de salud. Las prestaciones de atención secundaria y terciaria de salud pública estaba a cargo de los servicios de salud, 29 a lo largo de Chile, que poseían una red de establecimientos hospitalarios, Centros de diagnóstico terapéuticos (CDT), Centros de Referencia de salud (CRS) y Consultorios adosados de Especialidades (CAE).

El sistema de salud privado estaba conformado principalmente por las Isapres, pudiendo estas ser abiertas o cerradas ${ }^{27}$. Las Isapres abiertas prestaban sus servicios a través de proveedores privados de salud como clínicas, hospitales y profesionales independientes. En algunos casos las Isapres ofrecían en forma directa prestaciones de salud, integrando verticalmente las actividades de seguro y producción del servicio. Las mutuales también formaban parte del sistema privado de salud, éstas ofrecían cobertura a sus trabajadores afiliados para accidentes laborales y enfermedades profesionales. En 2010 existían tres mutuales en el país y estas proveían atención en instalaciones médicas propias.

Un importante grupo de trabajadores independientes y/o de la pequeña empresa que no estaban afiliados a las mutuales tenían cobertura de una entidad estatal, el Instituto de Previsión Social-IPS (ex Instituto de Normalización Previsional-INP) y, en caso de enfermedades profesionales o accidentes laborales, recibían atención en los hospitales del sector público.

La regulación del sistema era responsabilidad del Ministerio de Salud, quien tenía a su cargo la supervisión, evaluación y control de las políticas de salud. Por otra parte la Superintendencia de Salud, organismo público descentralizado, se responsabilizaba de supervigilar a las Isapres y al Fonasa, velando por el cumplimiento de las obligaciones que les imponga la ley, además fiscalizaba a todos los prestadores de salud públicos y privados, respecto de su acreditación y certificación.

\footnotetext{
${ }^{26}$ Existen diferentes tipos de centros de Atención primaria: Estación médico rural, posta de salud rural, Consultorios generales (urbanos y rurales), Servicio de Atención Primaria de Urgencia (SAPU), Consultorios de Salud Mental, Centro de salud familiar (Cesfam).

${ }^{27}$ Las Isapres abiertas son 7 y dan atención al 97,3\% de los afiliados al sistema privado; las Isapres cerradas, que prestan atención en salud a trabajadores de empresas o institución determinada, son 6 y atienden al 2,7\% de asociados al sistema privado. (Superintendencia de Salud. s.f.).
}

Página $\mid 143$ 
La mayor parte de los cuidadores de estratos socioeconómicos medios y bajos, población objeto de nuestro estudio, estaba afiliada o era beneficiada por el sistema público de salud. Éste tenía la modalidad de seguro del tipo de seguridad social, ya que los beneficios que se obtenían no poseen necesaria relación con el nivel de la cotización efectuada. Se produce la redistribución propia de estos sistemas, desde las personas de mayores ingresos hacia aquellas de ingresos más bajos. Además, el sistema público acogía a las personas y/o familias que no disponían de ingresos, los cuales eran clasificados como beneficiarios no cotizantes del Fonasa.

Osvaldo Larrañaga (1997: 11), economista y consultor de la Cepal, afirmaba que la estructura de los sectores público y privado de salud originaba un sistema de carácter dual que separa a la población en dos grupos. Ello ocurre, por un lado, porque la lógica de un seguro que funciona sobre bases individual y privada representa la discriminación según ingresos y riego médico, y, por otro lado, el carácter solidario del Fonasa estaba asociado a un mecanismo de selección adversa, puesto que las personas de alto ingreso y bajo riesgo médico tienen el incentivo a emigrar hacia el sistema privado. Así, ambos sistemas eran funcionales para dar origen a la estructura dual que concentra a las personas de altos ingresos/bajo riesgo en el sistema Isapre y aquellas de bajos ingresos/alto riesgo en el sistema Fonasa, institución que actuaba como seguro de última instancia y que viabiliza al fin de cuentas al sistema dual de seguros de salud.

Destacamos también las voces críticas existentes sobre el modelo de atención subyacente en la reforma de salud. El estudio realizado por Fanny Berlagoscky y Patricia Provoste (2002) analiza este tema desde la perspectiva de género.

En Chile, como en otros países, la reforma del sector sanitario se fundamentó en la necesidad de adecuar los sistemas institucionales de salud a los cambios epidemiológicos y demográficos, y en la intención de atender nuevas necesidades de salud y hacer más eficiente el uso de los recursos, frenando el alza continua de los costos del sistema institucional. De esta reforma se derivaron propuestas de cambio del modelo de atención, entre las que resalta la mayor importancia que se adjudicó al nivel primario de atención, que vio aumentada su capacidad de resolver, de prevenir y de promover la salud desde el espacio local; de esta forma, el hospital quedaría como centro de alta complejidad y menor necesidad de camas, y perdería su predominio 
institucional, quedando todos los niveles funcionando en red, en tanto la relación con la población se concentró en el nivel primario. Las implicaciones de esta propuesta sobre el sistema de género fueron varias, y serán comentadas a continuación.

Los grandes logros de la salud pública chilena en el siglo XX se asocian a la estrecha vinculación de las mujeres con el modelo de atención primaria ${ }^{28}$, ante el cual jugaron un irreemplazable papel auxiliar, ya que se encargaron de los controles, las vacunas y la nutrición de niñas y niños. Desde ese punto de vista, el modelo de atención fue altamente dependiente del desempeño de roles domésticos tradicionales, que garantizaban la cercanía al consultorio (centro de atención del nivel primario) y la disponibilidad de tiempo para las demandas e instrucciones que de aquí provenían. Habiendo superado las metas propuestas, y en el nuevo contexto epidemiológico, social y económico, este programa ha dejado de constituir la clave de la salud pública. El actual modelo de atención da importancia a la prevención y cuidado ambulatorio de nuevas enfermedades, así como a la "vida saludable", que se estima debe ser llevada hacia la población de menores ingresos, para lo cual resulta necesario generar nuevos hábitos y traspasar nuevos conocimientos. En esa dirección, adquieren creciente importancia, la familia, el espacio local y una cantidad de programas grupales de prevención y promoción de la salud, y de "autocuidado" de enfermedades crónicas. Se entiende que, con esto, se reducirían los costos de atención de enfermedades cada vez más costosas, en un contexto de país en desarrollo, con avances en sus ingresos medios, pero con grandes desigualdades en la distribución del ingreso y con un alto porcentaje de población adscrita a la "salud pública".

Todo lo anteriormente dicho explica por qué en las reformas del sector salud aparece con nitidez el discurso del acercamiento a la población -más precisamente el discurso apela a "la familia"- y de la corresponsabilidad en el cuidado de la salud, lo que no es una invitación a hacerse parte de las decisiones, sino una definición de las nuevas condiciones en que el sistema espera vincularse con la población y de los nuevos contenidos de ese vínculo. De manera no explícita, sino indirecta o tácitamente, este discurso es una convocatoria a las mujeres para ejercer nuevas tareas de cuidado doméstico de la salud y de articulación con el sistema institucional, ante la cual cabe

\footnotetext{
${ }^{28}$ El Programa "materno-perinatal" o "materno-infantil" fue el eje de esta articulación.
} 
argumentar que en lugar de avanzar hacia el reconocimiento de las mujeres como sujetos autónomos del derecho a la salud, se reitera una invitación a un papel subordinado, reforzando las tareas domésticas de cuidado de la salud.

En términos generales, las antiguas tareas se mantienen, en algunos casos con mayor demanda de tiempo, agregando otras nuevas, desglosándolas se advierte que:

- Se pretenden mantener las actividades relacionadas con la salud de los niños y las niñas, y también las tareas y tiempo de cuidado a las personas dependientes -en el propio domicilio de éstas-, contando con el tiempo de trabajo no remunerado de las mujeres.

- En relación a la hospitalización se producen cambios significativos, los hospitales públicos "incentivan" la mayor permanencia de familiares en el hospital, así como su participación en algunos cuidados del usuario mientras está en el hospital. Además, reducen los días de ingreso lo que permite al sistema economizar recursos. Esta decisión se toma cuando hay garantías de capacidad de cuidado y tiempo, que son ofrecidas casi invariablemente por una mujer, cuya vida se verá radicalmente constreñida durante ese período.

- En cuanto al cuidado de personas con enfermedades crónicas (diabetes, hipertensión, cardiovasculares), se han introducido nuevas líneas de trabajo desde la atención primaria destinadas a instalar prácticas de "autocuidado" o "autoayuda". Al control preventivo de estos usuarios, se agregan actividades grupales que también permiten reducir costos de atención, éstas involucran a las y los afectados, pero también a las responsables de la salud del grupo familiar.

- Asimismo, la cifra creciente de población en edad avanzada comprende una proporción de personas dependientes, a la que se suma otro tipo de causas de postración que demandan muchas horas de cuidado doméstico.

- A todo lo anteriormente descrito cabe agregar las iniciativas de promoción de salud que se están desarrollando masivamente a través de la red de atención primaria, que siguen un modelo de trabajo comunitario y grupal, recayendo, una vez más, sobre las mujeres. 
- Finalmente, el desarrollo de los programas de salud familiar -visto como el modelo ideal para canalizar la articulación entre el sistema institucional y las personasdescansan en una madre con su tiempo disponible.

En suma, las investigadoras de este trabajo afirmaban que el nuevo modelo de atención formulaba nuevas exigencias al sistema doméstico de cuidado de la salud, entrando en contradicción con la equidad de género en dos sentidos: primero, se disponía de las mujeres, estableciendo exigencias institucionales que llevaban a mantener a muchas de ellas ancladas al rol doméstico y limitadas para desarrollar otras opciones de vida; segundo, se daba por supuesto un tipo de organización familiar (familias numerosas, a menudo extensas, con una o más mujeres dedicadas exclusivamente al hogar, y que no trabajan de forma remunerada) que era predominante en décadas anteriores, pero que en la actualidad es minoritario, sin preguntarse por la viabilidad social del modelo propuesto.

\section{Planes o programas específicos en salud}

Dentro de este contexto queremos ampliar aquellos aspectos que tienen relación con los cuidadores y sus dependientes, por eso nos detenemos en explicar el Plan AUGE, el Programa de atención domiciliaria de personas con discapacidad severa, el Programa nacional de ventilación mecánica invasiva (VMI) domiciliaria en niños.

\section{- El Plan AUGE}

En el año 2002, fueron enviadas al parlamento una serie de proyectos de ley que buscaban realizar una serie de reformas al sistema sanitario en el ámbito de los derechos de los pacientes y de establecer un régimen general de garantías en salud. Dichas iniciativas se plasmaron en el establecimiento de un Sistema universal con Garantías Explícitas en Salud (GES), que comenzó a operar en enero de 2005 con el nombre de Plan de Acceso Universal con Garantías Explícitas -Plan AUGE- (Ministerio de Salud 2006).

El Plan AUGE garantiza el acceso a la atención de salud oportuna, de calidad y con protección financiera. Es igual para todos porque no discrimina por edad, sexo, condición económica, lugar de residencia o sistema de salud al que estén afiliadas las 
personas (Fondo Nacional de Salud s.f.). Este plan determinó una nueva forma de administrar los cuidados de salud, aumentando la eficiencia de los servicios, generando derechos en salud exigibles por parte de los ciudadanos y garantizando su cumplimiento.

El Plan AUGE se aplica a un conjunto priorizado de problemas de salud (69 que aumentarán a 80 en julio de 2013), condiciones y prestaciones de la misma, ya sean dichas asistencias de carácter promocional, preventivo, curativo, de rehabilitación o paliativo.

Las garantías en salud ofrecidas por el Plan AUGE son cuatro:

- Acceso; el Fonasa y las Isapres tienen la obligación de otorgar las prestaciones de salud garantizadas.

- Calidad; todos los prestadores de salud deben estar acreditados ante la Superintendencia de Salud de acuerdo con criterios de calidad.

- Oportunidad; hay plazos máximos para la entrega de prestaciones garantizadas.

- Protección financiera; se define un techo de copago por año para evitar los gastos catastróficos, estableciendo un máximo de contribución por copago de un beneficiario por prestación o grupo de prestaciones garantizadas.

Si realizamos una evaluación general del Plan AUGE, podemos afirmar que éste se constituyó en un notable avance en la atención en salud, ya que, en diciembre de 2010, había brindado atención a nueve millones y medio de casos, garantizando el acceso a atención de calidad para todos, al ofrecer protección financiera para los 69 problemas de salud determinados en el plan en ese momento. Asimismo, el Plan permitió la modernización del sector sanitario, al otorgar una mayor autonomía y flexibilidad en la administración de los establecimientos hospitalarios y permitió a los gestores de las redes centrar su quehacer en la articulación de la atención a la salud.

Dentro de los pocos estudios que se han realizado sobre el impacto del Plan AUGE, podemos mencionar que uno de los aspectos que destacan es que la legislación que le acompaña contribuyó favorablemente a disminuir la discriminación e inequidad de los grupos de "mayor riesgo" para el sistema Isapre, las mujeres en edad fértil y las 
personas mayores, que anteriormente debían pagar planes de salud muchos más costosos que el resto de los grupos (Superintendencia de Salud 2009).

\section{- Programa de Atención domiciliaria de personas con discapacidad severa}

El Programa de atención domiciliaria a personas con discapacidad severa constituye una estrategia sanitaria, que comenzó a ser ejecutada a nivel país desde el año 2006 en los establecimientos de Atención Primaria dependiente de los municipios, y en aquellos que dependen directamente de los servicios de salud. Este programa era más conocido con el nombre de Programa de Postrados.

Este Programa definía la atención domiciliaria como el conjunto de acciones de carácter sanitario que se realizaban en el domicilio, y daba atención a los problemas de salud de las personas que se encontraban en situación de discapacidad severa física, psíquica, o multidéficit, reversible o irreversible, con dificultad para realizar las actividades básicas de la vida diaria, entendiendo que el nivel de complejidad de los problemas a resolver no requerían la hospitalización ni la institucionalización del sujeto y que contaban con una red de apoyo. Por otro lado, el Programa buscaba preparar a las familias que cuidaban a este tipo de pacientes, entregando acciones de salud integrales, cercanas y con énfasis en la persona, su familia y su entorno; además, destacamos que este programa consideraba aspectos curativos, preventivos y promocionales, con enfoque familiar y de satisfacción usuaria, para mejorar, así, la calidad de vida de los afectados y sus familias.

Todo paciente que presente discapacidad severa era sujeto elegible de las acciones del equipo de salud de su centro de Atención Primaria, debiendo estar inscritos en él y ser beneficiarios del Sistema Público de salud.

Las componentes que comprende este Programa son los siguientes:

Visita domiciliaria integral, por parte del equipo de salud (médico, enfermera, técnico en enfermería, trabajadora social, kinesiólogo y terapeuta ocupacional), quienes debían realizar una evaluación biopsicosocial del dependiente y diseñar un plan de cuidados para este. Mensualmente, el equipo de salud debía verificar las condiciones de cuidado 
del dependiente. Además, los cuidadores debían estar formados, haciéndoles entrega de las herramientas necesarias para el cuidado integral del usuario.

Pago a cuidadores de personas con discapacidad severa, que corresponde a un apoyo monetario dirigido a los cuidadores de estas personas; se entregaba a familias que se encuentran en el rango de pobreza y/o indigencia. A esta ayuda se la conocía como "estipendio".

\section{- Programa Nacional de Ventilación Mecánica Invasiva (VMI) domiciliaria en niños}

Programa desarrollado por el Ministerio de Salud, dirigido a niños y adolescentes menores de 15 años con diversas patologías respiratorias que tenían necesidad de ventilación mecánica crónica, hospitalizados pero en condición estable, beneficiarios del sistema público de salud.

El programa planteaba que estos niños y adolescentes fuesen tratados en sus hogares, transfiriendo tecnología, prestaciones derivadas, capacitación y supervisión en los domicilios por equipos profesionales especializados de la Atención Primaria de salud.

Las prestaciones entregadas por el Programa eran:

- Equipos con la tecnología proporcional a sus necesidades.

- Prestaciones de hospitalización domiciliaria que incluían una visita semanal o extraordinaria de terapeutas (kinesiólogos con experiencia en terapia ventilatoria), visita de kinesiólogo (para aspectos motores y respiratorios dos veces) a la semana, visita de enfermera (quincenal para control y chequeo de la terapia ventilatoria y general, educación, seguimiento y sistemas de registros de ficha clínica y complementarios); cuidados de enfermería básica (turnos de técnico paramédico con entrenamiento específico en cuidados respiratorios de 12 horas diurno y/o nocturno).

En esta revisión nos parece necesario referirnos a dos instituciones privadas sin fines de lucro que prestaban atención en salud especializada a la población en estudio. La más importante de ella es la Fundación Teletón, institución que ha prestado servicios de salud integrales a la mayor parte de los niños con discapacidad física del país, aunque también describiremos sucintamente a la Fundación hospital Josefina Martínez de Ferrari. 


\section{Fundación Teletón}

La Fundación Teletón (Fundación Teletón 2013) era una corporación de derecho privado que realizaba periódicamente el evento Teletón en Chile, y cuyo objetivo era distribuir los bienes y recursos que obtuviesen destinándolos a satisfacer las necesidades de la Sociedad Pro Ayuda del Niño Lisiado, que era la institución que se encargaba de realizar el tratamiento y la rehabilitación.

Precisamente, la misión de Teletón era la rehabilitación integral de los niños y jóvenes, entre 0 y 24 años de edad que presenten alguna discapacidad motora (de origen neuromúsculo-esquelética), a través de programas médico terapéuticos, psicosociales, educacionales, de desarrollo personal y recreación, a cargo de equipos multidisciplinarios de profesionales y técnicos especialistas en la materia.

Las atenciones en salud que la institución prestaba eran: atenciones médicas (fisiatría, ortopedia, urología, odontología y otras especialidades médicas internas); atenciones terapéuticas (kinesiología, terapia ocupacional, educación, psicología, fonoaudiología, trabajo social, enfermería, servicio de hospitalización y nutrición); y servicios complementarios de rehabilitación (servicios médicos y quirúrgicos externos, exámenes y diagnósticos, insumos clínicos y medicamentos, ortesis, prótesis, sillas de ruedas y entrega de otros implementos de rehabilitación, servicio de transporte, alimentación y ayudas sociales para pacientes).

En el año 2011, la Fundación contaba con 11 Institutos de rehabilitación distribuidos a los largo del territorio en las siguientes ciudades: Arica, Iquique, Antofagasta, Atacama, Coquimbo, Valparaíso, Santiago, Talca, Concepción, Temuco y Puerto Montt; en estos se atendían anualmente a más de 24.900 niños y jóvenes.

\section{Fundación Hospital Josefina Martínez de Ferrari}

Este hospital, ubicado en la Región Metropolitana de Santiago, pertenecía a la Fundación que le da el nombre, era campo clínico de la facultad de Medicina de la Pontificia Universidad Católica, y se dedicaba a la atención integral de niños con patología respiratoria, enfermedades de la vía aérea o con necesidad de asistencia ventilatoria crónica. Contaba con un equipo de salud conformado por médicos, kinesiólogos, enfermeras, terapeutas ocupacionales, psicólogas, educadores, nutricionistas. 
Este hospital mantenía convenio con el Minsal y Fonasa para dar atención a niños beneficiarios del sistema público de salud.

A continuación, analizamos el sistema de pensiones y uno de los subsidios familiares, específico para personas discapacitadas que, en el desarrollo de esta investigación, funcionaba en Chile. Este abordaje nos ayudará a entender mejor la situación de los cuidadores de personas dependientes en este país.

\subsubsection{Sistema de Pensiones}

Como anteriormente señaláramos, hasta comienzos de la década de los 80 ' el sistema de pensiones chileno tenía por característica ser un régimen de reparto, en donde todos los trabajadores dependientes estaban cubiertos por él, por la obligatoriedad de afiliación; pero este deber no existía para los trabajadores independientes, lo que hacía que la cobertura fuera reducida para este grupo. El sistema previsional se organizaba en torno a las cajas de previsión, que eran empresas públicas. Estas instituciones previsionales llegaron a ser 35 , pero solo tres de ellas agrupaban a más del 90 por ciento de los contribuyentes del sistema. Las pensiones se determinaban en base a las cotizaciones de los últimos cinco años, no existiendo una relación entre el total de cotizaciones efectuadas y los beneficios a percibir. (Von Gersdorff 1984). El sistema, tal como se aplicó en Chile, presentaba una serie de incidencias: las desigualdades en las cotizaciones y en los beneficios otorgados por cada caja, que eran variables de acuerdo al nivel ocupacional; una legislación extremadamente complicada en cuanto a su administración, formas de calcular las pensiones y condiciones de obtenerla. Estimaban que el sistema colapsaría, debido a los cambios que experimentaba la estructura demográfica chilena y al desfinanciamiento por ello, resultando el Estado el principal garante de ese dinero.

Este sistema de pensiones fue modificado de forma estructural en 1980, en el proceso de privatización de los servicios públicos chilenos, en el cual se separaron las funciones de prestaciones de salud y las pensiones. Mediante un decreto ley se crearon las Administradoras de Fondos de Pensiones (AFP), instituciones financieras privadas encargadas de administrar los fondos y ahorros de pensiones. La reforma convirtió el 
anterior régimen de pensiones de reparto en un esquema de ahorro basado en cuentas de capitalización individual (CCI). Las pensiones fueron financiadas con los aportes obligatorios preestablecidos de acuerdo con los ingresos del empleado, del mismo modo en que se hacen los aportes a los programas de pensiones de los sistemas de seguridad social. Estas cuentas eran capitalizables según el rendimiento del mercado. Al llegar a la edad del retiro, el empleado recibía una pensión en correspondencia con lo acumulado en su cuenta individual (contribución definida), ajustado a lo aportado y al rendimiento del mercado (cuadro 1). Estas cuentas eran administradas por las AFPs, que funcionaban bajo el control de la superintendencia de AFP.

\section{Cuadro 1: Pensiones contributivas*}

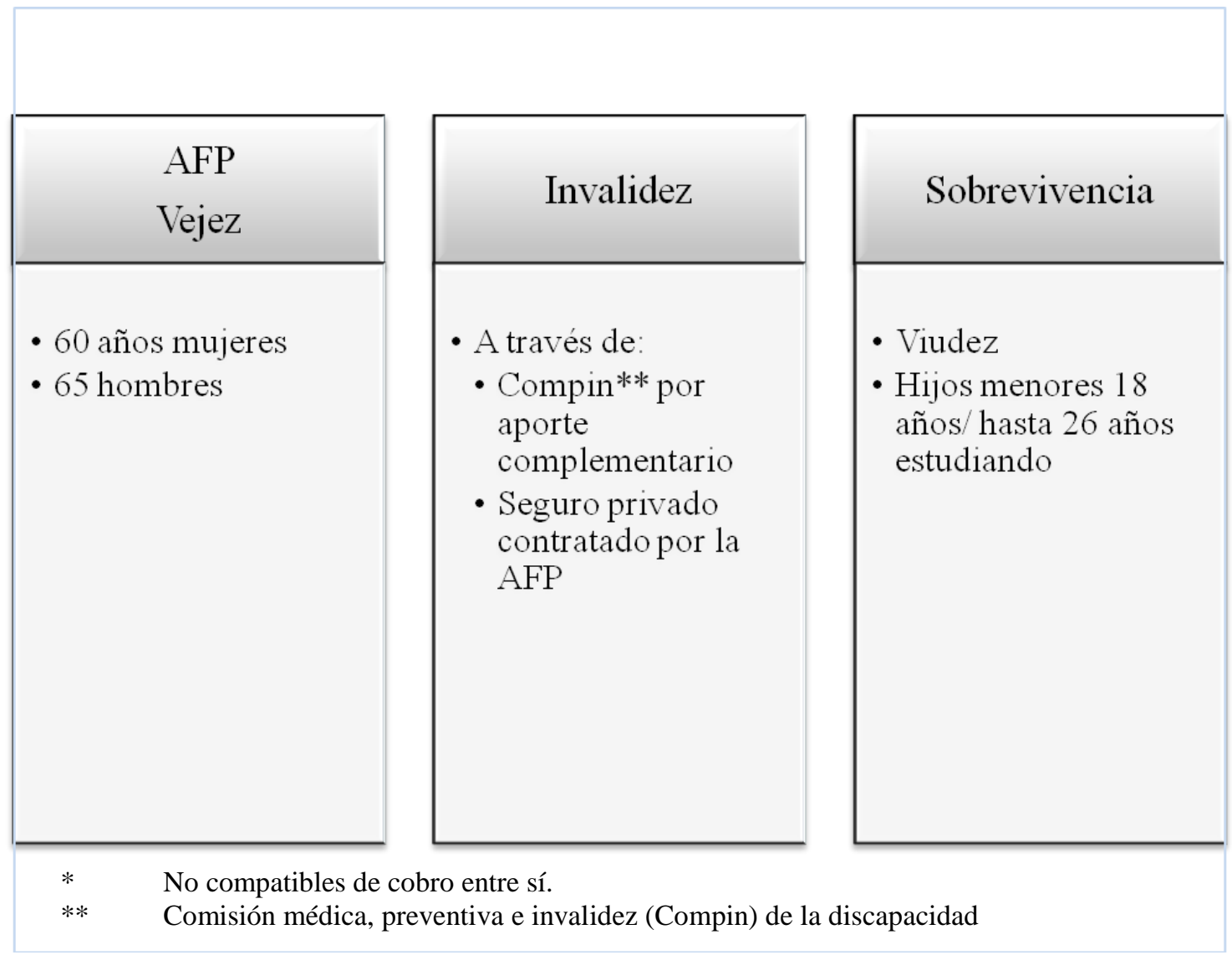

En el caso de la población mayor de 65 años, o con una discapacidad reconocida de forma oficial, que no contaran con ingresos económicos que le permitieran subsistir, debido a que sus cotizaciones previsionales fueran nulas o insuficientes, el Estado contemplaba la entrega de pensiones asistenciales. 
El sistema de capitalización individual funcionó de acuerdo con lo previsto, en la medida en que las cotizaciones de los trabajadores dependientes, con empleos estables, se efectuaban con regularidad a lo largo de toda su vida laboral. Sin embargo, para la mayoría de la población la situación era distinta debido a una serie de factores:

- Mayores expectativas de vida y la postergación de la entrada al mercado del trabajo remunerado.

- Incremento de la participación de la mujer en el mercado del trabajo pero con una inserción laboral más inestable que la del hombre, lo cual afectaba su capacidad para acumular fondos previsionales.

- La baja cobertura del sistema, ya que parte importante de la población (mujeres, trabajadores por cuenta propia, personas dependientes) no participaba en el sistema de pensiones.

- Escaso conocimiento, de los usuarios, de cómo operaba el sistema y desconfianza en el mismo.

- Creciente gasto fiscal, debido a las diferencias en las densidades de cotizaciones por sexo $^{29}$. Además, la estimación de tasas de reemplazo y las proyecciones demográficas indicaban que 1 de cada 2 afiliados dependerían, en un futuro reciente, del financiamiento estatal para obtener una pensión asistencial.

En definitiva, el sistema previsional no cumplía de forma satisfactoria con uno de sus principales objetivos, que era prevenir la pobreza en la etapa pasiva del ciclo de vida de los ciudadanos. En marzo de 2008 -gobierno de la presidenta Michelle Bachelet- se aprueba la llamada "Reforma Previsional", considerada la política pública social más importante del cuarto gobierno de la Concertación, plasmada en la ley 20.255 que cobra su vigor en julio del mismo año y está vigente hasta ahora. Los principios que estructuran el nuevo sistema de pensiones son:

- Derecho a la protección social, seguridad y certeza de ésta.

\footnotetext{
${ }^{29}$ Se define como densidad de cotización el número de meses cotizados en un periodo sobre el total de meses transcurridos. Sólo se consideran las historias laborales y cotizaciones entre los 18 y 60 años. Los hombres presentan densidades de cotización entre 0.5 y 0.8 ; es decir, que han cotizado entre $50 \%$ y $80 \%$ de los meses de su historia laboral. Sin embargo, en el caso de las mujeres, una gran proporción de éstas tiene densidades de cotización menores a 0.3 (Subsecretaría de Previsión Social 2007).
} 
- Legitimidad y participación ciudadana.

- Solidaridad; creación del Sistema de Pensiones Solidarias.

- Igualdad y equidad de género.

- Prioridad en las políticas públicas sociales.

- Responsabilidad previsional y social; incentivos al ahorro previsional voluntario.

- Eficiencia, transparencia y competencia de la industria.

- Sostenibilidad: responsabilidad fiscal.

- Disminución de la desigualdad y redistribución del ingreso.

- Rol público del Estado.

El sistema de pensiones chileno quedó conformado por tres pilares, el primero es el pilar redistributivo, el segundo, el de ahorro obligatorio y el tercero el de ahorro voluntario (Quintanilla 2012). Al segundo pilar, principal componente del sistema de pensiones chileno de capitalización individual con contribuciones, se le realizan una serie de modificaciones con la finalidad de mejorarlo (establece condiciones para mejorar la competencia entre las AFPs, licitado a los nuevos afiliados; crea un comité técnico de inversiones que asesora a la Superintendencia de Pensiones) e integrarlo con el primer pilar (cuadro 1). Pero la principal transformación de esta reforma estaba en el fortalecimiento del primer pilar, a través del financiamiento con recursos del Estado (entre otros el Fondo de Reserva de Pensiones FRP), lo que permitió la creación de un sistema de Pensiones Solidarias que benefició a quienes, por diversas razones, no tenían cotizaciones suficientes para financiar una pensión digna, los que podrían ser considerados las "excepciones" del sistema, pero que en la práctica representaban una parte importante de la población: mayores y discapacitados (Uthoff 2011). El sistema de pensiones solidarias estaba conformado por los siguientes componentes: Pensión Básica Solidaria (PBS) de vejez, Pensión Básica (PBS) de Invalidez, Aporte Previsional Solidario (APS) de Vejez y Aporte Previsional Solidario (APS) de invalidez (cuadro 2). 
Cuadro 2: Sistema solidario de pensiones chileno

\section{Pensiones solidarias, Ley 20.255 \\ (ex pensiones asistenciales PASIS y \\ pensiones mínimas con garantía estatal PMGE)}

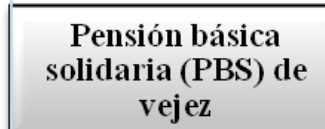

-Mayores de 65 años

- Sin cotizaciones o

insuficientes para

obtener jubilación

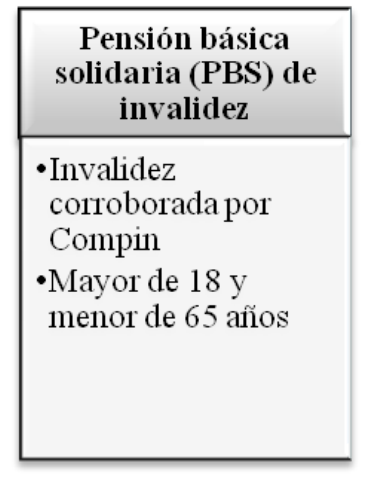

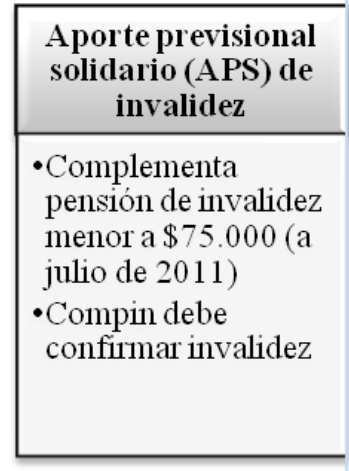

Los individuos que no contaban con ahorros previsionales y pertenecían al grupo más vulnerable, es decir aquellos que eran parte del $40 \%$ más pobre de la población, podían acceder a una PBS de vejez desde julio de 2008, con un valor inicial de $\$ 60.000\left(82 €^{30}\right)$. En julio de 2009, accedieron a este beneficio el $45 \%$ más pobre de la población y la pensión alcanzó la cifra de $\$ 75.000$ (102€). La cobertura para el año 2012 fue del 60\% para la población más pobre (Superintendencia de Pensiones 2013). En el caso de la PBS de invalidez, las condiciones de acceso eran iguales, sumándole la certificación de la Comisión Médica, Preventiva e Invalidez (Compin) de la discapacidad.

En el caso de quienes hubiesen cotizado, cumplan con los requisitos de elegibilidad y reciban una pensión inferior a $\$ 70.000$ (96€) en 2008, el Estado aportaba un monto denominado Aporte Previsional Solidario (APS) de Vejez que permitía complementar su pensión. El techo máximo de pensión para recibir este beneficio se incrementaba cada año, de modo tal que en el año 2012 recibían APS de Vejez todos aquellos pensionados que habían cotizado y recibieran una pensión inferior a \$255.000 (348€).

${ }^{30} \$ 732=1 €$ (cambio al 19 de noviembre de 2009). 
En los primeros años, las pensiones solidarias se concentraron en las personas de menores ingresos, para posteriormente alcanzar a las personas que integraban un grupo familiar perteneciente al $60 \%$ más pobre de la población. En diciembre de 2012, el sistema de Pensiones Solidarias beneficiaba en torno a 1,2 millones de personas en el país (Superintendencia de Pensiones 2013). Este sistema favorecía en mayor medida a mujeres que a hombres (63\% a diciembre de 2010), debido a que se primaba a éstas para conseguir dichos beneficios por razones derivadas del mercado laboral (baja tasa de participación en el mercado laboral, principalmente), su mayor expectativa de vida y la menor edad de retiro (Quintanilla 2012, 16).

La reforma previsional estructuró el pilar solidario del sistema de pensiones chileno, no solo ampliando la cobertura sino también generando certidumbre a la población por la protección que tendrán durante su vida pasiva. Sumado a lo anterior, el nuevo pilar se integró con el segundo pilar de tal forma que favoreció el incentivo al ahorro obligatorio de éste (a través de los APS).

\subsubsection{Subsidio familiar (SUF)}

Existía un grupo personas discapacitadas que quedaban excluidas de la recepción de pensiones, los menores de 18 años con discapacidad. En el caso de las familias de escasos recursos, existía la posibilidad de poder acceder al Subsidio Familiar (Ley 18.020) si entre sus miembros había menores de 18 años o personas con discapacidad (física, sensorial o mental) que vivieran a expensas de un adulto que no fuese trabajador dependiente afiliado a un sistema previsional.

Este subsidio, también conocido como Duplo, era entregado a la madre, o en su defecto el padre, o los guardadores que tuvieran a su cargo al menor o persona con discapacidad. Además, la recepción de este subsidio conllevaba el derecho a recibir prestaciones de salud gratuitas en el sistema público. 


\subsubsection{Educación}

Dentro de esta revisión sobre diversos aspectos de la política social chilena, creemos necesario explicar de forma sintética el sistema educativo, porque parte de la muestra de nuestro estudio hace referencias a esta área, específicamente las madres de niños con discapacidades.

Coincidiendo con las reformas estructurales efectuadas en la década de los 80 en áreas como la salud y las pensiones, la educación no estuvo exenta de esta tendencia. Uno de los principales cambios fue que la educación pública pasó a ser responsabilidad de los municipios, y se implementó un tipo de establecimientos, denominados "subvencionados", que recibían un subsidio estatal y que estaban administrados por privados (corporaciones y sostenedores privados). Con la lógica que opera el sistema, sostenedores municipales y privados debían competir para captar la preferencia de las familias para obtener el subsidio, por cada niño que esté matriculado en sus establecimientos; éste mecanismo contribuyó a generar enormes desigualdades en la calidad de la educación.

Los niveles del sistema educativo chileno eran: parvulario, básico (primaria), medio (secundaria) y superior (universitaria y técnica). La obligatoriedad y gratuidad de la educación en Chile era hasta los 18 años (educación media-secundaria), con una cobertura prácticamente universal.

Para los niños y jóvenes que presentan necesidades educativas especiales, el sistema educacional ofrecía la educación especial. Ésta desarrollaba su acción de forma transversal en los distintos niveles educativos, tanto en establecimientos de educación regular como en establecimientos de educación especial. En el año 2013, más de trescientos mil estudiantes recibían subvención estatal a través de este tipo de educación (Ministerio de Educación 2013).

Los establecimientos que impartían solo educación especial en Chile varían de acuerdo al tipo de déficit, por ello existían escuelas para niños y adolescentes con déficit visual, discapacidad auditiva, discapacidad motora, discapacidad por graves alteraciones en la capacidad de relación y comunicación y discapacidad intelectual y trastornos 
específicos del lenguaje. La edad de ingreso a este tipo de establecimientos oscila desde el tiempo en el que se diagnostica la enfermedad (alrededor de los dos años) hasta los 24 años, pudiendo extenderse hasta los 26 años.

Los establecimientos educativos públicos, para niños con necesidades especiales, tenían como requisito de ingreso la presentación de un certificado que acreditara la discapacidad. En algunas enfermedades, el diagnóstico era difícil de establecer, por ejemplo el autismo, y ello conllevaba que las familias que acogían en su seno a un niño con estas características se vieran obligadas a utilizar centros educativos privados. Esta opción no era posible para muchas familias.

\subsection{Características de la discapacidad en Chile}

En Chile, desde el punto de vista de los planes, programas y servicios sociales, las personas con discapacidad fueron identificadas como un grupo "prioritario" o "vulnerable", según el enfoque de las políticas sociales imperantes (de derechos o asistenciales). En febrero de 2010 comienza a operar en Chile una nueva institucionalidad estatal, el Servicio Nacional de la Discapacidad (Senadis), que tenía por finalidad promover la igualdad de oportunidades, inclusión social, participación y accesibilidad de las personas con discapacidad, principios establecidos en la Normativa sobre Igualdad de Oportunidades e Inclusión de Personas con Discapacidad (Ley 20.422). Este servicio formaba parte del Ministerio de Desarrollo Social (Servicio Nacional de la Discapacidad 2013).

El desarrollo de una institucionalidad directamente relacionada con la discapacidad comenzó con la publicación de la Ley $\mathrm{n}^{\circ} 19.284$, el 14 de enero de 1994, sobre Integración Social de Personas con discapacidad, una ley marco con contenidos programáticos que incorporó los principios de equiparación de oportunidades y de integración social de las personas con discapacidad desde un enfoque bio-psicosocial. Según el artículo 3, inciso 1, de la ley, se señalaba que:

Para los efectos de esta ley se considera persona con discapacidad a todas aquéllas que, como consecuencia de una o más deficiencias físicas, psíquicas o sensoriales, congénitas o adquiridas, previsiblemente de carácter permanente y con independencia 
de la causa que le hubiera originado, vea obstaculizada, en a lo menos un tercio, su capacidad educativa, laboral o de integración social (Chile. Ley N ${ }^{\circ} 19.284$ ).

Esta definición era coherente con la conceptualización publicada por la OMS en 1980, en su Clasificación Internacional de Deficiencias, Discapacidades y Minusvalías (CIDDM).

Posteriormente, en el año 2010, la ley 20.422, que dio origen a la nueva institucionalidad, estableció Normas sobre Igualdad de Oportunidades e Inclusión Social de Personas con Discapacidad modificando, entre otras cosas, la conceptualización de la discapacidad, señalando en su artículo $5^{\circ}$ :

Persona con discapacidad es aquella que teniendo una o más deficiencias físicas, mentales, sea por causa psíquica o intelectual, o sensoriales, de carácter temporal o permanente, al interactuar con diversas barreras presentes en el entorno, ve impedida o restringida su participación plena y efectiva en la sociedad, en igualdad de condiciones con las demás (Ministerio de Planificación 2010).

Esta ley representa un gran avance ya que adopta el paradigma de la Convención Internacional, expresado en el Clasificador Internacional sobre el Funcionamiento (CIF) de la Discapacidad y la Salud (Organización Mundial de la Salud, Organización Panamericana de la Salud 2001), y cambió el eje de la acción estatal desde el rol tradicional de asistencia al de proveedor de calidad de vida, poniendo el acento en la funcionalidad y vida independiente y no en el tratamiento de la deficiencia. La norma definió el derecho de equiparación de oportunidades como la ausencia de discriminación, directa o indirecta, que tenga su causa en una discapacidad. Así, en la base de las adecuaciones que se presentaron está el concepto de políticas públicas basadas en derechos, respetuosas de la dignidad, la autonomía y la independencia de las personas con discapacidad (Fondo Nacional de la Discapacidad 2008).

\subsubsection{Personas discapacitadas ¿Quiénes son?}

En América Latina las tasas de prevalencia de discapacidad oscilan entre el 1\% y $15 \%$. La amplitud de este rango se debe principalmente al tipo de definición utilizada en la medición de la discapacidad, ya que ésta varía ampliamente entre países y aún entre fuentes de un mismo país (Albertos 2006). Como anteriormente se expuso, la definición 
ha evolucionado desde un enfoque de "deficiencia" a uno de "funcionamiento". El primero identifica la presencia de discapacidades sensoriales o físicas, es decir, ceguera, mudez, problemas de movilidad, etc.; el enfoque funcional clasifica a las personas de acuerdo a su capacidad para desarrollar actividades cotidianas como caminar, cuidarse de sí mismos, trabajar, estudiar, etc. Estos dos tipos de definiciones generan estimaciones que pueden ser muy distintas y ello dificulta aún más las comparaciones entre países. Las encuestas que consideran definiciones amplias (enfoque de funcionamiento) suelen presentar mayores niveles de discapacidad que las mediciones con el enfoque de deficiencia.

Información proveniente de Censos efectuados en la década del 2000, indican que las personas con discapacidad representaban en Brasil el 14,5\% de la población, en Colombia 6,3\%, 2,3 en México y 1,1\% en Paraguay (Schkolnik 2010:189). Las grandes diferencias en las cifras reflejan la problemática que se plantea, y si bien los datos son obtenidos de forma diferente, es posible tener una visión general de la situación en América Latina, se calcula que en promedio, alrededor del $10 \%$ de la población de América Latina y el Caribe tiene alguna discapacidad, y aunque las tasas de prevalencia de la discapacidad sean muy variables, estamos hablando de un porcentaje no menor de la población.

De la misma forma que sucedía en Latinoamérica, la información sobre la discapacidad en Chile, hasta el momento de aplicación del primer Estudio Nacional de la Discapacidad (ENDISC-2004), no se había trabajado de la mejor forma. Los diferentes estudios realizados conceptualizaban la discapacidad de forma distinta, reflejándose en los instrumentos usados, de esta manera en algunos estudios se utilizaba el criterio de deficiencia para medir discapacidad y en otros el criterio funcional para ponderar el mismo concepto. Por ello, los datos estadísticos recogidos tanto a través del Censo 2002, de la ENDISC-2004, y de la Encuesta de Caracterización Socio-económica (CASEN) difieren cuantitativa y cualitativamente.

Los datos, entregados por el Censo $2002^{31}$, fueron obtenidos a través de una pregunta que consultó sobre deficiencias totales y severas, que reflejó que un 2,2\% de la

\footnotetext{
${ }^{31}$ Se utilizan los datos de este censo porque los obtenidos en el censo efectuado en 2012 aún no están disponibles.
} 
población presentaba una o más deficiencias, lo que equivalía a 334377 personas con discapacidad (Instituto Nacional de Estadísticas 2003). Dicho censo consideró como "discapacitados" a las personas que declararon ceguera total, sordera total, mudez, lisiado/parálisis y deficiencia mental. La validez de los datos del Censo radica en que es un instrumento que se aplica la totalidad de la población del país, por lo tanto los datos que aporta, si bien limitados por su conceptualización, permiten establecer una línea base en el número y condición de personas con discapacidades severas en el territorio comunas, provincias, regiones-.

En el caso de la ENDISC-2004, tanto la definición conceptual como el instrumento de recolección de datos estaban basados en la Clasificación Internacional del Funcionamiento, de la Discapacidad y de la Salud (CIF), que definía la discapacidad como la interacción negativa entre la condición de salud y el ambiente físico y social (criterios y prácticas sociales) con la consecuencia de una limitación en la actividad y restricción en la participación, lo que afecta a una persona para desenvolverse en su vida cotidiana dentro de su entorno físico y social.

La ENDISC-2004 ${ }^{32}$ (Fondo Nacional de la Discapacidad, Instituto Nacional de Estadísticas 2005) indicaba que:

- Un 12,9\% (2068072 personas) de la población chilena tenía una o más discapacidades. Esto significaba que el 34,6\% de los hogares del país (1549342 hogares) tenía al menos una persona con discapacidad, es decir, en uno de cada tres hogares había a lo menos un miembro con discapacidad.

- En las zonas urbanas se concentraba el 83,8\% de las personas con discapacidad y en las zonas rurales el 16,2\%. Aunque en términos absolutos había más personas con discapacidad en las zonas urbanas que en las rurales, en términos relativos la situación era diferente, ya que la tasa de prevalencia de discapacidad es de $15,5 \%$, casi tres puntos sobre la prevalencia nacional $(12,9 \%)$ y la prevalencia en el medio urbano era del $12,5 \%$. Por cada 5 personas con discapacidad en zonas rurales había 4 personas con discapacidad en zonas

\footnotetext{
${ }^{32}$ Encuesta a hogares aplicada a una muestra probabilística, trietápica a 13769 viviendas.
}

Página | 162 
urbanas, ello sugiere que la discapacidad no es un problema sólo relacionado con el urbanismo, la modernidad o la industrialización.

- En Chile eran más las mujeres discapacitadas, un 58,2\% (1204576 mujeres), que los hombres discapacitados, 41,8\% (863496 hombres); 1 de cada 7 mujeres tenían discapacidad, en cambio 1 de cada 9 hombres presentaban esta condición.

- La distribución de las personas con discapacidad, de acuerdo a rangos de edad, nos decía que el 86,1\% de la población con discapacidad en Chile era adulta (mayor de 29 años). Destacaba la prevalencia de la discapacidad en personas mayores de 65 años, de cada 5 mayores 2 presentaban discapacidad. Al introducir la variable sexo, hasta los 15 años la discapacidad predominaba más en el hombre que la mujer, entre los 15 y los 40 años se equiparaban y de los 40 en adelante se invertía radicalmente la cifra, había más mujeres que hombres con discapacidad.

- En la población con condiciones socioeconómicas bajas, la prevalencia de discapacidad pasaba de 12,93\% global al 20\%. Esta situación se acentuaba mucho más en la población indígena, que experimentaba a la vez pobreza y extrema pobreza.

- Del total de personas con discapacidad, un 2,5\% presentaba discapacidad severa (403942 personas), lo que implicaba que eran individuos que veían gravemente dificultada o imposibilitada la realización de sus actividades cotidianas, requiriendo del apoyo o cuidados de una tercera persona y no lograban superar las barreras del entorno. Un 3,2\% presentaba discapacidad moderada (513997 personas), es decir tenían una disminución o imposibilidad importante de su capacidad para realizar la mayoría de las actividades de la vida diaria, llegando incluso a requerir apoyo en labores básicas de auto cuidado, superando con dificultades sólo algunas barreras del entorno. La discapacidad leve se manifestaba en un 7,2\% de la población (1150133 personas), lo que significaba que presentaban síntomas o secuelas que les generaba alguna dificultad para llevar a cabo actividades de la vida diaria, sin embargo la persona es independiente y no requiere apoyo de terceros y puede superar barreras del entorno.

- En último lugar, 1 de cada 4 personas con discapacidad no había accedido en el último año a servicios relacionados con la misma. De las personas con 
discapacidad que habían accedido a servicios, 2 de 3 atenciones habían sido en salud primaria, le seguían los servicios de diagnóstico, rehabilitación, atención social, beneficios sociales, pensiones y subsidios, entrega de ayudas técnicas, educación y servicios de orientación e información. Asimismo, 3 de cada 4 personas con discapacidad que habían recibido servicios lo habían hecho en el sector público.

Los datos más recientes son los de la Encuesta de caracterización socio-económica realizada en $2009^{33}$ (Ministerio de Planificación 2010), en ella se preguntaba por “condiciones de larga duración" en lugar de "deficiencias", además realizaba preguntas que tenían relación con actividades básicas de la vida diaria. Algunos datos relevantes que entregaba este instrumento en su versión 2009 eran:

- Las personas con discapacidad representaban en 2009 un 7,6\% de la población total (1254949 personas), existiendo un 21,5\% de los hogares con algún miembro con alguna discapacidad y en un $11,9 \%$ de estos el jefe del hogar tenía alguna discapacidad.

- El 90,1\% de las personas discapacitadas presentaban más de una discapacidad, mientras que el 7,6\% de personas con discapacidad tenían dos discapacidades, y el $2,3 \%$ tres.

- Realizando un análisis por tramo de edades desde los 51 años a los 60 años, la proporción de población con alguna discapacidad se elevaba considerablemente, llegando a representar un $12,1 \%$ de la población de esa edad. El aumento era progresivo en los tramos siguientes: un 19,1\% entre los 61 y los 70 años; un $24,8 \%$ entre los 71 y 80 años; y un $42,8 \%$ con 81 ó más años.

- Las discapacidades más frecuentes eran: las dificultades físico y/o de movilidad, un $35,2 \%$ de todas las discapacidades; la ceguera o dificultad visual aun usando lentes, un 32,7\%; la sordera o problemas auditivos aun usando audífonos, un $13,6 \%$.

\footnotetext{
${ }^{33}$ La Encuesta CASEN, efectuada a través de todo el territorio nacional a hogares, actualmente es coordinada por el Ministerio de Desarrollo social (anteriormente Ministerio de Planificación). En este trabajo, se utilizan los datos de la Encuesta Casen 2009, ya que los de 2011 aún no están disponibles. Fueron entrevistados un total de 71.460 hogares, de 334 comunas del país, la encuesta cuenta con representatividad nacional, por zona urbana y rural.
} 
- En relación al nivel educacional, para el total de población mayor de 24 años, destacaba que un $14,4 \%$ de las personas con discapacidad no ingresó a la educación formal; un 30\% no completó la educación básica; el 16,5\% no completó la educación media y sólo un $6,1 \%$ completó la educación superior.

- Analizando la información de acuerdo a deciles de ingresos, el porcentaje de personas con discapacidad, en el primer decil (12,2\%), casi triplicaba al número de personas con discapacidad del décimo decil (4,5\%). En general, el porcentaje de población que poseía alguna discapacidad era mayor en los deciles de menores ingresos (Ministerio de Planificación 2009).

- Finalmente, al observar las estadísticas de acuerdo al grado de dependencia, pensando en las personas dependientes que eran objeto de cuidados, un 4,8\% (59577) de las personas con discapacidad presentaban una discapacidad grave y/o en situación de postración, un 9,4\% tenía una dependencia moderada, un $19 \%$ era leve y un $66,9 \%$ era autovalente.

El aumento de la proporción de las personas mayores de 65 años, en la población chilena, es un fenómeno que pronostica el aumento progresivo de las personas con discapacidad en el país. Los datos aportados por el Estudio Nacional de la Dependencia en las personas mayores (Servicio Nacional del Adulto Mayor, INTA, Microdatos 2009) indicaban que un 24,1\% de la población mayor de 60 años tenía algún tipo de dependencia. Este datos se desglosan de la siguiente forma: el 6,6\% de los mayores tenía dependencia leve; 5,0\% dependencia moderada y un 12,4\% dependencia severa, lo que quiere decir que necesitaban de cuidados para sobrevivir.

De acuerdo a proyecciones ${ }^{34}$ realizadas por el Instituto Nacional de Estadísticas y la Comisión Económica para América Latina y el Caribe para 2025, la población mayor de 65 años representaría un 14,07\% y en 2050 constituirá un $21 \%$ de la población chilena. Comparando la esperanza de vida al nacer que los chilenos tenían a mediados del siglo XX -54,8 años, 52,9 para hombres y 56,8 para mujeres-, con la de 2005 -78 años, 75,5 hombres y 81,5 mujeres- y su proyección para el año 2050 -82 años-, se estima que se cumplirán los pronósticos de aumento de la población con discapacidad (Instituto Nacional de Estadísticas y Comisión Económica para América Latina y el Caribe 2005).

\footnotetext{
${ }^{34}$ Se utilizan proyecciones para el 2010 porque aún no están disponibles los datos del Censo 2012, desagregados por edades.
} 
No existe ningún tipo de información nacional sobre los cuidadores de las personas dependientes. En su lugar podemos recordar el dato que entrega la encuesta CASEN 2009 sobre el número de hogares que cuentan con algún miembro discapacitado, 1009204 hogares, que correspondían al 21,5\% de los hogares chilenos.

\subsection{Cuidados informales en Chile}

\subsubsection{Cuidadores}

Antes de comenzar este epígrafe, quisiéramos señalar que la situación de los cuidados a la dependencia en Chile estaba condicionada, primordialmente, por cambios estructurales a nivel demográfico y cambios en la dinámica del mercado de trabajo. El primer factor, principalmente determinado por el envejecimiento de la población chilena, conlleva necesariamente un incremento de la necesidad de cuidados por parte de las familias. El segundo tiene relación con la incorporación creciente de las mujeres al mercado laboral, lo que implica que disminuye la disponibilidad de éstas como cuidadoras.

Anteriormente, en el capítulo I, revisamos las características del cuidado informal, en este apartado se abordará dicha temática en la realidad chilena. La revisión que realizaremos se basa en los estudios disponibles, que recién comienzan a explorar la materia y evidencian la necesidad de profundizar en ella.

El estudio de casos "Costos no visibles del cuidado de enfermos en el hogar. Estudio de casos en Chile" (Reca, Álvarez y Tijoux 2008) ${ }^{35}$, de carácter exploratorio sobre costos no visibles del cuidado de personas enfermas, analizó 21 situaciones de cuidado que correspondía a siete enfermedades, o situaciones de salud diferentes. Estas fueron seleccionadas por su adecuación al perfil epidemiológico actual y al envejecimiento de la población. La metodología se sustentó en el registro de actividades de la persona dependiente y del cuidador/a a lo largo de 24 horas. La importancia de este estudio es que constituyó el primero de este tipo realizado en el país, con el desafío de elaborar

\footnotetext{
${ }^{35}$ Publicado en 2008 pero realizado en 2002 en el marco del "Proyecto Género, Equidad y Reforma de la Salud en Chile" para OPS/OMS.
} 
una metodología para visibilizar las características y costos del cuidado doméstico de las personas con dependencias.

La investigación evidenció que las cuidadoras eran principalmente mujeres -de 21 casos sólo 2 hombres cuidadores- y familiares no remunerados, aunque se incluía a algunas cuidadoras remuneradas en las familias con mayores ingresos. La persona cuidadora no sólo prestaba asistencia y cuidados sino que compatibilizaba esa responsabilidad con la realización de tareas domésticas -aún consideradas propias de la "dueña o ama de casa"$\mathrm{y}$, en muchos casos, con otras actividades remuneradas. Cabe resaltar que las características encontradas en este grupo se inscriben en la tradición de la mujer "abnegada", que calla sus dificultades, manifestando en su mayoría sentimientos de soledad, angustia, depresión y presentando dolencias como insomnio, estrés y colon irritable.

Los tiempos de cuidado, separados por actividad y medidos en minutos durante 24 horas, por persona necesitada de atención fueron muy variables, siendo el más bajo el de politraumatismos, 340 minutos, y el más alto el de cuidado de Alzheimer, con 660 minutos. Es decir, desde 5,5 a 11 horas diarias. Se consideró, no obstante, que podía haber subestimación de algunos tiempos de cuidado, o actividades que permanecían ocultas bajo categorías como la de "acompañamiento" (planteándose afinar el método de registro en una nueva etapa de la investigación).

Es particularmente relevante que, frente a las necesidades de cuidado de las personas que padecían enfermedades que generaban discapacidad, no existían, al momento de la realización del estudio, oferta de servicios públicos, salvo excepciones como los recintos psiquiátricos para discapacitados mentales. Los hospitales públicos permitían el ingreso de los dependientes sólo en casos de crisis o agravamiento, y quienes dependían de sistemas privados no solían poseer recursos suficientes para contratar cuidadoras, o para ingresar a la persona dependiente en un recinto privado. Existía la hospitalización en casa, pero como servicio de lujo, inaccesible a la mayoría de la población.

Se observó, en el sistema institucional, la tendencia a la reducción del tiempo de hospitalización El cuidado de un dependiente en el hogar representaba, por una parte, una liberación de recursos hospitalarios y, por otra, un desplazamiento del trabajo y las responsabilidades hacia los familiares que tenían que hacerse cargo prácticamente - 
sobre todo en los niveles socioeconómicos bajos- de la totalidad de los cuidados, velando por la salud y trasladando al enfermo a los centros de atención cuando su estado se agravaba.

En el caso de las investigaciones referidas, específicamente, a cuidadores de personas mayores dependientes, en términos generales, se han centrado en las características sociodemográficas de las personas que los atienden.

El estudio denominado "El significado del paciente con demencia para el cuidador en una comunidad urbana y rural" (Vidal et al 1998) investigó a cuidadores/as de personas mayores, que sufrían de Alzheimer, en localidades rurales y urbanas de la Región del Bío Bío. Entre sus principales resultados, destacamos aquellos que indican que el 82,9\% de los cuidadores eran familiares; de esta proporción, el 64,3\% correspondía a hijos e hijas, $15,7 \%$ a cónyuges y 2,9\% a hermanos; sólo el 17,1\% restante estaba constituido por otros cuidadores, tales como personas remuneradas, amigos o vecinos. Las mujeres representaban un $84,3 \%$ de los cuidadores y el promedio del tiempo de cuidado era de siete años.

En relación al significado del paciente para el cuidador, este estudio concluyó que para alrededor de un $21 \%$ de los cuidadores la persona atendida era una carga para ellos. En términos de zona de residencia, este estudio detectó algunas diferencias, mientras que los cuidadores de áreas rurales destacaron la carga afectiva que les producía el cuidado, los del área urbana incidían en las limitaciones que el cuidado suponía para la satisfacción de sus necesidades personales, al considerar este cuidado como una obligación. Independientemente del área de residencia, en la mayoría de los cuidadores se observó una alta sobrecarga y un desgaste, explicitado en las entrevistas. En general, esta investigación permitió detectar que el cuidado de una persona mayor con una enfermedad mental conllevaba una alta carga emocional y que la mayoría de los cuidadores carecía absolutamente de preparación para desempeñarse como tal.

El estudio desarrollado por Cecilia Albala sobre la "Situación de los cuidadores domiciliarios de los adultos mayores dependientes con pensión asistencial" (Albala et al. 2007) describió la condiciones de 220 cuidadores y 318 mayores dependientes en cinco regiones del país, beneficiarios del Programa de atención domiciliaria de personas 


\section{Capítulo IV. Dependencia y cuidados en Chile}

con discapacidad severa ${ }^{36}$. Los resultados de esta investigación nuevamente mostraron que los cuidadores eran en su gran mayoría mujeres $(89,6 \%)$, en promedio 10 años menores que los hombres que realizaban esta labor. La mitad de ellos, sin importar el sexo, tenía 8 o menos años de educación. En general, los cuidadores eran mayoritariamente hijos $(53,8 \%)$ y cónyuges $(18,1 \%)$ y sólo en un $8 \%$ de los casos no se trataba de un familiar. La jornada de trabajo de los cuidadores, en más de un $90 \%$ de los casos, transcurría dentro del hogar, y algo más de la mitad de ellos además de proporcionar los cuidados al mayor postrado efectuaba otras labores del hogar. En general, casi un $11 \%$ de los entrevistados había tomado vacaciones el último año, pero las mujeres cuidadoras llevaban, en promedio, 6 años sin tomar vacaciones.

En el grupo de cuidadores que recibían estipendio ${ }^{37}$, sólo un $54 \%$ de ellos había recibido también la formación en cuidados. En cuanto a los cuidadores que no recibían estipendio, solo un 30\% había recibido dicha formación (Albala et al. 2007:39).

Del total de cuidadores, menos de la mitad compartía el cuidado (en todos los casos con otro familiar), lo cual tenía alto impacto en la calidad de vida y la carga del cuidador. Los análisis efectuados por los investigadores señalan que tanto el estipendio como el compartir el cuidado son factores protectores para la calidad de vida del cuidador, y que la demencia del mayor, la edad y la baja escolaridad del cuidador son factores de riesgo para la calidad de vida y la carga del cuidador.

Los resultados de esta investigación destacaban que la formación de los cuidadores era prioritaria para enfrentar de mejor forma la tarea de cuidar. Igualmente, recomendaban considerar una ayuda especial de soporte a los cuidadores de pacientes con demencia, patología demoledora para el cuidador y la familia del postrado.

Dentro de las investigaciones realizadas en el país, también encontramos algunas que daban especial importancia a la variable género en su análisis sobre los cuidados. Es el caso del documento elaborado por Rodrigo Herrera y Teresa Maffei en 2009 (Herrera y Maffei 2009), quienes realizaron un análisis desde la perspectiva de género sobre la situación de la demanda de cuidados en personas dependientes por hogares. De este

\footnotetext{
${ }^{36}$ Tratado en el apartado de salud pública. El Programa de apoyo a personas con postración severa o pérdida de autonomía, entre otros servicios, contempla la entrega de formación y un estipendio a los cuidadores.

${ }^{37}$ Por sus condiciones socioeconómicas deficitarias.
} 
documento de trabajo del Ministerio de Planificación parece relevante destacar las siguientes aseveraciones:

- La posibilidad de satisfacción de la demanda de cuidados estaba determinada por el sector socioeconómico que lo requiriese, por aspectos territoriales y culturales, también por la capacidad de cubrir esa demanda de la contraparte mediante personas, instituciones o privados.

- Los estratos socioeconómicos altos contaban con la capacidad financiera para "tercerizar" los cuidados a través de instituciones privadas o cuidadores especializados dentro de los hogares. La situación socioeconómica del hogar determinaba la permanencia de los miembros de la familia en el mercado laboral, así generaban ingresos y su calidad de vida no sufría los mismos deterioros a los que podía verse enfrentada una familia que no tenía la capacidad económica de pagar por estos servicios.

- Los estratos socioeconómicos en situación de pobreza acudían a la red institucional pública para satisfacer las necesidades educativas (a través de salas cunas ${ }^{38}$, jardines infantiles o escuelas especiales), de salud (centros de atención primaria y hospitales públicos), pero en el caso de no poder acceder a estas instituciones, ya que, como hemos explicado, estas eran muy escasas a nivel público, eran las familias las que cubrían esta demanda, siendo las mujeres, al interior de cada hogar, las que solían prestar el cuidado.

- La diferencia por los roles de género resultaba evidente y explicitaba la necesidad de generar políticas públicas que mitigaran los efectos negativos del cuidado en las mujeres. Las féminas, con personas dependientes al interior del hogar, debían dejar de realizar actividades remuneradas fuera del hogar, además por razones estructurales y culturales hacían que quedaran rezagadas del mercado laboral y restringidas al trabajo doméstico no remunerado.

- Por largo tiempo, la familia nuclear, con presencia de padres e hijos, fue considerada el modelo de familia sobre el cual se planifican las políticas públicas. Sin embargo, la familia nuclear escondía una gran diversidad de situaciones: existía una proporción importante de familias nucleares monoparentales, de familias sin hijos o donde ambos

\footnotetext{
${ }^{38}$ Servicio de cuidado y estimulación para niños y niñas entre los 84 días de vida (cuando acaba el post natal) y los 2 años de vida.
} 
padres trabajan de forma remunerada fuera del hogar. Los principales cambios, acaecidos en el período de 1990 y 2002, ocurrieron en relación con el mundo laboral femenino, puesto que una proporción creciente de mujeres se incorporó al trabajo remunerado. Además, el aumento de jefaturas femeninas en los hogares era porcentualmente importante en los estratos más pobres, lo que implicaba que ellas estaban siendo sostenedoras económicas y de la gestión reproductiva de los hogares.

Bajo una perspectiva similar, la investigación desarrollada en el Centro de Estudios de la Mujer (CEM) por Díaz, Medel, y Mauro (Díaz, Medel y Mauro 2006), sobre la visibilización de los costos de la producción de salud en el hogar, estudió de forma exploratoria el trabajo de cuidado de salud no remunerado en los hogares del Gran Santiago. Dicho estudio esbozó un perfil de las personas cuidadoras, estimó el grado de visibilidad de las actividades de cuidado de salud y realizó una medición del tiempo dedicado a este tipo de trabajo. El estudio comienza afirmando que el modelo de salud chileno se sustentaba en la complementariedad de los sistemas público y doméstico de salud, bajo la más tradicional división social de los roles sexuales (Medel et al. 2006: 5). En relación al perfil de los cuidadores y cuidadoras de salud, destacaba que la mayor parte eran mujeres (nueve de cada diez), de edades diversas, en su mayoría responsables del hogar, lo que no necesariamente implicaba que realizasen todas las tareas del hogar, pero sí debían organizarlo y hacerlo funcionar $(86,4 \%)$. Además, más de un quince por ciento de ellas, conjuntamente a la responsabilidad del hogar, era el responsable económico de ellos. Las mujeres de edad más avanzada tenían como única actividad el trabajo no remunerado (doméstico y de cuidado). Entre las mujeres más jóvenes había una proporción importante de cuidadoras que, a la vez, tenían un trabajo remunerado, esta situación se presentaba de particular forma entre los 45 y 54 años (48,7\% de las mujeres en esas edades), ello hacía que la carga global de trabajo alcanzase las 87 horas semanales.

En cuanto al tiempo destinado al cuidado de salud, las personas que invertían más tiempo en éstas eran las mujeres que sólo realizaban quehacer doméstico (trabajo no remunerado) y las personas jubiladas. Pero el estudio indica que no existían diferencias significativas entre el tiempo dedicado por hombres y mujeres al cuidado, el sesgo de género se manifestaba en la proporción de cuidadores hombres y mujeres existentes. 
Tampoco encuentran diferencias significativas en el tiempo de dedicación entre sectores socioeconómicos.

Sobre la valorización de actividades de cuidado de salud, la mayoría (77,3\%) realizaba una valorización de estas actividades con criterio económico, argumentando el gran esfuerzo y tiempo invertido, pero al mismo tiempo generaban argumentaciones relacionadas con los vínculos emocionales que se establecen entre la cuidadora y la persona cuidada. Los motivos de quienes no utilizaron un criterio económico giraban en torno al hecho de que el cuidado se hace para un familiar, porque "es su obligación" o porque "es su responsabilidad". La diferencia de género se manifestaba en que las mujeres explicaban las razones familiares versus los hombres que no se extendían en ellas.

La carga total de trabajo de las mujeres era más elevada que la de los hombres (10 horas versus 63 de los hombres), y ellas invertían más tiempo de esta carga laboral en el trabajo doméstico. La dedicación de tiempo de las cuidadoras aumentaba en la medida que disminuía el nivel socioeconómico de pertenencia, resultando que en el sector bajo las mujeres dedican una media de 75 horas y media, alcanzando un máximo de 94 horas promedio aquellas que realizaban trabajo remunerado y no remunerado.

Los tiempos destinados a los cuidados de salud afectaron la vida laboral de hombres y mujeres, pero las alteraciones diferían significativamente por género, ya que las mujeres interrumpían sus actividades laborales, perdían ingresos y amigos, en tanto que los hombres debían adecuar sus tiempos y horarios de trabajo para hacer frente a las tareas de cuidado de salud en el hogar.

Finalmente, dentro de las conclusiones más significativas de este estudio, las investigadoras destacaban la importancia y necesidad de apoyar a los cuidadores de salud no remunerados, en particular a las mujeres de sectores socioeconómicos con medios y bajos ingresos, que dedicaban mucho tiempo a estas actividades y tenían una fuerte carga laboral. Se debe agregar que la pérdida de ingresos en sus entornos familiares se debía a que se veían obligadas a abandonar sus empleos o disminuir sus horas de trabajo remunerado. Por último, se señalaba la necesidad de extender y ampliar el debate sobre estrategias y políticas públicas orientadas a mejorar la situación de los cuidadores. 
Considerando también la variable de género, la investigación realizada por Valderrama, Morris y Ulloa (2010), denominada "Estudio sobre discapacidad y género. Necesidades especiales de protección y asistencia de mujeres con discapacidad y mujeres cuidadoras de personas con discapacidad", indagó de forma cualitativa a mujeres cuidadoras de personas con discapacidad, entre otras. Esta investigación refería que casi todos los cuidadores eran familiares y mujeres (hijas, madres, parejas) de personas con discapacidad que asumían la responsabilidad del cuidado como parte de su rol y, en este sentido, no lo percibían como una opción sino como un deber derivado del afecto. Al trabajo, producto de la tarea de cuidar, le sumaban la realización de tareas domésticas, lo que generaba una carga de trabajo considerable en donde el apoyo familiar y de otras redes resultaban fundamentales para el cuidador. Sin embargo, la carga de trabajo no era repartida de manera equitativa con otros miembros de la familia, y el apoyo recibido se remitía a situaciones puntuales y no era permanente. En una situación de especial soledad se encontraban las cuidadoras separadas o madres solteras, sin redes de apoyo, que experimentaban deterioro en su salud mental y física a causa de la carga del cuidado.

Independiente de lo que significaba la carga de trabajo, las cuidadoras estaban orgullosas del trabajo que realizaban y se sentían reconocidas por sus familias, aunque muchas veces este reconocimiento no era explícito. Como reconocimiento de su trabajo como cuidadoras ellas pedían co-responsabilidad de sus familiares.

Finalmente, la investigación indicaba los conflictos que los cuidadores reconocían como parte de la relación cuidador-cuidado y que les generaban más repercusión en sus vidas, estos eran:

- Sentimiento de frustración por la situación de estancamiento personal y económico, que suponía la situación de una discapacidad severa, y que no podía ser atendida con ayudas técnicas apropiadas.

- Tensión por la asignación arbitraria de responsabilidades.

- Conflictos con otros familiares que, eventualmente, podrían colaborar en el cuidado pero que no prestaban apoyo a esta labor.

- Relaciones de sobreprotección, que no contribuían al desarrollo personal ni a la integración social de las personas con discapacidad. 
- Agotamiento por la magnitud de las tareas de cuidado, que podía traducirse en malas relaciones.

Elaine Acosta (2009: 15) afirmaba que, en Chile, la provisión de cuidados se entendía bajo la lógica del régimen familista, patrón que producía una dependencia sistemática de la familia para proveer de dichos cuidados, basándose en los principios de subsidiaridad. Para ello, el Estado "estimulaba" a la familia a desempeñar este rol, otorgándole ayuda o apoyos, pero no se hacía cargo de la problemática. En Chile, predominaba el modelo de máxima responsabilidad privada en relación con el cuidado de personas dependientes, siendo las mujeres de la familia quienes asumían la mayor parte de la carga de cuidados.

La autora afirmaba que la crisis que experimentaba el cuidado de personas dependientes en Chile, relacionada tanto con el déficit de cuidadores como con la devaluación social que experimenta la actividad, ameritaba la formulación de una política pública dirigida al cuidado de personas dependientes, en la que se garantizaran los derechos de éstos y de sus cuidadores; para ello se requería contar con una política pública familiar de carácter activo.

Finalmente, Acosta señalaba la necesidad de clarificar a nivel conceptual los procesos de provisión y distribución de las responsabilidades de cuidado y sus costos, así como la importancia y el significado del cuidado en la vida cotidiana, ya que, problematizándolos científicamente, se podría entender el cuidado como una responsabilidad social, y no de única responsabilidad de las familias, en especial de las mujeres.

Setién y Acosta (2009) realizaron un análisis comparativo de la gestión de la crisis de los cuidados y su relación con la feminización de las migraciones en Chile y España. En su trabajo, estas investigadoras afirmaban que la crisis que experimentaba el cuidado de personas dependientes estaba siendo abordada desde distintos enfoques en los dos países estudiados, a pesar de compartir las características de un régimen familista. En España, el Estado asumió progresivamente parte de las capacidades de cuidado que tradicionalmente desempeñaban las familias, desde el sistema de salud y los servicios sociales se liberó tiempo familiar que antes se destinaba al cuidado. Igualmente concluyen que en Chile seguía predominando la lógica de máxima responsabilidad 
privada en relación a sus dependientes. Eran las familias, y en la mayor parte de los casos las mujeres, quienes asumían la mayor parte de la carga de cuidados, sin que esta tarea fuese reconocida a nivel público. Los esfuerzos llevados a cabo por el último gobierno de la Concertación, en vías de la construcción de un Sistema de Protección Social, presentaba importantes vacíos, a nivel normativo y de política social, que impedían garantizar adecuadamente los derechos y deberes de los dependientes y de sus cuidadores.

El último estudio que queremos mencionar es el realizado por María Inés Araya (2011), quien realizó una revisión sobre el cuidado familiar de adultos mayores y discapacitados en Chile. Ella realizó una caracterización de los cuidadores en base a la investigación realizada por el CEM, anteriormente revisada, y al estudio desarrollado por el Instituto Nacional de Estadísticas (INE) chileno en 2008, sobre los usos diarios de tiempo. Destacaba la descripción del Programa de atención domiciliaria de personas con discapacidad severa (Programa postrados), que se veía como un inicio en el desarrollo de políticas de salud destinadas a la población en condiciones vulnerables y de dependencia, aunque se consideraba que debería mejorar con el fin del logro de los objetivos que se planteaban. Uno de estos puntos de mejora era la formación de las cuidadoras, componente del programa con más bajo cumplimiento, que afectaba a la atención adecuada del dependiente y al autocuidado en salud del cuidador.

Además, este programa estaba condicionado en su participación, de acuerdo a la condición socioeconómica de las familias, dirigiéndose a sectores más vulnerables y manteniendo invisible el cuidado de otros sectores como la clase media chilena, que experimentaba similares dificultades en desempeñar las labores del cuidado (simultáneamente deben trabajar de forma remunerada para solventar los gastos del dependiente). La condición de precariedad que adquirían estas familias, por la situación de cuidado y el desarrollo de una actividad remunerada fuera de casa, forzaba a que muchas mujeres dejasen sus empleos para dar atención a sus familiares, sacrificando su autonomía y pasando a ser económicamente dependientes de otros. (Araya María Inés 2011: 159)

¿Por cuánto más continuará cuidando la familia -la mujer-? Las tendencias indican que hoy existe un desbalance entre aquellos necesitados de cuidado, que crecen cada vez 
más, y aquellos capaces de proveer el cuidado, que son cada vez menos. ¿Qué pasa con la familia en el Chile de hoy? Debe tenerse presente el dato paradójico revelado por la Encuesta PNUD 2001, el cual apunta a que mientras, por una parte, la familia era lo que define las identidades de la inmensa mayoría de los chilenos, cerca del 60\% de ellos creía que su forma actual era una fuente de problemas y tensiones o que estaba en crisis. Las debilidades de la sociedad se transformaban en exigencias para la familia. Parte importante de la percepción de crisis que muestran los estudios se debe al agobio que produce esta sobrecarga en el ambiente familiar, así como a la experiencia de la dificultad funcional de ésta para enfrentar las nuevas tareas que el cambio cultural le ha asignado.

\subsubsection{Redes de Apoyo}

Con la finalidad de comprender mejor el contexto social de los cuidados informales en Chile, creemos necesario referirnos al estudio de las redes de apoyo social con las que cuentan cuidadores y dependientes. En este marco de estudio, encontramos el análisis realizado por Guzmán, Huenchuan y Montes de Oca (2003), realizado en base a resultados de investigaciones empíricas desarrolladas en América Latina sobre las redes de apoyo social de las personas mayores. La sistematización que realizan estos investigadores, sobre el tema, da como resultado una categorización que ayuda a comprender la complejidad de los sistemas de apoyo a las personas mayores en la región. A continuación se indica dicha categorización, con los ejemplos específicos para el caso chileno:

- Tamaño de la red. El tamaño de la red de apoyo no es constante en todas las etapas de la vida. Entre los factores que intervienen en la determinación del tamaño de la red de apoyo en la vejez figuran el efecto de la mortalidad en la generación de contemporáneos, los cambios de domicilio, la pérdida de la pareja y la jubilación. El tamaño promedio de las redes de apoyo a las personas mayores en el gran Santiago era de 1 a 2 personas $(39,6 \%)$, con diferencias según género, los hombres tenían una red más disminuida que las mujeres. Esta red en su mayoría era de orden familiar, principalmente co-residentes (Huenchuan y Sosa 2003). 
- Distribución de la red. La investigación publicada por Carmen Barros en 2001 (en Guzmán et al. 2003) realizada en las comunas de la capital informaba que el 75\% de los entrevistados podía contar con su familia en caso de necesitarla. Cuando requerían de apoyo recurrían primero a la pareja (43\%) y luego a los hijos e hijas (21\%), mientras que los hermanos prácticamente no eran considerados $(4 \%)$. La familia cumplía un papel importante en el apoyo instrumental a las personas mayores, el cónyuge y los hijos/as eran los principales proveedores de ayuda económica y cuidados, y era el cónyuge con quién las personas mayores contaban incondicionalmente, ya que con los hijos podían hacerlo sólo en un plazo breve o frente a situaciones específicas.

Los amigos y amigas constituían una fuente secundaria de apoyo, a la que se recurría en busca de respuesta a determinadas necesidades -apoyo cognitivo, principalmente- y que, al parecer, cobraba mayor importancia para las personas con escasas relaciones familiares. En este ámbito, también se observaban diferencias de género en cuanto a la importancia otorgada a las amistades: los hombres daban más importancia a las relaciones familiares que a las de sus amigos, mientras que la mitad de las mujeres concedían a ambas similar importancia. Las explicaciones, que los propios mayores proporcionaban a esta situación, tenían relación con el hecho de que las mujeres tenían más tiempo para compartir y conversar con las amistades, con la creencia de que la amistad entre los hombres era más superficial y la existente entre las mujeres era más permanente y cotidiana (esta última afirmación, a su vez, se asociaba con la idea de que la mujer, al relacionarse con sus familiares, debía mostrarse fuerte y ser la que atiende a los otros, en cambio con sus amigas podía actuar en forma más relajada).

- Tipos de apoyos que dan y reciben las personas mayores. Las investigaciones revisadas indicaban que las personas mayores recibían y otorgaban apoyos de todo tipo. Oscar Domínguez (en Guzmán et al. 2003) presentaba un panorama de la situación del intercambio de apoyo social en personas mayores basado en su investigación en ciudades chilenas de más de cien mil habitantes en 1984. El autor concluía que las familias, en general, brindaban apoyo emocional (compañía) y apoyo material a las personas mayores. Agregaba que las mujeres mayores eran las que recibían más apoyos de este tipo de sus familiares. Según datos actualizados al respecto, persistía la misma situación: lo que más recibían los adultos mayores, del Gran Santiago, era dinero (Huenchuan y Sosa 2003). A su vez, los mayores igualmente brindaban apoyos. En 
1984, las personas mayores, en un alto porcentaje, aportaban más apoyo material, incluso superior al que proveían en dinero y casa, que el que recibían. En 1998, por el contrario, las personas mayores daban más servicios que dinero (Huenchuan y Sosa 2003).

En lo que respecta a la valoración de las fuentes de apoyo a las personas mayores, Barros (en Guzmán et al. 2003) planteaba que existían diferencias según nivel socioeconómico, de tal forma que en los estratos bajos la mejor calificación la obtenía el cónyuge o la pareja, mientras que en los estratos medios correspondía a los hijos. Incluso en este estrato los peores evaluados fueron los cónyuges, debido principalmente a la opinión de las mujeres, quienes fueron entrevistadas en mayor proporción en la investigación citada. Esta diferencia podría deberse a que en el estrato bajo lo que se valoraba era la compañía, la ayuda material y económica, mientras que en el estrato medio, al momento de calificar, se tenía en mente la afinidad entre la pareja.

Huenchuan y Sosa (2003) analizaron las redes de apoyo social de las personas mayores en Chile, a través de la Encuesta sobre Salud, Bienestar y Envejecimiento (SABE) y de datos de la Encuesta de Caracterización Socioeconómica Nacional (CASEN) del año 2000. Entre los principales resultados de su pesquisa destacaron:

- Las personas mayores participaban activamente en redes de apoyo y eran una importante fuente de apoyo material e instrumental para sus familias.

- Realizando un análisis por género, los hombres tenían más dificultades para mantener o ampliar sus redes de apoyo social durante la vejez.

- La situación de las mujeres mayores era homogénea, ya que las mujeres solas presentaban dificultades para participar y pertenecer a una red de apoyo.

- Las redes de apoyo de las personas mayores incorporaban en menor medida fuentes extra-familiares. Las investigadoras detectaban la necesidad de fomentar su ampliación hacia otros ámbitos significativos, como la comunidad o las amistades. 


\subsection{Cuidados formales en Chile ${ }^{39}$}

Como señaláramos anteriormente, en la atención a las personas dependientes intervienen tres agentes: la familia cuidadora -cuidado informal-, el sector público con su oferta de servicios y prestaciones económicas y la oferta privada, tanto mercantil como no lucrativa -cuidado formal-. A pesar de que esta investigación versa sobre los cuidados informales, creemos necesario describir brevemente la situación de los cuidados formales en Chile, ya que así se podrá entender mejor el estado de los cuidados informales en el país.

Al inicio de este capítulo realizamos una contextualización donde tratamos aspectos de la política social chilena, revisando aspectos fundamentales relacionados con la salud, el sistema de pensiones y la educación en Chile, para no ser reiterativos en este apartado agregaremos los aspectos que hayan quedado pendientes.

La oferta de cuidados formales en el país responde a la forma en cómo la sociedad chilena ha asumido la demanda de cuidados de los grupos dependientes, principalmente personas mayores. Por ello, se da la coexistencia de entidades privadas con fines de lucro y entidades -privadas o públicas- sin fines de lucro. De acuerdo al estrato de la población en la que se centra esta investigación, solo nos referiremos a las últimas.

\subsubsection{EI Estado y los centros residenciales}

Actualmente en Chile, el rol desempeñado por el Estado en la atención residencial a personas dependientes es secundario, éste recae principalmente en la familia. En el caso de las personas mayores, esta realidad se plasma en la siguiente declaración, ejemplo paradigmático de la Política Nacional para el Adulto Mayor:

(...) que los problemas y situaciones que viven los adultos mayores no se solucionan o superan sólo con la acción del Estado. Por el contrario, parte importante de la problemática del adulto mayor debe ser resuelta por la propia comunidad $\mathrm{y}$, muy especialmente, al interior de la familia, la cual debe ser ayudada en esta tarea por toda la sociedad (Servicio Nacional del Adulto Mayor 2006:4).

\footnotetext{
${ }^{39}$ Resulta importante consignar que la investigación realizada en torno al tema de los cuidados en Chile está basada en la revisión de todos los estudios disponibles en la red, independiente de su actualidad o representatividad, ya que no existen estudios a nivel nacional que aborden la problemática.
}

Página $\mid 179$ 
Si nos basamos en las estadísticas disponibles para personas mayores, los ancianos que necesitaban de cuidados, por su dependencia severa, eran el 12,4\% de los mayores de 60 años en el año 2009 (Servicio Nacional del Adulto Mayor 2009), lo que equivalía a 208243 personas, pero las previsiones demográficas y sanitarias indican que la necesidad de cuidados -formales e informales- irá en aumento. Además, la necesidad de cuidados formales se verá acrecentada por los cambios que se han generado en la sociedad chilena en la última década que, sintéticamente, consiste en familias y viviendas más pequeñas y un aumento de las mujeres que trabajan fuera del hogar. En Chile, las instituciones que prestan cuidados formales a mayores se denominan Establecimientos de Larga Estancia para Mayores (ELEAM), bajo este concepto encontramos casas de reposo, hogares de ancianos, asilos, hospicios y otros similares que prestan servicios de residencia de larga estadía a mayores. El Reglamento de establecimientos de larga estadía para adultos mayores definían que:

Establecimiento de larga estadía para adultos mayores, o ELEAM, es aquel en que residen personas de 60 años o más que, por motivos biológicos, psicológicos o sociales, requieren de un medio ambiente protegido y cuidados diferenciados que allí reciben. Dichos cuidados tienen por objeto la prevención y mantención de su salud, la mantención y estimulación de su funcionalidad y el reforzamiento de sus capacidades remanentes. Para su funcionamiento, los Establecimientos de Larga Estadía para Adultos Mayores deberán contar con autorización otorgada por la Secretaría Regional Ministerial de Salud competente del lugar en que se encuentra ubicado. (Ministerio de Salud 2010: 2-3)

El Estado chileno, que hasta hace poco tiempo no desarrollaba ninguna iniciativa en este ámbito, al año 2013 contaba con dos tipos de alternativas residenciales para personas mayores con escasos recursos, que eran los establecimientos de larga estadía (ELEAM) y los condominios de viviendas tuteladas (para personas mayores autovalentes).

Los ELEAM de dependencia pública - municipal o de servicios de salud- sólo representaban un 2,9\% de los establecimientos de cuidado formal del país, estos eran doce, con dos de ellos operados por instituciones privadas (Hogar de Cristo y Hermanas de los pobres de la Maiquetía). Las plazas residenciales llegaban a las 548 a marzo de 2013 (Servicio Nacional del Adulto Mayor 2013). 
De acuerdo al catastro de ELEAM, efectuado en 2012 (Servicio Nacional del Adulto Mayor 2013), en Chile existían un total de 726 establecimientos que prestaban cuidados formales, de los cuales un 65,8\% eran instituciones privadas con fines de lucro y un $31,3 \%$ instituciones privadas sin fines de lucro. Del total de centros catastrados, un 93,1\% declaraba estar autorizado para funcionar (por el servicio regional del Ministerio de Salud), un 6,6\% en vías de autorización y un 0,3\% declaraba que la autorización había caducado. El mayor número de instituciones se encontraban en la Región Metropolitana, para el año 2007 se contabilizaba 368 instituciones en la región que contaban con autorización del Ministerio de Salud para funcionar (Secretaría Regional Ministerial de Salud de la Región Metropolitana 2007).

Se debe mencionar que el Reglamento de establecimientos de larga estadía para adultos mayores (Ministerio de Salud 2010) regula, en la actualidad, la instalación y funcionamiento de estos centros, sea desarrollado por organizaciones lucrativas o no lucrativas. Esta normativa representó un importante avance en la regulación de estas instituciones en el país, poniendo énfasis en que se procure la entrega de servicios apropiados, y de calidad, para los mayores y en la fiscalización del cumplimiento permanente de lo dispuesto por parte de las Secretarías Regionales Ministeriales.

\subsubsection{La acción de ONGs y Movimientos Asociativos}

La situación de desprotección social reinante en Chile, durante décadas, ha afectado principalmente a la población más vulnerable, es decir, a los viejos, discapacitados, niños, mujeres grupos que generalmente se encuentran en situación de pobreza. Como tratamos, al comienzo de este capítulo, dicha situación fue especialmente crítica en los años en el que país vivió bajo la dictadura militar, es precisamente en esa época cuando surgen o se consolidan muchas de las instituciones sin fines de lucro que hoy desarrollan una importante labor a favor de las distintas colectividades carenciadas. Fue también éste el contexto en el que estas entidades comenzaron a otorgar aquellas prestaciones que el Estado no proporcionaba. Con el retorno de la democracia, en 1990, el Estado chileno tuvo como prioridad el trabajo en políticas sociales que fueran a la par del desarrollo económico del país. En este nuevo escenario, muchas ONGs desaparecieron, pero otras cuantas se vieron fortalecidas gracias a subsidios estatales y apoyos de donantes, ya que focalizaron y especializaron su labor. 
De acuerdo al catastro de ELEAM, efectuado en 2012, entre las instituciones que prestaban servicios residenciales sin fines de lucro predominaban las del tipo "instituciones, fundaciones o congregaciones religiosas", muchas de éstas dependían de organizaciones de la sociedad civil especializadas en la temática de las personas mayores, y otras de la ayuda social en general. A continuación, se describen algunas de las más importantes instituciones que prestaban cuidado formal, tanto para mayores como para personas con discapacidad.

\subsubsection{Fundación de Beneficencia Hogar de Cristo}

Institución que tenía entre sus grupos objetivo a personas discapacitadas mentales y personas mayores, entre otros, en centros distribuidos a lo largo del país. Esta entidad desarrollaba su función a través de otras fundaciones para el abordaje más específico de problemáticas, en el caso de los discapacitados mentales lo hacía a través de la Fundación Rostros Nuevos. Su trabajo era desempeñado por profesionales y personal voluntario.

En el caso de las personas mayores, el Hogar de Cristo (Fundación Hogar de Cristo 2013) atendió a septiembre de 2012 a 5284 mayores a través de las siguientes modalidades de atención:

- Centro de día. El Centro de encuentro del adulto mayor (CEAM), dirigido a personas autovalentes frágiles y dependientes leves, ofrecía actividades diurnas de tipo sociocultural, recreativas, terapéuticas y de rehabilitación, que fomentaban la socialización, la autonomía funcional, la prevención de la dependencia y el autocuidado. En el tercer trimestre de 2012 atendió a 1038 mayores.

- Centro de día especializado. Es un CEAM que presta servicios similares al anterior, pero con personas mayores que presentan un grado de dependencia moderada. A fecha de septiembre de 2012 había prestado atención a 200 mayores.

- Atención domiciliaria. A través del Programa de atención domiciliaria para adulto mayor (PADAM), intervenía directamente en el domicilio de los usuarios. Éstos podían ser mayores autovalentes frágiles, dependientes leves, moderados o severos. El programa entregaba apoyo psicosocial y material. En el tercer trimestre había atendido a 3142 mayores a nivel nacional. 
- Residencias. Residencias de larga estadía orientadas a personas con dependencia moderada y severa, que no contaban con apoyo familiar y recursos económicos suficientes para permanecer en su medio. El tercer trimestre de 2012 prestó este servicio a 886 mayores.

El trabajo con personas discapacitadas mentales del Hogar de Cristo era desarrollado por una entidad relacionada llamada Fundación Rostros Nuevos, y estaba dirigido a personas adultas, en situación de pobreza y/o exclusión social, que presentaban discapacidad mental (intelectual o psiquiátrica), estabilizados clínicamente, con débiles o nulos vínculos familiares, y derivados preferentemente del Hogar de Cristo o de redes estatales. A junio de 2012 había atendido a 790 personas a través de los siguientes programas:

- Hogares. Programa de tipo residencial, donde se intentaba desarrollar rutinas, hábitos y funcionamiento interno lo más parecido a un ambiente familiar. Recibían atención y supervisión las 24 horas del día, respondiendo a sus necesidades básicas. La atención de salud general y psiquiátrica la recibían, en su mayoría, a través del sistema público de salud. La institución realizaba atención y orientación clínica, trabajo de vinculación familiar, integración comunitaria y desarrollaban distintos planes de rehabilitación. Existían distintas modalidades residenciales, tales como hogares protegidos, residencias protegidas y centros de larga estadía. El tercer trimestre de 2012 prestaron este servicio a 359 personas con discapacidad.

- Centros de rehabilitación laboral. La mayoría de los usuarios pertenecía a algunos de los programas de la institución, pero también contaba con un número de usuarios externos a ésta, provenientes de otras organizaciones relacionadas o de la comunidad. Se realizaban talleres protegidos ${ }^{40}$, se desarrollaban trabajos semiprotegidos ${ }^{41}$ en empresas que habían dispuesto determinadas plazas laborales para usuarios de la fundación principalmente, efectuando trabajos manufactureros y de servicios (jardinería y aseo).

\footnotetext{
${ }^{40}$ Talleres que combinan aspectos productivos con aspectos de desarrollo y aprendizaje que permitan a sus usuarios facilitar su proceso de integración social.

${ }^{41}$ En los trabajos semiprotegidos se utilizan instrumentos que permiten la inserción en el empleo ordinario de personas cumpliendo los siguientes objetivos: facilitar una actividad productiva y remunerativa, facilitar apoyos necesarios para desarrollar un trabajo en el empleo ordinario y conseguir el tránsito de los trabajadores discapacitados a un empleo ordinario (García 1998).
} 
- Programa de apoyo familiar. Intervención psicosocial a familias de la Región Metropolitana que tenía algún integrante con discapacidad psíquica y/o mental. Se entregaba ayuda material o económica, apoyo e intervención psicológica a la familia y/o cuidador.

- Programa de salud mental y psiquiatría comunitaria. Se basaba en la atención ambulatoria por parte de un equipo multidisciplinario de rehabilitación a personas con discapacidad psíquica y/o mental pertenecientes a las cuatro hospederías del Hogar de Cristo de Santiago. Se realizaba orientación y atención clínica, derivación a red de salud estatal, acompañamiento, atención en terapia ocupacional, articulación de redes de apoyo, trabajo con familia y la comunidad, además de coordinar la colaboración con equipos de las hospederías.

\subsubsection{Fundación Las Rosas}

Institución católica que contaba con más de 40 hogares de larga estancia para mayores en siete regiones del país, proveyendo cuidados a 2570 mayores en situación de pobreza. Desarrollaba su trabajo gracias a profesionales contratados y al trabajo de voluntarios (Fundación las Rosas 2013).

\subsubsection{Fundación Coanil}

Es una fundación de carácter privado y sin fines de lucro, que acogía y educaba a niños, jóvenes y adultos con discapacidad intelectual. La Institución atendía a niños, jóvenes y adultos entre los 0 y los 50 años que presentaban algún tipo de discapacidad intelectual, ya sea en hogares residenciales, en las escuelas, o a través de la capacitación y reinserción laboral. Además, apoyaba a las familias a través de centros multiprofesionales, con asistentes sociales, terapeutas y psicólogos, entre otros especialistas. Contaba con profesionales y técnicos pagados y el trabajo de voluntarios. La Fundación Coanil utilizaba las siguientes modalidades de atención que se relacionan con el tema en estudio:

- Hogares residenciales. La institución tenía 11 centros residenciales -mixto o sólo un sexo- para personas con discapacidad intelectual leve y/o moderado, severo - profundo, y en familias de acogida. Seis de los centros se ubicaban en la capital y cinco en regiones. En el año 2011 dieron atención a 766 niños, jóvenes y adultos. 
- Escuelas. La fundación tenía más de 30 escuelas y centros en todo el país que ofrecían diferentes niveles educativos (intervención temprana, pre básico, básico y retos múltiples, y escuela con especialidad en atención temprana), atendiendo a 2104 personas en 2011 (Fundación Coanil 2011).

También nos parece importante señalar el importante número de organizaciones de usuarios y de familiares que existían en el país y que prestaban servicios de cuidados a la comunidad en la fecha que realizó este trabajo. A continuación destacamos las entidades de este tipo que tenían más relevancia.

\subsubsection{Asociación Chilena de Padres y Amigos de los Autistas (Aspaut)}

Corporación de derecho privado sin fines de lucro que orientaba su acción a favorecer la calidad de vida de las personas con trastorno del espectro autista, a través de servicios educacionales y terapéuticos; también apoyaba a las familias de las personas afectadas por estos trastornos del desarrollo (Asociación Chilena de Padres y Amigos de los Autistas 2013). La asociación estaba formada por padres y familiares de personas afectadas.

Entre los servicios que la institución entregaba se debe destacar:

- La educación diferencial en escuelas especiales (contaban con seis escuelas en el país) y programas de apoyo a la integración escolar en la educación regular.

- Acciones terapeúticas, consistentes en arteterapia, hidroterapia, fonoaudiología, kinesiología, musicoterapia, psicológica, terapia ocupacional.

- Orientación familiar.

\subsubsection{Corporación Alzheimer Chile}

La Corporación Alzheimer Chile (Corporación Alzheimer Chile 2013) era una institución benéfica sin fines de lucro, fundada en 1990 por un grupo de familiares de personas con demencias, con el apoyo de profesionales dedicados al tema. Entre sus principales objetivos estaba: apoyar a los pacientes con enfermedad de Alzheimer o afecciones similares y a sus familias, para mejorar su calidad de vida; informar y sensibilizar a la opinión pública sobre la importancia de estas afecciones, su tratamiento y su prevención; promover y apoyar la creación de grupos de autoayuda similares en el 
país; establecer contacto con organizaciones afines a nivel nacional e internacional; finalmente, alentar la investigación científica y estudios clínicos de estas afecciones.

Los servicios que ofrecía esta corporación, la mayoría pagados, eran: grupos de autoayuda, formación a cuidadores, atención psicológica a familiares, atención kinesiológica (fisioterapéutica) a mayores con Alzheimer, talleres de estimulación, centro de día y atenciones a domicilio (médicas, de enfermería o kinesiología).

Además señalamos la existencia de la Asociación Nacional de Familiares y Amigos de Discapacitados Psíquicos (ANAFADIS), la Asociación de Padres de Niños con Epilepsia (APADENE) y la Fundación Down21-Chile. 


\section{PARTE II: TRABAJO EMPÍRICO Y ANÁLISIS}

\section{CAPÍTULO V: MARCO METODOLÓGICO}

\subsection{Introducción}

En este capítulo revisaremos aspectos referentes al desarrollo de los procesos usados en esta investigación. Comenzamos tratando el problema de investigación, su fundamentación y objetivos. En un tercer epígrafe, examinamos el abordaje metodológico cualitativo de la investigación, especificando en el diseño de la investigación con la Teoría Fundamentada. Posteriormente, especificamos nuestra población y muestra en estudio. A continuación se revisan las herramientas e instrumentos usados para la obtención de la información. Posteriormente, especificamos el trabajo de campo que nos permitió recoger la información que fue analizada. Y finalmente, describimos la metodología usada como guía del trabajo de campo y del análisis, junto a los mapas conceptuales con la estructura categorial desarrollada.

\subsection{Esquema global de investigación}

\subsubsection{Problema y preguntas de investigación}

Tal como se propuso en la introducción general de esta investigación doctoral, el problema de investigación que se intenta abordar dice relación con explorar y conocer la realidad psicosocial y cultural de los cuidadores informales de personas dependientes en Chile, ello con la finalidad de contar con fundamentos idóneos para generar propuestas de iniciativas político-sociales dirigidas a estos grupos. Para dar respuesta a ello nos formulamos las siguientes preguntas de investigación:

- ¿Cuál es la situación psicosocial y cultural de los cuidadores informales de personas dependientes, de sectores socioeconómicos medios-bajos y bajos, que habitan en la Región Metropolitana (RM) de Santiago de Chile? 
- ¿Existen diferencias en la situación de cuidadores informales rurales y urbanos?

- ¿Qué aspectos de la situación psicosocial y cultural de los cuidadores son susceptibles de mejorar a través de políticas sociales intersectoriales?

\subsubsection{Objetivos generales y específicos}

A raíz de las interrogantes anteriormente planteadas formulamos como objetivos de nuestra investigación lo siguiente:

\section{Objetivos Generales}

- Conocer la situación psicosocial y cultural de los cuidadores informales de personas dependientes, con niveles socieconómicos medios-bajos y bajos, habitantes de espacios urbanos y rurales.

- Conocer la concepción de cuidado que en el hábitat rural y urbano se tiene.

\section{Objetivos Específicos}

- Identificar las características y problemáticas de salud, sociales y culturales del cuidador informal y el entorno que le rodea.

- Describir las consecuencias que tiene el cuidar sobre la salud del cuidador.

- Explorar las formas en que cuidadores informales rurales y urbanos enfrentan la tarea del cuidado.

- Identificar el significado que los cuidadores atribuyen a la tarea del cuidado y a las circunstancias que generan la dependencia.

- Identificar la existencia de redes de apoyo social a los cuidadores entrevistados.

- Identificar las principales demandas que los cuidadores realizan al Estado. 


\subsection{Abordaje metodológico}

El tema de los cuidados a la dependencia cuenta con una serie de particularidades que influyeron a la hora de tomar la decisión de cómo investigarlo. Los estudios que, hasta la fecha de inicio de esta investigación, se habían realizado en el país, abordaban de forma tangencial el tema de los cuidados a la dependencia -centrados más bien en el dependiente-, y en su mayoría estaban orientados a cuantificar, pero sin profundizar en la figura del cuidador, en el conocimiento de su realidad particular. Esto fue lo que nos motivó a plantear el problema de investigación de esta investigación, formular las preguntas e intentar dar respuesta a ellas a través de los objetivos delimitados, y para ello consideramos que la mejor forma de abordaje era desde la metodología cualitativa, que busca ahondar en la realidad y entregarnos una visión más amplia de ésta.

Esta investigación se define como cualitativa, transversal, exploratoria y descriptiva.

Tal como nos señala Jiménez-Domínguez (2000), la metodología cualitativa parte del supuesto básico de que el mundo social está construido de significados y símbolos. De ahí que la intersubjetividad sea una pieza clave de la investigación cualitativa y el punto de partida para captar reflexivamente los significados sociales. La realidad social así vista está construida de significados compartidos de manera intersubjetiva.

La investigación cualitativa puede ser vista como el intento de obtener una comprensión profunda de los significados y definiciones de la situación tal como nos la presentan las personas, más que la producción de una medida cuantitativa de sus características o conducta (Ruiz e Ispizua 1989 y Wainwright 1997 en Jiménez-Domínguez 2000). Por ello la investigación cualitativa es interpretativa; es el estudio interpretativo de un problema determinado en el que el investigador es responsable en la producción de sentido.

Hammersley y Atkinson (1994) nos invitan a reconocer el carácter reflexivo de la investigación social, es decir, a aceptar que formamos parte del mundo social que estudiamos, ya que esto no es solo una cuestión metodológica, es un hecho existencial. Ellos indican que cualquier investigación social toma la forma de observación 
participante: implica participar en el mundo social, cualquiera que sea su papel, y reflexionar sobre los efectos de esa participación.

A este respecto, Coffey y Atkinson (2005) señalan que los datos que usamos son versiones parciales o incompletas del mundo social, producimos versiones de ese mundo por medio de nuestros datos y nuestros procesos de análisis. Así, el conocimiento es resultado de transacciones con el mundo social, modeladas por nuestros métodos de investigación y transacciones con los datos.

Dentro de la variedad de enfoques que se pueden adoptar desde la metodología cualitativa, consideramos que el más adecuado para guiar el proceso de investigación es la Teoría Fundamentada.

\subsubsection{Teoría Fundamentada como diseño de investigación}

El diseño de investigación se enmarcó dentro de la Teoría Fundamentada. Este esquema interpretativo sirvió de pauta para el abordaje general de la investigación, guiando el trabajo de campo y el análisis.

La Teoría Fundamentada (TF) o Grounded Theory, es una propuesta para generar teoría desde los datos y fue formulada por Barney G. Glaser y Anselm L. Strauss en 1967. Estos investigadores afirman: "detrás de la metodología, se esconde la verdadera oferta distintiva de la sociología en nuestra sociedad, que es la teoría sociológica y no solo las descripciones de las investigaciones" (Glaser y Strauss 1967, 30). La Teoría Fundamentada se plantea como un método concreto de acercamiento a la experiencia social de las personas y grupos sociales, que comienza con la recolección de material sobre dicha experiencia e intenta comprenderla a través de un método comparativo constante.

Las tradiciones teóricas más importantes en los Estados Unidos de la época se ven cuestionadas en esta teoría: el Estructural-Funcionalismo y la Escuela de Chicago. Glaser se formó en la Universidad de Columbia, fuertemente influenciado por Lazarsfeld y la tradición positivista. Strauss procedía de la Universidad de Chicago 
donde se formó entre interaccionistas simbólicos y pragmatistas como Park, Dewey, Mead y Blumer, que ponían especial énfasis en el trabajo de campo como forma de aprehender el funcionamiento de la realidad social. La publicación de The discovery of Grounded Theory (Glaser y Strauss 1967), donde se expone la Teoría Fundamentada, representa una crítica a cada una de las tradiciones en que los autores fueron formados. Ellos afirman que la Escuela de Chicago había sido incapaz de avanzar hacia un planteamiento sistemático e integrado de los datos cualitativos. Por otro lado, el funcionalismo estadounidense estaba enfocado en la verificación cuantitativa de teorías de rango medio (Merton), desde su visión grandes teorizaciones lógicas, pero con verificaciones empíricas mínimas. Ellos criticaban la separación que se daba entre los enormes planteamientos teóricos y la práctica de los investigadores sociales, con una investigación limitada a la recolección de datos cuantitativos en un determinado campo social sin cuestionar los conceptos que guiaban esa recogida de datos.

La Teoría fundamentada está compuesta por unos elementos fundamentales (Rodríguez Martínez 2008), a continuación se explican brevemente:

- Sensibilidad teórica del investigador: habilidad para crear y manejar conceptos, donde la creatividad es condición para poder interpretar los datos.

- La codificación, categorías y propiedades. Apenas iniciado el trabajo de campo el investigador comienza este proceso, en sus inicios con categorías simples, que conforme avance el proceso de investigación van enriqueciéndose. Básicamente, codificar consiste en nombrar, separar, compilar y organizar los materiales recogidos en el trabajo de campo. Una categoría es un elemento conceptual de una teoría, mientras que una propiedad es un aspecto de una categoría, elementos de una misma estructura con diferentes grados de abstracción.

- Hipótesis. Se tratan de intuiciones iniciales sobre la forma en que se relacionan los conceptos, vinculando dos o más conceptos, que intentan explicar el qué, el porqué, el dónde y el cómo de un fenómeno. Estas hipótesis se derivan de los datos, son abstracciones que deben ser validadas y reelaboradas por medio de la comparación continua de éstos (Strauss y Corbin 2002). 
- Muestras teóricas. Nos referimos a la recolección de datos guiada por los conceptos derivados de la teoría que se está construyendo y basada en el concepto de "hacer comparaciones", cuyo propósito es acudir a lugares, personas o acontecimientos que maximicen las oportunidades de descubrir variaciones entre los conceptos y que hagan más densas las categorías en términos de sus propiedades y dimensiones. Con respecto al número de materiales a recoger, la regla general es reunir datos hasta que todas las categorías estén saturadas, esto es lo que se denomina saturación teórica. El momento en que se debe detener el muestreo es cuando no hay datos nuevos e importantes que parezcan estar emergiendo en una categoría; la categoría esté bien desarrollada en términos de sus propiedades y dimensiones, demostrando variación; las relaciones entre categorías estén bien establecidas y validadas.

Integración. Con el desarrollo de hipótesis y nuevas codificaciones comienza a emerger la integración de la teoría. En esta etapa son útiles los memorandos ${ }^{42}$ que se redactaron en relación a los códigos. Integrar es descubrir las relaciones que existen entre las diferentes categorías, generando una visión de conjunto sobre el proceso social que se intenta describir.

De la teoría sustantiva a la teoría formal. La integración de la teoría puede surgir en diferentes niveles de generalidad. La teoría sustantiva es la que está referida a un campo social concreto, y la teoría formal es la que trata sobre las relaciones sociales y es posible de utilizar en diversos campos sociales concretos (Rodríguez Martínez 2008).

Glaser y Strauss (Glaser y Strauss en Rodríguez Martínez 2008) señalan que en este proceso de generar teoría debe considerarse que, "el análisis comparativo de diversos tipos de grupos sustantivos, a través de los que se pretende generar teoría fundamentada formal, pueden colocar al investigador lejos de conseguir interacciones sustantivas emergentes. Los modelos formales existentes de procesos, estructura y análisis son guías útiles para integrar las categorías de una teoría formal, siempre que se tenga en cuenta que la integración no está forzada por la teoría. Los modelos de integración para

\footnotetext{
${ }^{42}$ Los memorandos son registros escritos del análisis que pueden variar en tipo y forma. Pueden ser memorandos sobre la codificación; memorandos teóricos -notas sobre reflexiones del investigador en su labor; y memorandos operacionales -notas sobre procedimientos y recordatorias- (Strauss y Corbin 2002).
}

Página | 192 


\section{Capítulo V. Marco metodológico}

la teoría sustantiva que se deriva de los datos no son aplicables necesariamente a otras áreas sustantivas. Su transferencia sólo puede hacerse con mucha precaución, y solo después de haber intentado descubrir una primera integración emergente.” (p. 155-156)

Desde que en 1978 Glaser y Strauss iniciaran la Teoría Fundamentada, ésta se fue diversificando en varias tendencias. Del planteamiento original de los autores de la Teoría Fundamentada, surgen dos variantes; una de ellas es la que abandera Glaser, el cual pone el acento en la inducción y creatividad del investigador, cree que lo importante es la habilidad del investigador para descubrir lo que los datos van aportando y propone hipótesis a partir de las informaciones que ella le suministran. En tanto que Strauss, junto con Juliete Corbin, se decantan por la técnica, que es la que permite al investigador, independiente de las destrezas que posea, alcanzar la teoría buscada. La tendencia Strauss-Corbin aparece en el año 1990, constituyéndose en la versión más metódica de la Teoría Fundamentada. Estos investigadores explican con mayor detalle la metodología a seguir para lograr que emerja la teoría a partir de los datos.

Otra de las perspectivas es la Teoría Fundamentada Constructivista, desarrollada por Kathy Charmaz, ella retoma las ideas originales de la propuesta de 1967 e incorpora explicaciones de los sentimientos de los individuos a medida que experimentan un fenómeno o proceso, las creencias y valores del investigador, evitando emplear categorías predeterminadas.

Finalmente, la Teoría Fundamentada en el Posmodernismo formulada por Adele Clarke que retoma el concepto de mundos/arenas /discursos ecológicos, y propone tres mapas mapas circunstanciales, mapas de mundos/arenas sociales y mapas posicionales- que hacen énfasis en las diferencias más que en las concordancias, idea presente en la Teoría Fundamentada original.

Esta investigación se adhiere a los planteamientos expresados por Strauss y Corbin sobre el método a seguir para desarrollar una investigación a través de la Teoría Fundamentada. En el apartado método de análisis se describe el plan desarrollado para esta investigación. 


\subsection{Población y muestra}

El universo de este estudio estaba conformado por los cuidadores de personas dependientes que residían en zonas urbanas y rurales de la RM de Santiago de Chile (mapa 1, p. 200), de sectores socioeconómicos medios-bajos y bajos.

Con la finalidad de localizar a nuestros informantes consideramos pertinente realizar el estudio con cuidadores informales usuarios del componente: "Atención Domiciliaria de Personas con Discapacidad Severa", del Programa de Resolutividad en Atención Primaria efectuado por Ministerio de Salud chileno a nivel nacional. Los cuidadores usuarios que participan de este programa correspondían a personas de los estratos socioeconómicos requeridos, que prestaban atención a personas con dependencias severas de distintas edades, pero con un claro predominio de personas mayores. Este componente, en adelante denominado "Programa de Postrados",43, se desarrollaba a través de dos iniciativas:

- Visita Domiciliaria Integral (VDI). Conjunto de acciones de carácter sanitario realizadas en el domicilio, para atender los problemas de salud de las personas que se encontraban en situación de discapacidad severa ${ }^{44}$.

- Pago a cuidadores de pacientes con discapacidad severa. Consideraba el pago de una subvención a los cuidadores de personas con postración severa que calificaran para ello. Para que el cuidador pudiese optar a este beneficio debía estar inscrito en su centro de salud, ser beneficiario del sistema público de salud (Fonasa) o de algún programa gubernamental (Prais, D.L.869, Chile Solidario u otro), estar clasificado como pobre ${ }^{45}$ (indigente o no indigente) mediante la

\footnotetext{
${ }^{43}$ Éste es el nombre con el que se refieren a él los profesionales que lo gestionan en el ámbito sanitario, debido a que el nombre del componente es muy largo le dan uno más corto para referirse a él.

${ }^{44}$ La persona debe clasificar como postrado permanente y severo, -de acuerdo al índice de Katz- que requiera de apoyo total del cuidador, para bañarse, vestirse, usar el inodoro, alimentarse, continencia de esfínteres, trasladarse.

${ }^{45}$ La definición de pobreza utilizada en Chile está referida a la línea de pobreza, la cual se calcula en base al ingreso per cápita total del hogar; si ese ingreso no alcanza el valor de una canasta básica de alimentos (que contiene los requerimientos calóricos mínimos para asegurar la subsistencia del individuo, definida por la CEPAL), las personas que componen ese hogar son indigentes. Por otra parte si ese ingreso se encuentra entre una y dos canastas, las personas de ese hogar son pobres no indigentes (Ministerio de Planificación s.f.).
} 
evaluación social del trabajador social del equipo de salud o aplicación de Ficha Cas II por trabajador social del municipio.

Uno de los criterios que maneja la investigación cualitativa para definir el número de informantes es el principio de saturación de la información. Específicamente en la Teoría Fundamentada se trabaja con el concepto de muestreo teórico, que no fue posible ejecutar tal como lo indica la metodología debido a que el tiempo de trabajo de campo que hubiese requerido tal tipo de muestreo no estuvo disponible para la investigadora.

El plan de trabajo en Chile contemplaba una muestra inicial de entrevistas a 30 cuidadoras/es de personas dependientes, que formaran parte del programa anteriormente citado y que viviesen en comunas urbanas y rurales de la RM. Finalmente, fueron entrevistados 31 cuidadores, 16 en comunas urbanas y 15 en comunas rurales. Si bien no se desarrolló un muestreo teórico, sí logramos la saturación de la información en los temas a los que aluden los objetivos de esta investigación.

\subsection{Instrumentos a utilizar}

\subsubsection{Herramientas de recolección de datos}

Las herramientas de recolección de datos planeadas y/o usadas en el trabajo de campo fueron:

- Entrevistas semiestructuradas a cuidadores/as, que abordaban los aspectos psicosociales y culturales de su labor, y su concepción del cuidado.

- Observación cualitativa individual con participación directa moderada en la situación de cuidado del entrevistado. Se planeaba seleccionar de la muestra inicial una submuestra a ser estudiada, la elección de los casos a observar estaría determinada principalmente por la disposición del entrevistado/a a ello. La aplicación de esta actividad investigativa se planteaba a continuación de la realización de las entrevistas. La finalidad de participar de distintas jornadas de cuidado de los entrevistados consistía en enriquecer el análisis de la situación del entrevistador, capturando aquellos aspectos que no se hicieran evidentes a través de la entrevista. 
Finalmente, esta herramienta no fue posible de ejecutar, principalmente por dos motivos: el primero, la negativa e incomodidad que se obtuvo al momento de plantearla a las/os entrevistadas/os. Segundo, el objetivo de la observación era obtener más información sobre la situación de cuidado que la que fuese obtenida a través de la entrevista, pero gracias a que las entrevistas fueron desarrolladas casi en su totalidad en el lugar de cuidado fue posible apreciar y aprovechar la instancia de la entrevista para dar cuenta de dichos aspectos no considerados en la guía o pauta de entrevista.

- Entrevista abierta a informante clave, aunque no era una herramienta considerada en el diseño del trabajo de campo, se realizó una entrevista que respondió a una muestra por oportunidad. La persona entrevistada fue Nuria Alvarado, vicepresidenta de la Corporación Alzheimer Chile. La entrevista a la Sra. Alvarado nos aportó su experiencia como cuidadora y como participante activa de una organización de autoayuda de familiares que cuidan a sus parientes enfermos.

- Anotaciones y bitácora de campo. En el transcurso del trabajo de campo se registraron anotaciones en un diario de campo con datos sobre las gestiones para el desarrollo del trabajo de campo, la situación de entrevista, los lugares de entrevista, etc.

\subsubsection{Instrumentos de recolección de datos}

De acuerdo a los objetivos planteados y a través de la revisión de investigaciones que abordan la temática de los cuidadores, se consideró necesaria la elaboración y utilización de los siguientes instrumentos (originales en apartado Anexos):

- Consentimiento informado para los participantes de entrevistas (Anexo 1).

Documento en el que se informa al cuidador del objetivo de la investigación, las instituciones que la acreditan y el uso que se dará a los datos; se garantiza la confidencialidad de la información registrada en el consentimiento, el uso responsable de ésta, acorde a los objetivos señalados, y el anonimato de los participantes antes, durante y después del trabajo de campo.

Página | 196 
- Guión o pauta de entrevista (Anexo 2).

La entrevista semiestructurada a realizar se apoyó en un guión, que señalaba las temáticas, a las que interesaba que el entrevistado se refiriera durante el/los encuentro/s. La idea del guión era contar con un apoyo para el desarrollo de la entrevista pero inicialmente la idea era dejar fluir el relato del cuidador, e intervenir solo en caso de que se alejara de los temas que se pretendían abordar.

Se incita la conversación pidiendo al cuidador que se presente, solicitando que haga referencia a aspectos de su vida como estado civil, nivel educacional, historia laboral, cómo está conformada su familia, la percepción sobre su salud, las actividades que desarrollaba al momento de la entrevista (aparte del cuidado) y su situación socioeconómica. Tras esto, se insta al entrevistado a hablar sobre su labor como cuidador, haciendo énfasis en las actividades realizadas previamente a la situación de cuidado, el tipo y la calidad de relación anterior con la persona con dependencia, la trayectoria del cuidado, el detalle de las actividades que realiza a diario como cuidador, las disponibilidades de apoyos y formación, los cambios en su vida derivados del cuidado (personales, familiares, económicos), el espacio de cuidado y entorno (vivienda y espacios públicos) y las proyecciones futuras.

\section{- Ficha del cuidador (Anexo 3, cuadro 13)}

A través de este instrumento el investigador consignó información básica sobre el cuidador, datos como la edad, el estado civil, la escolaridad, el lugar de residencia, la composición de su grupo familiar, el oficio, los trabajos desempeñados, el tiempo que lleva cuidando, la formación en cuidados y las personas a cargo del cuidador.

\section{- Tareas del cuidador (Anexo 4)}

Tabla en donde se desglosan actividades relacionadas con los múltiples aspectos posibles del cuidado y la frecuencia con que se efectúan. Este instrumento se pensó con el motivo de observar el grado de dependencia del familiar y el tiempo dedicado por el entrevistador al cuidado. 
- Escala de sobrecarga del cuidador de Zarit (Caregiver Burden Interview) Adaptación española (Anexo 5).

Este instrumento, basado en la teoría general del estrés, se centra en medir el sentimiento subjetivo de sobrecarga del cuidador. La escala de Zarit es un instrumento autoadministrado del que existen varias versiones, la que se utiliza en esta investigación es la versión española (Martín, Salvadó, Nadal, Miji, Rico, Lanz, y Taussig 1996), validada en Chile (Breinbauer, Vásquez, Mayanz, Guerra y Millán 2009). Consta de 22 preguntas tipo Lickert de cinco opciones (1 a 5 puntos), cuyos resultados se suman en un puntaje total (22 -110 puntos). El resultado clasifica al cuidador en las siguientes categorías: "ausencia de sobrecarga" $(\leq 46)$, "sobrecarga ligera" (47-55) o "sobrecarga intensa" ( $\geq 56)$. La escala se aplicó al final de la entrevista.

\subsection{Trabajo de campo}

Tal como se ha explicado anteriormente la recolección de datos de esta investigación se realizó en la Región Metropolitana de Santiago de Chile, entre los meses de noviembre del 2010 a enero de 2011, que corresponden a la época de primavera y verano en el hemisferio austral. Intencionadamente se eligió esta época por la dificultad que hubiese podido presentarse en invierno para acceder a zonas rurales.

Esta etapa se presenta a modo de crónica y podría ser dividida en dos etapas:

\subsubsection{Gestiones para contactar con posibles entrevistados/as}

- Aproximadamente un mes antes de viajar a Chile se inició la comunicación con la encargada del Programa de Postrados (Ministerio de Salud de Chile - División Redes Asistenciales), consultando sobre la posibilidad de desarrollar el estudio con la colaboración de este programa. 
- La encargada del Programa se manifestó interesada, y consideró que lo más adecuado es que se realizara en el Servicio de Salud Metropolitano $\operatorname{Sur}^{46}$ (SSMS), debido a características de la muestra que nos interesaba abordar. Este servicio entregaría a la investigadora una base de datos de cuidadores en la zona.

- Reunión con el referente técnico del SSMS, donde se expuso el proyecto y se solicitó el listado de cuidadores. El encargado nos indicó que para ello la investigación debía ser aprobada previamente por el Comité de ética del SSMS.

- Presentación de proyecto y plan de investigación ante el Comité de 'Ética del SSMS para su aprobación.

- Paro nacional de funcionarios públicos, que retrasó la resolución del Comité de Ética.

- Resolución del Comité de Ética con observaciones confusas. Esta comisión solicitó a la investigadora entregar declaraciones firmadas por los cuidadores de que aceptaban ser entrevistados. Solicitud bastante contradictoria, porque precisamente se pedía la aprobación del proyecto para que el SSMS entregara un listado de éstos.

- Se solicita aclaración de observaciones al Comité y no se obtuvo respuesta en el período de permanencia en el país.

De forma paralela, ante la demora en la respuesta de las anteriores gestiones, se recurre a informantes clave que puedan ayudar en el contacto con los entrevistados. Tras la resolución contradictoria del Comité de Ética, los informantes clave se constituyen en la alternativa utilizada para llegar a los entrevistados/as.

- En los sectores urbanos contamos con el apoyo de profesionales encargadas del "Programa de postrados" de dos municipios de la RM: Lo Prado y Pedro Aguirre Cerda (PAC). En el caso de Lo Prado la profesional dirigía el Programa desde el Departamento de salud municipal; en PAC la profesional que facilitó el estudio fue la trabajadora social de uno los Centro de salud de la comuna. Estas comunas de la RM (mapa 1) eran municipios socioeconómicamente considerados como bajos y mediosbajos de acuerdo al nivel de ingresos de su población residente.

\footnotetext{
${ }^{46}$ El Servicio de Salud Metropolitano Sur estaba conformado por 8 municipios urbanos y 3 rurales.
}

Página | 199 
- En los sectores rurales el trabajo se desarrolló en localidades rurales de tres comunas de la RM ubicadas en la periferia de la región: Buin, Paine y Curacaví. En ellas contamos con el apoyo de profesionales del área sanitaria (Hospital de Curacaví, Posta de Hospital-Paine) que colaboraron facilitando listados de cuidadores en las zonas. También fue posible gracias a la colaboración de familiares y amigos que hicieron posibles los contactos y traslados en zonas más aisladas.

\section{Mapa 1: Región Metropolitana de Santiago*}

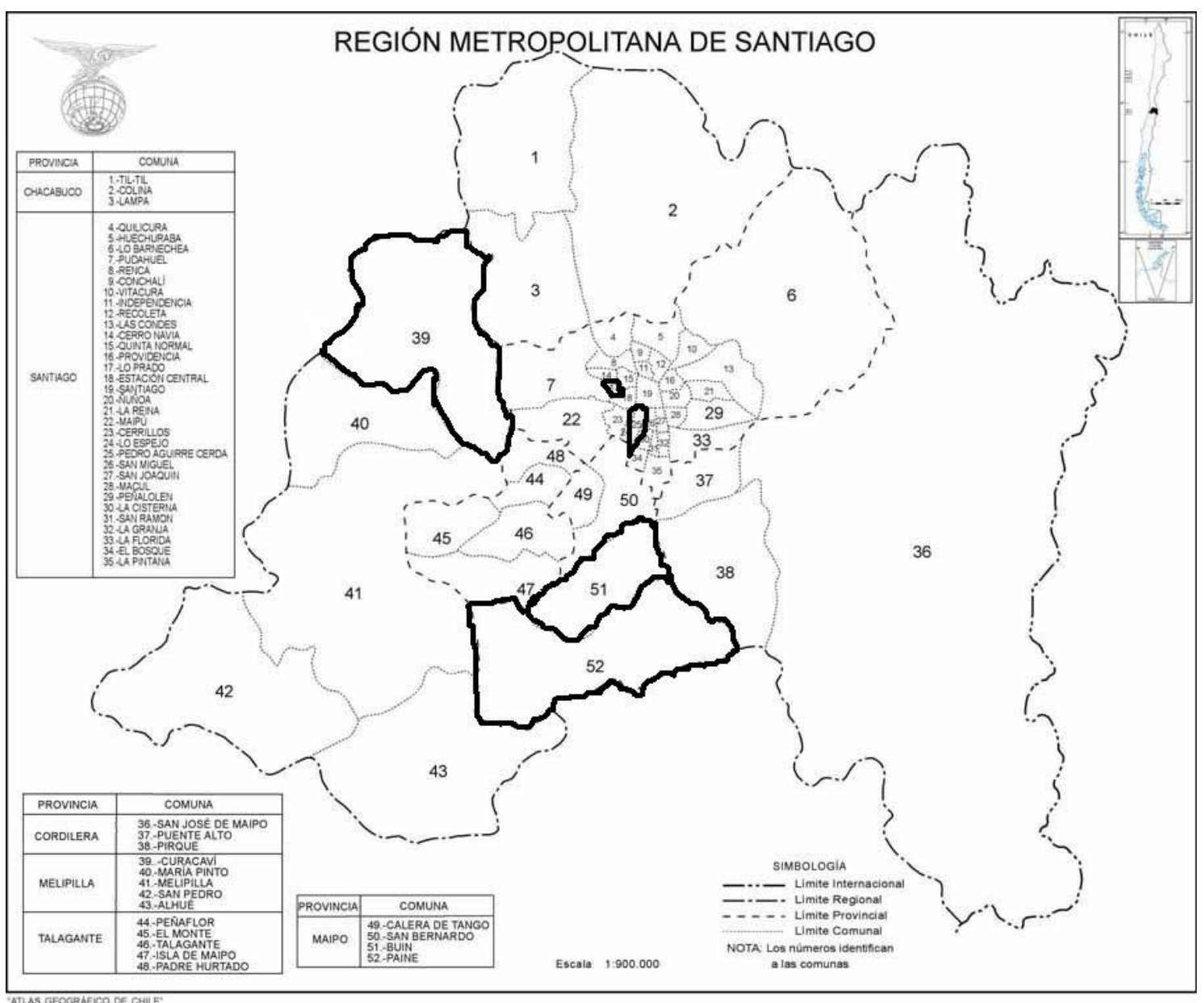

Delineadas en negro comunas urbanas Lo Prado (17), Pedro Aguirre Cerda (25) y comunas rurales Curacaví (39), Buin (51) y Paine (52).

* Mapa de Chile y de Sudamérica en Anexos. 


\subsubsection{Realización de entrevistas}

El tipo de muestra que se utilizó dependió de la zona en donde se desarrolló el trabajo de campo. En las zonas urbanas -PAC y Lo Prado- y en algunas de las localidades rurales -Curacaví, Paine y Hospital- la muestra fue del tipo homogéneo debido a que se obtuvieron las/os entrevistadas/os gracias al registro de personas incluidas en el programa de postrados.

En el caso del resto de las localidades la muestra fue del tipo en cadena o por redes, se identificaron informantes y participantes claves y a partir de ellos se logró llegar a otros sujetos posibles de entrevistar.

Las entrevistas fueron realizadas en los hogares de los cuidadores, a excepción de una que precisamente era la única cuidadora que no vivía con su familiar dependiente; esto permitió realizar una observación del entorno de cuidado. Generalmente, las conversaciones se realizaron a solas con el cuidador, pero en el caso de que fueran cuidadoras de niños con dependencias, algunos de ellos estuvieron presentes. Los cuidadores fueron bastante abiertos, todos nos enseñaron sus casas y las dependencias en donde estaban sus dependientes. Podemos afirmar que el nivel de empatía logrado fue óptimo y ello se refleja en el grado de confianza e intimidad de las entrevistas.

La duración de los encuentros fue variable, pero como promedio alcanzaron los 90 minutos. A ello se debe agregar el tiempo previo a la entrevista, es decir, contacto y/o visitas para acordar entrevista, y el período posterior a ella, tiempos que sirvieron a la investigadora para realizar observación del entorno de cuidado.

Todas las entrevistas fueron registradas con grabadora de audio y trascritas al ordenador de forma íntegra ${ }^{47}$, reproduciendo de forma fiel todo el registro sonoro y situacional consignado en las notas del investigador- de la entrevista (Sánchez Gómez y Revuelta 2005). Los instrumentos que se aplicaron al momento de la entrevista fueron vaciados a una base de datos (SPSS).

\footnotetext{
${ }^{47}$ El texto de las entrevistas llegó a las 450 páginas, en el mismo formato de este documento. No fue anexado a este escrito por motivos de espacio y confidencialidad de la información que ahí aparece.
}

Página $\mid 201$ 


\subsection{Método de análisis}

Como anteriormente se expresó, el método utilizado para el análisis de la información recopilada fue la Teoría Fundamentada en la versión de Strauss y Corbin. A continuación se describen los procedimientos realizados:

\subsubsection{Preparación de los datos}

Con la finalidad de poder facilitar el análisis de las entrevistas, la transcripción de éstas y las notas de campo fueron vaciadas en el programa ATLAS.ti (versión5.0). Para dar inicio al proceso de análisis se debió crear una Unidad Hermenéutica (UH) que fue denominada: Cuidadores informales en Chile, y se asignaron los documentos primarios (transcripción de las 31 entrevistas y las notas de campo).

\subsubsection{Reducción de los datos}

Tras lecturas sucesivas de las entrevistas y notas de campo, microanálisis de acuerdo a Strauss y Corbin, se procedió a iniciar el proceso de generación de citas en los documentos primarios, como primera reducción documental. Las citas en nuestros documentos fueron oraciones o párrafos que expresaban una o más ideas relacionadas con los objetivos del estudio. Además, conforme avanza el análisis se formulan memorandos con las ideas que van surgiendo a raíz de los datos.

Posteriormente, se realiza una segunda reducción documental a través de la codificación inicial, que en nuestro caso arrojó sobre 30 códigos iniciales. Desarrollamos la codificación abierta, es decir identificamos conceptos y luego los agrupamos en categorías, para así poder reducir el número de unidades con las que trabajar y desarrollar análisis con un mayor grado de abstracción. Se obtiene de este modo 21 categorías, que serán las que nos ayudarán a abordar el eje o categoría central de la investigación: los cuidados informales a la dependencia en Chile.

Las categorías fueron definidas en relación a sus propiedades y dimensiones. Entendemos por propiedades a las características generales o específicas o los atributos de una categoría, en tanto que las dimensiones representan la localización de una propiedad durante un continuo (Strauss y Corbin 2002). 


\subsubsection{Organización y presentación de los datos}

Procedemos a relacionar las categorías entre sí y con sus subcategorías, en donde las hubiere, realizando lo que se denomina codificación axial. En torno al eje de la categoría central se enlazan categorías (que para no confundir en el análisis hemos denominado temas) en cuanto a sus propiedades y dimensiones.

En este proceso intentamos dar respuesta a las preguntas de investigación, en nuestro caso abordar nuestra categoría central aspirando revelar el por qué sucede, dónde, cuándo y con qué resultados. El objetivo es relacionar la estructura con el proceso (Strauss y Corbin 2002: 139), este proceso es denominado por los autores paradigma.

El paradigma está compuesto por unas condiciones, una manera conceptual de agrupar las respuestas a las preguntas de por qué, dónde, cuándo y cómo. Estas contestaciones componen la estructura o conjunto de circunstancias o situaciones en las cuales están inscritos los fenómenos. Hay unas acciones/interacciones, que son las respuestas estratégicas o rutinarias dadas por los individuos a los asuntos, problemas, acontecimientos o sucesos que emergen bajo estas condiciones. Las acciones/interacciones están representadas por las preguntas quién y cómo. Finalmente, hay consecuencias que están representadas por preguntas relativas a qué sucede como resultado de estas acciones/interacciones o por qué los individuos no responden a situaciones por medio de acciones/interacciones (Strauss y Corbin 2002: 140). Creemos que el análisis realizado en esta investigación logra alcanzar este nivel de abstracción.

Un paso siguiente en el desarrollo de la metodología propuesta por la Teoría Fundamentada es la codificación selectiva, que busca integrar y refinar la teoría que se construye. Para ello es necesario lograr la saturación teórica, momento en que no surgen de los datos nuevas propiedades para las categorías (Andréu, García-Nieto y Pérez 2007), que es posible gracias al muestreo teórico, es decir la continua vuelta al trabajo de campo para buscar variaciones dentro de las categorías. Es en este punto en el que el desarrollo del análisis se detuvo, debido a la imposibilidad de regresar al campo para completar aquellos vacíos o brechas de la propuesta que se realiza.

Página | 203 
Capítulo V. Marco metodológico

Sabemos que queda pendiente en esta investigación el refinamiento de la teoría, revisar el esquema de categorías que se propone para buscar consistencia interna y brechas en la lógica, completar las categorías pobremente desarrolladas, revisar si existen categorías que puedan resultar sobrantes para el marco conceptual y validar el esquema teórico. Creemos que ello es posible de realizar en posteriores investigaciones. 
5.7.4. Mapa conceptual de estructura categorial desarrollada

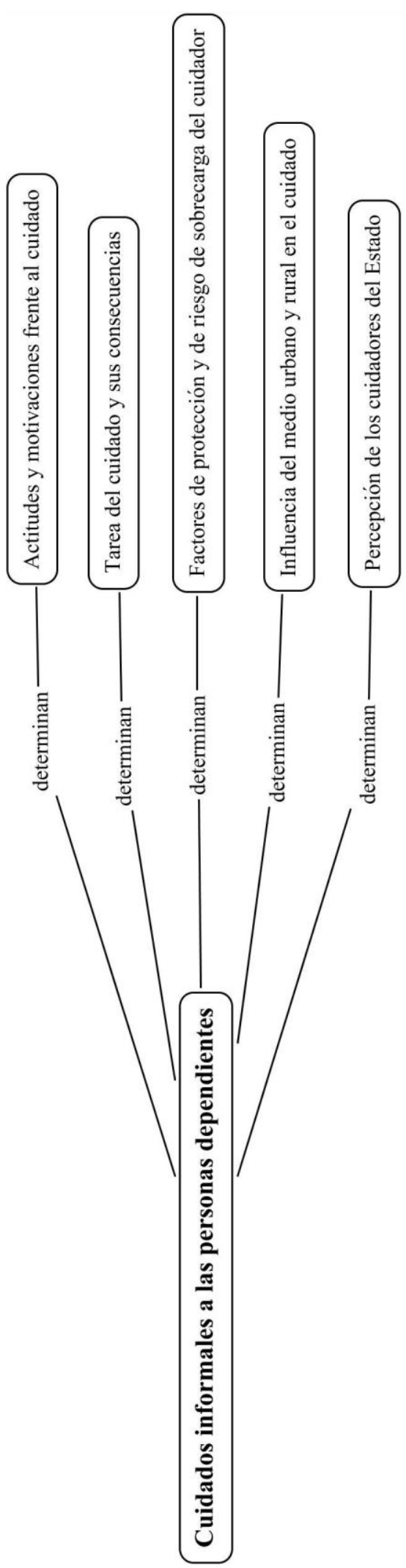

Página | 205 
Página | 206 
CAPITULO VI: ANÁLISIS

Pueden porque creen que pueden

Virgilio

\section{TEMA. ACTITUDES Y MOTIVACIONES DEL CUIDADOR FRENTE}

\section{AL CUIDADO}

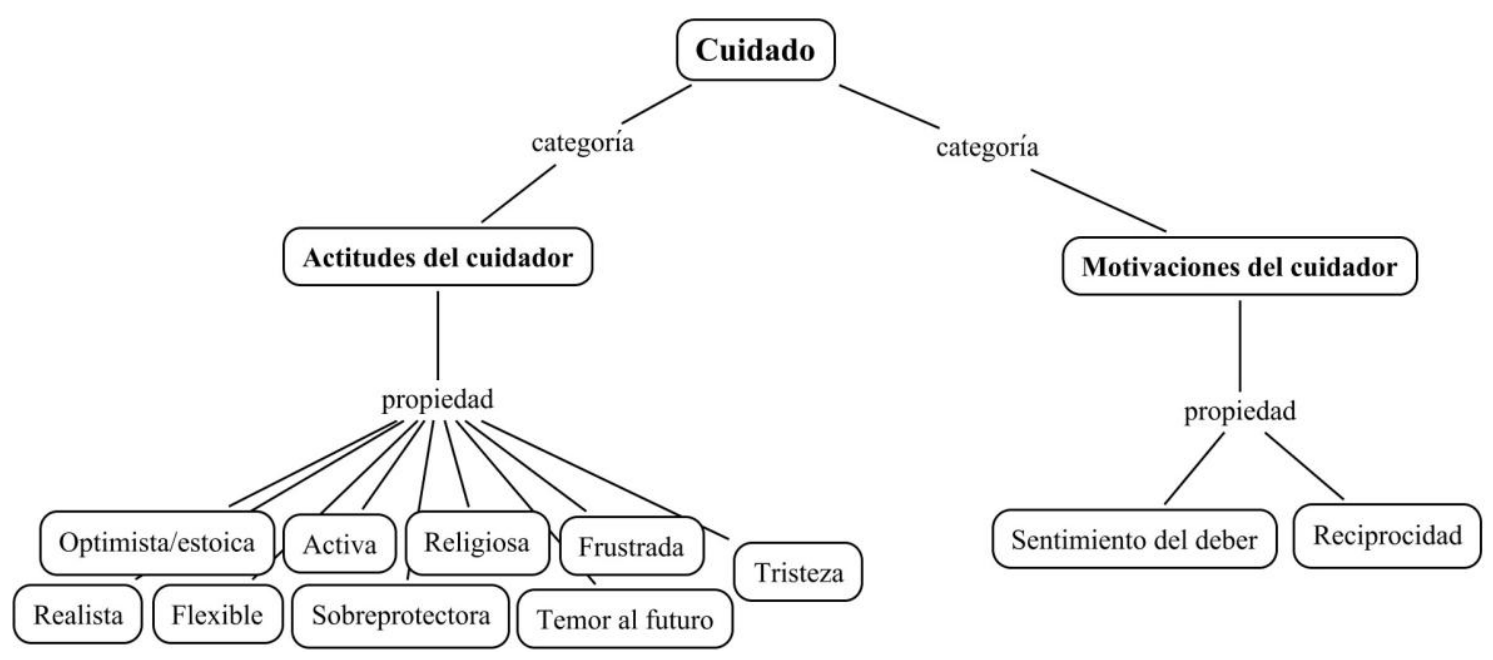

Mapa conceptual tema 1. Actitudes y motivaciones del cuidador frente al cuidado

\subsection{CATEGORÍA “ACTITUDES FRENTE AL CUIDADO”.}

En esta primera parte del análisis comenzamos analizando la primera categoría identificada en torno a la figura del cuidador y su labor, la que ha sido denominada como actitudes frente al cuidado y desarrollada a modo de propiedades.

Las formas, en que se puede asumir el cuidado del familiar dependiente, pueden tomar en su evaluación un posicionamiento positivo o negativo, con esto no queremos decir que la actitud sea pura, más aún pensando que la tarea de cuidar puede generar en el individuo representaciones mentales, sentimientos y comportamientos contradictorios. 
Asimismo se identifican en las propiedades el rasgo o componente de la actitud que predomina en su expresión.

Propiedades identificadas en los relatos discursivos:

Actitudes positivas:

1. Optimista (cognoscitivo)/estoica (conductual)

2. Realista (cognoscitivo)

3. Activa (conductual)

4. Flexible (conductual)

5. Religiosa (cognoscitivo)

Actitudes negativas:

6. Sobreprotectora (conductual)

7. Frustrada (cognitiva)

8. Temor al futuro (afectiva-conductual)

9. Tristeza

\section{Propiedad "Actitud positiva/optimista/estoica".}

Las/os cuidadoras/es enfrentaban la tarea del cuidado con naturalidad y normalidad, tendían a minimizar los costos que para ellas/os implicaba el dedicar gran parte de sus tiempos, de sus vidas, al dependiente.

- “(...) y el mismo neurólogo también, me dijo, cuando nos tratábamos con él, me dijo que él estaba admirado de ver que nosotros, como familia, y yo no nos había dado depresión, que no habíamos tenido mayores trastornos, haber pasado por una cosa tan fuerte, yo le dije: "No, ¿Qué saco?” Tengo que ser más fuerte con esto que está pasando tengo que saber sobrellevarlo, yo soy bien alegre, a mi me preguntan “¿Cómo estás?” Y puedo estar mal, digo: "Bien", siempre estoy contenta, no tengo problemas con nadie, soy siempre igual, entonces a lo mejor eso me ha llevado a sobrellevar esto mejor."

- "La actitud que tú tienes"

- "Sí, y siempre he pensado que a veces hay personas que están más mal que yo, 
entonces eso me ayuda a decir bueno, hay personas que están peor que yo.” (Entrevistada 16)

Esta actitud podía ser reforzada por la recepción de apoyos por parte de otros miembros de la familia o de su comunidad, que hacían que la tarea del cuidado no recayera sólo en el/la cuidador/a.

- “'Te sientes muy sobrecargada por tener que cuidarlos?"

- "No, es que aquí "todos los monos bailan", aquí es autoservicio, es que los que llegan aquí prácticamente no son visitas, y es que aunque no lo sepan yo se los digo. Por ejemplo, si a mi papá le da hambre, él llega pone el hervidor, busca pan, se hace una ensalada y se prepara algo “¿Quién quiere once $e^{48}$ ? Está listo el hervidor”, y el Juan igual [esposo].” (Entrevistada 18)

Se pueden observar diferencias en la actitud de los cuidadores de acuerdo al tipo de dependiente que estuviese a su cargo, en el caso de las cuidadoras que atendían a sus hijos, sobretodo en el caso de madres de niños dependientes, primaba la actitud positiva frente a la actitud más bien pesimista que solían tener los/as cuidadores/as de personas mayores, independiente del vínculo que exista entre ellos.

- “(...) para mí ninguna carga mi hijo, todo lo contrario, estoy feliz con él porque gracias a Dios lo tengo a mi lado, estamos nosotros y él nos ha demostrado lo contrario del diagnóstico que nos habían dado, él ha ido avanzando, igual deseando que él con el tiempo pueda caminar, a nosotros nos dijeron: "su hijo no va a caminar", no importa lo trasladamos en silla de ruedas, "su hijo no va a hablar", no importa porque con el tiempo yo lo voy a ir conociendo y yo me voy a comunicar con él, me voy a dar cuenta de lo que le pasa, y cosas así (...).” (Entrevistada 24)

- "Para mí era una felicidad andar con él, colgármelo y partir, porque no pesaba." (Entrevistada 30)

Alguna de las cuidadoras eran capaces de lograr un cambio en la actitud de los familiares que con ella viven, logrando que asumieran una actitud más positiva y

${ }^{48}$ Comida por la tarde- noche, generalmente acompañada con té.

Página $\mid 209$ 
partícipe en el cuidado del dependiente.

- "Te puedo decir que en la casa de mi marido es mi suegra la que les sirve a todos, y aquí es todo lo contrario, él [esposo] muda, él baña, él viste

- ¿A él le costó adaptarse?

- "Le costó asumir, pero yo soy media dura en las cosas que digo, de repente me excedo pero yo les dije que a mí ellos no me servían en esa actitud que estaban, no ganan nada con lamentarse, no ganan nada con preguntar por qué, no ganan nada.” (Entrevistada 18)

Se observó el caso de entrevistadas que llevaban años cuidando de un dependiente y que a esa tarea se agregó el hacerse cargo de otro(s) dependiente(s), y a pesar del aumento de trabajo, la experiencia previa les sirvió para sobrellevar su tarea.

- “Cómo le ha resultado a usted el cuidar a tres personas?"

- "Es que no es tan complicado, la gente dice: “Cómo lo haces para cuidarlos?”, y no es tan complicado, ni tanto el sacrificio tampoco, no sé porque las personas tanto que lo agrandan [pausa] de repente exige algo más pero no es algo que a uno la canse ni física, ni emocionalmente." (Entrevistada 2)

La condición positiva también se manifestaba con la intención de no culpabilizar, y por ende no afectar la salud del dependiente. Se daba esta actitud, asumida sin cuestionamiento, como parte de una conducta determinada por el lazo o parentesco que les unía con el dependiente, a pesar de que asumían en soledad el trabajo de cuidar, y teniendo también otros la obligación de ejercerla (padre o hermanos), ello no afectaba su disposición al cuidado, la actitud con la que lo enfrentaban. El cuidador experimentaba la alegría de saber que cumplía la tarea de la mejor forma posible.

"Y sabe que cuando el día sábado lo baño es como si tuviera harta plata, me quedo tranquila, porque lo vi que le corrió la agüita, que quedó limpiecito, quedo contenta cuando se baña y me tomo un vaso de vino contenta, de verdad (...)" (Entrevistada 19). 
La tarea de cuidar representaba para algunos cuidadores la oportunidad de dar sentido a sus vidas, de realizarse y de encontrar motivación en ella.

- “Se siente usted realizado cuidándola?

- "Sí, [se emociona, llora] siento que es lo que tenía que hacer acá en la tierra, lo malo es que me fui por otro lado, me metí en la droga y quería puro ${ }^{49}$ morirme, pero ahora ya no me importa nada, nada, nada... todos me dicen "no te echis ${ }^{50}$ a morir, tú soy joven, tu lucha, disfruta de la vida", no, para mí murió todo, porque yo no puedo seguir luchando de nuevo, menos a esta edad, después de que luché tanto, con todo lo que pasé y ahora volver a hacerlo de nuevo, no, ahora yo no soy capaz, ahora vivo como esté la cosa no más, el momento, digo yo respecto de mi vida, pero por mi madre yo hago todo, todo." (Entrevistado 26)

La positividad del cuidador, sobre todo del que cuidaba a niños, estaba dada por los avances que experimentaba el dependiente, por pequeños que éstos parecieran.

"Porque él, las maneras de demostrar que está contento es que palmea las manos, se ríe, es feliz, esa es la felicidad de él, cuando usted lo ve en las mañanas una sonrisa al despertar, y con eso uno tiene todo." (Entrevistada 30)

Una actitud que suele relacionarse con las actitudes optimistas o positivas de asumir la tarea del cuidado es realizarlo de forma estoica. A pesar de todo lo negativo que podía implicar en sus vidas la tarea del cuidado, las/os entrevistadas/os asumen una actitud serena, no se permitían siquiera expresar sentimientos negativos o quejas para no generar en el dependiente sentimientos de culpabilidad.

"No, sí descanso, pero de ratos no más, o sea en la noche, ahora estoy descansando, aunque siempre tengo algo que hacer, siempre, pero descanso en los momentos que hay que descansar, pero algo que no tenga en que pensar no, mi mamita me ocupa todo el tiempo, ahora estoy como un poco estresado, pero no importa, no importa, es mi vieja, yo no me voy a lamentar de eso, no, aquí estoy yo, para verla, para lo que necesite, y si se enferma y tengo que estar ahí toda la noche, ahí voy a estar”' (Entrevistado 26)

\footnotetext{
${ }^{49}$ Sólo.

${ }^{50}$ Eches.
} 
La dependencia que existía del cuidador implicaba que éste debía estar siempre dispuesto para proporcionar las atenciones que el dependiente requiriese, por tanto ello implicaba que el cuidador debía mantenerse sano.

\footnotetext{
"No tengo esa opción yo, no tengo la opción de salir, no tengo la opción de enfermarme, no tengo esos privilegios digo yo, porque para mí sería un privilegio enfermarme y decir: "me voy a quedar una semana en cama", no puedo, no puedo darme esos lujos, porque para uno esos son lujos ya." (Entrevistada 27)
}

Esta actitud se daba, a pesar de que la mayor parte de las personas entrevistadas desarrollaban la labor de cuidado sin tener muchas esperanzas de que la situación del dependiente mejorara sustancialmente y pudiera dejar de ser dependiente, y más aún, sin mayores ayudas de su entorno, prácticamente solas.

\footnotetext{
"Entonces se van complicando, a medida que van creciendo se van complicando, sería más fácil decir que a medida que van creciendo va pasando esto, van adquiriendo, van llenando más la hojita, si empezó con un diagnóstico de 2 palabras, ahora ya tiene como 3 hojas completas, entonces todo su diagnóstico se va complicando, y eso es lo que uno... tira sola." (Entrevistada 27)
}

\section{Propiedad "Realista"}

De acuerdo a la información y/o diagnósticos que los cuidadores conocían, asumían una actitud realista, ajustando las posibilidades de mejoría de los dependientes a su cargo.

- “QQué le pasaba a su papá o a sus hermanas? ¿Lo aceptaba así o no?”

- "Es que yo creo que ellos como estaba más lejos... sabían el diagnóstico y todo, estaban al tanto, pero a lo mejor el no estar con ella, todos los días, me refiero a no vivir con ella, no sé, lo tomaron de otra forma, pero uno se va preparando para esas cosas. Igual que yo sé que la Marta... yo lo tengo claro, sé que la Marta jamás va a ser una persona independiente, aunque mi sueño es verla parada, pero ya sé que no va a ser así, entonces no me hago esas expectativas."

- "Porque sabe hasta dónde va a llegar." 
- "Yo sé hasta dónde va a llegar, entonces uno lo tiene claro, uno tiene que partir de esa base para hacerse cargo de alguien... ser realista, ver las cosas como son, por ejemplo mi papá tiene buenas expectativas de llegar a caminar sin sus aparatos, sin su burro, sin sus cosas, entonces ahí hay que darle.” (Entrevistada 2)

De igual forma reaccionaban y ajustaban las expectativas de vida del dependiente y también la propia como cuidadores.

- "Yo tengo un cuaderno acá que es la vida del Adrián, médico que viene acá, enfermera que viene acá, yo les digo: "señorita, póngame una notita acá", por cualquiera circunstancia, el día de mañana pase algo y no tengo ese problema del enfermito, que se murió así y va a dar al Instituto Médico Legal, entonces yo aviso así, y ellas me vienen a dar el acta y todo."

- "Usted se pone en ese caso ya."

- "Sí, a mi me han dicho que lo de él es una enfermedad terminal, (...)." (Entrevistada 14)

\section{Propiedad "Activa"}

El cuidador de acuerdo a la experiencia adquirida, los tratamientos recibidos, y a los avances experimentados por el dependiente, desarrollaban una posición activa frente a los procedimientos médicos y terapéuticos que podían incidir en la situación de éste.

\footnotetext{
"En el hospital se ven muchas cosas y se aprende harto, porque todas esas cosas a mí me han servido para ella, porque si no yo no tengo ayuda de nadie, yo me las arreglo sola con ella" (Entrevistada 20).
}

Como se observa, esta posición podía ser abierta y dispuesta, pero también de rechazo de procedimientos que pudieran implicar un retroceso y deterioro en las habilidades que el dependiente había logrado o conservaba.

- "No, ahora no la he llevado, en realidad yo la saqué porque le querían poner esa manguerita aquí, en el estómago, y yo no quise, y la dejé de llevar, entonces todavía estoy en lista de espera para que me vuelvan a llamar."

Página $\mid 213$ 
Capítulo VI. Análisis

- “Y para qué era esa manguerita?”

- "Para alimentarla por sonda." (Entrevistada 2)

La posición activa se manifestaba además en la búsqueda de alternativas de atención y tratamiento del dependiente cuando las instituciones públicas, como el sistema de salud, no las proporcionaba a su debido tiempo o simplemente no se contaba con ellas ${ }^{51}$.

“Cómo hago? Fui al consultorio de Paine, no conseguí nada, "van a ir a verlo” me dijo la enfermera Schapheer, estuve toda una tarde con la puerta abierta, no vino nadie, después la volví a llamar, me dijo que tenía solamente 4 ambulancias para recorrer todo el sector y están todas ocupadas, con eso me dijo que no lo iba a ver. Después lo llevé aquí, al consultorio de Hospital, ese día tocó que no había médico, la enfermera no estaba, "espérela hasta las 2 de la tarde", la esperé, a una de las que vino hoy día, me dijo: "yo, el martes lo voy a ir a ver", lo vino a ver, me trajo un paquete de gasa, pero él no estaba, andaba en la diálisis, ya le habíamos conseguido la diálisis allá en Buin." (Entrevistada 11)

En este punto del análisis no debemos perder de vista el aspecto socioeconómico en la situación de las familias cuidadoras que, obviamente, limitaba las acciones que quisieran desarrollar para beneficiar la situación del dependiente.

También se hace visible esta actitud en el empeño de los cuidadores en que sus dependientes realizaran aquellas actividades para las que poseían destreza o para las que la habían recuperado.

- “¿Usted siente que su esposo le pide más ayuda de la que necesita?"

- "Sí, a veces me pide más ayuda y yo reclamo, pero por cosas muy sencillas, él me dice: "Préndeme la tele" y yo le dejo aquí el $\operatorname{control}^{52}$, no ha aprendido a usar el control "Cámbiame el canal", "Ponla más fuerte", entonces yo vengo de por allá a subirle o cambiarle de canal, "Pásame el poncho", yo le digo párate y anda a buscar el poncho, porque le sirve de ejercicio, no puede estar tanto rato sentado." (Entrevistada 20)

\footnotetext{
${ }^{51}$ Este tema será tratado en mayor profundidad en el desarrollo de la categoría en donde se analiza la percepción del Estado que tienen los cuidadores.

${ }_{52}$ Mando a distancia.
} 


\section{Propiedad "Flexible"}

La vida diaria de las familias, y en especial la del cuidador, sufrió una gran transformación y debieron estar dispuestos a flexibilizar sus rutinas para poder ejercer su labor; este cambio era bien sobrellevado por algunos de los cuidadores adaptándose a la nueva situación, restando dramatismo a las circunstancias vividas.

- "Porque normalmente ¿Qué era lo que hacía antes que ya no hace ahora?"

- "Trabajar, trabajar que es lo más importante... y más que nada las costumbres que uno tiene, pero grandes cambios tampoco hay, o sea decir: "Estoy perdiendo tanto...", no, pero si costumbres diarias de una casa que uno tiene, la forma de hacer las cosas, la forma de poner alguna cosa, de organizarse.” (Entrevistada 2)

- “Le resultó muy difícil a usted empezar a cuidar a su esposa?”

- “No, porque va en cómo es uno no más.” (Entrevistado 28)

La actitud flexible ante el cuidado solía estar acompañada del recibimiento de ayudas por parte de otros miembros de la familia o del entorno del dependiente (vecinos, amigos), eso era lo que permitía que la adaptación del cuidador al cambio fuera menos traumática y mejor aceptada.

\section{Propiedad "Religiosa"}

Estaba presente fuertemente en el discurso de algunas de las personas entrevistadas la vivencia de la tarea del cuidado como mandato o prueba de Dios. La religiosidad fue constantemente aludida para dar esperanzas o infundir fuerzas para enfrentar la tarea del cuidado.

"Eso es lo que pasa, no me arrepiento que el de arriba me haya dejado esta misión, es bonita labor sí, pero también cansa. Yo me siento tranquila de que yo he hecho lo más que he podido por mi papá, lo mantengo bien ahí, y la asistente del consultorio me ofreció que lo podía internarlo, si quería, “no", le dije yo.” (Entrevistada 31) 
Mención especial requieren las entrevistadas que tenían creencias religiosas cristianas de tipo evangélico, de importante presencia en los sectores populares de Chile.

\begin{abstract}
"Es que tengo mi fe puesta en Dios, el José es un milagro del Señor, es un milagro de Dios, porque un niño en estas condiciones, usted revise internet y vea cómo actúa un niño con trisomía 18, y viera al José se daría cuenta que es distinto, todos los doctores lo dicen, porque en José ha obrado, lo ha hecho ver, que escuche, le está haciendo dar pasos, está haciendo cosas que me dijeron que nunca iba a hacerlas, que José iba a estar siempre as'i" (Entrevistada 30)
\end{abstract}

El ejercicio de la religión evangélica se presentaba más exigente que el de la católica, las dos más practicadas en Chile, requería de asistencia diaria a la iglesia y de cumplir un estricto régimen de vida. El discurso de las entrevistadas que profesaban esta religión estaba lleno de referencias a la importancia de la fe en sus vidas, sobre todo el apoyo que ésta les proporcionaba en los momentos difíciles, que generalmente tenían que ver con las atenciones y la salud de sus dependientes.

\begin{abstract}
“(...) me pegué en este brazo, yo creí que me había zafado el brazo, eso fue un día viernes, en la noche no dormí nada, le pedí al señor que tuviera misericordia de mi vida, porque qué iba a ser de mi hijo si yo tenía el brazo $z a f a d o^{53}$ y el golpe en el cerebro, me levanté a duras penas, pero Dios me fortalece, él me restaura, esa es mi fe, mi confianza en Cristo, y aquí estoy." (Entrevistada 3)
\end{abstract}

\title{
Propiedad "Sobreprotectora"
}

La actitud sobreprotectora podía generarse desde los distintos tipos de relación que fueron abordados, pero indudablemente en donde resultaba más patente era en la relación madre cuidadora - hijo pequeño dependiente. Ellas, a pesar de estar informadas que lo mejor para sus pequeños era fomentar y desarrollar las habilidades que tenían, creaban relaciones que generaban más dependencia de su apoyo.

“(...) es que con el Alonso fue todo nuevo, empezar a criar, todo, por el hecho de que fueron 13 años de diferencia con el hermano, y estaba yo acá sola, (...) yo estuve tres

\footnotetext{
${ }^{53}$ Luxado.
} 
meses encerrada, no quería que se me resfriara, no quería que le pasara nada, como primeriza, con todos los cuidados, imagínese que a veces tenía que esperar que llegara el papá del trabajo para poder bañarme, agotada todo el día con el bebé, (...). Después el otro estrés que tuve fue cuando empezó a caminar, porque tenía que tratar de hacer todo antes de que él despertara para después estar pendiente de él, (...) y es que hay mamás que son muy preocupadas y eso es que de repente uno dice a lo mejor yo soy así, soy asá, soy sobreprotectora, de repente uno se siente culpable.” (Entrevistada 29)

Una de las cuidadoras entrevistadas precisamente se refería a lo perjudicial que podía resultar para el menor dependiente el actuar de forma sobreprotectora, ya que frenaba su capacidad de obtener progresos en su situación de dependencia.

\begin{abstract}
“(...) cuando la Marta salió [del hospital], yo caí un tiempo en eso de sobreprotegerla y al final me di cuenta de que la Marta no iba a ser ahora no más, en ese momento, que iba a estar así, que iba a ser toda su vida, a lo largo de su vida, porque yo no puedo estar toda la vida lamentándome, igual me duele en el fondo porque soy su mamá, pero no puedo estar toda la vida lamentándome y tratándola como "la pobre Marta", porque tampoco ella va a tener avances. No sé, yo lo veo desde ese punto de vista, creo que sobreproteger o sobredimensionar una situación no es bueno, o caer en la torpeza de hacerse toda la vida la pobrecita o yo tratarla así, no.” (Entrevistada 2)
\end{abstract}

Pero la situación de sobreprotección no resultaba exclusiva de las cuidadoras de niños, también se presentaba en algunos cuidadores de personas adultas. La sobreprotección de los adultos tenía por finalidad ahorrar parte del sufrimiento que ya vivían por su deteriorada salud y situación de dependencia, pero lamentablemente este comportamiento acarreaba al cuidador más trabajo, y generaba más dependencia.

“(...) pero ahí la decisión era pensar que si Raúl llega del hospital va a ver el baño diferente y él va a decir “¿Por qué lo hicieron? ¿Voy a estar toda la vida así?” era para que él no se choqueara y dijera "cambiaron todo por mí", entonces lo dejamos tal cual estaba." (Entrevistada 17)

El mantener una actitud sobreprotectora con el dependiente, muchas veces, generaba en este último actitudes tiranas o crueles con su cuidador/a. Un ejemplo es la experiencia 
vivida por una de nuestras entrevistadas, que se consideraba manipulada por su madre por la manera de cuidar a ésta; además la receptora de cuidados interfería continuamente en la relación de pareja que ella intentaba consolidar.

- (...) aquí todos... mi hija me echa la culpa a mí, la Marcelita, que la conoce, también me echa la culpa a mí que yo tengo la culpa, porque yo soy la que malcrío a mi mamá." - “¿Por qué? ¿Usted le da el gusto en todo?”

- "Claro, eso debe ser pues. Me dijo: "usted nunca va a tener una persona así, porque su mamá es aprensiva", mira sin ir más lejos anoche se quedó acá él [su pareja], yo igual estoy con la preocupación de que está sola, mi hija no estaba tampoco, entonces igual me vine a acostar acá, pero mire que es pilla ${ }^{54}$, estaba con la luz prendida todavía, ¡Y estaba despierta! Y sabía que yo no estaba en la pieza." (Entrevistada 6)

\section{Propiedad "Frustrada"}

El asumir la tarea de cuidar implicó para muchos de los cuidadores el realizar un cambio radical en sus vidas, en algunos casos sus proyectos personales se vieron truncados, como relató una de nuestras entrevistadas al referirse al momento de asumir el cuidado de su madre.

"Y yo en aquella época trabajaba, trabajé toda mi vida, desde jovencita, en una empresa muy grande donde yo estaba muy bien económicamente y tuve que renunciar." (Entrevistada 13)

La renuncia a su trabajo implicó para la entrevistada abandonar su proyecto de vida profesional, quedarse sin el principal ingreso de su familia, descendiendo la posición económica de su familia y sobreviviendo con los ahorros de los "buenos tiempos", y renunciar a una fuente de gratificación personal.

También, aquellas entrevistadas que debieron continuar con las actividades que antes realizaban (generalmente laborales), manifestaron actitudes de frustración enorme y nostalgia por los tiempos en donde gozaban de mayor libertad a la hora de organizar su vida diaria.

${ }^{54}$ Astuta. 
- “Cómo era su vida Sra. Javiera antes de que su papá se enfermara?”

- "Distinta, porque salía a trabajar más o menos tranquila, por ejemplo diligencias las hacía yo, todo sola, por ejemplo cosas de los camiones, repuestos, todo lo salía a hacer yo y ahora no... es un cambio rotundo, yo no se lo doy a nadie.” (Entrevistada 23)

\section{Propiedad "Temor al futuro"}

Una actitud presente en todas las personas entrevistadas de edad avanzada era el temor a que a ellas les sucediera algo en un futuro cercano, lo más probable era que pudiesen sufrir deterioros de salud que les dificultaran o impidieran el hacerse cargo de sus dependientes, en situaciones en donde eran prácticamente indispensables.

-"Y ¿Cómo usted ve el futuro con su esposo?"

- “Sobre su salud? ... ahí, en la cuerda floja, confío solamente en Dios, en la cuerda floja, o le pasa algo a él o me pasa algo a mí. Si le pasa algo a él, yo me muevo, me movilizo, y aunque sea paro un auto que vaya pasando por aquí, o voy al frente, o voy al lado y algo consigo, pero si me pasa algo a mí él no está capacitado para decir: "oiga mi esposa se desmayó, hay que llevarla al hospital”, no, no está capacitado él para eso [no se entiende lo que dice] ese es mi temor." (Entrevistada 11)

Pero este temor no sólo estaba presente en los cuidadores de edad avanzada, también aparecía en aquellos de edad media que no contaban con apoyos, que les permitieran confiar que se harían cargo del dependiente en caso de que el cuidador no estuviese en condiciones de hacerlo.

\footnotetext{
"Yo me veo cuidándola hasta el final, es lo único que tengo claro, lo que me da miedo es que yo me pueda enfermar, que yo me pueda enfermar, muchas veces me hago esa pregunta: "si me enfermo ¿Qué va a pasar con ella?" tengo claro que la tengo que cuidar hasta el final." (Entrevistada 13)
}

También estaba presente el temor constante a cuidar a alguien con una salud deteriorada, que en cualquier momento podía sufrir un empeoramiento de su situación. 
"De repente en las noches siento que tose, y ya sé que ya está, pero de repente no sentirlo, a veces me quedo dormida, y no sentirlo moverse, nada y me levanto porque pienso en que le ha pasado algo, que se haya muerto y no sé... hay que seguir hasta que él esté" (Entrevistada 23)

La responsabilidad, que en ellos recaía, hacía que los cuidadores vivieran en un clima de temor y tensión constante, impidiéndoles desarrollar otras actividades de forma normal.

\begin{abstract}
"Al Luis ahora que ha estado así [en esos momentos su situación de salud era delicada], (...) porque en la cocina por ejemplo pelo una papa y lo vengo a ver, pelo otra y lo vengo a ver, estoy limpiando el baño y lo vengo a ver, así me lo llevo, para poder controlarlo" (Entrevistada 24)
\end{abstract}

\title{
Propiedad "Tristeza"
}

Para finalizar, se observa en muchas de las personas entrevistadas el sentir de una gran tristeza que se ve reflejado en muchos de sus comentarios. La pena se experimentaba al observar la evolución negativa de sus familiares dependientes, sobre todo en los casos de aquellas enfermedades que generan gran deterioro físico y mental en personas adultas (Enfermedad de Alzheimer, Enfermedad de Huntington).

- "Mira el comienzo de la enfermedad de mi mamá fue atroz, fue horrible"

- "Cuando tenía períodos de consciencia e inconsciencia"

- "Claro, yo a veces lloraba junta con ella, fue la peor etapa, yo ahí lloraba mucho, me daba mucha pena." (Entrevistada 10)

El estado de deterioro y de abandono llevó a los cuidadores a tomar decisiones, por la tristeza que les generaba la situación del dependiente, que implicaron cambios absolutos en sus vidas.

"Y yo en aquella época trabajaba, (...) en una empresa muy grande donde yo estaba muy bien económicamente y tuve que renunciar, porque significaba que yo no quería más que mi vieja estuviera allá [cuidado formal], y emocionalmente quedé muy mal, de 
verla cómo quedó y todo [después de una caída y fractura de cadera]." (Entrevistada 13)

En el caso de las madres de niños dependientes esta actitud se relacionaba con lo que le pudiese suceder a sus hijos, cuando ellos no estuviesen cerca, o en el futuro cuando ellos ya no estén para protegerles. Esta actitud y la preocupación solía desencadenar problemas en la salud mental en el cuidador.

\footnotetext{
"Claro, entonces eso como mamá duele porque todo niño tiene derecho a estudiar, todo niño tiene derecho a crecer, desenvolverse, porque el día de mañana uno falta y piensa qué va a ser de ellos. (...) y lo otro que me angustia mucho, que me ha pasado mucho últimamente yendo al súper, que siento que lo miran con lástima, cuando se dan cuenta de su problema lo miran con lástima y como mamá duele, porque pienso que nadie está libre de esto.” (Entrevistada 29)
}

\section{Síntesis}

A través del análisis de los discursos de los cuidadores pudimos identificar diferentes actitudes frente al cuidado. Éstas fueron tratadas como propiedades de esta categoría, y resultaron ser las siguientes actitudes: positiva/optimista/estoica, realista, activa, flexible, religiosa, sobreprotectora, frustrada, temoroso/a al futuro y triste.

\subsection{CATEGORÍA “MOTIVACIONES PARA EL CUIDADO”.}

Dentro de los discursos de los entrevistados se reconocen básicamente dos motivaciones en asumir la tarea del cuidado, la reciprocidad y el sentimiento del deber; éstas se ven muchas veces mezcladas en los argumentos que las/os entrevistadas/os nos entregan.

\section{Propiedad "Reciprocidad"}

Generalmente, el asumir una actitud de entrega incondicional a la tarea del cuidado está mediado por las relaciones sanguíneas y los compromisos asumidos en la relación de pareja. El hacerse cargo del dependiente es algo que no es cuestionado y que suele 
realizarse con amor y dedicación, esta dimensión suele verse reflejada en la relación madre - hijo.

Del total de cuidadoras/es entrevistadas/os, nueve de ellos cuidaban de sus hijos dependientes. Podemos apreciar que dentro de esta dimensión, el tipo de relación más unánime en asumir una actitud de entrega y compromiso es la de las madres con sus hijos (niños o adultos). Ellas no expresan en su discurso ninguna actitud de reclamo o cuestionamiento acerca de su labor, el cuidarles y "sacrificarse" es parte de su rol como madres.

- “Siente usted que a causa del tiempo que usted gasta con su niño no tiene tiempo para usted?" [Pregunta 2 del instrumento Zarit]

- "es que yo creo que una madre siempre va a tener tiempo para su hijo, tenga la complicación que tenga, siempre se va a dar el tiempo para estar con él.” (Entrevistada 24)

Esta entrega se da independientemente de la edad del receptor de cuidados, ya que cuatro de las madres entrevistadas tenían hijos adultos a su cargo.

- "Usted lleva bastantes años cuidando, primero a su esposo"

- “17 años, y ahora tengo que estar cuidándolos a ellos, 7 años que cuido a mi hijo, más de 12 años que tiene la enfermedad él ya, más o menos la misma edad los dos, pero felizmente la Silvia [su hija, también con la enfermedad de Huntington] todavía puede caminar, le cuesta pero camina, se lava solita, pero hay que bañarla, ella no se puede bañar sola." (Entrevistada 3)

Así también la reciprocidad aparece marcadamente en la relación hija/o, nieta- madre dependiente. Principalmente, son las mujeres de la familia quienes se hacen cargo de sus padres, mayormente de sus madres. En el caso de los padres, estos son generalmente cuidados por sus esposas, y en caso de que ésta ya hubiese fallecido son las hijas quienes realizan la tarea. La forma en que los cuidadores hijos/nietos asumen la atención de sus padres dependientes responde generalmente al afecto basado en la reciprocidad, más específicamente en la reciprocidad generalizada, por los cuidados recibidos. 
- “¿Cómo usted se las ha arreglado para cuidar a su mamá?”

- "Con cariño, el cariño que le tengo, la pena que le tengo porque está enferma, porque ella siempre había sido... se valía sola hasta última hora, lavaba loza, hacía aseo, y ahora como la veo, me inspira, no sé de repente ella me dice: "parece que yo fuera tu hija." (Entrevistada 5)

Esta motivación está presente en todo el discurso de los hijos varones entrevistados, que relatan el cuidado de sus madres destacando en su discurso el amor que tienen a sus madres.

\footnotetext{
"Yo soy creyente, y contra viento y marea yo igual voy a estar con mi mamá, aunque esté enfermo y todo, por eso mismo no voy a jugar a la pelota $^{55}$, porque no me quiero lesionar, no quiero correr el riesgo de lesionarme un tobillo, porque haría todo más difícil para mí.” (Entrevistado 25)
}

Es más, uno de ellos realiza la distinción entre la forma en que un hijo puede atender a su madre frente a los cuidados que vienen de parte de la pareja. Podría ser que está implícita en esa actitud la reciprocidad o "agradecimiento" a la madre por haberle dado vida, un tipo de reciprocidad generalizada mucho más fuerte que la de pareja.

\footnotetext{
"Pero ahora con mi mami como está, le decía a mi papi que le diera, pero él tiene mala voluntad, no es el mismo amor de un hijo que el de un hombre, el hombre quiere lo mejor para él." (Entrevistado 26)
}

Otra forma de expresar la reciprocidad, que se observa en los argumentos de las personas entrevistadas, es que consideran que no hacen lo suficiente por sus dependientes, siempre se sienten en deuda con ellos. Esta actitud generalmente está cruzada por la situación socioeconómica, debido a que estas familias no cuentan con los medios económicos para poder satisfacer todas las necesidades del dependiente, especialmente las de rehabilitación. O también, porque algunas cuidadoras deben

\footnotetext{
${ }^{55}$ Fútbol.
} 
trabajar para poder mantener sus hogares y por tanto no pueden dedicar el tiempo que quisieran al cuidado del dependiente.

"Feliz de la vida con ella, sí, no me arrepiento de nada, me hubiese gustado haber hecho más cosas por ella, y la realidad la limita a uno, tengo que salir a trabajar para poder mantener la casa, y eso la limita porque no en todos los trabajos se tiene la facilidad de que como me digan hoy día: "vaya a tal parte, que le van a ver a la niña", yo tengo que ver si en el trabajo me permiten, el cómo poder yo ir.” (Entrevistada 27)

Se visualiza además que así como de forma ancestral, la tarea del cuidado ha recaído en la(s) mujer(es) de la familia como forma de expresar la reciprocidad, patrón que se repite de generación en generación.

“(...) y ella [la persona dependiente] se dedicó, desde que se separó, a cuidar a mis abuelos, ella los cuidó cerca de 30 años, dedicó su vida a ellos, a pesar de haber sido una familia muy numerosa, mis abuelos tuvieron 15 hijos, pero ella fue la única que se hizo cargo de mis abuelos, hasta que murieron ellos de viejito, viejitos." (Entrevistada 13)

Así como las mujeres son las que, de acuerdo a la costumbre, debieran hacerse cargo del familiar dependiente, el hombre no espera cumplir ese rol, y la tarea del cuidado les llega de forma inesperada, a pesar de que las condiciones familiares determinaran dicha situación, en este caso ser hijo único.

"Entonces perdí la pega ${ }^{56}$ y mi mami tenía síntomas no más [del Alzheimer], yo no sabía que iba a tener que cuidarla yo, nunca pensé eso.” (Entrevistado 26)

Debido a la experiencia de cuidado, a las consecuencias que ha implicado en la vida de los cuidadores, algunos de ellos ya dibujan un cambio de comportamiento respecto a esta actitud, ya que no desean que su descendencia, la femenina principalmente, sea objeto de las mismas penurias que ellas han vivido.

\footnotetext{
${ }^{56}$ El trabajo.
} 
"Yo también soy hipertensa, tengo la misma enfermedad de él [su padre dependiente], entonces le digo yo a los niños, a mis hijos, que si me llega a pasar algo, que no... que busquen donde dejarme, pero que ellos no se hagan cargo de lo que paso yo, no [1lora], es mucho, es mucho para una persona asumirlo, por eso les digo hagan una maleta y me dejan en un hogar, en alguna parte que alguno tenga que hacerse cargo, yo tengo dos hombres y una mujer, y no porque la Francisca sea la mujer ella tiene que verme, no pues, ustedes buscan, saben que yo tengo un hermano que dice que cualquier cosa recurran a él, por eso ustedes hablen con su tío, yo sé que les va a ayudar [llora] para que ustedes no pasen lo que yo estoy pasando, es mucho.” (Entrevista 29)

\section{Propiedad "Sentimiento del deber"}

Otra motivación que empuja a asumir la tarea del cuidado es el sentimiento del deber moral que el cuidador/a experimenta. En el caso de las cuidadoras que atienden a sus parejas, es frecuente observar en su discurso la posibilidad de asumir o de rechazar y/o rehuir esta tarea de acuerdo a cómo se haya "comportado" la pareja durante la relación. Si la pareja ha tenido un comportamiento adecuado es un "deber" cuidarle, esta opción es frecuentemente aludida por las cuidadoras de edad avanzada.

"Dije: "yo voy a cuidarlo en mi casa hasta que mis fuerzas me den", haya pasado lo que haya pasado durante mi matrimonio, porque aquí no estamos en un desquite. Porque para que estamos con cosas, hay señoras, mujeres, que dicen: "él me hizo esto, por qué yo voy a fregarme $^{57}$ por toda una vida", porque uno nunca sabe, vive con esta incertidumbre." (Entrevistada 14)

En las palabras de las mujeres más jóvenes predominan también el "deber", pero además se justifica la acción por el afecto a la pareja.

"Sí, es algo bien complicado, hay que estar en el pellejo del otro. Por eso digo yo de repente hay gente que si se enferma la pareja y se mandan cambiar y se olvidan, no, yo no puedo, a pesar de que yo... es algo que pasó, yo sé que él ya no es mi pareja como hombre, como marido con el que me casé, yo lo veo como un hijo mío, no lo veo con otros ojos, y no es porque tenga otra persona, no.” (Entrevistada 16)

\footnotetext{
${ }^{57}$ Arruinar, sacrificar.
} 
A pesar de que las entrevistadas reafirman su postura, ellas reconocen que existe la posibilidad de no responder al "deber moral" de cuidar a la pareja, debido a que ello implicaría el sacrificar sus vidas al lado de alguien que no les ha retribuido.

Dentro de los cuidadores entrevistados sólo uno cuidaba de su esposa, mientras que seis de las entrevistadas cuidaban de sus parejas, ello puede deberse en parte a que epidemiológicamente las mujeres tienden a volverse dependientes mucho más tarde que los hombres. Como anteriormente mencionábamos, el cuidado de las mujeres mayores dependientes tiende a caer en manos de las hijas u otras féminas de la familia.

En el caso del varón que se hacía cargo de su pareja, llama la atención que su discurso y actividad están empapados por el compromiso afectivo con el que lo hace. Se observa que la tarea de cuidar le ha desarrollado características que suelen asociarse al género femenino, la paciencia, el estar pendiente de los detalles, ponerse en el lugar del enfermo pensando en su bienestar.

- “YY su estado de ánimo don Arturo?”

- "Así como me ve usted, es que mi señora a veces me... es que es como niña también, anoche le dije: “¿Qué te vas a poner mañana?”, “ya, me voy a poner esto y un pantalón cafe $^{58}$, mira allá arriba hay una carterita café", ya, yo me subí, habían como 6 carteras $^{59}$ que tiene y no había ni una café, "pero si yo las tenía ahí, no sé quién me la sacó de acá y las pusieron acá y dónde dejaron mi cartera...", claro pero ella la tenía ahí hace como 4, 5 años, y ella piensa que en el momento tienen que estar ahí, porque yo no voy a salir con cartera [risas], entonces no le digo nada, porque veo que a ella le dan los nervios, porque quiere hacer algo, entonces yo cuento hasta 10, y le digo: "ve que no está", guardo todo y la cartera no está, son momentos que pasan, que uno no puede decir [en tono golpeado]: "sabes que no está la cartera y hace tanto tiempo que..."." (Entrevistado 28)

Pero el cuidado motivado por el sentimiento del deber puede asumirse y realizarse de forma resignada, obligada o conformista, debido a que al cuidador socialmente le

\footnotetext{
${ }^{58}$ Marrón.

${ }^{59}$ Bolso.
} 
corresponda realizarla o porque no existe otra persona en la familia que la pueda efectuar. Generalmente, la responsabilidad recae en la mujer que vive con el dependiente o que se encuentra más cercana física y/o afectivamente a él, es así que las relaciones más frecuentes cuidador-dependiente son: hija-madre/padre; madre- hijo/a; esposa- esposo. En el caso de la primera de estas relaciones se presenta el testimonio de una hija que cuida de su madre enferma:

“(...) Y después la empezó a criar, porque yo salí a trabajar y ella [la madre, la dependiente] se quedaba con mi hija, la mandaba al colegio, le preparaba su almuerzo, y después ella, la mamá de ella, la que tiene ahora, porque a mi mamá le dice "mami"... y bueno yo nunca pensé que yo me iba a quedar cuidándola a ella. (...) Entonces a lo que voy yo es que para no haberme criado con mi mamá, el haberme quedado con ella." (Entrevistada 6)

En la familia de la entrevistada hay otras mujeres, hermanas, que tenían mayor obligación que ella en cuidar a su madre, basándose en la idea de la reciprocidad, por eso la entrevistada reflexiona que ella como individuo no le debe "cuidados" a su madre, ya que ésta no la crió, pero sí hizo ésta tarea con la nieta, por lo que la reciprocidad a la que responde su cuidado no es directa.

La convivencia previa con la persona dependiente determina en gran parte en quién recae la responsabilidad del cuidado, es el caso de otra de nuestras entrevistadas, nieta de la enferma (que a pesar de contar con varios hijos e hijas), por el hecho de haber sido criada por su abuela y vivido junto a ella durante toda su vida es a quien corresponde, tácitamente, la tarea del cuidado.

\footnotetext{
"A mí no me han dicho: "gracias por cuidarla", no, nada, yo creo que ellos [sus tíos y tías] lo toman como una obligación por el tiempo que hemos estado siempre juntas, pienso yo." (Entrevistada 12)
}

La resignación/obligación es más frecuente de encontrar en las relaciones de cuidado esposa/cuidadora- esposo/dependiente, en donde el deber de cuidar está dado por los compromisos que se contraen con el vínculo del matrimonio y que suelen ser 
fuertemente asumidos por las parejas mayores, pero con resignación cuando las relaciones de pareja no han sido buenas.

"Hay veces que me dan deseos también de... dejar todo tirado, yo se los digo, ellas [las hijas] me dicen: "lástima que no puede”, “¡bah!” les digo yo "es cosa de decisión no más" cuántas mujeres dejan casa, dejan hijos y se van no más.” (Entrevistada 1)

La resignación en el cuidado suele verse mezclada con rabia debido a que algunos de los dependientes se han "buscado" las enfermedades que hoy en día los tienen en situación de postración.

“(...) apenas se sintió bien siguió haciendo todo lo que hacía antes, diciéndole uno que no debía hacerlo, y está como está ahora, entonces eso me da rabia, porque él quiso, si era tan sano él, bueno dentro de su enfermedad, pero de haberse cuidado no estuviera pasando lo que está pasando, yo sé que para él es incómodo vivir todo esto y debe sufrir, pero yo también, me llevo yo todo el peso con él... es harto complicada la cosa, pero aquí hasta que se pueda seguir.” (Entrevistada 23) 


\section{TEMA DE ANÁLISIS. TAREA DEL CUIDADO Y SUS CONSECUENCIAS}

Bajo este epígrafe, se concentra el estudio de varias categorías de análisis, se opta por un examen conjunto porque forman parte de un gran tema dentro de la materia tratada. Las categorías principales en las que se divide este apartado son: el cuidado, el cuidador, la persona con dependencia y las consecuencias del cuidado.

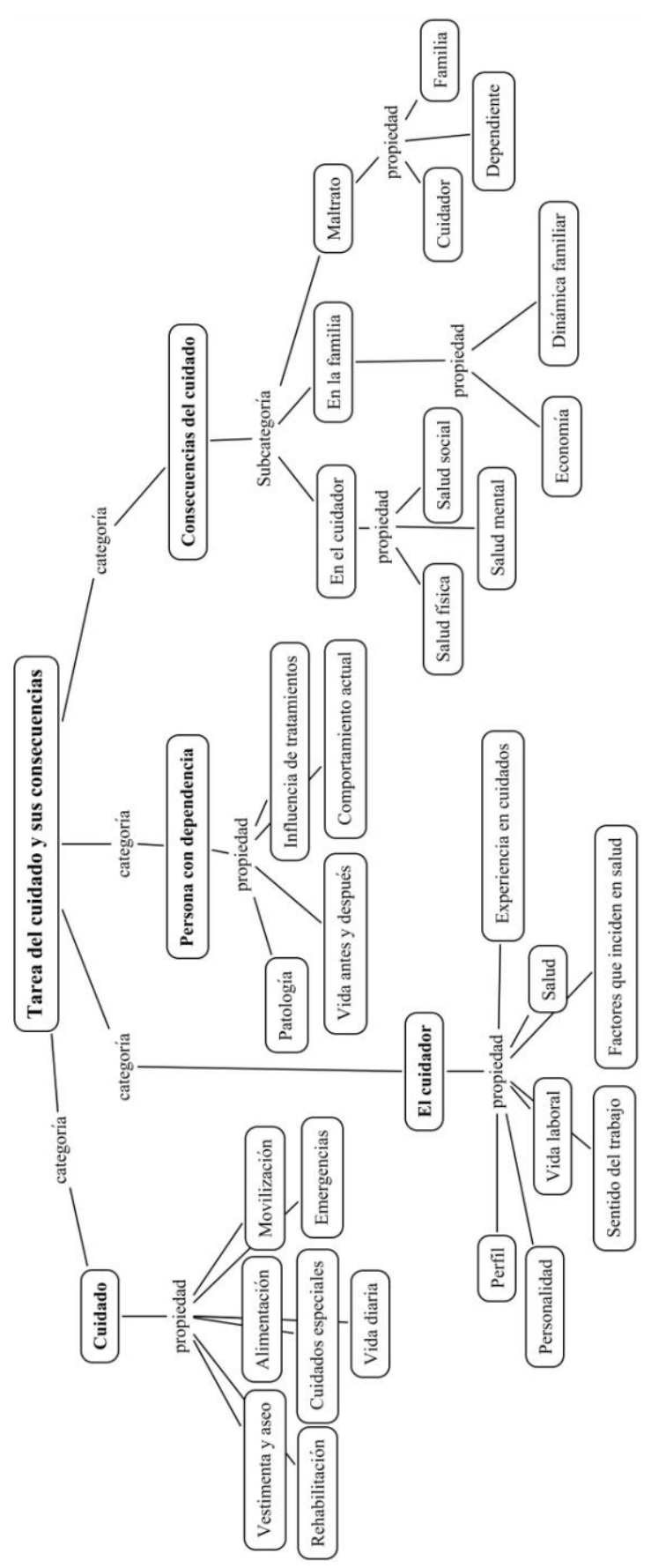

Mapa conceptual tema 2, Tarea del cuidado y sus consecuencias Página | 229 


\subsection{CATEGORÍA "EL CUIDADO"}

El cuidador, en su tarea de asistencia del dependiente, debía apoyarle en la realización de actividades instrumentales y/o básicas de la vida diaria, que demandaban gran parte de su tiempo y que muchas veces le impedían efectuar otras funciones. En el proceso de entrevista, los cuidadores fueron consultados por aquellas ocupaciones cotidianas, aunque también hemos recogido otras temáticas, indirectamente relacionadas con las actividades diarias, que son dignas de considerarse.

\section{Propiedad "Vestimenta y aseo personal del dependiente"}

La labor del cuidador, relacionada con el vestido y el aseo personal del dependiente, dependía del grado de dependencia que éste último tenía. En el caso de los cuidadores entrevistados, la mayor parte de los dependientes a su cargo necesitaba de ayuda y/o supervisión del cuidador en las tareas de vestido y/o limpieza personal; ello implicaba que los cuidadores debían estar presentes facilitándoles las tareas, proporcionándoles todo lo necesario para su realización.

- “¿Él en qué sentido depende de ti?”

- "Para comer hay que vigilarlo porque se ahoga todavía, (...) para ir al baño también hay que vigilarlo porque se moja, hay que estar vigilándolo que se tiene que lavar."

- “¿Pero él lo puede hacer solo?”

- "No, tengo que ayudarlo. Ayudarlo a vestirse en algunas cosas también, porque no tiene mucha movilidad de la mano derecha, la parálisis que tuvo le afectó todo el hemisferio derecho. (...) Si se enferma del estomago hay que ponerle pañales porque no alcanza a reaccionar para ir al baño, como un niño.” (Entrevistada 16)

Más de la mitad de los dependientes, atendidos por los cuidadores entrevistados, presentaba una dependencia total en este tipo de actividades. Las tareas de limpieza personal debían ser realizadas por el cuidador, y sólo algunos cuidadores contaban con apoyos de otros familiares para su desempeño y, aún en este último caso, el cuidador era quien asumía un rol protagónico en ellas.

- “Y ahora cómo lo hace para lavarle?”

Página $\mid 230$ 
- "No, le lavo en seco, tengo ese shampoo en seco, aunque en el verano, cuando hacen esas calores grandes, mi mamá le transpira mucho su cabecita y le digo a mi hija que porque no me ayuda a lavarle el pelo a mi mamita, la damos vuelta, corremos la cama, ponemos un balde, y una capa de esas para cortar el pelo, me pongo así, y ahí le lavo el pelo pero con agua, eso en el verano lo hago, no se lo hago todas las semanas, pero sí una vez cada 15 días, y el resto le voy lavando con el otro shampoo, es que sola no puedo." (Entrevistada 10)

Como se pudo observar, los cuidadores entrevistados echaban mano del ingenio a la hora de desempeñar estas labores, ya que a gran parte de ellos sus condiciones económicas no les permitían realizar adaptaciones, comprar artefactos o utensilios especiales que les facilitaran la realización de estas tareas.

Gran parte de estos dependientes no tenía control de esfínteres, lo que implica que debían usar pañales y ser aseados varias veces al día. El costo en pañales para estas familias implicaba un importante gasto, por ello tenían estrategias para intentar ahorrar en la medida que les fuese posible.

\footnotetext{
"Un paquete de pañales de 8 unidades vale casi $\$ 4.800$, y yo le pongo de dos pañales, le cambio 3 veces al día, son 6 pañales más la sabanilla, pero de repente la sabanilla me dura hasta 4 días, también son caras, son $\$ 5.000$ y vienen 8 , sabanillas gruesas, porque hay de todos precios, pero esas delgadas no le sirven, yo tengo harto cuidado al mudarlo para que no se le salga el pipí, y de los mismos pañales de un pañal saco tres pedazos y se lo pongo entremedito, ahí [en la zona de los genitales], porque él orina mucho, entonces eso le favorece que no se le salga el pipí para afuera, y nunca me lo van a encontrar hediondo a meado, porque yo lo manejo impecable al Mario." (Entrevistada 3)
}

A pesar de que hay personas dependientes que padecen de incontinencia, hemos comprobado, a través de los discursos, que el manejo del control de los esfínteres podía depender del nivel de formación de los cuidadores, de esta forma había cuidadores que insistían en que sus familiares mantuvieran el movimiento intentando aplazar el uso de pañales, a pesar de que esto implicara más trabajo; en cambio, otros cuidadores incidían en el aumento de la dependencia de sus familiares, ya que al intentar realizar los 
quehaceres, bien y rápidamente, impedían que el dependiente se ejercitara en ellos y perdiera las habilidades que poseía.

- ¿A ella tienes que ayudarla a trasladarse en algún momento?”

- "Sí, en el baño, ésta [la indica] es una sillita con baño, entonces en la noche a mí no me gusta ponerle la chata, ahí acostada, siempre, desde un principio que mantenga el movimiento, levantándose, aunque sea 2 o 3 veces por la noche, pero que tenga el movimiento." (Entrevistada 12)

“(...) le tengo que ayudar, en ella, en lo personal, para bañarla, y en la mañana que la visto yo por el hecho de la rapidez, porque ella es lenta, pero ella se viste y desviste sola." (Entrevistada 27)

En el ámbito del aseo personal se generaban situaciones complicadas para los cuidadores, por ejemplo, los hombres que cuidan de sus madres y que realizaban una labor que es vista como "poco apropiada" para un hijo, aunque esta dificultad es sólo inicial y resuelta en base a la reciprocidad del cuidado del hijo hacia la madre.

- “YY cómo fue para usted el tener que mudar a su mamá, limpiarla? Cuando empezó ese proceso ¿Fue difícil?

- "Mmm, de 1 a 7 yo podría decir que fue un 3,5 porque es algo nuevo para uno, yo no tenía idea de cómo poner un pañal, pero igual tuve que aprender. Pero en cuanto a asco no, a mí no me da asco, es mi madre.”

- “¿O pudor?”

- "No." (Entrevistado 25)

\section{Propiedad "Alimentación"}

A pesar de que existían diferentes grados de dependencia en los enfermos de los cuidadores entrevistados, todos los cuidadores desarrollaban actividades relacionadas con la preparación y el suministro de comidas a sus familiares.

En la preparación de los alimentos, muchos de los hogares debían hacer dos tipos de comidas, una para el dependiente y otra para el resto de los miembros de la casa, lo que 
implicaba dedicar más tiempo y además mayor costo económico.

- "Pero los días en que usted hace cazuela, todos comen cazuela"

- "Pero él no, porque la de nosotros lleva aliños y la de él no"

- "Cocina dos veces"

- "Claro, que para él hago para dos días, es un tazón y dos cositas más.” (Entrevistada 1)

Generalmente, intentaban simplificar la tarea cocinando para el dependiente para más de una comida. La labor de preparar alimentos para los dependientes estaba directamente relacionada con la patología que padecían, por ejemplo, en el caso de los dependientes más mayores generalmente las preparaciones debían ser bajas en sal y grasas, debido a que muchos sufrían hipertensión y/o diabetes.

"Por ejemplo, a mi mamá le hacía comida aparte por la diabetes que es más complicada, una ollita chica aparte para ella, por la papa y el zapallo ${ }^{60}$, pero para los demás cocino todo, pero todo liviano porque todo es sin sal, prácticamente sin sal, estamos los cuatro hipertensos.” (Entrevistada 9)

También está la tarea de suministrar el alimento al dependiente, ya que casi dos tercios de los dependientes debían ser alimentados por el cuidador u otro familiar. Las formas de alimentarle eran diversas y se daban casos en los que se utilizaba la cuchara pero también en otros, se usaba jeringas o sondas.

“(...) lo que pasa es que la Marta aprendió a comer, porque a ella yo le daba con gotario la comida, después pasé a la jeringa, y hasta que aprendió a comer con cuchara." (Entrevistada 2)

- “¿Y usted le tiene que preparar comida especial a su hijo?"

- "Sí pues, porque le doy la comida por sondas, tenía la sonda en la nariz, y después le abrieron acá [muestra el estómago], ya le han cambiado dos sondas, entonces por ahí lo tengo que alimentar, tanto sufrimiento para poderme acostumbrar a eso." (Entrevistada 3)

\footnotetext{
${ }^{60}$ Calabaza.
} 
Para los dependientes que eran alimentados a través de sondas o jeringas, sus comidas debían ser licuadas antes de administrárseles. En el caso del resto de las personas cuidadas, y dependiendo de las especificidades de sus patologías, los alimentos debían ser molidos o picados por el cuidador.

- “Usted debe moler o licuar su comida?"

- "No, no se la puedo moler porque el niño al molerle la comida..., por eso es que a veces dejo a mis hijas, pero para ellas es más rápido y le pasan por licuadora la comida, pero él no puede comer así porque se me atasca, de la orina y de la $\operatorname{cacuca}^{61}$, tiene que ser molido con tenedor." (Entrevistada 22)

Los dependientes que podían alimentarse por sí mismos debían hacerlo con la supervisión del cuidador u otro familiar, ya que realizaban la tarea con dificultad y/o podían sufrir complicaciones al tragar los alimentos.

"Yo le tengo que hacer todo, todo, él lo único que hace es comer con su manito izquierda, pero él se chorrea, hay que ponerle, de repente hay que partirle las cosas, es lo único que hace.” (Entrevistada 19)

Otra arista a considerar en la labor que el cuidador realizaba era la rigidez que tenían los horarios de comida de estos dependientes, que hacía que fueran prioridad en el quehacer diario y que en caso de la realización de actividades extraordinarias, como por ejemplo salir a realizar trámites o citas médicas, complicaban al cuidador.

“(...) cuando tengo que salir por ejemplo, ir al consultorio o al Barros Luco [hospital de la zona], yo cocinaba para dos días, y sí no para el día, para no verme tan afligida llegar a cocinar, porque en una oportunidad me pasó que no dejé cocinado, dije "A las $11 \mathrm{y}$ media vuelvo", eran las tres y todavía estaba en el Barros Luco, llegué a esa hora a hacer el almuerzo ${ }^{62}$, a darles almuerzo, ¿Quién me puede preparar el almuerzo? Almorzamos como a las 4 y media de la tarde, como no puedo molestar a mi hermana y a nadie más, entonces cuando llegué yo les hice almuerzo y estaban con hambre los

\footnotetext{
${ }^{61}$ Excremento.

${ }^{62}$ Comida.
} 
Capítulo VI. Análisis

tres.” (Entrevistada 9)

Un aspecto importante a comentar es el coste económico que implicaba para estas familias, con recursos económicos muy limitados, la alimentación de sus dependientes. Muchas de ellas postergaban otras necesidades con el fin de entregarles la alimentación adecuada.

\begin{abstract}
"Yo le tengo de todo, ahí en el velador tengo todo, prefiero a mi hijo antes de nada, y las comidas de él son... las puras verduras son $\$ 5.000$ que alcanza para tres días, porque le pongo espinacas, zapallo, papas, un poco de arroz, fideos, si no tengo espinacas le pongo acelga, si tengo zapallo italiano ${ }^{63}$ le pongo un zapallo también, y todo eso yo sí compro una lechuga. Me vale $\$ 2.600$ para tres días un poquito de posta ${ }^{64}$ así [dimensiona con la mano]." (Entrevistada 3)
\end{abstract}

\title{
Propiedad "Movilización del dependiente"
}

Las dificultades o falta de movilidad que padecían la mayor parte de los dependientes hacía que sus cuidadores tuvieran que realizar los traslados o movilizaciones cotidianas "a pulso": traslados cama-silla, silla-servicio, silla-bañera/ducha, cambios posturales en la cama, etc.

Los cuidadores de niños, que presentaban problemas de movilidad, veían que su tarea se iba complicando a medida que éstos iban creciendo. En este punto, se debe destacar que la situación de estos niños y de sus cuidadores se veía apoyada por una institución no gubernamental, la Fundación Teletón ${ }^{65}$. Cinco de los seis niños que presentaban discapacidades físicas, al momento de la entrevista, estuvieron o estaban siendo atendidos de forma gratuita en dicho lugar y sus cuidadores habían recibido formación en técnicas de movilización. Además, entregaban a sus usuarios ayudas técnicas básicas (por ejemplo: sillas de ruedas, ortesis), que facilitaban los traslados y desplazamientos.

\footnotetext{
${ }^{63}$ Calabacín.

${ }^{64}$ Corte de carne de vacuno.

65 Institución no gubernamental que desarrolla una importante labor en el diagnóstico, tratamiento y rehabilitación de niños y adolescentes con discapacidades físicas.
}

Página $\mid 235$ 
- "No, pero me refiero a que usted para poder a ella moverla, trasladarla, ¿Cómo lo hace?"

- "En brazos o en su coche [silla de ruedas de niño], dentro de la casa en brazos y afuera en coche."

- “¿A usted le han enseñado cómo tomarla para que no tenga dolor?"

- "Sí, lo que pasa es que ella asistió mucho a la Teletón, entonces a mí me enseñaron varias terapias, apoyos, ejercicios. (...) porque aparte de que le hacen terapia, a uno le enseñan también cómo hacer las terapias en la casa, cómo estimularla.” (Entrevistada 2)

En el caso de los adultos, el contar con una silla de ruedas representaba una enorme ayuda para los traslados tanto dentro de la vivienda como en el exterior. En el país, las personas mayores con problemas de movilidad física tenían derecho a recibir, a través de sus centros de salud, una silla de ruedas, aunque a veces el trámite fuese largo y no se consiguiera la ayuda técnica al poco de pedirla.

- "Mi hija se consiguió una silla de ruedas y en esa la movimos cuando quiere salir a tomar aire."

- “№ le dieron en el consultorio?”

- "La pedí pero está en trámite... ahí la saco para que salga a tomar aire ahí fuera." (Entrevistada 5)

Había movilizaciones, como los traslados de la silla a la cama o al retrete o sillón, que implicaban un esfuerzo considerable para el cuidador y que podían generar consecuencias en la salud física a éste, si no se manejaban técnicas específicas de movilización. La mayor parte de nuestros entrevistados no tenía ninguna formación en el cuidado, por tanto esta labor se transformaba en una dificultad evidente dentro de sus tareas cotidianas, lo que también repercutía en que los dependientes permanecieran la mayor parte del tiempo postrados en sus camas.

"Una vez pasamos mucho susto, yo creo que Dios nos salvó de que no se me mata Adrián, lo llevábamos al baño, lo sentábamos en una sillita en la ducha y ahí lo bañábamos, porque es lo ideal, pero a raíz de eso, mi hijo, Oscar, tiene 4 dedos menos, entre los dos lo llevábamos al baño, en una de esas él por apretarlo, Adrián hizo un quite así, porque él como enfermo cuando lo estaban apretando hizo otra cosa y casi se nos va

Página $\mid 236$ 
contra la pared, desde ahí decidimos no bañarlo más, él se lava por partes, en el pelo le paso de esas toallitas para las guaguas mojadas con colonia y le mantengo el pelo cortito, así voy por partes. (Entrevistada 14)

Los cuidadores intentaban estrategias diversas para poder movilizar al dependiente, teniendo en cuenta que en muchas ocasiones no contaban con la cooperación de otros miembros para ello.

- "Además para poder bañarlo era usted la que lo tenía que trasladar"

- "Si está al ladito del baño, su pieza está al ladito, la cama es de esos catres clínicos, muy alto, estábamos pensando en ponerle uno más bajo porque el que esté todo el día acostado es sacrificarlo mucho, le vamos a acomodar su cama, que tenía bajita, para poder levantarlo y así es más fácil echarlo en la silla y para mudarlo.” (Entrevistada 23)

\section{Propiedad "Tratamientos, procedimientos de rehabilitación"}

Dentro del conjunto de las actividades que desarrollaban a diario, muchos de los cuidadores debían desempeñar tareas de tratamiento y/o rehabilitación de sus familiares dependientes. Éstas podían formar parte de las indicaciones que habían recibido del personal médico que controlaba a sus familiares.

- "Estando de alta aquí en la casa, nos enseñaron a nosotros, a mí que era la que entendía un poco más de hacer curaciones, cómo curarlas."

- “¿Las enfermeras del hospital?”

- "Sí, cómo poner una inyección por ejemplo, que a él había que ponerle un anticoagulante todos los días, cómo se ponía, cuando ya se iba a dar de alta, "venga, mire, así, para que se la ponga a él”, no súper fácil, esa se ponía todos los días." (Entrevistada 17)

"Ah, es que la nutricionista le ha dicho que para bajar esto usted [se refiere a una sustancia] tiene que comer... en estos papeles que nos han dado (...) con esto yo sé que le puedo dar. (...) Claro, con eso me guío, y cosas que le van diciendo, ella me lo traspasa a mí, me dice: "Esto no tenís que dármelo porque dijo la doctora que tenía esto y no", entonces ya lo eliminamos." (Entrevistado 28)

Página $\mid 237$ 
También sucedía que muchos de los cuidadores, movidos por mejorar la calidad de vida de sus dependientes, buscaban y/o desarrollaban tareas de curación o rehabilitación.

\footnotetext{
"Me fui a la farmacia Kurth, ahí conozco a un farmacéutico de muchos años (...) y le conté lo que me pasaba, y él me dijo: "lo que tiene ahí, ese cuero negro es...” ¿Cómo me lo nombró? Necrosis, "usted lave todo bien lavado y con una pinza empiécelo a levantar porque eso es cuero muerto", y así lo hice, pero dominando mi miedo, mi dolor, porque la verdad yo jamás había visto qué es lo que era eso, una herida de esa naturaleza, empecé a levantar y debajo usted no sabe todo lo que había, era como una pequeña ollita con pus, yo levanté y aplasté un poquito así, y salió todo, y yo no pude aguantarme, salí a pasearme para acá, a tomar aire, a tomar valor, yo no me voy a olvidar nunca de eso, pero la Glorita volvió a respirar y vamos para adelante, así que de a poquito, le corte un pedazo, al otro día otro pedazo, hasta que lo corté todo, le saqué todo ese cuero negro, esa tapa que tenía, como una tapa de olla, le empecé a limpiar y le quedó un hoyo así, tan profunda que yo la medí, hasta aquí llegaba [muestra la primera falange de su dedo índice] el hoyo para abajo, y he gastado una montonera de plata en eso, porque cada remedio, la pomadita costaba $\$ 12.000$, y fuera de los desinfectantes, todo, pero seguí los pasos que me dijo el de la farmacia y a Dios gracias sanó, logré sanarlo." (Entrevistada 11)
}

\section{Propiedad "Cuidados especiales para los dependientes con déficits cognitivos y/o demencias"}

Más de dos tercios de los cuidadores realizaban la labor de apoyo y supervisión con familiares que sufrían de algún deterioro cognitivo o padecían algún tipo de demencia. Estos cuidados implicaban que, aparte de realizar tareas de alimentación y aseo personal, debían estar atentos a los comportamientos de sus dependientes para evitar situaciones de riesgo.

La demanda de vigilancia variaba mucho de acuerdo a la movilidad que el dependiente tuviera, al tipo de patología y a la fase de la enfermedad por la que estuviera pasando el enfermo. Por ejemplo, las madres de niños con problemas de deterioro cognitivo, pero que no experimentaban dificultades en su movilidad, debían estar constantemente 
pendientes de sus hijos para evitar la ocurrencia de accidentes. Situación similar era la que experimentaba otra de las entrevistadas, que cuidaba de su esposo, y que tenía que estar constantemente alerta.

\footnotetext{
"Una vez se me fue para el trabajo, para allá en General Velázquez [su antiguo trabajo, a más de 50 kilómetros], tomó una micro ${ }^{66}$, llegó y salió, y después como a las 2 horas me llamaron de allá del trabajo que estaba allá, ellos lo vinieron a dejar sí." (Entrevistada 16)
}

En el caso de los dependientes que no contaban con movilidad, aparte de la falta de cooperación en sus actividades básicas, los cuidados especiales tenían que ver con evitar que pudieran sufrir atragantamientos o caídas desde sus camas o sillas de ruedas.

\begin{abstract}
"Porque por último uno conversa con la persona, si está sana, y le dices: "Sabís quédate aquí no más, no te muevas", o "cómete la comida solita", pero cuando no hay razonamiento sobre lo que uno le está haciendo a la persona es sumamente difícil, porque yo a ella le puedo decir... yo la he visto de repente que masca esto [enseña un cable]." (Entrevistada 13)
\end{abstract}

\title{
Propiedad "Actuación ante emergencias"
}

La realización de las entrevistas se realizó trascurridos pocos meses del fenómeno sísmico que afectó a la zona centro sur del país ${ }^{67}$, evidentemente en la mayor parte de las entrevistas aparece mencionado este suceso. De hecho, una de las zonas rurales en donde se realizaron varias entrevistas -Champa y Hospital- es atravesado por una falla tectónica que generó daños importantes en las viviendas y la infraestructura pública. Las características sísmicas del país condicionan muchos comportamientos de sus habitantes, más aún de quienes tienen a cargo personas con dependencias. Prácticamente, todos los cuidadores tenían un plan de actuación frente a este tipo de sucesos tan frecuentes en el país.

\footnotetext{
${ }^{66}$ Un autobús interprovincial.

${ }^{67}$ El terremoto y tsunami ocurrido el 27 de febrero de 2010 que alcanzó una magnitud de $8.8 \mathrm{M}_{\mathrm{w}}$ (Escala sísmica de magnitud de momento).
} 


\begin{abstract}
"Nosotros, entre los que estamos acá en la casa, creamos conciencia, lo habíamos hablado antes, si hay un temblor fuerte, lo que sea, nosotros nos vamos a la pieza de él, no pensando en el terremoto, porque en un temblor no podemos sacarlo para afuera, cómo lo echamos a la silla y salir para acá y toda la cuestión, entonces cuando fue el terremoto yo estaba acostada acá en la pieza del fondo con mi mamá, cuando fue el terremoto yo no pensé en mi mamá, estando acostada al lado de ella, no pensé en ayudarla a ella a sacarla, porque pensé rápido que la mamá se puede bajar de la cama y salir para afuera sola, yo inconscientemente lo que hago es bajarme de la cama y con lo que me costó llegar a la puerta, a puros tropezones, para allá y para acá y llegué a la pieza de él, (...) estuvimos todo lo que fue el terremoto ahí con él en la pieza, nosotros no salimos afuera (...) mi preocupación fue mi hermano, siempre él, siempre él." (Entrevistada 17)
\end{abstract}

\title{
Propiedad "Organización de la vida diaria"
}

La cotidianeidad del cuidador se organizaba en función del familiar enfermo, generalmente en relación a los horarios de comidas y/o medicamentos que le debían administrar. Estas tareas eran prioridad, luego el cuidador cubría sus necesidades y realizaba las labores de hogar y/o trabajo.

- "Señora María y ¿Cómo es un día de usted? ¿A qué hora se levanta?”

- "A las 7 le doy los remedios a él, porque tiene insuficiencia renal crónica, a las 7 le doy los remedios, después le doy la leche a mi mamá, le preparo la mamadera ${ }^{68}$ a mi hermana, después pincho a mi mamá, como a las 8 , después yo tomo desayuno, después tengo que mudarlas, mudo a una y luego a la otra, cambiar sábanas, darle desayuno a mi hermana, de ahí me pongo a ordenar, un día ordeno el comedor, otro día ordeno las piezas, otro día me dedico a ordenar el jardín, otro día me dedico al patio, no todos los días hago lo mismo eso sí." (Entrevistada 9)

En los casos de los dependientes que padecían demencias tipo Alzheimer o vasculares, patologías que alteraban enormemente los horarios de descanso nocturno, los cuidadores no conseguían dormir de forma continua, y la falta de descanso inevitablemente condicionaba su desempeño diario.

\footnotetext{
${ }^{68}$ Biberón.
} 
- "Sí, duermo poco, de repente mi mamá no duerme, eso fue en los primeros años, a veces pasaba dos noches sin dormir, dormía en el día, de primeras se quejaba que le dolía el cuerpo, ahora no, porque ella se queda tranquila, se queda jugando con las muñecas, pero no siente dolores ahora, es raro cuando se queja de que le duelen las piernas... (...) estando despierta ella yo no puedo dormir."

- "Porque usted duerme al lado de ella."

- "Yo no puedo dormir porque en una de esas se puede caer de la cama, se puede ahogar y lo que es sentir a la gente quejarse y yo tengo el sueño livianito." (Entrevistada 20)

Los fines de semana no representaban ninguna diferencia para los cuidadores respecto a los días laborales, incluso había algunos casos en donde tenían más quehacer esos días porque venían familiares a visitar al dependiente, lo que implicaba que el cuidador, como dueño de casa, les debía "atender".

- “ ¿Y usted tiene alguna diferencia entre los días de fines de semana y los días de semana?"

- "No, son todos iguales, la única diferencia es que cuando vienen visitas tengo más pega no más."

- “¿No se atienden solas las visitas?”

- "No, tengo más pega, estoy preocupada de ellos." (Entrevistada 13)

La posibilidad que tenían la mayoría de los cuidadores de tomar un descanso o respiro era prácticamente nula, no tenían quien les remplazara, y cuando lo tenían sólo era por unas pocas horas diarias. La posibilidad de salir de vacaciones dependía de la estabilidad del estado de salud del dependiente.

"A principios de marzo teníamos planificado viajar a Quillota por el fin de semana, y el Luis el fin de semana presentó fiebre y no pudimos viajar, entonces yo digo: "Yo no me mando sola, el que me manda acá es el Luis, no me manda mi marido pero me manda el Luis" es un decir, todo depende de él, (...) entonces yo no hago planes, puedo tener la maleta lista para viajar mañana a Quillota, Quinteros o Curacaví, porque tengo un hermano que vive allí, y el Luis en un rato me puede decir lo contrario y ahí quedó todo, entonces no hago planes. El otro día me preguntaba mi hermano si iba a viajar a la playa este verano, no sé, no hago planes, no sé, lo único que quiero es que el Luis esté bien, 
pero si no puedo, si otro verano lo paso acá, lo paso acá no más, y eso.“ (Entrevistada 24)

En el caso de que fuese posible "salir de vacaciones", el cuidador debía seguir realizando su labor de cuidado, y la mayor parte de las veces sin las comodidades que pudiese tener en su hogar, lo que implicaba que las vacaciones no le servían para descansar.

\footnotetext{
"De vacaciones, bueno uno es que puede salir de vacaciones pero que para mí el descanso no existe, con mi hermana vamos a la playa de repente, pero llegó más cansada de lo que pude salir, y es que en el fondo yo igual tengo que hacerme cargo de ella aquí o donde esté, entonces yo puedo decir la voy a llevar a la playa por una diversión, pero las playas son todas de bajada, y la bajada ¡Uy es entretenida! Pero las subidas, no se las doy a nadie las subidas y con caminos tan largos.” (Entrevistada 27)
}

En suma, la dedicación del cuidador al enfermo podía implicar que no contaran con momentos de descanso en el día a día, ni en períodos determinados a modo de vacaciones, un aspecto que inevitablemente está relacionado con el deterioro de su salud.

\footnotetext{
"Casi no duermo, incluso son las 2 de la mañana y todavía no me acuesto, todos los días después de las 2 me acuesto. (...) Empiezo como a las 7 y media a moverme porque a las 8 hay que darle remedios, para darle el desayuno y todas las cosas, bueno en invierno me levantaba le daba los remedios, el desayuno y me acostaba otro rato, pero ahora ya en este tiempo no, como 7 y media estoy..." (Entrevistada 23)
}

\section{Síntesis}

El cuidado es una de las categorías fundamentales del análisis que desarrollamos en esta investigación. De acuerdo a las características de los discursos emitidos por nuestros/as entrevistados/as, podemos afirmar que las tareas relacionadas con la atención de sus familiares implicaban gran parte de sus tareas diarias, debido al alto nivel de dependencia de éstos. Los quehaceres, conocidos como actividades básicas de la vida 
diaria (ABVD), deben ser realizados y/o supervisados en su mayor parte por los cuidadores.

\subsection{CATEGORÍA "EL CUIDADOR"}

Esta categoría de análisis es medular para nuestra investigación, por ello intentamos sistematizar e indagar en toda la información que pudo ser recabada en el trabajo de campo acerca del cuidador.

\section{Propiedad "Perfil "sociodemográfico" de los cuidadores"}

Los cuidadores, tras la entrevista en profundidad, fueron consultados con respecto a sus datos sociodemográficos. A continuación se presenta la información más relevante conseguida.

La variable fundamental con la que se trabajó a la hora de desarrollar esta investigación es el hábitat en donde residían cuidadores y dependientes. En el cuadro 3 podemos observar la procedencia de las personas entrevistadas de acuerdo al medio en que vivían y los municipios a los que éstos corresponden.

Cuadro 3. Cuidadores, de acuerdo a medio en el que habitan, según el sexo y el municipio donde residen.

\begin{tabular}{|l|l|l|l|l|l|l|l|}
\hline \multirow{2}{*}{ Cuidadores } & \multicolumn{2}{l|}{ Sexo } & \multicolumn{3}{l|}{ Municipio } & \multicolumn{2}{l|}{} \\
\cline { 2 - 8 } & Mujer & Hombre & Lo Prado & PAC & Paine & Buin & Curacaví \\
\hline Urbanos & 13 & 3 & 7 & 9 & & & \\
\hline Rurales & 15 & & & & 7 & 4 & 4 \\
\hline
\end{tabular}

En relación a la edad de los cuidadores, en tramos de 10 años, podemos observar que la mayor parte de los cuidadores entrevistados se concentra entre los 40 y 69 años, resultando que la edad comprendida entre los 50 y 59 años es la que más cuidadores presenta. 
Si analizamos la relación que existe con los familiares a los que cuidan (cuadro 4), en su mayor parte son madres y padres de los cuidadores, en segundo lugar está el cuidado de los hijos, le sigue el de la pareja (principalmente esposos).

Cuadro 4. Edad de los cuidadores y parentesco con el familiar que cuidan.

\begin{tabular}{|c|c|c|}
\hline Edades de los cuidadores & Cuidadores & Parentesco con el dependiente* \\
\hline 30 a 39 años & 2 & $\begin{array}{ll}- & \text { Hijo (2) } \\
- & \text { Abuela (1) }\end{array}$ \\
\hline 40 a 49 años & 7 & $\begin{array}{ll}- & \text { Hija (1) } \\
- & \text { Hijo (2) } \\
\text { - } & \text { Esposo (1) } \\
\text { - } & \text { Madre (1) } \\
- & \text { Padre (2) } \\
- & \text { Tía (1) }\end{array}$ \\
\hline 50 a 59 años & 9 & $\begin{array}{ll}- & \text { Madre (5) } \\
- & \text { Padre (2) } \\
- & \text { Hija (1) } \\
- & \text { Hijo (1) } \\
- & \text { Hermano (1) } \\
- & \text { Hermana (1) }\end{array}$ \\
\hline 60 a 69 años & 7 & $\begin{array}{ll}- & \text { Madre (3) } \\
- & \text { Esposa (1) } \\
- & \text { Hijo (1) } \\
- & \text { Hermana (1) } \\
- & \text { Hermano (1) }\end{array}$ \\
\hline 70 a 79 años & 4 & $\begin{array}{ll}- & \text { Esposo (2) } \\
- & \text { Hijo (2) }\end{array}$ \\
\hline 80 y más años & 2 & - $\quad$ Esposo (2) \\
\hline
\end{tabular}

* No coincide necesariamente la cantidad de parientes dependientes con el tramo de edad, porque hay cuidadores que cuidan a más de un familiar. 
Los cuidadores estaban mayoritariamente casados y de los entrevistados que estaban solteros la mayoría tenía hijos (solo uno de ellos no los tenía).

Cuadro 5. Estado civil de los entrevistados

\begin{tabular}{|l|l|}
\hline Estado civil & Número de cuidadores \\
\hline Soltero/a & 8 \\
\hline Casado/a & 17 \\
\hline Separado/a o divorciado/a & 4 \\
\hline Viudo/a & 2 \\
\hline
\end{tabular}

En relación al nivel de estudios alcanzados por el grupo de cuidadores entrevistados, en el cuadro 6 se refleja este dato. Es necesario hacer una reflexión al respecto, ya que el nivel de estudios alcanzado varía bastante de acuerdo a la edad del entrevistado. En Chile la obligatoriedad de la educación básica ${ }^{69}$ (primaria) hacía que la mayor parte de los entrevistados que realizaron su ingreso a la escuela en los años cercanos a 1965 y posteriores tuviesen mayor escolaridad que los cuidadores de más edad. También se debe agregar que la "obligatoriedad" de la escolarización hasta antes de 1965 estaba en cursar hasta sexto año de primaria, y no octavo año como se estableció a posterior. Otro aspecto a considerar es que la mayor parte de las personas entrevistadas provienen de hogares con recursos económicos escasos, ello implica que para que asistieran al colegio, cuando éste no era gratuito ni obligatorio, implicaba un gran esfuerzo para sus familias.

\footnotetext{
${ }^{69}$ La reforma educacional chilena de 1965 establecía la ampliación de la educación primaria de 6 a 8 años con carácter común, gratuita y obligatoria.
}

Página | 245 
Cuadro 6. Nivel educacional alcanzado por los cuidadores

\begin{tabular}{|l|l|}
\hline Nivel educacional* $^{*}$ & Número de cuidadores \\
\hline Básica incompleta & 10 \\
\hline Básica completa & 4 \\
\hline Media $^{70}$ incompleta & 4 \\
\hline Media completa $^{*}$ & 10 \\
\hline Técnico-profesional $^{71}$ completa & 1 \\
\hline Universitaria incompleta & 1 \\
\hline
\end{tabular}

*Solo se mencionan las alternativas de respuesta que fueron citadas por los entrevistados. Un cuidador no aportó el dato.

Con respecto al lugar de residencia de los cuidadores, casi su totalidad, excepto dos, vivían bajo el mismo techo que el cuidador. Las excepciones las conforman dos cuidadoras de medios rurales, una de ellas vivía en el mismo terreno (sitio), pero en una edificación distinta, y la otra vivía en una casa fuera del barrio del dependiente, pero en el mismo pueblo.

Los cuidadores, por lo general, vivían junto a sus familias, que en mayor o menor medida apoyaban a éste en algunas de las tareas del cuidado. Los núcleos familiares estaban conformados por dos o más personas que viven bajo el mismo techo, pero que no necesariamente estaban dispuestos a ayudar al cuidador con el dependiente. Había cinco cuidadores que no contaban con nadie en el hogar que les ayudara en el cuidado de su familiar; casi la mitad de los entrevistados solo contaba con una persona que podía ayudarles. Esto da cuenta de un fenómeno que más adelante trataremos cuando analicemos la red de apoyos del cuidador.

\footnotetext{
${ }^{70}$ La educación media es un ciclo de cuatro años de estudio, que se cursa a continuación de la educación básica, también obligatoria y gratuita desde el año 2003.

${ }^{71} \mathrm{La}$ educación técnico-profesional a la que se hace referencia se cursa en los cuatro años correspondientes a la educación media, en liceos que imparten especialidades técnico- profesionales que otorgan un título técnico de nivel medio.
} 
Cuadro 7. Número de personas que viven con el cuidador y que podrían prestarle ayuda con el(los) dependiente(s)

\begin{tabular}{|l|l|}
\hline $\begin{array}{l}\text { Número de personas que pueden prestar } \\
\text { ayuda al cuidador }\end{array}$ & Cuidadores \\
\hline 0 & 5 \\
\hline 1 & 13 \\
\hline 2 & 8 \\
\hline 3 & 3 \\
\hline 4 & 2 \\
\hline
\end{tabular}

En relación al período que los cuidadores llevaban ejerciendo este rol, éstos fueron consultados por los años que llevaban desempeñando su labor. Para simplificar la información recogida se agrupó en tramos de años. Al analizar esta información podemos observar que más de dos tercios de los entrevistados llevaban menos de diez años cuidando. Igualmente importante es que había nueve cuidadores que llevaban más de diez años realizando esta labor, existiendo cuatro cuidadores que llevaban más de quince años en ello, generalmente madres que tienen hijos que ya son adultos y que desde su infancia son dependientes.

Cuadro 8. Tiempo que llevan cuidando

\begin{tabular}{|l|l|}
\hline Intervalos de años cuidando & Número de cuidadores \\
\hline Menos de un año & 3 \\
\hline Entre 1 año y 4,9 años & 9 \\
\hline Entre 5 años y 9,9 años & 10 \\
\hline Entre 10 años y 14,9 años & 5 \\
\hline Más de 15 años & 4 \\
\hline
\end{tabular}

Finalmente, los cuidadores fueron preguntados sobre sí habían recibido en algún momento formación que les ayudara a realizar de mejor forma su labor de cuidado, de 
ellos más de la mitad (diecisiete personas) no había recibido formación de ningún tipo para cuidar, los que sí la habían recibido (catorce) era una formación relacionada con los cuidados de enfermería, primeros auxilios, administración de insulina, colocación de sondas, o aprendizaje de ejercicios para que el dependiente los realizara.

El análisis que sigue se realiza en el marco de las entrevistas en profundidad. Al comienzo de éstas, lo primero que se pedía a las/os cuidadoras/es era que se presentaran, que en pocas palabras se autodefinieran. Éste petición dio como resultado que la mayor parte de las entrevistadas se definieran en relación a su estado civil (casada, viuda, soltera) y/o a su condición de madre. Inmediatamente después, los cuidadores mencionaron su condición de cuidadores y la relación de parentesco que los unía con sus familiares dependientes.

"Mi nombre es Paula Ugarte, tengo 52 años, soy la hija menor de la "Nina", ella tuvo tres hijas, tengo una hermana que vive en Santiago y trabaja y otra hermana que vive aquí en Paine, tengo 2 hijos, una hija que está en la universidad y que con suerte termina este año, y mi hijo, que es el que anda por ahí, que él tiene un pequeño problema de discapacidad. Esta es mi casa, yo me traje a mi mamá una vez que ella enfermó (Entrevistada 13)

La mayor parte de las entrevistadas provenía de hogares pobres en donde la situación económica vivida había determinado su vida. Un ejemplo claro es el nivel educacional de los cuidadores analizado anteriormente.

- "Usted nos contaba que había estudiado poquito..."

- "Poquito, hasta cuarto [básico-primaria] llegué porque justo mi mamá se murió y yo quedé con tres hermanitos más chicos, esa es seña que yo me tuve que salir del colegio pa' ayudar a cuidarlos, antes uno era demasiado pobre, no como la vida de ahora." (Entrevistada 4)

La situación de pobreza también incidió en la vivencia de contextos familiares difíciles para las/os entrevistadas/os, y en cierta forma determinó sus vidas actuales. Algunos de estos entrevistados eran miembros de familias extensas, que habían perdido en forma 
temprana al padre y en donde las madres debieron salir a trabajar y dejar a sus hijos a cargo de los hermanos mayores o de otros familiares.

- “¿Cuándo ustedes eran pequeños eran hermanables como hermanos?"

- "No, siempre hemos peleado"

- "Su mamá los crió a ustedes 9 y ¿su papá murió hace cuánto tiempo atrás?"

- "41 años, mi mamá quedó viuda joven, yo tenía 10 años cuando él murió"

- "Su mamá tuvo que sacarlos adelante a todos"

- "Sí, si yo le cuento a mi hija, si nosotros éramos pobres, pobres, pobres, en el colegio siempre nos discriminaban por lo mismo, porque éramos muy pobres." (Entrevistada 9)

Otro aspecto que las/os entrevistadas/os solían mencionar a la hora de presentarse era su procedencia y el lugar donde en ese momento vivían, seña de su identidad territorial y que determina muchos aspectos de su vida ${ }^{72}$.

Un aspecto que resulta interesante era que algunas de las entrevistadas al comenzar las entrevistas se veían sorprendidas y/o confundidas por la situación, ya que esperaban ser consultadas sobre sus dependientes, y no sobre ellas ni sobre lo que les sucedía.

"Mi nombre es Ángela Roa, tengo 32 años... sí, tengo 32, es que a mí nunca me preguntan la edad, me preguntan cualquier cosa de los chiquillos y me la sé." (Entrevistada 18)

A gran parte de los entrevistados les resultaba difícil hablar de sí mismos, de lo que eran, de lo que les sucedía. Puede deberse a que su vida es "vivida" a través del otro, su rol de cuidador lo copaba todo y no tenían más experiencias que esa.

\footnotetext{
${ }^{72}$ Se recuerda que fueron entrevistados quince cuidadores en zonas rurales y dieciséis en zonas urbanas de la Región Metropolitana de Santiago.
}

Página $\mid 249$ 


\section{Propiedad "Personalidad del cuidador"}

No es el objetivo de esta investigación realizar un análisis psicológico de los distintos aspectos de la personalidad en los cuidadores a través de las entrevistas, sin embargo existen aspectos o rasgos de personalidad que llaman la atención en el análisis y que consideramos importante mencionar.

Es distinguible dentro de los entrevistados un grupo de cuidadores ${ }^{73}$, la mayoría de edad madura, que se caracterizaban por presentar los siguientes rasgos de personalidad:

- Eran emocionalmente estables, es decir, afrontaban la vida, la realidad que les había tocado vivir con madurez y tranquilidad.

"Sí, fue un golpe tan fuerte que uno aprende a ser más fuerte, más dura, no sé que tanto seré pero uno aprende de esas situaciones a no alarmarse tanto por otras que no son tan graves, entonces uno aprende a relajarse un poco, a tomar las cosas no así histérica, ni volverse loca tampoco." (Entrevistada 2)

"Yo era súper carretera ${ }^{74}$, salía todos los fines de semana, nos íbamos a la playa con los amigos, salía para todos lados, pero cuando llegó él fue un cambio súper brusco, pero no me afecto... ¿Cómo lo puedo explicar? Fue mi cable a tierra, yo vivía en función de mí, era yo, yo, yo, y yo, pero él fue mi cable a tierra, yo creo que antes pasaba con depresión, que tal vez nunca me di cuenta, y ahora no, antes de tenerlo a él. Fue un cambio completo a mi vida, aparte de que llegó tan chiquitito.” (Entrevistada 18)

- "Sí, él me aconseja, y el mismo neurólogo también, me dijo, cuando nos tratábamos con él, me dijo que él estaba admirado de ver que nosotros como familia y yo, no nos había dado depresión, que no habíamos tenido mayores trastornos, haber pasado por una cosa tan fuerte, yo le dije: “No, ¿Qué saco?”. Tengo que ser más fuerte con esto que está pasando tengo que saber sobrellevarlo, yo soy bien alegre, a mi me preguntan: “¿Cómo estás?", y puedo estar mal, digo bien, siempre estoy contenta, no tengo problemas con nadie, soy siempre igual, entonces a lo mejor eso me ha llevado a sobrellevar esto mejor."

${ }_{74}^{73}$ Entrevistadas 2, 3, 10, 11, 12, 14, 18, 16, 24, y entrevistados 25 y 28.

${ }^{74}$ Salir a divertirse o salir de fiesta.

Página $\mid 250$ 
- "La actitud que tú tienes."

- "Sí, y siempre he pensado que a veces hay personas que están más mal que yo, entonces eso me ayuda a decir bueno, hay personas que están peor que yo." (Entrevistada 16)

- Eran conscientes, actuaban con juicio y perseverancia, se ajustaban a las normas.

- “¿Hace cuánto tiempo que no descansa, que no puede decir, voy a salir este fin de semana?"

- "No, es que no puedo salir, amigos que han venido y me han invitado a salir, me dicen: "No, déjala acostada no más, si total tu mamá ni idea", "No" les digo yo, tengo que saber cambiarle el pañal, tengo que saber si está tosiendo o no, si ella está bien, yo voy a estar bien.” (Entrevistado 25)

- Eran emprendedores, se conducían con decisión y creaban estrategias a la hora de enfrentarse a situaciones diferentes y no experimentadas con anterioridad.

“(...) yo tengo mi vida privada, mi espacio, que a veces sí, me siento triste, me da pena, [se emociona] pero como le digo mi carácter siempre ha sido así: “¿Levántate Yoya! y sigue para adelante", dentro de la vida, circunstancias, enfermedades, los niños, los viajes, porque nosotros hemos viajado, varias veces hemos estado en Perú, hemos formado hogar, ese hogar por enfermedades se ha desarmado, he llegado y he luchado sola por mis hijos, pasando privaciones, pero hemos llegado a tener otras casas, no es ésta la única casa propia que hemos tenido, (...) y después a los años se nos ocurrió venderla para comprar ésta [ríe] ve usted, que uno se cae [se equivoca], pero se tiene que volver a poner de pie de nuevo, no echarse a morir, claro uno llora, sufre, pero se levanta hacia arriba otra vez.” (Entrevistada 11)

- Se comportaban de forma serena, eran seguros de sí mismas.

- "Tanto sufrimiento para poderme acostumbrar a eso."

- “¿Para usted era muy tremendo?”

- "Sí, tremendo, porque yo con mi hijo me hice valiente, sabe señorita yo miraba a mi marido y me desmayaba." (Entrevistada 3)

-Eran autónomos, dentro de las limitaciones que tenían manejaban sus recursos y tomaban la iniciativa a la hora de decidir. 
- “¿Cree que su vida social se ha visto afectada por tener que cuidarlo?”

- "No fíjese, porque yo asisto a un grupo de adulto mayor en Buin, que no he ido por mi enfermedad, pero hace un año que estoy en esa agrupación, somos 50 personas, no he ido por mi vista, pero yo me las arreglo, planifico, (...) de 3 a 5 , y yo iba a tomar tecito afuera, ahí me daba un relax.” (Entrevistada 14)

Se observa que los cuidadores que presentaban estas características estaban en mejores condiciones de salud mental al momento de realizar la entrevista, es decir sicológicamente estaban mejor preparados para sobrellevar la tarea de cuidar a sus familiares. Si bien las situaciones vividas podían ser difíciles, ellos relataban y vivían su experiencia de cuidado comparativamente mejor que el resto de los cuidadores.

Al respecto también resulta importante destacar que se observó en varias de las entrevistadas $^{75}$ la capacidad de ser resilientes ${ }^{76}$, es decir eran mujeres que se habían visto sometidas a situaciones extremadamente adversas en sus vidas, de estrés prolongado, y que habían salido fortalecidas de ellas, sobreponiéndose al dolor.

Por otro lado, el resto de los cuidadores entrevistados presentaban rasgos de personalidad que resultaban negativos para enfrentar de buena forma la compleja situación de cuidado de una persona dependiente. Entre estos también se enumeran una serie de síntomas pertenecientes al trastorno depresivo.

- Poco estables, turbados, afectados en sus sentimientos.

- “Usted se siente cansada, agotada?"

- "Sí, muchas veces, de largar todo lejos.” (Entrevistada 4)

- Aprensivos, inseguros, preocupados.

- “¿Usted tiene temor por el futuro que le espera con su mamá?"

- "Sí, casi siempre, porque yo no duermo, he tenido días en que puedo dormir, pero me levanto para ver si ella está respirando, si no se me ha caído...” (Entrevistada 5)

\footnotetext{
${ }^{75}$ Entrevistadas 2, 3, 10, 11 y 18.

${ }^{76}$ La definición más aceptada de resiliencia es la de Garmezy (1991) que la define como "la capacidad para recuperarse y mantener una conducta adaptativa después del abandono o la incapacidad al iniciarse un evento estresante" (Becoña 2006).
} 
- Tensos, inquietos, rígidos

“(...) mi hija me coopera mucho, mi hija me dice: “SSabes qué mamá? Anda, yo me quedo, dime todo lo que hay que hacer", y ella sabe mudarla, sabe tratarla, y la trata mejor que yo, porque yo de repente me descontrolo, me dice: "Mamá, mamá, déjamela a mí", es mi cable a tierra. Entonces me pego la arrancada, y chao, chao. Yo colapso, y los momentos en que colapso, sobre todo, por ejemplo, anoche ella defeca, y se empieza a meter las manos, entonces la voy a ver y está con cacuca $^{77}$ hasta aquí, se la pasa por el pelo, eso significa que la tengo que agarrar, la tengo que bañar, la tengo que desnudar entera, cambiar la cama, hoy día no más me pasó.” (Entrevistada 13)

- Sintomatología depresiva: Anhedonia o imposibilidad de la capacidad de disfrutar.

- "Yo varias veces he querido dejar todo botado, irme, irme y dejar todo tirado y no saber de nada, nada de nada."

- “¿Usted encuentra que su estado de ánimo, su salud mental se ha visto afectada?”

- "Sí, yo no me proyecto con nada, de hecho mi hija me dice que este otro año va a tener guagüita y a mí me da lo mismo que tenga guagua [bebé] o no, para qué digo: "voy a ser abuelita" ¿Qué saco! Si no voy a disfrutar de la guagua, me da lo mismo, y mis amigas me dicen: “Cómo te va a dar lo mismo? Si es tan rico ser abuelita”, es que qué saco yo con ser abuelita si tengo que cuidar a mi mamá y a mi hermana, no voy a disfrutar lo que es ser abuela, me da lo mismo.” (Entrevista 9)

- Sintomatología depresiva: Astenia, sensación de debilidad y cansancio extremo. Estado de ánimo triste.

"Me autoanalizo y yo antes era más jovial, me daban ganas, por ejemplo de pinchar ${ }^{78}$ con un hombre, ahora no, el día viernes, sábado mi hermana me dice: "Sale", pero no me dan deseos, prefiero dormir siesta, descansar, que salir. Estoy cansada y aburrida, muy aburrida, a veces amanezco tan enferma que no quiero hacer nada, estoy con una depresión atroz, si a veces me las aguanto porque llegan mis hijos y yo creo que también les bajo el ánimo a ellos donde me ven así.” (Entrevistada 19)

\footnotetext{
${ }^{77}$ Excremento.

${ }^{78}$ Flirtear.
} 
- Sintomatología depresiva, estado de ánimo irritable.

- "Y su estado de ánimo señora Sara ¿Cómo es?"

- "Malo, muy malo, sin ánimo de nada, con la paciencia que yo tenía."

- “¿Está más irritable?”

- "Sí, irritable, peleadora, cansada, todo" (Entrevistada 27)

Además, creemos se debe prestar atención a la presencia de un rasgo de personalidad, que puede ser considerado perjudicial para la persona que desempeña el rol de cuidador, y presente en casi la mitad de los entrevistados, se trata de la sumisión, que generalmente se basa en la obediencia a las normas sociales con las que habían sido educados, y que se expresaba en someterse a las figuras de sus parejas, padres e incluso hijos, a pesar de que el dependiente fuera la figura a la que debían autoridad y que se encontrara incapacitado en lo mental. Este rasgo era predominante en las mujeres entrevistadas y por ello le rescataremos al tratar el tema del género.

- "¿Usted encuentra que el cuidar a su esposo le ha afectado de alguna manera el estado de ánimo que tiene?"

- "No, porque me tengo que acostumbrar no más pues. (...) A veces me siento cansada, pero tengo que hacerlo no más pues, no me queda otra." (Entrevistada 4)

- "Por lo que me decía su hermano dice que la cuida, pero se la tiene que llevar usted para allá ¿Dónde vive su hermano?”

- "Vive en San Bernardo, pero qué, si mi mami no se queda en ningún lado pues, ella de ir, va un ratito. (...) Pero a las 5 ya quiere irse, "Que la Josefa, qué estará haciendo ella,” o sea que está siempre con la mentalidad que yo dónde ando, “¿Estará en la casa la Josefa? Me irán a dejar y ¿Ella estará allá?”.” (Entrevistada 6)

- “¿Y cómo fue para usted el tener que hacerse cargo de cuidar a su mamá siendo que se llevaban mal?"

- “No sé, tuve que asumir no más po'.” (Entrevistada 18)

- “¿Y ha generado, la enfermedad de su señora, algún roce dentro de la familia?"

- "A mí no, o sea aquí la que más discute, pelea y se enoja conmigo es mi señora, porque estará enferma, pero alega un montón, entonces yo soy más pacífico, tranquilo, 
porque soy yo el que queda al medio, mi señora me dice: "no, no le hagas esto", y mi hija "papá tu..." es que no le puedo dar el favor ni a unas ni a otras." (Entrevistado 28)

En el caso de las madres cuidadoras, y a pesar de que el número de ellas fue reducido (ocho de treinta una), se observa que la situación de cuidado generaba tensiones entre la pareja o dificultaba el encuentro de ella. Ello ocurre tanto en el caso de mujeres jóvenes que eran madres "solteras", como en el de mujeres casadas que cuidaban de sus padres.

"Es lo que me dijo una vez mi esposo, me dijo: "Tú vives en torno al Alonso, y el Alonso está bien, no tiene nada"... lo que pasa es que nosotros tuvimos una crisis matrimonial, estuvimos separados 4 meses, y todo eso tocó cuando a mí me tocó los exámenes, todo eso, me tocó todo sola, ahí estuve con depresión, (...) él me lo dijo así, por eso siento que él no ha asumido lo que le pasa. Por ejemplo, le dije del colegio, que quería cambiarle de colegio, que qué pensaba, no dice, nada, no dice nada, no, yo tengo que solucionarlo, pero yo sé que si me equivoco, yo voy a ser la culpable, pero eso a uno le hace pensar, le hace sentirse sola además, entonces esas cosas no las capta él.” (Entrevistada 29)

"Quizás, después yo voy a pensar de otra manera, pero ahora como le digo yo no me proyecto con nada, y menos con nadie, con una pareja, no, nada, llevo como 10 años sola [silencio] digo para qué, a estas alturas... siento que mi vida no tiene sentido, no me proyecto con nada." (Entrevistada 9)

- "Me decía usted que la relación con su esposo se deterioró producto de la enfermedad de su mamá ¿Ustedes ya no viven juntos?”

- “Sí, si po' si vivimos juntos pero es que no es lo mismo, si incluso tuvimos una separación por eso, él me saca en cara lo de mi mamá, que yo no más tengo que cuidarla, que para todas las cosas yo, que él está de lado y así pues, entonces son 9 años que yo he tenido que soportar de todo, en cuanto a él y en cuanto a mis hermanos también, porque todos dicen que por el hecho de que uno está aquí, se está aprovechando de todo, que yo lo paso súper bien, según ellos.” (Entrevistada 20) 


\section{Propiedad "Vida laboral de los cuidadores"}

Dentro del instrumento de información socioeconómica aplicado a cada uno de los cuidadores pudimos conocer la situación laboral al momento de la entrevista. Gran parte de los cuidadores desempeñaba, aparte de las tareas de cuidado, el trabajo de "amas de casa $^{79, " ~(C u a d r o ~ 9) . ~ P o r ~ s u ~ p a r t e, ~ l a s ~ p e r s o n a s ~ q u e ~ t r a b a j a n ~ d e ~ f o r m a ~ a u t o ́ n o m a ~}$ mencionan que era el tipo de trabajo que más se acomodaba a su realidad como cuidadores, ya que podían distribuir sus tiempos de trabajo de acuerdo a los momentos libres del cuidado del dependiente y del hogar; la actividad mayoritaria de los que trabajaban de manera autónoma era la venta ambulante. En el caso de los cuidadores que eran trabajadores dependientes, desempeñaban empleos que se adaptaban a su tarea de cuidador. Dos de estas cuidadoras trabajaban en servicios de aseo, que contaban con turnos de trabajo que coordinaban con otro familiar para que les reemplazara en el cuidado del familiar las horas que ellas estaban en su trabajo. La tercera trabajaba en una empresa de un familiar y podía acudir con el dependiente a su lugar de trabajo.

Cuadro 9. Ocupación de los cuidadores al momento de la entrevista

\begin{tabular}{|l|l|}
\hline Ocupación & Número de cuidadores \\
\hline Cuidador/a y ama de casa & 20 \\
\hline Cuidador/a y con empleo dependiente & 3 \\
\hline Cuidador/a y con empleo autónomo & 8 \\
\hline
\end{tabular}

En relación a las historias laborales de las personas entrevistadas, éstas eran muy diversas, por ello en esta propiedad las dimensiones son variadas, comenzamos considerando que gran parte de las personas entrevistadas eran mujeres, una parte de ellas no habían trabajado nunca de forma remunerada fuera del hogar, pero la gran mayoría sí lo habían hecho en algún momento de su vida. En el caso de los tres cuidadores entrevistados todos trabajaron, pero con el aumento de la dependencia de sus

\footnotetext{
${ }^{79}$ Dueña de casa.
} 
familiares debieron dejar sus trabajos e intentar conseguir algo de dinero en actividades que les permitieran compatibilizarlo con el cuidado.

\section{Dimensión "No han trabajado de forma remunerada fuera del hogar”.}

Generalmente, eran las mujeres mayores entrevistadas las que no habían trabajado de forma remunerada fuera del hogar, o lo habían hecho desde casa en labores menores para que no interfirieran en el desempeño de su rol de dueñas de casa. Por lo general, esta era la situación vivida por mujeres mayores rurales ${ }^{80}$, que si desempeñaron alguna labor desde el hogar, fueron las de labores de costura, lavado de ropa "ajena" o cuidado de niños “ajenos".

“(...) antes cosía yo, mi máquina para que le digo como cosía, pero costurera no más no modista, porque cuando me traían algún arreglo acá, yo atendía a mi marido, lo dejaba durmiendo su siesta, de las 2 a las 5, que le doy su leche (...).” (Entrevistada 14)

Así como los trabajos desempeñados eran variados, también lo era la periodicidad con que se realizaban y la cantidad de dinero recibida por ello, lo que generaba que en algunos casos se constituyeran en importante soporte de la economía familiar, sin embargo, en otros casos suponía sólo una ayuda ocasional.

\section{Dimensión "Han trabajado, pero tuvieron que dejar de hacerlo".}

La situación laboral de la mayor parte de las personas entrevistadas era el desempleo ${ }^{81}$, principalmente por la incompatibilidad existente entre las tareas de cuidado y las del hogar con las del desempeño de un trabajo. Estas personas trabajaron de forma pagada y debido a la situación de dependencia de sus familiares debieron dejar sus trabajos.

\footnotetext{
"Y yo en aquella época trabajaba, trabajé toda mi vida, desde jovencita, en una empresa muy grande donde yo estaba muy bien económicamente y tuve que renunciar. Porque significaba que yo no quería más que mi vieja estuviera allá, y emocionalmente quedé muy mal, de verla cómo quedó y todo.” (Entrevistada 13)
}

\footnotetext{
${ }^{80}$ Entrevistadas $5,11,14,15,21,22$. Sólo la primera es entrevistada de zona urbana.

${ }^{81}$ Entrevistadas 1,2, 3, 4, 8, 9,10, 12, 13, 19, 20, 24, 25, 28 у 31.
} 
En el caso de los varones entrevistados, al momento de ser entrevistados, ninguno de ellos se encontraba desempeñando un trabajo remunerado estable fuera del hogar. Todos debieron dejar sus trabajos para poder atender al dependiente, a razón de que no había otra persona en el entorno familiar que lo hiciera. Los dos cuidadores más jóvenes, hijos de mujeres dependientes, realizaban de forma ocasional trabajos menores para poder aumentar en algo el exiguo presupuesto familiar. El cuidador de mayor edad dejó del todo su negocio independiente, que sostenía la economía familiar y que además significaba para él satisfacción personal.

\begin{abstract}
"Bueno igual ella recibe una pensión asistencial, y algunas cosas que tengo yo las llevo a la feria, yo no trabajo en la feria, se las paso a un caballero para que las venda, y eso, sí sale algún trabajito que yo puedo efectuar aquí igual lo hago, y bueno estando con todas las deudas llega esa platita [estipendio] que ha servido de mucho, de mucho, porque yo no puedo tener un trabajo estable porque no tengo con quien dejar a mi mamá, y lo de mi mamá es cuidado a diario, yo descanso cuando mi mamá está acostadita y yo cuando la veo que está durmiendo ahí yo me relajo.” (Entrevistado 25)
\end{abstract}

\begin{abstract}
"Yo después que acabé con el negocio no busqué un trabajo, sino que me puse a trabajar con un cuñado, yo tenía que dejar lista a mi señora para que se le llevaran [a la diálisis], después me iba a trabajar, después tenía que volver acá para que le hicieran almuerzo y esperar a que llegara, o sea más bien dicho no era nada lo que trabajaba, ya después ella empezó a... es que la dejaba lista en la silla, y la primera vez que se cayó me dijo; "no, sigue no más" si lo que me daban allá me servía para "parar la olla", y ya la $2^{\mathrm{a}}$ vez que se cayó cuando llegaron de allá a buscarla, se dieron cuenta y tuvieron que romper la ventana para entrar, porque estaba tirada en el suelo, así que ahí le dije yo que no trabajaba más, no más, total para comer no nos va a faltar." (Entrevistado 28)
\end{abstract}

\title{
Dimensión “Continúan trabajando a pesar de ser las cuidadoras principales”.
}

Las personas que se encontraban trabajando al momento de ser entrevistadas, lo hacían con grandes dificultades y en labores que les habían permitido acomodar los horarios de trabajo con los de cuidado. Generalmente, se dedicaban a actividades económicas que 
pudieran desarrollar de forma independiente -vendedoras ambulantes, agricultura, servicios de fotografía- o al área de los servicios -limpieza, vendedora-.

- “Cuénteme de eso señora Javiera? ¿Usted trabaja en las flores?”

- "En las flores, sí, en un invernadero de flores, vamos a hacer 12 años, sí no más. Primero estuvimos 5 años en un grupo, después pasaron 2 años y seguí yo sola.”(...)

- “¿Cómo usted coordina todos los trabajos que hace?”

- "Estoy toda la mañana pendiente de mi papi y de ahí, como a las 4, me voy al invernadero, ahí llega mi hija de la universidad y si no mi otro hijo que no estudia, pasa, le viene a dar vueltas, pendientes de las comidas más que nada, que estén a la hora, de mudarlo, bañarlo, esas cosas.” (Entrevistada 23)

"Yo salgo a trabajar, trabajo con mi hermana acá en la feria, me levanto a las 5 de la mañana, a ella la despierto, la dejo vestida y le pido el favor a mi vecina de arriba que me la vaya a dejar al colegio, y ella tiene una voluntad única de ir a dejarla al colegio y de vuelta me la vienen a dejar las compañeras, por el hecho de que aquí el barrio no es muy... es peligroso." (Entrevistada 27)

- "Aquí, que los dos trabajamos, yo trabajo aquí en la casa."

- “Qué es lo que haces aquí en la casa? Cuéntame.”

- "Mira yo hago todo lo que es coctelería, banquetería, tortas, todo lo que es tarjetería, encintados, cosas de artesanía, ahora tengo todo para hacer aritos de plata y esas cosas, pero no me alcanzó el tiempo, hago fotografías, o sea uso el computador en su máximo, el computador y la impresora." (Entrevistada 18)

Como mencionábamos, uno de los trabajos remunerados que con más frecuencia desempeñaban o habían desempeñado las cuidadoras, en algún momento de su vida, era el trabajo en empresas de limpieza, ya que al realizarse en turnos permitían al cuidador organizar y compatibilizar, aunque no exento del costo que para él implicaba, el cuidado con el trabajo.

"Ahí yo tuve que salir a trabajar a empresas de aseo, tratar de buscar lo que acomodar porque las empresas de aseo era lo único que a mí me acomodaba, porque tienen horarios, entonces yo tenía que acomodar mi horario con el que ella iba al colegio y yo poder trabajar, entonces era la única opción, yo trabajé en el registro civil y trabajé acá 
en el comando de ingenieros acá en Matucana, ahí yo tuve varias facilidades porque me quedaba cerca, cuando la Danielaa estuvo hospitalizada en el San Juan de Dios yo en mi hora de colación yo me iba al hospital, la mudaba, la bañaba, todo y después me iba a trabajar. Si las empresas de aseo tienen varios turnos, tienen de 7 a 3, de 3 a 11 y de 11 hasta el otro día, entonces ahí uno tiene la opción de buscar el que más le acomode a uno." (Entrevistada 27)

\section{Propiedad "Sentido que otorgaban al trabajo"}

En general, las personas entrevistadas al referirse al tema del trabajo sus discursos solían aludir a las siguientes dimensiones.

\section{Dimensión "El trabajo como forma de sobrevivencia"}

Esta dimensión se condice con la situación socioeconómica de la mayoría de los entrevistados, el trabajo era el medio que permitía a la familia el logro de unos mínimos, les permitía vivir el día a día. Una de las entrevistadas que se encontraba en búsqueda de empleo manifestaba que necesitaba conseguirlo de forma urgente, ya que como jefa de hogar no podía mantener económicamente su grupo familiar.

\footnotetext{
- “Cómo usted ve su futuro?”

- "[Silencio] no muy bueno, mientras no trabaje, no produzca, no va a estar bueno... esa es la parte que me afecta a mí, no poder cubrir necesidades, tampoco quiero vivir tan holgadamente, pero lo básico, a lo que todos aspiramos, vivir un poco relajados en lo económico, no estar tan, tan apretados como estamos, pero bueno, darle tiempo, no desesperar, porque cuando uno cae en la desesperación parece que las cosas se alejan." (Entrevistada 2)
}

\section{Dimensión "El trabajo como forma de evadirse"}

Otra dimensión, menos mencionada, pero no por ello menos importante, era utilizar el trabajo como una vía de evasión de la situación familiar complicada que vivían. El salir de casa a desempeñar una tarea fuera del hogar implicaba que los cuidadores se alejaban 
por un momento del agobio que les implicaba la problemática del cuidado y su influencia en la dinámica familiar.

“(...) cuando salgo no me dan deseos de volver... el trabajar allá es otro mundo [se refiere al último trabajo que tuvo], uno tiene que meterse ahí, porque "Mercedes" [lo dice como si la estuvieran llamando], entonces uno tiene que estar ahí, lo de acá dejarlo acá, ahí yo llegué a ser administradora.” (Entrevistada 1)

- "Salir a trabajar fuera de la casa, usted dice que es un deleite el salir, ¿Por qué es un espacio donde usted se siente más...?"

- "Más libre, pendiente de eso, distrae tanto, me ayuda tanto dedicarme a las flores." (Entrevistada 23)

\section{Dimensión "El trabajo como realización personal”.}

Se observó también la alusión del trabajo como forma de realización personal en algunas cuidadoras, ello ocurrió principalmente en aquellas que alcanzaron niveles de formación y/o jerarquía en lo laboral, y que ello les reportó a la vez una mejora en su situación económica. La situación vivida al momento de la entrevista les hacía rememorar con nostalgia sus logros.

“(...) trabajaba justamente en lo mismo, porque yo estudié secretariado, salí del comercial, hice montones de cosas, trabajé en un montón de cuestiones, cometí muchos errores, me casé muy joven, me dediqué a los hijos, me despreocupé de esa parte mía, de crecer más, en lo profesional crecer más, en esa parte, (...) y antes de eso yo hacía montones de cosas, hacía pintura, trabajaba en negocios, siempre fui como media comerciante, esa es la parte mía, que todavía incluso vendo todo tipo de artículos congelados, vendo aquí, a los vecinos." (Entrevistada 10)

"Yo trabajé por años en una empresa muy importante, trabajaba en ventas y tenía mucha gente a cargo mío, conozco mucha gente.” (Entrevistada 13) 


\section{Dimensión "Medio que otorgaba cierta independencia al cuidador"}

Esta dimensión era referida por las cuidadoras que antes de comenzar a ejercer como tales tenían un trabajo remunerado. La imposibilidad de trabajar les hacía depender de los proveedores principales, situación que les causaba desazón y angustia. Ellas comparaban el pasado, cuando contaban con cierta independencia, con el momento de la entrevista.

- "Sí, y yo no puedo salir a trabajar en nada, porque si uno sabe hacer cosas ¿A quién le vende? Entonces tengo que depender sólo de lo que mi marido me da, y eso que a veces le sacan en cara a uno que le dan plata, un sueldo mínimo es sólo para comer [se emociona]."

- "Eso es duro para usted"

- "Sí pues.” (Entrevistada 20)

En suma, el sobrellevar el desempeño de un trabajo, las tareas de cuidado y las domésticas generaban múltiples costos personales y sociales para el cuidador. Generalmente, la opción entre el trabajo y el cuidado era una de las dificultades más importantes experimentadas por los cuidadores, ya que sus familias no contaban con los medios económicos suficientes como para sostenerse y no depender del trabajo y, en muchos casos, los cuidadores eran los principales proveedores de sus hogares.

La pérdida del trabajo implicaba un empobrecimiento de las familias de los cuidadores, no se debe olvidar que gran parte de las familias entrevistadas eran de escasos recursos.

\section{Propiedad "Salud del cuidador"}

Uno de los aspectos importantes de abordar a la hora de describir al cuidador principal, era el estado de salud en que se encontraba en el momento de la entrevista, cuáles eran las principales patologías que se padecían, si recibían atención de salud y dónde la recibían. 
Prácticamente todos los entrevistados manifestaron estar aquejados de algún problema de salud. Había un grupo de entrevistados mayores de 50 años que padecían enfermedades crónicas $^{82}$ tales como diabetes, hipertensión, dolencias articulares (artritis, artrosis), várices, etc. Ellas se atendían en el sistema público de salud y recibían un tratamiento periódico para estas. No está demás agregar que patologías como la hipertensión arterial se veían agravadas por situaciones de estrés, es decir el cuidar (entendido como una tarea estresante) se constituía en un factor que influía negativamente en el cuidado de la enfermedad.

"Estoy malita, porque tengo artrosis a la rodilla, y donde tanto que camino en el día, porque ella me llama, yo estoy haciendo alguna cosa, llega la familia a verla, no me siento mucho rato, y en la tarde ya... no se me hinchan las piernas pero ya no puedo caminar casi, me duelen. Y tengo diabetes, soy hipertensa, yo digo que por todo eso..." (Entrevistada 5)

Los trastornos, dolencias o enfermedades atribuidas al cuidado por los entrevistados pueden describirse bajo las dimensiones que, a continuación, enumeramos.

\section{Dimensión "Salud física”.}

Los cuidadores reportaban dolores musculares y óseos localizados en zonas que se ven especialmente afectadas por las "movilizaciones" de los dependientes (manos, brazos, espalda, piernas). Dichas dolencias se habían convertido en crónicas y solían afectar bastante al bienestar de los cuidadores.

- “¿Y el lumbago es producto de...?”

- "De los traslados de la negra, de repente amanezco que no valgo un peso, pero hay que salir a trabajar y pa' callao no más.” (Entrevistada 27)

- "Usted me decía que tenía este problema en el brazo y también en la pierna ¿Qué es lo que le ha dicho el médico? ¿Qué es producto de qué?”

- "De lo mismo, debido a la fuerza, a lo que yo hago todos los días (...) y mi papá es grande, porque cuando yo lo paro de la cama, lo afirmo con éste brazo para poder

\footnotetext{
${ }^{82}$ Las patologías más frecuentes son la hipertensión y la diabetes, tanto su atención como su tratamiento farmacológico y de control periódico es gratuito para todos los residentes en Chile a través del Plan Auge.
}

Página $\mid 263$ 
lavarlo por atrás, para lavarle su popín, tengo que hacer la fuerza igual, porque es alto y se pone rígido, y conmigo es más quejón, “ay, ay que me voy a caer” y con mi hijo no lo hace, que se va a caer y que no sé qué, y no porque lo tengo afirmado, tengo una fuerza en mis brazos, a pesar de que lo tengo enfermo, pero tengo fuerzas." (Entrevistada 31)

\section{Dimensión "Salud mental".}

En este ámbito, la variedad de trastornos reportados por las personas entrevistadas era amplio, iban desde los problemas de sueño, el desanimo, la tristeza y cansancio excesivo, hasta la depresión (diagnosticada), estos últimos ejemplificados en la propiedad sobre la personalidad del cuidador. Generalmente, estos problemas no llegaban a ser tratados o no eran considerados como problemas que afectaban la salud del cuidador hasta que se llegaba a situaciones límite, por ejemplo crisis nerviosas.

\section{- “Usted fue al médico?”}

- "Sí, me hicieron exámenes de sangre, de orina, estaba todo bien, el doctor sacó en conclusión que lo mío es puro estrés, el sistema nervioso. Estoy tomando medicamentos, vitaminas y unos relajantes que me dio, me estoy tomando la mitad porque igual tengo que estar atenta al niño, las noches mías son súper preocupadas, yo me puedo acostar a las 10 de la noche, en invierno, y eran las 12, la 1 y yo estaba despierta, y en la mañana me levantaba a las 6 de la mañana, escuchaba un poco la máquina... no duermo tranquila, siempre estoy con la preocupación, y al principio era peor, casi no dormía, pero gracias a Dios había que arreglarse, había que ir aprendiendo, Dios nos dio la fuerza para seguir luchando con él, y como hemos visto que él ha avanzado harto con nosotros, ha ido avanzando harto..." (Entrevistada 24)

- “¿Y su estado de ánimo cómo es?”

- "Mmm, yo he pasado como dos depresiones, que se le va a hacer, me pongo muy sensible, a veces me... sí, estoy sensible. (...) porque aparte de todo la parte sentimental es bien dura, muy dura, porque ver a mi mamá como yo la conocí y como está ahora... es duro para mí." (Entrevistado 25)

También es importante destacar que había entrevistadas que, durante el período que llevaban cuidando a sus dependientes, o antes, habían padecido enfermedades graves 
tales como depresión, cáncer mamario, accidente vascular o glaucoma. Se debe considerar por tanto que su estado de salud no había sido el óptimo como para enfrentar una tarea tan desgastante, y que posiblemente influyera de forma negativa en la recuperación de la salud de quienes la padecían.

- "Aunque por mi enfermedad podría, porque yo tuve un accidente vascular, no tuve grandes problemas lo único que me quedó el ojo que me llora y llora, no se me calma.”

- “YY hace cuánto tiempo que tuvo el accidente vascular?”

- "Hace dos años."

- "Cuando su mamá comenzó con este mal”

- "Sí, se me había caído el párpado, eso fue lo más"

- ¿Y estuvo hospitalizada?

- "Sí, 18 días. Tenía problemas para hablar, no pronunciaba bien, todavía me cuesta, pero no como al principio, se me olvidan las cosas..." (Entrevistada 5)

Finalmente, se debe considerar que al momento de la realización de las entrevistas, 26 cuidadores presentaban sobrecarga intensa (cuadro 10) de acuerdo a la escala de Zarit (Martín Carrasco et al. 1996) $^{83}$. De acuerdo a la literatura especializada, este tipo de puntuaciones se asocian a morbilidades físicas, psíquicas y sociales, generalmente trastornos ansioso-depresivos.

Cuadro 10. Resultados Escala Zarit

\begin{tabular}{|l|l|}
\hline Puntaje final Escala de Zarit & $\mathbf{N}^{\mathbf{0}}$ de cuidadores \\
\hline Ausencia de sobrecarga $(\leq 46)$ & 3 \\
\hline Sobrecarga leve $(47-55)$ & 2 \\
\hline Sobrecarga intensa $(\geq 56)$ & 26 \\
\hline
\end{tabular}

${ }^{83}$ Aplicada después de la entrevista. 


\section{Propiedad "Factores que influyen en la salud del cuidador"}

La salud del cuidador estaba amenazada por la situación de cuidado, lo que implicaba una serie de conductas que llevaban al agravamiento de su condición.

\section{Dimensión "Instancias de respiro o descanso de los cuidadores"}

Los cuidadores prácticamente no tenían instancias de respiro o descanso, su labor les significaba estar prácticamente las veinticuatro horas alerta, incluso por la noche había cuidadores que no dormían.

- “¿Cómo duermes tú?”

- "A saltos, es que durmiendo los chiquillos yo duermo, para mí no hay eso de que la gente se levanta a las 9 de la mañana, o a las 8 a hacer algo, no, yo en ese sentido acomodé mucho de mi vida, mis horarios, mis cosas a los niños. O sea, si Felix está despierto hasta las 6 de la mañana, no importa que duerma hasta las 3 de la tarde, no podré dormir yo hasta las 3 , pero sí hasta la 1 , y me voy a levantar rapidito a hacer almuerzo, si es que mi papá no lo ha hecho, pero de repente paso mala noche... incluso a veces espero que él se duerma para yo terminar algunas cosas, no quiere que trabaje, me toma las manos, me apaga el computador, no quiere que trabaje, quiere que esté con él, ahí en brazos, por eso espero que se duerma y sigo haciendo las cosas." (Entrevistada 18)

\section{Dimensión "Control médico”}

Al consultar a los cuidadores sobre las enfermedades que padecían, evidenciaban la falta de control de éstas, incluso algunos de ellos no se encontraban bajo tratamiento o control, generalmente superponían la atención del dependiente antes que el mantenimiento de su salud, decían que no tenían tiempo para destinar en las esperas para ser atendidos en las consultas ya que dicho tiempo podría interferir en la atención a su familiar.

- “Usted donde se atiende?”

- "Aquí en el consultorio Avendaño, pero ahora llevo como 2 meses que no he podido seguir los controles por estar con ella, porque ella estuvo súper mal.” (Entrevistada 5) 


\title{
Dimensión "Seguimiento de tratamientos o indicaciones médicas"
}

El seguimiento de los tratamientos recomendados por el personal sanitario muchas veces se veía dificultado o simplemente no era posible realizarlo, debido a su incompatibilidad con el cuidado de los dependientes.

\begin{abstract}
"Aparte de eso, tengo hace 40 años una flebitis crónica en mi pierna, que eso requiere de reposo, y es una ironía cuando el doctor le dice a uno: "tiene que tener reposo" con un enfermo de este estilo, en estos momentos me está tratando un vascular, me decía que estar 4 veces en el día con la pierna en alto, todos los días, tenía que bajar de peso, me decía usted no puede trajinar todo el santo día con su marido pero ahora lo va hacer usted, antes era su marido primero, segundo y tercero, pero ahora va a ser diferente, usted primera y segunda, tercero puede ser su marido, porque él está postrado y usted está andando, usted lo está atendiendo, y su marido está bajo su responsabilidad ante el policlínico, así se van a hacer las cosas de aquí para adelante, yo la voy a controlarla, ya sé el problema que tiene, el de su marido, el suyo y vamos a irla tratando. Ahora yo he estado súper bien, mi pierna está flaquita, (...) el vascular me dijo no se va a mejorar, pero aquí la vamos a estar tratando cosa que no se empeore su problema (...) él me dio una serie de indicaciones." (Entrevistada 14)
\end{abstract}

Si consideramos que los cuidadores entrevistados al momento de ser consultados no tenían de alguien que les remplazase en su labor, el deterioro de su salud y la vivencia de enfermedades que les inhabilitaban implicaba que quedaban en total desprotección y se convertían también en dependientes. Sin embargo, la propia situación de cuidado hacía que ellos no fueran conscientes de ello.

- “Usted se siente sobrepasada por la situación?”

- "Sí, mucho, mucho, mucha responsabilidad y no sé si uno lo está haciendo bien o no, mucha responsabilidad, en todo caso él no tiene problemas, está sanito de su popo ${ }^{84}$, no tiene nada roto, nada, él mismo doctor lo ve y le dice: "Estai bien cabro" y ahí me dice: "Eres tú la que tiene que cuidarse, porque este viejo está bien, tiene pa' harto." (Entrevistada 23)

\footnotetext{
${ }^{84}$ Trasero.
} 
Una situación que es importante comentar es que uno de los hombres que cuidaba de su madre era drogadicto al momento de realizar la entrevista, adicto a la pasta base de cocaína $^{85}$. Producto de su adicción él había perdido su trabajo, y la forma de sustento de su grupo familiar. A pesar de formar parte de una familia extensa, el resto de los miembros no manifestaba ninguna intención de hacerse cargo de la madre dependiente, y el cuidador, a pesar de su enfermedad, desempeñaba de forma adecuada su labor de cuidado.

"Por eso le pido a Dios y por eso trato de estar bien, hago cosas buenas, de repente hago cosas malas, pero yo trato de estar bien, porque si yo no tratara, esa plata que yo recibí me la fumo toda, ahora estaría angustiado ${ }^{86}$, y no estaría haciendo esto, pescaría estas mismas tablas y las iría a vender, y me importaría un $p u c h o^{87}$ que mi sobrina se enojara, me importaría un pucho que mi mamá estuviera sola, pero no me he ido al fondo por ella y porque yo tampoco quiero, no quiero llegar al fondo, pero no la puedo soltar porque es una amiga, es mi compañía, me ayuda a estar, me ayuda a seguir (Entrevistado 26)

\section{Propiedad "Experiencia en el cuidar"}

\section{Dimensión "Experiencias anteriores de cuidado"}

De los cuidadores entrevistados, cinco de ellos ya habían cuidado anteriormente de algún otro familiar o habían trabajado como cuidador formal de personas dependientes. Ello nos indica que, aparte de contar con experiencia a la hora de enfrentar la tarea que desempeñaban en el momento de la entrevista, ya tenían un desgaste por ello.

“Aparte que tengo la experiencia del marido de ella, de mi abuelo, a él le dio un
aneurisma, él estuvo mal, entonces ahí eso fue pesado, había que mudarlo, hacerle todo
[¿A él tú también lo cuidaste?] También, con ella, entre las dos. Aparte que anterior a él
le dio Alzheimer, empezó a perder su memoria, salía como a las 3 de la mañana, yo lo
acompañaba para Manser, que era donde él vivía antes e íbamos a caminar como a las 3
de la mañana hasta que él decía "devolvámonos, devolvámonos para la casa”, y así, de

\footnotetext{
${ }^{85}$ Sustancia psicoactiva altamente adictiva y, debido a su composición, es altamente tóxica. Su precio es bajo en relación al de la cocaína, por ello se consume principalmente en sectores socioeconómicos bajos.

${ }_{87}^{86}$ Expresión usada para señalar que se está bajo los efectos de la Pasta base.

${ }^{87}$ Muy poco.
} 
repente se me salía y ahí salía a buscarlo.” (Entrevistada 12)

\begin{abstract}
"[¿¿Usted cómo aprendió, fue a algún curso?] No tampoco, aprendí sola, no sé si la necesidad... porque yo cuidaba enfermos antes, entonces a mí eso me sirvió, pero yo los enfermos que cuidé, en ocasiones tuve muchas veces que mudarlos, (...) hasta ahí trabajé yo, hasta que se enfermó mi mamá, de ahí ya no pude seguir trabajando, pero a mí me gustaba lo que hacía, siempre lo he hecho con amor, entonces eso me ha servido a mí para mi mamá, con más amor lo hago porque es para mi mamá, pero siempre que yo he trabajado con enfermos lo hago con amor, y me termino encariñando con los enfermos, me encariño "N", de hecho que todavía a las viejitas que cuidaba las tengo aquí en mi pensamiento, sueño con ellas a veces.” (Entrevistada 10)
\end{abstract}

\title{
Dimensión "Más de un dependiente a su cargo"
}

Algunos cuidadores, seis del total de entrevistados, cuidaban a más de un dependiente a la vez, generalmente son dos personas dependientes a su cargo. Para la mayor parte de los cuidadores, cinco para ser exactos, uno de los dependientes no requería ayuda en todas las actividades, el cuidador era más bien un apoyo en determinadas actividades.

- "Usted lleva bastantes años cuidando, primero a su esposo..."

- “17 años, y ahora tengo que estar cuidándolos a ellos, 7 años que cuido a mi hijo, más de 12 años que tiene la enfermedad él ya, más o menos la misma edad los dos, pero felizmente la Silvia [su hija] todavía puede caminar, le cuesta pero camina, se lava solita, pero hay que bañarla, ella no se puede bañar sola." (Entrevistada 3)

Existía un caso que resulta excepcional, en donde una cuidadora se hacía cargo del cuidado de tres familiares dependientes, de los cuales dos de ellos eran completamente dependientes y el tercero requería de ayuda en muchas de las AVD, pero, de acuerdo al diagnóstico que la cuidadora relataba, pronto quedaría postrado, al igual que su madre y hermana.

- "Mi mamá empezó con Alzheimer [aproximadamente hace 8 años atrás], el 21 de julio le dio un coma diabético acompañado con un accidente cerebro vascular. (...)"

- “¿Y su hermana?" 
- "A mi hermana a los 6, 7 meses le dio una meningitis, pero ella caminaba, andaba para todos los lados, y a los 60 años más o menos, se cayó, se descaderó, y ahí quedó postrada. Ella tiene 65 años ahora."

- "O sea hace 5 años que la está cuidando, hace 5 años que cuida a su hermana, a su mamá."

- "Y a mi otro hermano que está ahí postrado, o sea él se levanta igual, lo hago que se levante, no lo voy a dejar más postrado de lo que está, porque tiene hemiplejia". (Entrevistada 9)

\section{Síntesis}

Como comentábamos al inicio de esta categoría, nos interesaba realizar un análisis más extenso sobre el cuidador, debido a que es el protagonista de nuestra investigación. En síntesis, el perfil sociodemográfico de nuestros cuidadores estaba marcado por la situación socioeconómica en la que vivían, su nivel educacional era medio-bajo, la mayor parte era ama de casa, y las personas que trabajan desempeñaban empleos precarios. En cuanto a las edades, estás eran variadas, aunque se concentran entre los 40 y 69 años. La mayor parte de ellos estaban casados y cuidaban principalmente de sus padres, siguiendo, en orden descendente, el cuidado de los hijos y de la pareja (esposo). Estos cuidadores tenían bastantes dificultades para que algún otro familiar les reemplazara en ocasiones puntuales, lo más frecuente era que tuvieran solo una persona que les sustituyera. La mayor parte de los cuidadores llevaba menos de diez años realizando dicha labor, y no contaba con ningún tipo de formación para el cuidado.

En relación a los rasgos de personalidad de los cuidadores encontramos un grupo de ellos que poseían una serie de características -estables, maduros, juiciosos, emprendedores, serenos, seguros de sí mismos, con iniciativa y decisión- que les permitían sobrellevar la situación de cuidado de mejor forma. Además, se observa dentro de este grupo a cuidadoras que mostraron ser resilientes. Por otro lado, advertimos una serie de rasgos -inestables emocionalmente, inseguros, aprensivos, inquietos, rígidos- que resultaban desventajosos para enfrentar la tarea del cuidado de forma sana. Y en varias de las cuidadoras se presentan síntomas depresivos (anhedonia, estado de ánimo triste y/o irritable y/o, ansioso, debilidad y/o cansancio físico extremo, 
sentimientos de culpa e ideas de muerte o suicidas). Este análisis se complementa con los resultados de obtenidos al aplicar la escala de Zarit.

En cuanto a las ocupaciones que habían desempeñado los cuidadores, la mayor parte de las mujeres mayores que vivían en el medio rural no había trabajado de forma remunerada fuera del hogar (pero sí realizaron labores en el hogar por las que recibían algo de dinero). Un grupo importante de cuidadores debió abandonar sus empleos a causa de la imposibilidad de conciliar el trabajo remunerado con las tareas de cuidado del dependiente. Sin embargo, había cuidadores que sí trabajaban de forma autónoma o dependiente fuera del hogar, pero lo hacían con bastantes dificultades. El significado que los cuidadores otorgaban al trabajo giraba en torno a cuatro dimensiones: el trabajo como forma de sobrevivencia; el trabajo como medio que les otorgaba cierta independencia; el trabajo como una forma de evasión; y el trabajo visto como forma de realización personal.

La salud de los cuidadores depende mucho de la edad de éstos, pero todos manifestaron estar aquejados de algún problema de salud. Muchos de los que tenían más de 50 años padecían enfermedades crónicas -diabetes, hipertensión, problemas en sus articulaciones-. Los problemas físicos más frecuentes en los cuidadores eran los dolores musculares y óseos. En cuanto a la salud mental muchos presentaban trastornos de sueño, desanimo, tristeza y cansancio extremo, algunos con trastorno depresivo diagnosticado. Entre los factores que influían en la salud de los cuidadores, ellos comentaron la falta de instancias de descanso y el bajo nivel de control médico, respecto a sus dolencias, y de seguimiento de las indicaciones médicas.

Finalmente, existían cuidadores que ya habían desempeñado este rol anteriormente porque debieron cuidar de otro familiar dependiente o trabajaron como cuidadores formales. Por otro lado, otro grupo de cuidadores ejercía esta labor con más de un familiar dependiente a la vez. 


\subsection{CATEGORÍA "LA PERSONA DEPENDIENTE"}

Si consideramos que al momento de decidir la muestra de nuestros entrevistados el criterio principal fue el lugar de residencia, nos encontramos una diversidad enorme a la hora de describir a los familiares que de ellos dependen. Dentro de la variedad existente, creemos conveniente señalar que la edad es una variable importante, ya que gran parte de los entrevistados eran cuidadores de dependientes mayores de 60 años, pero existía un tercio de los cuidadores que lo eran de niños o dependientes que desde su infancia eran cuidados (cuadro 11).

Además, se debe señalar que el número de cuidadores no coincide con el número de familiares dependientes, ya que los treinta y uno cuidadores entrevistados cuidaban de treinta y tres familiares dependientes, eso ocurre debido a que había dos cuidadores que cuidaban a más de una persona ${ }^{88}$, no se debe olvidar además que se entrevistó a las dos cuidadoras de una misma persona dependiente ${ }^{89}$.

Cuadro 11. Edad del familiar

\begin{tabular}{|l|l|}
\hline Edades de los dependientes & Número \\
\hline Menores de 18 años & 7 \\
\hline Entre 19 y 59 años & 6 \\
\hline Más de 60 años & 20 \\
\hline
\end{tabular}

\section{Propiedad "Patologías"}

De acuerdo con lo expresado anteriormente, las edades de los dependientes condicionan mucho el tipo de patología que les ha llevado a convertirse en ello, por esto consideramos útil realizar la clasificación que sigue a continuación del recuento descriptivo de las enfermedades. Se debe advertir que las patologías, que se consignan en el cuadro 12, son las que fueron reportadas por los cuidadores al momento de

\footnotetext{
${ }^{88}$ La entrevistada 9 cuida de su madre y de dos hermanos y la entrevistada 18 cuida de sus 2 hijos.

${ }^{89}$ Entrevistadas 7 y 8.
} 
entrevistarles, y que no necesariamente eran las que habían generado la dependencia en el familiar al que principalmente cuidaban.

Cuadro 12. Enfermedad que sufre el dependiente

\begin{tabular}{|l|l|}
\hline Patología reportada por el cuidador & Número de dependientes \\
\hline $\begin{array}{l}\text { Accidentes cerebrovasculares y consecuencias } \\
\text { derivadas }\end{array}$ & 6 \\
\hline Alzheimer & 5 \\
\hline Demencia senil ${ }^{90}$ & 2 \\
\hline Retraso mental profundo & 2 \\
\hline Parálisis cerebral & 2 \\
\hline Discapacidad física & 3 \\
\hline amputación & 1 \\
\hline Autismo & 2 \\
\hline Enfermedad de Huntington & 1 \\
\hline Enfermedad renal terminal & 1 \\
\hline Infarto cerebral & 1 \\
\hline Meningitis & 1 \\
\hline Mielomeningocele & 1 \\
\hline Preinfarto & 1 \\
\hline Cáncer tiroideo & 1 \\
\hline Próstata & 1 \\
\hline Síndrome de Edwards & 1 \\
\hline Síndrome de Poland & 3 \\
\hline Epilepsia & accide \\
\hline
\end{tabular}

\footnotetext{
${ }^{90}$ Sabemos que este concepto no corresponde a ningún tipo de demencia, pero fue la respuesta recibida al consultar a nuestros entrevistados.
} 


\section{Dimensión "Tipos de enfermedades".}

- Dependencias generadas por enfermedades producto del estilo de vida.

Generalmente, eran los dependientes mayores de 60 años que producto de hábitos de vida poco saludables sufrían de enfermedades o trastornos tales como la diabetes o la hipertensión y que al verse agravadas solían generar grandes discapacidades producto de episodios tales como accidentes cerebrovasculares (ACV), comas diabéticos, ceguera, amputaciones de extremidades, insuficiencia renal. También se incluyen en este apartado a una de las dependientes, que sufría de un cáncer terminal de tiroides.

\footnotetext{
"A él le dio una.... Cómo se llama.... Una trombosis facial, a los tres, cuatro días le dio un infarto cerebral, le sacaron un escáner y le salieron las arterias reventadas del cerebro, estuvo algo de 6 días hospitalizado en el Félix Bulnes, le dieron de alta... él trató de levantarse como en dos oportunidades en el hospital, caminaba, le dieron el alta, y el día sábado aquí le da el accidente vascular y queda con todo el lado izquierdo inmovilizado." (Entrevistada 1)
}

"Mi mamá hace 8 años que está inválida, le amputaron una pierna, producto que le dio una trombosis en la pierna y no la pudieron salvársela, primero le hicieron un by pass, y no les resultó, después le salió una escara en el talón y nunca le sanó, estuvieron como 9 meses curándole el talón pero no hubo caso y cuando la llevaron para hacerle un injerto en el San Juan de Dios, estaba hospitalizada para injertarle y le dio la trombosis en la pierna, así que los doctores dijeron que tenían que amputarle.” (Entrevistada 21)

"Ella tiene un cáncer a la tiroides con metástasis y también tiene algo a los pulmones [le pregunta a la dependiente, su abuela, que está al lado]... la cuestión es que no se sabe. La operaron en el Hospital Barros Luco y ahí hizo un infarto cerebral, estando en el hospital.” (Entrevistada 12)

- Dependencias producto de enfermedades neuropsiquiátricas

También era característico de los dependientes mayores de 60 años el estar afectados por enfermedades degenerativas de tipo neurológico y/o psiquiátrico, la más frecuente era el Alzheimer, existían casos de demencias de tipo vascular y también dos de los 
cuidadores reportaba que su familiar sufría de demencia senil ${ }^{91}$. Se presenta además un caso de la enfermedad de Huntington y otro de un individuo de mediana edad que producto de una meningitis meningocócica quedó con secuelas neurológicas y funcionales importantes.

- "Su mamá tiene Alzheimer, ¿Desde cuándo lo tiene diagnosticado?”

- "Desde de agosto del 2004."

- "En ese momento ella ya manifestaba problemas ¿De qué tipo?"

- "Conductuales, de memoria, se perdió tres veces, ella salía pero después no se acordaba del camino, yo opté por quitarle las llaves porque salía pero después no se acordaba cómo regresar, entonces eso fue lo que comenzó a pasar.” (Entrevistado 25)

"17 años que no tengo a mi esposo, a mi esposo se le murieron las... en esos años el médico decía "las glándulas del cerebro", no sé si existen o tienen nuevos nombres ahora, porque a mi esposo lo hospitalizaron unos días para ver si era operable, y el doctor me dijo "Están todas muertas, si hubieran habido unas tres me habría atrevido a operarle", me dijo "Llévatelo, esta enfermedad es súper duradera, ármate de paciencia para que lo cuides, y me lo vas a traer a control”, entonces podía caminar apoyándolo, pero llegó un momento en que mi esposo estaba con esto así [muestra las extremidades torcidas], sabe que yo en esos años tenía una fuerza... me lo podía solo (...) Ehh, dos [hijos: Mario y Silvia] y mis dos nietos, hijos de él, que tuvo con distintas mujeres, y de la Silvi, las dos hijas mayores, en mi familia hay 6 personas con lo mismo." [Enfermedad de Huntington] (Entrevistada 3)

“A él le dio Meningitis neumocócica, la meningitis le provocó una hidrocefalia secundaria, la hidrocefalia le provocó dos infartos cerebrales bitalámicos, él quedó el primer año con una traqueotomía, con una gastro, tenía que alimentarlo por el estómago, durante todo el primer año, él no puede hablar, escucha entre un 30 y un 40\%, camina entre comillas, más o menos, camina con bastón, hay que estar vigilándolo siempre porque tiene reacciones como un niño, tiene partes de su cerebro que actúan bien, pero hay otras que no son normales para la edad [45 años] que tiene él. (Entrevistada 16)

\footnotetext{
${ }^{91}$ No se logró obtener el dato del diagnóstico exacto del tipo de demencia padecido.
}

Página $\mid 275$ 
- Dependencias producto de enfermedades neurológicas infantiles

Dentro de los cuidadores entrevistados, un tercio de ellos cuidaba a sus hijos que padecían de algún tipo de enfermedad neurológica, que les generaba distintos tipos de dependencia. En este grupo se pueden distinguir aquellos dependientes que ya son adultos (4) y a los niños dependientes (7). Los tipos de enfermedades que padecían eran de variada índole: daños neurológicos al nacer, retraso mental profundo, parálisis cerebral, trastornos del espectro autista (pendientes de diagnóstico al momento de la entrevista), síndromes de Poland ${ }^{92}$ y Möbius $^{93}$, Mielomeningocele ${ }^{94}$, síndrome de Edwards ${ }^{95}$.

\begin{abstract}
"El mayor tiene parálisis cerebral, es tieso, en fin no tiene posibilidades de caminar ni de valerse por sí solo, porque fue muy grande el daño que tuvo al nacer, el más chico está en veremos todavía, el diagnóstico, está con genetista, neuróloga y todo eso por algún trastorno de la comunicación, pero no sé en realidad.” (Entrevistada 18)
\end{abstract}

"Yo lo cuido buu, es que mi hijo de guagüita nació enfermito, él tiene un retraso mental y epilepsia, así que mi hijo no... lo traté en la Teletón, lo traté en Erasmo Escala y todo." (Entrevistada 22)

“El Luis nació con dos síndromes de Möbius con Poland, el Möbius no fue tanto lo que le perjudicó, fue más el Poland, que es la parte respiratoria, nació con el pectoral hundido, con pie box, paladar fisurado o sea fueron muchas complicaciones las que él tenía, estuvo tres meses en la UCI del Barros Luco y después estuvo 4 meses en la UCI del Exequiel y 1 año 1 mes en el Josefina Martínez que es un hospital para niños con problemas respiratorios." (Entrevistada 24)

\footnotetext{
${ }^{92}$ El Síndrome de Poland es una enfermedad de carácter raro y congénito en el que se ve afectado el desarrollo muscular, que asocia grados diversos de anomalías torácicas y alteraciones del miembro superior homolateral.

${ }^{93}$ El síndrome de Möbius o de Moebius es una enfermedad neurológica congénita extremadamente rara. Dos importantes nervios craneales, no están totalmente desarrollados, lo que causa parálisis facial y falta de movimiento en los ojos. Los efectos clínicos son múltiples, entre otros, dificultades iniciales para tragar que pueden llevar a déficit de desarrollo y los problemas que conllevan la falta de sonrisa, el babeo, y el habla y la pronunciación defectuosas.

${ }_{94}$ Es un defecto de nacimiento en el que la columna vertebral y el conducto raquídeo no se cierran antes del nacimiento. Esta afección es un tipo de espina bífida.

${ }^{95}$ El síndrome de Edwards, también conocido como trisomía 18, es un tipo de aneuploidía humana que se caracteriza usualmente por la presencia de un cromosoma adicional completo en el par 18.
} 
“Alonso tiene retraso del lenguaje, todavía no tiene un diagnóstico definitivo de lo que él tiene, pero es muy posible que tenga autismo. Alonso en muchas cosas está recién despertando de todo, tiene 6 años, él hasta el año y medio era un bebé normal, decía sus palabras, pero al año y medio, 2 años empezó a retroceder en todo, todo lo que él decía ya no lo decía, todo lo pedía por señas. (Entrevistada 29)

"José tiene una trisomía 18 (síndrome de Edwards), la trisomía 18 son los niñitos que no ven, no escuchan, no hablan, son múltiples enfermedades, tiene un riñón dilatado, una escoliosis alta y una baja, traía 4 soplos y el ducto, no traía cámara gástrica. (Entrevistada 30)

- Dependencia producto de accidente

Sólo uno de los cuidadores entrevistados se hacía cargo de un familiar que padecía una paraplejia producto de un accidente de tráfico.

- "Él tuvo un accidente en camión, se volcó en la carretera, (...) bueno hace aproximadamente 8 años."

- “¿Él no puede caminar?”

- "No, de la cintura hacia arriba tiene todo el movimiento, todo, todo pero de la cintura hacia abajo no, lo pusieron en hartos tratamientos, hartas cosas, pero no." (Entrevistada 17)

\section{Dimensión "Pluripatologías/comorbilidad”}

Fue frecuente observar en los dependientes mayores una multiplicidad de patologías asociadas generalmente al padecimiento de diabetes, hipertensión arterial e índices de colesterol elevados. Dichas enfermedades habían generado en los dependientes situaciones tales como ACV, insuficiencia renal, problemas cardíacos, etc.

- "Mire él tenía la diabetes, pero la tenía demasiado avanzada, lo operaron de la próstata y él quedó mal." (...)

- “¿Y su esposo aparte del problema que tiene de la próstata, de que no controla, tiene 
algún problema de visión o de movilidad?"

- "No pues, no tiene él fuerza para pararse, hay que tomarlo como un niño chico, hay que mudarlo, todo, tomarlo de la silla a la cama, porque él no tiene fuerza para estar parado." (Entrevistada 4)

- "Ella [la dependiente, su madre] tiene hipertensión, depresión, ahora se le declaró la diabetes" (...) ella no, no quiere, está hundida ahí, más que estos últimos días ha pasado puro durmiendo, se levanta de la silla y está durmiendo ahí.

- "A lo mejor es por los medicamentos."

- "No sabe usted cuántos medicamentos ha tomado, cuantos médicos ha visto, mi hermana menor, que ella también está pendiente, la ha llevado a varios médicos, le han dado cualquier remedio para el dolor, pero no, es el dolor que tiene en el muñón, justo arriba de la rodilla [síndrome del miembro fantasma], y ahora ya último dice que está cansada, imagínese tantos años sentada, porque uno un rato estar sentada se cansa." (Entrevistada 21)

\section{Dimensión "Discapacidades"}

Las enfermedades padecidas por los familiares de los cuidadores también pueden ser vistas desde el punto de vista del grado y del tipo de dependencia.

La mayor parte de los familiares dependía por completo de sus cuidadores, de un total de treinta y tres dependientes, veinte de ellos eran dependientes totales. Con ello se entiende que no podían ejecutar ninguna de las actividades básicas de la vida diaria ${ }^{96}$, acciones como bañarse, vestirse, usar del inodoro, trasladarse, control de esfínteres y alimentación.

- "Mi mamita tiene Alzheimer, hace como 10 años o más, pero ahora a ella le ha avanzado bastante."

- “Su mamá hay algo que pueda hacer por sí misma?”

- "Nada, nada." (Entrevistado 26)

“No, no, la Marta nació sanita, ella se enfermó a los 2 meses de edad le dio una

${ }^{96}$ De acuerdo al Índice Katz.

Página $\mid 278$ 
encefalitis herpética y eso la dejó con graves secuelas, si la Marta tiene un 85\% [de invalidez]... es severo lo de ella, pocas posibilidades tiene... de hecho ahora se sienta, antes no se sentaba, ahora aprendió a sentarse solita." (Entrevistada 2)

"Él tiene retardo mental profundo, él no hace nada, lo único que hace solo es comer pan, pero yo se lo doy con miedo porque como es enfermo se lleva mucho pan a la boca, las demás cosas no, (...) así que yo le doy todo, lo tengo que mudarlo, bañarlo, todo, él tiene 37." (Entrevistada 15)

El resto de los familiares dependientes presentaba dependencias en algunas de estas actividades, por ejemplo los niños que presentaban trastornos de comunicación debían ser orientados en todo momento, podían comer, vestirse, bañarse solos pero necesitaban de constante supervisión. Así también les ocurría a aquellos familiares que estaban en etapas iniciales de demencias, ellos tenían que ser orientados en el desempeño de las tareas más simples.

- “AA él le cuesta comunicarse con todo el mundo?"

- "Comunicarse verbalmente"

- "Pero con señas, órdenes, ¿Él te entiende?"

- "Sí, me entiende (...) el Felix igual se atiende solo, cuando quiere o lo que quiere él, pero igual hay que mudarlo, bañarlo, vestirlo, todo, las galletas se las comerá solo, la bebida se la tomará solo, pero cuando está de ánimo come bien, solo, pero si no, hay que dársela, hay que atenderlo.” (Entrevistada 18)

"El Alonso no, ya no usa pañales, pero a veces uno sabe cuando tiene ganas de ir al baño pero otras veces se hace, entonces tengo que andar siempre con la mochila con ropa. (...) ¿Sabe qué es lo que le pasa al Alonso? cuando hay mucha gente él se descompensa." (Entrevistada 29)

Dentro de las dependencias parciales, también se daba el caso de aquellos que dependían sólo en lo físico de sus familiares, es decir podían tener afectadas las 
funciones tales como la movilidad, el uso del inodoro, la continencia, el vestido, el baño, pero eran autónomos desde el punto de vista cognitivo.

- “Qué es lo que tiene su papá?”

- "Un accidente vascular, él no habla, está consciente sí, pero no habla, usa pañal, no camina, mueve el lado izquierdo, ahora ya se afeita solo, le paso la máquina y él se afeita."

- “¿Él puede comer solo?”

- "Ahora sí, hace... de septiembre que come solo, porque antes se alimentaba por sondas, por la nariz." (Entrevistada 23)

Las dependencias estaban íntimamente relacionadas con las secuelas de las enfermedades padecidas y con el deterioro que sufrían quienes estaban postrados. Debido a la diversidad de patologías de los dependientes, resultaban difíciles de clasificar, pero entre las más frecuentes destacamos: en lo físico, imposibilidad o dificultades de movilidad, pérdida de destreza con las manos, incontinencia de esfínteres, úlceras por presión; en lo mental, síntomas depresivos (trastornos del sueño, del apetito, irritabilidad, etc.), trastornos de comunicación (falta o pérdida de lenguaje), trastornos asociados a la demencia (deterioro del ritmo sueño-vigilia, comportamientos violentos, pérdida de la memoria reciente, confusión mental).

\section{Dimensión "Gravedad de las patologías"}

De acuerdo a los testimonios entregados por los cuidadores, en relación a los episodios más complicados vividos por sus familiares, seis de ellos estuvieron en peligro de morir debido a las patologías que padecían.

- “Su niño qué edad tiene ahora?”

- "Tiene 6 años 10 meses. Mi hijo traía 4 soplos y el ducto, me dijeron que no lo iban a operar, porque era chiquitito, chiquitito y de corta vida, de hecho me dijeron que al nacer iba a morir. (...) mayor esperanza no tuve de él, me dijeron que moriría en el vientre, el doctor que lo veía me decía que el niño no pasaba de los 15 días, después los 20 días, después un mes, después 6 meses, después del año no pasa, y el niño seguía acá, seguía acá.” (Entrevistada 30) 
"Le dio una insuficiencia renal terminal, entonces el médico que la vio me mandó a hacer los exámenes (...) y el médico le dijo "mira a tu mamá le dio una enfermedad a los riñones que los tiene sequitos, entonces ella no les dura 48 horas si ustedes no la llevan a... le voy a decir francamente que si ustedes la llevan a la posta [servicio de urgencia público] se la van a devolver, ella está grave y eso es verdad". Le dijo "Si ustedes tienen algo de lo que puedan echar mano, y pueden llevarla a la Católica [Clínica privada] ahí van a poder hacer algo y salvarla”, así que como yo tenía un negocito le dije llevémosla, de alguna manera el señor cierra una puerta pero abre una ventana, así que la llevamos allá, llegamos como a las 9, a las 10 y media ya la estaban dializando, estuvo un mes ahí, hospitalizada, 15 días en la UTI (Unidad de Tratamiento Intensivo) mal, mal." (Entrevistado 28)

Asimismo, y de acuerdo a la misma fuente citada, las enfermedades de veinte de los familiares de estos cuidadores tenían la característica de ser progresivas.

"O sea emocionalmente sí, porque igual, dentro de todo es mi mamá, yo siempre he estado con ella, y nunca había actuado de esa forma, yo me empecé a dar cuenta de que se estaba enfermando y bueno en todo ese período se empezó a agravarse más, después ya perdió la movilidad, le costaba caminar, yo la sacaba a comprar el pan, se cayó un par de veces, perdió la estabilidad, el sistema como que le anduvo fallando y después ya no podía caminar nada.” (Entrevistado 25)

- “CCómo usted ve su futuro con su mamá?"

- "Me da miedo, de que no pueda comer y le tengan que poner mangueras, [1lora] yo la voy a cuidar, pero voy a sufrir por ella, tengo temor, yo no quiero que ella sufra, que si Dios se la va a llevar que se le lleve, pero que no sufra, que esté bien, sin ninguna herida, igual no quisiera que se fuera, pero se tiene que ir, acepto que se vaya, pero que se la lleve bien, en sueños, tranquila, en paz." (Entrevistado 26)

\section{Propiedad "Vida antes y después de la enfermedad"}

En la mayor parte de los dependientes adultos, el cambio en sus vidas después de la enfermedad fue rotundo, negativo y progresivo, es decir, su salud empeoraba y se deterioraba conforme pasaba el tiempo. 
“(...) porque yo siempre jugaba con él, jugábamos a hacer gallitos, entonces lo pillaba y ¡Paf! Le ganaba. Ese día que llegó hacía gallitos... al otro día cuando se le murió el lado izquierdo ahí el ya no hacía gallitos, y ésta mano, la izquierda, se le enroscó, así la tiene [muestra forma de cuña].” (Entrevistada 1)

"Sí, porque él está como un niño, no es lo mismo que antes que él se podía valer por sí solo, años atrás, tomaba una escoba, barría la vereda en la casa de él, todo, él se hacía sus cosas, iba al baño solo, ahora ya no, ahora ya está en la pura cama no más, no quiere estar... de la silla a la cama, (...) no está sentado ni siquiera 10 minutos." (Entrevistada 31)

En el caso de los dependientes que lo eran desde niños, en muchos casos, se producía el fenómeno a la inversa, es decir lograban evolucionar desde una deteriorada situación de salud a un estado algo más óptimo, producto de las intervenciones (medicas, educativas) que habían recibido.

- "No, ella, ella más que nada, es esfuerzo de ella, es bien empeñosa, la Marta le pone harto empeño, igual que aprendió a tomar cosas, las toma, las patea, hay cosas que no hacía."

- "Y usted ha visto que ha ido avanzando"

- “Sí, poquitito, pero ya no está así, puro acostada.” (Entrevistada 2)

No debemos olvidar que la vida de los dependientes era relatada por sus cuidadores, por tanto tenemos que considerar que pudieran existir un sesgo o filtro en sus relatos y los énfasis que daban a determinados temas. Es el caso de aquellos dependientes que padecían enfermedades que habían sido generadas por sus hábitos de vida, los cuidadores ponían el acento en que sus familiares hicieron caso omiso a las advertencias recibidas al respecto, y de cierta forma se "buscaron" la enfermedad.

“Mire los dos ataques grandes que le dieron, él ahí en las carreras ${ }^{97} . "$ (Entrevistada 1)

"Claro, él se sintió bien y empezó a ir a la cancha, a salir, comía asados, tomaba, comía cosas que no debía comer "Papá le va a hacer mal”, porque él tenía su dormitorio arriba

\footnotetext{
${ }^{97}$ Se refiere a los lugares donde se realizan apuestas para carreras de caballos, en los alrededores de estos locales existen bares y se suele asociar la adicción a las apuestas con la adicción al alcohol.
}

Página $\mid 282$ 
antes y pasaba derecho a acostarse porque sabía que yo le iba a decir algo, "Papá estas con remedios, te va a hacer mal", discutíamos siempre, los domingos sobretodo, salía a las 9 de la mañana y no llegaba hasta las 9 de la noche, entonces apenas se sintió bien siguió haciendo todo lo que hacía antes, diciéndole uno que no debía hacerlo, y está como está ahora." (Entrevistada 23)

Otro aspecto importante que destacaban los cuidadores, en sus relatos, eran las características de las personalidades de los dependientes, los roles que cumplían en sus familias, en sus entornos, antes de sobrevenir las enfermedades y dependencias. Si bien no todos los cuidadores abordaban este aspecto en sus entrevistas, a través de los relatos de los que sí lo hacen se pueden observar dos perfiles o roles en los dependientes mayores.

En el caso de los varones mayores dependientes, se observaba que predominaba el rol del hombre proveedor, que desarrollaba su vida en el espacio público, con muy poca participación en el ámbito privado, en el hogar, lo que se constituía en una enorme dificultad a la hora de jubilarse o quedar incapacitado, ya que debía permanecer todo el tiempo en un lugar que no le era propio.

\footnotetext{
- “¿Él era responsable?”

- "Sí, siempre mi plata"

- “Aseguraba la plata de la casa, lo que había que pagar?”

- "Eso lo veía yo, él daba no más." (Entrevistada 1)
}

\begin{abstract}
"Yo por ejemplo acá en la casa me dedicaba, César se pagaba, me pagaba a mi [ríe], me daba la plata y yo era la encargada de pagar las cuentas, distribuir todo, ir a comprar, yo me preocupaba si las niñitas estaban enfermas, de todo (...) entonces yo me preocupaba de todos los gastos, yo me organizaba, en ese sentido organizarme acá en la casa no me costó y yo le ayudaba a hacer cosas aquí en la casa a César.” (Entrevistada 16)
\end{abstract}

Un segundo rol que aparecía de forma destacada en los discursos de los cuidadores, sobre las mujeres mayores dependientes, era el de mujeres-madres que tuvieron que sacar adelante a sus familias en ausencia de una pareja, de una figura masculina que 
ayudara en la labor de crianza de los hijos o en el mantenimiento del hogar.

- “41 años, mi mamá quedó viuda joven, yo tenía 10 años cuando él murió"

- "Su mamá tuvo que sacarlos adelante a todos."

- "Sí, si yo le cuento a mi hija, si nosotros éramos pobres, pobres, pobres." (Entrevistada 9)

"Ella era la que si se echaba a perder la llave ella la arreglaba, o buscaba al maestro, todas esas cosas, si había que pintar ella era la que se ponía a pintar, todo eso, y es que yo era el que proveía todo, ahora no, ahora he tenido que estar pintando, (...) eso sí ella toda su vida ha sido enferma de la limpieza, y así y todo como tengo ella me pone un 4 o un 5 [risas].”(Entrevistado 28)

Este rol se reflejaba también en el resto de la descendencia familiar, ya que muchas de esas mujeres realizaron también la labor de crianza de sus nietos. No debemos olvidar que ellas eran de extracción humilde y para poder sobrevivir tuvieron que trabajar al mismo tiempo que cuidaron de sus hijos y/o nietos.

\begin{abstract}
“Trabajólica, así yo la defino, trabajólica porque hasta el último día ella tempranito andaba y le hacía la leche a mis hijos, estaba ella con sus mamaderas ${ }^{98}$ ahí, prácticamente ella a nosotros nos... nosotros dependíamos mucho de ella, y eso ella echa de menos, el quehacer, es inquieta." (Entrevistada 12)
\end{abstract}

"Tuvo 8 [hijos] y los nietos se quedaron con ella, (...) mi mamá los crió, dentro de su pobreza, porque antes nosotros éramos súper pobres, mi papá se enfermó joven de cáncer, murió a los 62 años, y mi mamá quedó con la parcela, que recién se la habían entregado, y encalillada ${ }^{99}$ hasta los ojos, y con los chiquillos todos chicos, porque mi hermano menor quedó de 16 años.” (Entrevistada 20)

Los cuidadores relataban también episodios que eran percibidos como degradantes o que causaban menoscabo al dependiente. Estos sucesos estaban relacionados con el deterioro que sufrido, producto de las enfermedades que padecidas.

\footnotetext{
${ }^{98}$ Biberones

${ }^{99}$ Endeudada.
} 
- “YY él se da cuenta? ¿Él fue pudoroso cuando más joven? Me refiero a que teniendo hijas, hay muchos hombres que..."

- "No si él... cuando está lucido a veces llora, por decirle que cuando las niñas estaban chicas, ellos nunca lo vieron en calzoncillos, porque pa' empezar nosotros teníamos esta pura pieza grande, la cama de ellas cada una y la cama de nosotros, "Papá me voy a acostar", el papá se daba vuelta, o que él se fuera a acostar "Ya, me voy a acostar" ya ellas se tapaban la cabeza." (Entrevistada 1)

- "Sí [tenía olvidos], y escondía las cosas, escondía las cosas de valor, las guardaba, tenía ese delirio de persecución, "Que yo estoy hedionda", "Pero si no tienes ningún olor, estas rica, no tienes ningún olor", "No, tú estás mintiendo", entonces no... Mira el comienzo de la enfermedad de mi mamá fue atroz, fue horrible."

- "Cuando tenía períodos de consciencia e inconsciencia."

- "Claro, yo a veces lloraba junta con ella, fue la peor etapa." (Entrevistada 10)

\section{Propiedad "Influencia de los tratamientos en el estado de ánimo del dependiente".}

Las personas dependientes, debido a las enfermedades que padecían estaban sujetas a continuas intervenciones médicas que iban desde la administración de medicamentos y utilización de ayudas técnicas, pasando por la rehabilitación e ingresos médicos, hasta las intervenciones quirúrgicas. Dichas situaciones generaban en el dependiente cambios en su estado de ánimo, que podían llegar a convertirse en una patología más a tratar.

"Estuvo casi el mes [ingresada], estaba desesperada ella porque tampoco estaba acostumbrada a esto, fue totalmente imprevisto lo que sucedió, no estaba en esto para que... no lo imaginábamos. (...) Esto fue en mayo, como el 22 de mayo, así que ahí empezamos con las rehabilitaciones, se bajonea también, pero también está con antidepresivos, yo digo que le estamos dando todos los cuidados que necesita." (Entrevistada 12)

“(...) y después la curación de la escara, eso que sí que fue tremendamente, más allá de lo que nosotros podíamos hacer aquí, llevándolo a control allá, ya tiene una escara, lo primero que hacíamos era dar aviso altiro a la enfermera allá que lo veía, porque volver acá al hospital era terrible, lloraba igual como si fuera un niño chico, cuando le decían:

Página $\mid 285$ 
"Sabe don Lino que lo vamos a dejar aquí" se le venía el mundo encima, pero para nosotros era más... que estuviera en el hospital que están todos los medios, más que lo que uno puede tener en su casa, que estuviera allá, para que sanara y así nos llevábamos con él, allá, acá, allá acá, todo un proceso, súper largo.” (Entrevistada 17)

\section{Propiedad "Comportamiento actual"}

De acuerdo al testimonio de los cuidadores, las personas dependientes que habían sufrido cambios en su carácter o comportamiento generalmente lo relacionaban con las enfermedades que padecían. Los más notorios eran los cambios que se observaban en los dependientes que padecían demencias o enfermedades neurológicas.

"No fíjate, mi mamá tuvo su enfermedad no con tanta violencia, como yo ya había cuidado enfermos, en etapas que son... no propiamente Alzheimer, pero sí había cuidado yo demencia senil, pero mi mamá no fue muy agresiva, tuvo momentos violentos pero muy poco, por ejemplo cuando se hacía, yo la sacaba a caminar y de repente llegaba y se... yo te hablo de un comienzo, y de repente se hacía caca, y yo la retaba, pero mamá cómo no te aguantaste un ratito si estamos llegando a la casa, y ahí ella se ofuscaba, era una manera de defenderse, de ponerse violenta conmigo, pero yo la apaciguaba, me portaba... me tenía respeto en ese aspecto.” (Entrevistada 10)

“(...) a veces sí, es que mi hermano es el que más me estresa, es mandón, esos días que estaba en el hospital estaba fascinada con ellas dos [su madre y hermana, también dependientes], súper tranquila, relajada, me acostaba temprano, 10, 10 y media, y ahora con él no, porque a las 11 de la noche termino de darle los remedios a él (...) es como cabro chico, igual que cabro chico, no se da cuenta de lo que hace, entonces él me estresa." (Entrevistada 9)

"En el policlínico le daban Alprazolam, para tranquilizarlo pero resulta que fue peor darle el Alprazolam se ponía más agresivo. (...) Sí, se ponía muy agresivo, muy grosero, también ha llegado a ese extremo porque qué no me ha dicho.” (Entrevistada 31) 
También se observaban cambios en el estado de ánimo, generalmente tendientes a estados depresivos en aquellos dependientes que sólo padecían discapacidades físicas.

\begin{abstract}
"En la silla no más, es que sabe lo que le pasó cuando le amputaron la pierna ella se vino abajo, nunca aceptó, ella no quiso poner, pienso yo, de su parte porque siempre que le íbamos a ayudar a pararle, a hacerle cosas ella decía que no, que le dolía mucho, y hasta el día de hoy llora que le duele, y ahora está postrada en la silla. (...) De ánimo a veces está decaída, a veces quiere comer, a veces no, así pasa. (...) incluso antes cuando estaba bien le pasábamos cositas para que hiciera, pero ya después se quiso decaer y ya no, ahí pasa agachadita, sentadita en la silla." (Entrevistada 21)
\end{abstract}

\footnotetext{
"No, duerme bien, lo que sí de primeras dormía todo el día, y de noche se pasaba tosiendo, era más para llamar la atención, no quería ver tele, nada, ahora no, le prendo la tele y, para que no duerma toda la tarde porque si no, se lleva pensando, piensa, mira para afuera, se siente inútil y cómo era, tan activo.” (Entrevistada 23)
}

\title{
Síntesis
}

Las personas dependientes que eran cuidadas por nuestros entrevistados tenían características muy diversas, en cuanto a edades podemos identificar un grupo importante de mayores de 60 años (veinte personas), otro con siete niños menores de 18 años y seis personas en edad adulta. Las patologías padecidas, sobre todo en el caso de los mayores, estaban determinadas por la edad, mayormente ACV, enfermedad de Alzheimer y otras demencias. Entre los familiares adultos hay dos casos de retrasos mentales profundos y para el resto de los dependientes no existe un patrón que se repita. Las dependencias pueden ser clasificadas de acuerdo a las enfermedades $\mathrm{o}$ circunstancias que la originaron en: dependencias generadas por el estilo de vida llevado por el dependiente, dependencias producto de enfermedades de tipo neuropsiquiátricas, dependencias producto de enfermedades neurológicas infantiles y dependencias producto de accidente. Era frecuente en los dependientes mayores el desarrollo de pluripatologías. En cuanto al grado de dependencia, y de acuerdo al testimonio aportado por los cuidadores, veinte de los familiares tenían una dependencia total del cuidador, el resto tenía afectadas algunas de las ABVD y/o necesitaba de supervisión constante del 
cuidador. La gravedad de las patologías de los familiares en algunos casos había estado en el límite de la muerte, además en veinte de los casos eran enfermedades degenerativas.

En el caso de las personas mayores la enfermedad implicó un cambio negativo, drástico y/o progresivo en sus vidas. Los niños y adolescentes dependientes tenían mejor evolución y generalmente progresaban desde una situación crítica a un cierto bienestar y mejora de sus patologías. Los roles desempeñados por los dependientes se veían especialmente afectados, especialmente en el caso de los hombres adultos y mayores que comúnmente se desempeñaban en los llamados espacios públicos, pasaban a habitar el ámbito privado del hogar y dejaban de ser los proveedores y responsables de éste. En el caso de las mujeres dependientes, se relata que sus vidas estuvieron marcadas por el sacrificio de cuidar a sus familiares (hijos, nietos, padres), muchas de ellas solas o con una figura masculina ausente.

Las enfermedades padecidas y/o los tratamientos a los que fueron sometidos los familiares generaban cambios negativos en sus estados de ánimo. En el caso de quienes sufrían enfermedades mentales o neurológicas los cambios en el comportamiento del familiar-agresividad, por ejemplo- eran atribuidos por el cuidador a la enfermedad. Los dependientes físicos tendían a manifestar comportamientos más depresivos.

\subsection{CATEGORÍA "CONSECUENCIAS DEL CUIDADO EN LA VIDA DEL CUIDADOR"}

En el análisis de la experiencia de cuidar a otros, encontramos que las personas que fueron entrevistadas nos entregaban su versión sobre los costos que había implicado para sus vidas esta tarea. Se pudo distinguir dos "individuos" a los que el cuidado afectaba y que, de acuerdo a la estructura de análisis, fueron considerados subcategorías. Al final de esta categoría se trata como una subcategoría el tema del maltrato en la situación de cuidado, como una consecuencia de éste. 


\section{SUBCATEGORÍA “Consecuencias generales para el cuidador por el apoyo a su familiar"}

La principal consecuencia negativa del trabajo que el cuidador realizaba, para apoyar a su familiar, era el deterioro que sufría su salud, entendida ésta en sus aspectos físicos, mentales y sociales. Un factor común, en el deterioro de la salud en sus múltiples dimensiones, era la falta de tiempo del cuidador para dedicarse a sí mismo.

\section{Propiedad "Salud física"}

El primer, y más mencionado, efecto negativo del cuidado estaba referido al deterioro de la salud física del cuidador. Prácticamente todas las personas entrevistadas reportaron algún malestar o enfermedad física atribuible a su tarea como cuidador.

\footnotetext{
"Y desde ahí yo lo he cuidado, lo llevaba al baño, lo atendía, lo lavaba, lo vestía, lo atendía más que ahora, porque estaba en silla de ruedas, estaba en silla de ruedas y para allá, para acá, incluso yo quedé afectada de la columna por eso, mucho.” (Entrevistada
} 11)

Se debe considerar que parte importante de los cuidadores eran personas mayores que también padecían patologías. Éstas se veían agravadas por la tarea del cuidar, ya que tenían dificultades para seguir las indicaciones médicas y/o no tenían un control médico adecuado; esto último sucedía porque no tenían tiempo para ello. Incluso, ellos manifestaban haberse sentido temerosos al asumir la tarea del cuidado de sus familiares por su propia situación de salud y por la falta de apoyos.

Además, los traslados y el trajín diario constituían una importante causa para que los entrevistados vieran deteriorada su salud física, incluso los hombres entrevistados, a pesar de ser jóvenes, veían resentido su bienestar. Generalmente, ello se debía a que no manejaban técnicas apropiadas de movilización y/o a que no contaban con entornos, ni aparatos que hicieran accesible la atención de sus familiares.

\footnotetext{
"Sí, sí, por ejemplo ahora mismo tengo adolorido todo éste brazo, porque tener que levantarla, con el peso de ella y todo. Una vez nos caímos, gracias a Dios yo caí primero y ella cayó encima mío, dolor de espalda, me ha pasado eso, que ando adolorido.”
} 
Capítulo VI. Análisis

(Entrevistado 25)

\title{
Propiedad "Salud mental"
}

La afectación de la salud mental era otro aspecto aludido por nuestros entrevistados, el exceso de trabajo hacía mella en este aspecto de la salud de los cuidadores.

\begin{abstract}
"A mí me habían dicho que esto del ojo era por tensiones que se le acumulaban a uno, el estado nervioso, la tensión de mi marido, me levantaba a las 8 y media y no paraba hasta las $11 \mathrm{y}$ media, que los remedios, que la comida, que todo, yo le corto el pelo, lo afeito a mi marido... entonces el día a mí se me hacía..." (Entrevistada 14, 13:13)
\end{abstract}

Las dificultades y decepciones vividas por los cuidadores, en el esfuerzo porque sus dependientes tuvieran bienestar y pudieran desarrollar las habilidades con las que contaban, afectaban el estado de ánimo de los cuidadores, generando trastornos.

\footnotetext{
“Claro, eso es lo que quería la “Fono ${ }^{100 ”, ~ y ~ r e c o r r i ́ ~ a c a ́, ~ t o d o ~ e l ~ s e c t o r, ~ V i ́ n c u l o, ~ C h a m p a, ~}$ Paine y no, en todos [los colegios] me cerraban las puertas, no lo recibieron una porque usaba pañales, otra porque no hablaba, eso fue un calvario para mí, ahí uno se da cuenta de la discriminación de la gente, yo tampoco les pedía a ellos que le hicieran nada, porque yo me iba a quedar afuera, si había que entrar a mudarlo yo iba a entrar a mudarlo, pero tampoco se me dio esa posibilidad, entonces eso ha sido una depresión constante.” (Entrevistada 29)
}

La exposición a situaciones de violencia generadas por el dependiente -principalmente de los que padecían algún tipo de demencia-, generaban sentimientos de tristeza e impotencia en los cuidadores de este tipo de dependientes.

"Mire me afecta, hay días que me caen las lagrimas de verlo, por qué el ser humano tiene que ser así, porque yo lo miro, le hago cariño, a veces cuando está de malas no le hago, o me trata mal y lo dejo, de primeras me salía llanto, me sentía mal cuando me trataba mal, pero después pasó, me acostumbre a que si uno solo hace las cosas por qué me voy a sentir mal, es mi papá, está enfermo, hay que entenderlo. Así que ahora me

${ }^{100}$ Fonoaudióloga, logopeda. 
sube, me baja ${ }^{101}$ como quiere, me trata mal, ahora lo dejo no más, salgo del dormitorio y lo dejo, que se calme solo.” (Entrevistada 31)

La falta de tiempo, de períodos de respiro, generaba múltiples consecuencias en el estado anímico de los cuidadores. Una de las consecuencias más mencionadas era el sentimiento de que sus vidas se veían postergadas en el presente e impedía realizar proyecciones futuras.

- "¿Qué siente que ha postergado de su vida?"

- "Tener una familia, por ejemplo, tener más vida social, tener un trabajo, tener una casa propia, pero prefiero cuidar a mi mamá.” (Entrevistado 25)

Además, su tarea como cuidadores, y la dedicación exclusiva a esta tarea, les impedía realizar actividades -laborales o formativas- que les permitieran mejorar sus condiciones de vida y, por consiguiente, las de sus grupos familiares, situación que generaba en ellos sentimientos de frustración.

"Mi vida personal la dejé totalmente de lado, a veces tengo que dejar cosas de los niñitos por estar cuidándolo a él [su padre dependiente], y la Ana me dice: "Mamá, si tú hubieses estado trabajando...", yo le digo: "Ana, yo hubiese estado trabajando en el municipio", porque le hice la campaña al alcalde que hay ahora, pero cuál es el problema, una persona menos de $\$ 250$ mil no nos va a pedir, digo yo, por cuidar a mi papá y el quehacer de la casa, porque esta casa es bien grande, y tengo avecitas, entonces es complicado, yo le digo “¿Cómo?” Incluso estaba lavando las camisetas del club [de fútbol] y con eso me ayudo, porque la Ana tiene que sacar fotocopias, tiene que anillar cosas, documentación y se paró el campeonato, así que estoy media escuálida ${ }^{102}$, pero ella me decía "igual vamos a salir adelante." (Entrevistada 19)

Las limitaciones de tiempo también provocaban que el cuidador renunciara a actividades que para ellos resultaban fuente de disfrute, esparcimiento y descanso, y por consiguiente también se producía una afectación en la salud mental.

- “AA usted el hecho de cuidarla a ella le ha afectado en su estado de ánimo?”

\footnotetext{
${ }^{101}$ Le insulta.

${ }^{102}$ Sin dinero.
} 
- "A veces, porque tú quieres hacer cosas, quieres hacer más cosas, a lo mejor realizarte en otras cosas, a mi me gusta mucho aprender a hacer cosas. (...) estaba en un taller que era de tango y asistía a unos talleres de pintura en madera, Bauer, y todo eso yo lo hice cuando mi mamita estaba en un comienzo su enfermedad, y que yo la podía dejar en la casa, un rato se quedaba con mi pareja un rato, y yo iba a los talleres, que no me quedaban tan lejos porque como yo estaba en Santiago centro, no me quedaban lejos, entonces yo me movía rápido, y eso, pero hace falta, hace mucha falta, para distraerte, si hace falta." (Entrevistada 10)

En este aspecto, nuevamente, aparece la frustración como sentimiento presente en sus discursos, ya que no tenían instancias de disfrute, que les permitieran tener un paréntesis en sus vidas.

- “¿En qué ha tenido que adaptar su vida? ¿Qué ha tenido que cambiar? por ejemplo

- "Es que cuando estaba en Villaseca yo me sentía más joven, iba a hacer mis compras, iba a pasear, iba donde una hija, iba donde la hija de allá, de acá de Rancagua, o venía una nieta: "abuelita vamos a tal parte" y yo salía, iba al centro de madres, iba a la iglesia. Y ahora no tengo nada, no tengo nieta, no tengo salidas, no tengo centro de madres, aquí hay, pero yo como le digo no puedo dejarlo solo, las reuniones a la junta de vecinos no puedo ir, va la vecina y ella me informa, ayer mismo era la final del mes de María y no pude ir, porque justo estaba medio raro ayer, las pulsaciones le bajan, las pulsaciones del corazón.” (Entrevistada 11)

En suma, el cuidador veía deteriorada su salud mental y manifestaba sentimientos de tristeza, impotencia y frustración que en muchas ocasiones le llevaban a generar perturbaciones serias del ánimo como trastornos depresivos y ansiedad, etc. Si bien dentro de los objetivos de este estudio no se consideró la aplicación de algún test que midiera dichas patologías, en el trabajo de campo realizado se observó que gran parte de los pacientes presentaban sintomatología propia de los trastornos anteriormente mencionados. 


\title{
Propiedad "Salud social" 103
}

Todos los entrevistados mencionaban que, desde que cuidaban de su familiar, prácticamente no habían tenido momentos de respiro y menos vacaciones. Las referencias a todas las actividades que habían dejado de hacer en el ámbito del disfrute del tiempo libre y del desarrollo de la vida social eran frecuentes y estaban marcadas por la falta de tiempo libre y la poca colaboración de otros en el cuidado del dependiente.

"El día que lo vienen a buscar a las diálisis, yo me voy en el mismo auto y que coincidan con las fechas de pago, y me deja allá afuera don Nicolás, de ahí tomo un colectivo que me deje en Buin, cobro y hago todas las compras a toda carrera, porque tampoco me queda mucho tiempo (...) Corriendo, corriendo, porque tengo que llegar aquí cinco y media.” (Entrevistada 11)

La salud social del cuidador se vio seriamente afectada por la falta de tiempo y la ausencia de reemplazo en su labor, aspectos que limitaban su posibilidad de realizar otras actividades distintas de las del cuidado y que le impedían una normal integración y desarrollo en el medio social.

\begin{abstract}
"Desde que mi papá sufrió esto, no puedo decir voy a disfrutar un fin de semana, o decir me voy a ir una semana la playa, como mis hermanas lo hacen, yo no puedo, si Marcos me dice... por mí, yo no puedo decir: "Vamos a salir el día domingo los dos", si a la única parte que salimos el día domingo, vamos al cementerio a ver a mi hermano, a los abuelos de él, y esa es la salida que tenemos los dos (...) y almorzamos el día domingo cuando él está aquí [Marcos, su pareja], y de ahí tengo que ir para arriba donde mi papá. No tengo todo un día de descanso, no tengo, porque si el día domingo quisiera descansar toda la tarde, no puedo, porque tengo que llegar a la casa, ver si mi papá está sucio, hay que cambiarlo, lavar, el día domingo yo lavo igual [existe una costumbre que los días domingos no se debe lavar, por una cuestión religiosa], si pa' mí todos los días son iguales." (Entrevistada 31)
\end{abstract}

\footnotetext{
${ }^{103}$ Un estado de completo bienestar físico, mental y social, y no solamente la ausencia de enfermedad o dolencia. (OMS, 1948 Constitución de la Organización Mundial de la Salud, aprobada en la Conferencia Internacional de Salud de 1946, y que entró en vigor el 7 de abril de 1948). La capacidad de interaccionar bien con la gente y el ambiente, habiendo satisfecho las relaciones interpersonales (http://www.saludmed.com/Salud/CptSalud/CptSaDim.html).
} 
Específicamente, en el caso de las entrevistadas que cuidaban de alguno de sus padres y que no tenían pareja al momento de ser entrevistadas, la falta de tiempo limitaba notablemente la posibilidad de establecer y mantener una relación.

- “Usted dice que no puede pensar el tener una pareja?”

- "No, porque yo no tengo el tiempo, yo tenía una pareja y cada vez que me llamaba le decía yo "No puedo salir, tengo que hacer esto" entonces al final a uno no la entienden, piensan que uno puede dejar solos los cabros $^{104}$ y no se puede, entonces al final ya se aburren y no llaman más.” (Entrevistada 27)

La falta de tiempo, y de remplazo en la tarea del cuidar, afectaba también a otros miembros de la familia, que debían asumir las consecuencias de la nueva dinámica familiar.

\footnotetext{
"Antes yo podía salir con la niña, la hija [con síndrome de Down] de mi hermana que falleció, podía salir a la hora que quisiera, día domingo, día sábado, día festivo nos invitaban a almorzar, yo salía con ella, porque ella es muy buena para salir, lo único que le gusta es salir, o ir a la feria, o ir a un Mall $^{105}$, que la lleve a almorzar, que la lleve a mirar, al cementerio a ver a su mamá, entonces esas cosas ya no las puedo hacer mucho." (Entrevistada 8)
}

Como podemos ver, la situación de cuidado afectaba no solo a los cuidadores, el grupo familiar también veía afectada su dinámica cuando uno de sus miembros se transformaba en dependiente; este tema será tratado en la siguiente subcategoría.

\section{SUBCATEGORÍA "Consecuencias del cuidado en la familia"}

\section{Propiedad "Economía familiar"}

Una consecuencia, presente en todas las experiencias investigadas, era el deterioro económico que sufría el grupo familiar producto de la situación de cuidado. Este

\footnotetext{
${ }^{104}$ Chicos, hijos.

${ }^{105}$ Centro comercial.
} 
aspecto del cuidado, desarrollado de forma indirecta al revisar la historia laboral del cuidador y que más adelante revisaremos como una categoría en el tema factores de protección y riesgo de sobrecarga, implicaba que la precaria situación económica se debía, en este ámbito, a factores como:

\section{- La pérdida del trabajo}

- Aceptación de trabajos mal remunerados

- Imposibilidad de conseguir un trabajo que se adapte a las condiciones que implicaba el asumir la tarea de cuidador.

Otro factor que deterioraba notablemente la economía de estas familias eran todos los gastos relacionados con la dependencia, entiéndase por ello los gastos médicos y farmacéuticos, los nutricionales y de artículos de limpieza. Se debe recordar que en Chile existen muy pocas iniciativas públicas que apoyen al dependiente y/o sus familias en su cuidado, dependiendo de la patología reciben atención sanitaria más o menos especializada, pero el resto de los gastos corre a cuenta de sus familias.

\section{Propiedad "Dinámicas familiares"}

Anteriormente fue analizado el deterioro de la salud del cuidador en sus tres dimensiones: física, mental y social. Al analizar esta última podemos darnos cuenta que las relaciones familiares indudablemente se ven afectadas por la situación de cuidado.

El tiempo y las energías que el cuidador debe dedicar al dependiente inevitablemente afectan la dinámica familiar, ya que cuenta con menos tiempo para el resto de la familia; sobre todo si pensamos que la persona que cuida suele ser mujer, por lo general madre/esposa y, por el contexto cultural, la que está encargada de que el hogar “funcione”. La complicación es mayor aún cuando no existe cooperación en el cuidado del dependiente de parte de otros miembros de la familia.

\footnotetext{
"Exactamente, entonces cuando yo empecé a estar más tiempo con el Luis en el hospital, yo no almorzaba acá, me levantaba, hacia aseo, almuerzo, todo y me iba. Mi mamá también empezó a decaer, se cayó, estuvo como dos semanas en cama por el golpe que tuvo, y me acuerdo que un día me amanecí en la posta con ella porque se le
} 
había subido la presión, yo llegué de ver al Luis, como a las 9 de la noche y la fui a ver a la posta y tenía la presión por las nubes, (...) y estuvimos hasta las 8 de la mañana en el hospital, entonces yo ese día no llegué temprano al hospital, yo le dije a mi mamá, y ella también, no me quería decir nada, pero que ella se sentía sola, entonces le dije que iba a conversar con el Luis y a partir de mañana yo voy a empezar a almorzar contigo, y de ahí me iba al hospital y estaba hasta más tarde con el Luis, (...) pero ya después empecé a estar más con mi mamá porque ella se sentía sola, ella estaba acostumbrada a que yo estaba todos los días a la hora de almuerzo, al desayuno, a la once, entonces los desayunos eran más rápidos, no era con sobremesa de una hora, era un ratito porque avanzaba la hora y había que hacer todo más rápido.” (Entrevistada 24)

Los conflictos en las familias de los cuidadores eran experimentados de diversas formas, pero fueron múltiples las referencias sobre problemas con distintos miembros de la familia, generalmente causados por la dedicación principal que debían dar al familiar dependiente en desmedro del resto de los miembros.

- “¿Cuánta diferencia de años hay entre él y su hija?”

- "8 años. Son los dos de diferentes papás, entonces en el momento que la Daniela nació, yo tenía que pasar en el hospital y yo a lo mejor le presté mucha atención a la Daniela con todo su problema, y me despreocupé de él, a lo mejor ese fue mi error... pero era una lucha que yo estaba dando, porque a pesar de todo el diagnóstico que traía la Daniela, yo no quería que se fuera, entonces estaba dando una lucha por un lado y me desligué de la otra lucha que tenía, entonces yo digo: nadie es perfecto, todos nos equivocamos pero tampoco quedó solo, no quedó botado, entonces no encuentro, no sé qué más puedo hacer, no sé, no encuentro...” (Entrevistada 27)

Así también, el no reconocimiento de la tarea de cuidar, tanto en su carga e intensidad, implicaba que dicho trabajo no debería influir en el "normal" funcionamiento del hogar, lo que de por sí generaba tensión en la relación del cuidador con el resto de la familia, tensión que a veces era expresada y otras se vivía desde la más profunda resignación.

- "¿Y producto de cuidar a su hijo usted ha notado que su salud se ha afectado? Por ejemplo tiene dolor de espalda, de brazos, de huesos"

- "Eso sí, porque de tanta preocupación, estoy acostumbrada, porque casi no almuerzo, porque en servirles a tantos y después darle a él, a veces ni almuerzo, yo después me 
como cualquiera cosa, no sé cómo aguanto sin almorzar, tengo mucho que hacer, después me pilla el tiempo, es mucho para cuidarlo a él, yo digo a mi me hubiera gustado tener más tiempo para cuidarlo a él pero es difícil porque yo lo tengo que hacer todo." (Entrevistada 15)

En el caso de que el dependiente cuidado fuese uno de los padres, el conflicto familiar recurrente se generaba cuando era sólo uno de los hijos quien se hacía cargo del cuidado del dependiente y no recibía ayuda de ningún tipo -material o humana- en su tarea, a pesar de existir una obligación "moral" de los demás. La vida del resto de los miembros de la familia seguía su curso, era la vida del cuidador la que se veía drásticamente alterada.

- ¿¿Y esto les ha generado problemas en la familia? El tener que cuidar a su mamá"

- "Es que nadie se ha hecho ni un problema, la verdad es que nadie, nadie. Nosotros lo hemos hecho todo. Cosas de reuniones caleta ${ }^{106}$, nos hemos juntado todos, los 7 hermanos, por ejemplo que diga un hermano: "yo me voy a llevar este fin de semana a mi mamá y la voy a llevar a la casa", mi hermano mayor por ejemplo, que se puede decir que él se la ha llevado, no se la lleva tampoco, sino que me pide que yo se la lleve, entonces cuando él llama para acá que quiere llevarse a mi mamá mi hija me reta, me dice: “Mamá si él la quiere venir a buscar ¡Que él la venga a buscar!” (Entrevistada 6)

Dentro de las personas que fueron entrevistadas, existían situaciones extremas, es el caso de una cuidadora que estaba a cargo del cuidado de su madre postrada, su hermana postrada y un hermano que estaba en camino a ser totalmente dependiente. La mujer se encontraba prácticamente sola en el desempeño de esta tarea y contaba con una situación económica bastante deteriorada, la relación con el resto de la familia era totalmente controvertida, debido a esta situación de cuidado.

- “Y usted siente que alguien le reconoce lo que usted hace?”

- "No"

- “¿Ninguno de sus hermanos?"

- "No. Lo que yo les he dicho a ellos, cuando yo les he pedido que me paguen las imposiciones, me han dado respuestas tan tontas, tan absurdas, ya, les digo yo, cuando

${ }^{106}$ Muchas. 
quieran vender la casa les voy a demandar que me paguen toda las imposiciones, los voy a demandar digo yo. (...) ¿Quién me va a devolver todo esto? Nadie... sí cuando yo tengo que cambiar mis lentes, que los tengo que cambiar todos los años y yo les digo a ellos yo tengo que ir al oftalmólogo, y yo tengo que pagar por ir al oftalmólogo, por los lentes tengo que pagar, y mi hija, si no fuese por mi hija yo no podría ir al oftalmólogo, no podría hacerme los exámenes, me tengo que hacer todos los años un chequeo por el glaucoma, porque para más mi cuñada me pegó en el ojo derecho, por defender a mi mamá me llegó a mí el $c{ }{ }^{107}$ (golpe de puño), entonces me dejó el ojo derecho con complicaciones, así que me lo tengo que controlar todos los años." (Entrevistada 9)

En el caso de familias donde se daba la cooperación en el cuidado del dependiente, la renuncia a las actividades habituales era "democratizada" y distribuida homogéneamente por el cuidador principal y otros miembros de la familia.

- “Entre las dos estuvieron cuidándolo?”

- "Sí, cuidándolo, ella dejó de estudiar el primer año, había entrado recién a la universidad, tuvo que dejar todo botado, estar un año sin retomar los estudios porque tenía que ayudar a cuidarlo, no podía yo sola, porque para moverlo y todas las cosas no se podía, pero gracias a Dios no. Y problemas de que haya tenido depresión tampoco, lo hemos sabido sobrellevar bien." (Entrevistada 16)

También, dentro de las relaciones familiares, un tema mencionado en reiteradas ocasiones por las personas entrevistadas era el deterioro que sufrían las relaciones de pareja debido a la situación de dependencia de algunos de sus miembros.

En el caso de que el dependiente fuera un hijo/a, existían parejas en donde los dos asumían el cuidado del hijo dependiente, pero en los casos observados esta realidad era infrecuente. Lo más normal era que el padre se comportara como mero proveedor, y solo algunos ayudaran en aspectos puntuales del cuidado. Incluso, dentro de la relación de pareja se producían quiebres debido al "exceso" de atención prestadas hacia el hijo enfermo en desmedro de la pareja.

"Es lo que me dijo una vez mi esposo, me dijo: "Tú vives en torno al Alonso, y el Alonso está bien, no tiene nada"... lo que pasa es que nosotros tuvimos una crisis ${ }^{107}$ Golpe de puño. 
matrimonial, estuvimos separados 4 meses, y todo eso tocó cuando a mí me tocó los exámenes [del hijo dependiente], todo eso me tocó todo sola, ahí estuve con depresión, baje 10 kilos, (...) él me lo dijo así, por eso siento que él no ha asumido lo que le pasa. Por ejemplo, le dije del colegio, que quería cambiarle de colegio, que qué pensaba, no dice, nada, no dice nada, no, yo tengo que solucionarlo, pero yo sé que si me equivoco, yo voy a ser la culpable, pero eso a uno le hace pensar, le hace sentirse sola además, entonces esas cosas no las capta él.” (Entrevistada 29)

Lo relatado anteriormente sucedía también en el caso de que el dependiente fuera alguno de los padres del cuidador. Habitualmente era la mujer quien cuidaba de su padre o madre, sus parejas muchas veces se mantenían al margen y se quejaban de que la relación de pareja no pudiera seguir igual que antes. Se planteaba en las cuidadoras un dilema en relación a cuál era su deber, o qué deber era más fuerte, si el de comportarse como buenas hijas y cuidar a sus padres o el de ser "buenas esposas". La situación de tensión en las parejas, producto de la situación de cuidado, llevaba a que las rupturas y separaciones de parejas fueran frecuentes en las familias que cuidaban de alguno de sus padres.

"Él sí, estaba aburrido, él [su pareja] estaba aburrido y me lo decía, que estaba aburrido de esta vida, que no podíamos aprovechar, salir, disfrutar juntos, y como te digo la relación estaba un poquito quebrantada, pero bueno él decía que me amaba, que me quería tanto, quizás habrá sido tan así, no sé.” (Entrevistada 10)

- "Me decía usted que la relación con su esposo se deterioró producto de la enfermedad de su mamá ¿Ustedes ya no viven juntos?”

- “Sí, si po' sí vivimos juntos pero es que no es lo mismo, si incluso tuvimos una separación por eso, él me saca en cara lo de mi mamá, que yo no más tengo que cuidarla, que para todas las cosas yo, que él está de lado y así pues, entonces son 9 años que yo he tenido que soportar de todo, en cuanto a él y en cuanto a mis hermanos también, porque todos dicen que por el hecho de que uno está aquí, se está aprovechando de todo, que yo lo paso súper bien, según ellos.” (Entrevistada 20) 


\section{SUBCATEGORÍA "El maltrato"}

El tratamiento de este tema surge de forma espontánea en el discurso de las personas entrevistadas, ya que no se encontraba dentro de los argumentos que pretendían ser tratados durante la entrevista. Se observa que su mención confirma la presencia de maltrato del cuidador a la persona dependiente, pero también del sujeto que es atendido al cuidador. Además, es destacable que situaciones de violencia familiar preexistentes son incrementadas por la propia situación de cuidado.

\section{Propiedad "El cuidador como maltratador"}

En los discursos de los cuidadores es distinguible la presencia de maltrato, que era expresado principalmente por los cuidadores de personas adultas. En el caso de los cuidadores de niños no se logró detectar en sus relatos la presencia de algún tipo de maltrato, de hecho la actitud frente al dependiente y a la relación de cuidado asumida por este tipo de cuidadores era más positiva y menos deteriorada que la de los cuidadores de personas mayores.

De acuerdo a la clasificación del maltrato en distintos tipos, físico, psicológico, negligencia, violencia económica y otros tipos de maltrato, a través de los discursos de los entrevistados se pudo identificar la presencia del maltrato psicológico y de la negligencia.

\section{Dimensión "Maltrato psicológico"}

La forma más frecuente en que se presentaba el maltrato psicológico era infantilizando al familiar dependiente, considerándole como si fuese un niño. Este comportamiento se observó en los cuidadores de personas mayores con algún tipo de deterioro mental (demencias).

- “Usted se siente enojada cuando está cerca de él?”

- “Claro que a veces lo reto... cuando está limpio, está mudado, le di comida ¿Qué más? ¿Sí o no?’(Entrevistada 1) 
“Ahora estoy así [nerviosa] porque ella está mañosa, de repente me pide que le haga las cosas, pero así como está, no me gusta verla así. A veces se pone violenta... es igual que una niña chica, igual.” (Entrevistada 5)

El maltrato psicológico podía expresarse de distintas formas, una de ellas era a través del miedo o temor que el cuidador infunde en la persona dependiente, reprimiéndole como si fuese un niño y exigiéndoles que realicen tareas o acciones que ya no son capaces por su estado de salud.

“(...) pero mi mamá no fue muy agresiva, tuvo momentos violentos pero muy poco, por ejemplo cuando se hacía, yo la sacaba a caminar y de repente llegaba y se... yo te hablo de un comienzo, y de repente se hacía caca, y yo la retaba: "Pero mamá cómo no te aguantaste un ratito si estamos llegando a la casa", y ahí ella se ofuscaba, era una manera de defenderse, de ponerse violenta conmigo, pero yo la apaciguaba, me portaba... me tenía respeto en ese aspecto.” (Entrevistada 10)

\section{Dimensión "Negligencia"}

Otra forma de expresión del maltrato observada es la negligencia, se daba cuando los cuidadores ignoraban o amenazaban al dependiente y sus solicitudes, haciendo uso de la situación de poder en que estaban. La negligencia tomaba la forma de abandono cuando se daban situaciones como las que se describen en este verbatim.

"Cuando la dejo acostada todo el día es cuando la castigo, yo me enojo con ella y le digo: “¿Sabís qué? no te voy a levantar hoy día”, "¿Y por qué no me vas a levantar? Yo me quiero levantar, pásame la ropa, yo me voy a levantar sola", y trata de vestirse ella." (Entrevistada 6)

La entrevistada privaba a la dependiente de su libertad, de la "posibilidad" de tener alguna alternativa de establecer relaciones sociales con otro que no fuera el cuidador.

“(...) pero hay momentos en que no puedo sacar eso de mi cabeza [el consumo de droga], es algo que a uno lo ciega, no hay otra mirada, incluso dejo de lado a mi mamá, o sea no la dejo de lado pero de ahí la vengo a ver, la dejo un espacio de tiempo, que 
podría dárselo a ella, la dejo, ay si total me puede esperar un poquito más, a ese extremo." (Entrevistado 26)

El fragmento discursivo que acabamos de mostrar expresa el abandono como forma de maltrato debido al consumo de drogas. De acuerdo a la literatura especializada, este último se constituye en un factor de riesgo asociado al maltrato.

\section{Dimensión "Factores de riesgo asociados a la situación de maltrato"}

La complejidad de las relaciones que se establecen en la situación del cuidado hace evidente la situación de estrés o sobrecarga que experimentaba el cuidador, ésta se hace evidente en los relatos de la mayor parte de las personas que cuidaban de dependientes mayores.

- ¿UUsted se siente irritada cuando está con su mamá?”

- "No, cuando me saca los choros del canasto no más [ríe], porque mire, de repente está ahí, y empieza "Josefa" y de repente yo estoy en el baño, le digo "Mamá ya voy", y sigue "Josefa” [dando gritos], entonces llego al lado de ella y le digo “¿Pa' qué me llama?", "No, si estaba sonando el teléfono”, “no puedo venir po’ mamá, si estaba ocupada", pero ella eso no lo entiende mucho.” (Entrevistada 6)

En las experiencias relatadas por los cuidadores se observaba que las variables que inciden en el elevado nivel de estrés que presentaban eran la falta de apoyo familiar, la inexperiencia en desarrollar este tipo de actividades y la precaria situación económica de la mayor parte de las familias entrevistadas. Todas estas variables o dimensiones se constituyen en factores de riesgo asociados a la situación de maltrato en mayores.

- “Usted cree que la podría cuidar mejor de lo que lo hace?”

- "Emocionalmente sí, porque cuando estoy colapsada, prefiero irme, respirar porque la puedo maltratar psicológicamente, la puedo gritar, le puedo hablar fuerte, de hecho mi hija me tranquiliza con eso, me dice: "Mamá, tranquila, ya"." (Entrevistada 13) 


\section{Propiedad "La persona dependiente como maltratador"}

La agresión en la relación de cuidado no es un comportamiento exclusivo del cuidador. En las entrevistas realizadas, los cuidadores relataron episodios violentos generados por los individuos dependientes. De acuerdo a dichos testimonios, es posible clasificar los tipos de sujetos receptores de cuidados, de acuerdo a sus comportamientos violentos, en dos grupos: comportamientos violentos de enfermos que padecen demencias y los comportamientos violentos generados por discapacitados físicos.

\section{Dimensión "Comportamientos violentos en la demencia”}

Las personas dependientes que padecían algún tipo de demencia tenían, al momento de la entrevista, conductas violentas físicas o psicológicas (verbales principalmente) con sus cuidadores.

\footnotetext{
“Adrián estuvo en un comienzo atrevido, después pasó eso, ¿Por qué? No sé. Pegaba $\operatorname{combos}^{108}$, cuando hablaba, a mi me celaba, cuando me veía salir me decía: "vas a ir a pololear ${ }^{109, ", ~ p o r ~ l o ~ c l a r o, ~ c o n ~ p a l a b r a s ~ q u e ~ n o ~ s e ~ p u e d e n ~ r e p e t i r, ~ e n t o n c e s ~ y o ~ l l o r e ́ ~}$ mucho" (Entrevistada 14)
}

“Para como ella estuvo el primer año, mal po', súper mal, que ella no quería nada, que pasaba llorando, que me pegaba, me pellizcaba." (Entrevistada 20)

“(...) cuando él se sienta muy alterado, ahí hay que darle [tranquilizante] porque a veces se pone muy alterado, cuando me pilla descuidada me da sus combos donde me caigan. Sí, le da la rabieta que no lo puedo parar.” (Entrevistada 22)

Como se puede observar, dichos comportamientos generaban en los cuidadores gran pesar y desconcierto, ya que eran conscientes de que la situación mental de la persona que cuidaban era la causante de dichas conductas de maltrato.

\footnotetext{
${ }^{108}$ Golpes de puño.

${ }^{109}$ Salir con una finalidad amorosa o sexual.
} 


\section{Dimensión "Otros comportamientos violentos"}

Algunos de los familiares adultos, que sólo eran físicamente dependientes de los cuidadores, efectuaban un tipo de violencia psicológica con éstos, ejecutada, principalmente, a través de agresiones verbales

- “ ¿Y ha generado, la enfermedad de su señora, algún roce dentro de la familia?”

- "A mí no, o sea aquí la que más discute, pelea y se enoja conmigo es mi señora, porque estará enferma pero alega un montón, entonces yo soy más pacífico, tranquilo, porque soy yo el que queda al medio, mi señora me dice: "no, no le hagas esto", y mi hija "papá tu..." es que no le puedo dar el favor ni a unas ni a otras." (Entrevistado 28)

\section{Propiedad "Violencia en la familia del cuidador"}

Uno de los testimonios de los cuidadores daba cuenta de que las situaciones de violencia podían estar presentes en el entorno de la situación de cuidado. Las tensiones que se vivían al interior de las familias se podían ver acentuadas por la presencia de una persona dependiente en ella.

- “(...) porque para más mi cuñada me pegó en el ojo derecho, por defender a mi mamá me llegó a mí el combo, entonces me dejó el ojo derecho con complicaciones, así que me lo tengo que controlar todos los años."

- “Ella le iba a pegar a su mamá?”

- "Sí, y me llegó a mí el combito, entonces yo he estado mal, me siento cansada, sin ánimos de nada, de repente descanso un minuto, dos minutos y sigo batallando, es sufrida la rutina." (Entrevistada 9)

\section{Síntesis}

Las principales consecuencias derivadas de la situación de cuidado afectaron fundamentalmente al cuidador y a su familia. El cuidador ve deteriorada su salud física, mental y social, y las familias vieron afectadas especialmente sus economías familiares, su funcionamiento habitual y las relaciones entre sus miembros. Se evidencia en el discurso de algunas de las personas entrevistadas la presencia de maltrato desde y hacia 
el cuidador, y también se acentúan situaciones de violencia familiar existentes a causa de la situación de cuidado. En el maltrato desde el cuidador hacia el dependiente, las formas más frecuentes en que éste se manifestaba eran maltrato psicológico infantilización- y negligencia. Entre los factores de riesgo asociados a la situación de maltrato se identificaron la falta de apoyo familiar, la inexperiencia en la tarea de cuidar y la precaria situación económica de las familias, los cuales incidían directamente en la sobrecarga del cuidador. El maltrato del dependiente hacia el cuidador fue realizado por dependientes que padecen algún tipo de demencia -violencia física o psicológica- y por algunos de los dependientes adultos que ejercen violencia psicológica (verbal, principalmente) hacia sus cuidadores. Finalmente, también se observa que la situación de cuidado potencia contextos previos de tensiones y malas relaciones entre los miembros de la familia del cuidador. 


\section{TEMA. FACTORES DE PROTECCIÓN Y RIESGO DE SOBRECARGA DEL CUIDADOR}

En este apartado del análisis quisiéramos englobar distintos aspectos que forman parte de los factores que pueden resultar protectores y/o generadores de la sobrecarga que experimenta el cuidador debido a la tarea que desempeña.

La mayor o menor densidad que adquieren las categorías en el análisis responden a la profundidad con la que dichos temas son abordados por las personas entrevistadas. Así, categorías como género o la situación socioeconómica de los cuidadores y sus familias cuentan con un amplio desarrollo de propiedades y dimensiones; y otras como la relación cuidador dependiente, las redes de apoyo, el cuidado formal, el futuro del cuidador están menos tratadas. Finaliza esta parte del análisis con un apartado denominado manifestaciones de sobrecarga, que nos parece importante que aparezca en este epígrafe para estar contextualizado.

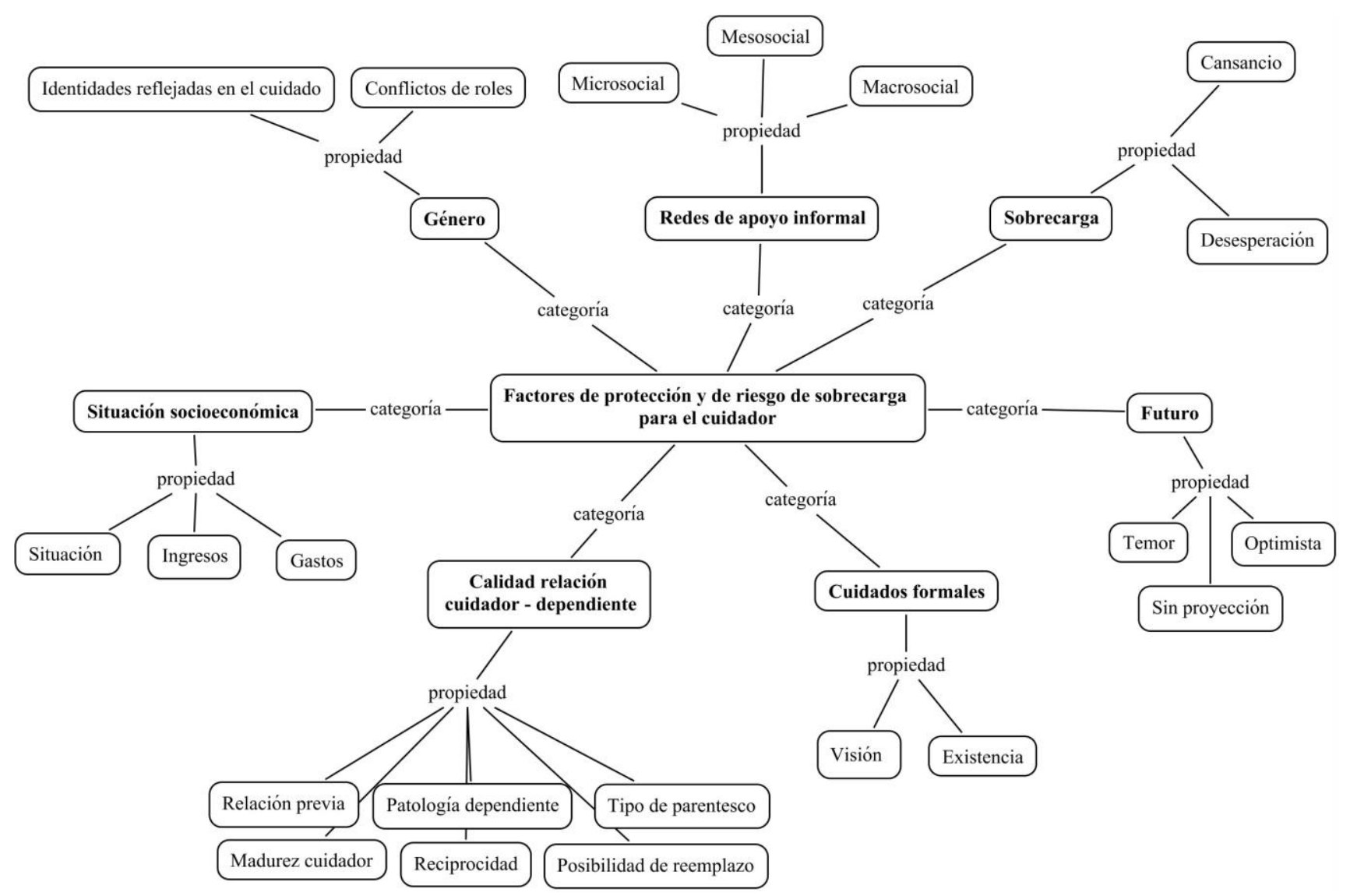

Mapa conceptual tema 3, Factores de protección y de riesgo de sobrecarga 


\subsection{CATEGORÍA “GÉNERO”}

Los discursos de las personas que fueron entrevistadas en nuestra investigación reflejan características que pueden ser analizadas desde la perspectiva de género. Pensamos que esta categoría puede constituirse en riesgo de sobrecarga del cuidador, ya que la mayor parte de las personas que cuidan son mujeres y están expuestas a mayores desigualdades. En el análisis de la categoría género podemos identificar las siguientes propiedades.

\section{Propiedad "Identidades de género reflejados en el cuidado"}

La mayor parte de las personas entrevistadas fueron mujeres, identificamos a través de la situación de cuidado las identidades que asumen éstas y que reflejan la forma en que ellas se definen y se relacionan con sus familias y con su entorno.

\section{Dimensión "Mujer que asume el cuidar de forma tradicional"}

Las entrevistadas parten definiéndose en relación a los miembros de sus familias, generalmente como esposas y/o madres.

"Yo tengo 41 años y tengo 4 hijas, una de 21, 13, 10 y 9... ¿Qué más le puedo decir?

No se me ocurre." (Entrevistada 2)

En el discurso de las entrevistadas el cuidado estaba asociado directamente a su condición de género, es la(s) mujer(es) quien(es) cuida(n), el(los) hombre(s) provee(n) y secundariamente puede(n) cooperar en el cuidado, pero eso es tarea principal de la(s) mujer(es).

- “YY usted considera que le reconocen lo que hace por su papá, el resto de la familia?”

- "Yo pienso que sí, porque mis hermanos, ellos no dicen: "Mi papá está mal” porque si no "Me lo tengo que llevar yo", pero no, nunca me han dicho nada, me dicen: "Ve tú, si tú eres la que sabe"."

- “EEllos le ayudan de alguna forma?”

- "Uno sí, me deposita veinte mil pesos todos los meses y me dice: "Cualquier cosa que necesitís me avisai", pero igual trato de no molestarlo, y los otros no pueden, pero 
tampoco lo vienen a ver, eso es lo que digo yo que podrían venir a verlo o decir nos lo vamos a llevar una semana nosotros y no. (...) Yo pienso que también influyen las señoras, fueran mujeres, hijas, lo harían, porque estarlo mudando, bañando, todo eso. Pero nunca les ha nacido decir: "Yo lo llevo o lo veo un tiempo"." (Entrevistada 23)

Dentro de esta forma tradicional de asumir el cuidado, observamos que las mujeres que eran cuidadoras de sus parejas evidenciaban en sus relatos relaciones marcadas por la obediencia a la voluntad de sus cónyuges.

- “¿Señora Carmen y usted siempre ha estado en la casa? ¿Siempre ha sido dueña de casa?

- "Sí, porque mi marido nunca me permitió trabajar porque yo tengo una familia, unas hermanas muy difíciles, entonces para no hacerse problema él de que yo iba a trabajar o no sé, de cualquier cosa, de que no dijeran: "Se casó y no le da a la mujer", nunca me permitió, sí podía hacer, por ejemplo, si la vecina me pedía que le lavara unas sábanas, yo encantada, pero más allá no, costuritas y hasta antes de que yo me enfermara de mi vista, yo hacía bastas, ponía cierres, angostaba, hacía arreglos de ropa.” (Entrevistada 14)

- "Usted antes de cuidar a su papá ¿Qué hacía señora Irma? ¿Trabajaba?”

- "No, no me dejan trabajar."

- "No, pero antes."

- "No me dejan trabajar ni mis hijos, ni Marcos [su pareja], no, es que yo siempre me he dedicado a labores sociales Cruz Roja, Bomberos, en todas esas cosas yo he participado, muchos años atrás trabajé en un hogar de ancianos también, eso me ha servido harto..." (Entrevistada 31)

Así también, todas estas cuidadoras expresaban una visión de su papel profundamente sumiso. Esta actitud era una constante en las cuidadoras mayores entrevistadas, ellas habían sido socializadas en acatar la voluntad de sus parejas, aceptando de forma resignada el deber de cuidarles.

- “ ¿Usted encuentra que el cuidar a su esposo le ha afectado de alguna manera el estado de ánimo que tiene?"

- "No, porque me tengo que acostumbrar no más pues."

Página | 308 
- “No se nota más triste, más cansada, más nerviosa?”

- "A veces me siento cansada, pero tengo que hacerlo no más pues, no me queda otra." (Entrevistada 4)

"Pero va en el cuidado, pero yo digo no, con la mano en el corazón, haya pasado lo que haya pasado con mi marido, no quiero decir que fue buenísimo, fue malo, malo, no, ahora es el desquite, no, eso lo hace Dios, yo lo pongo en manos de Dios, que sí me ayude a mí, el tiempo de estar con él me haga más liviana la carga. Eso me lo dicen: "Pucha Sra. Carmen, usted nunca fue salidora", que de repente hay una fiestecita o un paseo, no, yo no puedo ir, ¿Con quién dejo a mi marido? "No, vayan ustedes" descartaba todo eso, pero ¿Por qué? No me lo busqué.” (Entrevistada 14)

De forma parecida se daba la relación de las cuidadoras de sus parejas con sus hijos, como suele suceder la responsabilidad del cuidado recaía íntegramente en una persona y no se repartía entre los más cercanos al dependiente. En el caso de las mujeres que cuidaban de sus parejas o hijos, y que tenían hijos que estaban en condiciones de ayudarles, finalmente tendían a resignarse a que debían desarrollar esta labor en soledad y con muy poca cooperación del resto de los miembros de la familia.

“(...) yo he estado muy triste y muy sentida con mis hijos, pero ya, uno como madre, uno perdona todo pues mijita, ahora ya ellos vienen, yo los recibo con todo cariño, con alegría, yo ya di vuelta la hoja, pero yo aclaré las cosas, no crea que se la llevaron tan pelás, se lo dije, porque no era gran cosa la ayuda que yo pedía, no la pudieron dar, ya.” (Entrevistada 11)

- "¿Usted encuentra que su familia le reconoce lo que usted hace por su hijo?"

- "No [lo dice muy triste] ellos viven su vida no más, todos...

- "¿No le toman el peso a lo que es cuidar a..."

- "A su hermano"

- "Y en ese sentido eso le ha generado algún problema a la familia, el que ellos no lo reconozcan."

- "Sí [lo dice en voz baja, temerosa de que alguien más le escuche] (Entrevistada 15) 
Así también, una actitud sumisa y resignada era la que asumían las cuidadoras de sus padres dependientes. Las hijas que desempeñaban esta tarea reflejan en sus hablas la ingrata responsabilidad que les había tocado asumir y la desidia del resto de sus hermanos y hermanas en el cuidado de sus padres dependientes. Las hijas cuidadoras debían asumir este papel de forma obvia y natural cuando no había más mujeres en la familia que lo pudieran hacer.

- “¿Cuántos hijos tuvo ella?”

- "Cuatro, yo soy la única mujer."

- “YY cómo única mujer a usted le ha tocado cuidarla?"

- "Sí, siempre."

- “YY sus hermanos?"

- "No, mis hermanos se preocupan de ella, de venir a verla todas las semanas, pero no, ella no se va con ellos, tampoco son muy apegados a ella, y él que era apegado falleció... (Entrevistada 5)

Y se dieron casos en donde a pesar de que habían más mujeres en la familia, era una de ellas las que asumían el cuidado, debido a la existencia de una jerarquía en el orden de cuidado; dicha jerarquía consistía en que la responsabilidad recaía en quien estuviera viviendo más cerca del padre dependiente y/o en quien tuviera mejor relación con él y/o en quien le debía reciprocidad porque en el pasado recibió un trato especial de parte de ellos. Es decir, la cuidadora devolvía la mano que sus padres le habían tendido en el pasado, otorgándoles cuidados en ese momento.

"Lo otro es que tengo una hermana que estamos viendo, ella por el hecho de que está muy lejos ella no cuida a mi mamá, pero ella todos los meses me manda $\$ 30.000$, esa es la forma de ella de ayudar, porque como vive tan lejos no puede hacerse cargo de mi mamá, y la que puede hacerse cargo de mi mamá, la que está más cerca acá, nunca está, no se puede contar con ella, y los demás ya son hombres pues." (Entrevistada 6)

En el caso de las madres que cuidaban de sus hijos dependientes la postergación era el patrón común. Todas, sin excepción, anteponían el cuidado de sus hijos a su propio 
bienestar. Se privaban en aspectos tan básicos como alimentarse apropiadamente o atender a sus enfermedades.

- "¿Y producto de cuidar a su hijo usted ha notado que su salud se ha afectado? Por ejemplo: tiene dolor de espalda, de brazos, de huesos..."

- "Eso sí, porque de tanta preocupación, estoy acostumbrada porque casi no almuerzo, porque en servirles a tantos y después darle a él, a veces ni almuerzo, yo después me como cualquiera cosa, no sé cómo aguanto sin almorzar, tengo mucho que hacer, después me pilla el tiempo, es mucho para cuidarlo a él, yo digo a mi me hubiera gustado tener más tiempo para cuidarlo a él pero es difícil porque yo lo tengo que hacer todo." (Entrevistada 15)

- ¿Usted se ha tratado alguna vez por la depresión?”

- "Eh, estuve con estos médico naturales y, pero que yo me pueda... lo que pasa es que para mí es tan así, en cuanto en lo económico me afecta, porque si el Alonso se enferma yo prefiero... nos ha pasado que le ha dado un resfriado fuerte, yo prefiero llevar al Alonso al médico que atenderme yo, y ya me ha pasado dos veces lo mismo, que nos hemos enfermado los dos...” (Entrevistada 29)

El calificar la situación de cuidado del hijo como "postergación” resultaba innombrable para estas madres cuidadoras. Ni siquiera se permitían el cuestionar el tiempo que el cuidado de sus hijos les demandaba, era parte de su rol como madres y cuidadoras.

- “Siente usted que a causa del tiempo que usted gasta con su niño no tiene tiempo para usted?" [Pregunta 2 de Escala de sobrecarga del cuidador de Zarit]

- "Es que yo creo que una madre siempre va a tener tiempo para su hijo, tenga la complicación que tenga siempre se va a dar el tiempo para estar con él.” (Entrevistada 24)

Las cuidadoras entrevistadas resultan indispensables, no contaban en su entorno con alguien que fuese capaz de reemplazarlas, más que a pequeños momentos del día. 
"Yo no puedo pensar que el día de mañana yo me quiero mandar a cambiar a cualquier parte, no saber de nada, no puedo hacerlo, es incierto." (Entrevistada 14)

- "Desde que tiene a Alonso ¿Usted ha podido salir de vacaciones o un par de días sola, sin él?"

- "No, puedo salir sí, pero por un ratito, o sea hubo un tiempo en que no lo hacía, pasaba puro aquí, solamente en la casa, en la casa, cuidando al Alonso, teniendo la casa limpia, esperando a la gente con la comida caliente, pero yo salir no, como mucho a las reuniones, siempre fui responsable en eso sí, porque tampoco podía dejar de lado al más grande.” (Entrevistada 29)

Por otro lado resulta importante destacar que, al observar las trayectorias de vida de las entrevistadas mayores, ellas relataban que la experiencia del cuidado ha formado parte de sus vidas, incluso muchas de ellas comenzaron desde pequeñas en esta tarea.

- "Sra. Carmen ¿Usted fue al colegio?”

- "Sí, pero yo estuve hasta tercero, cuarto no más [primaria] porque en esos años mi papá nos dejó botados, nosotros éramos 9 hermanos y yo era la mayor y yo le ayudaba a hacer las cosas [tareas de la casa tales como limpiar, cuidar de los más pequeños, etc.] a mi mamá para pudiera criarnos a nosotros, yo no tuve el privilegio (...).”(Entrevistada 3)

Las infancias de las entrevistadas estuvieron marcadas por la pobreza, que obligaba (especialmente en el caso de las familias numerosas) a que las hijas mayores asumieran el cuidado del resto de sus hermanos.

"Yo tengo el número 7 de arriba hacia abajo, por lo tanto a las hermanas mayores nos tocó criar a los hermanos más chicos, el menor de todos, la guagua, me tocó a mí, y el que tuvo el accidente es el penúltimo, Raúl, o sea para mí como si hubiesen sido hijos míos los dos hermanos más chicos.” (Entrevistada 17) 
La vida de las entrevistadas mayores había transcurrido otorgando cuidados, siendo niñas comenzaron cuidando a sus hermanos pequeños, más tarde se casaron tempranamente y tuvieron que cuidar de sus familias (esposos e hijos), y luego en su tarea de abuelas, ayudaron a sus hijos en la crianza de los nietos.

\footnotetext{
"Iba mucho a Rancagua yo, donde la hija de Rancagua, porque ahí yo tengo nietas, que yo he criado de guagüitas [bebes] a esas nietas, tengo una que tiene 17, 18 años ahora, esa quedó de 4 meses conmigo, y de mi casa salió caminando, entonces uno les tiene un cariño especial... y después también la de... es que me he quedado con todos mis nietos, las que tiene Norma, que están en la universidad ahora las chiquillas también, los nietos porque mi hijo tiene 2 hijos, ya están jóvenes, adultos ya, uno es profesor y el otro trabaja en una empresa, a todos esos chiquillos los he criado yo, "años felices" les digo yo." (Entrevistada 11)
}

Las experiencias relatadas por las cuidadoras mayores nos permiten hablar de un historial de cuidados, ellas reprodujeron el rol que tradicionalmente les fue asignado. Contaban con un perfil de género claramente distinguible, sus infancias estuvieron marcadas por la pobreza, fueron hijas de familias numerosas, con bajo nivel educacional, casadas tempranamente, dedicadas al cuidado de la familia, con un rol muy marcado de amas de casa, con trabajos informales desempeñados generalmente para que no interfirieran en sus principales obligaciones con la familia y su cuidado. Por ello les resultaba normal e incuestionable el desempeñar esta actividad con sus hijos, nietos, padres y parejas.

Como anteriormente lo describimos, existía una suerte de norma o regla que se solía dar a la hora de hacerse responsable de la persona dependiente, a la hora de designar quién era cuidador principal. En el caso de que la persona dependiente fuese el esposo, la primera persona en quien recaía la responsabilidad era en su esposa, si esta no podía realizar dicha labor (por tener un estado de salud más deteriorado) eran las hijas las que debían asumirla. Si había más de una hija, tal como se describió anteriormente, se observa que la que se hizo cargo (voluntaria o involuntariamente) era la hija que vivía con la persona dependiente o más cercana a ella o que le debía reciprocidad (por 
ejemplo, que había vivido siempre con sus padres, que sus padres le habían ayudado en la crianza de sus hijos, etc.).

- “¿Usted tiene más hermanas o hermanos?”

- "Yo tengo hermanos, pero están en Rancagua ellos, son tres hombres y yo."

- “¿Usted se lo trajo [a su padre] para acá porque era la única mujer?”

- "Es que con él casi siempre vivíamos juntos, por ejemplo ellos tenían su departamento y yo vivía al lado cuando me casé, estuvimos siempre juntos, por los niños y todo, prácticamente se criaron con ellos, bueno y los chiquillos [los hermanos de la entrevistada] tampoco nunca dijeron: "Papá véngase conmigo" y él siempre estaba acostumbrado a estar con nosotros, incluso trabajaba con mi marido en Lo Ovalledor (...).’'(Entrevistada 23)

"Sí, toda la vida he vivido con ellos [abuelos], es que mi mamá me tuvo soltera, así que yo me crié con ellos, yo siempre reclamaba porque mi mami [la abuela dependiente a la que cuida] no me dejaba salir, que las juntas aquí, que las juntas allá y en realidad tenía razón, uno después ve, con madurez, que uno agradece cómo fue con uno, porque me crió a la antigua." (Entrevistada 12)

Si las cuidadoras llegaban a recibir ayuda del resto de la familia era en forma de dinero o en sustituirles por espacios cortos de tiempo cuando era imprescindible.

Finalmente, un rasgo observado, en este tipo de cuidadoras tradicionales, era que producto de la relación conservadora y tradicional que se desarrollaba en sus familias se generaban situaciones de violencia en la relación con sus dependiente, generalmente cuando eran parejas o en la relación padre dependiente - hija cuidadora.

“Adrián estuvo en un comienzo atrevido, después pasó eso ¿Por qué? No sé, pegaba combos [puños], cuando hablaba, a mi me celaba, cuando me veía salir me decía: "Vas a ir a pololear ${ }^{110 ",}$, por lo claro, con palabras que no se pueden repetir, entonces yo lloré mucho." (Entrevistada 14)

\footnotetext{
${ }^{110}$ Reunirse con el novio.
} 


\section{Dimensión "Mujeres cuidadoras que asumen esta tarea de modo no tradicional"}

Esta dimensión de la propiedad, referida a las identidades de género reflejadas en el cuidado, se observa y describe de forma incipiente en los discursos de algunas de nuestras entrevistadas, pero consideramos importante describir los aspectos en donde percibimos un cambio con respecto al patrón del comportamiento tradicional con respecto al cuidado.

En el colectivo de las mujeres cuidadoras existían algunas que, a pesar de desempeñar su actividad de forma tradicional, denotaban en sus discursos que lo hacían impelidas por la obligación "moral" que se les había impuesto. Esta actitud se presentaba en las esposas o hijas cuidadoras, nunca en madres cuidadoras.

\footnotetext{
"Hay veces que me dan deseos también de... dejar todo tirado, yo se los digo, ellas me dicen: "Lástima que no puede”, “Bah!”, les digo yo "Es cosa de decisión no más” cuántas mujeres dejan casa, dejan hijos y se van no más.” (Entrevistada 1)
}

Existía en ellas la intención de rebelarse ante una situación que consideran injusta, creían que no les correspondía cuidar porque en sus relaciones no había funcionado la reciprocidad. Es el caso de esposas que habían tenido historias de parejas marcadas por las carencias económicas generadas por situaciones de adicciones de sus parejas (alcoholismo, ludopatías, etc.). A estas mujeres les había tocado "sacar adelante" a sus familias en condiciones adversas y por ello veían "injusto" el que les correspondiese cuidar a estas parejas. Así también ocurría en el caso de hijas cuya relación con el/los padres, a los que le proporcionaban cuidados, no había sido del todo buena y cuando eran niños o adolescentes no recibieron los cuidados de parte de ellos. Existía impotencia en sus relatos, ya que veían que no tenían opción dentro de la forma en que se habían establecido sus relaciones, que no tenían alternativa y ellas eran las únicas que podían proporcionar el cuidado, pero si hubiese existido la posibilidad no lo hubiesen hecho.

Pero también en las cuidadoras entrevistadas hay un grupo de ellas, jóvenes cuidadoras de sus hijos dependientes, que desempeñaban su rol de cuidadoras pero que dejaban de cumplir otros roles que, por su género, "les correspondían". 
"Lo que pasó fue que cuando el Martín estaba chiquitito yo les dije una vez: "O ven la guagua $^{111}$ o comen comida, si ven la guagua yo hago comida, si no ven la guagua se cagan de hambre", y listo, porque yo no iba a dejar que la guagua llorara para hacer almuerzo, no como no más, una ensalada, una fruta y listo, o sea no, en ese sentido yo no me estreso porque todos tienen manos. Aparte que con mi papá siempre hemos sido los dos... es que en el refrigerador hay de todo para que coman, si quieren prepararse algo hay de todo para prepararse algo, es que sabes lo que pasa es que yo no me desgasto en esa cuestión de hacer aseo, yo hago aseo, barro, pero con él [señala a su hijo] no me dura, es imposible, denante comió maní, rocío maní, come cereales, rocía cereales." (Entrevistada 18)

La carga de trabajo en el hogar era tal que para ellas lo fundamental era desempeñar bien su rol de madres cuidadoras, si no existía tiempo para el resto de actividades propias de éste simplemente no las realizan. Además, tenían conciencia de que el resto de los miembros adultos de la familia podían desarrollar estas tareas independientemente de su género.

"Y eso es lo que pasa con el Alonso, también él, acá en la casa, mucho va a mí, aunque estén los demás, entonces yo le digo: "Dígale al papá que le haga" y cuando le digo eso él va y le dice al papá, lo lleva para mostrarle las cosas.” (Entrevistada 29)

- “ ¿Te sientes muy sobrecargada por tener que cuidarlos?”

- "No, es que aquí "Todos los monos bailan"112", aquí es autoservicio, es que los que llegan aquí prácticamente no son visitas, y es que aunque no lo sepan yo se los digo. Por ejemplo, si a mi papá le da hambre, él llega pone el hervidor, busca pan, se hace una ensalada y se prepara algo “¿Quién quiere once? Está listo el hervidor”, y el Juan igual (esposo).” (Entrevistada 18)

Las cuidadoras más jóvenes intentaban hacer que sus parejas y el resto de la familia fuesen partícipes del cuidado de sus dependientes, o que realizaran las tareas que ellas no podían desarrollar por el tiempo que debían dedicar al cuidado. Estas mujeres

\footnotetext{
111 Bebé.

${ }^{112}$ Expresión usada para decir que todos tienen la capacidad para hacer las tareas del hogar.
}

Página $\mid 316$ 
pretendían que en sus hogares se diera una repartición de las tareas más equitativa, lo que muchas veces les generó conflictos con sus parejas.

- "Te puedo decir que en la casa de mi marido es mi suegra la que les sirve a todos, y aquí es todo lo contrario, él muda, él baña, él viste.”

- “¿A él le costó adaptarse?

- "Le costó asumir, pero yo soy media dura en las cosas que digo, de repente me excedo pero yo les dije que a mi ellos [esposo y padre de la entrevistada] no me servían en esa actitud que estaban, no ganan nada con lamentarse, no ganan nada con preguntar por qué, no ganan nada..." (Entrevistada 18)

Detectamos, también, en los relatos de algunas de nuestras entrevistadas, la intención de romper con la reproducción del rol de cuidadora. La experiencia de cuidar les hacía pensar en sus hijos, específicamente en sus hijas, e intentaban liberarles de dicha responsabilidad.

"Yo también soy hipertensa, tengo la misma enfermedad de él [su padre dependiente], entonces le digo yo a los niños, a mis hijos, que si me llega a pasar algo así, que no... que busquen donde dejarme, pero que ellos se hagan cargo de lo que paso yo, no [1lora] es mucho, es mucho para una persona asumirlo, por eso les digo hagan una maleta y me dejan en un hogar, en alguna parte que alguno tenga que hacerse cargo, yo tengo 2 hombres y una mujer, y no porque la Francisca sea la mujer ella tiene que verme, no pues, ustedes buscan, saben que yo tengo un hermano que dice que cualquier cosa recurran a él, por eso ustedes hablen con su tío, yo sé que les va a ayudar [llora] para que ustedes no pasen lo que yo estoy pasando, es mucho.” (Entrevistada 23)

\section{Dimensión "Hombres ausentes del cuidado"}

La identificación de esta dimensión se desprende de los relatos de nuestras entrevistadas que compartían características del rol tradicional de cuidadoras, y que convivían con hombres que no participan de forma activa del cuidado de sus familiares, sino que generalmente desempeñaban el rol de proveedores, reflejando la división sexual del trabajo. 
"Claro, porque me pasa mi marido lo que me corresponde y yo tengo que hacerlo alcanzar para todo, porque a él le cancelan una vez al mes nada más, (...) más que está el lolo grande estudiando, es más difícil.” (Entrevistada 29)

En el caso de que el dependiente fuese un hijo/a, la pauta era que el padre se comportara como mero proveedor, y alguno ayudaba en aspectos puntuales del cuidado.

\begin{abstract}
"Sola, sola, yo pienso que debido a eso van las depresiones de repente, que a uno la pilla toda así, cuando empecé con la batalla de los colegios, de los médicos, del neurólogo, me sentí muy sola, demasiado sola, a lo mejor tenía mucha familia al lado, pero era yo la que tenía que andar para allá y para acá, era yo la que tenía que ir a entrevistas, era yo la que tenía que aceptar no, era yo la que me venía llorando por el camino de pensar que no me explicaban bien cómo eran las cosas.” (Entrevistada 29)
\end{abstract}

También estaba la experiencia de las mujeres que cuidaban de sus parejas y donde los hombres que integraban la familia (hijos, por ejemplo) les era asignado y/o asumían un rol de proveedores económicos, pero no participan de forma activa en otorgar cuidados al dependiente.

- "Usted sólo tiene hijos hombres ¿Ellos le ayudan de alguna manera con el cuidado del papá?"

- "No, ellos me ayudan en el sentido de pagarle a una persona, por ser ahora, en lo económico. Éste hijo que está acá, Oscar, es torpe, él se pone muy nervioso y no saben, bueno es cosa de práctica, si se van dando las cosas van aprendiendo, pero como ellos no están al tanto de decir: "Hoy día me toca a mí mamá, déjeme a mí, yo lo voy a mudar, a mudar a mi papá”, no saben cómo hacerlo, cómo hay que limpiarlo, y así pues, ellos no saben esa situación, prefieren pagarle a una persona para que me lo atienda, y más adelante voy a seguir con eso yo para que me lo venga a mudar no más, el resto: comida, remedios, todo eso ya lo tomo yo." (Entrevistada 14)

Se observa en este testimonio la reproducción de los roles tradicionales, a los hombres les correspondían tareas de producción y a las mujeres de reproducción, entre ellas el cuidado. Tanto esta cuidadora, como la que a continuación exponemos, reafirmaban el rol de que el hombre no cuenta con la "habilidad" natural, ni la disposición de cuidar, ni será capaz de adquirirla, y que la mujer lo hace porque sí la posee. 
- "Y en caso de que usted tuviera que salir, ¿Usted tiene a alguien que le reemplace acá en el cuidado de su esposo?"

- "No, tengo a mi hijo aquí, pero él es hombre ¡Qué va a saber!” (Entrevistada 4)

La participación del hombre en las tareas de cuidado siempre era minoritaria y marginal, se contaba con él para momentos puntuales y tareas determinadas, su actuar era percibido como un "favor".

\begin{abstract}
"A veces no tengo a nadie a quien dejar y me dice mi viejo: "Anda no más viejita yo me quedo con el Saulíto", él se queda con el niño, pero yo voy a hacer el trámite voy y vuelvo rapidito, es que mi marido no entiende mucho del niño, así que por eso." (Entrevistada 22)
\end{abstract}

Por otro lado, dentro de esta identidad de género masculina se identifica una actitud de negación o rechazo total al cuidado. Esta postura se daba en diferentes intensidades y situaciones.

\begin{abstract}
"Sí, ella vive en otro lado, y tampoco no tiene por qué, yo darle mi responsabilidad a mi hija si yo tengo hermanas y hermanos que podrían venir a ayudarme. Ellos dicen que no me ayudan porque ellas son mujeres [su madre y hermana dependientes], “¿Cómo nosotros vamos a mudarlas a ellas que son mujeres?”, bueno, les digo yo: “¿Cómo tengo que mudar a Raúl que es hombre?” (Entrevistada 9)
\end{abstract}

En el caso del cuidado de la madre (y hermana también en este caso), los hijos no cuidaban, la principal excusa para negarse a cooperar en esta tarea era aludir a que la/s persona/s dependiente/s era/n de sexo contrario y existía un lazo de familiaridad que le impediría actuar y manipularle/s (limpieza, muda).

En el caso de que la persona dependiente fuese mujer y tuviera pareja, caso de tres mujeres mayores afectadas por enfermedad de Alzheimer o demencia vascular, se podía dar el caso de que el esposo o conviviente simplemente no coopere o lo haga de mala forma. 
“(...) pero ahora con mi mami como está, le decía a mi papi que le diera [la comida], pero él tiene mala voluntad, no es el mismo amor de un hijo que el de un hombre, el hombre quiere lo mejor para él." (Entrevistado 26)

La situación más extrema, que se dio en esta situación, fue que las parejas de estas mujeres dependientes se negaron a atenderlas y terminaron abandonándolas al ver agravadas sus patologías.

“Conoció a un señor viudo de Temuco, y se fue a vivir a Temuco con él, dejó su casa acá a una hermana. Se fue a Temuco por varios años y fue muy feliz con ese señor, y con el tiempo mi mamá enfermó, y cuando mi mamá enfermó este señor la devolvió." (Entrevistada 13)

- "Entonces su deber era él estar con ella, yo haberla dejado con él. Pero yo dije: "Yo me la llevo, yo la cuido", pensando que me iba a ayudar."

- "Además, por lo que nos cuenta, cuando se enfermaba ella venía para acá."

- "Claro, el nunca la cuidó, cuando se sentía bien ella se iba." (Entrevistada 8)

\section{Dimensión "Hombres que asumen la tarea del cuidado"}

Son pocos los hombres que asumen la tarea de cuidadores, ya que si es que llegaban a intervenir en la situación de cuidado lo hacían de forma secundaria. Entre todas las personas entrevistadas solo fue posible contactar con tres hombres que se desempeñaban como cuidadores principales. Dos de ellos cuidaban de sus madres y el último a su esposa.

La condición previa a la situación de cuidado de estos entrevistados correspondía al patrón tradicional de tareas a desempeñar por un hombre, la de proveer para el hogar, con una mujer que hiciese que en éste todo funcionara.

"Claro, y ella era la que si se echaba a perder la llave ella la arreglaba, o buscaba al maestro, todas esas cosas, si había que pintar ella era la que se ponía a pintar, todo eso, y es que yo era el que proveía todo, ahora no.” (Entrevistado 28) 
Pero recae la responsabilidad de cuidar en estos hombres porque existía la voluntad de hacerlo por el cariño que sentían por la persona dependiente, y además no había mujer en la familia que pudiese desempeñar el rol.

"Entonces perdí la pega y mi mami tenía síntomas no más [de Enfermedad de Alzheimer], yo no sabía que iba a tener que cuidarla yo, nunca pensé eso." (Entrevistado 26)

Se observa que los hombres que adoptaban el rol de cuidador principal desempeñaban tareas y desarrollaban habilidades, características, sensibilidades o cualidades consideradas femeninas.

- ¿A usted aquí en la casa le toca hacer todo?”

- "Sí po', el aseo, la comida, lavar, limpiar, ver al perro, comprar, todo, o sea trabajo igual de 7 a 11 de la noche." [Risas]

- “¡Trabaja más!”

- “Pero soy apatronado!” (Entrevistado 28)

Generalmente, el aprendizaje del cómo cuidar lo hacían forzados por la necesidad, al verse en la situación crítica. La vivencia de los hombres del cuidado era distinta a lo que sucede con las mujeres que fueron socializadas desde pequeñas en el cuidado del otro.

- “Usted en algún momento ha recibido alguna formación para cuidarla a ella, capacitación? ¿O cómo lo ha hecho?”

- "Con voluntad, con amor, ¿Qué haría yo si yo estoy enfermo? ¿Cómo me ayudaría esa persona si estoy enfermo? ¿Qué necesitaría yo? me pongo a pensar, veo qué le falta a ella, hay que lavarla, pero sé las cosas que tengo que hacer... no sabía cocinar tampoco, nadie me enseñó." (Entrevistado 25)

Nuestros cuidadores desarrollaron habilidades que tradicionalmente se asocian a la femineidad", uno de ellos era homosexual y encontró en el cuidado de su madre la “justificación” de su orientación sexual.

"Yo siempre sufría por la homosexualidad, y yo decía ¿Por qué? Quería tener un hogar, quería tener hijos, porque soy apegado a eso, me hubiera gustado tener hijos a quien 
enseñar, alguien que me quisiera y no me lo dio, ¿Por qué salí así? Y ahora sé porque, era para cuidar a mi vieja, tenía que ser homosexual, no fui mujer, fui hombre, pero tenía que ser suave, cómo dijera, más sentimental, meticuloso, cuidadoso, me entiende, entonces todo lo que yo soy, lo estoy utilizando en mi madre, en quererla, en amarla tanto, es tan rico para mí eso.” (Entrevistado 26)

\section{Propiedad "Conflicto de roles"}

Logramos distinguir dentro del análisis de esta categoría dos aspectos en donde el cuidado genera conflicto o disrupción. Generalmente, las situaciones a las que hacemos mención son evidenciadas por las cuidadoras más jóvenes.

\section{Dimensión "El cuidado de hijos o padres es un factor que puede dificultar el mantener una buena relación de pareja”.}

En una parte anterior del análisis, al tratar las consecuencias del cuidado, se analizó este aspecto, pero consideramos importante mencionarlo al tratar el tema del género ya que representa para las entrevistadas una seria dificultad a sobrellevar.

Muchas de las entrevistadas que cuidaban de sus hijos o de sus padres relataban que dicha actividad había afectado sus relaciones de pareja, tanto si estaban en pareja como cuando ellas habían intentado establecer una nueva relación.

- "Su prioridad siempre ha sido su familia."

- "Siempre, si es que yo digo de traer una persona aquí en mi casa me da mucho miedo con todo lo que pasa, no saldría a trabajar tranquila que quedara un hombre extraño... a ella que no se sabe defender, y yo tener una pareja y vaya a pasar una desgracia aquí, no prefiero estar sola y no pensar que algo malo le pueden hacer, porque ahora confiar de un hombre, y que exista un hombre de buenos sentimientos, yo creo que son contados con los dedos, y si hay están ocupados ya, tiene sus parejas y todo, entonces al traer una pareja acá a la casa me da mucho miedo, prefiero estar sola, pero igual pienso yo de repente la soledad igual mata, de no tener uno a alguien que le diga, por último, "que amaneciste fea hoy día", ya es alguien que está preocupado de uno, pero son lujos."

- "Para usted, en estos momentos ¿Eso es un lujo?" 
- "Sí, yo lo veo así, para mi pedir eso es como pedir un lujo, tener [llora] voy a tratar de... cuando vaya al doctor de decírselo.” (Entrevistada 27)

Tras el testimonio de esta entrevistada podemos visualizar que dentro de su estructura tradicional de género ella quería tener una pareja, pero la desconfianza en "los hombres" le hacía postergar sus deseos a favor de proteger a su hija adolescente. Debió elegir entre el cuidar y el tener pareja.

\begin{abstract}
“(...) pero cada persona tiene sus problemas, y en muchos casos, no en muchos, en casi todos, con excepciones contadas con los dedos, son casos en donde están compenetradas las parejas, porque si usted se da cuenta de que los dos están al tanto de la situación, o comprenden que la mamá se cansa, que la mamá necesita un ratito libre, son contaditos con los dedos, de las mamás que yo conozco son separadas, con parejas o maridos, pero es muy solitario llevarlo, y más porque en parte uno tiene que entenderlo porque los hombres salen a trabajar, llegan en la tarde, salen temprano, los ven los fines de semana, en la tarde un ratito cuando llegan, se acuestan, duermen y la rutina es así, entonces la que lo lleva todo, la que lo lleva al médico, es uno la que le da el remedio, todo eso es la mujer." (Entrevistada 29)
\end{abstract}

En el caso de las mujeres que tenían pareja, la situación de cuidado podía llegar a generar quiebres dentro de la relación de pareja debido al desequilibrio en tiempo y cuidados al dependiente en desmedro de la pareja. Generalmente, los hombres no asumían un rol protagónico en el cuidado de los hijos dependientes, como hemos señalado anteriormente se remitían a desempeñar el rol productivo.

\title{
Dimensión "El cuidado es de difícil conciliación con el rol de trabajadora (trabajar fuera de casa de forma remunerada)"
}

La demanda de tiempo y energías que implicaba el cuidado, por un lado, y la visión tradicional del rol de la mujer dentro de la familia, por otro, implicaban que la tarea de cuidar fuese incompatible con el trabajo para las mujeres cuidadoras entrevistadas, más aún para aquellas de ámbitos rurales y con mayor edad. 
"Sí, y yo no puedo salir a trabajar en nada, porque si un sabe hacer cosas ¿A quién le vende? Entonces tengo que depender sólo de lo que mi marido me da y eso que a veces le sacan en cara a uno que le dan plata, un sueldo mínimo es sólo para comer [se emociona]." (Entrevistada 20)

En este conflicto rondan los roles del hombre proveedor y la mujer reproductora, que acentúa las jerarquías y situaciones de dominación que hubiesen podido existir en la relación de pareja.

\section{Síntesis}

La categoría que acabamos de analizar, a través de la identidad de género reflejada en el cuidado, podría ser considerada de forma genérica como un factor de riesgo de sobrecarga. Debido a las dimensiones analizadas referidas a la mujer que asumía la tarea de cuidado de forma tradicional y a la alta frecuencia con que los hombres están ausentes del cuidado, la asunción del rol de cuidador por parte de un varón también podría constituirse en un factor de sobrecarga. En el caso de las mujeres que asumían su tarea de forma no tradicional, ellas intentaban mitigar la sobrecarga desprendiéndose de otras ocupaciones. Así también los conflictos de roles descritos se constituían en factores de sobrecarga en sí mismos. 


\subsection{CATEGORÍA "SITUACIÓN SOCIOECONÓMICA DE LOS CUIDADORES Y SUS FAMILIAS"}

Esta categoría procura abordar los aspectos que determinan las condiciones socioeconómicas de los cuidadores y sus familias. La elección de centrarnos en estudiar cuidadores y familias, de estratos socioeconómicos bajos o medios-bajos, constituye a priori la identificación de esta categoría como un importante factor de sobrecarga para el cuidador.

\section{Propiedad "Situación socioeconómica del cuidador y su familia"}

\section{Dimensión "Precariedad de las economías familiares"}

Con la intención de ubicar cuidadores que formaran parte de sectores socioeconómicos bajos y medios-bajos, la mayor parte de las personas entrevistadas fueron contactadas a través del programa de postrados del MINSAL ${ }^{113}$, cuyos usuarios ingresan a éste de acuerdo a su nivel socioeconómico (bajo). Entonces, la realidad con la que nos encontramos estaba marcada por la vulnerabilidad socioeconómica de estas familias.

Las economías familiares de la mayor parte de las cuidadoras entrevistadas eran bastante precarias, cubrían las necesidades básicas de sus integrantes, pero cualquier situación extraordinaria, como gastos no contemplados, desestabilizaba los ingresos y les llevaba a priorizar en función de lo más urgente o importante.

\footnotetext{
"Entonces tocó que le dio una neumonía, entonces ya de ahí no lo llevamos más... llegó un momento en que quisieron ponerle sondas al estómago, por uno u otro motivo ya no lo llevamos, no tuvimos locomoción [forma de transportarle] para llevarlo..." (Entrevistada 1)
}

"Y en la Teletón, cuando la Daniela estaba enyesada con esos yesos, tenía que entrar a llamar a la Teletón que me vinieran a buscar en caso de los controles, o juntar mis monedas y llevarla en taxi no más, porque el consultorio no da la opción de decir

\footnotetext{
${ }^{113}$ Todas las personas entrevistadas en sectores urbanos forman parte de este programa, también una parte de las que fueron entrevistadas en sectores rurales (Localidad de Hospital, comuna de Paine).
}

Página $\mid 325$ 
"necesito que me lleven a la Daniela de aquí a la Teletón", eso no se puede." (Entrevistada 27)

Los verbatims anteriormente citados dan cuenta de la deprimida situación económica de las familias, que les impedía o dificultaba realizar un correcto seguimiento en el tratamiento de las patologías de sus dependientes, ya que trasladarlos a los centros asistenciales para ellos implicaba un gasto extra muchas veces imposible de asumir.

Así también, en el trabajo de campo, fueron entrevistadas personas que contaban con un nivel de ingresos un poco mayor (medios-bajos), con características socioeconómicas que los hacían quedar al margen de cualquier ayuda estatal o subvención, pero dados los gastos en los que debían incurrir con su(s) dependientes(s) hacían que su situación económica se tornara vulnerable.

\footnotetext{
"Por ejemplo, nosotros no estamos en ningún programa del Estado, nada, porque mi marido trabaja, tiene su profesión, yo tengo mi cuarto medio [bachillerato], y no hay nada, no entramos en ninguna, incluso la ficha CAS, la de Protección social, me salió 12 mil puntos y eso que mi marido estaba sin pega, pero como tiene estudios superiores y yo cuarto medio, no importó que los niños tuvieran alguna dificultad, usaran o no pañales permanentes, no.” (Entrevistada 18)
}

La precariedad de las situaciones socioeconómicas de las familias investigadas se vio reflejada en múltiples aspectos materiales. Para el caso de nuestra investigación, las carencias observadas y expresadas en los discursos de los cuidadores generalmente estaban teñidas por la angustia de no poder brindar al familiar dependiente los cuidados básicos necesarios por insuficiencia de recursos.

\footnotetext{
"Había momentos en que no hallaba que hacer, porque hay que saber comprarle pañales.” (Entrevistada 3)
}

"Sí, me la dieron en el consultorio [una silla de ruedas] y colchón anti escaras, me
dieron uno, pero ya vamos en el tercero, se rompe... teníamos dos, entonces le
poníamos uno para arreglarlo, le poníamos el otro, llegó el momento en que los motores 
se echaron a perder, como que están para un año no más. (...) en el consultorio dan uno solo, hablé en el consultorio y no, que ellos dan uno solo." (Entrevistada 1)

En el caso de los padres cuidadores de niños dependientes, estos evidenciaban su preocupación por no poder otorgar a sus hijos estimulación o incluso un diagnóstico certero de sus patologías por la falta de recursos económicos.

"Si yo pudiera darle más, si yo tuviera dinero, yo pescaría mi cabro chico y lo llevaría a Mundo Mágico, a Fantasilandia [parques de atracciones], entonces si yo pudiera darle más, yo le daría en ese sentido, porque tomaría un auto y le diría: "Ya, déjeme ahí", pero como yo sé que no tengo eso, en ese sentido le contesto que yo podría hacer más por él, (...) pero no puedo hacerlo porque la plata no alcanza, qué más puedo hacer por él que sacarlo a dar vueltas no más, si lo invitan a un cumpleaños de un familiar lo llevo." (Entrevistada 30)

"Sí, lo tengo que hacer particular [pagar un examen médico], y no pude hacerlo en noviembre porque estaba en el colegio, ni en diciembre porque se me resfrió, tuve que llevarlo al pediatra, tuve que comprar remedios, todas esas cosas, entonces quedé de llevarlo ahora en las vacaciones." (Entrevistada 29)

Dentro de las carencias observadas en el trabajo de campo, y que son comprobadas en los relatos de los cuidadores, estaba la imposibilidad de contar con un espacio físico adecuado para las necesidades del familiar dependiente. Aunque este tema es tratado en detalle a continuación, en el tema dedicado a la influencia del medio urbano y del medio rural en el cuidado, nos interesa relevar la información desde la perspectiva socioeconómica.

- "Para limpiar a su hijo, para bañarlo ¿Cómo lo hace?"

- “Acá yo lo baño así no más, yo lo siento y lo baño allá afuera [indica el patio de la casa], le echo el agua por arriba, como él no se para, para él es más seguro que lo bañe sentado, claro que me cuesta sola pa' bañarlo, pero menos mal que camina algo, si tuviera que caminar en brazos con él sería..." (Entrevistada 15) 
Las viviendas de estas familias generalmente contaban con lo básico para que fuesen habitadas, pero no con dimensiones y/o adaptaciones para las personas que tenían dificultades de movilidad.

- “Duermen juntas?”

- "Sí, porque aquí no puedo hacer ampliación, una por la plata y lo otro aquí dentro no puedo porque le quito espacio a ella, entonces tengo que ingeniármelas." (Entrevistada 27)

- “Su casa usted la tuvo que adaptar para recibir a su hijo?”

- "Sí, por ejemplo desarmar el comedor, aquí había un dormitorio y de aquí para allá era el comedor, y mandar a guardar las cosas, yo ahora solamente tengo puro dormitorio, todo más reducido, nunca pensé que iba a quedar una pieza (habitación) tan grande y bonita, las cosas se dieron, más que nada fue ayuda de la familia también, porque cuando a nosotros nos avisaron que el Luis se venía a la casa mi marido hacía poco que había comenzado a trabajar con el transporte escolar, entonces no había plata disponible, se tuvo que hacer la instalación [eléctrica)] nueva, se tuvo que forrar de nuevo, se pintó y se fueron dando de a poco las cosas, me regalaron muebles, velador (mesa de noche) para guardar sus cosas, cajoneras, amigas, hermanas, la familia, tuve que hacer un gasto para traerlo, tuve que transformar acá." (Entrevistada 24)

En el anterior testimonio, la familia del cuidador fue la que cooperó materialmente para poder adaptar un espacio para el niño dependiente. La falta de espacio y recursos económicos era un freno para brindar mayor bienestar a los dependientes, y había circunstancias en que las condiciones de las viviendas llegaban a revestir peligro para sus habitantes.

“Esta casa es antigua, la hicieron el 85' [año en que ocurrió un terremoto en la zona] con los restos de la otra casa, tiene harto peso arriba. Y ahora una señora me dio unos paneles después del terremoto [se refiere al último terremoto, en febrero de 2012], y me hicieron una pieza más allá, para cambiarla a ella, para que estuviera más livianita porque el terremoto fue terrible para mi, estuvimos las dos solitas, encerradas, yo lo único que veía era que íbamos a quedar debajo de la casa, y eso que yo me programaba para una cosa así, yo siempre lo pensaba, que yo le tenía miedo a esta casa que si pasaba esto, yo iba a tomar a mi mamá y la iba a meter debajo de la cama, y ese día yo no hice 
nada, nada, nada... bueno lo único que trataba de taparla a ella con un cojín pero yo me veía con la casa encima." (Entrevistada 20)

Además, en algunas de las viviendas visitadas se constataban situaciones de hacinamiento, existían viviendas donde habitaban más de dos familias bajo un mismo techo, haciendo "fondo común" para comer.

- "Usted aquí vive con su hijo, con su nieto..."

- "Mi hija vive en esa pieza con su hija, pero yo tengo que cocinar, ella me da diez mil mensuales de la plata que ella recibe, ella tiene dos cargas familiares, esa es toda la plata que me da, y la luz que le exijo porque... si no me cree yo le voy a mostrar el recibo de la luz, cincuenta y tantos mil pesos casi todos los meses de luz, entonces eso lo dividimos entre tres, de repente salen diecisiete mil quinientos, dieciséis mil. Entonces yo pongo mi parte y la Silvia tiene que poner su parte.” (Entrevistada 3)

Es necesario destacar el dato que surge al analizar los hogares que fueron entrevistados, de los veintisiete hogares donde la persona que cuidaba era mujer, doce de ellos correspondían a núcleos familiares monoparentales. En estos hogares sostenidos económicamente por mujeres la vivencia de la pobreza era un factor común.

"De repente me quedo dormida al segundo que me acuesto, pero a las 2, 3 de la mañana me despierto y ya no hay caso porque me tengo que levantar, todo esto es por la plata que no hay en la casa, digo tengo esto, y uno se va complicando más. (...) claro, porque aquí es mi plata la que entra no más, entonces con mi plata hay que pagar todo, y entonces cuando llegan estas fechas [se refiere a navidad] no tengo plata, yo a ninguno le puedo hacer regalos porque no hay, entonces todo eso me complica [lo dice sollozando], complica que vayan pasando y no hay una solución.” (Entrevistada 27)

La situación económica de estas familias era bastante precaria e inestable debido a la dificultad que se les planteaba a las cuidadoras a la hora de buscar trabajo. Como anteriormente lo mencionábamos, en la categoría del género, si tenían un trabajo fuera de casa generalmente era un trabajo informal que les permitía tener flexibilidad en el 
tiempo que se le dedicaba. Pero la mayor parte no tenía más opción que quedarse en casa cuidando del dependiente, y buscar desde ahí alternativas para sobrevivir.

\begin{abstract}
"Inscribiéndome por aquí, por allá por ayuda, porque yo dejé de trabajar y no tuve más ingresos, y tengo una hija en la universidad, y tengo un hijo que es discapacitado y no trabaja, así que cambiamos todo nuestro esquema de vida, nos bajamos del mundo en que vivíamos, empezamos a botar esto, ya no se paga más esto, no se paga esto otro, devolvemos cable, devolvemos aquí, devolvemos allá, ya no se va más a comer afuera, no se va más al supermercado, el auto no se cambia, no quedamos con un auto, etc., etc." (Entrevistada 13)
\end{abstract}

- “Usted no trabaja fuera de la casa?”

- "No, por ahora no. Estoy buscando trabajo eso sí, porque necesito trabajar, uno no vive de estar en la casa... en eso estoy." (Entrevistada 2)

Considerando la compleja y vulnerable situación económica de las familias de las cuidadoras y cuidadores entrevistados, se observa que la postergación de las necesidades del cuidador era un factor común.

\footnotetext{
"Yo estoy muy enferma mi niña, míreme la hernia que tengo, tengo dolores a los huesos, ahora se me quebró este diente que no me lo he podido arreglar, primero pagar la matrícula de mi hija, me duelen los huesitos donde hago fuerza con él, la espalda, la columna, el pecho, los brazos, éstas partes de aquí.” (Entrevistada 19)
}

\title{
Dimensión "Historia de pobreza"
}

La vida de la mayor parte de estas familias estaba marcada por la pobreza, algunas de las personas entrevistadas rememoraban en sus discursos las necesidades y penurias vividas en el pasado.

\footnotetext{
"Es que yo hace en años que vivo acá, todo el mundo nos conocemos acá, es una manzana entera aquí que vivíamos casi juntos antes, allá en Sierra Bella, se formó un comité, ¿Me entiende? Y cuando se tomaron esos sitios en la Victoria, ahí me vine a tomar los sitios yo, tenía a mi hijo mayor que tenía un año y 7 meses, y él tenía dos
} 
meses, ¡Chiquitito! La sufrí, pero, ahí estuvimos varios meses, y después los militares tasaron aquí, y de ahí para allá todavía eran puras chacras, si cuando nosotros llegamos acá, en el año 58' ahí empezaron a tasar sitios de nuevo, si habían choclos, sandías, melones, de todo para allá... oh, pero sabe que sufrimos mucho, porque nos dieron los puros sitios, y yo como mi marido se tomaba [bebía] la plata, se iba con mujeres y se amanecía, llegué con 4 palos y 10 fonolas [cartón prensado impregnado para techos provisorios], ese fue el techo que tuve, menos mal que fue el verano, de a poco, de a poco hicimos unas piezas de barro, barro con paja, y después a los años nos salió la autoconstrucción y aquí estamos, entonces... porque mi marido se fundía la plata, yo sufrí mucho, mucho.” (Entrevistada 3)

Situaciones como el alcoholismo, embarazo adolescente o muerte de progenitores eran frecuentes en el pasado de las familias de los cuidadores que tenían menos recursos económicos, un elemento común en este tipo de familias que confirman la reproducción de la pobreza.

- "Cuarenta y un años, mi mamá quedó viuda joven, yo tenía diez años cuando él murió."

- "Su mamá tuvo que sacarlos adelante a todos."

- "Sí, si yo le cuento a mi hija, si nosotros éramos pobres, pobres, pobres, en el colegio siempre nos discriminaban por lo mismo, porque éramos muy pobres, es que la discriminación nunca se va a terminar." (Entrevistada 9)

“(...) entonces trabajé toda mi vida, desde los 9 años trabajé, me casé, quedé embarazada y me dediqué a la casa.” (Entrevistada 29)

\section{Dimensión "Solvencia económica"}

Existía un grupo de cuidadores, minoritario dentro de la muestra entrevistada, que contaba con una situación económica que les permitía enfrentar los gastos de la enfermedad de sus dependientes sin tener que limitar sus gastos en las necesidades básicas de su hogar y miembros.

“En estos momentos no estoy sobrada, pero no me falta." (Entrevistada 14) 
Las familias que contaban con una situación económica más holgada, en relación al resto de los entrevistados, eran todas de entornos rurales. Casi todos los familiares dependientes de estos entrevistados formaban parte del Programa de atención domiciliaria de personas con discapacidad severa ${ }^{114}$, anteriormente mencionado, pero debido a que su nivel de ingresos no era deficitario, no recibían estipendio.

\begin{abstract}
"Cambiarla allá, hubiéramos sabido antes también... bueno allá es caro, los tratamientos son caros, por eso que mucha gente opta por lo otro que es gratis o más barato [se refiere a la salud pública], pero no es la mejor, no es lo que corresponde, es una aspirina que le dan a uno, en cambio allá en la clínica le dan lo que realmente necesita, y nosotros no hicimos eso, no llegamos antes allá, y es que mi mami también es porfiadita, esperó hasta el último momento, pero era también por un tema económico, pero ahora gracias a los locales y la ayuda del hijo menor, se ha podido también costear todo eso." (Entrevistada 12)
\end{abstract}

La posibilidad de poder entregar al enfermo una atención en salud oportuna, especializada y de calidad en Chile es una alternativa que se logra pagando el costo de la atención privada. De este modo, este tipo de familias podía desembolsar dinero para la compra de medicamentos, ayudas técnicas, realizar adaptaciones en las viviendas, traslados del dependiente a terapias o atención, incluso una de estas familias podía permitirse el pagar por unas horas diarias a una persona que coopere en el cuidado del dependiente.

- "Y en el caso de que su papá se enferme, tenga una urgencia ¿Usted tiene cómo llevarlo al hospital?"

- "Sí, en vehículo, sí. Hasta hace poco lo llevaba a Santiago, porque estaba tomando anticoagulantes, también había que llevarlo allá, hacerle los exámenes, esperar, yo siempre lo traslado donde sea." (Entrevistada 23)

- “¿Cree que su vida social se ha visto afectada por tener que cuidarlo?”

114 También conocido como "Programa de postrados". 
- "No fijese, porque yo asisto a un grupo de adulto mayor en Buin, que no he ido por mi enfermedad, pero hace un año que estoy en esa agrupación, somos cincuenta personas, no he ido por mi vista, pero yo me las arreglo, planifico porque nos reuníamos los días martes por la tarde y Yasna, otra socia de la agrupación que viene a hacer aseo aquí, y ella venía por la tarde para que yo pudiera ir a Buin, de tres a cinco, y yo iba a tomar tecito afuera, ahí me daba un relax." (Entrevistada 14)

Generalmente, los recursos económicos con los que estos entrevistados contaban, y que les permitía poder desenvolverse económicamente de mejor forma, estaban relacionados con el patrimonio y con la ayuda económica de sus hijos.

"Ella trabajó toda su vida, trabajó mucho para tener sus negocios ahí, tres locales comerciales, y eso ha ayudado harto, y el hijo menor que también tiene buena situación y él aporta con algo también." (Entrevistada 12)

\section{Propiedad "Ingresos"}

\section{Dimensión "Ingresos recibidos por pensiones, subvenciones, ayudas y/o programas"}

Los grupos familiares entrevistados contaban con ingresos exiguos. Monetariamente, estos provenían principalmente de pagas por trabajo, pensiones y subsidios del Estado. También recibían ayuda material de parte de ONG's y diversos programas del Estado.

El dinero que ingresaba a la economía de las familias, aportado por el/la jefe/a de hogar como pago a su trabajo, generalmente, era el único por este concepto, ya que sí existía otra persona en edad de trabajar, ésta era la persona que cuidaba del dependiente (y como hemos visto anteriormente, el número de cuidadores que compatibilizaban el trabajo remunerado con la tarea del cuidado era escaso).

"Mire, últimamente no me he sentido bien, porque he estado muy angustiada, con mucha pena, mucha preocupación, como ya se acerca fin de año, ya sé que una plata que es relativamente segura, deja de recibirse, mi marido empieza estos meses a hacer viajes." (Entrevistada 24) 
Como anteriormente mencionáramos, una tercera parte de los cuidadores eran además jefes/as de hogar, lo que implicaba que debían crear estrategias de trabajo para conseguir ingresos económicos.

\begin{abstract}
"Bueno igual ella recibe una pensión asistencial, y algunas cosas que tengo yo las llevo a la feria, yo no trabajo en la feria, se las paso a un caballero para que las venda, y eso, si sale algún trabajito que yo puedo efectuar aquí igual lo hago, (...) porque yo no puedo tener un trabajo estable porque no tengo con quien dejar a mi mamá, y lo de mi mamá es cuidado a diario, yo descanso cuando mi mamá está acostadita y yo cuando la veo que está durmiendo ahí yo me relajo.” (Entrevistado 25)
\end{abstract}

\begin{abstract}
"Yo tengo mi máquina, tengo mi máquina de pie, la que bordaba, una Remington de sobremesa y tengo una overlock... y también cuando pude me compré un horno semindustrial que a veces nos llegan pedidos de empanadas, hacemos empanadas, tres portes de empanadas, ahí hacemos el trabajo.” (Entrevistada 1).
\end{abstract}

Una fuente importante de ingresos para estas familias eran las pensiones ${ }^{115}$. Una pequeña parte de éstas correspondían a jubilaciones derivadas de cotizaciones realizadas durante la vida laboral del dependiente o de los cuidadores.

- “La señora Gabriela recibe alguna pensión?”

- "Sí, su jubilación, su pura jubilación no más. (...) Era empleada doméstica ella, es como de ciento veinte mil pesos, y eso es poquito para lo que nos alcanza." (Entrevistada 8)

Pero la mayor parte de las pensiones que estas familias recibían eran pensiones no contributivas, la pensión básica solidaria, que el estado chileno entrega a las personas mayores de 65 años que no habían cotizado (o que éstas no alcancen un mínimo), o a personas que acrediten un grado de minusvalía que les impida trabajar.

\footnotetext{
${ }^{115}$ Este tema será desarrollado en detalle en la categoría pensiones, del epígrafe Percepción sobre el estado.
} 
"Mi señora se pensionó y yo hace como... en septiembre me dieron una pensión de ayuda, porque yo tenía imposiciones pero no tenía como para jubilarme, porque del año 75 que quedé sin trabajo y me puse a trabajar particular." (Entrevistado 28)

Otro ingreso, mencionado por la mayor parte de las personas entrevistadas, correspondía al llamado "estipendio", dinero que el Estado entregaba a través de los centros de salud a los cuidadores de dependientes que tuvieran condiciones económicas precarias. La cantidad de este subsidio era simbólica ${ }^{116}$ y, a pesar de que era un dinero para el cuidador, éste lo destinaba a lo que hiciera falta al dependiente.

"Mire yo ahora recibo, he recibido, por la ley que sacó la presidenta, de esos veinte mil pesos que le dan, estuvieron como dos años que no me dieron, pero me lo dieron la plata de dos veces, para mí fue una tremenda ayuda porque con esa platita, de repente uno pide fiado porque no da pa' tanto la plata. Yo detesto pedir fiado porque al abrir una cuenta en un negocio nunca le van a anotar lo que valen las cosas, sino que al ser fiadas le agregan unos pesos de más pues, eso detesto yo, pero salí de eso gracias a Dios, y me sirve pues, para pagar el agua, pa' pagar luz, comprar gas, en el invierno casi toda mi plata se va en puro gas." (Entrevistada 3)

Los programas desarrollados por el Estado, en el ámbito sanitario, constituían una ayuda a los ingresos de estas familias. Mencionamos, primeramente, el llamado Programa de atención domiciliaria de personas con discapacidad severa, ejecutado desde los centros de salud públicos y que contemplaba una serie de acciones -atención domiciliaria, transporte, entrega de medicamentos y ayudas técnicas, etc.- que si bien no implicaba la entrega de dinero, significaba un ahorro para las economías de estas familias.

“(...) tiene colchón antiescaras, su catre clínico, su silla de ruedas, pero esa me la dieron en el "poli" [policlínico, centro de salud], esa no la compré, el colchón antiescaras también, nos lo dieron allá para proteger sus escaras, pero igual hay que lubricarlo en todas las mudas y cambiarlo de posición para que así no se produzcan. (...) los remedios de él me los dan todos en el poli." (Entrevistada 14)

${ }^{116} \mathrm{Al}$ cambio, en la época en que se desarrolló el trabajo de campo, equivalen a $28 €$.

Página $\mid 335$ 
Otro programa sanitario público que apuntaba en la dirección anteriormente señalada (de ayuda a las familias) era (todavía sigue en vigor) el Programa AUGE ${ }^{117}$, que garantizaba la atención en salud de varios de los dependientes de acuerdo a las patologías padecidas.

"Y gracias a eso es que se pudo seguir dializando allá porque el banco empezó a pagar la diálisis, si yo nunca he pagado un veinte de esos años que se dializaba, porque mi señora hará un año que está con AUGE, pero antes todo lo pagaba el Banco del Desarrollo, lo único que de la pensión le están descontando como siete mil mensual, si usted saca la cuenta cada año que se dializaba eran cuatro o cinco millones... (...) y de ahí nos dieron el pase para que la vinieran a buscar y a dejar gratis, y así ha sido todo.” (Entrevistado 28)

También, existen ONG's que prestan ayuda material a las familias de varios de los dependientes. Principalmente, ésta se concretaba en la donación de pañales para adultos, necesarios para los dependientes que no controlan esfínteres, y que significan una parte importante del gasto en las economías de estos hogares. La organización mencionada por todos es el Hogar de Cristo, institución de inspiración católica que entre sus labores sociales está el apoyo a los "postrados".

"En el Hogar de Cristo, le estuvieron dando pañales, pero los dan por un tiempo no más, pero no han dado más, dieron como dos años, después yo hablé con la asistente y me siguieron dando, pero después ya me dijeron que no habían más pañales. Pero ahora andaban haciendo una campaña que estaban dando para los postrados pañales.” (Entrevistada 15)

\section{Dimensión "Ayudas de sus redes"}

Entre los ingresos con que estas familias contaban estaba la ayuda que le proporcionaban sus conocidos, principalmente la familia cercana. Estos apoyos se manifestaban principalmente en apoyo a través de dinero, especies o servicios.

${ }^{117}$ Acceso Universal con Garantías Explícitas en Salud, detalle del programa en capítulo IV del marco teórico. 
"Los exámenes que le estoy haciendo al Felix han ido de a poquito subiendo, cada vez más caros, ahora tengo que hacerle uno que sale cuatrocientos cincuenta mil (...) mira, gracias a Dios tengo a mis suegros que me ayudan harto, no son gente de plata, pero los dos trabajan y están pendientes, mucha ayuda de mis suegros, de mi papá, y aquí que los dos trabajamos, yo trabajo aquí en la casa.” (Entrevistada 18)

"Y la otra es que yo les pedí una ayuda monetaria a mis hijos, con el fin de hacer una huerta, (...) pero no lo conseguí, no lo conseguí, no, de todos los hijos, solo de una, porque hay una hija que viene, nos trae ayuda, viene una vez al mes, nos trae mercadería ${ }^{118}$, me compra remedios, y es la más pobre de todas.” (Entrevistada 11)

\begin{abstract}
"Un sobrino me ha estado llevando [al hospital donde realizan terapia a su hijo], me iba a buscar, porque mi marido no podía, por el trabajo es imposible, entonces eso también, estar molestando a otras personas, uno se siente complicada, yo sé que él lo hace con mucho cariño porque es su primo, somos sus tíos, pero igual uno, yo al menos me sentía así, estar molestando, pidiendo ayuda a otra gente, no son personas extrañas, pero yo digo a lo mejor pueden ocupar su tiempo en otras cosas, porque mi sobrino igual durante su trabajo se ofrecía y me iba a buscar al hospital.” (Entrevistada 24)
\end{abstract}

\title{
Propiedad "Gastos vinculados al cuidado"
}

\section{Dimensión "Necesidades del dependiente"}

Reconocemos, en los relatos de nuestros entrevistados, la necesidad de enfatizar lo difícil que les resultaba solventar todos los gastos relacionados con el cuidado de sus dependientes. Los costos, que son asumidos con dificultad por las familias, se relacionaban directamente con el grado de dependencia, y pueden ser plasmados en los siguientes recursos, que son los que generan dichos gastos:: pañales, productos de farmacia y parafarmacia, alimentos especiales, equipamientos (colchón antiescaras, cama clínica, sillas de ruedas), medicamentos, tratamientos y consultas médicas, exámenes privados, desplazamientos para atención médica o rehabilitación, etc.

${ }^{118}$ Ultramarinos 
El gasto más común entre los dependientes era el de pañales desechables, ya que una gran parte de éstos no controlaban esfínteres y debían hacer uso de este artículo. El gasto en la compra de estos productos podía llegar a significar una parte importante de las pensiones recibidas por estas familias.

"Ella tiene una pensión de setenta mil pesos y yo, en los puros remedios, gasto cuarenta mil, en los pañales no le digo cuanto. Por ahí, por intermedio de contactos, me logré comunicar con el Hogar de Cristo que me ayuda con un poco de pañales. (...) ella ocupa cinco a seis pañales en el día, y en la noche son dos, le pongo doble pañal, sus cremas, todas sus cosas, afortunadamente hemos podido hasta aquí, todavía sobrevivir un poco, pero me ha producido muchos, muchos trastornos.” (Entrevistada 13)

Los dependientes que estaban postrados debían contar con cuidados higiénicos especiales para su piel, para ello debían realizar la compra de productos cosméticos y de farmacia que les ayudaran a evitar la formación de úlceras de presión.

- ¿YY el cuidado de su mamá implica mucho gasto?”

- "Los pañales, implica todo, los apósitos, las cremas, una cantidad de cosas, mi mamá tiene una escara atrás, que salió el 2007 con ella, así una cosa atrás [la ejemplifica con la mano], del hospital de aquí.” (Entrevistada 10)

En lo nutricional, los alimentos específicos, que por lo general alcanzaban valores altos en el mercado por su especialización, se constituían en gastos que en ocasiones resultaban inabordables para estas familias.

“(...) que no hay bolsillo que aguante, el Luis al comienzo gastaba cuatrocientos mil y tantos mensuales, porque tomaba pura leche, tenía que tener quince tarros mensuales, no le podía dar comida ni nada porque él estaba en estudio, porque estuvo tomando la leche Purita Cereal cuando llegamos acá, le hizo mal, estuvo tomando la Petit junior, estuvo tomando no sé qué otra leche más y ahí con esa ya ha ido bien, porque se estaba desnutriendo totalmente, porque todo le hacía mal, y había que cambiarle pañales cada 10 minutos." (Entrevistada 24) 
Como tratáramos en el apartado de los ingresos, algunos de los gastos que estaban relacionados con la actividad de cuidado del dependiente eran resueltos a través de las ayudas, programas o subvenciones. Por ejemplo, los dependientes que eran usuarios del programa de postrados, podían ser beneficiados con equipamientos más específicos a su situación como colchones antiescaras, catres clínicos o sillas de ruedas. Muchas de estas ayudas sólo se otorgaban por una vez y no podían ser renovadas, aunque con el uso el equipamiento entregado se haya deteriorado y estropeado. En ese caso, eran las familias las que debían adquirir un nuevo equipo o repararlos, pensando en que para las economías de éstas significaba un gasto enorme.

\footnotetext{
“(...) y el colchón antiescaras que me habían dado en el Hogar de Cristo se me rompió, y yo le compré los parchecitos que valen dos mil y tantos pesos, dio resultado pero después se rompió en varias partes más. Entonces yo, primeramente le echábamos la culpa al motor, tuve que comprarme un motor, yo lo pagué. Con esos ciento dos mil pesos yo tengo que comer, pagar las cuentas y todo, lo saqué y lo tengo pagado gracias a Dios, y ahora le saqué un colchón antiescaras, lo estoy pagando, recién llevo una letra." (Entrevistada 3)
}

El programa AUGE, del cual eran beneficiarios varios de los dependientes cuyos cuidadores fueron entrevistados, contemplaba para cada una de las patologías elegibles un abanico de acciones solventadas por el sistema público de salud, que consistían principalmente en atenciones médicas, medicamentos, entrega de equipamiento y servicios asociados. Pero todo lo que no estaba señalado dentro de las garantías explicitas en salud debía ser financiado por las familias de estos enfermos.

"Los remedios que hay que comprarle, hay unos que son baratos, eso no es problema,
pero cuando tiene problemas de descompensación, de alzas de algunas cosas, la doctora
la ve y le da ahí mismo una receta, pero que son caras (...). claro, por ser la semana
pasada, no sé si fue martes o jueves de la diálisis, le baja la presión y fue tanto lo que le
bajó la presión que la enfermera, la sacaron antes y la mandaron altiro a que se hiciera
un examen, porque en cualquier momento le podía dar un ataque al corazón porque
tenía 40 de presión, (...) entonces el mismo caballero que la trae, la tomó y la llevó,
porque como ellos conocen todo eso, entonces ahí ya hay que sacar un bono y pagar el
examen, gracias a Dios el mismo chofer pagó lo que salió el examen y después le
devolvimos la plata, nos ha pasado varias veces que le han tenido que hacer otros Página 339 
exámenes y las doctoras le han comprado los bonos, porque no se puede esperar." (Entrevistado 28)

En el caso de los dependientes, que no eran sujetos elegibles de programas o subvenciones las familias, éstos debían costear los gastos que implicaba tener al dependiente en buenas condiciones. Es así como dentro de lo estrechas que eran sus economías debían solventar gastos en equipamiento, medicamentos, etc.

\footnotetext{
- "Ahora cuando hay que hacerle exámenes, cuando hay que hacerle scanner..."

- "Porque ¿Todo lo tiene que pagar particular?

- "Claro, los scanner, los remedios que hay que comprarle, ¿Qué más? Cuando se enferma del estómago el gasto en pañales, que eso es más gasto, pero eso es a lo lejos, no es siempre." (Entrevistada 16)
}

\begin{abstract}
"No, ella está en cama clínica, yo tengo en cama clínica a mi mamá, yo creo que ahí estaría para la corneta [estaría muy mal], está en cama clínica mi mamá, siempre ha estado en cama clínica gracias a Dios, ahora yo tengo esa cama, esa cama es de ella, porque en un comienzo se la arrendaba, ahora es de ella esa cama." (Entrevistada 10)
\end{abstract}

El pago de los desplazamientos en vehículo del enfermo también significaba un gasto importante para las familias de los dependientes, ya que estos debían realizarse en transporte privado, taxis o arrendar un vehículo que lo permitiera.

- “Y cómo lo hace cuando a él lo tiene que llevar por ejemplo al médico?”

- "Al médico, antes no pedía jamás ambulancia porque nunca había, sabe que yo me tenía que conseguir plata cuando no tenía, para llevarlo en un taxi, y sabe lo que es molesto para él, porque no se puede doblar, es terrible.” (Entrevistada 3)

\title{
Síntesis
}

Comenzamos analizando esta categoría abordando la situación general de estas familias, mostrando un marco general de la situación económica que ellos tienen. En este estudio pudimos observar la situación de vulnerabilidad y/o precariedad económica de muchos 
de los cuidadores entrevistados, detectando, incluso, que algunas de las familias a las que pertenecían dichos cuidadores experimentaban economías de subsistencia. Se debe destacar que casi la mitad de los cuidadores son mujeres jefas de hogar, que tienen enormes problemas para sostener económicamente a sus familias.

Además, se agrega que algunos de los relatos de las personas entrevistadas remiten al pasado y permiten comprobar que son familias que tienen una historia de pobreza que sigue reproduciéndose.

Pero, también, entre de los cuidadores investigados, existía un grupo pequeño de familias que contaban con medios económicos que les permitían tener una relativa "solvencia económica" para costear los gastos que implica el cuidado del dependiente, algunas incluso podían costear atención privada de salud. Estas familias eran de entornos rurales y contaban con bienes y/o ayuda de sus familiares (hijos).

Los ingresos que las familias entrevistadas percibían principalmente estaban relacionados con la paga por sus empleos (ingresos generalmente inestables), estrategias de empleo informal, pensiones y subsidios. Consideramos también, como ingresos para estas familias, las ayudas que ONG's y el mismo estado chileno brindan en especies o servicios. Otra dimensión de los ingresos estaba dada por las ayudas que estas familias recibían de sus redes, generalmente la familia cercana, en forma de dinero, especies o servicios.

Si acotamos los gastos de las familias mencionadas a los que se generaban producto del cuidado, el gasto más mencionado por los entrevistados eran los pañales, ya que la mayor parte de los dependientes no controlaba esfínteres, en muchas familias también era el más cuantioso de solventar. Le seguía todo lo relacionado con la nutrición y el cuidado higiénico del postrado, también equipamientos y/o ayudas técnicas que ayudaran al dependiente y cuidador en el mantenimiento de éste. En el caso de patologías complejas, las familias debían costear el pago de análisis, exámenes, medicamentos, tratamientos y desplazamientos en vehículos que no eran proporcionados por el sistema público de salud. 


\subsection{CATEGORÍA "FACTORES QUE INFLUYEN EN LA CALIDAD DE LA RELACIÓN CUIDADOR - DEPENDIENTE"}

Antes de pasar a desarrollar esta categoría quisiéramos indicar que ésta se encuentra bastante relacionada con la propiedad "identidades de género reflejadas en el cuidado", que forma parte de la categoría género, por ello intentaremos no repetir ideas en nuestro abordaje. Recordemos, entonces, que en ese apartado analizamos las formas en que se asume el cuidado desde el género y cómo esto puede llegar a constituirse en un elemento de protección o de sobrecarga para el cuidador.

En base a los casos que han sido investigados, los tipos de relaciones entre cuidador y dependiente podían ser catalogadas como "buenas" y otras como "de aceptación resignada", actuando el signo de la relación como elemento de protección o sobrecarga del cuidador. Los factores que influyen en que se dé uno u otro tipo de relación serán tratadas como propiedades de esta categoría.

\section{Propiedad "Relación previa a la situación de dependencia entre cuidador y familiar".}

De acuerdo a los testimonios recogidos, las dimensiones que podía adoptar esta categoría varían entre la existencia de una buena relación o de una mala relación antes de la situación de dependencia. En el caso de que existiese una buena relación previa, ésta se tendía a prolongar, a pesar de las circunstancias difíciles que conlleva la dependencia. Por otro lado, cuando se había tenido una relación regular o mala, la actitud que asumía el cuidador, generalmente, era aceptar con resignación el "deber de cuidar".

- “(...) para mí esto ha sido una experiencia, que al principio yo estaba bien reacia a cuidarlo, pero después tuve que conformarme y "apechugar" como se dice y cuidarlo.

(...) al principio... porque yo estaba rebelde a eso... porque..."

- “¿Usted ha vivido feliz sus años de matrimonio?”

- "Es que él era muy amigo de sus amigos, primero sus amigos...” (Entrevistada 1) 
"Siempre fuimos amigas, amigas las dos, yo era su pachacha ${ }^{119}$, ella era mi pachacha, ella no hacía nada sin preguntarme a mí, y con mis hijos eran sus hijos, ella fue muy buena madre, una hormiga, muy buena madre, amiga, hermana, buena hija, buena tía, ella era excelente, con unos valores, con una amistad." (Entrevistada 13)

"Es que con él casi siempre vivíamos juntos, por ejemplo ellos tenían su departamento y yo vivía al lado cuando me casé, estuvimos siempre juntos, por los niños y todo, prácticamente se criaron con ellos, bueno y los chiquillos [hermanos de la entrevistada] tampoco nunca dijeron: "Papá véngase conmigo", y él siempre estaba acostumbrado a estar con nosotros, incluso trabajaba con mi marido en Lo Ovalledor, le ayudaba harto, a mi en el invernadero me ayudaba mucho, era mi brazo derecho.” (Entrevistada 23)

\section{Propiedad "Tipo de relación de parentesco"}

Existen tipos de parentescos que determinan de antemano que la relación será positiva, era el caso de todas las madres que cuidaban de sus hijos, independiente de la edad de éstos.

"Tengo una visión distinta a muchas personas, para mí los chiquillos son todo y trato de hacer lo mejor por ellos, lo que sea no importa, de alguna manera se arregla, no me complico.” (Entrevistada 18, madre de 2 niños dependientes)

“(...) porque yo me acuesto tarde, porque mi hijo de repente duerme en el día y en la noche se desvela, yo le digo: "Papito, es tarde, usted tiene que dormir, porque la mamita está cansada", y con el remedio se va quedando dormido, está bien tapadito y yo me voy a acostar." (Entrevistada 3, madre de 2 adultos dependientes)

\section{Propiedad "Madurez emocional del cuidador"}

Consideramos esta propiedad al analizar varios de los relatos ofrecidos por nuestros entrevistados, ya que éstos, a pesar de haber tenido mala relación o malas experiencias

\footnotetext{
${ }^{119}$ Pequeña.
} 
con sus familiares en el pasado, al asumir el rol de cuidador, no tenían conductas revanchistas o resignadas y establecían una buena relación con el enfermo, superando las diferencias del pasado.

“(...) le digo a Dios: "Pucha mi mami que esté tranquilita, saque todo eso de su mente, a mí castígame" (...) ella como ser humano también tuvo sus pecados, pero yo le perdono todos sus pecados, todo, todo, mi mami para mí fue una santa, yo iba a lavar con ella cuando chico, sé lo que sufría cuando mi papi le pegaba, cuando nos daba de comer, nos lavaba las tiritas $^{120}$, nos planchaba la ropa, por eso la amo, por eso le perdono todo [llora]." (Entrevistado 26)

- “YY cómo era la relación entre usted y su papá antes de que él se enfermara?"

- "Buena, es que años que vivo con él yo, cuando vivíamos acá en el Centro, (...) al año siguiente yo me lo llevé, porque yo le venía a dejar el almuerzo acá, nunca lo abandoné, cuando viví con él acá, porque mi papi era bueno para el trago [bebedor], pasaba en el suelo cuando tomaba, allá salía yo a buscarlo. Si yo años que vivo con él." (Entrevistada 31)

\section{Propiedad "Existencia de reciprocidad del cuidador con el dependiente"}

La existencia de reciprocidad en los cuidados es una propiedad que se daba entre cuidadores hijos/parejas y dependientes padres, abuelos / pareja. Generalmente, se generaba una relación positiva cuando el cuidador sentía que su labor era una forma de demostrar al dependiente agradecimiento por la forma en que lo hicieron anteriormente por él.

\footnotetext{
"Sí, toda la vida he vivido con ellos, es que mi mamá me tuvo soltera, así que yo me crié con ellos [abuelos], yo siempre reclamaba porque mi mami [la abuela] no me dejaba salir, que las juntas aquí, que las juntas allá y en realidad tenía razón, uno después ve, con madurez, que uno agradece como fue con uno, porque me crió a la antigua, y ahora yo no tengo problemas de que no puedo salir, que esto o lo otro, que mis hijos me atan, no, no me veo limitada, uno agradece mucho eso." (Entrevistada 12)
}

${ }^{120}$ Ropas muy usadas. 
"Es que mi señora lo valora, uno no puede decir ella no valora lo que hago porque si yo estuviera en el pellejo de ella, con los dolores que tiene, yo agarraría... (...) ya llevamos 44 años casados, cuando yo he estado mal ella es la que ha estado al lado mío, me ha estado apoyando, porque lo hijos son harina de otro costal." (Entrevistado 28)

Pero esta propiedad podía tomar un matiz de resignación a razón de lo que el familiar, que se convirtió en dependiente, hizo en el pasado y de cómo lo hizo. Entonces, el cuidador respondía entregando atención, pero muchas veces condicionado por cómo se dio anteriormente la relación.

“(...) y en el fondo yo no sé si es como un pago que le estoy haciendo por lo que ella hizo con mi hija, porque en realidad yo no me crié al lado de mi mamá pero mi hija sí, (...) como le digo mi mamá es muy dependiente de mi, que de repente "No quiero ir para allá”, ¿Por qué? Porque no estoy yo.” (Entrevistada 6)

\section{Propiedad "Tipo de patología padecida por el dependiente"}

Especialmente en los dependientes que sufrían de algún tipo de demencia, la relación entre cuidador y dependiente se veía empañada por la patología padecida. En el caso de nuestros entrevistados, la Enfermedad de Alzheimer o las demencias vasculares afectaban el comportamiento del dependiente y, por ende, la relación que se daba con su cuidador.

- "Mira, el comienzo de la enfermedad de mi mamá fue atroz, fue horrible."

- “Cuando tenía períodos de consciencia e inconsciencia?”

- "Claro, yo a veces lloraba junta con ella, fue la peor etapa, yo ahí lloraba mucho, me daba mucha pena." (Entrevistada 10)

"La de mi mamá y yo... eh, no, no es mala relación con mi mamá, pero como le digo yo puedo estar sola con mi mami y mi mami se porta así, en cambio con mis hermanas es insoportable (...) si estamos las tres es a mí la que llama, soy yo a la que llama, aunque esté mi otra hermana, "La Josefina ¿Dónde está?”, “Mamá si la Josefina fue a comprar, 
yo se lo hago", "No, si yo la voy a esperar, yo la espero a ella", yo le digo "El único nombre que te sabís es el nombre mío", no y la única que la domina soy yo." (Entrevistada 6)

En esta propiedad nos fue posible identificar claramente una dimensión negativa de la relación entre cuidador y dependiente, que consistía en una relación infantilizadora que establecía el primero con el segundo, producto de las consecuencias conductuales en el dependiente del padecimiento de una enfermedad mental. Ésta es una actitud que solía repetirse en los cuidadores de personas adultas y mayores, y consistía en catalogar sus comportamientos comparándolos constantemente con los de un niño, infantilizando al dependiente en el trato y en la imagen que dan de ellos.

“(...) él está con pañales, día y noche está con pañales porque no controla nada, nada. (...) yo tenía el dormitorio allá arriba $\left[1^{\circ}\right.$ piso] y tuvimos que bajarlo porque no podía llevarme pa' arriba pa' abajo, es seña $a^{121}$ que yo tengo acá el dormitorio, la cama de los dos, él vive como un niño chico" (Entrevistada 4)

“(...) él vive en otro mundo, no se preocupa de los gastos, si alguien está enfermo aquí en la casa, él vive en su mundo ahora, entonces al final yo me tengo que hacer cargo de todas las cosas ahora, soy como la mamá de él también, al final tengo otro hijo [ríe]" (Entrevistada 16)

\section{Propiedad "Posibilidad de reemplazo en el cuidado"}

La orientación que adoptaba la relación del cuidador con el dependiente podía depender de que el primero contara con cooperación en el cuidado y la posibilidad de reemplazo en éste, ya que el nivel de carga experimentado, debido a su labor, podía determinar el ánimo con que se relacionaba con su familiar. Además, contar con ayuda, o la posibilidad de reemplazo en la tarea de cuidar, disminuía el nivel de angustia y presión del cuidador.

\footnotetext{
${ }^{121}$ Por eso.
} 
"Mi hermana, la Vicky, con ella, es que nosotros nos llevamos súper bien, eso es lo que
tenemos, a lo mejor el papá con su dureza que tenía él con nosotros, cuando éramos
chicos, a lo mejor eso nos sirvió mucho, mucho, querernos mucho entre hermanos y
ayudarnos, muy hermanables desde chicos, nunca peleábamos por pelear, no, (...) por
eso mismo, nosotros súper hermanados sobretodo con lo de Raúl, apoyarlo mucho,
quererlo mucho. (...) A nosotras, a mi hermana y a mí, cuando vamos al hospital nos
felicitan por mí hermano, de verlo lo bien que está, de verlo lo bien cuidado, nos dicen
"Pucha que lo quieren, la familia, pucha que lo quieren harto", porque él siempre anda
ordenadito, limpiecito, todo impecable, el cuidado y el cariño para él." (Entrevistada 17)

Asimismo, esta propiedad nos indica cuál es el clima o calidad de la relación existente entre los distintos miembros de la familia, factor que podía llegar a determinar el tono de las relaciones entre cuidador y dependiente.

\subsection{CATEGORÍA "REDES DE APOYO INFORMAL"}

Las redes de apoyo al cuidador, como categoría de análisis, ha sido abordada tangencialmente desde distintas categorías previamente analizadas. Intentando no ser reiterativos en el análisis, no profundizaremos en aspectos que ya han sido tratados y nos limitaremos a mencionarlos.

En la primera parte del análisis, cuando trabajamos el tema de la actitud con la que el cuidador asume su tarea, definimos dos propiedades, la actitud positiva y la actitud flexible, es importante insistir que éstas se ven influidas por la presencia y actuación de las redes de apoyo.

Por otro lado, al realizar el análisis de los recursos económicos de las familias visitadas, en la propiedad dedicada a los ingresos recibidos por éstas, se señalaron las ayudas monetarias, en especies y/o servicios, que principalmente la familia cercana realizaba.

Considerando la información disponible, y desde el punto de vista del apoyo social percibido, podemos constatar que las redes de apoyo de los cuidadores consultados eran las siguientes, que para el motivo del análisis serán consideradas como propiedades: 
Capítulo VI. Análisis

- Apoyo de familia (microsocial)

- Apoyo de vecinos y amigos (mesosocial)

- Apoyo de organizaciones sociales (macrosocial)

\section{Propiedad "Apoyo de familia (microsocial)"}

\section{Dimensión "Ayuda efectiva"}

Entre todas las redes de apoyo a la tarea del cuidador, la red más íntima y más mencionada por éstos era la ayuda que provenía de la familia cercana del cuidador y del dependiente. Considerando quién es la persona enferma, la cooperación podía provenir de hijos, hijas, nietos, nietas, padres, hermanos, hermanas, abuelos, abuelas, etc. Los familiares directos que vivían bajo el mismo techo eran los que posiblemente más apoyos brindaban.

"Para que voy a decir que me ayudan, no, no me ayudan [sus hermanos], son mis hijos y yo, mis dos hijos que están conmigo y ellos son los que me ayudan. (...) Cuando está sucio, me lo lavan, me le hacen su cama cuando yo no puedo hacerlo, ellos me ayudan en eso, tengo dos hijos excelentes conmigo." (Entrevistada 31)

Los apoyos en el cuidado pueden variar, había entrevistados que contaban con familiares que, aparte de dar apoyo emocional, sabían desempeñar todas las tareas que implicaba el cuidado del dependiente, y otros que sólo recibían apoyos para tareas y períodos puntuales del cuidado.

"Y si pido ayuda a alguien me ponen cara larga [hermanas], mi hija me coopera mucho, mi hija me dice: “¿Sabes qué mamá? Anda, yo me quedo, dime todo lo que hay que hacer" y ella sabe mudarla, sabe tratarla, y la trata mejor que yo porque yo de repente me descontrolo, me dice: “¡Mamá, mamá!, déjamela a mí”, es mi cable a tierra. (Entrevistada 13)

"Ahh, ahí tengo a mi papá, él se queda, vive aquí con nosotros, o sea nosotros vivimos con él. (...) lo único es que no muda chiquillos, entonces ahí tiene que salir a buscar a 
mi hermana o a mi vecina del frente, cuando se queda con ellos, pero lo otro es que hace comida, da comida, da colaciones, sabe lo que comen." (Entrevistada 18)

Existían casos en que la cooperación en el cuidado, otorgada a modo de reemplazos por espacios de tiempo pequeños, permitieron al cuidador poder "cultivar" otras redes de apoyo y tener respiros en su labor. Esto también puede ser considerado como un apoyo emocional.

"Yo voy al centro de madres, voy a los abuelos, ahí cuando nos toca le digo a una de mis hijas o de mis nietas, les digo si puede venir, o si no llamo a la María, una nieta, que no vive conmigo, vive afuera, y yo le digo: “¿Puedes venir negra para que yo pueda ir a los abuelos? Para irme a distraer un ratito", "Ya mamá" me dice ella." (Entrevistada 22)

\section{Dimensión “Apoyo indirecto”}

El apoyo de los familiares también podía manifestarse de forma indirecta, es decir dando facilidades a los cuidadores en actividades que formaran parte del cuidado. En los testimonios de nuestros entrevistados, esto se podía ver reflejado en ejemplos como permitirle acudir al trabajo con el dependiente o contar con un medio de transporte para movilizar más cómodamente a niños discapacitados.

\footnotetext{
“Trabajo con mi hermano, atiendo una fábrica de vibrados, hacemos panderetas, cosas de cemento y aglomerados, atiendo la fábrica y voy con él [su esposo dependiente]. (...) Como es de la familia, entonces yo voy con él, todos los días vamos en la mañana y en la tarde me vengo con él. En otro trabajo no podría trabajar, imposible." (Entrevistada 16)

"No, si la familia, mi cuñado, trabajaba en los colectivos, él me llevaba, cuando podía que era casi todos los días y si no me tenía que ir en colectivo no más. (...) Aquí me "echaban" arriba, y me llevaba en brazos a uno y al otro sentado al lado, y allá cuando me bajaba lo primero que hacía era armar la silla y bajar a los dos.” (Entrevistada 18)
} 
Resulta importante considerar que, en la categoría donde fueron tratadas las consecuencias del cuidado, analizamos los efectos de éste en la familia, identificando el deterioro de la dinámica de las relaciones familiares y la presencia de conflictos por el "no apoyo" de los miembros del núcleo familiar en las tareas del cuidado de la persona dependiente, constituyéndose esto en un factor de sobrecarga. Recordemos que principalmente aparece el "no apoyo" de los hermanos e hijos cuando la persona dependiente es uno de los padres y el "no apoyo" de la pareja cuando el dependiente es el hijo.

Asimismo ocurre con el apoyo comprometido y no cumplido de los familiares con el dependiente, resulta importante destacar una situación que se daba de forma similar en varias de las familias consultadas en donde la persona dependiente era padre o madre con hijos adultos. Solía realizarse una reunión con los miembros de la familia, en donde se comprometían a ayudar en dinero, servicios o especies al cuidador principal, pero de forma efectiva ese apoyo no siempre se materializaba.

\footnotetext{
"Aparte que existían compromisos de la familia: "Que ya, que te vamos a ayudar en esto, que te vamos a ayudar en esto otro", pero eso no fue nunca, nunca se cumplió eso, y yo peleaba mucho con mis hermanas, peleaba mucho con la familia de ella, porque ella era muy querida por sus hermanas y todo, por el ejemplo que ella tuvo en vida con sus papás, los hermanos que la alababan mucho, que la querían, le prometían esto y lo otro, y nunca pasó nada, entonces al comienzo yo peleaba mucho con ellos "Que me dijeron esto, qué me iban a ayudar", "Ustedes me dijeron aquí, me dijeron allá" y con el tiempo me di cuenta de que eso no iba a ser así, y que me estaba haciendo muy mal a mí, tenía rabia con todo el mundo, con mi hermana especialmente, tuve capacidad para reaccionar, me estaba estresando, me estaba enfermando, y en realidad no valía la pena que siguiera pensando en eso, era lo que tenía que hacer no más.” (Entrevistado 13)
}

\footnotetext{
"Al principio se juntaron todos, "Ya le vamos a hacer un sueldo al Julio y que él la cuide", (...) cincuenta mil mensuales creo, "Ya, yo voy a poner diez", yo no tengo trabajo, al final nadie hizo nada." (Entrevistado 26)
}

La familia no era necesariamente fuente segura e incondicional de ayudas para el cuidador en su labor con el dependiente; como podemos ver, gran parte de los conflictos 
que en ella se generaban eran porque una parte de sus miembros no realizaba acciones de refuerzo en los aspectos en los que podían ser otorgados los apoyos, es decir en la dimensión emocional, material, instrumental e informacional de dichos apoyos; por tanto la falta del apoyo esperado se constituía en un importante factor de sobrecarga para los cuidadores

\section{Propiedad "Ayuda de vecinos y amigos (mesosocial)"}

Una importante fuente de ayuda para el cuidador principal estaba constituida por los vecinos y amigos, esto era independiente del área en donde se desarrolló el estudio, aunque debemos recalcar que los cuidadores de zonas rurales consideraban la relación que se daba con sus vecinos como un aspecto positivo y diferenciador de vivir en una zona urbana.

La mayor parte de las personas entrevistadas refiere que sus vecinos estaban preocupados por la situación que aquejaba al cuidador y dependiente y que, en algún momento, le habían prestado ayuda. De acuerdo a la frecuencia de esos apoyos, podemos distinguir dos dimensiones: apoyos en situaciones puntuales y apoyos permanentes.

\section{Dimensión "Apoyo de vecinos y amigos en situaciones puntuales”}

Generalmente, este tipo de apoyos era entregado en situaciones excepcionales y consistía principalmente en suplir o cooperar en alguna actividad del cuidado y en facilitar algún trámite o servicio; por lo tanto, este apoyo podía ser instrumental y/o informacional.

"Una ventaja [vivir en su barrio], porque a veces cuando yo salgo, les digo a las vecinas que me echen una miradita para acá, miran si buscan, o cualquier cosa, siempre me dicen que: "Cualquier cosa que necesites nos avisai no más, que nosotros..." (Entrevistada 9) 
"La Ángela consiguió una entrevista en el colegio donde iban los niños de ella y ahí entró altiro, me lo evaluaron, sin matricula sin nada me lo recibieron, y hasta este año son dos años que va ahí." (Entrevistada 29)

\title{
Dimensión "Apoyo permanente de vecinos y amigos"
}

Algunos de los entrevistados contaron con apoyos permanentes de vecinos y amigos, esta situación era más frecuente en los cuidadores que no tenían apoyos familiares para el cuidado. Para ellos, estos vecinos y amigos se transformaron en la familia con la que no contaban.

\begin{abstract}
"Yo salgo a trabajar, trabajo con mi hermana acá en la feria, me levanto a las 5 de la mañana, a ella la despierto, la dejo vestida y le pido el favor a mi vecina de arriba que me la vaya a dejar al colegio, y ella tiene una voluntad única de ir a dejarla al colegio y de vuelta me la vienen a dejar las compañeras, por el hecho de que aquí el barrio no es muy... es peligroso. (...) ella, cuando la Daniela está acá en la casa, le pregunta si es que necesita algo, o de repente ella se me pasa entera, ella baja, la limpia, la muda, yo nada que decir de mi vecina [nada malo], yo digo es la segunda madre de mi hija, gracias a Dios me puso esta vecina aquí, cerca mío y yo puedo salir a trabajar, porque el resto... aquí venden marihuana, venden de todo.” (Entrevistada 27)
\end{abstract}

\footnotetext{
"El vecino me trae, él me dice: "Llámeme no más, yo la traigo", él como trabaja en Santiago me pasa a buscar, nos juntamos el Tottus [supermercado], por ahí nos ponernos de acuerdo, y él me trae las cajas, un saco de alimento para los perros, son unos vecinos de oro." (Entrevistada 11)
}

Las ayudas que proporcionaba la red de apoyo de vecinos y/o amigos era similar a la que la familia realizaba, predominando los aspectos instrumentales y emocionales. 


\section{Propiedades "Apoyo de organizaciones (macrosocial)"}

\section{Dimensión “Apoyo recibido”}

Antes de comenzar con este punto quisiéramos aclarar que las ayudas (materiales principalmente) provenientes de instituciones no estatales -ONG's-, fueron ya comentadas en la categoría recursos económicos (propiedad ingresos).

En este apartado nos referiremos específicamente a organizaciones sociales, las principales mencionadas por nuestros entrevistados eran las organizaciones comunitarias y las religiosas. Las experiencias relatadas por nuestros entrevistados indican que la participación pasada, o la facilitada en el momento de la realización de la entrevista, posibilitaban el vínculo para que la comunidad conociera la situación del cuidador y del dependiente, y actuara apoyándole. Las funciones de dichos apoyos podían variar de acuerdo al tipo de agrupación, las organizaciones religiosas apoyaban fundamentalmente en lo espiritual, aunque también lo hacían en lo material.

\footnotetext{
"Bueno, iba a la iglesia adventista, pero después de esto no pude asistir más, pero vienen acá a visitarnos los hermanos de la iglesia, nos vienen a visitar todas las semanas. (...) ellos han sido fundamentales en este proceso, porque me han ayudado, son buenos consejeros, entonces uno lleva mejor esto, el proceso, lo asimila mejor." (Entrevistada 12)

- “La iglesia [evangélica] para usted ha significado un apoyo?”

- "Siempre me han ayudado, pero no siempre me tienen que dar, porque hay gastos, nosotros estamos agrandando el lugar para que sea propio."

- "Pero no me refiero sólo a un apoyo económico sino que al apoyo espiritual."

- "Sí, siempre lo tengo, y material tuve una ayuda siempre.” (Entrevistada 3)
}

Se debe destacar que los apoyos recibidos por organizaciones religiosas mencionados correspondían principalmente a iglesias cristianas no católicas, la iglesia evangélica y la iglesia adventista. Algunos de los entrevistados mencionan que eran católicos, pero no mencionaron que su comunidad les hubieran apoyado directamente (la "iglesia católica" lo hacía de forma indirecta a través de la Fundación Hogar de Cristo). 
En el caso de algunos de nuestros entrevistados, la participación en una organización se debía precisamente a la situación de dependencia de su familiar, era el caso de las organizaciones de discapacitados que se crearon con la finalidad de conseguir beneficios, principalmente provenientes de subsidios otorgados por el Estado. El apoyo de éstas era principalmente informativo e instrumental.

\footnotetext{
"Sí, la organización de los discapacitados que está en Curacaví, ahí está inscrito mi hijo, tengo la credencial, todo. (...) y yo voy a reunión por el niño, las hacemos aquí en la Rita, en la sede de la junta de vecinos, ahí hacemos las reuniones y cuando puedo voy también, porque cuando no tengo con quien dejar al niño no puedo tampoco, y ahí también me lo vienen a ver, ahí me daban los pañales, en la organización de los discapacitados, (...) incluso el otro día yo le dije a la señorita Patricia, que está en la organización, que esa silla ya no le sirve a mi hijo (...). Por eso me decía la señora Patricia, que es la presidenta de ahí, me decía: "Yo estoy atenta con Saulito" cualquier cosa es para Saulito.” (Entrevistada 22)
}

Los apoyos surgían también de organizaciones en donde participaron los dependientes cuando no estaban incapacitados. Es el caso que a continuación citamos, en donde el apoyo brindado era material y emocional.

\footnotetext{
"Cuando le dieron el alta, vinieron los amigos del club de pesca y caza a hacerle un recibimiento, para nosotros también era grato saber que no lo abandonaban y nunca. Raúl estando en el hospital, porque acá se da mucho que por un amigo se hacen beneficios, ellos dijeron vamos a hacer un beneficio para "Moralito", (...) así que hacían ellos juegos de rayuela, comidas, un montón de cosas, y después venían "Esto es para Moralito, ustedes saben en qué, para los pasaje, para esto, para lo otro", un sobre con trescientos, trescientos cincuenta mil pesos." (Entrevistada 17)
}

\section{Dimensión "Posibles apoyos"}

La participación de los cuidadores en organizaciones sociales pudo verse impedida por la situación de cuidado, que limitaba enormemente el tiempo libre disponible de los entrevistados. Varios de ellos relataban haber participado de agrupaciones vecinales, y creemos que es posible que dichas organizaciones pudieran constituirse en fuentes de apoyo futuro. 
"Acá en la junta de vecinos, fui presidenta de la junta de vecinos, eso era cuando tenía tiempo, estuve dos años.” (Entrevistada 23)

\begin{abstract}
“Sí po’, yo estaba en la junta de vecinos, pero después empecé a tener problemas porque las señoras hablaban que yo no iba a reunión, y ya después mi mamá se enfermó, menos, (...) ahora hicieron un grupo de discapacitados, hace como cuatro años que están funcionando y si tienen cosas que hacer yo les ayudo de aquí, por mi mamá, yo les coopero en lo que puedo, si hacen cosas yo les ayudo. (...) Por ejemplo, la otra vez estaba haciendo cojines con lana, bordados, y mandaban para acá y yo les ayudaba. (Entrevistada 20)
\end{abstract}

\title{
Síntesis
}

El apoyo social percibido por nuestros entrevistados proviene fundamentalmente del entorno familiar, siendo los familiares que viven bajo el mismo techo los que más apoyos puntuales prestaban, pudiendo ser estos directos o indirectos. Los vecinos y amigos también eran una fuente importante de ayudas, sobre todo cuando los cuidadores no contaban con apoyos familiares. Y la cooperación recibida por parte de organizaciones -de tipo instrumental y/o emocional-, provenía principalmente de organizaciones comunitarias y de iglesia. Como anteriormente comentamos, la falta de apoyo de los miembros de la familia cercana se convertía en un importante factor de sobrecarga. La existencia de apoyos de vecinos y amigos y organizaciones locales se constituía en un factor de protección de ésta. 


\subsection{CATEGORÍA “CUIDADOS FORMALES"}

El análisis de esta categoría es producto de la fuerza con la que aparece en los discursos, a pesar de no formar parte de las temáticas consideradas en el guión con el que se entrevistaba a los cuidadores. Al referirnos al cuidado formal estamos haciendo alusión tanto al cuidado proporcionado por personas que reciben un pago por ello y realizan esta labor en el domicilio del dependiente, como al prestado por instituciones que se dedican a ello. Es importante considerar el contexto chileno en el análisis de esta categoría, ya que el Estado no contaba con instituciones de cuidado formal (los llamados "hogares de ancianos"). Las alternativas institucionales existentes eran las residencias privadas, las instituciones de la iglesia y las residencias no autorizadas o "piratas". Estas dos últimas eran las que podrían haber estado al alcance, económicamente hablando, del grupo estudiado.

\section{Propiedad "Visión del cuidado formal"}

Dimensión "El cuidado formal visto como negativo, ya que no proporciona apoyo emocional al dependiente"

En los discursos de nuestros entrevistados pudimos detectar que el cuidado formal, a través de la institucionalización del dependiente o del apoyo de un cuidador formal en el domicilio, estaba considerado de forma negativa. Ello sucedía, principalmente, porque pensaban que los cuidados que realiza un extraño no son iguales a los entregados por un familiar, por la creencia en que la atención, que un cuidador formal procurara a su familiar, le faltaría el cariño y la dedicación que un cuidador familiar sí proporciona.

"Si vinieron aquí unas niñas, a decirme que me ayudaban, que venían de la municipalidad, "No", les dije yo, yo no voy a dejar que alguien le venga a dar comida a mi mamá porque no lo van a hacer con el amor que lo hago yo, que le laven la carita, que la peinen como lo hago yo, igual en un hospital yo no la voy a dejarla, porque yo sé cómo verla, yo sé cómo hacerlo." (Entrevistado 26) 


\title{
Dimensión "El cuidado formal no es una alternativa”
}

Por otro lado, había cuidadores que nos relataron haber vivido malas experiencias con relación al cuidado formal institucionalizado, en donde éste complicó la salud de sus familiares dependientes ya que los cuidados fueron provistos en condiciones calamitosas.

"Yo hice la promesa, bueno no promesa a nadie, de yo misma cuidarlo hasta el final, pero en mi casa, tenerlo hasta el final, si no me muero yo antes, cuidarlo yo hasta el

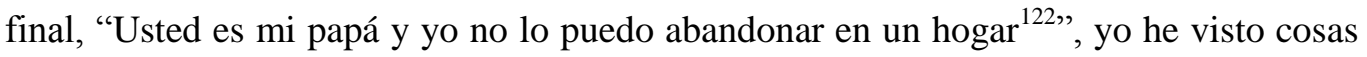
en los hogares que no me gustan y por esa razón me retiré de este hogar de aquí, si vi cosas muy fuertes, y yo no lo voy a llevar allá para que... claro, porque a mí me dolió mucho cuando yo vi cosas acá en el hogar con los ancianitos que no tenían un familiar siquiera que los defendiera, nadie, yo no pude estar, no, no me gusta." (Entrevistada 31)

\begin{abstract}
"Yo no quería más que mi vieja estuviera allá, y emocionalmente quedé muy mal, de verla cómo quedó y todo [después de una caída]. (...) yo iba a verla donde ella estaba y estaba bien, era una casa de familia, no era un hogar de ancianos, de una señora con mucha experiencia que cuidaba abuelitos en su casa, pero no más de cuatro. Ella tenía su dormitorio, era una casa, de familia, ella estaba bien ahí, bien cuidada, cerquita, (...) estaba bien, pero después ya no. (...) y se vino para acá conmigo, y de ahí que me hice cargo de ella, hace cuatro años." (Entrevistada 13)
\end{abstract}

El cuidado formal institucionalizado no se constituía en una alternativa para los cuidadores entrevistados porque, como anteriormente señalamos, el tipo de instituciones a las que económicamente ellos podrían haber accedido -las de beneficencia y las no autorizadas- precisamente eran las que más mal catalogadas estaban dentro de su imaginario.

En cuanto a los cuidadores formales, las opiniones solían tener más matices, la dimensión que sigue refleja una mirada más positiva de éste, pero hay entrevistados que no lo tenían como alternativa.

\footnotetext{
${ }^{122}$ Se refiere a un Hogar de ancianos, nombre con el que comúnmente se denomina a las instituciones de larga estancia para personas mayores en Chile.
}

Página $\mid 357$ 
"Y yo seguí trabajando, pagándole a una persona para que me ayudara y todo, pero me producía mucho problema porque estaban todo el día llamándome: "Que la Nina hizo tal cosa", "Que la Nina no quiere comer", "Que la Nina hizo esto", entonces estaba yo... no podía trabajar, tenía que pedir permiso, partir para acá y mi puesto, el que yo tenía era importante, yo manejaba gente, tenía gente a mi cargo, entonces empezó a ocasionar problemas en mi trabajo, así que tuve que tuve que tomar la decisión de dejarlo, y dejé mi trabajo, tenía un negocio también particular, cerré el negocio, todo y me quedé aquí, cuidándola." (Entrevistada 13)

La misma cuidadora, que anteriormente relataba su mala experiencia con la "residencia" no autorizada, intentó que el dependiente fuese cuidado en su propio hogar por un cuidador formal, con la intención de mantener su puesto laboral, pero nuevamente esta alternativa no dio buenos resultados. Por eso, finalmente fue ella la que se dedicó a cuidarle.

\section{Dimensión "El cuidado formal domiciliario como posible apoyo a la labor del cuidador”}

Al pensar en la posibilidad de recibir apoyo de otros para el cuidado del dependiente en el domicilio, los cuidadores lo veían como apoyo a la labor que ellos realizaban, pero sin dejar de ser ellos los principales responsables y hacedores de las labores de cuidado. Generalmente, veían el apoyo de cuidadores formales a modo de asistencias en tareas que les resultaran físicamente más pesadas o secundarias.

- “Usted desearía poder encargar el cuidado de la Sra. Julia a otra persona?”

- "Ehh, a una persona que realmente supiera, sí, yo estaría tranquila si quedara en buenas manos. (...) Sabe lo que pienso yo, que a estas alturas que otra persona la cuide no la va a entender como la entiendo yo, que me ayude a lo mejor cuando yo tenga que salir, a ratos, o hacer cosas allá, que se quede con ella, cosas bien específicas." (Entrevistada 12) 


\section{Dimensión "El cuidado formal en institución como posibilidad futura para el cuidador en su vejez"}

Desde la experiencia vivida como cuidador, se daba la reflexión sobre lo difícil e injusto que era que esta tarea recayera generalmente en una sola persona y que ésta fuera la mujer más cercana (hija, esposa). Por ello, la petición expresa de esta cuidadora era que en caso de enfermedad que generara dependencia se le ingresara en una institución de cuidado formal, rompiendo así con la "tradición familiar" del cuidado informal.

\footnotetext{
"Yo también soy hipertensa, tengo la misma enfermedad de él, entonces le digo yo a los niños, a mis hijos, que si me llega a pasar algo así que no... que busquen donde dejarme, pero que ellos se hagan cargo de lo que paso yo, no [llora] es mucho, es mucho para una persona asumirlo, por eso les digo hagan una maleta y me dejan en un hogar, en alguna parte que alguno tenga que hacerse cargo, yo tengo 2 hombres y una mujer, y no porque la Francisca sea la mujer ella tiene que verme, no pues, ustedes buscan, saben que yo tengo un hermano que dice que cualquier cosa recurran a él, por eso ustedes hablen con su tío, yo se que les va a ayudar [llora] para que ustedes no pasen lo que yo estoy pasando, es mucho." (Entrevistada 23)
}

\section{Propiedad "Existencia de cuidado formal"}

Entre los cuidadores entrevistados, existían dos de ellos que tenían apoyo de un cuidador formal en el domicilio. El primero de los casos correspondía a una cuidadora mayor que, producto de una grave patología ocular, debió buscar ayuda de una persona de confianza, que le reemplazó en su labor de ama de casa y cuidadora de su esposo. Esta cuidadora tenía el apoyo económico de sus hijos y así podía costear el servicio de cuidado.

\footnotetext{
"Entonces tengo una persona que me hace todas esas cosas y me lo atiende a él, me lo muda a él, pero él ya la conoce, antes de que enfermara yo, si llegaba a salir en un día, ella me lo venía a mudar. (...) Claro, una vez que a mí me den de alta ya de mis dos ojos, ahí yo retomo el aseo de mi casa, la comida, el lavado, pero el cuidado de él, en cuanto a mudas, voy a estar con la misma señora, porque ella ya lo conoce hace muchos años, y él la conoce a ella también. Ella lo levanta en el aire, porque ella es más joven,
} 
más fuerte también, lo acomoda bien, como debe ser, le hace sus masajes." (Entrevistada 14)

Por otro lado, estaba la situación de la cuidadora de un niño dependiente, con múltiples complicaciones vitales ${ }^{123}$ y que debía estar las veinticuatro horas del día asistido. En este caso era el Estado el que, a través de un programa de salud específico, apoyaba a la familia y pagaba el servicio de cuidado especializado por las noches.

- “El niño tiene que tomar medicamentos temprano por la mañana?”

- "Sí, a las 7, pero ahí las niñas se lo dan, las técnicos [se refiere a técnico en enfermería], porque ellas están de ocho a ocho, en las noches viene la técnico que lo ve, yo me hago cargo de él desde las 8." (Entrevistada 24)

\section{Síntesis}

En la visión que los entrevistados tenían del cuidado formal, entiéndase por éste el cuidado del dependiente por una persona que es pagada por ello o el ingreso en una institución que preste este servicio, predominaba la opinión negativa. Ello por diversos motivos, que a continuación enumeramos:

- Porque creían que el cuidado no era solo dar "servicios" al dependiente, sino que debía ser hecho con cariño y dedicación, y eso no lo tendría el cuidado formal.

- Porque habían tenido experiencias negativas con el cuidado formal prestado por instituciones y, en menor medida, con el cuidado formal domiciliario, y eso les llevó a rechazarlo de plano como una alternativa para el cuidado del dependiente.

Pero había algunos cuidadores que veían al cuidado formal en domicilio como una alternativa o apoyo en su labor, siempre aclarando que no dejarían de ser los cuidadores principales. Así también, había un cuidador que expresaba que en caso de convertirse en dependiente su decisión era que le otorgaran cuidados formales en una institución y no someter a alguno de los miembros de su familia a ser su cuidador. Se observa que las

${ }^{123}$ El niño padecía síndrome de Poland y síndrome de Möbius.

Página $\mid 360$ 
opiniones positivas pueden estar mediadas por las posibilidades económicas de acceso, que tenían estos cuidadores y sus familias y al cuidado formal, ya que los cuidadores de menores recursos económicos ni siquiera se plantearon este tema.

De forma minoritaria, dos cuidadores contaban con apoyos de cuidado formal, ello debido a la gravedad de la situación de sus dependientes y a que recibían apoyos económicos que les permitían pagar el coste de estos servicios. A pesar de que los casos en donde se constató la existencia de cuidado formal fueron pocos, podemos afirmar que éste se constituyó en un factor protector de la sobrecarga.

\subsection{CATEGORÍA "AUTOPERCEPCIÓN DEL FUTURO POR PARTE DEL CUIDADOR"}

Los entrevistados fueron consultados acerca del futuro, de cómo se veían ellos en relación a la situación del dependiente y fruto de sus respuestas, hemos construido las propiedades y dimensiones que a continuación presentamos.

\section{Propiedad "Enfrentamiento temeroso del futuro"}

\section{Dimensión "Temor al desamparo del dependiente"}

Entre los cuidadores entrevistados existía un grupo que al ser preguntados sobre el futuro expresaba sentir temor. Este era un grupo claramente diferenciable, eran los cuidadores cuyas edades sobrepasaban los sesenta años, concretamente trece cuidadores, y los que cuidaban de sus hijos, nueve del total. Su principal miedo era a enfermarse o fallecer y pensar en que sus familiares quedarían desamparados.

“... ahí, en la cuerda floja, confío solamente en Dios, en la cuerda floja, o le pasa algo a él o me paso algo a mí. Si le pasa algo a él, yo me muevo, me movilizo, y aunque sea paro un auto que vaya pasando por aquí, o voy al frente, o voy al lado y algo consigo, pero si me pasa algo a mi él no está capacitado para decir: "Oiga mi esposa se desmayó, hay que llevarla al hospital", no, no está capacitado él para eso, ese es mi temor." (Entrevistada 11) 
"No sé... malo [ríe de forma nerviosa] quiera Dios que se lo lleve a él primero y después a mi porque yo digo qué va a ser de él, él es más joven que mi así que puede vivir... la otra vez me habían dicho que vivía hasta los 25 años no más, y no po’ se pasó, ellos viven hasta cuando Dios diga no más. (Entrevistada 15)

Especialmente, el temor surgía al constatar que no existía dentro del grupo familiar nadie que se hiciera cargo de forma permanente del dependiente, en caso de que el cuidador principal faltara.

\section{Dimensión "Temor al empeoramiento en la salud del dependiente”}

Una parte importante de los entrevistados cuidaba de personas mayores -entre setenta y noventa y tres años- que padecían de enfermedades degenerativas, motivo por el cual gran parte de esos cuidadores manifestaba experimentar temor al futuro. Ellos sabían que la situación del dependiente iba a empeorar con el paso del tiempo, tenían gran miedo a las complicaciones, deterioro y dolor que pudiese experimentar éste, y que ello significara que su tarea como cuidador se iba a complicar a la par de ese proceso.

\footnotetext{
"Me da miedo de que no pueda comer y le tengan que poner mangueras, [1lora] yo la voy a cuidar, pero voy a sufrir por ella, tengo temor, yo no quiero que ella sufra, que si Dios se la va a llevar que se la lleve, pero que no sufra, que esté bien, sin ninguna herida, igual no quisiera que se fuera, pero se tiene que ir, acepto que se vaya, pero que se la lleve bien, en sueños, tranquila, en paz.” (Entrevistado 26)
}

\footnotetext{
"Uy, cómo, a ver, [silencio], incierto, realmente esa es la palabra [se emociona mucho], porque yo quisiera tener una varita mágica y que se cambiaran las cosas, pero no es así, la realidad es la que tenemos, yo no puedo pensar que el día de mañana yo me quiero mandar a cambiar a cualquier parte, no saber de nada, no puedo hacerlo, es incierto.” (Entrevistada 14)
}

Estos cuidadores, en su mayoría, eran hijas/os o parejas de los dependientes, que contaban con pocos apoyos en su labor, por eso sufrían angustia al constatar que la situación de salud del dependiente empeoraría. 


\section{Propiedad "Sin proyección futura"}

\section{Dimensión "La situación de sus familiares les hace vivir solo en el presente"}

Entre los entrevistados existía un grupo que, al ser consultados sobre el futuro, expresaban que no estaba dentro de sus pensamientos, limitaban su vivencia al presente, al "día a día", ello se debía, principalmente, porque sabían que la situación de sus familiares no experimentaría mejoría y porque eran personas que, por sus edades, tenían varias décadas de vida por delante.

- “YY cómo ves tú el futuro con él?"

- "Lo veo igual que ahora."

- “No te proyectas?"

- "No, no me puedo proyectar, porque uno se proyecta con un hijo, que va a creciendo, madurando, él no, yo sé que va a seguir igual.” (Entrevistada 16, cuida de su esposo de 45 años)

Es importante destacar que este discurso estaba presente prácticamente en todas las madres de niños/adultos dependientes, cuyas patologías no les permitía tener esperanzas de mejoras significativas en su situación, y les planteaba de paso el dilema anteriormente tratado del quién se hará cargo cuando ellas no estuvieran.

“¿Mi futuro? Ya no lo veo ya, vivo el día a día no más, porque si me pongo a mirar a futuro no veo futuro, prefiero vivir el día a día." (Entrevistada 27)

"Eh, feliz, porque yo soy muy agradecida de la vida, agradezco por las penas y por las alegrías, porque pienso que uno tiene que vivir el día a día con esto, y pienso que el Alonso también ha sido una bendición, como lo ha sido mi otro hijo, pienso que es un regalo que tengo de la vida, entonces siento que... lo que pasa es el miedo a que uno falte, eso me da temor." (Entrevistada 29) 


\section{Dimensión "El no desarrollo de vida propia por la situación de cuidado"}

Existían cuidadores que reflexionaban en relación al futuro que les esperaba cuando sus familiares fallecieran ya que, producto de llevar muchos años dedicados al cuidado del dependiente, no habían desarrollado otros aspectos de sus vidas. Ellos no tenían expectativas en relación a ese momento, sentían que habían "desatendido" aspectos de su vida y que les sería muy difícil recuperarlos.

\footnotetext{
"No veo futuro, no veo mucho futuro, pero soy optimista, fíjate, pienso que puede haber un cambio en mi vida, no sé, de repente eso me preocupa, me siento a veces, me acuesto, a veces me quedo sola acá en la noche pensando ¿Qué haré? A mis años no es mucho lo que pueda escoger, y eso es preocupante." (Entrevistada 10)

- “¿Y cómo ve usted su futuro?”

- "Al lado de mi viejo no más, acompañándolo, si ya mi vida no va a ser lo que yo quería hacer antes." (Entrevistada 31)
}

\section{Propiedad "Optimismo, con planes futuros"}

Entre todas las personas entrevistadas sólo una de ellas manifestó contar con planes futuros, ello a pesar de que era una de las entrevistadas de edad más avanzada (80 años) y de que su esposo dependiente era también de los más envejecidos (93 años).

\footnotetext{
"Ahora tenemos un plan, sí, porque como esto no dio resultados, y no me quiero quedar sola para siempre aquí, pusimos un aviso de venta, (...) y yo le digo nosotros vendimos la parcela y yo me compro una casa de esas, chiquita, ya no quiero casa grande, para qué quiero casa grande si nadie me viene a ver, me compro una casa de esas, al ladito de la casa de ella [hija], y nos comunicamos, abrimos una comunicación, ella en su casa y yo en la mía, y en eso hemos estado. Ese plan tengo para futuro.” (Entrevistada 11)
}

Es cierto que sus planes eran a corto plazo y tenían relación con movilizarse para salir del aislamiento en que se encontraban, en este caso, deseaba acercarse a alguno de sus hijos y, así, lograr, al menos, mayor apoyo emocional de su parte, porque en ese 
momento se consideraba abandonada. Se debe tener en cuenta la historia personal de esta entrevistada, ella nos relató que en su vida le había tocado "comenzar nuevamente" en numerosas ocasiones y en distintos espacios geográficos, podríamos afirmar que era una persona resiliente, y a ello se la agrega que la situación económica de esta familia era mejor que la media de los cuidadores entrevistados.

\section{Síntesis}

La pregunta sobre el futuro resultó ser complicada para los cuidadores, muchos de ellos no pensaban ni se proyectaba, solo vivían el día a día. En los relatos de los cuidadores podemos encontrar tres tipos de discursos característicos:

- Temor al futuro, por el empeoramiento de la salud del dependiente o de la salud del cuidador.

- Sin proyección al futuro, ya que vivían el presente porque la situación del dependiente no experimentaría mejoría y porque la situación de cuidado les había impedido desarrollar una vida propia que les permitiera imaginar un futuro distinto.

- Con proyecciones futuras, a pesar de que era el discurso de solo una de las cuidadoras entrevistadas, creemos importante destacar que existía en el grupo estudiado una visión diferente de la mayoritaria. 


\subsection{CATEGORÍA "MANIFESTACIONES DE SOBRECARGA"}

Habiendo analizado una serie de factores que pueden constituirse en elementos protectores o generadores de sobrecarga, nos pareció importante considerar dentro de este apartado de análisis dos comportamientos, que se revelan en el proceso de la entrevista en los cuidadores y que indican sobrecarga en los cuidadores. Éstos son el cansancio y la desesperación.

\section{Propiedad "Cansancio"}

Presente en la mayoría de los discursos estaba el cansancio físico y mental que sufrían los cuidadores, pero éste se manifestaba abiertamente en la entrevista sólo en algunas ocasiones, debido a que procuraban no hacerlo evidente en frente de los dependientes, más aún si éstos tenían sus habilidades cognitivas intactas. La mayor parte de los entrevistados llevaba años cuidando de sus dependientes, y con muy pocas posibilidades de relevo en su vital tarea.

“(...) por eso que estoy cansada pues mi niña, de repente la Yola me dice: "Tómate un relajante muscular", porque amanezco con esto aquí tenso, los brazos me duelen, por el peso, la Ana me dice: "Mamá, aprende a relajarte, para las piernas hace elongaciones", ah, es que estoy tan cansada que cinco minutos que me quede quietita me miro los pies y trato de relajarme todo el cuerpo y no puedo, es una responsabilidad tan grande con mi papi." (Entrevistada 19)

El cansancio resultaba mayor aún cuando la edad del cuidador era avanzada, ocho de las personas entrevistadas tenían más de 65 años, y generalmente cuidaban de mayores como ellas y con pocos apoyos del resto de la familia.

“[llora] Ya no estoy nada para lo que estuve antes, yo estuve bastante mal, pero después ya, como decimos los viejos "Nos echamos las penas a la espalda" y seguimos tirando la carreta que es la vida, no queda otra, así que yo [se emociona] lo baño, lo afeito, lo visto, y todo lo que él necesita." (Entrevistada 11)

"Si incluso ahora estaba pensando en entregar el cargo [1lora]." (Entrevistada 21) 
La evasión se presentaba como una consecuencia de la actitud de sobrecarga que emergía en algunos de los discursos de los cuidadores, quienes por momentos manifestaban sus intenciones de escapar de la pesada tarea que tenían sobre sí.

- “Usted se siente cansada, agotada?”

- “Sí, muchas veces, de largar todo lejos.” (Entrevistada 4)

Si bien la situación que vivían con el familiar podía resultar insostenible, todavía era más terrible cuando el propio cuidado generaba o agravaba otras problemáticas familiares.

- “Cómo ve el día de mañana con esto, con la enfermedad de su esposo? ¿Piensa usted en el día de mañana?"

- "Sí."

- “QQué es lo que piensa?”

- "Que me voy a ir de la casa."

- "Esa es la idea loca que se le atraviesa."

- "Sí, que mi responsabilidad va llegar hasta cuando esté él" (Entrevistada 1)

En el testimonio que acabamos de revisar se refleja un conflicto familiar aparte de la problemática misma del cuidado, una de las dos hijas del matrimonio vivía en la casa de sus padres junto a su familia $y$, de acuerdo a la observación de campo realizada, ella intentaba manejar la vida de su madre (la cuidadora), lo que hacía que para ésta sobrellevar la tarea del cuidado fuese más complicada aún y la llevara a pensar en salir de su propio hogar.

\section{Propiedad "Desesperación"}

Otra manifestación o consecuencia de la sobrecarga a la que estaba expuesto el cuidador era desarrollar un comportamiento de desesperación. Éste se presentaba habitualmente en el primer período en que los cuidadores se responsabilizan del dependiente, como una conducta que determinaba su actuar. Generalmente, estaba determinado por la falta de apoyos, sanitarios, sociales y familiares, en el cuidado del dependiente. En el siguiente verbatim, se expresa gráficamente lo anteriormente descrito. 
- “(...) entonces por eso ella tampoco pudo levantar [mejorar] cuando recién le dio eso, porque pasaba enferma, y yo aquí sola, sin saber qué hacer (...).”

- “¿Fue difícil ese primer año? ¿Por qué?”

- "Porque uno sin saber, una enfermedad nueva para uno, yo nunca había visto un caso así, terrible pues." (Entrevistada 20).

Más aún insoportable es la situación que vivían las entrevistadas que estaban a cargo de más de un dependiente, que no contaban con apoyos importantes en su trabajo, y que manifestaban un gran deterioro de su salud mental y física.

- "Me gustaría salir a la playa unos dos, tres días, no quisiera saber de nada, de relojes, ni de noticias, de nada."

- "Le dan ganas de decir de repente: "Ya, no los cuido más"."

- "Sí, este año estuve a punto de irme, a ver, mi hermano cayó el 22 de agosto hospitalizado, no el 22 de octubre, y unos días antes había tenido problemas aquí, yo estaba colapsando, porque mi hermano es mal genio, (...) yo miro a mi hermana y miro a mi mamá [ambas dependientes] y digo “¿Cómo las voy a dejar solas?”¿Cómo las voy a dejar solas? porque yo sé que si me voy las van a meter a un hogar de ancianos, de hecho a mi hermano andan haciendo los trámites para ir a dejarlo a un hogar de ancianos, yo soy la que no ha querido que lo metan en un hogar de ancianos." (Entrevistada 9) 


\section{TEMA DE ANÁLISIS. "INFLUENCIA DEL MEDIO URBANO Y RURAL EN EL CUIDADO"}

Nuestro muestreo y análisis, intencionadamente, se orientó a conocer si existían diferencias en el cuidado, de acuerdo al medio donde vivieran los cuidadores y sus dependientes. En el tema que trabajamos a continuación se intenta abordar la problemática del cuidado desde ésta óptica, para ello distinguimos tres categorías de análisis: los espacios públicos, la vivienda del dependiente, y las ventajas y desventajas de habitar en cada medio.

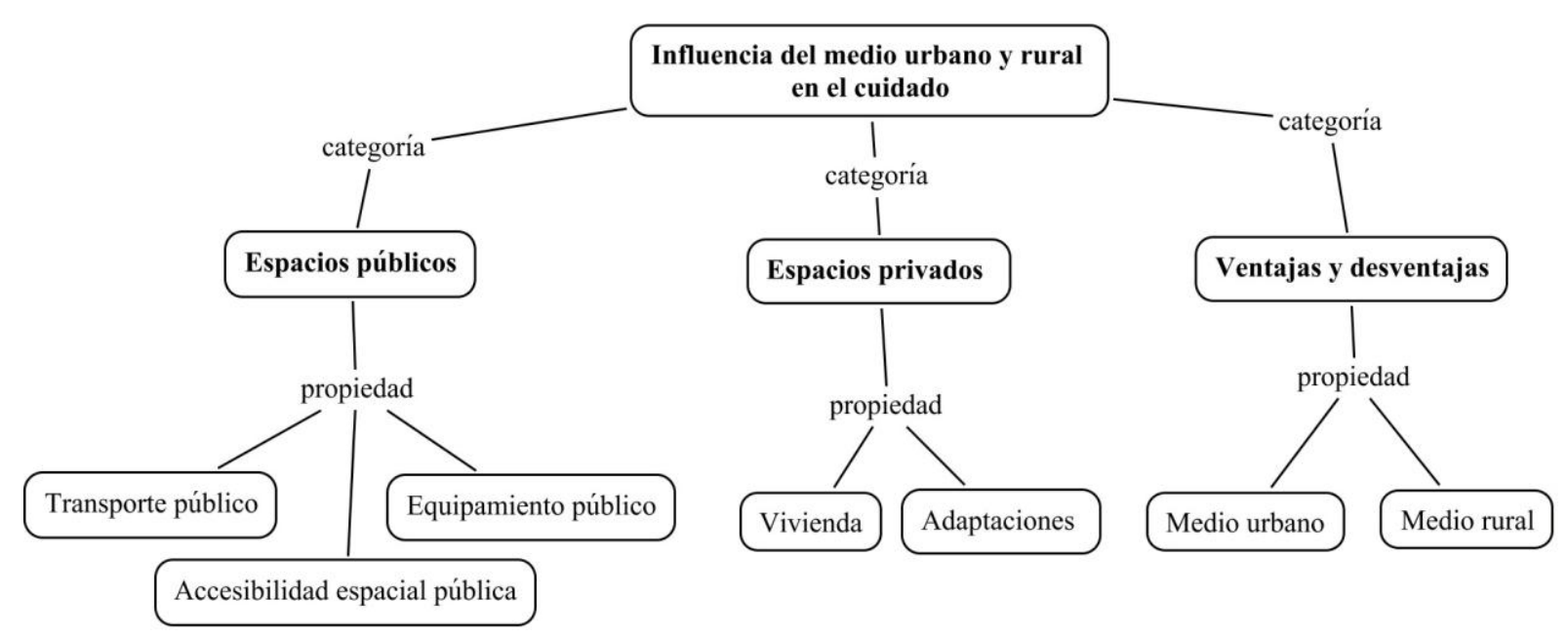

Mapa conceptual tema 4 Influencia del medio urbano y rural en el cuidado 


\subsection{CATEGORÍA "ESPACIOS PÚBLICOS"}

\section{Propiedad "Transporte en los medios urbano y rural"}

\section{Dimensión "Existencia de transporte público"}

En general, los cuidadores entrevistados que habitaban en municipios urbanos (Lo Prado y Pedro Aguirre Cerda) contaban con buena comunicación y una red de transporte público extensa -autobuses, metro, taxis, taxis-colectivos-.

- “EEl vivir en este barrio para usted es una ventaja o una desventaja don Arturo?”

- "Para mí es una, a mi señora siempre le ha gustado, pero yo encuentro que ha sido una ventaja, porque tengo el Metro cerca, sobre todo ahora, (...) ahora en la línea nueva que hicieron por San Pablo, tienen ascensores puedo ir directamente al hospital en el Metro, y fuera de eso la locomoción que tengo aquí en Neptuno con Dorsal, justo hay una que me deja en el hospital, y gracias a Dios es un recorrido que tiene rampa las micros ${ }^{124}$, porque las únicas que tiene rampa son las cuncunas esas [se refiere a los buses oruga], pero las que van por dentro casi ninguna tienen rampa (Entrevistado 28)

En el caso de los municipios rurales la distribución de los transportes públicos resultaba desigual, ya que había zonas dentro de ellos que estaban medianamente comunicadas y otras que simplemente estaban aisladas, ya que no contaban con ningún sistema de transporte público, ese era el caso de una de nuestras entrevistadas que vivía en Lomas del Aguila, Paine.

- “Usted encuentra que es mejor vivir aquí por ese motivo?”

- "Por ese motivo no más, pero quisiera una cosa así más balanceada, allá qué tengo allá, yo a donde vaya aunque sea en metro yo voy a poder salir, pero tengo colectivo a la puerta, cualquier cosa, un ataque una enfermedad ya están más cerca los hijos, tengo movilización. En cambio acá, en ese sentido, estamos aislados, yo dependo de mi vecina ¿Y si mi vecina no está?” (Entrevistada 11)

${ }^{124}$ Autobuses. 


\section{Dimensión "Accesibilidad física y económica del transporte público"}

Accesibilidad física

El sistema de transporte público de Santiago, que circulaba en las zonas urbanas de la capital, estaba formado por vehículos de distintas características. Algunos de ellos eran buses accesibles con sillas de ruedas, estos autobuses se denominan "troncales" y no necesariamente transitaban por todos los barrios de los municipios seleccionados en el estudio. También existía otro tipo de vehículos llamados "buses de acercamiento" que no eran accesibles en silla de ruedas, por tanto sólo algunos de los cuidadores podía trasladar a sus dependientes en el transporte público. Los dependientes que contaban con cierta movilidad tenían serias dificultades para acceder a este tipo de transporte. En el caso del metro, las líneas de nueva construcción poseían ascensores y salva-escaleras, pero en las líneas antiguas había muchas estaciones que no resultaban accesibles.

- “¿Y usted para la Teletón cómo lo hace para trasladarse con el niño?”

- “¿Cómo lo hago?, antes, cuando era más chiquitito, tomaba el colectivo y el metro y me bajaba en el metro Ecuador."

- "Lo llevaba en brazos ¿Y ahora?"

- "Sí, ahora tomo la 107 o cualquiera que va a la Teletón, la tomo ahí me bajo y entro"

-"Porque tiene como para subir la silla."

- "Tengo un coche ${ }^{125}$, que llego y lo subo. (...)"

- “Cómo considera que es la disposición de la gente en las micros para llevarla?”

- “(...) han sido muy pocas veces las que he tenido dificultades, pero más han sido porque no se permiten los coches, hay que cerrar los coches, y subir con la guagua ${ }^{126}$, con el bolso, es difícil, es terrible de difícil, y ahora me van a pasar una silla de ruedas en la Teletón así que vamos a ver cómo va a funcionar.” (Entrevistada 30)

En las zonas rurales, los medios de transportes existentes no eran accesibles para personas que tuviesen dificultades de movilidad, más aún para aquellos que dependían de una silla de ruedas para poder desplazarse, la mayor parte de los dependientes y sus cuidadores no podía hacer uso del transporte público.

\footnotetext{
${ }^{125}$ Carrito de bebé.

${ }^{126}$ Bebé.
} 
- “CCómo lo hacías para llegar con ellos [sus dos hijos dependientes] a Buin?”

- "No, si la familia, mi cuñado trabajaba en los colectivos, él me llevaba, cuando podía que era casi todos los días y si no me tenía que ir en colectivo no más."

- "Pero ¿Cómo lo hacías con el niño mayor?"

- "Aquí me "echaban" arriba, y me llevaba en brazos a uno y al otro sentado al lado, y allá cuando me bajaba lo primero que hacía era armar la silla y bajar a los dos.”

(Entrevistada 18)

\section{Accesibilidad económica}

Si consideramos que la mayor parte de las personas entrevistadas eran personas con situaciones económicas deficientes, y que las condiciones de salud de la mayor parte de sus familiares dependientes no les permitían desplazarse en autobuses y/o colectivos, sus traslados debían ser realizados en taxis. El elevado costo de este tipo de servicio hacia que los desplazamientos fueran limitados sólo a lo indispensable, generalmente a cuestiones de índole médica.

- "Y es que para trasladarlo tiene que tomar un vehículo por lo general."

- "Sí, a veces tomo un radio-taxi, a veces tomo un colectivo acá en la esquina, llamo para que me pasen a buscar, me cobran un poquitito menos, me cobran novecientos pesos, el radio-taxi me cobra mil quinientos, porque el Exequiel me queda muy a trasmano en locomoción, y ahora que pusieron unas micros resulta que tienen peldaño, no son como las de Transantiago, porque para subirme en esas micros tengo que subir el coche en brazos, y para subirlo pesa mucho, entonces tengo que saber movilizarme, uno tiene que buscar las vías de cómo hacerlo para llegar al lugar.” (Entrevistada 30)

Esta característica era común a sectores urbanos y rurales, pero de acuerdo a la menor disponibilidad de servicios, accesibilidad física y distancias de las zonas rurales, la accesibilidad se dificulta aún más cuando es vista desde el punto de vista del gasto.

- “De sus enfermedades se trata en el consultorio?”

- "De ninguna, a veces cuando estoy enferma, enferma, a mi me mandaron con urgencia a un psicólogo, fui a pedir hora olvídese, no tengo tanto tiempo para ir a pedir hora 
porque hay que estar ahí constante, me dicen que no está la agenda lista, que aquí, que allá, es lejos de aquí."

- "Claro porque implica o irse caminando o en colectivo."

- "En colectivo y a veces no tengo plata para el colectivo, (...) me fui de a pie y me vine de a pie, es complicado por eso no puedo ir a pedir hora para que me vean.”

(Entrevistada 19)

"Incluso el neurólogo que lo trata a él me había dado la dirección de uno [colegio] que está ahí en la Gran Avenida, en el paradero 5, pero de acá es muy lejos, imagínese los primero días que fui al colegio de Buin, me salía pesado porque tenía que pagar dos locomociones y más quedarme yo allá, (...) porque había semanas en que no podía ir y la idea mía era que si iba al colegio que fuera todos los días para que se acostumbrara y todo, pero como me salía muy pesado, había semanas en que no me alcanzaba la plata y no lo podía llevar hasta fin de mes" (Entrevistada 29)

\section{Dimensión "Transporte particular"}

Los cuidadores urbanos entrevistados no contaban con medios de transporte particular propio. Los que contaban con algún familiar que les pudiera trasladar generalmente recurrían a ellos, pero esto les resultaba incómodo. Y los que no tenían dentro de sus redes de apoyo quién los trasladase debían realizar un importante esfuerzo económico y pagar por el servicio.

"Un sobrino me ha estado llevando [al hospital], me iba a buscar, porque mi marido no podía, por el trabajo es imposible, entonces eso también, estar molestando a otras personas, uno se siente complicada, yo sé que él lo hace con mucho cariño porque es su primo, somos sus tíos, pero igual uno, yo al menos me sentía así, estar molestando, pidiendo ayuda a otra gente, no son personas extrañas, pero yo digo a lo mejor pueden ocupar su tiempo en otras cosas, porque mi sobrino igual durante su trabajo se ofrecía y me iba a buscar al hospital, y llegaba aquí y me decía: "Tía ya me voy” porque tenía que volver a su trabajo, eso me afectó también.” (Entrevistada 24)

"En el mismo lugar y de allá la vienen a buscar y a dejar [centro de diálisis], al principio tenía que pagar el auto también, esos me cobraban la mitad, pagaba como cincuenta mil 
mensuales, esos son tres veces a la semana, día por medio, así que después, gracias a Dios, allá mismo nos preguntaron cuántos años que lleva..., y de ahí nos dieron el pase para que la vinieran a buscar y a dejar gratis, y así ha sido todo.” (Entrevistado 28)

Algunos de los cuidadores rurales contaban con acceso a transporte particular propio, otros podían conseguir con sus redes de apoyo el traslado en caso necesario. Y otros debían pagar por estos servicios, lo que implicaba un menoscabo para sus economías familiares.

“Aquí en el consultorio, yo la llevo en la silla para allá y si tengo que ir a Buin o al Barros Luco [en Santiago], la echo al auto y la llevo. Ahora, si no tuviera vehículo me consigo, yo soy bien busquillas para esas cosas, me consigo uno, me ha pasado que de repente me ha tocado médico en Santiago y estoy en panne ${ }^{127}$, cualquier cosa, y me voy y busco, entre primos, amigos, no me hago ningún problema. (Entrevistada 13)

\section{Propiedad "Equipamiento público"}

\section{Dimensión "Equipamiento sanitario-comunitario"}

El sistema de salud público chileno convivía con un sistema privado de salud, éste último se constituía en la alternativa de las personas que tenían más recursos económicos, cuando existía saturación del sistema público. Por otro lado, la dependencia administrativa y económica de los centros de atención primaria era municipal en su mayor parte, lo que generaba grandes diferencias en la atención que se prestaba entre municipios, más evidente aún era comunas rurales (con pocos recursos) donde los servicios eran limitados y deficientes.

Centros de salud (CS)

Durante los últimos 20 años en Chile se ha desarrollado un fortalecimiento de la atención primaria. En las zonas urbanas estudiadas los CS que atendían a la población

${ }^{127}$ Automóvil estropeado. 
eran principalmente CESFAM $^{128}$. La cercanía física de estos establecimientos era una característica a destacar, ya que los cuidadores y sus pacientes no debían recorrer grandes distancias para acudir a ellos. Además, los tipos de servicios entregados posibilitaban que el dependiente fuese atendido en casa, movilizando al personal médico de su zona (médico de familia, enfermera, kinesiólogo y trabajadora social), quienes le visitaban en controles periódicos. Las condiciones socioeconómicas de los cuidadores urbanos hacían que solo vieran como opción de atención en salud, la salud pública. Solo uno de los cuidadores urbanos entrevistados (uno de quince) acudió al sistema privado de salud, y gracias a la implantación del programa AUGE ${ }^{129}$ logró cobertura del tratamiento médico de su dependiente en él.

- ¿Vivir en este barrio para usted implica una ventaja o una desventaja por la enfermedad de su mamá?

- "Una ventaja porque el consultorio está ahí, está cerca, porque si fuera más lejos, ahí sí que me sería... por mis piernas." (Entrevistada 5)

- "El vivir acá, en este barrio, para usted ¿Implica una ventaja o una desventaja a la hora de tener que cuidar a su niño?

- "No, una ventaja, porque yo veo mamás que vienen de Paine, vienen del norte, es más su... y yo estoy acá mismo, y aparte que de la Teletón, si a mí, por ejemplo el José estuvo en sala, hace como un año atrás, sala es donde están profesores que lo están evaluado (...), y en ese tiempo me ofrecieron si quería que me lo pasaran a buscar en la ambulancia, y yo dije que sí, me pasaban a buscar, entonces como yo no trabajo, estoy dedicada a él." (Entrevistada 30)

\footnotetext{
${ }^{128}$ Centros de salud familiar, forman parte de la red asistencial de menor complejidad, cuya administración depende mayoritariamente de los departamentos de salud municipal y en menor grado de los Servicios de Salud, están localizados en sectores urbanos y rurales, con un horario de atención de 8:00 a 17:00 horas y con una extensión hasta las 20 horas que considera prestaciones de morbilidad medica, atención odontológica y controles de salud preventivos de otros profesionales. Funcionan bajo la modalidad de población a cargo y entregan las prestaciones definidas en el plan de salud familiar (promoción, prevención, curación y rehabilitación)

${ }^{129}$ Plan de Acceso Universal de Garantías Explícitas (AUGE). Las Garantías Explícitas en Salud (GES) son un derecho y deben ser las mismas, independiente de si la persona es beneficiaria del sistema público (FONASA) o del sistema privado (ISAPRE). Otorga a los usuarios cuatro garantías: acceso, oportunidad, cobertura financiera, calidad. Se garantizan prestaciones a un conjunto priorizado de programas, enfermedades o condiciones de salud (69 al año 2012).
} 
En los sectores rurales, las problemáticas en este ámbito estaban dadas por las distancias a las que se encontraban los centros de salud, la calidad de los servicios prestados y la falta de servicios disponibles. Los tres municipios rurales donde se realizó el estudio presentaban disparidades al respecto, pero estas tres carencias estaban presentes.

"Es que uno ya está ambientada, ya se ambienta, siempre hemos tenido que salir a médico lejos... está asumido.” (Entrevistada 21)

"Mira a lo mejor al vivir en Santiago tendría a lo mejor más opción de ir a un centro de rehabilitación, porque se supone que hay más, hay algún centro en Santiago, acá no, acá en Buin no hay." (Entrevistada 16)

Servicio de transporte de dependientes

El servicio de transporte de enfermos, en las zonas urbanas estudiadas, que se prestaba en los centros de salud, hospitales públicos e instituciones como la Teletón estaba limitado a los trayectos estrictamente necesarios. Sólo uno de los municipios contaba con disponibilidad de transporte para las personas "postradas". Aquellos dependientes, cuyas enfermedades se encontraban dentro del listado de patologías cubiertas por el plan AUGE, tenían garantizados los desplazamientos hacia los centros de salud donde se sometieran a diagnósticos o tratamientos (diálisis, por ejemplo).

- “O sea usted tenía que llevarla a pulso para el Yazigi [centro de salud]?”

- "Sí, a pulso para allá. Y de aquí igual si necesito yo que me la vengan a buscar yo voy y hablo allí en el consultorio, y en la Teletón cuando la Daniela estaba enyesada con esos yesos tenía que entrar a llamar a la Teletón que me vinieran a buscar en caso de los controles o juntar mis monedas y llevarla en taxi no más, porque el consultorio no da la opción de decir: "Necesito que me lleven a la Daniela de aquí a la Teletón", eso no se puede. Pero de consultorio a hospital que ellos me la deriven se puede, pero yo no tengo la opción de decir "yo necesito una ambulancia para ir a tal lado." (Entrevistada 27)

Como anteriormente comentábamos, los desplazamientos proporcionados por el sistema público de salud eran limitados y ni siquiera consideraban casos extremos, como el que a continuación se menciona, ya que el niño dependiente debía viajar a sus controles de 
salud conectado al menos a 2 máquinas (respirador y otra que mide sus signos vitales) en un trasporte privado, generalmente proporcionado por familiares.

- “YY usted tiene que llevar a Luis al Exequiel [Nombre del Hospital]?

- "Sí, lo tengo que trasladar yo, y para ir al Hospital Pedro Aguirre Cerda también tenemos que trasladarlo nosotros."

- "O sea no viene una ambulancia que lo lleve."

- "No." (Entrevistada 24)

Anteriormente señalábamos que la salud primaria dependía económicamente de los municipios, y si estos son rurales deben atender a territorios más extensos, donde la población está dispersa. En el ámbito rural el servicio de ambulancias era prácticamente inexistente, se limitaba a los servicios de urgencia y los desplazamientos garantizados por el plan AUGE.

- “¿A ella cuando le dio el accidente vascular ustedes dónde la llevaron?”

- "Cuando la recogimos, la sacudimos, me la llevé a urgencias a Curacaví."

- “CCómo lo hicieron?”

- "Contratamos un colectivo, porque es lejos y en ese tiempo había menos ayudas para los postrados entonces habían menos recursos, aquí poco se ve la ambulancia, la ambulancia para este sector nunca la encuentra usted, siempre que uno necesita dicen: "No está la ambulancia", "Que anda en Santiago", "Que está en viaje", "Que está en panne”, entonces nunca se encuentra, ahora que está el SAMU [Servicio de atención médica de urgencia] uno tiene que recurrir a él.” (Entrevistada 20)

Gran parte de los cuidadores rurales entrevistados ni siquiera contemplaban como alternativa de traslado de sus familiares en ambulancia, simplemente intentaban solucionar las necesidades de transporte con sus reducidos medios.

"Y la ambulancia, el primer día, que fue un auto, porque la ambulancia se perdió, no lo pudo encontrar, mandaron un auto, y el auto se le echó a perder no se qué cosa por subir hasta arriba, total que reclamó el chofer y dijo que él no iba más a buscar ese enfermo ahí ¿Qué puedo hacer yo en este caso? Ya, le dije a mi hijo: "Mañana venga usted, 
traiga la camioneta y nos vamos a mi casa, está más lejos, pero está plano." (Entrevistada 11)

\section{Propiedad "Accesibilidad espacial pública"}

\section{Dimensión "Accesibilidad en el barrio"}

Considerando los relatos de los cuidadores urbanos, y pensando en las necesidades especiales que ellos tenían por su labor, por ejemplo la movilización del dependiente, las zonas urbanas se encontraban bastante bien equipadas, contaban con centros de salud cercanos, el estado de las aceras y de las calles era aceptable y tenían un sistema de trasporte público que facilitaba sus desplazamientos.

- "Y acá en el barrio, ¿Cómo están las calles?

- "No, aquí están buenas las calles, están todas buenas.” (Entrevistada 6)

En el caso de los cuidadores que vivían en entornos rurales era diferente, como anteriormente constatamos no contaban con transporte público adecuado para trasladar a sus enfermos, los centros de salud, hospitales o postas rurales estaban alejados, y se sumaba a ello el estado de los caminos y/o calles y aceras que se encontraban en un estado deficiente.

- "Yo tenía que llevarlo para todos lados en la silla de ruedas, acá hay espacio, pero yo lo llevaba para adelante también."

- "Claro, y ahí no hay nada pavimentado."

- "Un día queríamos ir a la capilla de Sta. Rosa de Lima, pero llegamos hasta la vuelta no más, ni a él ni a mí nos dio la fuerza, así que ya no salimos, es fue mi paseo, el paseo que nos dimos con la silla de ruedas, después ya nos quedamos aquí adentro no más." (Entrevistada 11) 


\title{
4.2. CATEGORÍA "VIVIENDA DEL DEPENDIENTE"
}

\section{Propiedad "Vivienda del dependiente"}

Las condiciones socioeconómicas de las familias de los dependientes determinan la accesibilidad de sus viviendas; quisiera señalar que en este epígrafe, concretamente, las afirmaciones plasmadas se realizan en base a los discursos de los entrevistados y a las notas realizadas en el trabajo de campo.

En el ámbito urbano, entre las principales problemáticas observadas, en las viviendas de las familias estudiadas, destacamos la falta de espacio en los hogares, llegando en algunos casos a situaciones de hacinamiento. También, constatamos la mala calidad de las viviendas, en su mayoría viviendas "sociales", que adolecían de aislación térmica, algunos de los materiales de la casa presentaban deterioro, etc.

\begin{abstract}
“(...) es que la Daniela estuvo mucho tiempo lavándose los dientes en la cocina, y no cabía, entonces para bañarla yo tenía que tomarla en brazos con ella, no pegarle en la puerta, entonces junté la plata y pedí que me hicieran, entonces saqué la puerta de la cocina... uno viste un santo, desviste uno para vestir el otro, y no tengo otra opción, y para el piso [suelo] me inscribí en esta cosa de el programa de mejoramiento por la municipalidad, me colocaron cerámica en el departamento [antes el suelo era de cemento)." (Entrevistada 27)
\end{abstract}

Un aspecto importantísimo, que facilita o dificulta la labor del cuidador, era la presencia o ausencia de barreras arquitectónicas en las viviendas. Prácticamente todos los hogares visitados no estaban adecuados para atender las necesidades especiales del dependiente, uno de los episodios más relatados por los cuidadores era la forma en que aseaban al dependiente, debido a que no contaban con servicios adaptados.

"Ponte tu para bañarla yo le ponía un piso ${ }^{130}$, con decirte que últimamente yo abría esa puerta y daba vuelta la silla de ruedas y para lavarle el pelo, y se lo lavaba ahí, en el baño, lo hacía yo, sosteniéndola así, sosteniendo la silla de ruedas así [con el pie] y aquí lavándole el pelo y ahí sosteniéndola, con el pie, yo sola, las dos solitas.” (Entrevistada 10)

\footnotetext{
${ }^{130}$ Taburete.
} 
En el caso de las viviendas visitadas en zonas rurales, destacamos que éstas eran más espaciosas que las urbanas, pero algunas de ellas estaban en pésimo estado debido a que estaban fabricadas en adobe y se vieron seriamente afectadas por el último terremoto que afectó la zona central chilena.

"Es que como son casa antiguas, casa de campo, es todo grande, las puertas son anchas, no como en otras casas que vas a pasar con la silla de ruedas y quedas encajada." (Entrevistada 18)

\begin{abstract}
"El terremoto fue terrible para mi, estuvimos las dos solitas, encerradas, yo lo único que veía era que íbamos a quedar debajo de la casa, y eso que yo me programaba para una cosa así, yo siempre lo pensaba, que yo le tenía miedo a esta casa que si pasaba esto, yo iba a tomar a mi mamá y la iba a meter debajo de la cama, y ese día yo no hice nada, nada, nada... bueno lo único que trataba de taparla a ella con un cojín pero yo me veía con la casa encima." (Entrevistada 20)
\end{abstract}

Las casas de los entrevistados rurales generalmente habían sido edificadas por las propias familias, pero también en ellas se daban problemas como la falta de aislamiento térmico y la presencia de barreras arquitectónicas. Igualmente, el lugar de la casa que menos adaptado se encontraba era el baño, que en algunas de estas viviendas estaba ubicado fuera de la construcción principal, lo que generaba una dificultad más para el cuidador, sobretodo en la época invernal.

“Acá yo lo baño así no más, yo lo siento y lo baño allá afuera [indica el patio de la casa], le echo el agua por arriba, como él no se para, para él es más seguro que lo bañe sentado, claro que me cuesta sola pa' bañarlo, pero menos mal que camina algo, si tuviera que caminar en brazos con él sería...” (Entrevistada 15)

El contar con mayor espacio les permitía realizar ampliaciones o redistribución de los espacios de la casa. Este punto será tratado en la propiedad que sigue. 


\section{Propiedad "Adaptaciones y/o estrategias adoptadas"}

Las familias de los dependientes, en especial sus cuidadores, procuraban estrategias para poder realizar su labor de forma más cómoda. A pesar de sus limitadas posibilidades económicas emprendieron una serie de acciones.

Las viviendas de las áreas urbanas estaban limitadas por el espacio, aparte del dinero, para la realización de transformaciones en los interiores de las casas. Las habitaciones y el servicio eran las partes de la casa que más urgían ser adaptadas.

- “¿Duermen juntas?”

- "Sí, porque aquí no puedo hacer ampliación, una por la plata y lo otro aquí dentro no puedo porque le quito espacio a ella, entonces tengo que ingeniármelas." (Entrevistada 27)

"Incluso aquí, donde duerme él, era una ventana común y corriente, eran dos ventanas, hubo que partirla, porque por aquí los de la ambulancia llegaban hasta aquí no más [señala el salón de la casa] y de aquí en sábanas pa’ dentro. Entonces ya, hagamos una puerta, vamos haciendo la puerta. (...) Un maestro tuvo que sacarme la ventana, haciendo el rasgo y otro caballero de la vidriería hacernos la ventana y ya." (Entrevistada 1)

Cuando no se contaba con dinero para realizar reformas, una de las opciones más recurridas era cambiar el uso de los espacios, para intentar salvar alguna barrera arquitectónica (escaleras, por ejemplo), contar con algo más de amplitud y cercanía al servicio.

\footnotetext{
“Es seña que tuvimos que... yo tenía el dormitorio allá arriba [primer piso] y tuvimos que bajarlo porque no podía llevarme pa' arriba pa' abajo, es seña que yo tengo acá el dormitorio [en lo que antes era el salón], la cama de los dos.” (Entrevistada 4)
}

En el caso de los servicios, habitualmente, el problema eran sus reducidas dimensiones en este tipo de viviendas, lo que dificultaba enormemente las labores de higiene del 
dependiente, por ello la mayor parte de los cuidadores realizaba "baños en cama" al dependiente.

"En el baño no, no la podemos [asear], no ve que tenemos un baño chiquitito, angosto, la silla de ruedas no nos alcanza. (...) nosotros tenemos una bañera así que es de la guagua $^{131}$, ahí la damos vuelta, le lavamos el pelo primero, yo le pongo un hule a la cama, y ahí la trapeamos, y después la vamos enjuagando por partes, ésta parte primera y después la otra.” (Entrevistada 8)

Una ayuda, al alcance de las posibilidades económicas de estos entrevistados, era instalar manillas de sujeción para los dependientes que tenían movilidad reducida, ubicándolas en sitios estratégicos de la vivienda -habitación, servicio-.

“(...) por lo mismo yo he tratado de ver si yo la puedo llevar así, la llevo un poquito caminando, y al baño también, porque el baño tiene unas manillas de donde se sujeta ella, también tiene unas manillas, que se puede parar." (Entrevistada 6)

En las viviendas rurales no existía limitación del espacio, contaban con terreno donde realizar ampliaciones de habitaciones, pero no siempre con el dinero para ello, en ese caso recurrían también al cambio de uso de las habitaciones de la casa.

"Le agrandaron el dormitorio, es que la casa de ella no es tan chica tampoco pero para andar con una silla dentro, le hicieron el baño y el dormitorio más grande." (Entrevistada 21)

"Tuvimos que adaptar aquí, como la casa es de segundo piso, nosotros teníamos los dormitorios arriba, tuvimos que guardar todo lo del comedor, todos los muebles sacarlos y hacer un dormitorio abajo, armar un dormitorio para tener un dormitorio para él porque no podía subir escalas, ya el segundo año ya logró subir, ahora sube y duerme arriba. (...) Tuvimos que tener un baño químico abajo [en el patio de la casa], porque el baño está arriba.” (Entrevistada 16)

${ }^{131}$ Bebé. 
La amplitud de las viviendas rurales contaban con la dificultad para ser calefaccionadas, y ninguna de ellas tenía sistema de calefacción para toda la vivienda.

\footnotetext{
"Creo que sí, porque tengo la estufa y en el tiempo de invierno prendo la estufa, a gas que es menos tóxica, y me la llevaba para la pieza, con agüita, pañales, toalla Nova ${ }^{132}$, algodón, así lo limpiaba calientito, después sacaba la estufa. Creo que sí, porque mi casa es amplia." (Entrevistada 14)
}

Como se relató antes, la dificultad para asear al dependiente también estaba presente en estas viviendas, la única diferencia estribaba en que los baños eran más amplios, aunque la mayoría tenía bañeras. Tal como mencionábamos, muchos de los dependientes eran aseados en sus camas, pero otros cuidadores idearon estrategias para poder desarrollar esta labor.

"En la tina ${ }^{133}$ del baño le ponemos una tablita así, ancha y le ponemos una esponja para que él se siente, y de ahí él se baña sólo, yo le echo el agua no más, él se lava su pelo, todo, y ya después él se seca y lo ayudo yo a secarlo.” (Entrevistada 17)

\subsection{CATEGORÍA "VENTAJAS Y DESVENTAJAS DE LOS MEDIOS URBANOS Y RURALES PARA EL CUIDADOR"}

\section{Propiedad "Ventajas y desventajas de vivir en el medio urbano para el cuidador"}

Es posible que en esta propiedad reiteremos afirmaciones realizadas a lo largo de este tema de análisis, por eso intentaremos ser breves en indicar cuáles son los aspectos positivos y negativos de vivir en ambos medios.

La cercanía y disponibilidad de servicios eran aspectos que los cuidadores urbanos destacaban como ventajas de vivir en comunas de la ciudad de Santiago. Otro aspecto que también fue mencionado fue el de la infraestructura vial, concretamente el estado de calles y aceras que, a decir de nuestros entrevistados, era adecuado.

\footnotetext{
${ }^{132}$ Papel de cocina.

${ }^{133}$ Bañera.
} 
En cuanto a los aspectos negativos, mencionados por los entrevistados, estaba el aumento de la delincuencia y la peligrosidad de los barrios estudiados, Lo Prado y Pedro Aguirre Cerda son comunas populosas del Gran Santiago donde existían sectores focalizados de venta de droga

\begin{abstract}
"Puede ser una ventaja porque conozco todo el sistema, donde me tengo que desplazar, donde tengo que ir, donde tengo que comprar, o sea los tiempos yo los controlo aquí viviendo tantos años, (...) pero también es una desventaja porque el barrio se ha puesto muy malo, demasiado malo, aquí andan pegando puñaladas, entonces hay que salir y ver si hay alguien en la esquina o sentados ahí porque si queda la casa sola se puede meter alguien, se ha puesto malo, antes no era así, era más tranquilo, porque hay mucha delincuencia, delincuencia juvenil, y como hoy en día los cabros $^{134}$ son imputables [quiso decir inimputables], no miran para ningún lado, andan asaltando, andan robando y un sinfín de cosas." (Entrevistado 25)
\end{abstract}

\title{
Propiedad "Ventajas y desventajas de vivir en el medio rural para el cuidador"
}

Las ventajas de vivir y cuidar a una persona dependiente en un área rural fue definida de forma sintética por una de las entrevistadas, ella aludía al concepto de calidad de vida para describir los aspectos positivos de vivir en una zona rural, en concreto se aludía a la posibilidad de disfrutar de un medio ambiente limpio ${ }^{135}$, de residir en viviendas espaciosas y en barrios tranquilos donde sentían que había "comunidad", cooperación y preocupación entre los vecinos, también se destacaba la existencia de una red de apoyo fuerte.

- "El vivir aquí, en Hospital ¿Para usted implica una ventaja o una desventaja?”

- "Ventaja, de todas maneras, por la calidad de vida, porque yo viví años en Santiago y de hecho me vine a vivir acá por eso, porque Santiago es una selva, porque yo aquí feliz, voy acá atrás recojo zapallos, la fruta, la verdura que yo quiera, tengo espacio, la gente misma, uno conversa con la gente, es otra cosa, se cuidan los vecinos unos con otros, tengo aire, tengo sol, tengo viento." (Entrevistada 13)

\footnotetext{
${ }^{134}$ Chicos.

${ }^{135}$ Este aspecto resulta de especial importancia en la Región Metropolitana de Santiago, porque en invierno la zona urbana de la ciudad se ve afectada por altos índices de contaminación que pueden llegar a ser perjudiciales para la población que en ellas habita, especialmente para niños y personas mayores.
}

Página 384 


\begin{abstract}
"Una ventaja pienso yo, porque me imagino, por ejemplo, en un departamento ${ }^{136}$, que esté ahí, encerrado, debe ser más estresante para una persona, y para el que lo cuida también porque estar en ese... por lo menos acá yo salgo a regar, salgo a barrer, me voy a dar una vuelta para allá para la parcela, voy a ver las flores, para mí es un deleite salir de aquí afuera y aunque sea a comprar a la esquina, yo encuentro que estar en Santiago o en el pueblo no creo que sería igual." (Entrevistada 23)
\end{abstract}

Pero la gran desventaja que encontraban los sujetos estudiados en el medio rural estudiado era la situación de aislamiento, ésta era una característica presente en los discursos de todos nuestros entrevistados de zonas rurales. En las categorías anteriores de este tema, analizamos las escasas alternativas de transporte público y privado, la deficiente infraestructura vial, lo lejano que se encontraban los centros de atención sanitaria y las nulas alternativas de transporte de sus dependientes $\mathrm{y}$, obviamente, esta peculiaridad se extiende a otros servicios básicos como los colegios, el municipio, las farmacias, los supermercados, etc.

La distancia desde los domicilios hacia los servicios básicos (CS, escuelas, municipio, supermercados, farmacias), que en algunos casos podríamos calificar de incomunicación, se constituía en una severa dificultad para los cuidadores de personas dependientes, ya que si no contaban con algún medio de transporte público cercano o transporte particular propio, debían costear el precio de taxis o depender de la voluntad de sus redes de apoyo. Todas estas dificultades limitaban, enormemente, los desplazamientos de los cuidadores, ya que tampoco podían soslayarlas con dinero, por las características de sus economías familiares.

“(...) el neurólogo que lo trata a él me había dado la dirección de uno [colegio] que está ahí en la Gran Avenida, en el paradero cinco, pero de acá es muy lejos, imagínese los primero días que fui al colegio de Buin, me salía pesado porque tenía que pagar dos locomociones y más quedarme yo allá, después pusieron el furgón [transporte escolar] y ahí como que me... un poco, porque había semanas en que no podía ir y la idea mía era que si iba al colegio que fuera todos los días para que se acostumbrara y todo, pero

${ }^{136}$ Piso. 
como me salía muy pesado, había semanas en que no me alcanzaba la plata y no lo podía llevar hasta fin de mes." (Entrevistada 29)

\section{Síntesis del tema}

El objetivo del tema tratado nos llevó a analizar las múltiples dimensiones de vivir en medios urbanos o rurales para el cuidador y su familia. El estudio de los relatos y de las notas de campo recogidas nos permitieron reconocer tres categorías: los espacios públicos, la vivienda del dependiente y las ventajas y desventajas de residir en cada medio.

Al analizar los espacios públicos de acuerdo al medio, encontramos grandes diferencias entre lo urbano y lo rural. El primero tenía una red de transporte público amplia y con relativa accesibilidad física, cosa contraria ocurría en los municipios rurales. La accesibilidad económica era similar en ambos espacios, cuidadores urbanos y rurales tenían similares condiciones económicas, pero más afectada en el caso de lo rural por las pocas alternativas de transporte público disponible, lo que significaba que tenían que hacer un gasto mayor para realizar desplazamientos con el dependiente. En cuanto al equipamiento sanitario-comunitario, los cuidadores de las zonas urbanas consideraban que este tipo de servicios -Centros de salud, escuelas, municipio, comercio- estaba a su alcance; lo contrario ocurría a los cuidadores rurales, las enormes distancias que debían recorrer los hacía sentir aislados. El transporte de los dependientes resultaba complicado en ambos medios, debido a que la disponibilidad de hacerlo en vehículos adaptados ambulancias, por ejemplo- era limitada, la situación se agravaba en las zonas rurales donde los trayectos eran mayores. La accesibilidad de los espacios públicos, íntimamente ligada a la disponibilidad y cercanía de centros sanitarios-comunitarios y a la existencia y estado de infraestructura vial, claramente era mejor en el medio urbano que en el rural.

Al analizar el hogar del dependiente y el cuidador, pudimos observar que las viviendas urbanas carecían de espacio, eran de mala calidad, y tenían múltiples barreras arquitectónicas. En el caso de las casas rurales visitadas, los principales problemas observados eran: el deterioro de éstas, los problemas de aislamiento térmico y las 
barreras arquitectónicas. Un factor común a ambos medios era el problema de accesibilidad a los servicios.

Entre las adaptaciones y/o estrategias adoptadas por los cuidadores y sus familias para mejorar las condiciones de la vivienda, en pos de hacer más llevadera la labor del cuidado, destacaban el cambio en el uso de los espacios de la casa, la realización de pequeñas reformas, la utilización de accesorios y el aseo del dependiente en la cama.

Finalmente, en la última categoría analizada de este tema, entre las ventajas de vivir en el medio urbano señalamos la cercanía y disponibilidad de servicios (de salud, educación, transporte, etc.), y la infraestructura vial disponible y moderadamente accesible. Las desventajas estaban dadas principalmente por la peligrosidad de los barrios donde vivían algunos de los cuidadores entrevistados.

El habitar en el medio rural contaba con los siguientes aspectos positivos para los cuidadores entrevistados: medio ambiente limpio, viviendas espaciosas, barrios tranquilos y una red de apoyo vecinal. La gran desventaja de este medio era la situación de aislamiento en la que vivían concretada en la carencia de infraestructura vial, transporte público deficiente, centros de atención sanitarios y comunitarios lejanos y nulas posibilidades de transporte accesible para sus dependientes. 


\section{TEMA "PERCEPCIÓN DE LOS CUIDADORES DEL ESTADO"}

La relación del Estado con los cuidadores y dependientes ya ha sido tratada dentro de categorías como la realidad socioeconómica (propiedad ingresos, a través de los subsidios) o como los espacios públicos. En este tema, trataremos áreas que son de especial sensibilidad para los cuidadores y de gran importancia para su labor con los dependientes a su cargo, como son la salud, las pensiones, la educación y las demandas que creen que el Estado podría ayudarles a solventar.

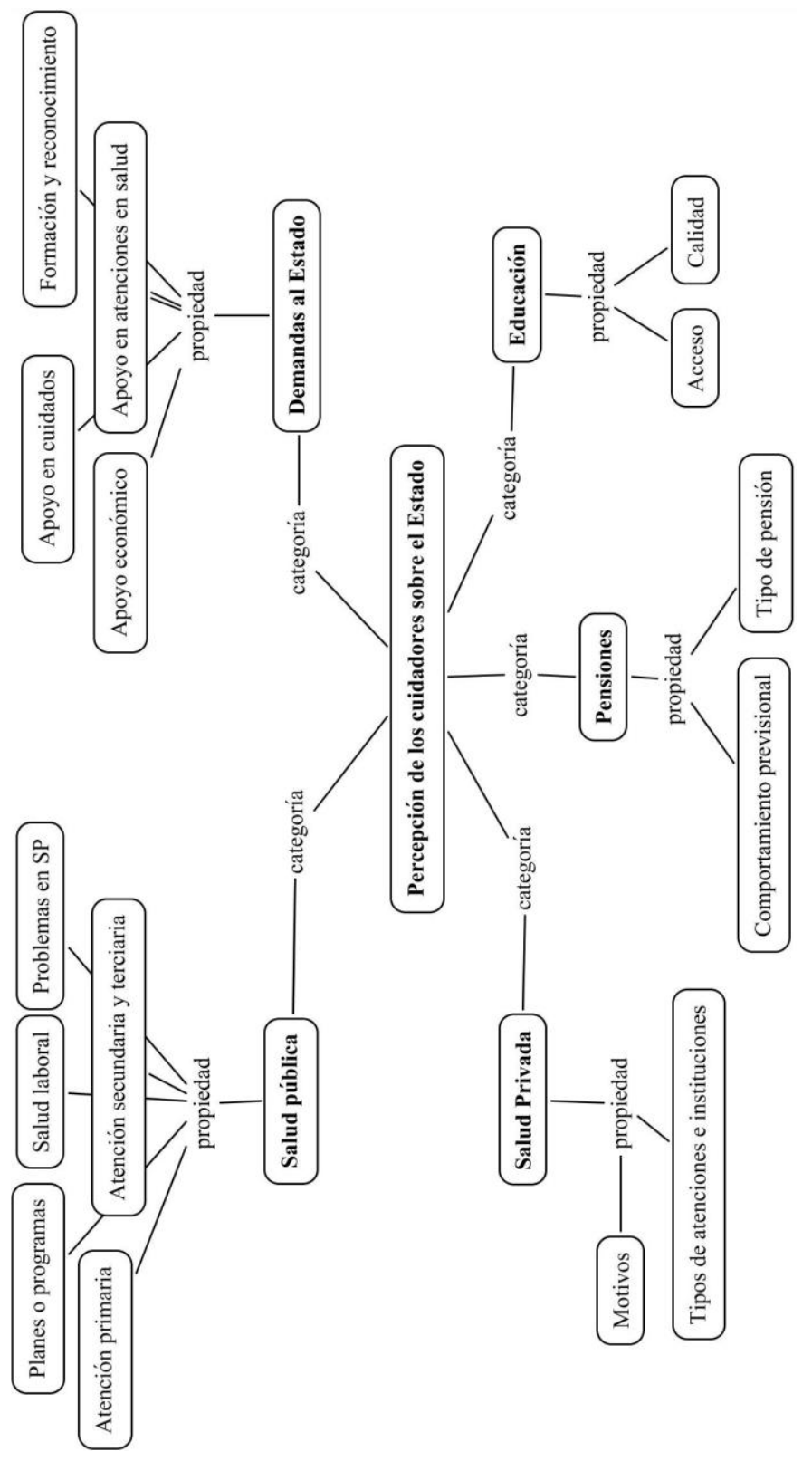

Mapa conceptual tema 5 Percepción de los cuidadores del Estado 


\subsection{CATEGORÍA "SALUD PÚBLICA"}

Las referencias que nuestros entrevistados realizaban al tema de la salud, primeramente, estaban referidas a la atención en salud de sus dependientes, a cómo resolvieron las problemáticas que les ocurrían, y al tipo y calidad de la atención recibida. De forma secundaria, ellos referían sus problemas de salud.

El sistema de salud pública chilena privilegiaba la atención de la población a través de la atención primaria. Por ello, la relación más frecuente de nuestros cuidadores y sus dependientes con el sistema de salud público era con los centros de salud o policlínicos de la atención primaria, instancia por la que comenzaremos el análisis de esta categoría.

\section{Propiedad "Atención primaria"}

Como señalamos anteriormente, en el tema referido a la influencia del medio urbano y rural en el cuidado informal, el acceso a la atención primaria era desigual para las comunas rurales y las urbanas. Las distancias a las que se encontraban los centros de salud, postas rurales y policlínicos, y los recursos con los que contaban diferían enormemente y por consiguiente eso afectaba la atención de salud brindada.

\section{Dimensión "Programa de Atención domiciliaria de personas con discapacidad severa ${ }^{\text {137 }}$}

Se debe considerar que las primeras, y mayoritarias, referencias de los cuidadores al sistema de salud tenían relación con los procesos de salud de sus dependientes, y más específicamente con el Programa de atención domiciliaria de personas con discapacidad severa, ejecutado desde el nivel de atención primaria. Todos los dependientes de cuidadores urbanos formaban parte de este programa, y gran parte de los rurales también (a excepción de tres dependientes).

${ }^{137}$ Llamado también Programa de postrados. 
Este programa tenía los siguientes componentes: visitas domiciliarias, formación del cuidador, y entrega de estipendio. Además, se asocian a estos servicios la entrega de ayudas técnicas, medicamentos y alimentos, y el transporte de los dependientes.

\title{
- Visita domiciliaria
}

Uno de los elementos fundamentales del Programa del que hablamos eran las visitas que realizaba el equipo médico del centro de salud al que estuviera inscrito el dependiente. Estas visitas pretendían entregar una atención de salud integral al dependiente y proporcionar al cuidador herramientas que le permitieran asumir su labor.

De acuerdo a lo que el Programa estipulaba, el equipo médico de cabecera del dependiente debía visitarlo al menos en doce ocasiones. Dos de estas visitas debían ser realizadas por una enfermera $\mathrm{u}$ otro profesional capacitado que realizara una actualización de la historia clínica del dependiente. Además, recomendaba una visita trimestral para evaluar el impacto del cuidador en los cuidados al paciente postrado, el resto de las visitas corresponden a los llamados cuidados domiciliarios y debía ser realizada por técnicos paramédicos. También, contemplaba dos visitas anuales por el kinesiólogo (fisioterapeuta) para intervenir en la postura y movilidad del dependiente, y en la prevención de enfermedades generadas por el sobre esfuerzo físico en el cuidador.

Los cuidadores entrevistados, en las dos comunas urbanas, manifestaban que la atención domiciliaria recibida, por parte de los equipos de salud, era adecuada y, según sus relatos, acorde a lo estipulado en el planeamiento del Programa.

\begin{abstract}
"Bueno a la Marta la vienen a ver aquí y a mi papi también, (...) La enfermera, y el doctor también viene a ver a la Marta, les toca en diciembre, y a mi papi también le toca en diciembre, y el kinesiólogo lo viene a ver a él. (...) ahora empezaron una terapia, ahora es primera vez que viene, que tiene que caminar para empezar a usar bastón.” (Entrevistada 2)
\end{abstract}

"Los vienen a ver acá a la casa como postrados. (...) el doctor Román y la doctora Marín. (...) Sí, de primera vino a evaluarlos la enfermera, vino la asistente social, y después vienen los médicos, cada cuatro meses, y si es mucha urgencia yo les aviso y 
vienen antes. Yo por mi no tengo nada que decir, ellos se han portado súper bien.” (Entrevistada 9)

Al analizar las situaciones de los cuidadores de las tres comunas rurales, las realidades resultaban parecidas en sus carencias, ya que el nivel del cumplimiento del programa estaba bajo los estándares comprometidos, principalmente por el número y frecuencia con que se realizaban las visitas domiciliarias.

\footnotetext{
"Sí, lo vienen a verlo, a veces a los 6 meses y si tiene algo lo vienen a ver más seguido. (...) de aquí del Poli [Posta de salud rural de Valdivia de Paine], aquí en Valdivia donde está la posta de ahí lo controlan, a todos los postrados los vienen a ver a las casas. Menos mal porque es un sacrificio llevarlo, porque él no camina, bueno camina que yo lo lleve afirmado desde acá a la casa de allá, afirmándolo, pero así solito no.” (Entrevistado 15)

- “¿A él lo ha venido a ver alguna vez un médico a la casa?"

- "Sí, del consultorio, pero ahora hace tiempo, yo diría como un año, que no vienen, a veces viene una enfermera del consultorio." (Entrevistada 19)
}

De acuerdo a lo relatado por la directora de uno de estos centros de atención, una posta rural, los limitados recursos que manejaban -transporte, personal, medicamentos y material de curas- les impedían acceder a la población dispersa de sus áreas de la forma en que el programa les indicaba.

\section{- Formación de cuidadores}

Un objetivo primordial del Programa era la capacitación de los cuidadores para que estos pudieran desempeñar de forma óptima su labor, sin poner en riesgo su propia salud. Esta actividad formativa se realizaba generalmente en los mismos centros de salud, pero esta condición resultaba un obstáculo para su cumplimiento, debido a que gran parte de los cuidadores no disponía de alguien que les reemplazara en su labor.

- ¿Usted ha recibido capacitación para cuidarlo?” 
- "No, del hospital me llamaron una vez pero no tuve con quien dejarlo, cuando recién había caído él, y estaba delicado por el asunto del corazón y todo eso, no tuve quién se quedara con él para asistir.” (Entrevistada 23)

Los cuidadores que sí habían recibido la formación reconocieron que les fue de enorme ayuda en el desempeño de las distintas aristas de su labor. A estos cuidadores les había sido posible acudir a este curso gracias a que tenían con quien dejar al cuidador.

“(...) yo hice un mini curso, yo llegué hasta donde hay que pinchar, ahí se terminó, porque no me den poner inyecciones, curaciones, no, yo soy lo más cobarde que hay. Pero nos enseñaron, según la enfermedad del paciente, teníamos que ver las comidas que él tenía que comer, el trato, cómo había que tratar al enfermo, no tratarlo mal porque está enfermo pero es consciente del trato que uno le da, si uno lo está tratando mal él se va a dar cuenta, él es consciente, no habla, pero si uno lo aprieta, lo mazamorrea $^{138}$, sabe que no lo están tratando bien, cómo limpiarlo, por dónde se empieza a limpiar al enfermo, porque muchas veces uno es ignorante, a mi no me pilló mal, porque yo empezaba desde aquí [indica la cabeza] hasta la punta de los pies (...)él se lava por partes, en el pelo le paso de esas toallitas para las guaguas mojadas con colonia y le mantengo el pelo cortito, así voy por partes. (...) en Buin, en el consultorio Héctor García, es un policlínico nuevo [es un CESFAM ${ }^{139}$ ].” (Entrevistada 14)

Pero la formación en el Programa de atención a postrados no estaba limitada a las instancias formativas en el centro de salud, sino que se suponía que en las visitas domiciliarias la enfermera debía elaborar y evaluar ajustes a un plan de cuidados para el cuidador, y el técnico en enfermería debía reforzar la educación de los cuidadores, para ayudarles a asumir su labor de mejor forma.

- "Si usted tuviera la oportunidad de recomendar al Estado ¿En qué le gustaría que le apoyaran como cuidador?"

- "Que me explicaran cómo hacerlo mejor con mi mamá, claro por ejemplo mi mamita está inquieta en la noche y ¿Qué hago con ella? bueno me dijeron que cuando estuviera baja de presión le subiera las piernas, hay varias cosas que yo aprendí a hacerlas y otras que he escuchado, y cuando el médico venía para acá me explicaba, pero no tengo

\footnotetext{
${ }^{138}$ Remece.

${ }^{139}$ Centro de Salud Familiar.
} 
tiempo para andar en ningún lado, o sea unos minutos, una media hora.(...) claro, si vinieran sería mucho mejor, porque así ya estoy... porque uno va haciendo según lo que va pasando en el día, lo que le va pasando al enfermo." (Entrevistado 26)

\title{
- Estipendio
}

El reconocimiento de la labor, que el cuidador realizaba, se veía materializado en el pago de un estipendio mensual. La cantidad de dinero que recibían era de veinte mil pesos $^{140}$, una cantidad que resultaba "simbólica", aún para el costo de vida en Chile. Para que el cuidador recibiera este beneficio debía acreditar su vulnerabilidad económica $^{141}$. No todas las personas entrevistadas estaban favorecidas con este dinero, pero las que sí lo recibían generalmente hacían uso de él en cuestiones relacionadas con el dependiente.

\begin{abstract}
"Sí, a mi me daban... todas las personas que estábamos cuidando enfermos, por intermedio de la municipalidad, a nosotras nos daban " $\mathrm{X}$ " pesos mensuales, que se llamaba "estipendio", entonces no sé si a todos les daban lo mismo, no sé, me daban veinte mil pesos. (...) y de ahí me servía para ayuda de los pañales porque en pañales con él yo me gasto setenta mil mensuales. (Entrevistada 14)
\end{abstract}

Lo más usual es que los cuidadores que recibían este beneficio lo destinaran al mayor gasto que tenían con el dependiente, los pañales. Se observa en sus relatos que no eran consientes que ese pago fuera para ellas/os, lo asociaban al dependiente y sus necesidades.

\footnotetext{
${ }^{140}$ Equivalencia en euros: veinte mil pesos eran veintisiete euros con ochenta céntimos al 20 de diciembre de $2010(1 €=\$ 720)$

${ }^{141}$ Clasificado como Fonasa A o B, o estar en el primer quintil de vulnerabilidad de acuerdo a la Ficha de protección social. http://observatorio.ministeriodesarrollosocial.gob.cl/glosario.php
}

Página| 393 


\title{
Dimensión "Otras prestaciones de la atención primaria”
}

- Transporte

Aunque el anterior programa no contemplaba dentro de sus prestaciones el transporte de los dependientes en ambulancia hacia a los centros de salud, gran parte de los cuidadores urbanos relacionaban la disponibilidad de este servicio con él mismo.

\begin{abstract}
"Al médico, antes no pedía jamás ambulancia porque nunca había, sabe que yo me tenía que conseguir plata cuando no tenía, para llevarlo en un taxi, y sabe lo que es molesto para él, porque no se puede doblar, es terrible, ahora gracias a Dios hay ambulancias, lo vienen a buscar y a dejar." (Entrevistada 3)
\end{abstract}

En los servicios primarios de salud rural, como ya lo tratáramos anteriormente, la disponibilidad de la ambulancia era limitada y los traslados de los dependientes a los centros de salud debían ser resueltos por los cuidadores. Pero en los sectores rurales donde existían SAMU ${ }^{142}$, las ambulancias de estos servicios realizaban el transporte de los enfermos a los servicios de salud.

“(...) contratamos un colectivo, porque es lejos y en ese tiempo había menos ayudas para los postrados, entonces habían menos recursos, aquí poco se ve la ambulancia, la ambulancia para este sector nunca la encuentra usted, siempre que uno necesita dicen: "No está la ambulancia, que anda en Santiago, que está en viaje, que está en panne”, entonces nunca se encuentra, ahora que está el SAMU uno tiene que recurrir a él. (...) Ahí en Curacaví, se instalaron hace como dos años parece. (...) Claro, porque si uno necesita ellos la ayudan, ellos la vienen a ver, si es necesario llevarla la llevan, pero en ese tiempo, cuando a mi mamá le dio eso no, en ese tiempo había una kinesióloga en el hospital que trabajaba allá no más, ella no salía, por ejemplo a terreno." (Entrevistada 20)

- Entrega de medicamentos, ayudas técnicas y alimentos

De igual manera que sucedía con el transporte, la entrega gratuita, que realizaba el centro de salud, de medicamentos, ayudas técnicas -silla de rueda, colchón antiescaras, etc.- y alimentos especializados -sopa "años dorados" y leche fortificada- para los

${ }^{142}$ SAMU, Servicio de Atención Médica de Urgencia, dependiente del sistema de salud público.

Página | 394 
dependientes, formaba parte de otros programas, pero se otorgaban a los dependientes con la finalidad de complementar y dar una atención integral a la persona postrada y al cuidador. La entrega de las ayudas técnicas estaba controlada por la trabajadora social del equipo médico del centro de salud y sujeta a las condiciones socioeconómicas del dependiente y su familia.

"Sí, yo fui un día y se la pedí a la visitadora [trabajadora social], porque no tenía en qué moverlo, entonces un día fui donde la visitadora y me pasó esa silla que tiene él ahora, me ha servido harto.” (Entrevistada 4)

“Tiene colchón antiescaras, su catre clínico, su silla de ruedas, pero esa me la dieron en el poli, esa no la compré, el colchón antiescaras también, nos lo dieron allá para proteger sus escaras, pero igual hay que lubricarlo en todas las mudas y cambiarlo de posición para que así no se produzcan. (...) No, los remedios de él me los dan todos en el poli, a no ser que no haya un día, porque de repente se encuentra uno que no hay, a mi me los dan todos, los tres remedios que tomo yo." (Entrevistada 14)

\section{Propiedad "Planes o programas de salud"}

Las atenciones en salud de los dependientes también podían tener cobertura a través de diferentes planes de salud pública vigentes al momento de realizar el trabajo de campo. El más mencionado es el Plan AUGE ${ }^{143}$ que en el momento del estudio daba cobertura de atención a sesenta y nueve patologías. Existían entre los dependientes dos personas que necesitaban diálisis, todas sus costos eran asumidos por el servicio de salud público, aunque recibieran la atención en centros privados de salud.

“(...) ahí supimos cuánto costaba la diálisis mensual, costaba cuatrocientos mil en ese tiempo, mensual, porque es día por medio, así que ahí mandaron a mi hija a conseguirse un préstamo de salud al Banco del Desarrollo, me parece. Y gracias a eso es que se pudo seguir dializando allá [hospital Clínico de la Universidad católica, centro privado] porque el banco empezó a pagar la diálisis, si yo nunca he pagado un veinte de esos años que se dializaba, porque mi señora hará un año que está con AUGE, pero antes

${ }^{143}$ Plan de Acceso Universal con Garantías Explícitas en Salud.

Página 395 
todo lo pagaba el Banco del Desarrollo, (...) como le digo el señor cierra una puerta pero abre una ventana, así que ahí siempre ha seguido.” (Entrevistado 28)

También, otra entrevistada se refiere al Programa Nacional de Ventilación Mecánica Invasiva (VMI) domiciliaria en niños (Ministerio de Salud 2007), desarrollado por el Ministerio de Salud, que le permitió a su hijo dependiente ser dado de alta del hospital y vivir con ellos en casa.

"Es por el Estado, a mi me pasan el oxígeno, las sondas, suero, las bajadas, porque el Luis se alimenta por bajadas, por goteo, y se alimenta por jeringas, lo que es la comida y el almuerzo, los guantes, las telas, gasas, todas esas cosas." (Entrevistada 24)

Además, dicho programa pagaba técnicos paramédicos que realizaban el cuidado del niño por las noches, y un servicio de emergencias privado (Help) que estaba disponible de forma más rápida que la asistencia pública.

“(...) es parte del programa, a mí el programa me pasa el celular, las máquinas, la Help, todas esas cosas." (Entrevistada 24)

\section{Propiedad "Atención secundaria y terciaria en salud"}

La opinión de los cuidadores sobre la atención pública en especialidades e ingreso en hospitales era diferente a la de Atención Primaria o programas derivados de la misma; la mayor parte de ellos relataba experiencias negativas tanto para ellos como para los dependientes a los que cuidaban. La queja más frecuente tenía relación con la demora en la atención en las especialidades médicas

\footnotetext{
"Yo tuve un dolor al cerebro muy grande, me llevaron al hospital, y el doctor me dijo que él me tenía que poner una inyección en el cerebro, porque yo tenía una venita por aquí, una venita por acá, que era muy peligroso... Todavía estoy esperando la hora, estoy hablando de hace más de un año y me dan unos dolores al cerebro terribles." (Entrevistada 3)
}

- “¿Tu niño menor me decías que lo están evaluando en el hospital?” 
- "No particular, en el INTA ${ }^{144}$, lo que pasa es que en los hospitales se demoran demasiado, yo no puedo ir al hospital porque me pasó algo, después te dicen que vayas al consultorio tres días después y al final no te ve ningún especialista, con los niños hay que tener especialista, así que con los niños todo es particular." (Entrevistada 18)

La última entrevistada nos contaba que debido a la urgencia de las problemáticas de salud de uno sus hijos dependientes habían tenido que hacer el esfuerzo y recurrir a la salud privada, ya que en la salud pública les resultó imposible tener un diagnóstico. Éste era uno de los caminos que tenían las familias que podían hacer frente a los costos de la salud privada, más adelante trataremos este tema en la categoría Salud privada.

La experiencia de algunos de los cuidadores y/o dependientes que habían sido atendidos por centros hospitalarios tampoco estaba exenta de críticas, las principales tenían relación con un trato inadecuado por parte del personal médico. Esta problemática la desarrollaremos más adelante.

“(...) la hospitalizaron ahí y me la dejaron ahí, en una sala, ahí no más, en observación, no le hacían nada, en una sala aislada ahí, y hasta como el tercer día me dieron los nervios ahí, y yo empecé a encarar al médico que había ahí en ese entonces, le dije que si la tenían ahí para no hacerle nada que me la entregaran y yo me la traía para mi casa, que para tenerla así yo la tenía en mi casa y ahí me dijo: "Vamos a ver lo que podemos hacer", ahí me la llevaron de nuevo a Santiago, pidieron hora y la llevaron altiro en la tarde, y ahí ya arrojó el daño que tenía, me dijeron esto y esto tiene, traía un tratamiento de allá que le había dado el neurocirujano, pero nada más no le hicieron nada más, ya de ahí me la trataron ahí unos días, parece que fueron veinte días que estuvo hospitalizada y de ahí ya me la mandaron para la casa, me dijeron: "Te la vamos a dar de alta", pero así, mi mamá no estaba en condiciones, me la entregaron, dijeron no hay nada que hacer." (Entrevistada 20)

${ }^{144}$ Instituto de Tecnología de los Alimentos de la Universidad de Chile.

Página $\mid 397$ 


\section{Propiedad "Salud Laboral"}

Dentro de los cuidadores que fueron entrevistados existía uno que cuidaba de su hermano quien, producto de un accidente laboral, padecía una dependencia física. Esta persona era atendida a través del Instituto de Seguridad Laboral (ISL), organismo dependiente del Instituto de Previsión Social (IPS). El ISL era una entidad estatal que en caso de accidentes y enfermedades laborales entregaba servicio de recuperación de la salud y mitigación económica de los daños causados por los accidentes.

“(...) afortunadamente se hizo por Fonasa, se pagó un resto, pero ahí lo acogió altiro el INP [el IPS] como accidente laboral, así que fue muy poco lo que nosotros pagamos, hospitalización, en el Hospital San José, todo eso lo cubrió el Hospital y después hacer todos los trámites, que costó cualquier cantidad de cambiarlo de hospital, del San José al J. Aguirre [hospital universitario privado], pero se logró cambiar.(...) Porque era mejor, por supuesto que sí, mejor atención, mejor todo, porque en el San José en esa época el hospital estaba muy nuevo, bonito, pero no tenía la atención que tenía que tener él.” (Entrevistada 17)

Si las atenciones en salud del dependiente no podían ser cubiertas por el sistema público, existía la prestación de servicios por centros privados con cargo a la entidad estatal, que es lo que narraba la entrevistada: el dependiente fue hospitalizado en un centro público, pero al no tener la atención adecuada fue trasladado a un hospital clínico privado. La atención en salud recibida no se remitía a los procedimientos médicos (consultas, hospitalizaciones, rehabilitación), sino que también a la entrega de ayudas técnicas, productos de enfermería y limpieza del dependiente, y a los traslados necesarios para su tratamiento.

“(...) los closets $^{145}$ que hay están ocupados prácticamente con sus cosas, porque gracias a Dios a él le dan todo lo que él tiene que usar. (...) De ahí mismo del hospital, por el INP [IPS], a él le dan todo, hoy en día a él le dan más que nada por precaución, porque como él tiene la colostomía y se tiene que sondear, así que es más por precaución, le dan la mantilla, le dan el jabón, le dan las sondas, le dan el gel.” (Entrevistada 17)

145 Armarios. 


\section{Propiedad "Problemas de la salud pública"}

En los relatos de nuestros entrevistados resultaban patentes las críticas al sistema de salud público, éstas básicamente se centraban en los aspectos que ahora tratamos.

\section{Dimensión "Trato inadecuado del personal sanitario"}

En la propiedad donde revisamos la Atención Secundaria y Terciaria en salud, el último testimonio evidenciaba la incorrección del comportamiento del personal médico médicos, enfermeras/os, auxiliares de enfermería- con los pacientes y/o cuidadores. Los cuidadores relataban variados episodios de omisión de información sobre el estado de salud del enfermo, falta de empleo de los medios adecuados de diagnóstico, o desinformación sobre los procedimientos que se realizaban y las consecuencias de éste, etc.

\footnotetext{
“A veces escuchar que están haciendo un favor a ti en darte una aspirina o poniéndote el oxigeno, bueno, nos falta mucho a nosotros como país todavía, nos falta todavía crecer, a mucha gente digo, no puedo echar a todos los médicos en la misma bolsa, pero le falta mucho todavía... (...) he tenido harta suerte, no puedo ser malagradecida, sino que con mi mamá tuve esa vez ese altercado con el doctor, pero fue como un doctor "especial", yo le puse "especial”, que el tipo no debería haber estado ahí, ni debería estarlo, porque no me pareció un médico, no sé, me pareció un carnicero, podría haber estado en otra profesión, pero como médico no, le quedaba grande, para nada, sin embargo los otros médicos, cuando mi mamá quedó hospitalizada, cero drama cuando conversé, cero drama." (Entrevistada 10)
}

\section{Dimensión "Negligencias hospitalarias"}

A pesar de que forma parte de la anterior dimensión, quisimos dar un espacio diferenciado a las negligencias debido a la frecuencia con que se presentan en el entorno hospitalario.

"Lo que pasa es que a mí me dan preeclampcias en los embarazos, yo soy un cacho ${ }^{146}$ embarazada, a los dos meses el doctor me dejó en reposo absoluto, todo iba bien hasta que me dio preeclampcia a partir de los seis meses y medio para adelante, empecé con

\footnotetext{
${ }^{146}$ Problema.
} 
problemas y él nació a los siete meses, y como estuve hospitalizada en Buin, hospital público, malo, no es por desmerecer pero es malo, para ellos todo era normal y yo como primeriza no sabía, para mí era todo normal lo que me decían.” (Entrevistada 18)

“(...) ahí uno entra a pensar por qué, y el no poder hacer algo por él, cuando estaba chiquitito y lo llevaba al Exequiel [nombre del hospital], me acuerdo que una vez estuvo con una fiebre muy fuerte, tenía $39^{\circ}, 40^{\circ}, 41^{\circ}$ de fiebre, entonces le bajaban la fiebre, después 38 y medio, me decían: "Mamá llévatelo, ya está bien” y yo le decía: "Señorita, pero todavía está con fiebre", "No importa, llévatelo no más" y me devolvía para la casa, y era... yo me daba cuenta, era porque pensaban que el José iba a fallecer, entonces eso me causaba mucha pena." (Entrevistada 30)

“(...) sí hubieron varias irregularidades por las que yo hice un reclamo, no tenía los mejores cuidados [en el hospital], generalmente ella dejaban que se orinara, no estaban al pendiente de ella como debería ser, siempre se hacían los lesos $^{147}$, los llamaba y ellos se iban no más. Al final yo pedí una autorización y estaba desde la mañana, lo más temprano que podía hasta última hora, para darle los cuidados que ella merecía y necesitaba." (Entrevistada 12)

Los relatos de algunos de nuestros entrevistados reflejaban que en sus problemáticas de salud no se actuó de forma diligente y adecuada, el personal médico que les atendió puso en peligro la salud de sus dependientes por la omisión de tratamiento.

Una de las negligencias más relatadas por los entrevistados, que habían tenido a sus dependientes ingresados en hospitales, era que en sus estancias en dichos recintos se les habían generado úlceras de presión. Este daño se forma por la no movilización del paciente encamado, es decir por la omisión en los cuidados necesarios para una persona que tiene movilidad reducida.

"Y como le digo un día lo fui a acomodarlo y me di cuenta de que tenía heridos los talones, llamé a la enfermera y le pregunté, me dijo: "Yo le voy a echar un remedito", al otro día cuando fui tenía vendados los talones, pero no le vieron la escara que tenía en la colita, una escara así [indica el tamaño de una pelota de tenis]. (...) En cama, casi mes y

${ }^{147}$ Le ignoraban.

Página $\mid 400$ 
medio, pero ¿Cómo los del hospital no se fijan? Está bien una escara chiquita, pero era una cosa impresionante y profunda, fíjese que llegaba aquí, a la segunda coyuntura de mi dedo, le llegó al hueso, y así lo dieron de alta.” (Entrevistada 11)

Prácticamente todos los dependientes que estuvieron períodos ingresados en hospitales fueron dados de alta con escaras en su cuerpo.

"Ella cuando estuvo hospitalizada, cuando se golpeó, estuvo hospitalizada un mes en el Barros Luco [hospital] y me la entregaron, cuando le dieron el alta, llena de escaras, los talones eran hoyos que se veía el hueso, la cola [final de la espalda] eran hoyos, aquí eran hoyos, y tenía que ir yo al consultorio a buscarle materiales de aseo, no me la venían a ver, y hasta la fecha no me la vienen a ver." (Entrevistada 13)

Este reclamo se cruza con otro de los más mencionados por los entrevistados, la falta de recursos

\section{Dimensión "Falta de recursos materiales"}

Tal como adelantábamos en la anterior dimensión, otro de los problemas que fue denunciado por los cuidadores en sus relatos era la falta de recursos materiales de los servicios de salud, en general. El último testimonio, en donde se relata la dramática situación de las escaras generadas por la negligencia del personal médico, la cuidadora asumió humana y materialmente la mejoría de su dependiente, situación que se repitió de forma similar para todos los cuidadores que tuvieron la misma problemática de salud.

\footnotetext{
"Cuando me lo entregaron del hospital, lleno de escaras, gasté cualquier plata, no sé, yo miro pa' arriba y le doy gracias a Dios, pa' sanar su herida, comprar las gasas todo, sabe que en el policlínico me tenían hasta dos horas parada para darme un pedacito de gasa así y, con suerte, a veces, le tenía que rogar a la niña que tiene que ver con eso, él que manda la cuestión esa, para que me dieran un suero así, yo no ando limosneando, perdóneme la expresión, pero prefiero mortificarme, dejar cualquier cosa atrás pero las cosas se las compro a mi hijo.” (Entrevistada 3)
} 


\section{Síntesis}

La primera instancia en salud pública, y la más recurrida, para los cuidadores y sus dependientes, era la Atención Primaria en salud. Ello se debía principalmente a la lógica con que el sistema de sanitario público chileno funcionaba, y porque desde esta instancia se desarrollaba el Programa de atención domiciliaria de personas con discapacidad severa, que centraba su apoyo a los dependientes a través de las visitas domiciliarias, y a los cuidadores con formación y entrega de un estipendio mensual. Desde los centros de salud, también se realizaban otras prestaciones que iban dirigidas a la población en estudio: transporte, entrega de medicamentos, ayudas técnicas y alimentos. Las opiniones de los entrevistados diferían de acuerdo al área en que vivieran, ya que la Atención Primaria en zonas urbanas era mucho mejor evaluada que en las zonas rurales.

Dependientes y cuidadores también veían abordadas sus problemáticas sanitarias a través de distintos planes y programas de salud, el Plan Auge era el más relevante de los que tenían vigencia al momento de la realización del trabajo de campo de este estudio.

La opinión de los cuidadores sobre la Atención Secundaria y Terciaria en salud pública era diferente a la Primaria, la mayor crítica estaba relacionada con la demora en la atención de parte de especialistas y el trato inadecuado recibido en hospitales. Sobre la salud laboral, se obtuvo solo el testimonio de un cuidador cuyo dependiente era atendido a través de esa figura, y manifestaba estar satisfecho con el servicio que les estaba otorgando.

Las principales problemáticas de salud pública denunciadas por los cuidadores tenían relación con el trato inadecuado del personal sanitario -principalmente en la Atención Secundaria y Terciaria-, las negligencias hospitalarias -las úlceras de presión, las más mencionadas- y la falta de recursos materiales. 


\subsection{CATEGORÍA "SALUD PRIVADA"}

Como ya se explicó en el capítulo dedicado al contexto chileno, el sistema de salud en Chile tenía dos variantes -público y privado- entre las que las personas podían optar estar atendidas. La opción de uno u otro sistema estaba limitada, principalmente, a cuestiones de índole económica, ya que las primas a pagar en el sistema privado resultaban insostenibles para personas de estratos socioeconómicos medios bajos y bajos. De todos nuestros entrevistados, sólo una familia pertenecía al sistema privado Isapre-, el resto de los entrevistados que había hecho uso de la salud privada, lo había hecho solo en situaciones especiales.

Además, en esta categoría incluimos las instituciones de carácter benéfico que cumplían un importante rol en el diagnóstico y/o tratamiento de patologías que el sistema público no daba respuesta.

\section{Propiedad "Motivos por la atención en la salud privada"}

\section{Dimensión "No tenían atención oportuna en la salud pública"}

Considerando que la mayor parte de nuestros entrevistados eran de escasos recursos, existía un grupo de ellos que había recurrido a la salud privada, realizándolo en atenciones puntuales (exámenes, consultas diagnósticas, etc.) o tratamientos más largos, como ingresos hospitalarios o servicios de diálisis. La posibilidad de recurrir a esta instancia se realizaba con enormes esfuerzos económicos por parte de las familias, y generalmente estaba provocada porque el diagnóstico y/o tratamiento de los problemas de salud del dependiente o cuidador no tenían respuesta oportuna en el sistema público.

"[el médico] le dijo: "Si ustedes tienen algo de lo que puedan echar mano, y pueden llevarla a la Católica [hospital clínico privado], ahí van a poder hacer algo y salvarla", así que como yo tenía un negocito le dije: "Llevémosla, de alguna manera el señor cierra una puerta pero abre una ventana", así que la llevamos allá, llegamos como a las nueve, a las diez y media ya la estaban dializando.” (Entrevistado 28) 
“(...) acá hay unas enfermedades que entran en el Plan AUGE, pero la enfermedad de él no está dentro del AUGE, no es catastrófica, según los parámetros de acá de Chile no es catastrófica la enfermedad. (...) No, por ejemplo cuando él estuvo grave en la UCI, después los gastos yo los tuve que pagarlos, todos, y esta es una enfermedad realmente catastrófica." (Entrevistada 16)

La entrevistada pone el acento en que la enfermedad no es considerada como "catastrófica", porque si así fuese habría tenido asegurada una atención oportuna, de calidad y gratuita en el sistema público gracias al Plan AUGE.

\section{Dimensión "No obtuvieron diagnóstico en la salud pública"}

Otra motivación que aparece en las experiencias relatadas por los cuidadores es que el sistema público no tenía instancias que permitieran diagnosticar y/o tratar determinadas patologías, era el caso de las dos madres entrevistadas cuyos niños estaban pendientes de diagnóstico por trastornos del espectro autista.

\footnotetext{
"Me gustaría que cada vez que el Alonso tiene un problema que haya una facilidad de atenderlo, porque igual, al final hay en todas las clases sociales, a lo mejor los que tienen más pueden hacerlo mejor y atenderse mejor, pero los que no tenemos es complicado, nos cuesta mucho... y como le decía yo, no lo pude llevar en noviembre, ni lo pude llevar en diciembre [a que lo evalúen de forma privada], entonces no lo pude matricular, yo le dije a la directora, voy a llevarlo en las ocasiones donde no me toca pagar furgón, que no me toca pagar lo otro, entonces para poder que me lo evalúen.” (Entrevistada 29)
}

\section{Propiedad "Tipos de atenciones e instituciones en salud privada"}

\section{Dimensión "Instituciones de beneficencia"}

Las atenciones privadas en salud, en instituciones de beneficencia, relatadas por nuestros entrevistados eran todas atenciones dirigidas a niños y adolescentes. Estas fundaciones surgieron en contextos en donde la salud pública no daba respuesta a las patologías de esta población. 
La Fundación Teletón daba atención de salud y rehabilitación prácticamente a todos los niños y jóvenes con dependencias físicas del estudio. Esta institución también hacía entrega de ayudas técnicas y se encargaba del trasporte hacia sus centros de atención.

\begin{abstract}
"Yo pedí una interconsulta para la Teletón, y me fue bien en la Teletón, ahí yo la empecé a llevar a terapias, incluso en la Teletón si uno no tiene plata te dan la plata de la locomoción, la cosa es que tu no faltes, a la Marta le dieron silla de ruedas, no la dan la prestan, las canaletas para cuando se paraba allá, una tabla, usa un sitting en el coche, que es una silla dura, en la silla se le pone adentro, todas esas cosas las dan en la Teletón.” (Entrevistada 2)
\end{abstract}

Se debe destacar la atención especializada e integral que recibían, en esta fundación, tanto los niños dependientes como el cuidador y la familia.

"Sí, en la Teletón ha estado en terapia en piscina, en terapia ocupacional donde le enseñan a ocupar las manos, a con distintas cositas, pasarle cositas por la piel para que sientan, el algodón con algo más áspero, las cosas más suaves con lo más grueso, todo eso así, y en kine [kinesiología], le hace ejercicios, cuando recién lo llevé al PAL donde está la psicóloga, la fisiatra, la kinesióloga, la terapeuta, hay como cuatro o cinco profesionales los cuales están viendo el actuar mío y el actuar del niño, por ser la psicóloga ve que yo estoy mal psíquicamente con lo que me está ocurriendo, ella me da una hora extra, me atiende y si en un momento dado yo necesito de ella, yo pido una hora y me atiende." (Entrevistada 30)

Otra fundación de carácter privado, que otorgó asistencia médica, hospitalización y formación en cuidados a uno de los niños dependientes, fue el Hospital Fundación Josefina Martínez, especializado en el tratamiento de niños con patologías respiratorias crónicas.

“El Luis nació con dos síndromes de Möbius con Poland, el Möbius no fue tanto lo que le perjudicó, fue más el Poland, que es la parte respiratoria, nació con el pectoral hundido, con pie box, paladar fisurado o sea fueron muchas complicaciones las que él tenía, estuvo tres meses en la UCI del [hospital] Barros Luco y después estuvo 4 meses en la UCI del [hospital] Exequiel y un año un mes en el Josefina Martínez que es un hospital para niños con problemas respiratorios.” (Entrevistada 24)

Página 405 
Este hospital entregaba atención integral y gratuita a niños y sus familias de escasos recursos. El objetivo del hospital era brindar un programa de rehabilitación individualizada para el niño, junto a la formación de los padres para facilitar la reinserción del menor en su medio familiar y social.

“[es ] una fundación, ahí podían ir mis hijas, cuñados, todos podía ir a verlo y hacer las mismas cosas que yo, por ejemplo bañarle, darle sus comidas, esas cosas como cosas básicas, pero aspirarlo, todas esas cosas las hacíamos yo, mi esposo y mi hija." (Entrevistada 24)

\title{
Dimensión "Isapres"148
}

Como anteriormente señaláramos, había una única familia que formaba parte del sistema de salud privado, nos contaba la madre cuidadora que para el diagnóstico y tratamiento de la enfermedad de su hijo el sistema no les había cubierto ninguna de las atenciones médicas o pruebas diagnósticas.

\begin{abstract}
“(...) yo prefiero llevar al Alonso al médico que atenderme yo, y ya me ha pasado dos veces lo mismo, que nos hemos enfermado los dos... y por ejemplo un neurólogo actualmente, está atendiendo solamente, ni siquiera por Isapre, ni por nada, sino que particularmente. No sé por qué no está cabiendo en los planes de las Isapres, por ejemplo el último que tuve que llevar al Alonso, tuve que pagar y después reembolsar. (...) [su esposo está] Claro, tiene Isapre, trató de cambiarse a Fonasa, pero quedaría afuera el mayor, y el mayor está estudiando.” (Entrevistada 29)
\end{abstract}

De acuerdo a cómo se señala en el capítulo IV, el sistema de Isapres funcionaba con planes de salud que, dependiendo de las características de los afiliados y de la cobertura en atenciones y servicios, tenía un precio que era variable. Por lo que la entrevistada refería, el plan que daba "cobertura" a su familia era limitado y restringía las atenciones en salud de su familia.

\footnotetext{
${ }^{148}$ Instituciones de salud previsional.
} 


\section{Síntesis}

La atención privada en salud en Chile estaba restringida a la población con mayores recursos económicos, ya que las Isapres cobraban primas que resultaban insostenibles de cubrir para personas de recursos limitados, como la muestra de nuestro estudio. Por ello, la relación que pudieron establecer algunos de nuestros cuidadores con este tipo de salud era circunstancial y se debía principalmente a que no obtuvieron atención oportuna en el sistema público de salud, o a que no obtuvieron un diagnóstico en éste.

Dentro de los establecimientos privados aludidos encontramos la importante labor que realizaban instituciones de beneficencia, donde la más mencionada era la Teletón. En el caso de las Isapres, solo tenemos el testimonio de una familia afiliada a dicho sistema y que veía limitadas sus atenciones en salud por las restricciones del plan de atención que tenían.

\subsection{CATEGORÍA "PENSIONES"}

Tal cómo se explicó en el capítulo IV, el sistema previsional chileno sufrió en el año 1980 una profunda transformación, pasó desde un sistema de reparto, a cargo de las cajas previsionales, a un régimen de capitalización individual para pensiones de vejez, invalidez y sobrevivencia. Las Aseguradoras de Fondos de Pensiones (AFP) pasaron a administrar prácticamente todo el sistema previsional a partir del año 1982.

Las referencias al tema previsional en nuestros entrevistados fueron espontáneas y por lo general surgían a razón de las referencias a los ingresos con los que contaban en sus familias.

Casi todos los dependientes y cuidadores mayores de 65 años recibían al momento de la entrevista una pensión contributiva o una pensión asistencial no contributiva (a cargo del Estado). 


\section{Propiedad "Comportamiento previsional"}

Tal como funcionaba el sistema previsional en el pasado, todos los trabajadores dependientes estaban obligados a imponer en el sistema previsional (primero el de cajas y después AFP), pero los trabajadores independientes no tenían obligación de imponer en el sistema previsional.

“(...) cuando se empezó a dializar no era jubilado, menos mal que fue poco, o sea tenía la edad pero no tenía hechos los papeles, menos mal que en donde estaba en el hospital le hicieron los papeles rápido, y ahí le salió que estaba pasado en los años también, porque como aquí eran parcelas, así que no eran apatronados y quedaron sin previsión.” (Entrevistado 15)

“(...) lo que nunca hice fueron imposiciones, cometí el grave delito, porque para mí es un delito, no es errar, siempre boletié ${ }^{149}$ no más, pura boleta. (...) voy a tener que allegarme a lo que da el gobierno no más, yo creo, nada más, bueno mis hijos siempre me dicen mamá a ti nunca te va a faltar nada, pero no es lo mismo tener lo tuyo que disponer del bolsillo ajeno, entonces eso también es un poquito preocupante, empiezo a pensar ¿Qué voy a hacer? ¿Qué voy a hacer? no sé, algo me saldrá. (Entrevistada 10)

Los dos testimonios anteriores reflejan la realidad de bastantes dependientes y cuidadores entrevistados, al haber trabajado de forma independiente no tuvieron la obligación de cotizar en el sistema previsional, y ello implica que no tenían más opción que acogerse a la solicitud de una pensión asistencial entregada por el Estado.

El temor a la desprotección en la vejez era manifestado por los cuidadores más jóvenes que veían que al no poder trabajar estaban quedando en una situación vulnerable y a expensas de la "caridad" de sus familiares y del Estado.

"Lo que yo les he dicho a ellos [sus hermanos] cuando yo les he pedido que me paguen las imposiciones me han dado respuestas tan tontas, tan absurdas, ya, les digo yo, cuando quieran vender la casa les voy a demandar que me paguen toda las

\footnotetext{
${ }^{149}$ Con "boletear" se refiere al trabajo independiente donde se emiten boletas de honorarios por los servicios profesionales realizados, circunstancia en la que no se obligaba a realizar cotizaciones previsionales.
} 
imposiciones, los voy a demandar digo yo.(...) Pero por qué no lo he hecho, porque no he tenido tiempo, no he tenido tiempo de ir a un juzgado y hacer la demanda, porque es cosa de ver una cartola $^{150}$ y ver lo que he perdido en imposiciones ¿Quién me va a devolver todo esto? Nadie...." (Entrevistada 9)

\section{Propiedad "Tipos de pensiones"}

\section{Dimensión "Pensión básica solidaria (vejez o invalidez)"}

Dentro del sistema previsional vigente, al momento de la realización del trabajo de campo de esta investigación ${ }^{151}$, el Estado otorgaba una pensión denominada Pensión básica solidaria a aquellas personas que no contaran con contribuciones en el sistema previsional, o que tuviera insuficientes cotizaciones para jubilarse. Estas pensiones podían otorgarse por vejez o invalidez y ser solicitadas, habiendo cumplido una serie de requisitos, consistentes en pertenecer al $60 \%$ más pobre de la población chilena, en el caso de la pensión solidaria básica de vejez, el tener más de 65 años, y en el caso de la de invalidez, acreditar frente a la institución correspondiente la discapacidad y grado, y, por último, tener más de 18 años de edad y menos de 65 .

Al centrar nuestro estudio en los estratos socioeconómicos más empobrecidos, encontramos que casi todos los cuidadores mayores de 65 años y sus dependientes (por vejez o invalidez) recibían alguna de las pensiones de este apartado.

- “¿Alguien de su familia recibe alguna pensión?"

- "La Marta por invalidez y mi papi recibe la asistencial.” (Entrevistada 2)

Una cuidadora nos relata que su familia percibía dos tipos de asistencias otorgadas por el Estado, la pensión básica solidaria por vejez y el Subsidio Único Familiar; en el relato la entrevistada hacía referencia a la pensión que recibía su padre como "asistencial" aludiendo al antiguo nombre que tenía, ella estaba hablando de la pensión básica solidaria por vejez. Las cantidades de dinero que alcanzaban estas pensiones no llegaban a las de un sueldo mínimo, que era equivalente a doscientos treinta y ocho

\footnotetext{
${ }^{150}$ Cartilla donde se indican los fondos previsionales.

${ }^{151}$ En marzo de 2008 comienza la vigencia de la ley 20.255, sistema de pensiones solidario, que reforma el sistema de pensiones chileno.
} 
euros de la época, lo que implicaba que la situación económica de estas familias era bastante precaria, más aún si el cuidador u otro miembro de la familia no tenían un trabajo remunerado.

\begin{abstract}
“(...) mi papá, vive con una pensión que no alcanza para nada, eso debería ser más valorado, que los adultos mayores tengan un mejor estándar de vida, porque con setenta y cinco mil pesos $[104,17 €]$ ¿Qué hacen? no tanto para quien los cuide, sino que para ellos mismos, ellos tienen que comer todo un mes, necesitan cosas, entonces eso debería ser más valorado que quien los cuida, esa es mi opinión, la misma Marta a ella le pagan cincuenta y dos mil $[72,22 €]_{i}$ Qué hago yo con eso? Entonces en ese punto yo creo que está equivocado esto aquí, esta como muy mirado "a huevo" como se dice, no está valorada esa parte, porque los adultos mayores no pueden trabajar y los que tienen pensión de invalidez no lo pueden hacer tampoco, entonces debiera ser diferente la pensión.” (Entrevistada 2)
\end{abstract}

Estas ayudas eran tramitadas desde el municipio, por ello muchos de los entrevistados creían que la pensión las otorgaba la municipalidad.

- “Los dos tienen jubilación?”

- "De la municipalidad." (Entrevistada 1)

\title{
Dimensión "Subsidio único familiar (SUF)"
}

En el caso de las cuidadoras de menores de 18 años con discapacidad, ellas hablaban de una "pensión" asignada por la situación de sus hijos, y siendo más exactos el dinero que recibían era el Subsidio Único Familiar (SUF) otorgado por el Estado a la madre (padre o responsable del niño) de familias de escasos recursos.

- "Sí, él tiene su pensión de invalidez."

- “YYa lo evaluaron en el Compin [Comisión Médica, Preventiva e Invalidez]?”

- "Sí, desde que nació, porque lo revisaron los médicos del Exequiel [hospital], y de ahí los médicos del Compin. No es que llegue y pase, lo vuelven a ver, le hacen sus exámenes y todo, el tiene su pensión gracias al Señor." (Entrevistada 30) 
Tal como mencionaba la entrevistada anterior, el menor debía ser evaluado médicamente y después se presentaban sus antecedentes frente a la Compin, institución estatal que corroboraba la situación de discapacidad para la obtención de esta ayuda. Arriba, en la categoría salud, tratamos el tema de aquellas patologías que no lograban diagnosticarse en el sistema público, eso obviamente resultaba un impedimento para que las entrevistadas que no contaban con un diagnóstico certero de sus hijos, caso de los niños con trastornos del espectro autista, pudiesen acceder a este beneficio.

"Mire, por ejemplo en el colegio hay varias mamás que recibieron una pensión por el chiquitito, hay mamás que les salió, como un año le dan un pensión, el Estado les da una pensión, los niños que están en silla de ruedas a todos les dan una pensión, hay casos como el Alonso que le dan Lesepadín, le salió hace un año una atención, que se la dan por Compin, pero ello lo evalúan, si tiene algún problema o algo, yo no he hecho ese trámite porque usted ve al Alonso y el Alonso se ve como un niño normal." (Entrevistada 29)

\section{Dimensión "Pensionados por AFP"}

El sistema de pensiones que operaba, y sigue operando, en Chile era de capitalización individual $^{152}$, ello significaba que cada trabajador reunía durante su vida laboral un fondo manejado financieramente por la administradora a la que estuviese afiliado (para darle rentabilidad), y del cuál podía disponer al momento de su jubilación (que podía solicitarla de forma anticipada) o en caso de discapacidad. El comportamiento laboral y previsional de la población en estudio -tanto dependientes como cuidadores- podría ser calificado como "informal", ya que la mayor parte de ellos se desempeñó como trabajador independiente. Pero existía un grupo pequeño de ellos que trabajó de forma dependiente y tenían una pensión contributiva a través de una AFP.

\footnotetext{
“(...) le dolían mucho sus rodillas, más o menos a los 85 años, a lo mejor un poco antes él iba a trabajar muy adolorido de sus rodillas, cojeando, y un día yo no pude y le dije: "Sabe qué no vaya más a trabajar, nos vamos arreglar con la pensión", me dio pena de ver que mi marido estaba tan enfermo de sus rodillas, una artrosis.” (Entrevistada 11)
}

${ }^{152}$ Este punto se explica con mayor detalle en capítulo IV. 
El cálculo mensual de las pensiones estaba basado en lo acumulado y rentabilizado individualmente por cada trabajador, pero este testimonio refleja que la situación económica de los trabajadores que sí habían cotizado en su vida laboral no necesariamente era mejor. El dinero que recibían estaba por debajo del sueldo mínimo y no era suficiente para cubrir las necesidades de los dependientes y sus familias.

“¿En la AFP? Pero ya se agotaron... acá a los sesenta ya me llamaron para que fuera a retirar mi plata, pero como siempre es la fruncia $^{153}$ de que en todas partes la plata nunca está demás, entonces íbamos recibiendo... y la plata se acabó.” (Entrevistada 1)

El tamaño del fondo previsional, que en el caso de nuestro grupo de estudio es pequeño, y el aumento de la esperanza de vida en el país influían en situaciones como las que se describen antes, llegaba un momento en que el dinero se acababa y las personas quedaban con la única alternativa de solicitar la pensión solidaria de vejez al Estado.

\section{Dimensión "Pensión de sobrevivencia"}

Esta era una pensión contributiva que podía recibir la o él cónyuge del cotizante fallecido, sus hijos menores de 18 años, los menores de 24 que estuviesen estudiando o los hijos discapacitados de cualquier edad. Anteriormente, se le daba el nombre de pensión de viudez, es por eso que las cuidadoras entrevistadas hacen referencia a ella con dicho nombre.

"Si yo dejo de trabajar tendríamos que estar solamente con lo que recibe mi mamá. [Una pensión] De viudez, mi mamá recibe ciento veinte mil pesos (...).” (Entrevistada 6)

"Era asesora del hogar. (...) Un patrón mi impuso dos años y ellos después se fueron a Brasil, entonces en esos años tiré la libreta de cesantía y me quedé con la pura inscripción... hasta el día de hoy, pero la misma pensión que yo recibo de viudez es lo que hubiera sacado si hubiera impuesto, porque una hermana también trabajó y saca la misma plata, así que..." (Entrevistada 3)

\footnotetext{
${ }^{153}$ Situación complicada o molesta.
} 
Los testimonios muestran la situación de una dependiente y una cuidadora que recibían este tipo de pensión que era a cuenta del fondo de capitalización individual (AFP) del cotizante, lo que implicaba que este fondo, al momento de extinguirse, implicaba también la extinción de la pensión.

\section{Dimensión "Pensión de invalidez contributiva"}

Existe sólo un caso de un dependiente que recibía una pensión de invalidez, quien producto de un accidente laboral quedó en situación de incapacidad total para seguir trabajando. El grado de invalidez - parcial, total o total que requiere de la ayuda de terceros- debía ser corroborado por el Compin. El pagador de esa pensión podía ser el Instituto de Previsión Social (ISP ex INP), las AFP y/o el seguro de invalidez y sobrevivencia (en caso de que hubiese estado cubierto), en el caso de este dependiente no se tiene certeza de quién era el pagador de su pensión.

\section{Síntesis}

El sistema de pensiones en Chile ha sufrido en las últimas décadas una serie de cambios, el más radical fue el que se realizó en 1980 y que implantó un régimen de capitalización individual administrado por AFPs.

La mayor parte de los mayores de 65 años, cuidadores y sus dependientes, recibía pensiones básicas solidarias (tanto por vejez como por invalidez); esta ayuda se producía por haber trabajado de forma remunerada pero de manera independiente y sin cotizar para su jubilación. Las personas que estaban en dicha situación debieron solicitar al Estado este tipo de pensiones.

El SUF era entendido como una "pensión", este beneficio se otorgaba a las madres/padres/cuidadores de niños menores de 18 años con discapacidad y escasos recursos.

Los pensionados - cuidadores y dependientes- por AFPs eran menos y contaban con cuantías escasas, la mayor parte de éstas no alcanzaban el sueldo mínimo de la época. 
Además, al agotarse su fondo de pensión debían solicitar la pensión básica solidaria. La pensión de sobrevivencia, antigua pensión de viudez, también era recibida por algunas cuidadoras. Finalmente, uno de los dependientes recibía una pensión de invalidez contributiva, producto de un accidente laboral que le generó una incapacidad total.

\subsection{CATEGORÍA "EDUCACIÓN"}

Dentro de la muestra de cuidadores entrevistados había seis madres de niños y adolescentes con discapacidades y en edad escolar, por tanto este asunto surgió de forma espontánea y repetitiva en sus discursos. De forma general, la dinámica de esta categoría es parecida a la observada en otras áreas de los servicios públicos, en las zonas rurales había menor acceso, oferta y calidad de servicios educacionales.

\section{Propiedad "Acceso a la educación"}

En Chile los niños, jóvenes y adultos que tenían necesidades educativas especiales tenían dos opciones educativas: establecimientos de educación regular y centros de educación especial. Esto es lo que el Estado chileno, a través del Ministerio de Educación, establecía para que esta población accediera, participara y progresara en el currículum nacional en igualdad de condiciones y oportunidades. La integración de esta población en centros de educación regular implicaba que dichos establecimientos debían integrar en sus proyectos educativos la atención a la diversidad y a las necesidades educativas especiales.

Además, debemos considerar que tal como estaba estructurado el sistema educacional en Chile, la educación especial también tenía oferta de colegios subvencionados ${ }^{154}$, con aportes del Estado por alumno que asistiera.

De acuerdo a las experiencias relatadas, dos de las entrevistadas en zonas urbanas tenían hijos en edad escolar, pero con discapacidades distintas - una predominantemente

${ }^{154}$ Colegios concertados. 
física y la otra del desarrollo ${ }^{155}$ y física-, eso determinaba que sus experiencias fuesen diferentes.

En el caso de una entrevistada cuya hija tenía una dependencia física, la adolescente asistía a un establecimiento de educación regular que poco a poco había sido adaptado en su accesibilidad.

"El colegio está apto para el desplazamiento con una silla de ruedas, lo han ido perfeccionando, los profesores le facilitaban el baño de ellos, (...) porque ella tenía que venir acá a hacerse el cati $^{156}$ todos los días, a las 11 de la mañana ella tenía que venir aquí a hacer su cati, hacer pipí y volver al colegio, la acompañaban las compañeras, las auxiliares, en ese sentido tuvo bastante apoyo, pero después con el Mitrofanoff ${ }^{157}$ que se le hizo, ella se puede cateterizar en cualquier parte." (Entrevistada 27)

Se observa además que, en el colegio, existía disposición del personal -profesores, auxiliares- y alumnos para generar las condiciones para integrar a la adolescente.

La realidad de la otra cuidadora era diferente, su hijo aparte de presentar discapacidad física, padecía también discapacidad intelectual, lo que hacía mucho más complicada su integración en el sistema regular. El niño necesitaba de un establecimiento especial.

- "Porque si hubiera un colegio especial, por ejemplo pocos niños por curso..."

- "Sí, ahí yo lo llevaría. Pero acá los colegios son con hartos niños, al menos donde yo he ido a ver son con hartos niños (...) A lo mejor la hay pero yo no la sé tampoco, no podría decirle, puede que haiga por ahí alguno, puede que me quede a trasmano, que no pueda llegar, pero por el momento no es la prioridad esa, porque yo encuentro que está muy chiquitito, muy “pollito” todavía, ya no sé al otro año.” (Entrevistada 30)

El problema para ella era encontrar un colegio especial, con pocos niños por nivel, para que tuviera una atención más individualizada, y no que la integración al sistema escolar representara un peligro para el niño y una preocupación más para la madre.

\footnotetext{
${ }^{155}$ Discapacidades intelectuales, trastornos del espectro autista, parálisis cerebral, y otras.

${ }^{156}$ Cateterismo o sondaje vesical.

${ }^{157}$ El procedimiento de Mitrofanoff es un procedimiento quirúrgico en que el apéndice se utiliza para crear un conducto entre la superficie de la piel y la vejiga urinaria.
}

Página $\mid 415$ 
“(...) él no habla todavía, y yo he visto de repente a niñitos que han ido, han llegado golpeaditos, se han caído, y es normal, porque las profesoras no van a estar pendientes, con tanto niño. (...) Tengo miedo de que José llegue golpeado, esperar un añito más y de ahí lo voy a meter a... porque de hecho en la Teletón me han buscado colegio para que yo lo lleve, pero yo no he querido." (Entrevistada 30)

El acceso a la educación de los niños dependientes de zonas rurales resultaba mucho más dificultoso, tal como hemos constatado en el análisis de otros aspectos -sanitario, accesibilidad física, etc.- las zonas rurales no estaban lo suficientemente bien equipadas en los servicios sociales y comunitarios que ofrecían. El ámbito educativo no resultaba una excepción, al menos en una de las áreas estudiadas, zona de la comuna de Paine al sur de la Región Metropolitana de Santiago, donde pudimos recoger los testimonios de dos cuidadoras con niños con discapacidades del desarrollo.

\footnotetext{
"Sólo se preocupa el Estado de la gente normal, pero cuando viene la Teletón, de hacer rampas, de que el joven pueda trabajar en un supermercado, hace la propaganda de que está allá, está acá, pero lo que ve día a día no pasa eso, siempre van dejando a las personas que tienen sus problemas, entonces uno ve casos como el del Alonso afuera. Por ejemplo, acá han hecho muchos colegios, pero ningún colegio que diga es para estos niños que realmente lo necesitan, por ejemplo el neurólogo a mi me mandaba a un colegio que está en la Gran Avenida, en el paradero 5, que eso significa para mi trasladarme casi todo Santiago, y yo vivo acá prácticamente en el sur, entonces eso no hay acá." (Entrevistada 29)
}

Una de las entrevistadas rurales, cuyo hijo ya es adulto, reclamaba que en su momento no tuvo un centro educacional adecuado para que su hijo hubiese desarrollado habilidades que le ayudaran a tener en su adultez una mejor calidad de vida.

"Sí porque a mí me hubiera gustado que él hubiera aprendido, hubiera tenido donde estar, donde hubiera aprendido más." (Entrevistada 15)

La posibilidad de que sus hijos dependientes se integrasen a colegios regulares en zonas rurales era nula, así lo expresaba la misma entrevistada: 
"No hay colegios, que si el niño es epiléptico no encuentras cupo en el colegio, no entienden eso, porque si el médico les manda un papel, por esto o lo otro, en ese sentido acá el municipalizado [colegio], dicen el niño tiene que empezar como todos los demás y aprender como todos los demás, no le dan posibilidades, entonces al niño qué le va pasando, que siempre va ir quedando atrás, atrás, atrás, eso es lo que me pasaba con el Alonso ¿Qué le iba a decir yo? que por ejemplo, tengo que buscar un colegio donde yo sé que al Alonso lo van a tratar con el problema que tiene y que va a ir avanzando, porque tampoco quiero que el Alonso quede en una esquina sin saber, ni aprender nada, en un colegio grande yo sé que va a ir por puro poner la asistencia y él no va a avanzar, entonces la idea mía es que el Alonso avance, que crezca como persona, que pueda desenvolverse él solo.” (Entrevistada 29)

Se manejaba públicamente un discurso sobre la "integración" de los niños con capacidades especiales, pero los colegios regulares de educación no estaban adecuados -infraestructura, equipamiento, ayudas técnicas, formación de recursos humanos- para que ellos se desarrollaran, aprendieran, en definitiva se integraran.

En esta zona los niños tenían la opción de un colegio especial subvencionado, que recibía a niños con todo tipo de discapacidades.

"En Buin, a más de 20 kilómetros de acá, y tampoco el colegio está supliendo las necesidades de los niños... debería, esa es la idea, esa fue la idea con que se hizo, pero el colegio no está supliendo en nada, o sea yo mandar los cabros $^{158}$ para allá no. (...) Si este mismo año ha habido varios accidentes con niñitos en el colegio... esa es una de las cosas que está pasando en el colegio." (Entrevistada 18)

Este testimonio nos abre las puertas para una segunda propiedad a tratar, la calidad de la educación que era entregada a estos niños dependientes.

${ }^{158}$ Niños. 


\title{
Propiedad "Calidad de la educación especial"
}

Las cuidadoras consultadas, que al momento de la entrevista habían tenido experiencias con establecimientos de educación especial, nos hacían notar que uno de los puntos débiles era la falta de disciplina y relajo con el que los profesores realizaban su labor.

\begin{abstract}
“(...) la Daniela estuvo en ese colegio cuando chica, y es que me desilusionó el colegio porque los niños hablaban con muchos garabatos $^{159}$, muchas cosas, y las tías ${ }^{160}$ me decían: "Ah, si no pasa nada”, entonces las tías, aunque sea un niño discapacitado igual hay que enseñarle respeto, todo, y en ese colegio no había respeto, porque los niños las trataban viera usted los niños, y las tías los miraba y se reían porque ellas por ser niños discapacitados no tenían por qué aguantar esas cosas, porque los niños no son tontos, pueden ser enfermos, pero tontos no son, entienden.” (Entrevistada 27)
\end{abstract}

La cualificación de este tipo de establecimientos también estaba determinada por los recursos humanos especializados que trabajaban en ellos. Se sospecha que la oferta de servicios y recursos que los colegios subvencionados realizaba, para así tener un mayor número de alumnos y por consiguiente mayor dinero por subvención estatal, no era real y carecían de profesionales, instalaciones o actividades para atender las especiales necesidades de los niños.

\footnotetext{
"Es que no valía la pena el tremendo esfuerzo, cuando a mí me tocaba pagar el pasaje, sí me hubiese tocado pagarlo todos los días iba a gastar ochenta mil mensuales ¿Para qué? No había fonoaudióloga porque supuestamente había una profesora de lenguaje, él necesita mucho lenguaje, trabajó una sola vez con él en el año, o sea tú vas barajando y dices ¿Para qué?” (Entrevistada 18)
}

¿Para qué el esfuerzo? Claro pusieron un furgón escolar ${ }^{161}$ en el colegio, que el colegio financiaba una parte del pago del furgón, pero el furgón no tenía papeles de furgón escolar y todavía no los tiene. (...) Era todo al lote ${ }^{162}$, y eso no, ¿Para qué? (Entrevistada 18)

\footnotetext{
${ }^{159}$ Malas palabras, groserías.

${ }^{160}$ Educadoras, profesoras.

161 Transporte escolar.

${ }^{162}$ Mal organizado.
} 
El esfuerzo de llevar a sus hijos a un colegio, en donde no estaban recibiendo la atención y formación requeridas, hizo que esta cuidadora sacara a sus hijos del sistema formal educativo y resolviera de forma individual la educación de sus hijos.

\begin{abstract}
"Pero igual está viniendo una niña, una educadora diferencial [especial], está estudiando y viniendo a la casa a trabajar con ellos. (...) Es que es hija de un amigo, yo le hablé y ella siempre a mis chiquillos los..., sobre todo al mayor, ella lo vio nacer, siempre me preguntaba por el mayor y ahora está fascinada porque está con ellos, a ella le gusta." (Entrevistada 18)
\end{abstract}

En el caso de los adolescentes con alguna discapacidad, los cuidadores buscaban establecimientos donde recibieran formación laboral que les permitiera en el futuro desarrollarse en ese aspecto.

- "Ayer fui a preguntar a ver si la pongo en un taller laboral, para que ella pueda aprender, porque a mí me interesa que el día de mañana ella pueda, que ella tenga algo útil.”

- “¿Son talleres que dan acá en la comuna?”

- "Estee, lo único que me complica es que es en la estación Toesca, antes del Parque O’Higgins, entonces el Metro Santa Ana no tiene ascensor y en la estación Toesca tampoco, eso es lo único que me complica, porque ayer lo miré, me entusiasmó eso de encuadernación.” (Entrevistada 27)

La posibilidad de encontrar este tipo de centros en la misma comuna de residencia era baja, ya que el número de establecimientos de este tipo era reducido y dependía del tipo de discapacidad que afectara al dependiente. Además, como relata la entrevistada, la estación de metro más cercana al centro no era accesible en silla de ruedas, lo que dificultaba enormemente los desplazamientos de personas con discapacidad física. En las zonas rurales investigadas, los cuidadores tenían a sus hijos aún pequeños y no hicieron referencia al respecto, pero con la información disponible sobre este tipo de centros formativos ${ }^{163}$ la oferta en estas áreas era inexistente.

${ }^{163}$ Obtenida de la página web del Ministerio de Educación chileno: www.mineduc.cl.

Página 419 


\section{Síntesis}

Las posibilidades educativas de los niños $\mathrm{y}$ adolescentes con discapacidades eran reducidas, si bien en la ciudad contaban con una oferta mayor de establecimientos regulares y establecimientos especiales; sin embargo, las condiciones de dichos establecimientos y la calidad de la formación que allí se impartía no eran las mejores.

La situación que experimentaban en zonas rurales era similar a la de otros servicios sociales, la oferta era reducida y la calidad de los servicios ofrecidos era menos que regular. La posibilidad de formación laboral sólo era accesible para quienes vivían en entornos urbanos.

\subsection{CATEGORÍA “DEMANDAS DE LOS CUIDADORES AL ESTADO”}

A nivel estatal la única iniciativa directa de apoyo a los cuidadores era el Programa de atención domiciliaria de personas con discapacidad severa, que fue analizado en detalle dentro de la categoría salud pública. Este programa ejecutado por los centros de atención primaria -Cesfam, policlínicos, consultorios- estaba destinado a apoyar al dependiente y al cuidador a través de sus distintos componentes. Los elementos que iban en directo beneficio del cuidador eran el estipendio y la formación para desempeño de su labor.

No debemos dejar de considerar que, en la medida que los dependientes tuviesen sus necesidades cubiertas -salud, educativas, económicas vía pensiones-, la labor de los cuidadores podía realizarse de mejor forma. Este hecho es reforzado por la respuesta de los cuidadores al ser consultados por cómo les gustaría que el Estado les ayudase, ya que sus primeras referencias son a ayudas para sus dependientes antes que para ellos. Al reiterar la pregunta y acentuar qué era lo que ellos necesitaban surgieron una serie de expectativas sobre cómo el Estado podría apoyarles. Tales posibilidades de apoyo a su labor serán consideradas como propiedades de esta categoría. 


\section{Propiedad "Apoyo económico"}

La referencia más aludida por nuestros entrevistados tenía que ver con alguna forma de apoyo que mejorase su situación económica. Dicho apoyo podía concretarse en forma de un pago o subsidio por su labor de cuidado, o el apoyo económico/logístico para desarrollar un trabajo -dependiente o independiente- que pudiese ser realizado desde la casa.

"Que lo ayudaran a uno. Por ejemplo, que le hicieran un sueldo, una cosa así, que le ayudaran a aliviar un poco la carga." (Entrevistada 4)

Las economías familiares de nuestro grupo de estudio eran bastante precarias, más aún cuando el cuidador debía renunciar o limitar su trabajo remunerado por las labores de cuidado y de falta de apoyos en su labor, es por eso que planteaban la necesidad de apoyos económicos.

\footnotetext{
"Mire yo el otro día no más estuve diciendo, porque aquí se juntaron señoras, porque vino una señora que sabe mucho sobre las leyes del trabajo, sobre jubilaciones y todo eso, yo le dije "el Estado debería pagar más a la persona jubilada porque uno en la casa está visto y comprobado que uno trabaja más tiempo que lo que puede trabajar fuera", yo lo he visto porque antes de que mi hermano tuviera el accidente yo salía a trabajar, yo nunca me quedé.” (Entrevistada 17)
}

Otras de las entrevistadas, que trabajaba también fuera del hogar, planteaba que se otorgaran ayudas para crear fuentes de ingresos en el mismo domicilio, para que fuese menos complicado compatibilizar la situación de cuidado con la mantención económica del hogar.

“(...) y lo otro es que igual a mi me gustaría, en realidad quedarme yo cuidando a mi mamá. (...) Por ejemplo, hacer algo acá en la casa, algo que me hiciera para que yo estuviera acá en la casa, no salir a trabajar y estar cuidando a mi mamá." (Entrevistada 6) 
"Yo lo que necesitaría es algún apoyo para sacar adelante mi trabajo, tampoco que me regalen nada, sacar más adelante mis cosas, pero yo no encajo en nada, no soy jefa de hogar, tendría que estar separada, de aquí a que me separe de mi marido si mi marido es un siete ${ }^{164}$, son cosas que te limitan, porque vives bien con tu pareja, no puedes postular a esto, porque tienes estudios no puedes postular a esto otro, y no se fijan en el trasfondo de las cosas, en eso, capacitaciones." (Entrevistada 18)

Como quedó reflejado en la categoría donde tratamos la situación económica del grupo en estudio, había familias que se encontraban en condiciones un poco mejores que la media, ya que en el pasado habían logrado acumular una serie de bienes y/o contar con mayor formación. Pero estas condiciones hacían que obtuviesen mayores calificaciones en la encuesta de caracterización socioeconómica (utilizada por el Estado para distribuir los beneficios sociales), y por ello no podían siquiera postular a ayudas.

\begin{abstract}
“A mí, si me lo preguntan hoy día en este minuto, yo diría que me ayuden económicamente, yo pienso que uno debiera tener un ingreso mínimo, tipo pensión o una cosa así, a mi me dijeron que había una cuestión, que le daban veinte mil pesos a una persona cuando se hacía cargo de un enfermo, pero depende de la condición social, y poco menos uno tiene que estar durmiendo en la calle, una cosa así para que se la den. Porque desgraciadamente, aquí en Chile, hoy día, a mi no me creerían que tengo problemas económicos, porque tengo mi casa, que está bien cuidadita, limpiecita, que tengo mi autito del año 80, "Ah, esta señora no necesita", pero desgraciadamente confunden los términos, entonces si yo estuviera sucia, llena de mocos, con los pies sucios, con la casa asquerosa, "Ah, esta señora necesita”. (Entrevistada 13)
\end{abstract}

Las economías de estas familias también estaban afectadas y, si bien es cierto gozaban de ciertas comodidades, la situación de dependencia de sus familiares había generado un desbalance en la situación económica de sus hogares.

\footnotetext{
${ }^{164}$ Equivale a decir que es muy bueno, porque siete es la nota más alta en la escala de calificación en Chile.
} 


\section{Propiedad "Apoyo en cuidados"}

Otra solicitud, mencionada por los cuidadores, era la posibilidad de recibir ayuda en el cuidado de sus dependientes, algunos la veían necesaria para tareas particulares y que les requiriese destrezas o fuerzas que no poseían.

\footnotetext{
"Que me ayudaran, por ejemplo, con mi hermano, con él, que me ayudaran a bañarlo, porque yo no lo puedo bañar, y si mi hermano Claudio no lo viene a bañar, él no se baña. Que una persona pudiera ayudarme a bañar, aunque sea una vez en la semana.” (Entrevistado 9)
}

Una de las cuidadoras, que además era jefe de familia y debía trabajar fuera de casa, proponía la posibilidad del cuidado formal en las horas en que ella estuviese trabajando, ya que siempre estaba con la preocupación por el bienestar de su padre dependiente.

\footnotetext{
"No sé, poder pagarle a una persona que lo viera tiempo completo o en la tarde cuando yo salgo para poder salir tranquila, que fuera medio día, eso sería como una ayuda." (Entrevistada 23)
}

La idea que los cuidadores comentaban se podría ver reflejada en un servicio de ayuda a domicilio, tal como el que los municipios españoles prestan a través servicios sociales o el que entregan ONG's como Cruz Roja o Caritas.

\section{Propiedad "Apoyo en atenciones en salud"}

Otra solicitud de los cuidadores tenía que ver con las consecuencias del cuidado en la salud mental de los dependientes, ellos consideraban que deberían tener más apoyos en esta área.

"No sé, yo pienso que deberían haber más apoyos en cuanto a psicólogos porque es duro para los que cuidan, es duro." (Entrevistada 20)

Pero sus demandas también se extendían a otros ámbitos de la salud que podrían ser abordados con una perspectiva más integral de la relación cuidador - dependiente. 
"Y en cuanto a salud, que uno no puede salir po', a mí nunca me han querido vacunar cuando hacen las vacunas de invierno ¿Y por qué? Porque no tengo la edad, porque no tengo una enfermedad, porque no tengo asma, eso es lo que me dicen, yo no tengo derecho a una vacuna como la vacunan a ella, ¿Y si yo me enfermo? la contagio a ella, la otra semana estuvimos las dos enfermas, porque yo me resfrié fuerte, me tiró un día a la cama y ella también se me enfermó, pero no hay esas ayudas para uno." (Entrevistada 20)

\title{
Propiedad "Formación y reconocimiento"
}

Finalmente, señalamos la opinión de una de las entrevistadas a la que en su centro de salud no le habían otorgado formación para el cuidado. Ella creía que una de las cosas que el Estado debería propiciar era la instrucción integral de los cuidadores.

\begin{abstract}
"Eh... una, deberían capacitarnos y darnos un entrenamiento como corresponde, darnos por lo menos un título de enfermería, porque uno hace la práctica completa en esta cosa. Desde el momento en que uno toma una persona así, un familiar, uno debería aprender a tomar la presión, poner inyecciones, utilizar suero, utilizar todo lo que se necesita en estas cosas, yo creo que eso sería un reconocimiento, y durante todo el tiempo que las personas estén así, por lo menos 2 veces en la semana estudiar, hacer un curso, y así uno las tiene mejor. Y a futuro, cuando pase todo esto, tiene un trabajo, es un trabajo seguro, porque uno tiene la experiencia y tiene el título, eso yo creo que sería un reconocimiento, porque generalmente las personas que cuidamos no tenemos estudios superiores. Y si uno tiene la paciencia y tiene la voluntad ¿Qué mejor?” (Entrevistada
\end{abstract} 12)

La solicitud que expresaba esta cuidadora estaba formulada pensando en que los conocimientos y la experiencia adquirida podrían a futuro significar una fuente de trabajo para el cuidador, al acceder a conocimientos que podría permitir desempeñarse como cuidador formal. 


\section{Síntesis}

En el análisis de las demandas, que los cuidadores realizaban al Estado, pudimos distinguir cuatro reclamos claros:

- La necesidad de apoyos económicos a las familias de los dependientes, que podía verse materializado en subsidios o "sueldo" por la labor de cuidado, o en ayudas para desarrollar trabajos en el domicilio. Esta era la demanda más requerida.

- Apoyos en cuidados, a modo de ayudas a domicilio, que alivien la tarea de los cuidadores.

- Apoyos en la salud del cuidador, principalmente en la salud mental.

- Formación del cuidador y reconocimiento de la experiencia para que en un futuro pueda desempeñarse como cuidador formal. 
Página | 426 


\section{CAPÍTULO VII. DISCUSIÓN Y CONCLUSIONES}

\section{DISCUSIÓN}

\section{Situación psicosocial y cultural de los cuidadores informales de personas dependientes}

Los cuidadores informales de personas con dependencias, de esta investigación, en su mayoría eran familiares directos y mujeres, dato análogo con el patrón de comportamiento del país y la región (Vidal et al. 1998; Albala et al. 2007; Díaz 2006; Reca et al. 2008; Valderrama et al. 2010). Ma Ángeles Durán realizó en 2006 un perfil social de los cuidadores españoles, que en los aspectos que a continuación siguen coinciden con el perfil de cuidadores que fueron objeto de nuestro estudio. Eran mayoritariamente mujeres; con una concentración de cuidadores entre los 50 y los 60 años; la mayoría no tenía un trabajo remunerado fuera del hogar, y si lo tuvieron debieron abandonarlo (Díaz et al. 2006); tenían dificultades económicas; asumían casi exclusivamente el cuidado del dependiente, y contaban con enormes dificultades para mantener sus relaciones sociales; prestaban atención al familiar dependiente durante largos años y lo más probable era que lo siguieran haciendo; no tenían tiempo ni oportunidad de cuidarse a sí misma/o; y sentían temor con respecto al futuro.

La realidad de cuidados estudiada correspondió a la de los cuidadores principales o primarios (De los Reyes 2001), que asumían la responsabilidad íntegra de cuidado de la persona con dependencia. En el caso de los dependientes mayores, éste rol por lo general era desempeñado por esposas, hijas e hijos, operando claramente la jerarquía de sustitución (Cicirelli 1990; Pérez et al 1996; Cantor en Rivera 2001; Robles 2006a; Albala et al 2007; Valderrama, Morris y Ulloa 2010).

En el caso de las mujeres cuidadoras, la asignación de este rol ocurre sin posibilidad de negociación, resultándoles inevitable asumir la responsabilidad de cuidar a su familiar dependiente. En el cuidado de dependientes mayores, a las primeras a las que se les imponía esta labor era a las esposas, si éstas no estaban en condiciones eran las hijas -la que vivía más cerca, con la que tuvieran mejor relación, la que le debía reciprocidad, la soltera, la más generosa-, las nietas, hermanas o sobrinas (Robles 2006b). Para los 
dependientes más jóvenes -niños y adultos con dependencias- eran las madres quienes cuidaban.

Cuando la persona con dependencia era una mujer, el cuidador era una hija, y sólo en el caso de que no existiera o no pudiera era un hijo el que se hacía cargo del cuidado de la madre dependiente. La situación más excepcional era que un hombre se hiciera cargo del cuidado de su pareja.

La historia laboral de las mujeres cuidadoras estaba marcada por una presencia ausente en el mercado laboral (Pérez Orozco 2005), por el proceso de escisión que se genera entre los espacios públicos y privados por los que éstas han transitado. La situación de cuidado forzó a la mayor parte de ellas a abandonar sus trabajos remunerados, lo que repercutía notoriamente en las condiciones económicas de sus familias (Díaz, Medel y Mauro 2006; Herrera y Maffei 2009). Las cuidadoras que mantenían sus empleos estaban sujetas a una carga de trabajo excesiva.

Si aplicamos el análisis histórico de la relación del cuidador y la persona con dependencia que utiliza Rodríguez (1994), la figura del cuidador tradicional como la del cuidador moderno-urbano son igualmente frecuentes entre los cuidadores de personas mayores.

Las cuidadoras tradicionales, determinadas por la división sexual del trabajo que reparte responsabilidades y subjetividades en la sociedad (Izquierdo 2003b), asumían de forma sumisa y/o resignada el rol de quien cuida, con reconocimiento de su labor remitido a los ámbitos familiares. Es más, muchas de ellas venían entrenándose en ese rol desde tempranas edades, con sus hermanos, y posteriormente cuando fueron madres con sus propios hijos, tenían ya un historial de cuidados, generándose lo que Tobío (2002) identifica como la redistribución generacional en la responsabilidad de cuidar. Este tipo de cuidadoras priorizaba las necesidades de los demás frente a las propias, postergando dichas necesidades, con el riesgo que conlleva este comportamiento, al poder producir situaciones de empobrecimiento y privación (Bubeck 1995) que la exponían a relaciones de dominación e incluso explotación (Durán 1999). 
Las cuidadoras que respondían al perfil de cuidador moderno-urbano, que tenían una trayectoria laboral previa a la situación de cuidado, al sumar el rol de cuidadora generaron tensiones al interior de las familias -criticidad, rebeldía, abandono de otros roles- por la contradicción en los diversos papeles que debieron desempeñar, situación que no se observó en el caso de los cuidadores tradicionales (Robles 2003). Este tipo de cuidadoras intenta que el resto de los miembros de la familia se involucren y responsabilicen del cuidado de la persona con dependencia, situación no exenta de conflicto en sus núcleos.

En la lógica de la división sexual del trabajo, esos hombres ausentes del cuidado que formaban parte de las familias estudiadas - esposos, hermanos, hijos-, responden a la lógica del hombre provisor- protector, el hombre como cabeza de familia (Izquierdo 1998), pero que no toma parte de labores que acontecen en el hogar. Este hombre concibe que la mujer -cuidadora- es quien debe complementarle en el logro de sus objetivos. $\mathrm{M}^{\mathrm{a}}$ Jesús Izquierdo (2003b) considera que se establece una "solidaridad forzada", una solidaridad impuesta entre los miembros de la familia, donde la mujer debe hacerse cargo de los más débiles -niños, mayores y enfermos-, porque el hombre se ha hecho cargo de ella y los que están por debajo de ella.

Los hombres que desempeñan la labor de cuidadores son una minoría, ellos presentaban características bastante excepcionales. A pesar de que eran proveedores económicos en sus hogares, debieron asumir el rol de cuidadores porque no había quién más realizara esta tarea con sus dependientes y porque expresaban sentir un profundo cariño a sus familiares dependientes -madres y esposa-. Ellos además debieron desempeñar otros roles dentro del hogar, ya que los dependientes a su cargo eran quienes los realizaban hasta antes de su incapacidad. El desempeño de estos roles "femeninos" representó un desafío para ellos, que no habían sido socializados en la gestión reproductiva de los hogares.

Del mismo modo, si analizamos los relatos de los cuidadores en estudio desde la tipología aportada por el Colectivo IOE (Colectivo IOE 1995), sobre los discursos de cuidadores informales en España, podemos afirmar la predominancia del discurso asociado a la solidaridad "comunitaria", con referencia a la estructura familiar tradicional y a la actitud de "sacrificio" de los cuidadores por su familiar dependiente. 
También resultó identificable en los testimonios, aunque de forma minoritaria, la ideología de la solidaridad "orgánica", ya que algunos cuidadores demandaban del Estado más soporte y el desarrollo de una institucionalidad que les apoyase.

De acuerdo a la dinámica que está adquiriendo la sociedad chilena, se debe tener en cuenta que las posibilidades de cuidado se estarían limitando por el aumento de las perspectivas laborales de las mujeres, por su acceso a niveles educacionales más altos, y por el tamaño, cada vez menor, de las familias chilenas (Cameron y Moss 2007, RuizRobledillo y Moya-Albiol 2012).

Considerando las actitudes y motivaciones identificadas en los cuidadores que fueron sujeto de nuestra investigación, la rama de actitudes "positivas" frente al cuidado optimista/estoica, realista, activa, flexible, religiosa- estaba imbuida del condicionamiento psicosocial de la mujer a orientar su acción con respecto a otros, a permanecer atenta a sus necesidades, a hacer todo lo posible por el logro de su bienestar (Durán 1999); este tipo de actitudes pueden ser atribuidas al cuidador tradicional.

En la tipología de actitudes denominadas negativas, la actitud frustrada era una de las condiciones que predominó en las cuidadoras que tenían un perfil más cercano al cuidador moderno-urbano. Estas mujeres - generalmente hijas- debieron asumir el rol de cuidadoras y limitar o abandonar su participación en la vida pública, en el mercado laboral. Tal como lo describe Robles (2006a), la presión de la obligación filial en este tipo de cuidadoras hizo que abandonaran sus proyectos personales de vida y asumieran forzadas la labor de cuidado.

La visión que tenían los cuidadores sobre el futuro estaba relacionada con la actitud que expresaban sobre el cuidado, así quienes manifestaban no tener proyección futura generalmente eran los cuidadores que asumieron una actitud frustrada. El enfoque optimista sobre el futuro era asumido por quienes adoptaban alguna de las actitudes positivas frente al cuidado. Finalmente, la mirada temerosa -por la salud precaria del dependiente y el posible desamparo de éste- estaba presente tanto en quienes asumían actitudes negativas como en algunos de los cuidadores que expresaban actitudes positivas (realistas, religiosa). 
Las motivaciones que los cuidadores declararon tener para desempeñar la tarea de cuidar - la reciprocidad y el sentimiento del deber- tenían límites difusos en los discursos de los entrevistados, donde las argumentaciones de tipo afectivo se mezclaban con las que aludían a que el cuidar era su responsabilidad, su obligación, de forma similar a lo que detectaron Díaz, Medel y Mauro (2006) y Valderrama, Morris y Ulloa (2010).

Actitudes y motivaciones contrapuestas pueden llegar a subsistir dentro del discurso de un mismo cuidador, Badgett y Folbre (1999) ya lo señalaban cuando hacían hincapié en los matices de significados que adquiría la palabra cuidado en la lengua inglesa (to care, to care for, to care about, to take care, to take care of) como prestar atención, expresión de afecto, preocupación, inquietud o pena con el otro. Se refiere entonces que el cuidado no solo implica un sentimiento, sino que también una responsabilidad con las connotaciones de valor que estos significados pueden adquirir (positivos o negativosque puede ser impuesta por la costumbre o el compromiso afectivo).

Las consecuencias del cuidado en el cuidador abarcan múltiples aspectos de su existencia. Si consideramos la cantidad de horas que debían dedicar al dependiente y a las tareas del hogar, éstas repercutían inevitablemente en su salud física, mental y social, situación que era especialmente notoria en los estratos socioeconómicos bajos que eran los que más horas dedicaban a estas labores, tal como lo confirma la investigación de Díaz, Medel y Mauro (2006).

Específicamente, las repercusiones en su salud estaban determinadas por dolencias físicas y agotamiento, síntomas depresivos y ansiosos, y tensiones familiares que afectaban su salud mental (Valderrama, Morris y Ulloa 2010). En lo referido a su salud social, los cuidadores experimentaban la pérdida de sus redes sociales con la interrupción de sus actividades laborales, y la falta de tiempo libre que les dificultaba el poder compartir con sus familiares y amigos. Además, los posibles conflictos derivados de la dedicación mayoritaria del tiempo del cuidador al dependiente, de la falta de apoyos en las tareas del cuidado, de la escaza valoración de la labor desempeñada por el cuidador, deterioraban considerablemente las relaciones familiares y de pareja, rasgos también respaldados por las investigaciones de Díaz, Medel y Mauro (2006) y Valderrama, Morris y Ulloa (2010). 
Además, una de las consecuencias derivadas de la situación de cuidado, presente en algunas de las experiencias recopiladas, fue la presencia de maltrato y de conductas agresivas. En cuanto al maltrato desde el cuidador al dependiente, de acuerdo a la tipología aportada por Muñoz Tortosa (2004), nos referimos a maltratos psicológicos o emocionales -infantilización del dependiente mayor, infundir temor- y negligencia pasiva -ignorar solicitudes del dependiente-. Se identificaron los factores de riesgo presentes en el cuidador que maltrataba (Pérez Rojo 2008), estos eran: la sobrecarga o estrés experimentado, inexperiencia en tareas de cuidado, falta de apoyo familiar y las dificultades económicas de las familias. Los comportamientos agresivos desde el dependiente hacia el cuidador consistían en agresiones físicas o psicológicas (verbales), las primeras efectuadas por dependientes que padecían demencias (Alzheimer's Disease International 1994; Losada, Montorio, Izal, y Márquez 2006). A pesar de que la evidencia empírica de esta investigación no lo refleja, la presencia de maltrato del dependiente al cuidador generalmente está asociado a que exista maltrato desde el cuidador al dependiente (Muñoz 2004).

La consecuencia más notoria, derivada de la actividad de cuidar, era la pérdida de ingresos de la familia producto de la dificultad del cuidador en desempeñar un trabajo remunerado (Díaz, Medel y Mauro 2006; Valderrama, Morris y Ulloa 2010). En nuestra muestra, una proporción importante de las familias eran monoparentales con jefatura femenina, lo que significaba que ellas eran responsables de la gestión reproductiva de los hogares y además sus sostenedoras económicas (Herrera y Maffei 2009).

Considerando el estrato socioeconómico en el que se centró esta investigación, se corrobora la afirmación de Heymann (2002) que dice que los menos favorecidos en la sociedad actual cuentan con menos recursos para satisfacer las necesidades de cuidado. En estas familias, las mujeres eran quienes debían cubrir las necesidades de cuidado de sus dependientes al interior del hogar, ya que a nivel público las instituciones que desempeñaban esta labor eran escasas. Ello hacía inevitable el abandono de las actividades remuneradas fuera del hogar, quedando estas mujeres rezagadas del mercado laboral y restringidas al trabajo doméstico no remunerado (Herrera y Maffei 2009). Para estas cuidadoras, las posibilidades de mejora en las condiciones socioeconómicas de sus familias eran muy remotas, es por ello que Himmelweit (2008) 
asevera que, considerando la asignación de género que posee el cuidado, cuanto más desigual son los ingresos, mayor es la desigualdad entre hombres y mujeres.

La precaria economía de estos hogares se vio paliada por la red de apoyo social más próxima -familia cercana: cónyuge, hijos, padres, hermanos-, que proporcionó apoyos instrumentales o materiales -dinero, especies, servicios, ayudas en el cuidado- al cuidador y su familia. Esta red íntima o microsocial (Lin et al. 1986 en Gallardo 2013) aportaba además apoyo emocional e informacional, y se constituía en la red más significativa para el individuo (Barros 2001 en Guzmán et al. 2003), de la cual el cuidador esperaba intercambios y responsabilidad mutua constantes, lo que no siempre sucedía (Barrón 1996). Las cuidadoras de familias monoparentales se encontraban en situación de especial vulnerabilidad, su red íntima era reducida y ello repercutía en el deterioro de su salud (Valderrama et al. 2010).

En el nivel mesosocial, los apoyos recibidos de parte de amigos y vecinos se constituyeron en una importante fuente de ayuda para los cuidadores, sobre todo para los que tenían escasas relaciones familiares (Barros 1994, 2002 en Guzmán et al. 2003); este apoyo era independiente del medio - urbano o rural- en el que habitaran. Dichas asistencias pudieron ser del tipo material -a modo de cooperaciones puntuales en el cuidado-, informacionales y emocionales.

Las redes de apoyo macrosocial, específicamente las informales, que brindaron apoyos a estas familias, eran de tipo religioso, y otorgaban ayudas principalmente en lo emocional y, en ocasiones, en lo material; también obtuvieron importantes apoyos materiales e informativos de organizaciones de tipo comunitario (ONG's). Al igual que señalaban Huenchuan y Sosa (2003), en su análisis sobre las redes de apoyo de las personas mayores, los cuidadores mayores contaban con menos contactos en los niveles mesosocial y macrosocial de apoyo que en el microsocial o íntimo.

La sobrecarga de los cuidadores se manifestaba en dos rasgos: cansancio y desesperación. En su mayoría contaban con reconocimiento de sus familiares por la labor que realizaban, pero deseaban que dicho reconocimiento fuese expresado a modo de apoyos constantes en su tarea (Valderrama et al. 2010), lo que hubiese disminuido su nivel de sobrecarga (Ruiz-Robledillo y Moya-Albiol 2012, 28). Un factor demandado 
por los entrevistados y que tenía directo impacto en evitar la sobrecarga, por ende en la calidad de vida del cuidador, era la formación de los cuidadores. Así lo recomienda Albala (2007), indicando que resultaría prioritaria para enfrentar de mejor forma la tarea de cuidar.

En relación a la actividad misma del cuidado, consideramos una serie de actividades vestimenta, aseo personal, alimentación, movilización tratamientos y procedimientos de rehabilitación, cuidados especiales, actuación ante emergencias, organización de la vida diaria-, que, junto al resto de tareas del hogar, se organizan más allá de un conjunto de tareas domésticas, ya que se convierten en necesidades que hay que satisfacer (Carrasco 2006a), considerándose trabajo doméstico y de cuidados (Durán 1999; Robles 2003a; Carrasco 2006b). Esta forma de explicar el fenómeno permite superar el esquema producción-reproducción para abordar las actividades del cuidado, y entenderlo como partes de un todo más complejo cuyo objetivo es la satisfacción de las necesidades humanas y el mantenimiento de la vida (Carrasco 2006a).

Se debe considerar, además, que el cuidar implica la realización de unas tareas concretas, y no necesariamente significa que en su ejecución esté implícita la entrega de afecto hacia el dependiente, aspecto señalado como diferenciador entre el cuidado informal y formal. Los cuidadores estudiados aludían constantemente al cariño y/o dedicación con que hacían las tareas para sus dependientes, existiendo infinitas formas para ello, estableciendo así distintos tipos de relación y calidad de cuidado (Bosch en Carrasco 2006a).

Las características de los dependientes que eran cuidados por nuestros entrevistados se corresponden con las características de la población dependiente en el país y con su comportamiento demográfico. Una cantidad importante de ellos eran personas mayores de 60 años, proporción que se condice con la Encuesta Nacional de Discapacidad Endisc-2004- (Fondo Nacional de la Discapacidad, Instituto Nacional de Estadísticas 2005), como con la Encuesta de caracterización socio-económica -Casen- (Ministerio de Planificación 2010). Las principales patologías padecidas por este grupo eran los ACV (y sus consecuencias derivadas) y/o demencias (Alzheimer, vascular). Los cuidadores de este tipo de dependientes eran principalmente hijas, hijos y esposas. El 
resto de los sujetos objeto de cuidados eran niños, adolescentes y adultos cuidados por sus madres y hermana.

Los factores que influyen en la calidad de la relación del cuidador con el dependiente eran los siguientes: calidad de la relación previa a la situación de dependencia; tipo de relación de parentesco; madurez emocional del cuidador; existencia de reciprocidad del cuidador con el dependiente; posibilidad de reemplazo en la tarea de cuidar; y tipo de patología padecida por el dependiente. Algunas de estas características pueden constituirse en factores de riesgo de maltrato, aunque en el caso de que el dependiente padezca alguna enfermedad que le genere deterioro cognitivo los resultados no son concluyentes (Perez Rojo 2008).

El cuidado formal no era una alternativa para estos cuidadores; el acceso a instancias residenciales o centros de día era prácticamente inexistente para ellos por sus condiciones socioeconómicas y por la falta de disponibilidad de servicios públicos. Además, la mayor parte los cuidadores consultados no lo considera una opción porque concebían el cuidado de su familiar dependiente como parte de sus obligaciones, manejando un discurso ideológico del tipo "solidaridad comunitaria" (Colectivo IOE 1995), típico de cuidadores con bajo nivel educacional y con estructuras familiares tradicionales. 


\section{Posibles diferencias en la situación de cuidadores informales rurales y urbanos}

Al centrar nuestra discusión en el medio en que se desenvuelve el cuidador, creemos necesario reflexionar separando dos ámbitos de influencia en su labor, por un lado, señalaríamos los aspectos externos o del contexto material y, por otro, los aspectos psicosociales y culturales que predominan en su hábitat.

En los aspectos psicosociales y culturales que afectaban o influían en el cuidador podemos identificar, en los entornos rurales, un discurso ideológico más cercano a la solidaridad comunitaria descrita por el Colectivo IOE (1995), apegado a la lógica del cuidador tradicional (Rodríguez 1994); en dicho medio, los cuidadores eran mujeres, que no estaban trabajando de forma remunerada fuera del hogar cuando debieron asumir el cuidado del dependiente, y lo hicieron de forma sumisa y/o obediente y/o resignada y/o postergada. Tal como lo indicara Vidal (Vidal et al. 1998), la carga afectiva es predominante en los discursos de las cuidadoras del medio rural.

En estas familias opera la lógica de la jerarquía de sustitución (Robles 2006a), que en primer lugar fija a la mujer-esposa, o mujer-madre como quien debe hacerse responsable de los cuidados. En el caso específico de dependientes mayores varones, la cónyuge es quién debía asumir el cuidado, y sólo en el caso de que no pudiera -muerte o enfermedad- le reemplazaba la hija. En este orden, le siguen las hijas, independiente del sexo del dependiente y del medio en que se desarrolle la situación de cuidado. Observamos en nuestro estudio una diferencia con respecto a lo que plantea Robles (2006a) para el caso del cuidado de los padres, ella afirma que por el control social del cuerpo existirían preferencias de cuidados a que las hijas cuiden de las madres y los hijos de los padres, situación que en los casos estudiados no se observó, también correspondía a las hijas el encargarse del cuidado de sus padres mayores independiente del sexo. El rol de los hijos de padres dependientes era actuar como proveedores, ya que la naturaleza no los había "dotado" para el cuidado; la división sexual del trabajo era marcada, no había cuidadores varones.

En los entornos urbanos, el discurso ideológico predominante era semejante al moderno-urbano (Rodríguez 1994), las mujeres, que asumieron el rol de cuidadoras esposas, hijas, madres-, debieron abandonar, disminuir sus horas de trabajo o buscar 
empleos que les permitieran desempeñar su responsabilidad de cuidado, algunas de ellas eran jefas de hogar. Resultó más frecuente el observar conflictos y tensiones al interior de estos grupos familiares, derivados de la adopción del cuidador del nuevo rol social y la contradicción que se generaba por intentar compatibilizar éste con los demás roles (Vidal et al. 1998; Robles 2003). Muchas de las cuidadoras manifestaron desempeñar la tarea de cuidar impelidas por la obligación moral del lazo familiar (Vidal et al. 1998) más que por la reciprocidad (Colectivo IOE 1995), aunque con influencia también de la jerarquía de sustitución. Ellas intentaron generar cambios en su entorno familiar con miras a que el resto participara y asumiera roles protagónicos en la atención del dependiente y las tareas del hogar. En el caso de los hombres cuidadores entrevistados, todos de zonas urbanas, manifestaban situaciones -abandono del trabajo, adopción de nuevos roles- y motivaciones para el cuidado -el afecto principalmente, y obligación moral- también concordantes con el discurso moderno-urbano.

En el ámbito de las redes de apoyo social, tanto en las áreas urbanas como rurales, los cuidadores indicaron que contaban con apoyo social proveniente de los niveles microsocial, mesosocial y macrosocial (Barón 1996). El apoyo social más importante era el que provenía de sus familiares más cercanos (Barros 2001 en Guzmán et al. 2003); en el segundo nivel los cuidadores urbanos y rurales destacaban los apoyos instrumentales e informacionales, pero en los discursos de los cuidadores de áreas rurales este aspecto era destacado por considerarse un factor positivo que contribuía a la calidad de vida que para ellos implicaba el vivir en una zona rural; se consideraba un factor favorecedor de un buen cuidado respecto al ámbito urbano, ya que en éste este tipo de apoyos no siempre existían. Finalmente, al nivel comunitario o macrosocial, se observó que la densidad y cercanía de los agentes de estas redes era mayor en zonas urbanas que en las rurales.

En relación al contexto material o los aspectos externos que rodeaban y afectaban a los cuidadores en su labor, en el análisis realizamos una división con motivo de facilitar su estudio: espacios públicos y vivienda. En general, la más clara diferencia en cada una de estas categorías, de acuerdo al medio, estaba dada por la accesibilidad.

Los espacios públicos rurales contaban con un transporte público deficiente o inexistente, que carecía de accesibilidad física. Este motivo hacía que para poder 
desplazarse con sus dependientes debían hacerlo en transporte privado (si no contaban con vehículo propio, debían pagar por ello) o, en última instancia, esperar a que el servicio de ambulancias acudiese en caso de urgencia. El equipamiento sanitario y comunitario de entornos rurales también tenía estas características, los centros de salud y/o hospitales estaban alejados, eran reducidos en número y prestaban servicios de menor calidad; su entorno vial (calles, aceras) no estaba asfaltado, y las áreas verdes comunitarias eran inexistentes.

La situación de los cuidadores urbanos era distinta, contaban con una amplia y diversificada red de transporte público, medianamente accesibles -los autobuses y líneas de metro nuevas lo eran-. Los servicios de salud estaban cercanos, eran accesibles, con servicios de atención a domicilio y con algunos de los traslados cubiertos por el servicio de ambulancias de los centros de salud. El equipamiento comunitario de sus barrios era aceptable, a pesar de que vivían en comunas de bajas condiciones socioeconómicas.

En el caso de las viviendas, la situación de éstas en entornos rurales se contraponía con la experimentada en las zonas urbanas, ya que en las últimas se presentaba como dificultad generalizada la falta de espacio, que en ocasiones llegaba al hacinamiento, y la mala calidad de las viviendas (viviendas sociales), factores que determinaban que éstas tuvieran barreras arquitectónicas que dificultaban la labor del cuidador.

La realidad de las viviendas rurales difería con las anteriores por cuestión de espacio, la amplitud y la posibilidad de reformas facilitaba el desempeño del cuidador. Sin embargo, parte de estas casas estaban deterioradas en sus estructuras, tenían dificultades para ser calentadas mediante calefacción, y algunas presentaban barreras arquitectónicas que dificultaban los desplazamientos a personas con movilidad reducida

Finalmente, un aspecto que resultaba desventajoso para los cuidadores urbanos era la peligrosidad de sus barrios, derivados del consumo y tráfico de drogas. Por el contrario, los cuidadores rurales destacaban la tranquilidad de sus entornos, junto a la posibilidad de vivir en un entorno menos contaminado, y la cooperación de sus vecinos. La situación de aislamiento rural se constituía en la desventaja consensuada para sus cuidadores. 


\section{Aspectos de la situación psicosocial y cultural de los cuidadores que son susceptibles de mejorar desde la política social}

Las políticas sociales chilenas responden a un tipo de estado de bienestar particular que ha estado definido por el modelo neoliberal que el país implementó en la década de los 80, con una estrategia política intensa de privatizaciones de servicios públicos. A partir de los años 90, con el retorno del país a la democracia, lentamente se fueron introduciendo modificaciones que intentaron reducir los efectos negativos de dicha política, fortaleciendo el debilitado sector público.

De acuerdo al modelo teórico generado por Esping-Andersen (2000), sobre los distintos modelos de Estado de bienestar, y de los regímenes que se corresponden con éstos, podemos determinar para cada uno cuáles y cómo son las políticas sociales que desarrollan, con sus derechos y prestaciones correspondientes, las oportunidades laborales y el grado de igualdad social que generan. La definición de estos modelos está dada por la combinación de tres instituciones fundamentales: Estado, mercado y familia. En los resultados de las múltiples composiciones de estos factores se describen dos procesos de independencia o autonomía del bienestar de las personas y sus familias, la desmercantilización y la desfamiliarización.

Dentro de los modelos teóricos descritos por el autor, podemos afirmar que el régimen que se desarrolló en Chile en la década de los 80 contaba con una clara supremacía del régimen llamado residual o liberal, caracterizado por la predominancia de la individualización de los riesgos, donde la promoción de soluciones se dejó en manos del mercado, con un Estado secundario en la resolución de las problemáticas sociales. El alcance de la labor del Estado chileno se limitó a satisfacer necesidades básicas de los ciudadanos con menos recursos económicos, con alcances y extensión limitada. Éste asumió un claro enfoque asistencial basado en necesidades y un sesgo hacia la focalización (Navarro Ruvalcaba 2006, Raczynsky 1999). De forma progresiva, con el retorno a la democracia en el país, el régimen de bienestar liberal ha ido perdiendo supremacía, cediendo paso a una intervención más protagónica del Estado en el aseguramiento del bienestar de los ciudadanos, pero aún el régimen de Estado de bienestar chileno presenta bajos niveles de desmercantilización y un familismo implícito (Acosta 2009), ya que un fuerte peso de la resolución de las problemáticas está en 
manos de los individuos, sus familias y la asistencia de organizaciones no lucrativas (Instituto de Mayores y Servicios sociales 2004).

Afinando aún más el análisis, recogemos la observación que tanto Lewis (1992), Lewis y Ostner (1994 en Pérez Orozco) y Himmelweit (2008) hacen de la necesidad de considerar en el modelo teórico de los estados de bienestar, dentro del proceso de desfamiliarización, la idea del "varón sustentador" (breadwinner), que para el caso chileno correspondería a la de un varón sustentador "fuerte" en tránsito hacia un varón sustentador "modificado", en una sociedad donde poco a poco se van reconociendo los derechos de las mujeres como trabajadoras y madres al mismo tiempo.

Específicamente, en el área de política social que más se relaciona con las temáticas de esta investigación, el sistema sanitario chileno ha experimentado transformaciones importantes estos últimos 20 años. Larrañaga (1997) afirmaba que la estructura del sistema de salud chileno originó un sistema dual que separó a la población en dos grupos: a) los ciudadanos que podían pagar los servicios del sector privado, el cual funcionaba bajo la lógica de un seguro individual que en su acceso, cobertura y valor discriminaba por ingresos y riesgo médico; b) las personas que eran amparadas por un sector público -Fonasa- de carácter solidario. Esta conformación generó una organización sanitaria que, por un lado, concentraba a las personas de altos ingresos y bajo riesgo en el sistema privado y, por otro, agrupaba a una mayoría, que poseía bajos ingresos y presentaba alto riesgo, en el sistema público, área que asumía a todos los sujetos que no eran "elegibles" para el sector privado.

La estructura sanitaria actual es producto de una serie de reformas emprendidas a partir del año 2000 (ley no 19.888, ley no 19.895 , ley no 19.937 , ley no 19.966 , ley $\left.n^{\circ} 20.015\right)$. En el sector público, la Atención Primaria de salud se vio fortalecida especialmente (Infante y Paraje 2010), con un enfoque de atención integral y comunitaria (Ministerio de Salud s.f.). El sistema privado de salud también sujeto a modificaciones, principalmente a través del Plan AUGE (ley $\mathrm{n}^{\circ}$ 19.966) vigente a partir del 2005 (Ministerio de Salud 2006, Fondo Nacional de Salud s.f.1, Valdivieso y Montero 2010, Lenz 2007). Dichas reformas apuntaron especialmente al ámbito de la regulación (ley $\mathrm{n}^{\circ}$ 19.888 , ley $n^{\circ} 19.895$, ley $\left.n^{\circ} 20.015\right)$, con objeto de reducir las arbitrariedades en que 
incurrían estas instituciones privadas prestadoras de servicios de salud (BecerrilMontekio, Reyes y Annick 2011).

En el ámbito de las pensiones, la dinámica resulta parecida, después de la política privatizadora emprendida en 1982 en donde casi la totalidad de los cotizantes pasaron a formar parte de un régimen de capitalización individual (Von Gersdorff 1984), en el año 2008 se emprende la llamada "Reforma previsional" (Quintanilla 2012, Uthoff 2011) que buscaba solventar las inequidades del sistema de las AFP's y garantizar el derecho a la protección social a toda la población, independiente de que hubiesen cotizado durante su vida laboral.

Si nos remitimos a la esfera de los cuidados, no podemos hablar de la existencia de un sistema de atención a la dependencia en el país, porque no existe una concertación de acciones, a nivel ministerial o sectorial, que trabaje conjuntamente para dar asistencia a las personas dependientes y sus cuidadores. Asimismo no existe un lineamiento de política social que aborde esta problemática. Sin embargo, sí podemos evidenciar desde el ámbito sanitario, específicamente en la Atención Primaria, una acción concertada de corte asistencialista y focalizada en los más vulnerables -el Programa de atención domiciliaria de personas con dependencia severa-.

Nos parece fundamental destacar que en el ámbito sanitario público chileno, producto de las reformas efectuadas en esta área, se generó un cambio importante en el modelo de atención adjudicando especial importancia al nivel primario, priorizando en la prevención y el cuidado ambulatorio. Ello implicó la realización de una tarea educativa en donde adquiría un rol protagonista la familia, como corresponsable en el cuidado de la salud, pero en realidad se trata de una llamada no explícita a que la mujer asumiera esta tarea (Berlagoscky y Provoste 2002). Este nuevo modelo de atención agregó otras exigencias al sistema doméstico de cuidado de la salud, contradiciendo la equidad de género de dos formas; en primer lugar, disponiendo de las mujeres, estableciéndoles exigencias que las anclaba en el rol doméstico, y, en segundo lugar, dando por supuesto una organización familiar (familias numerosas, hombre jefe de hogar) predominante en décadas anteriores, pero cambiantes en la actual sociedad chilena (Berlagoscky y Provoste 2002; Medel et al. 2006). 
Ya desde la concepción de políticas sociales a nivel estatal, se observa que se planifica considerando la más tradicional visión social de los roles sexuales, pensando en que las mujeres estarán disponibles para cuidar. Por ejemplo, el potencial de cuidados familiares en demografía es calculado a razón del número de mujeres en edad de cuidar (Instituto de Mayores y Servicios Sociales 2004; Medel et al. 2006). Asimismo, se debe considerar que tanto los Estados como las empresas son subvencionados por las mujeres en la medida que ellas se encargan de los dependientes (Durán 1999; Robles 2006a).

Específicamente, los sujetos del grupo socioeconómico, en el que centramos nuestra investigación, se ven forzados a desempeñar la labor de cuidadores, porque no tienen la capacidad económica para comprar estos servicios en el mercado (Tronto 2002); los menos favorecidos, en la sociedad chilena, son los que tienen menos recursos a su disposición para satisfacer las necesidades de cuidado (Heymann 2002; Himmelweit 2008).

La parcialidad que adoptaba el apoyo del Estado a la dependencia y sus cuidados, y las condiciones socioeconómicas que experimentaban los entrevistados y sus familias hacían que la primera demanda expresada hacia la administración fuera de tipo económica. Le seguían la necesidad de apoyos en el cuidado en el domicilio, los apoyos dirigidos a la salud física y mental del cuidador y la formación para el cuidado, tal como Araya (2011) lo señalaba, con reconocimiento oficial del cuidador para que a futuro pudiese representar una opción laboral.

El estudio de la situación particular de los cuidadores y el estado de la cuestión de la dependencia y los cuidados en el país, permiten afirmar que existe una crisis en el cuidado de los dependientes (Acosta 2009). En términos generales, esta crisis se relaciona directamente con la disminución de las personas en disposición de cuidar y con la desvalorización de la actividad misma de cuidado (Ruiz-Robledillo y MoyaAlbiol 2012). Pero, a nuestro parecer, la esencia de la situación de crisis pasa por la consideración de la actividad de cuidar como una responsabilidad individual -de la familia- y no como una responsabilidad de todos - de la sociedad-. La lógica subsidiaria del Estado en relación a los cuidados, que desplaza íntegramente la responsabilidad en las familias, nos indica que el modelo que impera es el de máxima responsabilidad privada (Acosta 2009; Setién y Acosta 2009). 
La difícil situación en que se encuentran los cuidados merece la formulación de una iniciativa estructurada de parte del Estado, que identifique en esta tarea las actividades necesarias, la distribución de las responsabilidades y los costos reales de ésta, "resignificándola", sacándola de la esfera privada familiar y conceptualizándola en la esfera pública como una actividad social (Bubeck 1995). El deprimente estado actual, y la crítica situación futura de los cuidados, necesitan del diseño e implementación de una política pública integral que garantice los derechos de los dependientes y sus cuidadores. Dicha política debería estar dentro de las dinámicas que en estos últimos años han intentado conformar un sistema de protección social, constituyéndose en uno de sus pilares. 


\section{CONCLUSIONES}

El ámbito de los cuidados a la dependencia en Chile resultaba un área de estudio poco desarrollada, algunos de los estudios realizados abordaban la temática de forma tangencial al estudiar a los dependientes. Otras investigaciones aportaban al conocimiento desde una mirada cuantitativa, pero con la falta de densidad que la información de este tipo permite tener. Por ello es que esta investigación se desarrolló con el propósito de profundizar el conocimiento sobre la realidad psicosocial y cultural de los cuidadores informales de personas dependientes en Chile con objeto de realizar propuestas para el diseño de iniciativas político-sociales que aborden sus problemáticas.

A modo de síntesis, podemos llegar a una conclusión general:

Los cuidados en Chile, tanto en zonas urbanas como rurales, eran responsabilidad exclusiva de las mujeres. El Estado chileno se encontraba cumpliendo un rol subsidiario en esta problemática, aún en los sectores más deprimidos de la sociedad. Estos rasgos junto a la variable socioeconómica, la dinámica poblacional y la creciente incorporación de la mujer al mercado laboral, hacían que la situación de los cuidados en Chile estuviera en situación de crisis y apremiante intervención.

Además, conforme al trabajo de investigación desarrollado podemos añadir las siguientes conclusiones que profundizarán en la conclusión general expuesta anteriormente:

- Los cuidadores informales de personas dependientes de la Región Metropolitana, tanto en áreas rurales como urbanas, eran mayoritariamente mujeres, cuyas edad promedio fluctuaba entre los 50 y 60 años. Ellas cuidaban principalmente de personas mayores (padres, pareja), le siguen el cuidado de niños, adolescentes y adultos (hijos).

- En general, el rol del cuidador se encontraba invisibilizado y encubierto en el resto de papeles que desempeñaba. El discurso presente en una parte importante de las/os cuidadoras/es entrevistados era del tipo solidaridad comunitaria (Colectivo IOE 1995) que se correspondía con el ideal de cuidador tradicional (Rodríguez 1994), 
que estaba inmerso en una estructura familiar tradicional, o la representación de ella, y donde actitudes como la "abnegación" y el "sacrificio estoico" estaban presentes en sus relatos. Así también, otra parte de los cuidadores puede ser clasificado como cuidadores moderno-urbanos, que asumieron la tarea de cuidar a la par de haber estado trabajando fuera del hogar, situación que generaba numerosas tensiones y conflictos, y les llevaba a asumir con actitud frustrada su labor. Tras algunos de estos discursos existe una narrativa del tipo "solidaridad orgánica", ya que los cuidadores emplazaban al Estado a asumir un papel más partícipe en los cuidados. Más adelante especificaremos este aspecto en relación a la variable de origen (urbana o rural) de los cuidadores.

- El cuidado era responsabilidad de las mujeres. Las cuidadoras eran principalmente madres, hijas y esposas de los dependientes y en sobre ellas operaba la jerarquía de sustitución. Ellas debieron asumir la tarea de cuidado, algunas de forma forzosa, como parte de las tareas que naturalmente se venían asignando a su género. Las cuidadoras tradicionales, que asumían sumisamente su rol tenían enormes dificultades en generar ingresos propios, vivían en hogares empobrecidos, lo que las exponía a situaciones de dominación y riesgo de explotación. Las cuidadoras moderno-urbanas experimentaban tensiones en sus hogares por la multiplicidad de roles y los pocos apoyos que recibían en su labor. Los hombres de estos hogares se limitaban a cumplir con el rol de proveedores-protectores, pero no tomaban parte de las labores relacionadas con el cuidado del dependiente y el mantenimiento del hogar.

- Los hombres cuidadores solo asumían este rol en ausencia de una mujer que lo hiciera. Ese es el motivo final al que aducen los hombres que se desempeñaban como cuidadores.

- Los factores que influían en la calidad de la relación cuidador - persona dependiente eran: la calidad de la relación previa a la situación de dependencia; el tipo de relación de parentesco; la existencia de reciprocidad del cuidador con el dependiente; la madurez emocional del cuidador; la posibilidad de apoyos y/o reemplazos en el cuidado; y el tipo de patología padecida por el dependiente.

- Dentro de las consecuencias más importantes derivadas del desempeño de la tarea del cuidar están: 
- La salud física, mental y social del cuidador se advierte afectada por la labor de cuidar. En cuanto a la salud física, el agotamiento y las dolencias físicas (musculares, esqueléticas) fueron los problemas más reportados. Los síntomas depresivos y ansiosos eran los más aludidos en el deterioro de la salud mental de los cuidadores. En lo social, la falta de tiempo libre, la pérdida o debilitamiento de sus redes sociales y los trastornos en la convivencia familiar -que en algunos casos llegaron a constituir conflictos familiares graves- resultaban de su rol de cuidadores.

- Se debe destacar que la sobrecarga, en forma de cansancio y/o desesperación, era un factor común a todos los cuidadores entrevistados. La mayor parte de los cuidadores contaban con reconocimiento familiar de su labor, pero esperaban que además les apoyasen de forma constante en su labor.

- La situación de cuidado afectaba directamente las condiciones socioeconómicas de los hogares. Considerando que la investigación se centró en grupos socioeconómicos medios-bajos y bajos, las condiciones económicas de las familias de las/os cuidadoras/es entrevistadas/os colocaban a éstas en una situación de pobreza porque los cuidadores principales, muchos cabeza de familia, no podían desempeñar un trabajo estable o solamente lo podían ejercer de forma parcial; además debemos tener en cuenta que existían varios hogares monoparentales donde una mujer-cuidadora era la principal proveedora, propiciando también situaciones que podrían considerarse como catastróficas, desde el punto de vista económico.

- De forma excepcional, presente en algunas de las experiencias investigadas, se observó maltrato desde el cuidador al dependiente, en forma de maltrato psicológico o emocional -infantilizar, atemorizar al dependiente- y negligencia. Entre los factores de riesgo asociados a este comportamiento del cuidador estaban: la sobrecarga del cuidador, la inexperiencia en la labor de cuidado, la falta de apoyo familiar y las dificultades económicas de la familia.

- En relación a los significados que los cuidadores daban a la tarea del cuidar, éstos estaban directamente relacionados con las motivaciones para ello, fue frecuente encontrar en los relatos de un mismo sujeto -cuidadores de personas dependientes adultas o mayores- justificaciones de tipo afectivo -reciprocidad principalmente- y 
también argumentos relacionados con la obligación. Los significados que este tipo de cuidadores atribuían a su labor eran variables en el discurso y recorrían el continuo afectivo - obligación, matices atribuibles a factores tales como el tipo de relación con el dependiente, la calidad de dicha relación, el tipo y la calidad de apoyos recibidos. En cuanto a las madres cuidadoras de hijos con dependencias, ellas planteaban como única motivación la razón afectiva, sin cuestionamiento del rol de cuidadora, directamente ligado a su condición de género y el rol de madre.

- Considerando la variable hábitat, las formas en que cuidadores rurales y urbanos enfrentaban el cuidado estaban influenciadas por aspectos culturales y psicosociales que estructuraban un discurso ideológico particular. En áreas rurales predomina un discurso cercano a la solidaridad comunitaria (Colectivo IOE 1995) representado en la figura del cuidador tradicional, que asume y sobrelleva la tarea de cuidar de forma sumisa y/o resignada. En cambio en zonas urbanas prevalece un tipo de cuidador moderno-urbano (Rodríguez 1994), que afronta este nuevo rol impelido por la obligación moral del lazo familiar, y manifiesta que ello ha generado numerosos costos personales y tensiones familiares.

- El contexto material para desempeñar la tarea del cuidado, en áreas urbanas o rurales, estaba claramente diferenciado por un concepto: la accesibilidad. Los espacios públicos rurales eran notoriamente deficientes en accesibilidad física, de transporte y en servicios comunitarios, en comparación con los espacios urbanos. Al revés sucedía en relación a los espacios privados urbanos que, por lo general, correspondían a viviendas sociales con espacios reducidos y de mala calidad. Los hogares rurales eran más amplios, con posibilidades de adaptación, pero con deterioros en sus estructuras y de difícil calefacción.

- En relación a las redes de apoyo, la red íntima o microsocial se constituía en la más importante red de apoyo para los cuidadores. Esta red, conformada por la familia cercana, proporcionaba apoyos de tipo emocional, instrumental y material. De esta red, el cuidador esperaba intercambios, que no siempre eran otorgados. El nivel mesosocial -vecinos, amigos- implicaba una importante red de apoyo en lo material, emocional e informativo, sobre todo para los cuidadores de familias monoparentales o con escasas relaciones familiares. Finalmente, en la red macrosocial, eran las organizaciones de tipo religioso las que más activamente apoyaban a los cuidadores, 
siguiendo a éstas las organizaciones de tipo comunitario, otorgando fundamentalmente apoyos de tipo emocional y material.

- En general, no existen grandes diferencias entre las redes de apoyo de cuidadores urbanos y rurales. Sí debemos destacar que, en el nivel mesosocial, los cuidadores rurales destacan los apoyos informacionales e instrumentales recibidos, por las condiciones de aislamiento en que vivían. Además, en el ámbito macrosocial la densidad y cercanía de los apoyos era mucho mayor en zonas urbanas que en rurales.

- En cuanto a la política social, el Estado de bienestar chileno vivió un tránsito desde el régimen neoliberal o residual, predominante en los años ochenta, a un rol más protagónico del Estado, introducido a partir de los años noventa, en ámbitos tales como la salud y las pensiones, pero aún con bajos niveles de desmercantilización y desfamiliarización.

- En el país no existía un lineamiento de política social que abordara la atención a la dependencia, solo iniciativas parciales que de forma asistencial y focalizada apoyaban al dependiente y su cuidador, principalmente desde el ámbito sanitario.

- En el ámbito de estudio de nuestra investigación, el peso del familismo del Estado de bienestar chileno se expresaba en la idea subyacente que existía en las pocas iniciativas destinadas al dependiente y su cuidador. En salud, por ejemplo, se planificaban planes y programas públicos teniendo aún en mente la representación “varón sustentador-mujer ama de casa", realidad que ya no era la predominante en la sociedad chilena. La lógica de los cuidados a los dependientes se sustentaba en esta idea que contradice la equidad de género.

- A raíz de lo anterior, podemos afirmar que la forma en que se resuelve la responsabilidad de los cuidados en Chile está en crisis, debido a que aumenta el número de personas susceptibles de necesitar de cuidados, por el envejecimiento de la población, y disminuye el número de potenciales cuidadores, con la incorporación de la mujer al mercado laboral, mayores niveles educativos de éstas, y el tamaño reducido de las familias chilenas.

- El origen de esta crisis se basa en la idea que los cuidados son una responsabilidad individual -de la familia-, y no de la sociedad en su conjunto, por la lógica neoliberal imperante en el país. El Estado de bienestar chileno debe encaminar su actuar con miras a enfrentar esta realidad como un problema social. Para comenzar, 
amerita que el Estado deje de ser subsidiario en la resolución de esta problemática y asuma un rol más protagónico, comenzando por los ámbitos mayormente demandados por los cuidadores como ayudas económicas a las familias, apoyos en el domicilio, centros de día para mayores e iniciativas dirigidas a cuidadores con el fin mejorar su salud física, salud mental y la formación para el cuidado.

- Consideramos importante destacar que esta investigación constituye uno de los primeros estudios desde el ámbito cualitativo del tema de los cuidados a la dependencia en Chile. De acuerdo al diagnóstico inicial, el conocimiento sobre este tema en el país estaba limitado a estudios cuantitativos. La utilización de la teoría fundamentada, como guía en el trabajo de campo y análisis de los discursos de los entrevistados, nos permitió profundizar en las experiencias de los cuidadores y sus entornos inmediatos, buscando enriquecer éste ámbito de conocimiento desde la sociología y las ciencias sociales.

- Así también, al estudiar el tema de los cuidados a la dependencia desde la perspectiva de género realizamos una contribución, ya que en Chile no se había abordado este ámbito desde la visión del género.

- En cuanto a los resultados inesperados de la investigación, la temática del maltrato resultó un hallazgo inesperado en el desarrollo de esta investigación. No era un tema incluido en la pauta de entrevista, pero sí aparece en ellas sin haberlo provocado, con naturalidad y sin conciencia de que los comportamientos que los cuidadores describían pudieran corresponder a maltrato.

Dentro de las limitaciones de nuestra investigación creemos necesario señalar las siguientes:

○ Limitación territorial. La investigación se circunscribió a zonas urbanas y rurales de la Región Metropolitana de Chile, como primer acercamiento a los cuidados a la dependencia en Chile; hubiese resultado óptima la realización de un trabajo de campo más extenso y representativo del país, pero económica y humanamente fue imposible abarcar otros territorios.

- Limitación administrativa. El trabajo de campo del estudio estaba planeado para ser desarrollado a través del Programa de atención domiciliaria de personas con 
dependencia severa, dependiente del Ministerio de Salud y sus servicios de salud territoriales, y ejecutado a través de los centros de salud municipales. Se contó con el apoyo formal del Ministerio, quien remitió a la doctoranda a uno de sus servicios metropolitanos para que éste proporcionara una base de datos de cuidadores. Se sometió la investigación a revisión por parte del comité de ética de este servicio, la aprobación por parte del comité fue condicionada a la presentación de declaraciones firmadas de los cuidadores -a los que aún no se conocía-, lo que nos hizo pensar que toda la documentación entregada no fue revisada. Todo este proceso implicó gastar un tercio del tiempo destinado a la recogida de datos en el país. Ante esta situación se resolvió contactar a los entrevistados a través de informantes clave y las redes de contactos.

- Limitación temática. El considerar un amplio espectro de cuidadores - de niños, adultos y mayores- pudo afectar el nivel de análisis y de logro de resultados más concluyentes para la investigación. Asimismo, la consideración de la región en estudio - la más poblada del país- supuso considerar zonas rurales de ésta que no necesariamente tienen el nivel de aislamiento de las zonas extremas del país (cordilleranas, patagónicas, altiplánicas, etc.), y así poder visualizar la naturaleza de las problemáticas de los sectores rurales.

○ Limitación metodológica. Nuestra investigación se desarrolló guiada metodológicamente por la Teoría Fundamentada, cuyo propósito principal es generar teoría a partir de los datos. Creemos que los aportes teóricos alcanzados a través del análisis están en construcción, principalmente por los motivos que anteriormente se mencionan y la imposibilidad de volver al campo de forma reiterada para conseguir completar teoría.

Finalmente, creemos necesario el desarrollo de investigaciones que profundicen en la materia de los cuidados a la dependencia considerando los siguientes aspectos o variables:

○ Grupos de dependientes por edades, principalmente nos referimos a cuidadores de personas mayores.

- Grupos de dependientes por patologías, por ejemplo estudiar el cuidado de personas con demencias o personas con discapacidades físicas. 
- Considerar la variable socioeconómica e investigar cómo se resuelve el cuidado en sectores medios. De acuerdo a lo observado en el trabajo de campo, las familias que debían sobrellevar el cuidado de un dependiente tendían a deteriorar sus condiciones socioeconómicas, y las familias de clases medias se encuentran fuera de los programas sociales de apoyo, ya que estos se focalizan en los grupos de menos recursos económicos.

- Considerando que en las zonas rurales es donde se concentra un porcentaje importante de personas mayores, resultaría indicado realizar un estudio en mayor profundidad de la situación de los cuidados considerando además la variable indígena.

- Evaluar el impacto de los programas de apoyo a dependientes y cuidadores del país, investigando en profundidad aquellos que representan experiencias exitosas. 
Página | 452 


\section{BIBLIOGRAFÍA}

Abellán, Antonio. 2000. "Nuevo modelo del funcionamiento y la discapacidad." Revista Multidisciplinar de Gerontología 3: 189-194.

Acosta, Elaine. 2009. "El cuidado de personas dependientes en la políticas sociales en Chile: ¿Quién cuidará de nosotros/as?". Revista A-MÉRIKA 3: 1-27. Obtenido el 1 de abril de

(http://www.revistaamerika.deusto.es/servlet/BlobServer?blobheadername3=MDTType \&blobcol=urldata\&blobtable=MungoBlobs \&blobheadervalue $2=$ inline $\% 3 \mathrm{~B}+$ filena me/490/245/ELAINE\%20ACOSTA\%20(VOLUMEN\%202\%20N\%DAMERO\%203).p df\&blobheadername2=Content-

Disposition\&csblobid=1178114097641\&blobheadervalue $1=$ application/pdf\&blobkey=i d\&blobheadername $1=$ content type \&blobwhere $=1244563220919 \&$ blobheadervalue $3=$ abinary\%3B + charset $\% 3 D U T F-$ $8)$.

Albala, Cecilia, Hugo Sánchez, Clara Bustos y Alejandra Fuentes. 2007. "Situación de los cuidadores domiciliarios de adultos mayores dependientes con pensión asistencial." Informe final, Instituto de Nutrición y Tecnología de los Alimentos (INTA), Universidad de Chile, Santiago de Chile.

Albertos, Carmen. 2006. "Situación de las personas con discapacidad en América Latina y el rol del BID.” Presentado en Seminario Internacional Desarrollo Inclusivo y Discapacidad: oportunidades y desafíos, Octubre, Santiago de Chile.

Alto Comisionado de las Naciones Unidas para los Derechos Humanos. 1975. "Declaración de los derechos de los impedidos." Proclamada por la Asamblea General en su resolución 3447, de 9 de diciembre de 1975. Obtenido el 4 de octubre de 2009 (http://www.inclusion-ia.org/espa\%F1ol/Norm/derechos-impedidos.htm). 
Bibliografía

Alzheimer's Disease International. 1994. Ayuda para cuidadores de enfermos con demencia. Geneve: Department of Social Change and Mental Health, World Health Organization.

Amezcua Manuel y Alberto Gálvez. 2002. "Los modos de análisis en la investigación cualitativa en salud: perspectiva crítica y reflexiones en vos alta." Revista española de Salud Pública 76: 423-436.

Andréu Abela, Jaime, Antonio García-Nieto y Ana María Pérez Corbacho. 2007. Evolución de la Teoría Fundamentada como técnica de análisis cualitativo. Madrid: Centro de investigaciones Sociológicas, Colección Cuadernos Metodológicos №40.

Araya, María Inés. 2011. "El cuidado familiar de adultos mayores y discapacitados en Chile." Pp 153 - 160 en El trabajo de cuidado en América Latina y España, documento de trabajo $\mathrm{n}^{\circ}$ 54, dirigido por María Ángeles Durán. Madrid: Fundación Carolina. Obtenido el 3 de abril de 2013 (http://www.fundacioncarolina.es/esES/publicaciones/documentostrabajo/Documents/DT54.pdf\#page=150).

Asociación Chilena de Padres y Amigos de los Autistas (ASPAUT). 2013. "Página web institucional". Obtenido el 5 de abril de 2013 (http://www.aspaut.cl).

Asociación Estatal de Directores y Gerentes en Servicios Sociales de España. 2008. "Síntesis de las jornadas de análisis y evaluación de la implantación de la Ley celebradas en Alcázar de San Juan los días 28 y 29 de marzo y dictamen del observatorio". Obtenido el 26 de septiembre de 2009. (http://msierrahoyos.googlepages.com/OBSERVATORIO-

DICTAMENSOBREELDESARROL.pdf).

Badgett, M. V. Lee y Nancy Folbre. 1999. "Quién cuida de los demás, normas sociosexuales y consecuencias económicas." Revista Internacional del Trabajo 118: 347-365. 
Barrón, Ana. 1996. Apoyo social: aspectos teóricos y aplicaciones. Madrid: Siglo veintiuno de España editores.

Becerril-Montekio, Víctor, Juan de Dios Reyes y Annick Manuel. 2011. "Sistema de salud de Chile". Salud Pública de México 53, 2: 132-143.

Becoña, Elisardo. 2006. "Resiliencia: definición, características y utilidad del concepto". Revista de Psicopatología y Psicología Clínica 11: 125-146.

Benería, Lourdes. 1999. "El debate inconcluso sobre el trabajo no remunerado.” Revista Internacional del Trabajo 118: 321-346.

Berlagoscky, Fanny y Patricia Provoste. 2002. "Modelo de atención y género: las condicionantes socioculturales de la Reforma de la Salud en Chile". Proyecto Género, Equidad y Reforma de la Salud en Chile, Organización Panamericana de la Salud/Organización Mundial de Salud, Santiago de Chile.

Boletín Oficial del Estado (BOE). 2006. "Ley 39/2006 de 14 de diciembre, de Promoción de la autonomía personal y atención a las personas en situación de dependencia." BOE 229. Obtenido el 22 de septiembre de 2009. (http://www.imsersodependencia.csic.es/).

Breinbauer Hayo, Hugo Vásquez, Sebastián Mayanz, Claudia Guerra y Teresa Millán. 2009. "Validación en Chile de la Escala de Sobrecarga del Cuidador de Zarit en sus versiones original y abreviada". Revista Médica de Chile 137: 657-665.

Bubeck, Diemut Elisabet. 1995. Care, Gender, and Justice. Oxford: Clarendon Press

Cameron, Claire y Peter Moss. 2007. "La atención a personas dependientes en Europa: Conceptos actuales y perspectivas futuras”. Intervención Psicosocial 1: 7-22.

Carrasco, Cristina. 1991. El trabajo doméstico. Un análisis económico. Ministerio de Trabajo y Seguridad Social, Colección Tesis Doctorales, Madrid. 
------. 2006a. "La Paradoja del cuidado: necesario pero invisible.” Revista de Economía Crítica 5: 39-64.

------. 2006b. “La Economía Feminista: Una Apuesta Por Otra Economía.” Obtenido el $\begin{array}{lllll}\text { de } & 21 & \text { de } & \text { Mayo } & \text { de }\end{array}$ (http://www.egeneros.org.mx/admin/archivos/economia_feminista.pdf).

Casado, David. 2009. "El nuevo sistema de atención a la dependencia. Una agenda de investigación". Boletín Economía y Salud 64, Asociación de Economía de la Salud. $\begin{array}{lllllll}\text { Obtenido } & \text { el } & 25 & \text { de } & \text { septiembre } & \text { de } & 2009\end{array}$ (http://www.aes.es/Publicaciones/Boletin\%2064.pdf).

Chile Solidario. s.f. “Descripción sistema ¿Qué es Chile Solidario?”. Obtenido el 25 de noviembre de 2009 (http://www.chilesolidario.gov.cl/sist/sist1.php).

Cicirelli, Victor. 1990. "Relationship of personal-social variables to belief in paternalism in parent caregiving situations." Psychology and aging 5: 458-466.

Coffey, Amanda y Paul Atkinson. 2005. Encontrar el sentido a los datos cualitativos. Estrategias complementarias de investigación. Alicante, España: Publicaciones de la Universidad de Alicante.

Colectivo Ioé. 2005. “Libro primero. Investigación cualitativa.” Pp. 33-208 en Cuidados en la vejez. El apoyo informal editado por Ministerio de Servicios Sociales, Instituto Nacional de Servicios Sociales (INSERSO). Madrid: INSERSO.

Consejo de Europa. 1998. "Recomendación Nº R (98) 9 del Comité de Ministros a los Estados Miembros relativa a la dependencia. Consejo de Europa." Obtenido el 5 de octubre de (http://www.imsersomayores.csic.es/documentos/documentos/consejoeuropa-rec98901.pdf). 
Bibliografía

Corporación Alzheimer Chile. 2013. "Página web institucional”. Obtenida el 5 de abril de 2013 (http://www.corporacionalzheimer.cl).

Delicado, Victoria. 2006. "Características sociodemográficas y motivación de las cuidadoras de personas dependientes". Praxis Sociológica 10: 200-234.

Díaz, Ximena, Julia Medel y Amalia Mauro. 2006. Cuidadoras de la vida. Visibilización de los costos de la producción de salud en el hogar. Impacto sobre el trabajo total de las mujeres. Centro de Estudios de la Mujer (CEM): Santiago de Chile. Obtenido el 28 de marzo de 2013 (http://www.cem.cl/pdf/cuidadorasvida.pdf).

Durán, Ma Ángeles. 1999. Los costes invisibles de la enfermedad. Bilbao: Fundación BBVA.

------. 2006. "Dependientes y cuidadores: El desafío de los próximos años.” Revista del Ministerio del Trabajo y Asuntos Sociales 60: 57-73.

Espina, Alvaro. (s.f.). "La sociología del bienestar de Gøsta Esping -Andersen y la Reforma del Estado de Bienestar en Europa”. Documento de trabajo $n^{\circ} 27122001$, DGPOLECO, Ministerio de Economía, Madrid.

Esping-Andersen, Gøsta. 1993. Los tres mundos del Estado del bienestar. Valencia: Edicions Alfons el Magnanim.

------. 2000. Fundamentos sociales de las economías postindustriales. Barcelona: Ariel.

Franco, Rolando. 1996. "Los paradigmas de la política social en América Latina". Revista de la CEPAL 58:9-22.

Ferrera, Maurizio. 1995. "Los Estados del bienestar del sur en la Europa social.” Pp. 85112 en El Estado de bienestar en la Europa del sur coordinado por L. Moreno y S. Sarasa. Madrid: Consejo Superior de Investigaciones Científicas. 
Flaquer, Lluís. 2000. Las políticas familiares en una perspectiva comparada. Barcelona: Fundación "La Caixa”.

------. 2004. 'La articulación entre la familia y el Estado de Bienestar en los países de la Europa del sur". Papers 73: 27-58.

Fondo Nacional de Salud. s.f. 1 "Acceso Universal con Garantías Explícitas en Salud.” $\begin{array}{lllllll}\text { Obtenido } & \text { el } & 26 & \text { de } & \text { noviembre } & \text { de } & 2009\end{array}$ (http://www.fonasa.cl/prontus_fonasa/antialone.html?page=http://www.fonasa.cl/prontu s_fonasa/site/edic/base/port/auge.html).

s.f. "Cuadro: Estimación de los beneficiarios del Seguro Público de Salud y su participación respecto a otros sistemas, número de personas, años 1999-2011." Obtenido el 13 de marzo de 2013 (http://www.fonasa.cl/wps/wcm/connect/internet/sageneral/informacion+corporativa/estadisticas+institucionales/estadisticas+institucionale s).

Fondo Nacional de la Discapacidad (FONADIS) e Instituto Nacional de Estadísticas. 2005. Primer estudio nacional de la discapacidad en Chile, ENDISC - Chile 2004. Santiago de Chile: FONADIS. Obtenido el 22 de marzo de 2013 (http://www.ine.cl/canales/chile_estadistico/encuestas_discapacidad/discapacidad.php).

Fondo Nacional de la Discapacidad (FONADIS). 2008. Pueblos originarios y discapacidad. Informe final. Santiago de Chile: Unidad de estudios, Fondo Nacional de la Discapacidad. Obtenido el 22 de marzo de 2012 (http://www.senadis.gob.cl/resources/upload/documento/9cbeab83f7cf14508ade9c8d41 13ec1a.pdf).

Fundación Coanil. 2011. Memoria técnica 2011. Obtenido el 5 de abril de 2013 (http://www.coanil.cl/pdf/memoria_tecnica_coanil_2011.pdf.)

Fundación Hogar de Cristo. 2013. "Página web institucional". Obtenido el 5 de abril de 2013 (http://www.hogardecristo.cl/). 
Fundación Las Rosas. 2013. "Página web institucional”. Obtenido el 5 de abril de 2013 (http://www.flrosas.cl/).

Fundación Teletón. 2013. "Página web institucional”. Obtenido el 15 de marzo de 2013 (http://www.teleton.cl/).

García, Vidal. 1998. "Centros especiales de empleo como puente hacia el microemprendimiento de las personas con discapacidad". Revesco - Revista de Estudios Cooperativos 65:73-114.

García-Calvente, María del Mar, Inmaculada Mateo-Rodríguez, Ana P. Eguiguren. 2004. "El sistema informal de cuidados en clave de desigualdad". Gaceta Sanitaria 18: 132-139. Obtenido el 13 de abril de 2013 (http://scielo.isciii.es/pdf/gs/v18s1/03sistema.pdf).

Gallardo, Lorena. 2013. “Apoyo social y etnicidad en personas mayores de la región de Arica-Parinacota de Chile: una propuesta para la intervención en trabajo social." Tesis doctoral. Departamento de Trabajo Social y Servicios Sociales, Universidad Complutense de Madrid, Madrid.

Gispert, Rosa. 2009. "Hacia una mayor adecuación y equidad del programa de ayudas a las personas con dependencia”. Revista Española de Salud Pública 3: 355-359.

Glaser, Barney G. y Anselm L. Strauss. 1967. The discovery of Grounded Theory: strategies for qualitative research. New York: Aldine de Gruiter.

Gómez, Manuel y Carmen Morán .2012. "El gobierno extingue la cotización de 145.000 cuidadoras de ancianos". El País.es, 29 de noviembre de 2012. Obtenido el 28 de agosto de 
Guzmán, José Miguel, Sandra Huenchuan, Verónica Montes de Oca. 2003. "Redes de apoyo social de las personas mayores: marco conceptual”. Revista Notas de Población 77: $35-70$.

Hammersley Martyn y Paul Atkinson. 1994. Etnografía: Métodos de investigación. Barcelona: Paidós.

Hernández, Roberto, Carlos Fernández-Collado y Pilar Baptista. 2010. Metodología de la Investigación. Cuarta edición. México D.F.: McGraw-Hill/Interamericana.

Herrera, Rodrigo y Teresa Maffei. 2009. "Demanda de cuidados en personas dependientes por hogar: un análisis de género”. Documento preliminar, Departamento de Sistemas de Información Social, División Social, Ministerio de Planificación, Santiago de Chile.

Herrera, Rodrigo, Osvaldo Larrañaga y Amanda Telias. 2010. "La ficha de protección social". Documento de trabajo, Programa de las Naciones Unidas para el Desarrollo (PNUD) - Chile, Santiago de Chile. Obtenido el 21 de marzo de 2013 (http://www.pnud.cl/areas/ReduccionPobreza/2012/2010_3.pdf).

Heymann, Jody. 2002. "Can Working Families Ever Win? Helping parents succeed at work and caregiving." Boston Review 27. Obtenido el 3 de junio de 2010. (http://bostonreview.net/BR27.1/heymann.html).

Himmelweit, Susan. 2008. "Rethinking care, gender inequality and policies." Presentado en reunión de expertos sobre: "Equal sharing of responsibilities between women and men, including care-giving in the context of HIV/AIDS" United Nations, Division for the Advancement of Women, Octubre, Ginebra.

Homedes, Nuria y Antonio Ugalde. 2005. "Las reformas de salud neoliberales en América Latina: Una visión crítica a través de dos estudios de caso". Revista Panamericana de Salud Pública 17(3): 210-220. 
Bibliografía

Hospital Josefina Martínez. 2013. Página web Hospital Josefina Martínez, enfermedades respiratorias infantiles. Obtenido el 15 de marzo de 2013 (http://www.hospitaljosefinamartinez.cl/).

Huenchuan, Sandra y Zulma Sosa. 2003. "Redes de apoyo y calidad de vida de personas mayores en Chile". Revista Notas de Población 77: 103-138.

Iborra, Isabel. 2005. "Concepto y tipos de maltrato de mayores." Pp. 17-28 en Violencia contra personas mayores editado por I. Iborra. Barcelona: Editorial Ariel.

Infante, Antonio y Guillermo Paraje. 2010. "La reforma de salud en Chile.” Documento de trabajo 2010 - 4, Programa de las Naciones Unidas para el Desarrollo (PNUD), Santiago de Chile.

Instituto de Mayores y Servicios Sociales (IMSERSO). 2004. Atención a las personas en situación de dependencia en España. Libro blanco. Madrid: Ministerio de Trabajo y Asuntos Sociales.

Instituto Nacional de Estadísticas (INE). 2003. Censo de población y vivienda 2002. Santiago de Chile: Instituto Nacional de Estadísticas.

Instituto Nacional de Estadísticas (INE), y Comisión Económica para América Latina y el Caribe (CEPAL). 2005. Chile: Proyecciones y estimaciones de población: total país 1950-2050. Santiago de Chile: CEPAL

Instituto Nacional de Estadísticas. 2009. "Sistema de demografía y estadísticas vitales. Proyecciones de población". Obtenido el 11 de febrero de 2011 (http://palma.ine.cl/demografia/menu/Genera/indice.aspx).

Instituto Nacional de Estadísticas (INE). 2012. "Estadísticas vitales. Informe anual 2010”. Obtenido el 13 de marzo de 2013 (http://www.ine.cl/canales/chile_estadistico/demografia_y_vitales/estadisticas_vitales/p df/vitales_2010.pdf). 
Bibliografía

Izquierdo, Mª Jesús. 1998. El malestar en la desigualdad. Madrid: Cátedra.

------. 2001. "Razón y sentimiento en las relaciones de pareja: ¿Del contrato al diálogo?" Presentado en Congreso Los hombres ante el nuevo orden social, Emakunde (Instituto Vasco de la Mujer), Centro Kursal Elkargunea, Junio, Donostia, País Vasco.

------. 2003a. "Del sexismo y mercantilización del cuidado a su socialización: hacia una política democrática del cuidado". Presentado en Congreso Internacional SARE 2003: "Cuidar cuesta: costes y beneficios del cuidado", Octubre, Bilbao.

------. 2003b. "El cuidado de los individuos y de los grupos: quién se cuida. Organización social y género." Presentado en Segón Congrés de Salut Mental. Grup de treball: Identitat, génere I salut mental. Barcelona.

Jiménez, Antonio. 2007. "El sector de la salud y la atención a la dependencia". Documento de trabajo No 111, Fundación Alternativas, Madrid.

Jiménez-Domínguez, Bernardo. 2000. "Investigación cualitativa y psicología social crítica. Contra la lógica binaria y la ilusión de la pureza" Revista Universidad de Guadalajara 17, Dossier Investigación cualitativa en salud. Obtenido el 28 de julio de 2013 (http://www.cge.udg.mx/revistaudg/rug17/3investigacion.html).

Jacobzone, S., E. Cambois y J.M. Robine. 2000. "Is the health of older persons in OECD countries improving fast enough to compensate for population ageing?" OECD Economic Studies 30. Obtenido el 23 de Septiembre de 2009 (http://www.oecd.org/dataoecd/31/20/2732545.pdf).

Kessel, H., N. Marín, N. Maturana. 1996. "Primera conferencia nacional de consenso sobre el anciano maltratado". Revista Española de Geriatría y Gerontología 31: 367372. 
Bibliografía

Korpi,Walter. 1989. "Power, politics and state autonomy in the growth of social citizenship: social rights during sickness in eighteen OECD countries since 1930". American Sociological Review 54: 309-328.

Larrañaga, Osvaldo. 1997. "Eficiencia y equidad en el sistema de salud chileno". Proyecto Cepal/GTZ: Reformas financieras al sector salud en América Latina y el Caribe, Comisión Económica para América Latina (Cepal), Santiago de Chile.

Lenz, Rony. 2007. "Proceso político de la reforma AUGE de salud en Chile: algunas lecciones para América Latina Una Mirada desde la Economía Política”. CIEPLAN Serie Estudios Socio / Económicos № 38.

Lewis, Jane. 1992. "Gender and the Development of Welfare Regimes". Journal of European Social Policy 3: 159-173.

López Gil, Ma Jesús, Ramón Orueta, Samuel Gómez-Caro, Arancha Sánchez, Javier Carmona, Francisco Javier Alonso. 2009. "El rol de cuidador de personas dependientes y sus repercusiones sobre su calidad de vida y su salud." Revista Cínica de Medicina de Familia 2: 332-339. Obtenido el 16 de abril de 2013 (http://scielo.isciii.es/pdf/albacete/v2n7/original3.pdf).

de Lorenzo, Rafael. 2003. "El futuro de las personas con discapacidad en el mundo. Desarrollo humano y discapacidad." Informe al Club de Roma, capítulo español. Fundación ONCE.

de Lorenzo, Rafael y Alvaro Martínez. 2006. "La futura ley de dependencia como pilar fundamental de la protección social en España”. Revista Española de Tercer Sector $3: 49-80$.

Losada, Andrés, María Márquez-González, Cecilia Peñacoba, Dolores GallagherThompson y Bob G. Knight. 2007. "Reflexiones en torno a la atención a los cuidadores informales de personas con demencia y propuesta de una intervención interdisciplinar." Psicología Conductual 1:57-76. 
Losada, Andrés, Ignacio Montorio, María Izal, y María Márquez. 2006. Estudio e intervención sobre el malestar psicológico de los cuidadores de personas con demencia. El papel de los pensamientos disfuncionales. Madrid: Ministerio del Trabajo y Asuntos Sociales, IMSERSO.

Lozares, Carlos. 1996. “La teoría de redes sociales”. Papers 48: 103-126.

Martín Carrasco, Manuel, Isabel Salvadó, Susana Nadal, Laurindo Carlos Miji, José María Rico, Purificación Lanz y Maribel I, Taussig. 1996. "Adaptación para nuestro medio de la Escala de Sobrecarga del Cuidador (Caregiver Burden Interview) de Zarit". Revista de Gerontología 6: 338-346.

Mesa-Lago, Carmelo. 1999. "Política y reforma de la seguridad social en América Latina”. Nueva Sociedad 160: 133-150.

Ministerio de Educación. 2013. “Educación especial”. Obtenido el 20 de marzo de 2013 (http://www.educacionespecial.mineduc.cl/).

Ministerio de Planificación. s.f. "Definición de pobreza ¿Cómo se mide la pobreza? ¿Qué es la canasta básica de alimentos?”. Obtenido el 25 de noviembre de 2009 (http://www.mideplan.cl/casen/faq.html).

-----. 2010. Encuesta CASEN 2009. Informe ejecutivo Discapacidad. Santiago de Chile: Ministerio de Planificación. Obtenido el 22 de marzo de 2013 (http://www.ministeriodesarrollosocial.gob.cl/casen2009/discapacidad.php) (http://www.ministeriodesarrollosocial.gob.cl/casen2009/Discapacidad_casen_2009.pdf ) .

------. 2010. Ley 20.422 establece Normas sobre Igualdad de Oportunidades e Inclusión Social de Personas con Discapacidad. Obtenido el 22 de marzo de 2013 (http://www.leychile.cl/Navegar?idNorma=1010903\&buscar=ley+20422.) 
Ministerio de Salud. 2000. Plan Nacional de Salud Mental y Psiquiatría. Santiago de Chile: Ministerio de Salud.

------. 2006. “Segundo Régimen de Garantías Explícitas en Salud”. Santiago de Chile. $\begin{array}{llllll}\text { Obtenido el } & 15 & \text { Enero } & \text { de }\end{array}$ (http://webhosting.redsalud.gov.cl/minsal/archivos/guiasges/segundo_regimen_garantia s_explicitas.pdf).

------. 2007. "Protocolo de ventilación mecánica invasiva en APS". Obtenido el 15 de marzo de 2013 (http://www.avni.cl/PDF/ProtocoloVMI.pdf).

------. 2010. Reglamento de establecimientos de larga estadía para adultos mayores. Decreto $N^{\circ} 14$ de 2010. Santiago de Chile: Ministerio de Salud.

------. 2011. Programa de Atención domiciliaria a personas con discapacidad severa. Santiago de Chile: Ministerio de Salud, Subsecretaría de Redes Asistenciales, División Atención Primaria.

------. s.f. Diseño e implementación de una metodología de evaluación, seguimiento y acompañamiento de la reforma de la salud de Chile. Resumen ejecutivo: Ministerio de salud, Cooperación Alemana en Chile, Agencia de Cooperación Internacional.

------. "Encuesta Nacional de Salud 2009-2010”. Obtenido el 13 de marzo de 2013 (http://epi.minsal.cl/estudios-y-encuestas-poblacionales/encuestaspoblacionales/encuesta-nacional-de-salud/resultados-ens/).

------. “Casos GES (AUGE) acumulados a diciembre de 2010”. Obtenido el 14 de marzo de $2013 \quad$ (http://www.supersalud.gob.cl/documentacion/569/w3-propertyvalue3746.html).

Ministerio del Trabajo y Previsión Social. 2008. "Ley nº 20.055 establece reforma previsional". Obtenido el 18 de noviembre de 2009 (http://www.leychile.cl/Navegar/?idNorma=269892\&idVersion=2009-07-29\&idParte). 
------. 2008. "Ley 20.055. Reforma Previsional”. Santiago de Chile, Subsecretaría de Previsión Social. Obtenido el 18 de noviembre de 2009 (http://www.subprevisionsocial.cl/index.php?option=com_rubberdoc\&view=doc\&id=1 $47 \&$ format=raw\&lang=es).

Ministerio Secretaria General de la Presidencia. 2011. "Principales logros en los siete ejes del gobierno de Sebastián Piñera y la reconstrucción del terremoto”. Obtenido el 21 de marzo de 2013 (http://www.gob.cl/cumplimiento/assets/files/Informe-de-principaleslogros-del-Gobierno-octubre-2011.pdf).

Molina, Juan Máximo, María de los Ángeles Iáñez, Benjamín Iáñez. 2005. "El apoyo social como modulador de la carga del cuidador de enfermos de Alzheimer." Psicología y Salud 001: 33-43.

Montorio, Ignacio, María Izal, Almudena López y María Sánchez. 1998. “La entrevista de carga del cuidador. Utilidad y validez del concepto de carga". Anales de Psicología 002: 229-248.

Muñoz Tortosa, Juan. 2004. "Maltrato y negligencia en personas mayores”. Pp. 15-40 en Personas mayores y malos tratos editado por J. Muñoz. Madrid: Ediciones Pirámide.

Murillo, Soledad. 2003. "Cara y cruz del cuidado que donan las mujeres." Presentado en Congreso Internacional SARE 2003: "Cuidar cuesta: costes y beneficios del cuidado", Octubre, Bilbao.

Navarro, Vicenç. 2006. El subdesarrollo social de España. Causas y consecuencias. Barcelona: Anagrama.

Navarro Ruvalcaba, Mario. 2006. "Modelos y regímenes de bienestar social en una perspectiva comparativa: Europa, Estados Unidos y América Latina”. Desacatos 21, Centro de Investigaciones y Estudios Superiores en Antropología Social. Obtenido el 14 de julio de 2009 (http://www.ciesas.edu.mx/Desacatos/Ini.html). 
Organización Mundial de la Salud. 2001. "Clasificación Internacional del Funcionamiento, de la Discapacidad y de la Salud (CIF)". Madrid: Ministerio de Trabajo y Asuntos Sociales. Secretaría General de Asuntos Sociales. Instituto de Migraciones y Servicios Sociales (IMSERSO). Obtenido el 26 de marzo de 2013 (http://www.imsersomayores.csic.es/documentos/documentos/oms-clasificacion02.pdf).

------. 2002. Declaración de Toronto para la Prevención Global del Maltrato a las Personas Mayores. Ginebra: Organización Mundial de la Salud.

Organización Panamericana para la Salud. 2012. "Situación de Salud en las Américas. Indicadores Básicos 2012”. Consultado el 13 de marzo de 2013 (http://ais.paho.org/chi/brochures/2012/BI_2012_SPA.pdf).

Pérez, J.M., J. Abanto, J. Labarta. 1996. "El síndrome del cuidador en los procesos con deterioro cognoscitivo (demencia).”Atención Primaria 18: 194-202.

Pérez Orozco, Amaia. 2005. "Perspectivas feministas en torno a la economía: el caso de los cuidados." Tesis doctoral. Universidad Complutense de Madrid, Madrid.

Pérez Rojo, Gema. 2008. "Factores de riesgo asociados hacia el maltrato de personas mayores con demencia en el ámbito comunitario". Zerbitzuan 43: 19-31.

Piñera, Sebastián. 2010. "Primer discurso presidencial - 11 de marzo de 2010". Obtenido el 21 de marzo de 2013 (http://www.gob.cl/discursos/2010/03/11/palacio-dela-moneda-11-de-marzo-de-2010.htm).

Population Division of the Department of Economic and Social Affairs of the United Nations Secretariat. 2008. "World Population Prospect: The 2008 revision”. Obtenido el 24 de septiembre de 2009 (http://esa.un.org/unpp). 
Prats, Jaime. 2013. "La dependencia retrocede". El País.es, 3 de junio de 2013. $\begin{array}{lllllll}\text { Obtenido } & \text { el } & 28 & \text { de } & \text { agosto } & \text { de } & 2013\end{array}$ (http://sociedad.elpais.com/sociedad/2013/06/02/actualidad/1370193140_195891.html).

Quintanilla, Ximena. 2012. "Elementos solidarios del sistema de pensiones". Documento de trabajo $n^{o}$ 54. Superintendencia de Pensiones: Santiago de Chile. Obtenido el 20 de marzo (http://www.safp.cl/portal/informes/581/articles8617_pdf.pdf).

Raczynski, Dagmar. 1999. Pobreza y desigualdad en América Latina: temas y nuevos desafíos. Paidós: Buenos Aires.

Raczynski, Dagmar y Claudia Serrano. 2005. "Las políticas y estrategias de desarrollo social aportes de los años 90 y desafíos futuros.” Pp. 225-283 en La Paradoja Aparente. Equidad y Eficiencia: Resolviendo el Dilema, editado por P. Meller. Santiago de Chile: Editorial Taurus.

Reca Inés, Madelin Álvarez y M. Emilia Tijoux. 2008. "Costos no visibles del cuidado de enfermos en el hogar. Estudio de casos en Chile." Pp.179-193 en La Economía Invisible y las Desigualdades de Género. La importancia de medir y valorar el trabajo no remunerado, editado por Organización Panamericana de la Salud. Washington D.C.: Organización Panamericana de la Salud. Obtenido el 26 de marzo de 2013 (http://portal.uam.es/portal/page/portal/UAM_ORGANIZATIVO/OrganosGobierno/Vic errectoradoInfraestructuraProm/Institutomujer/MASTER\%202009-

2010/L.2La\%20economia\%20invisible\%20y\%20desig\%20genero\%20Panamericana\%2 0200.pdf).

De los Reyes, Ma Cristina. 2001. "Construyendo el concepto cuidador de ancianos." Presentado en IV Reunión de Antropología do Mercosul, foro de investigación: Envejecimiento de la población en el Mercosur, noviembre, Curitiva, Brasil. 
Rivera Navarro, Jesús. 2001. Redes familiares en el cuidado del anciano con demencia. Análisis evolutivo de un estudio poblacional. Madrid: Consejo Económico y Social, Comunidad de Madrid.

Rivera, Jesús y Carmen Gallardo. 2005. Grupos de ayuda mutua y asociaciones relacionadas con la salud. Claves de un nuevo modelos socio-sanitario. México D.F.: Plaza y Valdés.

Rivera Urrutia, Eugenio. s.f. "Política y equidad en el bicentenario: el caso de la política social en el gobierno de Sebastián Piñera." Pp 62 -79 en Una nueva forma de gobernar, Fundación Equitas y Fundación Friedrich Ebert. Santiago de Chile. Obtenido el 21 de marzo de 2013 (http://www.fundacionequitas.org/descargas/barometro/barometro0103.pdf).

Robles, Leticia. 2003a. "Doble o triple jornada: el cuidado a enfermos crónicos." Estudios del hombre 17: 75-99.

-----. 2003b. “Género, pobreza y cuidado: la experiencia de mujeres cuidadoras pobres urbanas.” Pp. 123-152 en Envejeciendo en la pobreza. Género, vejez y calidad de vida, editado por V. Salgado y R. Wong. Cuernavaca, México: Instituto Nacional de Salud Pública.

------. 2003c. "Una vida cuidando a los demás. Una "carrera" de vida en ancianas cuidadoras". Presentado en el 51 Congreso Internacional de Americanistas, Simposio Viejos y Viejas Participación, Ciudadanía e Inclusión Social, Julio, Santiago de Chile.

------. 2004. "El cuidado en el hogar a los enfermos crónicos: un sistema de autoatención." Cadernos de Saúde Pública 20: 618-625.

-----. 2006a. "El cuidado a los ancianos: La feminización de la obligación filial.” Pp. 247-285 en Miradas sobre la vejez. Un enfoque antropológico, editado por L. Robles, F. Vázquez, L. Reyes e I. Orozco. México: El Colegio de la Frontera Norte y Plaza y Valdés. 
Bibliografía

-----. 2006b. "La vejez: Nuevos actores, relaciones sociales y demandas políticas." Revista Relaciones 105: 140-175.

Rodríguez Cabrero, Gregorio. 2004. "Protección social de la dependencia en España". Documento de trabajo Nº44, Fundación Alternativas, Madrid.

Rodríguez Martínez, Pilar. 2008. "La Teoría Fundamentada: un plan metodológico para respetar la naturaleza del mundo empírico”. Praxis Sociológica 12: 137-172

Rodríguez, Josep A. 1994. Envejecimiento y familia. Madrid: Centro de Investigaciones Sociológicas.

Ruiz-Robledillo, N. y L. Moya-Albiol. 2012. "El cuidado informal: una visión actual." Revista de Motivación y Emoción 1: 22-30.

Salido, Olga y Luis Moreno. 2007. "Bienestar y políticas familiares en España". Política y Sociedad 2: 101-114.

Sánchez Ayéndez, Melva. 1994. "El apoyo social informal". Pp 360- 368 en La atención de los ancianos: un desafío para los años noventa, editada por E. Anzola, D. Galinsky, F. Morales, A. Salas, M. Sánchez. Washington D.C: Organización Panamericana de la Salud (OPS).

Sánchez Gómez, Ma Cruz, y Francisco I. Revuelta. 2005. "El proceso de transcripción en el marco de la metodología de la investigación cualitativa actual." Enseñanza 23: 367-386.

Schkolnik, Susana. 2010. "América Latina: medición de la discapacidad a partir de los censos y fuentes alternativas." Pp 179-206 en Seminario-taller Los censos 2010 y salud, publicado por la Comisión Económica para América Latina (CEPAL) Santiago de Chile. Serie seminarios y conferencias $n^{\circ}$ 59. Obtenido el 22 de marzo de 2013 (http://www.eclac.cl/publicaciones/xml/9/41589/LCL3543_SemyConf59.pdf). 
Secretaría Regional Ministerial de Salud de la Región Metropolitana. 2007. "Hogares para ancianos autorizados". Obtenido el 5 de abril de 2013 (http://www.asrm.cl/Archivos/Servicios/ELEAM_13.04.07.pdf).

Serrano, Claudia y Dagmar Raczynski. 2003. "Derechos sociales básicos, superación de la pobreza y protección social ante la vulnerabilidad”. Santiago de Chile: Asesorías Para El Desarrollo. Obtenido el 10 de noviembre de 2009. (http://www.asesoriasparaeldesarrollo.cl/files/derechos_sociales_basicos.pdf).

Servicio Nacional de la Discapacidad. 2013. “Quienes somos, introducción”. Obtenido el 22 de marzo de 2013 (http://www.senadis.gob.cl/pag/9/353/introduccion).

Servicio Nacional del Adulto Mayor (SENAMA). 2006. Plan Nacional para el Adulto Mayor. Santiago de Chile: Servicio Nacional de Adulto Mayor.

Servicio Nacional del Adulto Mayor, Instituto de Nutrición y Tecnología de los Alimentos (INTA), Centro Microdatos. 2009. "Estudio Nacional de la dependencia en las personas mayores". SENAMA: Santiago de Chile. (http://www.senama.cl/filesapp/Estudio\%20Nacional\%20de\%20Dependencia\%20en\%2 0las\%20Personas\%20Mayores.pdf).

------. 2013. "Pagina web institucional". Obtenido el 6 de abril de 2013 (http://www.senama.cl/).

------. 2013. Estudio de actualización del catastro de Establecimiento de larga estadía (ELEAM) de las regiones de Tarapacá, Antofagasta, Atacama, Coquimbo, Valparaíso, Libertador General Bernardo O'Higgins, Maule, Bío-Bío, Araucanía, Los Lagos, Aysén del General Carlos Ibáñez del Campo, Magallanes y Antartica chilena, Los Ríos, Arica y Parinacota y Región Metropolitana. SENAMA: Santiago de Chile. Obtenido el 6 de abril de

2013

(http://www.senama.cl/filesapp/INFORME\%20FINAL\%20CATASTRO\%20ELEAM\% 20NACIONAL\%202012\%20REVISADO.pdf). 
Servicio Nacional de la Mujer (SERNAM). 2009. "Minuta estadística SERNAM". Santiago de Chile: SERNAM. Obtenido el 25 de noviembre de 2009 (http://www.sernam.cl/cedocvi/minuta/doc/MIN_20090908_142639.pdf).

Sistema de Autonomía y Atención a la Dependencia e Instituto de Mayores y Servicios Sociales (SAAD-IMSERSO). 2009. "Estadísticas del sistema para la autonomía y la atención a la dependencia. Situación a 1 de abril de 2009”. Madrid: SAAD-IMSERSO Servicio de Estadísticas de la Subdirección General Adjunta de Valoración, Calidad y Evaluación. Obtenido el 16 de septiembre de 2009. (http://www.segsocial.es/imserso/estadisticas/saad/estsisaad20090401.pdf).

Setién, María Luisa y Elaine Acosta. 2009. "La gestión de la crisis de los cuidados y su relación con la feminización de las migraciones. Análisis comparativo de los modelos de Chile y España". Presentado en I Congreso anual de red-ESPANET: treinta años de Estado de bienestar en España. Logros y retos para el futuro, Noviembre, Oviedo. $\begin{array}{lllllll}\text { Obtenido el } & 3 & \text { de } & \text { abril de } & 2013 & \text { (http://espanet- }\end{array}$ spain.net/congreso2009/archivos/ponencias/TP11P05.pdf).

Sistema de Protección Integral a la Primera Infancia. 2007. "Presentación Chile Crece Contigo. Instrumentos para la gestión”. Obtenido el 30 de noviembre de 2009 (http://www.crececontigo.cl/upfiles/userfiles/file/Presentacion_Chile_Crece_Contigo.pd f).

Strauss Anselm y Juliete Corbin. 2002. Bases de la investigación cualitativa. Técnicas y procedimientos para desarrollar la teoría fundamentada (traducción de Eva Zimmerman). Medellín: Universidad de Antioquia.

Subsecretaría de Previsión Social. 2007. Boletín Previsional 1. Santiago de Chile: Subsecretaría de Previsión Social. 


\section{Bibliografía}

Sunkel, Guillermo. 2006. "Políticas familiares y regímenes de bienestar en América Latina.” CEPAL, 16 y 17 octubre 2006. Obtenido el 16 de septiembre de 2009. (http://www.winnernet.org/imagenes/fotos/informacion/politica_bienestar.pdf).

Superintendencia de Salud. 2009. "Discriminación y equidad de género pre y post reforma de salud año 2009”. Obtenido el 13 de marzo de 2013 (http://www.supersalud.gob.cl/documentacion/569/articles-5795_recurso_1.pdf).

------. s.f. Estadística consolidada de cartera del sistema Isapre año 2012. Obtenido el 13 de marzo de 2013 (http://www.supersalud.gob.cl/documentacion/569/w3-propertyvalue3818.html).

Superintendencia de Pensiones. 2013." Número de beneficiarios y porcentajes, del estado de los beneficios otorgados por el pilar solidario". Sistema de Pensiones $\begin{array}{llllll}\text { Solidarias. } & \text { Obtenido } & 20 & \text { de } & \text { marzo de }\end{array}$ (http://www.safp.cl/safpstats/stats/pageCCEE.php?menu=sps\&item=nbmpm).

Tobío, Constanza. 2002. “Conciliación o contradicción: Cómo hacen las madres trabajadoras” Pp. 15-43 en Conciliar la vida. Tiempos y servicios para la igualdad editado por Consejo de la Mujer de la Comunidad de Madrid. Madrid: Dirección General de la Mujer.

Touza, Carmen, Ma Paz Segura y Carmen Prado. 2009. “¿Qué entendemos por malos tratos hacia las personas mayores?" Pp. 19-26 en Personas mayores en riesgo editado por C. Touza. Madrid: Ediciones Pirámide.

Tronto, Joan. 2002. "The Value of Care A Response to Can Working Families Ever Win?" Boston Review 27. Obtenido el 3 de junio de 2010. (http://bostonreview.net/BR27.1/tronto.html).

Uthoff, Andras. 2011. "Reforma al sistema de pensiones chileno". Serie financiamiento del desarrollo, Comisión Económica para América Latina (Cepal), Santiago de Chile. 
Bibliografía

$\begin{array}{lllllll}\text { Obtenido } & \text { el } & 19 & \text { de } & \text { marzo } & \text { de } & 2013\end{array}$ (http://www.eclac.org/publicaciones/xml/9/45269/lcl3422.pdf).

Valcarce, Amparo. 2008. "Ley de promoción de la autonomía y atención a las personas en situación de dependencia”. Presupuesto y Gasto Público 50:201-204.

Valderrama, Consuelo, Pablo Morris y Miguel Ulloa. 2010. "Estudio sobre discapacidad y género. Necesidades especiales de protección y asistencia de mujeres con discapacidad y mujeres cuidadoras de personas con discapacidad. " Asesorías para el Desarrollo: Santiago de Chile. Resumen ejecutivo obtenido el 27 de marzo de 2013 (http://www.asesoriasparaeldesarrollo.cl/docs/16824124.pdf).

Valdivieso, Vicente y Joaquín Montero. 2010. “El plan AUGE: 2005 al 2009.” Rev Med Chile 138: 1040-1046.

Vázquez-Barquero, J., S. Herrera, A. Ramos, L. Gaite, Grupo Cantabria en Discapacidades. 2001. "Clasificación internacional del funcionamiento de la discapacidad y de la salud (CIF): antecedentes, marco conceptual y estructura." Papeles Médicos 10: 177-184.

Vidal, Daisy, Mercedes Zavala, Manuel Castro, Pilar Quiroga y Gonzalo Klaasen. 1998. "El significado del paciente con demencia para el cuidador, en una comunidad urbana y $\begin{array}{llllll}\text { rural." } & \text { Obtenido } & \text { el de } & & \end{array}$ (http://www2.udec.cl/ ssrevi/numero2/articulos/significado.htm).

Von Gersdorff, Hermann. 1984. "El sistema previsional chileno los últimos diez años". Estudios de Economía 22: 88-115. Obtenido el 16 de marzo de 2013 (http://www.econ.uchile.cl/uploads/publicacion/7064d1c5-6892-44db-bac3907390a4fb88.pdf).

Yanguas, José Javier, Francisco Javier Leturia y Miguel Leturia. 2001. “Apoyo informal y cuidado de las personas mayores dependientes." Obtenido el 30 de septiembre de 
Bibliografía

2009. (http://www.imsersomayores.csic.es/documentos/documentos/yanguas-apoyo02.pdf).

Zunzunegui, $\mathrm{M}^{\mathrm{a}}$ Victoria y Pablo Lázaro. 2008. "Integración y fronteras entre la atención sanitaria y la atención social. Informe SESPAS 2008”. Gaceta Sanitaria 22: 156-162.

\section{LEYES}

Chile. Ley $\mathrm{N}^{\mathrm{o}}$ 19.284, sobre la Integración Social de las personas con Discapacidad, 5 de enero de 1994. Diario Oficial de la República de Chile del 14 de enero de 1994.

Chile. Ley 19.888 de Financiamiento. Biblioteca del Congreso Nacional de Chile, Ley Chile, 13 de agosto de 2003. Obtenido el 15 de julio de 2013. (http://www.leychile.cl/Navegar?idNorma=213493\&buscar=Ley+19.888).

Chile. Ley 19.895 de Solvencia de ISAPRES. Biblioteca del Congreso Nacional de Chile, Ley Chile, 28 de agosto de 2003. Obtenido el 15 de julio de 2013. (http://www.leychile.cl/Navegar?idNorma=214042\&buscar=Ley+19.895).

Chile. Ley $\mathrm{N}^{\mathrm{o}} 19.937$ de Autoridad Sanitaria y Gestión. Biblioteca del Congreso Nacional de Chile, Ley Chile, 24 de febrero de 2004. Obtenido el 15 de julio de 2013. (http://www.leychile.cl/Navegar?idNorma=221629\&buscar=Ley+19.937).

Chile. Ley N 19.966 del Régimen General de Garantías en Salud: Establece un régimen de garantías en salud (Plan AUGE). Biblioteca del Congreso Nacional de Chile, Ley Chile, 3 de septiembre de 2004. Obtenido el 15 de julio de 2013. (http://www.leychile.cl/Navegar?idNorma=229834).

Chile. Ley $\mathrm{N}^{\circ} 20.015$ Modifica la ley $\mathrm{N}^{\mathrm{o}}$ 18.933, sobre Instituciones de Salud Previsional. Biblioteca del Congreso Nacional de Chile, Ley Chile, 17 de mayo de 
Bibliografía

2005

Obtenido

el

15

de

julio

de

2013.

(http://www.leychile.cl/Navegar?idNorma=238102).

España. Ley 39/2006 de 14 de diciembre, de Promoción de la autonomía personal y atención a las personas en situación de dependencia." Boletín Oficial del Estado (BOE) 229. Obtenido el 22 de septiembre de 2009. (http://www.imsersodependencia.csic.es/). 


\section{Anexo 1. Consentimiento informado para los participantes de entrevistas \\ “Cuidadores informales de personas dependientes en Chile, aspectos psicosociales y culturales”.}

Este tiene como propósito conocer la realidad sociocultural de los cuidadores informales para ayudar en la generación de estrategias sociales y sanitarias que permitan el mejoramiento de las condiciones de vida de los cuidadores, las personas a su cargo y la familia que les rodea, facilitando la toma de decisiones futuras de acuerdo a criterios de realidad. A cargo del Departamento de Sociología de la Universidad de Salamanca de España y el Ministerio de Salud de Chile.

En ese contexto, usted está invitado/a a participar en una Entrevista para conocer su opinión respecto de su situación social, cultural y psicológica. Esta entrevista se llevará a efecto el —, a las _ _ Hrs., en Será una conversación de aproximadamente 1 hora. Usted no recibirá retribución económica por participar en esta actividad. Esta conversación será una oportunidad para dar su opinión. Usted no tiene que responder aquella(s) pregunta(s) que no desee responder y siempre podrá retirarse y terminar su participación, si es que no se siente confortable.

De parte del equipo responsable se tomarán todos los resguardos para el buen cuidado de la privacidad y confidencialidad que este tipo de estudios amerita. Su colaboración será muy importante. La participación es completamente voluntaria. El negarse a participar o el retirarse no significará ninguna sanción o pérdida de beneficios que de otra forma usted habría tenido derecho a gozar.

Si Usted tiene preguntas sobre esta actividad, por favor, no dude en consultar. Muchas Gracias.

Deiza Troncoso Miranda.

Investigadora Responsable

Página $\mid 477$ 
FIRMAS DEL CONSENTIMIENTO. Fecha:

(nombre del entrevistado) ha sido

(su nombre), he sido informado sobre esta actividad, sus posibles beneficios, riesgos y molestias. Expreso, a través de este medio, que estoy de acuerdo en participar voluntariamente en esta actividad. Reconozco que soy libre de rechazar este consentimiento y abandonar esta actividad en cualquier momento, y que si ello ocurre no me significará ninguna sanción o pérdida de beneficios que de otra forma habría tenido derecho a gozar informado de la naturaleza y propósito de esta actividad, incluyendo cualquier riesgo implicado en este evento. Él o ella han tenido tiempo para hacer cualquier pregunta $\mathrm{y}$ tales preguntas han sido respondidas de la mejor forma posible por el equipo responsable. 


\section{Anexo 2. Guión o pauta de entrevista}

\section{Consideraciones previas}

- En esta pauta guía de entrevista se intenta reseñar la guía de asuntos o temas a los que se espera que el entrevistado/a se refiera, en su defecto se plantea la realización directa de las preguntas que se señalan.

- El lenguaje utilizado intenta adecuarse al nivel cultural de la muestra.

\section{PRESENTACIÓN}

- Para comenzar me gustaría que se presentara, que me dijera su nombre, donde nació, cuánto hace que vive en este lugar, etc., lo que usted quiera contarme a modo de presentación.

De acuerdo a lo que la entrevistada haya contado en la presentación se pueden agregar las siguientes preguntas:

\section{- Estado civil.}

- Nivel educacional.

- ¿Hasta qué curso usted estudió(a)? ¿Dónde realizó(a) sus estudios?

\section{- Historia laboral.}

- Además de cuidar a (nombre la de persona a la que cuida) ¿Qué otros trabajos ha realizado?

\section{- Hogar.}

- ¿Dónde vive usted?

- ¿Con quién vive usted? Me puede contar sus edades y a qué se dedican ellos. 
- ¿Cómo se encuentra usted en su casa? (se busca que se refiera a si está cómoda en ella, si la ubicación de la vivienda es buena, cómo son los medios de transporte de su barrio).

- Salud.

- ¿Cómo considera que es su salud? (buena, regular, mala) ¿Padece usted alguna enfermedad o dolencia? ¿Se encuentra diagnosticada? ¿Controla su enfermedad? ¿Recibe tratamiento para ello?

- ¿Ha experimentado alguna dolencia o molestia que usted crea que es generada por el trabajo de cuidar?, ¿ha sido diagnosticada?, ¿controla su enfermedad?, ¿Recibe tratamiento para ello?

- ¿Con cuánta frecuencia acude usted a su (centro de salud o consultorio)? ¿Cómo considera que es la atención de salud que recibe?

\section{- Actividades actuales.}

- Además del trabajo de cuidado que realiza ¿usted trabaja fuera de casa y/o estudia? ¿Cuánto tiempo le dedica al trabajo fuera de casa y/o estudio?, ¿Cómo organiza su tiempo entre las labores de cuidado y el estudio y/o trabajo fuera de casa?

- ¿Participa usted en alguna organización de su barrio o comunidad (religiosa, centro de madres, junta de vecinos, partidos políticos)?, ¿Cuál es la frecuencia de participación? En el caso de que no participe, se le pregunta: ¿sale de casa?, ¿con qué frecuencia lo hace?

\section{- Situación socioeconómica.}

- ¿Cómo considera su situación económica?

- ¿Quiénes aportan económicamente al sustento de su hogar?

- ¿Existen aportes económicos que vengan de personas que están fuera del hogar?

- Usted, alguien de su grupo familiar y/o su familia ¿Recibe alguna pensión o subsidio? 


\section{SOBRE LA LABOR DE CUIDADO:}

\section{- Trayectoria.}

- Respecto de (nombre la de persona a la que cuida) ¿Qué tipo de relación existe entre usted y (nombre la de persona a la que cuida)?

- ¿Desde cuándo usted cuida a (nombre la de persona a la que cuida)? ¿Qué lo motivó a realizar el cuidado de (nombre la de persona a la que cuida)?

- ¿Qué actividad realizaba antes de dedicarse a cuidar a (nombre la de persona a la que cuida)?

- Considerando que antes de cuidar a (nombre la de persona a la que cuida) usted realizaba otra actividad ¿Qué cambios en su vida han significado asumir este rol?, ¿Ha tenido que modificar su rutina o estilo de vida a causa de las actividades de cuidado que realiza?

- Aparte de cuidar a (nombre de la persona con discapacidad), ¿realiza actividades de cuidado en otros lugares?

- Este último año ¿ha tenido vacaciones? Si contesta "No" preguntar: ¿hace cuánto tiempo atrás fueron sus últimas vacaciones?

\section{- Trabajo de cuidar.}

- Describa un día de cualquiera en que usted cuide a (nombre la de persona a la que cuida), ¿existe diferencia entre ese día y los del fin de semana?

- Si realiza labores del hogar ¿qué labores del hogar realiza?, ¿cuánto tiempo le dedica a estas actividades?, ¿cómo compatibiliza esas labores con las de cuidado? 
- ¿En este hogar hay más personas que requieran de sus cuidados (sean o no discapacitadas)?, ¿Cuál es el parentesco que tiene con estas personas?, ¿qué edad tienen?, ¿los cuida permanentemente o de forma eventual?

- ¿Cómo evalúa la relación que existe entre usted y la/s persona/s que cuida?

- ¿Cuánto tiempo lleva cuidando a (nombre la de persona a la que cuida)?, ¿cómo han sido estos últimos (poner dato aportando anteriormente- años, meses) de vida? Se busca que se refieran al tiempo que llevan cuidando.

\section{- Disponibilidad de apoyos y formación para cuidar.}

- En su rol de cuidador ¿Existe alguna otra persona que le pueda ayudar o reemplazar en caso de que usted no pueda cuidar a (nombre la de persona a la que cuida)?, ¿Qué actividades desarrollan?, ¿hay hombres que lo hagan?

- ¿Cuán capacitado se considera usted para realizar el trabajo de cuidador?, ¿cómo aprendió a realizar las actividades de cuidado?, ¿cuenta con algún tipo de preparación para desempeñarse como cuidador?

- ¿Se relaciona de alguna manera con alguna institución comunal, regional o estatal?, ¿ha recibido algún tipo de apoyo, tanto para usted como para la persona a la que cuida?

- Costos del cuidado y efectos en el cuidador.

- ¿Qué cambios en su vida ha significado el dedicarse al cuidado de (nombre la de persona a la que cuida)?, ¿ha tenido que modificar su rutina o estilo de vida a causa de las actividades de cuidado que realiza? (por ejemplo: dejar de trabajar, menos vida social, dejar de realizar algunas actividades)

- Específicamente, dedicarse a cuidar a (nombre de la persona con discapacidad), ¿ha tenido efectos en su vida personal o afectiva, en su estado 
de ánimo y/o en su salud mental? (Indagar en posible stress, depresión) ¿en qué medida siente que puede disponer de su propio tiempo?

- (No formular esta pregunta si ya se ha referido al tema) ¿Ha experimentado alguna dolencia o molestia que usted crea que es generada por el trabajo de cuidar?, ¿ha sido diagnosticada?, ¿controla su enfermedad?, ¿recibe tratamiento para ello?

- ¿Cuán reconocido se encuentra usted en su rol de cuidador/a?, ¿cómo son las relaciones entre usted y el resto de la familia de (nombre la de persona a la que cuida)?

- Las exigencias de cuidado de una persona con discapacidad a veces pueden producir roces o tensiones al interior de la familia. En esta familia, ¿se han dado estos problemas? En general, ¿cómo considera Ud. que esta familia enfrenta o sobrelleva esta situación?

- Y en el ámbito económico, ¿ha tenido efectos? (ej. por dejar de recibir un sueldo, por altos costos que implica la atención de la persona con discapacidad)

- ¿Considera que las actividades de cuidado que usted realiza deberían ser valoradas o valorizadas de alguna manera ya sea por parte de la familia de la persona con discapacidad, o por el Estado?, ¿por qué?

\section{- Espacio de cuidado- Ubicación Urbana-rural.}

- Con respecto al lugar en el que usted desempeña la tarea de cuidado de (nombre de la persona con discapacidad) ¿considera usted que la vivienda está adaptada para la atención de (nombre de la persona con discapacidad) y hacer su trabajo más llevadero?, ¿Qué cree usted que hace falta?

- Cuando (nombre de la persona con discapacidad) debe desplazarse fuera de su hogar ¿cómo lo realiza?, ¿recibe ayuda de otras personas para ello?

Página $\mid 483$ 
Anexos

- El vivir en (nombre del barrio o de la zona en la que habiten) ¿implica una ventaja o desventaja a la hora de cuidar a nombre de la persona con discapacidad)?

\section{- Proyecciones.}

- ¿Cómo ve usted su futuro?

Página | 484 


\section{Anexo 3. Ficha del cuidador}

\section{Cuadro 13. Información básica del cuidador}

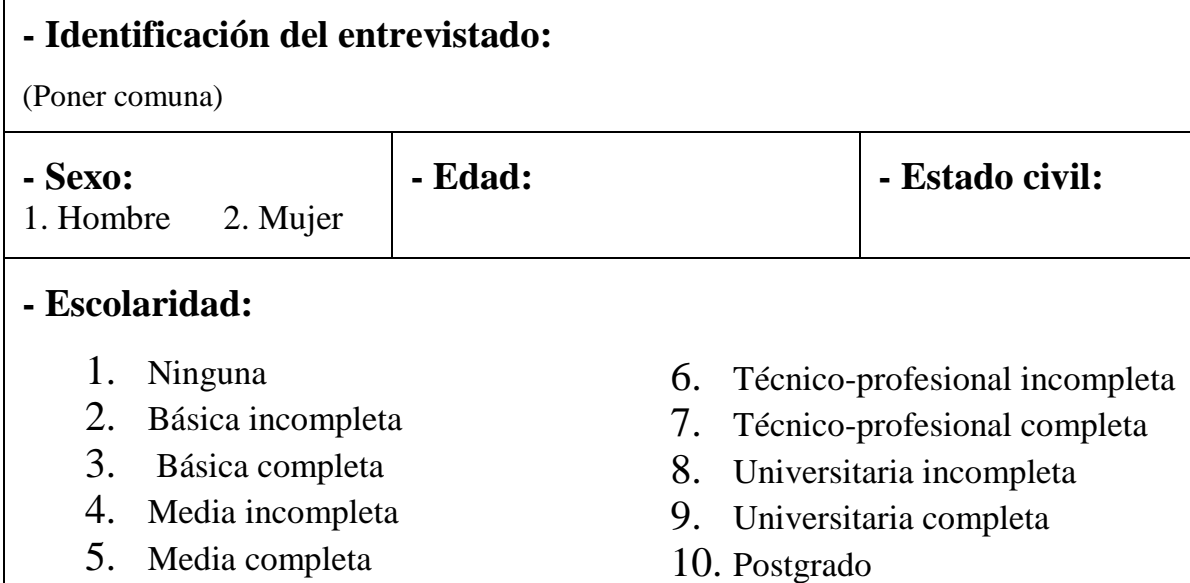

- Lugar de residencia:

(misma casa que la persona que cuida o fuera de ella)

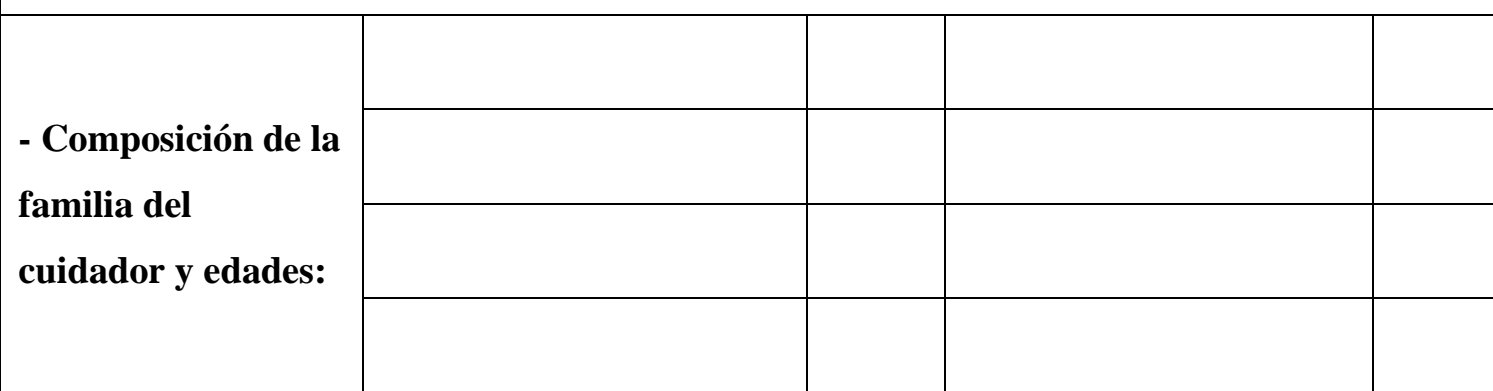

- Oficio o profesión:

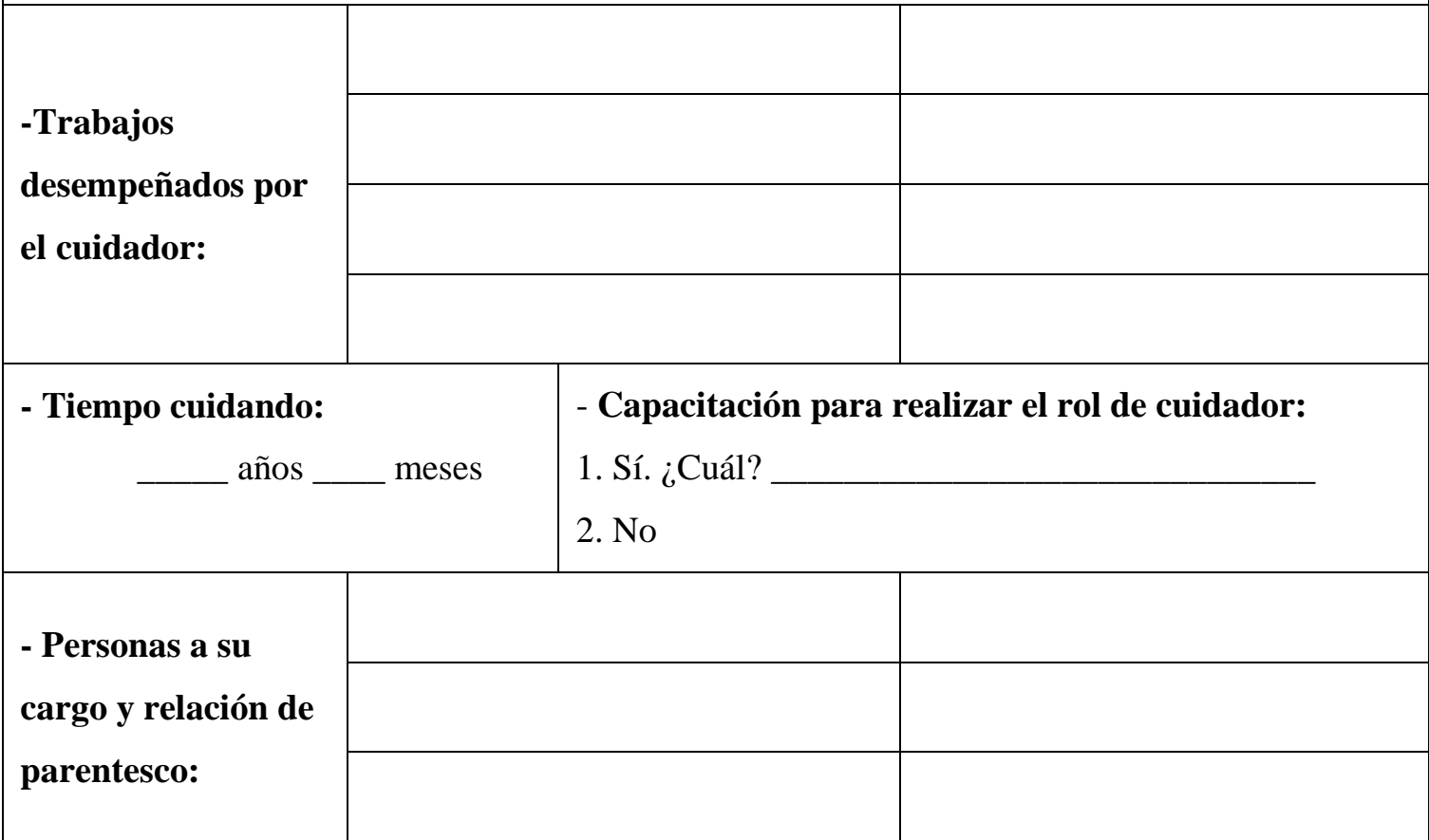

Página $\mid 485$ 


\section{Anexo 4. Tareas del cuidador}

\begin{tabular}{|c|c|c|c|c|}
\hline Como cuidador, usted debe... & Todos los días & $\begin{array}{c}\text { Frecuentemente } \\
\text { (3 ó } 4 \text { días a la } \\
\text { semana) }\end{array}$ & $\begin{array}{c}\text { Ocasionalmente } \\
\text { (1-2 días a la } \\
\text { semana) }\end{array}$ & Nunca \\
\hline \multicolumn{5}{|c|}{ Hacer terapia o tratamientos (por ejemplo, ayudarle a realizar ejercicios) } \\
\hline \multicolumn{5}{|l|}{ Controlar alguna manifestación de la dependencia } \\
\hline \multicolumn{5}{|l|}{ Administrar medicinas } \\
\hline \multicolumn{5}{|l|}{ Cocinar para todos los habitantes del hogar } \\
\hline \multicolumn{5}{|l|}{ Cocinar comidas especiales a la persona dependiente } \\
\hline \multicolumn{5}{|l|}{ Dar alimento a la persona con dependiente } \\
\hline \multicolumn{5}{|l|}{ Bañar, asear o vestir a la persona con dependencia } \\
\hline \multicolumn{5}{|c|}{ Fomentar el desarrollo intelectual de la persona con dependencia } \\
\hline \multicolumn{5}{|c|}{ Organizar y acomodar el entorno de la persona con dependencia } \\
\hline Organizar la rutina de la persona con dependencia & & & & \\
\hline
\end{tabular}

Página | 486 


\begin{tabular}{|l|l|l|l|l|}
\hline Como cuidador, usted debe... & Todos los días & $\begin{array}{c}\text { Frecuentemente } \\
\text { (3 ó 4 días a la } \\
\text { semana) }\end{array}$ & $\begin{array}{c}\text { Ocasionalmente } \\
\text { (1-2 días a la } \\
\text { semana) }\end{array}$ & \multicolumn{1}{c|}{ Nunca } \\
\hline Hacerle compañ́a a la persona con dependencia & & & & \\
\hline Entretener a la persona con dependencia & & & & \\
\hline Acompañar en actividades de recreación fuera de la casa & & & \\
\hline Trasladar a la persona con dependencia & & & & \\
\hline Acompañarlo al servicio de salud & & & & \\
\hline Hacer trámites & & & \\
\hline Comprar medicamentos & & & \\
\hline Comprar alimentos para la persona con dependencia & & & \\
\hline
\end{tabular}

Página | 487 


\begin{tabular}{|l|l|l|l|l|}
\hline Como cuidador, usted debe... & Todos los días & $\begin{array}{c}\text { Frecuentemente } \\
\text { (3 ó 4 días a la } \\
\text { semana) }\end{array}$ & $\begin{array}{c}\text { Ocasionalmente } \\
\text { (1-2 días a la } \\
\text { semana) }\end{array}$ & \multicolumn{1}{c|}{ Nunca } \\
\hline Comprar implementos para la persona con dependencia & & & \\
\hline $\begin{array}{l}\text { Otras actividades que recuerde ahora y que no haya mencionado, } \\
\text { ¿cuáles? }\end{array}$ & & & \\
\hline
\end{tabular}




\section{Anexo 5. Escala de sobrecarga del cuidador de Zarit (Caregiver Burden Interview), adaptación española}

Instrucciones: A continuación voy a mencionarle una serie de frases que reflejan cómo se sienten algunas personas cuando cuidan a otra persona. Después de leer cada frase, indique con qué frecuencia se siente usted de esa manera, escogiendo entre NUNCA, CASI NUNCA, A VECES, FRECUENTEMENTE y CASI SIEMPRE. No existen respuestas correctas o incorrectas.

\begin{tabular}{|c|c|c|c|c|c|}
\hline Preguntas a realizar & $\begin{array}{c}1 \\
\text { Nunca }\end{array}$ & $\begin{array}{c}2 \\
\text { Casi } \\
\text { nunca }\end{array}$ & $\begin{array}{c}\mathbf{3} \\
\mathbf{A} \\
\text { veces } \\
\end{array}$ & $\begin{array}{c}4 \\
\text { Bastantes } \\
\text { veces } \\
\end{array}$ & $\begin{array}{c}5 \\
\text { Casi } \\
\text { siempre }\end{array}$ \\
\hline 1. ¿Siente que su familiar solicita más ayuda de la que rea & & & & & \\
\hline $\begin{array}{l}\text { 2. ¿Siente que, a causa del tiempo que gasta con su famili } \\
\text { para usted mismo? }\end{array}$ & & & & & \\
\hline $\begin{array}{l}\text { 3. ¿Se siente estresada/o al tener que cuidar a su familiar } \\
\text { responsabilidades? (por ej.: con su familia o en el trabajo) }\end{array}$ & & & & & \\
\hline 4. ¿Se siente avergonzada/o por el comportamiento de su & & & & & \\
\hline 5. ¿Se siente irritada/o cuando está cerca de su familiar? & & & & & \\
\hline $\begin{array}{l}\text { 6. ¿Cree que la situación actual afecta a su relación con ar } \\
\text { forma negativa? }\end{array}$ & & & & & \\
\hline 7. ¿Siente temor por el futuro que le espera a su familiar? & & & & & \\
\hline
\end{tabular}

Página | 489 


\begin{tabular}{|c|c|c|c|c|c|}
\hline Preguntas a realizar & $\begin{array}{c}1 \\
\text { Nunca }\end{array}$ & $\begin{array}{c}2 \\
\text { Casi } \\
\text { nunca }\end{array}$ & $\begin{array}{c}\mathbf{3} \\
\mathbf{A} \\
\text { veces }\end{array}$ & $\begin{array}{c}4 \\
\text { Bastantes } \\
\text { veces }\end{array}$ & $\begin{array}{c}5 \\
\text { Casi } \\
\text { siempre }\end{array}$ \\
\hline 8. ¿Siente que su familiar depende de usted? & & & & & \\
\hline 9. ¿Se siente agotada/o cuando tiene que estar junto a su familiar? & & & & & \\
\hline $\begin{array}{l}\text { 10. ¿Siente usted que su salud se ha visto afectada por tener que cuidar a } \\
\text { su familiar? }\end{array}$ & & & & & \\
\hline $\begin{array}{l}\text { 11. ¿Siente que no tiene la vida privada que desearía a causa de su } \\
\text { familiar? }\end{array}$ & & & & & \\
\hline $\begin{array}{l}\text { 12. ¿Cree que su vida social se ha visto afectada por tener que cuidar de s } \\
\text { familiar? }\end{array}$ & & & & & \\
\hline $\begin{array}{l}\text { 13. ¿Se siente incómoda/o para invitar amigos a casa, a causa de su } \\
\text { familiar? }\end{array}$ & & & & & \\
\hline $\begin{array}{l}\text { 14. ¿Cree que su familiar espera que usted le cuide, como si fuera la única } \\
\text { persona con la que puede contar? }\end{array}$ & & & & & \\
\hline $\begin{array}{l}\text { 15. ¿Cree usted que no dispone de dinero suficiente para cuidar a su } \\
\text { familiar, además de sus otros gastos? }\end{array}$ & & & & & \\
\hline $\begin{array}{l}16 \text { ¿Siente que no va a ser capaz de cuidar de su familiar durante mucho } \\
\text { más tiempo? }\end{array}$ & & & & & \\
\hline
\end{tabular}




\begin{tabular}{|c|c|c|c|c|c|}
\hline Preguntas a realizar & $\begin{array}{c}1 \\
\text { Nunca }\end{array}$ & $\begin{array}{c}2 \\
\text { Casi } \\
\text { nunca }\end{array}$ & $\begin{array}{r}\mathbf{3} \\
\mathbf{A} \\
\text { veces }\end{array}$ & $\begin{array}{c}4 \\
\text { Bastantes } \\
\text { veces }\end{array}$ & $\begin{array}{c}5 \\
\text { Casi } \\
\text { siempre }\end{array}$ \\
\hline \multicolumn{6}{|l|}{$\begin{array}{l}\text { 17. ¿Siente que ha perdido el control sobre su vida desde que la } \\
\text { enfermedad de su familiar se manifestó? }\end{array}$} \\
\hline \multicolumn{6}{|l|}{ 18. ¿Desearía poder encargar el cuidado de su familiar a otra persona? } \\
\hline \multicolumn{6}{|l|}{ 19. ¿Se siente inseguro acerca de lo que debe hacer con su familiar? } \\
\hline \multicolumn{6}{|l|}{ 20. ¿Siente que debería hacer más de lo que hace por su familiar? } \\
\hline \multicolumn{6}{|l|}{ 21. ¿Cree que podría cuidar de su familiar mejor de lo que lo hace? } \\
\hline $\begin{array}{l}\text { 22. En general: ¿Se siente muy sobrecargado por tener que cuidar de su } \\
\text { familiar? }\end{array}$ & & & & & \\
\hline TOTAL & & & & & \\
\hline
\end{tabular}




\section{Anexo 6. Mapas Chile y Sudamérica}

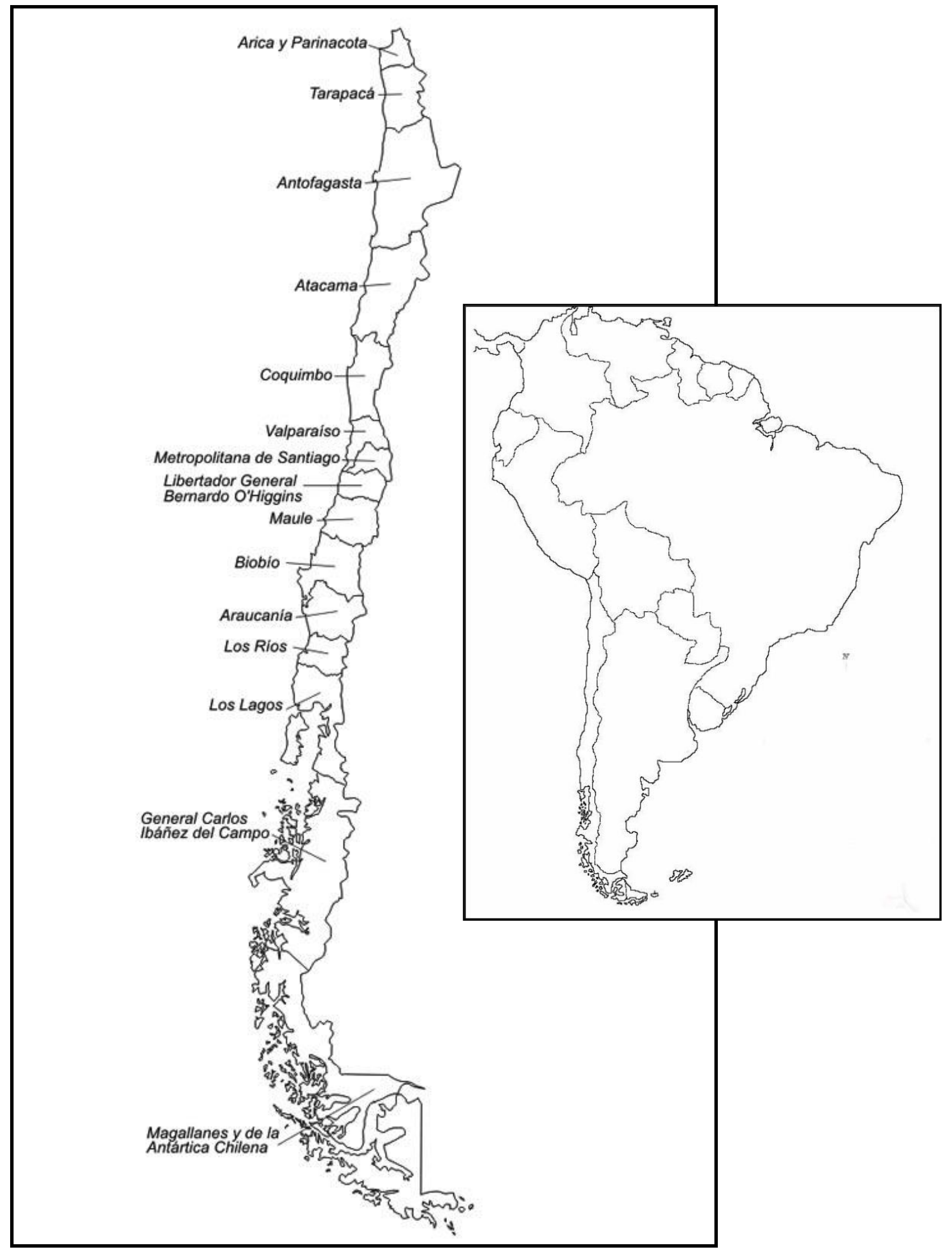

Página 492 


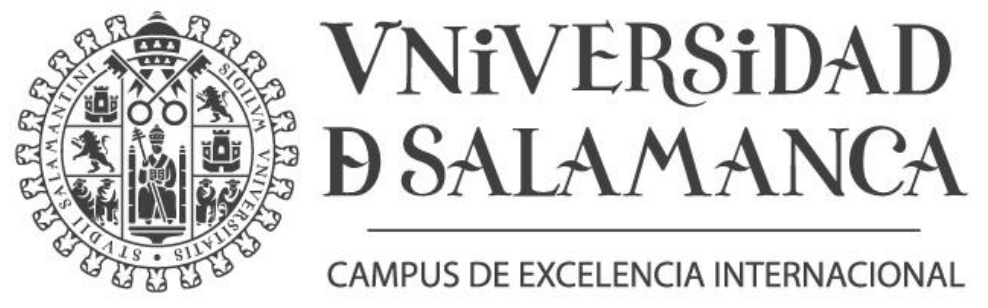

